PROCEEDINGS OF THE UNITED STATES NATIONAL MUSEUM

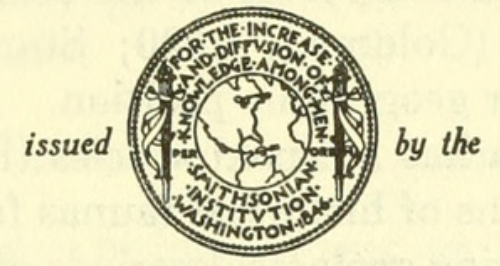

SMITHSONIAN INSTITUTION

U S. NATIONAL MUSEUM

\title{
BITING MIDGES OF THE GENUS CULICOIDES FROM PANAMA (DIPTERA : HELEIDAE)
}

\section{By Willis W. Wirth ${ }^{1}$ and Franklin S. Blanton ${ }^{2}$}

\section{Introduction}

In 1951 the junior author began a 3-year assignment as entomologist to the U. S. Army Caribbean at Fort Clayton in the Panama Canal Zone. During this assignment surveys for blood-sucking insects, which were begun at military installations in the Canal Zone and various maneuver areas, were extended to cover a wide area over the Republic of Panama (Blanton, Galindo, and Peyton, 1955). The senior author determined the Culicoides that were collected and he cooperated in describing the numerous new species that were soon discovered. Some of these new species were described in joint papers as the work progressed, but it was soon realized that a major revision of the Panama species was needed, and we then devoted our efforts to the present paper.

When our studies began, 16 species of Culicoides had been reported from Panama (Fairchild, 1943; Barbosa, 1947; Fox, 1947; Ortiz, 1950a). By intensive collecting, primarily with light traps, the number has been increased to 88 . By additional collecting in selected

${ }^{1}$ Entomologist, Entomology Research Division, Agricultural Research Service, U. S. Department of Agriculture, Washington, D. C.

2 Lieutenant Colonel. MSC. Retired. Formerly at Department of Entomology, Walter Reed Army Institute of Research, Washington, D. C. 
localities such as the eastern Darien Mountains, the Chiriquí highlands, the southern Chiriquí gallery forests, and the Caribbean rain forests, and by a special program of collecting and rearing from larval habitats we believe this number can be materially increased. This phenomenal number of species of a single genus in an area as small as the Republic of Panama is a result of the ecological diversity of this mountainous country (Goldman, 1920; Standley, 1928; Kenoyer, 1929 ) and of its peculiar geographic position. As an isthmus between two continents Panama has received species that have been stranded from waves of migrations of historical faunas from north to south and from south to north during geological periods of time (Chapman, 1917; Schuchert, 1935; Griscom, 1935, 1940, 1950).

For their generous cooperation and assistanc: in making the field collections and sorting specimens in Panama, we are greatly indebted to the following persons and organizations: Col. Francis P. Kintz, Surgeon, and Lt. Col. Edward J. Dehne, Chief of Preventive Medicine, U. S. Army Caribbean, and the personnel of the 25th Preventive Medicine Survey Detachment; the Gorgas Memorial Laboratory, especially Dr. Pedro Galindo, Dr. G. B. Fairchild, and Dr. Harold Trapido; and the Inter-American Geodetic Surveys, especially $\mathrm{Mr}$. Elton Vickers.

We particularly thank Mr. Gordon A. Marsh, of the University of California, for making the many thousands of measurements of specimens, a laborious task performed as a technician at the Walter Reed Army Institute of Research.

The illustrations accompanying this paper were made by Miss Sakiko Asano, Mr. Kei Daishoji, Mr. Akira Shimazoe, and Miss Kazuko Tsukamoto of the 406th Medical General Laboratory, U. S. Army in Tokyo, Japan, under the direction of Mr. Kakuzo Yamasaki, and by Mr. Thomas M. Evans, scientific illustrator of the Walter Reed Army Institute of Research, Washington, D. C. The Japanese artists were under the direction of Maj. Hugh L. Keegan, MSC, Department of Entomology, and Col. Joe M. Blumberg, MC, Commanding Officer of the 406th Medical General Laboratory.

For taxonomic advice and cooperation, including frequent exchange of specimens and manuscript notes, we thank our co-workers on the taxonomy of American Culicoides: Dr. O. P. Forattini of the Universidade de São Paulo, Dr. Irving Fox of the University of Puerto Rico, and Dr. Ignacio Ortiz-Cordero of the Instituto Nacional de Higiene of Caracas, Venezuela. We are indebted to Dr. A. da Costa Lima of the Instituto Oswaldo Cruz for the loan of type material from the Lutz collection, to Dr. Irving Fox of the University of Puerto Rico for the loan of numerous type specimens described by himself and Dr. W. A. Hoffman, and to Mr. Paul Freeman and the trustees of the British 
Museum (Natural History) and to Dr. Alan Stone of the U. S. Department of Agriculture for assistance on the types of Williston and Macfie. Dr. P. A. Woke of the U. S. Public Health Service and Dr. L. E. Rozeboom of Johns Hopkins University also furnished Panama material for study, including some specimens from field collections which in part formed the type series of new species described by Fox (1947) and Barbosa (1947).

\section{Economic Importance}

The role of Culicoides biting midges as vectors of pathogenic organisms has hardly been investigated enough to give any index of their potential importance, but it seems likely that their role is minor compared with that of mosquitoes. fleas, lice, and ticks. However, studies already made indicate that Culicoides may play an important role in disease transmission, principally as vectors of filarial worms (Buckley, 1934, 1938; Chardrome and Peel, 1951; Dampf, 1936; Henrard and Peel, 1949; Hopkins, 1952; Hopkins and Nicholas, 1952; Mirsa, Mirsa, and Ortiz, 1952; Steward, 1933) and of certain groups of viruses such as bluetongue of sheep (du Toit, 1944; Price and Hardy, 1954) and fowlpox (Tokunaga, 1937).

By their annoying attacks in tremendous numbers, Culicoides can make life almost unbearable in areas where certain anthropophilic species occur. The most pestiferous American species is Culicoides furens (Poey), which in some coastal areas is troublesome enough to retard the development of otherwise favorable resorts (Adamson, 1939; Dove, Hall, and Hull, 1932; Myers, 1935; Painter, 1926). This species is a pest along the Panama coasts. At Fort Kobbe in the Canal Zone women and children frequently request medical treatment for secondary infections resulting from Culicoides bites. C. furens is doubly annoying because it is one of the few species of Culicordes that will readily enter houses, and the females are so small that ordinary or untreated window screens are no barrier to them.

The importance of Culicoides and other small, hairy members of the Heleidae as pollinators of tropical economic plants has only recently been discovered. Posnette (1944) found that heleid midges are the chief pollinators of cacao in Trinidad, and Warmke (1951, 1952 ) that they are the most important pollinators of the Pará rubber tree in tropical America. Included among the known rubber pollinators are C. diabolicus Hoffman and C. jamaicensis Edwards (Wirth. 1956 ).

\section{Geography and Climate in Panama}

Geography (Goldman, 1920; Schuchert, 1935): Panama, the southernmost of the Central American republics, lies at the narrowest 


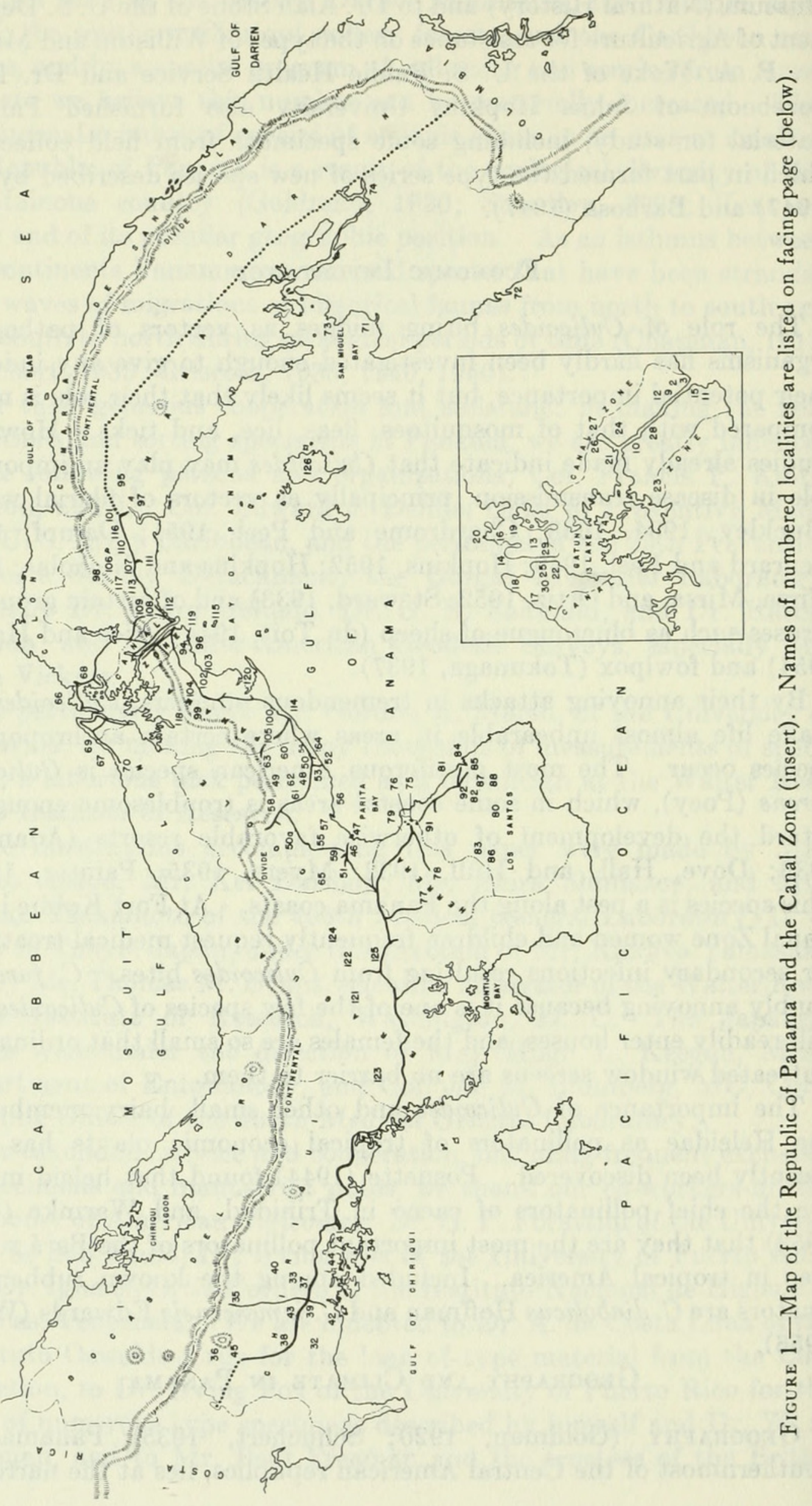




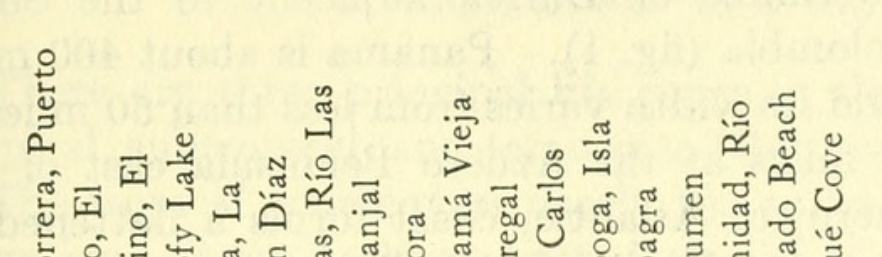

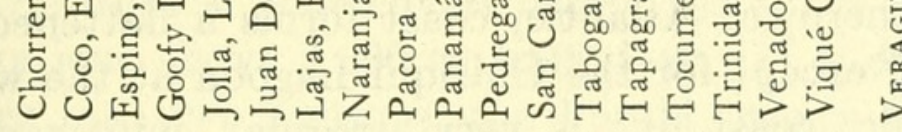

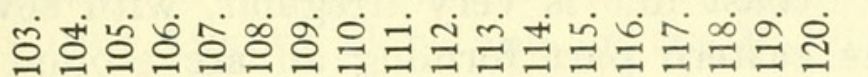

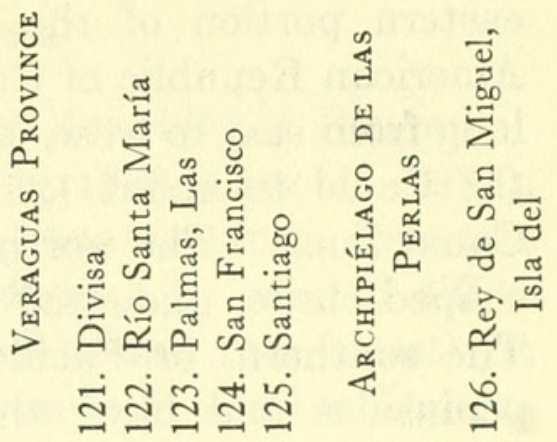

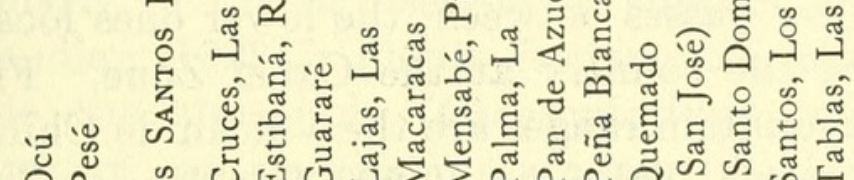

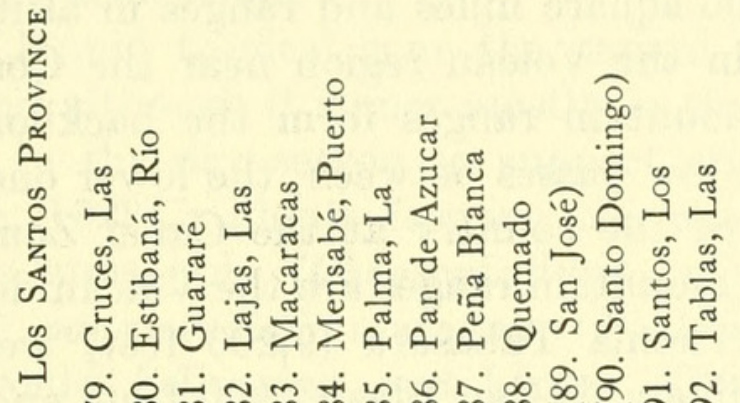
रீळ

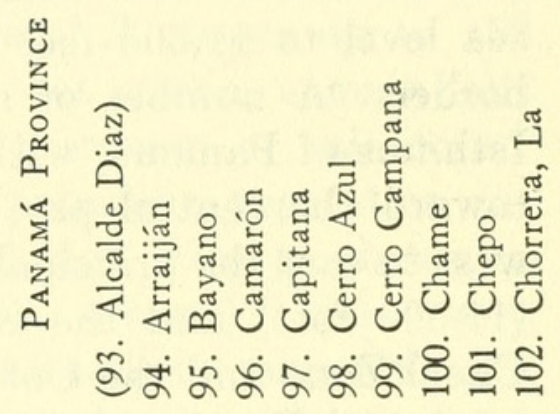

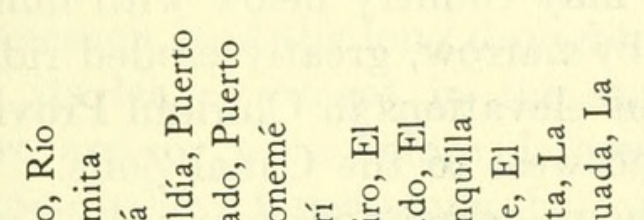

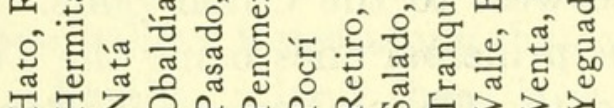

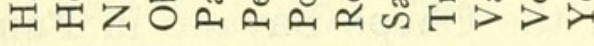

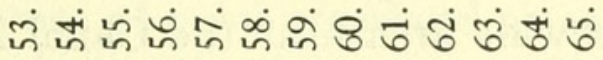

0
0
$z$
0
0
م.
$z$
0
0
0
0

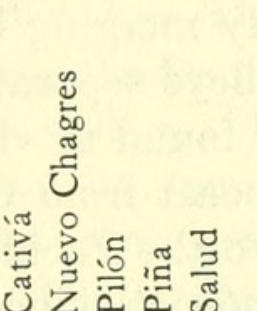
ชิ宀 영

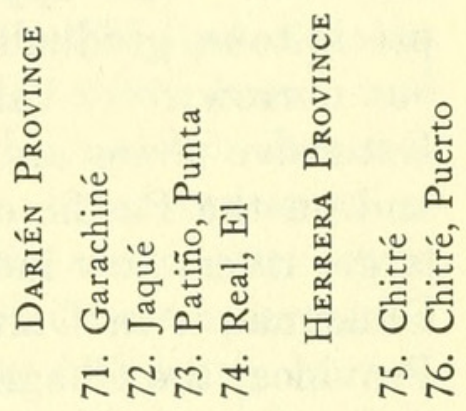

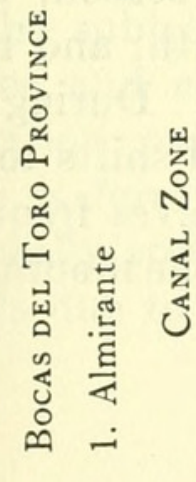

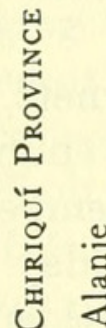
$\sum \sum \sum$

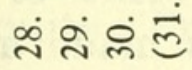

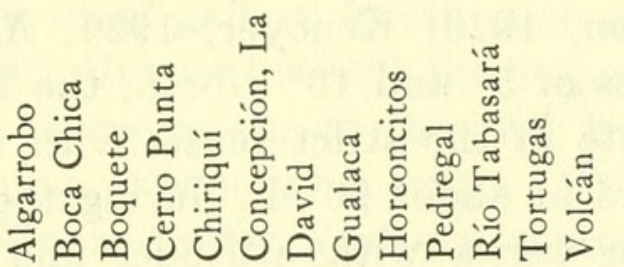
ஸ்

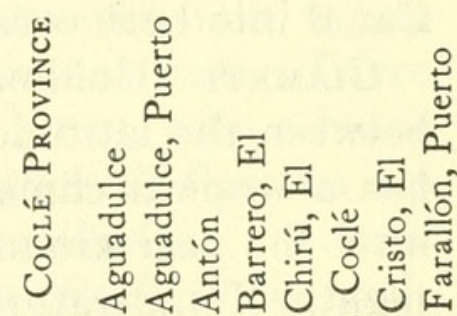

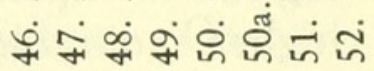

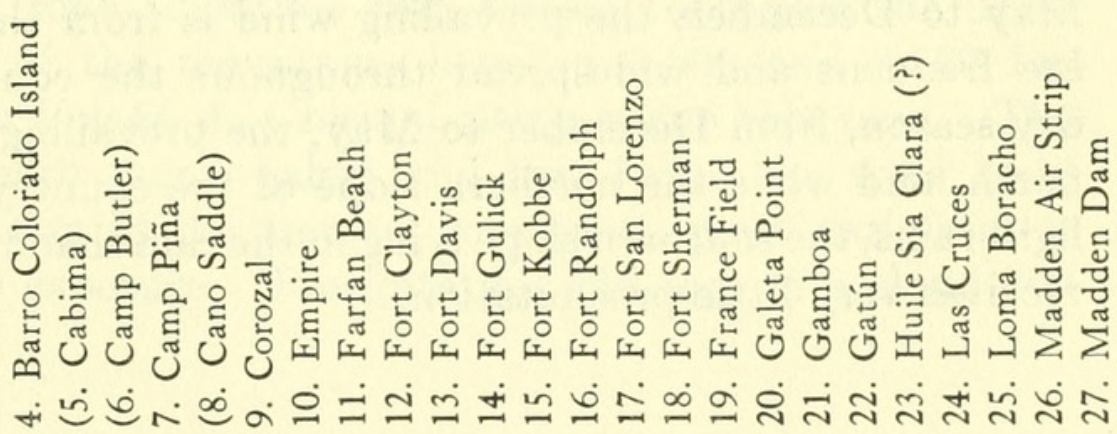


eastern portion of the Isthmus of Darién adjacent to the South American Republic of Colombia (fig. 1). Panama is about 400 miles long from east to west, and its width varies from less than 50 miles at the Canal to about 125 miles at the Azuero Peninsula east of the Canal Zone. The northern, or Atlantic, coast forms a flattened Sshaped curve, undented except for the Chiriquí Lagoon at the west. The southern, or Pacific, coast line is very irregular, with several peninsulas and bays, the eastern part forming an arc around the Gulf of Panama. A number of islands lie off the coasts. Panama has an area of over 34,000 square miles and ranges in altitude from sea level to 11,500 feet in the Volcán region near the Costa Rican border. A number of mountain ranges form the backbone of the Isthmus of Panama, with low passes between, the lower ones located toward the central part of the country at the Canal Zone. From west to east the principal mountain ranges are the Volcán de Chiriquí (11,500 feet) and the Serrainia Tabasará (9,200 feet) west of the Canal Zone and the Cordillera de San Blas (2,900 feet) and the Serrainia del Darién (7,500 feet) closely bordering the Atlantic coast to the east. The upper slopes of the mountains are steep but not precipitous, gradually merging into hilly country below with numerous narrow river valleys separated by narrow, greatly eroded ridges. Extensive plains are found at various elevations in Chiriquí Province and on the Pacific coast from Chepo west to the Canal Zone. The larger rivers flow into the Pacific, the principal ones being the TuiraChucunaque in Darién Province and the Chepo-Bayano in Panamá Province; the Chagres River drains a wide area near the Canal Zone and originally flowed into the Atlantic, but now is impounded in Madden and Gatún Lakes and flows through the locks of the Panama Canal into both oceans.

Climate (Goldman, 1920; Kenoyer, 1929; Arnett, 1950): Lying between the latitudes of $5^{\circ}$ and $10^{\circ}$ North, the Republic of Panama has a tropical climate in the strict sense, with temperatures at sea level the year around of about $90^{\circ} \mathrm{F}$. during the day and $70^{\circ} \mathrm{F}$. at night. Temperature varies with altitude, and thus some of the higher mountains are temperate. The annual cycle is made up of two seasons, the wet and the dry. During the wet season, from May to December, the prevailing wind is from the south, and rains are frequent and widespread throughout the country. During the dry season, from December to May, the prevailing wind shifts to the north, and while the northern slope of the country receives frequent light rains, the southern slope lying in the rain shadow of the mountains receives very little precipitation. 


\section{Life Zones in Panama}

There are three principal life zones in the Republic of Panamatropical, subtropical, and temperate (Goldman, 1920; Griscom, 1935).

The tropical zone covers nearly the entire country except for some elevations above 3,000 to 3,500 feet. It is divided by rainfall differences into two sections, the humid tropics (lowland rain forest) on the entire Atlantic slope and on the Pacific side of eastern Darien, and the arid tropics (arid deciduous forest and savanna) on the remaining Pacific slope.

In the humid tropical zone the annual rainfall ranges up to 150 inches, and although it comes mostly in the wet season, enough falls regularly in the dry season to support an evergreen or rain forest (Standley, 1928). Plants forming the characteristic vegetation include the star-apple (Chrysophyllum), wild fig (Ficus), almendro (Dipteryx panamensis), maragua (Poulsenia armata), and many palms, aroids, heliconias, and lianas. Characteristic mammals are tapirs, monkeys, cats, opossums, squirrels, and arboreal anteaters and sloths.

In the arid tropical zone the rainfall is less, about 85 inches in the wet season, and the long drought causes the forest to turn brown and lose its leaves except in the stream valleys. In western Panama there are, or were before deforestation by man, extensive areas of open or gallery forest along the coastal border, with trees of impressive size. Farther inland there is a belt of low scrub forest interrupted by areas of open grassland or savannas, which are frequently burned over during the dry season. Farther up the slopes of the mountains the forest reappears and becomes better developed. In eastern Panama, merging into the Pacific or South American rain forest, there is a different type of gallery forest, such as that in the Tuyra River valley, called by Griscom (1935) the cuipo forest, with a fauna all its own. Plants characteristic of the arid tropics of Panama are the guarumo (Cecropia arachnoides), cuipo (Cavanillesia), cocobola (Dalbergia retusa), Spanish cedar (Cedrela), guava (Psidium guajava), mesquite (Prosopis), cacti, and many grasses and sedges. Characteristic mammals include peccaries, forest rabbits, foxes, and deer.

The subtropical zone (montane rain forest) comprises the upper slopes and crests of the mountains between 3,000 and 8,500 feet elevation, only the Volcán de Chiriquí rising above this zone. This zone is forested, with many palms and tree ferns, the trees being generally smaller than in the tropical zone, with great variations in kinds due to slope exposure. Precipitation and fogs in a cloud belt 
due to condensation from the northeast trade winds are features of this zone. The subtropical zone is extensive in the Chiriquí highlands and in the two mountainous spurs of the Andes near the Colombian border. Characteristic plants include Podocarpus, oaks, palms, and many ferns, epiphytes, and lianas.

The temperate zone (temperate forest) is confined to the summit of the Volcán de Chiriquí above 8,500 feet elevation. Decrease in moisture and lower temperatures, dropping to below freezing, result in a stunting of the vegetation (pygmy forest) and a heavy overgrowth of moss and lichens. Low ericaceous and myrtaceous shrubs become dominant, among them Dendrophthora spp., Arcytophyllum lavarum, and Maytenus woodsonii.

\section{Distribution of Culicoides by Life Zones}

We can make only tentative lists of the species of Culicoides characteristic of each life zone, principally because so many of the localities are not completely typical of a zone and most of the collections were not made under optimum conditions in each zone.

We have chosen the localities of Almirante and Mojinga Swamp as fairly typical of the humid tropical rain forest on the Atlantic side, and the localities of Tocumen and Aguadulce as typical of the arid tropical savanna country on the Pacific coast. All four of these localities have the complication of proximity to coastal salt marshes with a representation of salt marsh species.

The contrast, however, in the relative abundance of the species found in these two types of environment is evident from table 1. From the table it will be seen that when the salt marsh species (see the following paragraph) are excluded, only six species are common throughout the tropical zone: debilipalpis, diabolicus, dicrourus, galindoi, hylas, and leopoldoi. Seven species are abundant in the humid tropics but absent in the arid tropics: acotylus, castillae, fluvialis, paraensis, propriipennis, pusilloides, and uniradialis. Only one species, insignis, is abundant in the arid tropics cow-pasture country but absent in the Almirante and Mojinga rain forests. Almirante has three abundant species-elutus, nigrigenus, and panamensis - not found at Mojinga, and Mojinga has only one abundant species, caprilesi, not found at Almirante. Of the rarer species, twoginesi and pusillus - are found in all four localities, two-jamaicensis and macrostigma - are found in all but Aguadulce, and one-foxiis found in all but Almirante. Twenty rare species were taken in the humid but not in the arid tropics: antefurcatus, aureus, balsapambensis, camposi, carsiomelas, crescentis, daedaloides, gabaldoni, glabrior, lanei, mojingaensis, pachymerus, patulipalpis, pifanoi, pilosus, poikilonotus, spurius, tenuilobus, tetrathyris, and verecundus. Four- 
teen additional rare species were found only at Almirante: almirantei, azureus, commatus, covagarciai, daedalus, lyrinotatus, marshi, metagonatus, mirsae, pampoikilus, phaeonotus, rangeli, scopus, and transferrans. only six rare species were found at Mojinga only: alahialinus, carpenteri, guyanensis, imitator, limai, and stigmalis.

TABLE 1.-Approximate maximum numbers of specimens of Culicoides collected per trap night in light traps in humid and arid areas of Panama

\begin{tabular}{|c|c|c|c|c|}
\hline \multirow{2}{*}{ Sp } & \multicolumn{2}{|c|}{ Humid tropics } & \multicolumn{2}{|c|}{ Arid tropics } \\
\hline & Almirante & Mojinga & Tocumen & Aguidulce \\
\hline diabolicus & 1000 & 50 & 100 & 1000 \\
\hline insignis & - & - & 100 & 1000 \\
\hline hylas & 100 & 25 & 1 & - \\
\hline leopoldoi & 100 & 50 & 50 & - \\
\hline dicrourus & 50 & 1 & 1 & - \\
\hline propriipennis & 50 & 1 & - & - \\
\hline furens & 10 & 50 & 10 & 1 \\
\hline reticulatus & 1 & 50 & - & - \\
\hline iriartei & 25 & 1 & - & - \\
\hline pusilloides & 25 & 1 & - & - \\
\hline wokei & - & 20 & - & - \\
\hline galindoi & 10 & 1 & 1 & - \\
\hline acotylus & 10 & 1 & - & - \\
\hline elutus & 10 & - & - & - \\
\hline fluvialis & 10 & 1 & - & - \\
\hline castillae & 10 & 1 & - & - \\
\hline nigrigenus & 10 & - & - & - \\
\hline panamensis & 10 & - & - & - \\
\hline paraensis & 10 & 1 & - & - \\
\hline gorgasi & - & 10 & - & - \\
\hline debilipalpis & 1 & 10 & - & 1 \\
\hline caprilesi & - & 10 & - & - \\
\hline uniradialis & 1 & 10 & - & - \\
\hline
\end{tabular}

From the lists given in the preceding paragraph the following ten tidal salt marsh species have been eliminated although they were occasionally recorded from some of the localities: arubae, barbosai, furens, gorgasi, iriartei, phlebotomus, reticulatus, trinidadensis, willistoni, and wokei. These species have never been recorded from inland localities, and their abundance at typical salt marsh localities is confirmed by the list of species taken in such habitats given in table 2 .

Our lists of species characteristic of the higher elevations are doubtless incomplete owing to our small number of collections from 
the temperate and subtropical life zones. We have found seven species-chrysonotus, dunni, efferus, lutealaris, luteovenus, venezuelensis, and volcanensis - confined in Panama to the Volcán region in the lower part of the temperate zone. We record seven species-covagarciai, elutus, magnipalpis, metagonatus, pampoikilus, rostratus, and scopus - as typical of the subtropical zone at Cerro Campana and El Valle, although some of these and three others-nigrigenus, rangeli, and transferrans - range from the Volcán down to the humid tropics at Almirante.

TABLE 2.-Comparison of maximum numbers of species of Culicoides characteristic of the Pacific coastal salt-marsh locations taken per night in light traps

\begin{tabular}{|c|c|c|c|c|}
\hline Species & $\begin{array}{l}\text { Darién Prov. } \\
\text { (Garachiné) }\end{array}$ & $\begin{array}{l}\text { Coclé Prov. } \\
\text { (Puerto } \\
\text { Farallón) }\end{array}$ & $\begin{array}{c}\text { Herrera Prov. } \\
\text { (Puerto } \\
\text { Chitre) }\end{array}$ & $\begin{array}{l}\text { Los Santos } \\
\text { (Puerto } \\
\text { Mensabe) }\end{array}$ \\
\hline trinidadensis & 1000 & 100 & 50 & - \\
\hline furens & 50 & 50 & 200 & 300 \\
\hline gorgasi & 50 & 50 & 20 & 10 \\
\hline reticulatus & 50 & 50 & - & 25 \\
\hline willistoni & 10 & 200 & 20 & - \\
\hline phlebotomus & 10 & 50 & - & - \\
\hline arubae & - & - & 500 & 1 \\
\hline debilipalpis & - & 30 & 1 & 50 \\
\hline iriartei & 1 & 1 & 1 & 50 \\
\hline wokei & 1 & 20 & 10 & - \\
\hline diabolicus and insignis & 10 & 50 & 100 & 30 \\
\hline hylas & 1 & 10 & - & 1 \\
\hline pusillus & 10 & 1 & - & 10 \\
\hline camposi & 1 & - & - & - \\
\hline caprilesi & 1 & - & - & - \\
\hline dicrourus & 1 & - & - & - \\
\hline gabaldoni & - & - & - & 1 \\
\hline ginesi & - & - & - & 1 \\
\hline imitator & - & - & - & 1 \\
\hline jamaicensis & 1 & 1 & 1 & - \\
\hline leopoldoi & 1 & 1 & - & 1 \\
\hline paraensis & - & 1 & - & 1 \\
\hline patulipalpis & 1 & - & - & - \\
\hline pifanoi & 1 & - & - & - \\
\hline uniradialis & 1 & - & - & - \\
\hline
\end{tabular}

According to Chapman (1917), the fauna of the humid tropical rain forests of Panama is essentially an extension of the Amazon Basin fauna through the intervening rain forests of western Colombia and Ecuador. This Colombian-Pacific fauna was cut off from the 
upper Amazon by the Andean uplift in the Tertiary period. Chapman also found a remarkable similarity in the subtropical bird fauna of Colombia to that of Costa Rica and western Panama, with about 60 species in common. He could explain this similarity only by postulating a former continuous extension of the Andes Mountain system at altitudes not less than 5,000 feet throughout Panama. The temperate avifauna of Costa Rica, on the other hand, is not closely related to that of Colombia, indicating that this mountain connection never exceeded a height of 9,000 feet. The subsidence of the Panama Isthmus to its present elevation in what Chapman called the Panama "fault," has resulted in the extinction of the subtropical fauna in the intervening area except for a few relicts such as the Culicoides we have reported from Cerro Campana and El Valle. The fauna of the arid tropical zone of Panama, according to Griscom (1935), is an extension of the Central American faunal subregion, and not closely related to that of South America, except for the gallery forest species, which find their relatives in the arid Dagua and Magdalena areas and the arid north coast of Colombia.

\section{Breeding Places}

General accounts of the breeding habits of Culicoides are given by Carter, Ingram, and Macfie (1920) and Hopkins (1952) for West Africa; Hill (1947), Lawson (1951), and Kettle and Lawson (1952) for Britain; and Williams (1951) for North America. Little rearing work has been done on Neotropical Culicoides, the only important references being Lutz (1913), Painter (1926), Fox (1942), Carpenter (1951), and Woke (1954). The known breeding places of Panama Culicoides are given in table 3 .

Favorite larval habitats include the following: mud and sand at stream, pond, and ditch margins or margins of practically any small body of still or slowly running water; compost piles, rotting leaf mold, and other vegetable matter that stays wet constantly. In the tropics larvae may be found in rotting banana stalks and wet, decaying fruits and stems of plants; mud or wet organic material in or at the sides of rot holes in trees, stumps, bamboo joints, coconut shells, rotten boat bottoms, and the like; wet debris in the leaf or flower axils of waterholding plants such as pitcher plants, aroids, bromeliads, Heliconia, and Pandanus; and crab holes. Picado (1913) showed heleid larvae that resemble Culicoides taken from bromeliads in Costa Rica. Ryckman and Ames (1953) reared Culicoides copiosus Root and Hoffman from rotting stems of the cactus Cereus gigantea in Arizona. 
TABLE 3.-Known breeding places of Panama Culicoides

\begin{tabular}{|c|c|c|}
\hline Species & Locality & Habitat (Authority or Collection Data) \\
\hline arubae & Aruba, D. W. I. & $\begin{array}{l}\text { Crab holes (Fox, 1942; Fox and Hoff- } \\
\text { man, 1944) }\end{array}$ \\
\hline castillae & $\begin{array}{l}\text { Barro Colorado I., } \\
\text { C. Z. }\end{array}$ & $\begin{array}{l}\text { Flowers of Heliconia mariae, June } 1940 \text {, } \\
\text { J. Zetek No. } 4667 \text { (USNM) } \\
\text { Flowers of Heliconia platystachys, Sept. } \\
\text { 1940, J. Zetek No. } 4690 \text { (USNM) }\end{array}$ \\
\hline furens & Honduras & $\begin{array}{l}\text { Sand and mud near tidal canal (Painter, } \\
\text { 1926) }\end{array}$ \\
\hline & Balboa, C. Z. & $\begin{array}{l}\text { Tidal salt marsh (Carpenter, 1951; } \\
\text { Woke, 1954; Blanton, Graham, and } \\
\text { Keenan, 1955) }\end{array}$ \\
\hline heliconiae & Venezuela & $\begin{array}{l}\text { Bromeliads (Fox, 1942; Fox and Hoff- } \\
\text { man, 1944) }\end{array}$ \\
\hline & Honduras & Water holding plant (Fox, 1948) \\
\hline & Trinidad & $\begin{array}{l}\text { Flowers of Heliconia elongata (Wirth } \\
\text { and Blanton, 1956a) }\end{array}$ \\
\hline hoffmani & Puerto Rico & Tree hole debris (Fox, 1949) \\
\hline hylas & $\begin{array}{l}\text { Barro Colorado I., } \\
\text { C. Z. }\end{array}$ & $\begin{array}{l}\text { Bred from Calathea violacea (Wirth and } \\
\text { Blanton, 1956a) }\end{array}$ \\
\hline jamaicensis & Ancón, C. Z. & $\begin{array}{l}\text { Reared from rotted calabash (Hoffman, } \\
\text { 1925) }\end{array}$ \\
\hline luteovenus & California & Tree hole, creek mud (Wirth, 1952a) \\
\hline panamensis & $\begin{array}{l}\text { Barro Colorado I., } \\
\text { C. Z. }\end{array}$ & $\begin{array}{l}\text { Flowers of Heliconia mariae, June } 1940 \text {, } \\
\text { J. Zetek No. } 4667 \text { (USNM) }\end{array}$ \\
\hline phlebotomus & Honduras & $\begin{array}{l}\text { Wet, low depressions behind sandy } \\
\text { beach, water from seepage at high } \\
\text { tide (Painter, 1926) }\end{array}$ \\
\hline pifano $i$ & $\begin{array}{l}\text { Barro Colorado I., } \\
\text { C. Z. }\end{array}$ & $\begin{array}{l}\text { Flowers of Heliconia mariae, June } 1940 \text {, } \\
\text { J. Zetek No. } 4667 \text { (USNM) }\end{array}$ \\
\hline pusillus & Brazil & Mangrove mud (Lutz, 1913) \\
\hline reticulatus & Brazil & Crab holes (Lutz, 1913) \\
\hline trinidadensis & Balboa, C. Z. & $\begin{array}{l}\text { Tidal salt marsh near mangrove (Woke, } \\
\text { 1954) }\end{array}$ \\
\hline verecundus & $\begin{array}{l}\text { Barro Colorado I., } \\
\text { C. Z. }\end{array}$ & $\begin{array}{l}\text { Bracket fungus, Aug. 1944, J. Zetek No. } \\
5175 \text { (USNM) }\end{array}$ \\
\hline
\end{tabular}

\section{Biting Habits}

Lutz (1913) in Brazil took Culicoides reticulatus and insignis on man, horse, and cow; pusillus on man; paraensis on man; and debilipalpis on man and horse. Painter (1926) found the pestiferous species at Puerto Castilla, Honduras, to be furens and phlebotomus. Adamson (1939) found the following species in Trinidad to bite man (named in order of their importance) : phlebotomus, diabolicus, guyanensis, furens, and debilipalpis. 
Gibson and Ascoli (1952) reported on the anthropophilic Culicoides in the human onchocerciasis zone of Guatemala near San Pedro Yepocapa: C. paraensis was the dominant and most annoying species, biting at any hour and in any weather; castillae fed under the same conditions as paraensis but was rare; neither of these species could ingest microfilariae. C. stigmalis bit frequently between $4: 30$ and $6 \mathrm{p} . \mathrm{m}$. when the sky was partly overcast, but this species was not abundant, and although it could ingest microfilariae, they did not develop. C. diabolicus bit only during or immediately after a light rain, and did not feed as avidly on man as the others; no good test was possible on its ability to ingest and support microfiliariae. No natural filarid infestation was found in 929 wild flies of these four species.

Woke (1954) at Balboa, Canal Zone, collected furens biting man in sunlight and in shade of mangrove trees, under electric lights and also in darkness, from 9 a. m. to 9 p. m. He collected guyanensis biting man between 7 and 8 p. m., trinidadensis about man, and wokei flying about man in shade of mangrove trees and in full sunlight between 9 and 10 a. m. On Tobago Island he took furens, paraensis, and debilipalpis biting man, and at Corinto, Nicaragua, he collected furens and phlebotomus on man.

Wirth (1955b) reported the following Panama species from the collections of Gibson and Ascoli in Guatemala taken while biting man: paraensis, pachymerus, stigmalis, diabolicus, castillae, and debilipalpis. At the same time Gibson and Ascoli took luteovenus, diabolicus, debilipalpis, and panamensis feeding on horse and mule.

In the U. S. National Museum collection there are the following unpublished records of Panama species taken on man: barbosai, Balboa, Canal Zone, P. A. Woke, No. 1014a; diabolicus, St. Patrick Estate, Trinidad, 1954-1955, T. H. G. Aitken and W. G. Downs; pusillus, Cumaca, Trinidad, June 16, 1954, Aitken and Downs; and of the following species biting other animals: arubae, Corazal, Canal Zone, May 18, 1914, S. T. Darling, from ear of mule; foxi, Fort Kobbe, Canal Zone, Blanton, horse trap; Piraja, Brazil, Apr. 16, 1929, Davis and Shannon, animal bait; barbosai, Fort Randolph, Canal Zone, Blanton, horse trap.

In summary, the following species of Panama Culicoides are known to feed on man: barbosai, castillae, debilipalpis, diabolicus, furens, guyanensis, pachymerus, paraensis, phlebotomus, pusillus, reticulatus, and trinidadensis.

\section{Control Measures}

The control of Culicoides has received little attention in Panama compared with the classic measures used to abate mosquitoes during and since the construction of the Panama Canal. Carpenter (1951) 
and Blanton, Graham, and Keenan (1955) gave details on efforts to control the enormous population of Culicoides furens (Poey) at Fort Kobbe, which adjoins Farfan swamp on the west bank of the Pacific entrance of the Canal. The most successful measure was the installation of tide gates at the mouth of the Farfan River in August 1950. After the rainy season had passed, by February 1951, the action of these gates in eliminating salt water from the marshes caused the water level to recede to the deeper ditches and channels. This change resulted in the growth of luxuriant vegetation on the drier ground and a great reduction in the Culicoides population. The tide gates were only of temporary construction, and owing to their gradual deterioration by the end of 1953 the water level in the marsh had risen and the salinity had increased so that furens again became a serious pest. Airplane spraying of the marshes with dieldrin and lindane at the rate of 1 pound and chlordane at 2 pounds per acre gave good control for several weeks, but was too expensive for any but emergency measures. Fog and mist sprays for adult control were almost useless, since the adults emerged in large numbers daily from the marsh during the breeding season. Painting window screens with DDT gave some protection inside houses, but some insects would pass the barrier and bite before the insecticide took effect.

\section{Methods of Collection and Study}

The primary source of our specimens has been the material obtained by the junior author from surveys for insects of medical importance at military installations in the Republic of Panama and the Canal Zone (Blanton, Galindo, and Peyton, 1955). These surveys were begun in the Canal Zone, but were gradually expanded to take in as large an area of the Republic of Panama as possible. Most of the surveys were made on the principal road systems of the Republic, but several were made at installations in Darién Province, accessible by boats of the Inter-American Geodetic Survey at Patino Point. A large series of collections was made at Almirante in Bocas del Toro Province in connection with the yellow fever studies carried on by the Gorgas Memorial Laboratory.

Nearly all our material was obtained by means of New Jersey light traps operated primarily for studies on mosquito distribution. Light traps were operated in about 150 localities (see map in fig. 2 for the principal locations). In each locality it was customary to operate as many as three generators and six or more light traps within a radius that could be serviced by a survey crew of two to eleven men. A Shannon trap was also operated in some areas. This trap is a tentlike enclosure made of cheesecloth or mosquito netting, hung from the four upper corners by tying cord or rope to limbs or trees at a height which 
allows approximately 2 feet of clearance at the bottom of the tent. A light is hung inside near the top of the tent, and the insects that enter at the bottom are captured from the sides with an aspirator or killing bottle.

For a 2-year period beginning August 1951 the following collections were made in 517 nights of trap operation:

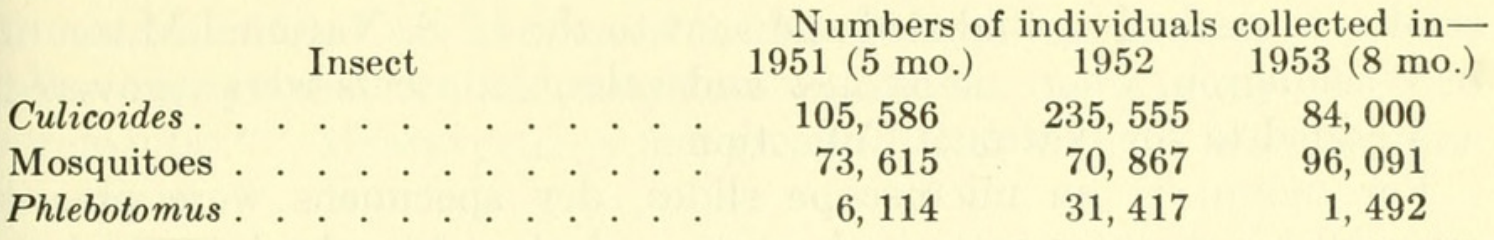

Of the 150 localities where traps were operated, only the following received concentrated attention with more than 10 nights of operation, the remainder having been visited only from 1 to 10 nights each:

Locality

Almirante

Garachiné

Jaqué

La Jolla

Loma Boracho

Mojinga Swamp .

Patino Point

Tocumen .
Nights Months

$58 \quad 6$

$12 \quad 1$

$11 \quad 2$

$16 \quad 10$

$22 \quad 12$

$76 \quad 12$

$74 \quad 4$

$26 \quad 9$

In spite of this coverage most of Panama has been very inadequately surveyed. The only possible exception is the Mojinga Swamp, where the trapping was done constantly over the entire period. At Almirante most of the trapping was done at one yellow fever tree station in a deep tropical rain forest, and many other habitats were not sampled. For unavoidable technical reasons the Darién trap locations were unsatisfactory for sampling Culicoides populations. Far too few collections were made from the subtropical mountain locations at Cerro Campana in Panamá Province and El Valle in Coclé Province, where nevertheless many unique records were obtained. The transect up the slope of the Volcán in Chiriquí Province was far too scanty to obtain more than a barest indication of that interesting temperate fauna. We have been able to secure only species that will come to light or horse-baited traps. From studies in North America we suspect that up to 10 or 20 percent of the fauna would never be taken in light traps and even fewer at animal bait. Thus at least a dozen additional species could very likely have been taken by a program of collection and rearing from larval habitats, had that been possible.

The light traps were equipped daily with jars containing fresh potassium cyanide, and the catches were placed each morning in pasteboard pill boxes and brought into the laboratory. A layer of 
melted paradichlorobenzene had been poured in the bottoms of the pill boxes to afford protection against molds and museum pests, and the insects were placed in thin layers between padded filter cotton. The boxed specimens were stored in heated cabinets until the insects could be sorted. The insects of medical importance were determined in the laboratory or sent to specialists, and the residue of insects or trash was packed and labeled and sent to the U. S. National Museum in Washington, where many new and valuable insects were recovered and added to the National Collection.

For mounting on microscope slides, dry specimens were placed overnight in a warm saturated solution of phenol in absolute alcohol. By the next day the specimens were well cleared and were then transferred to a solution containing equal parts of Canada balsam and the liquefied phenol. After a few minutes they could be transferred to slides for dissection. Dissection consisted in cutting off the wings and mounting them in a separate drop of the mixture on one end of the slide under a separate cover glass, cutting off the head and orienting it anterior side up, and cutting off the abdomen and orienting it ventral side up. It was necessary to cut off the male genitalia between the eighth and ninth segments in order always to orient the specimen ventral side up. A small piece of broken cover glass was added to prevent undue flattening and the cover glass applied. After labeling, the slides were placed in a warm drying oven for about two weeks, and extra balsam was added from time to time to replace the mixture lost by evaporation of the phenol.

The types of the new species and most of the material studied are deposited in the U. S. National Museum. Paratypes and determined series of as many of the Panama species as available will be deposited in the following collections: British Museum (Natural History), London, England; Gorgas Memorial Laboratory, Ancón, Canal Zone; Instituto Nacional de Higiene, Caracas, Venezuela; Instituto Oswaldo Cruz, Rio de Janeiro, Brazil; Musée Royal d'Histoire Naturelle, Brussels, Belgium; Universidade de São Paulo, São Paulo, Brazil; and the University of Puerto Rico, San Juan, Puerto Rico.

In the distribution records, the first country given is that of the type locality and the remaining countries are listed alphabetically. The Panama localities are listed alphabetically by province; these localities are given according to the Esso Standard Oil highway map of Panama and the American Geographical Society's "Map of Hispanic America, 1:1,000,000." Some new distribution records for certain countries are given, based on specimens in the U. S. National Museum collection; for these the names of the towns or other data are added in parentheses. Unless otherwise indicated, all Panama records are based on specimens collected by the junior author in light traps. The 
new Honduras and Nicaragua records are based on material collected in light traps operated in the yellow fever surveys by the Gorgas Memorial Laboratory under the direction of Pedro Galindo.

Our measurements are made with an ocular micrometer and, with rare exceptions, are of specimens cleared in phenol and mounted on slides in balsam. Measurements are usually made of a series of about 10 specimens and are presented in the descriptions according to the following system: "mean (minimum-maximum, $\mathrm{n}=$ number of measurements)." Measurements not given in that manner are of single specimens.

\section{MORPHOLOGY}

Figures 2, 3

The descriptions and figures of the structure of Culicoides given by Carter, Ingram, and Macfie (1920) are still classical, although valuable studies on the head structure have since been made by Jobling (1928) and Gad (1951), and on general anatomy by Tokunaga (1937) and Lee (1948). The following account is a revision of the generalized description of characters of the Heleidae given by Wirth (1952a).

HEAD: The head is subspherical, with the anterior surface more or less flattened and in line with the anterior surface of the proboscis. The dorsal surface of the head consists of the broad posterior occiput

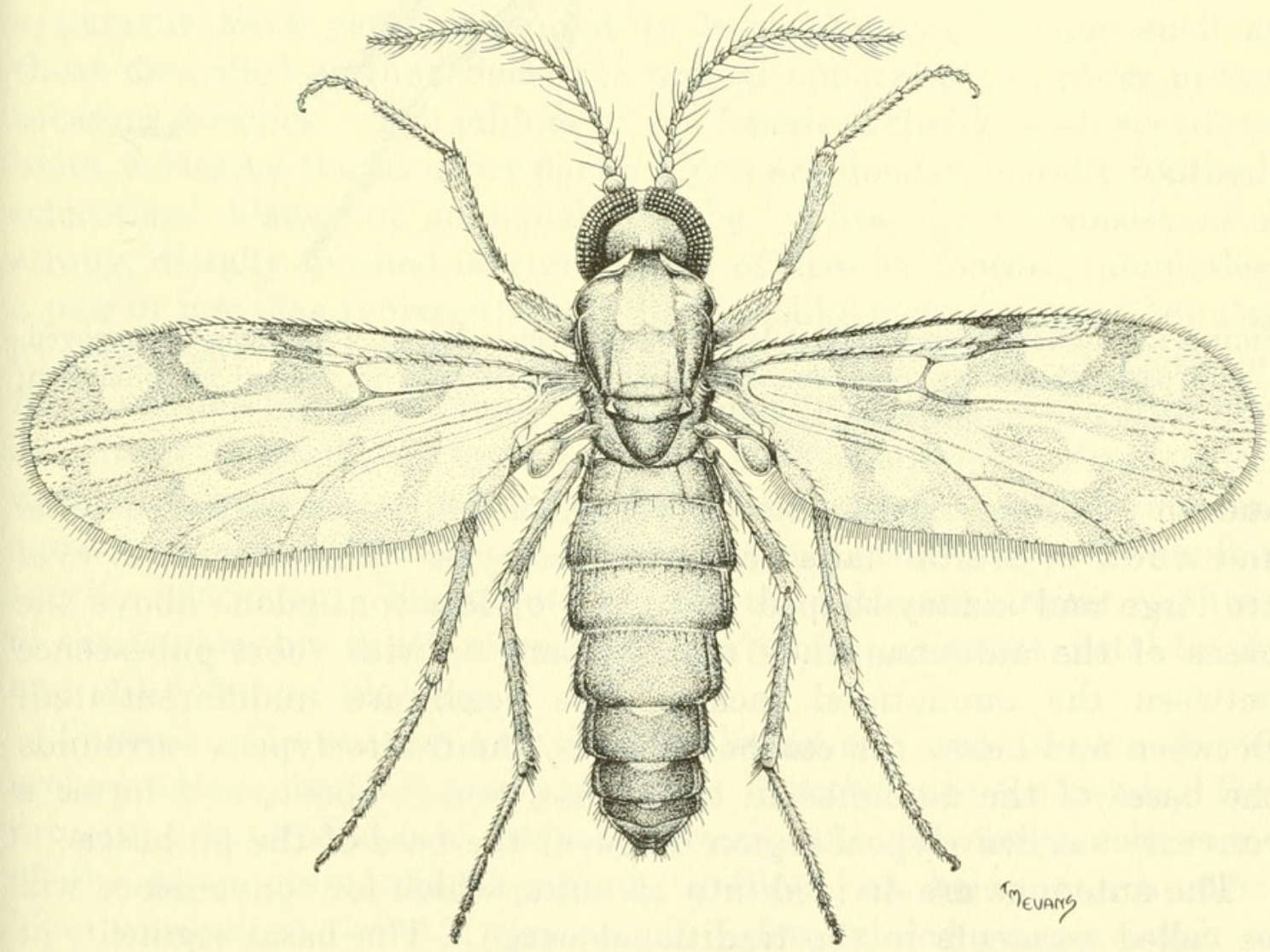

Figure 2.-Culicoides diabolicus Hottman, dorsal aspect of female. 


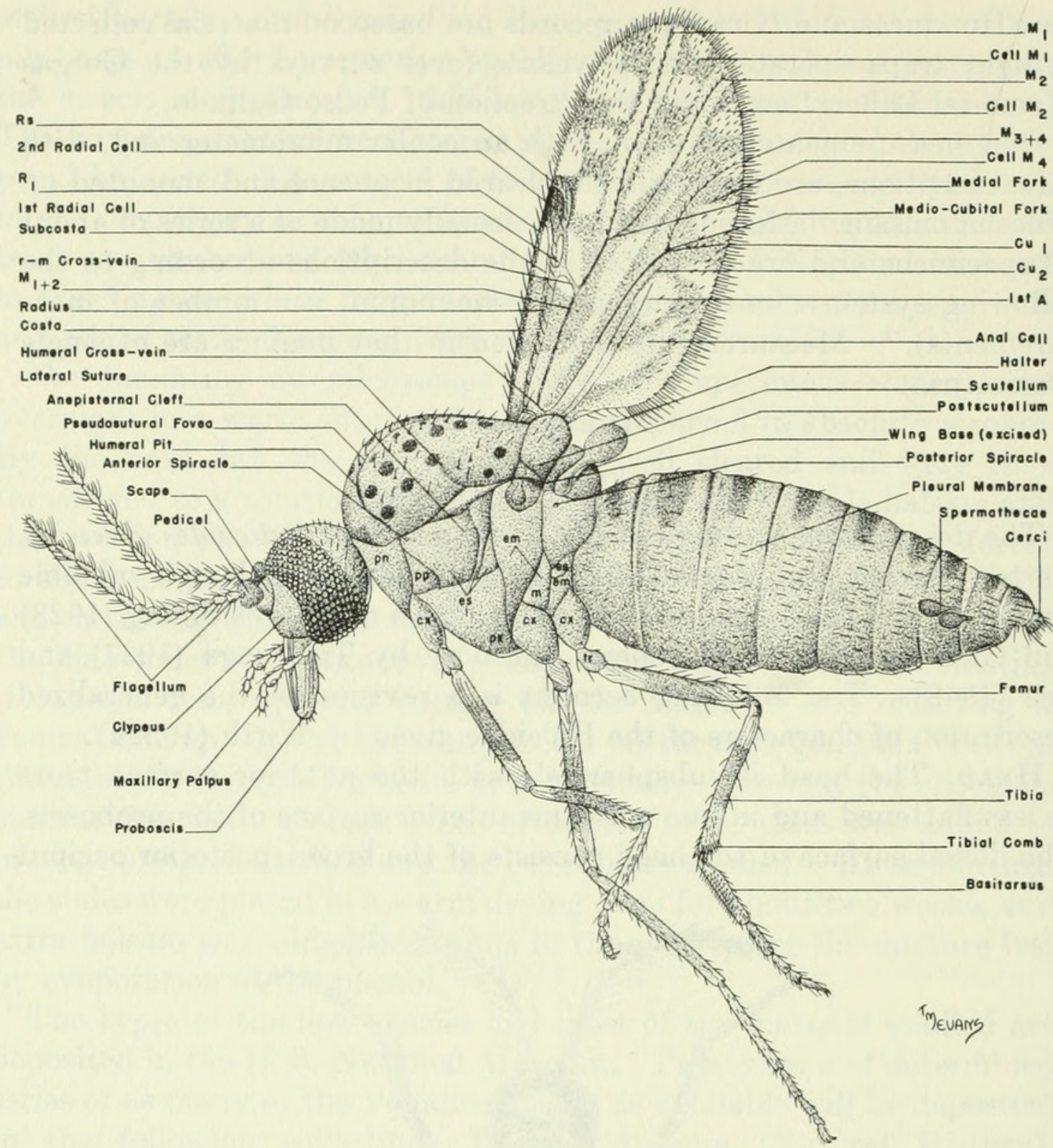

Figure 3.-Culicoides furens (Poey), lateral view of female, left wing and right legs removed, with parts labeled (cx, coxa; em, epimeron; es, episternum; m, meron; pn, pronotum; pp, propleuron; px, precoxale; tr, trochanter).

and an undifferentiated anterior vertex, usually with scattered setae and a row of orbital hairs bent over the eyes. The compound eyes are large and kidney-shaped and more or less contiguous above the bases of the antennae; they may be bare or with short pubescence between the ommatidial facets. The ocelli are undifferentiated. Between and below the compound eyes, the frontoclypeus surrounds the bases of the antennae in the frontal region above, and forms a convexly swollen clypeal region below at the base of the proboscis.

The antennae are divided into 15 units, which for convenience will be called segments in the traditional usage. The basal segment, or scape, is ringlike and hidden by the greatly enlarged pedicel. Seg- 
ments 3 to 15 form the flagellum, which in the female is divided into three portions - an elongated third segment, the subequally shortened segments 4 to 10 , and the elongated segments 11 to 15 . All the flagellar segments bear scattered small hairs, and in addition each of the proximal eight bears a whorl of long hairs, or verticils. In the male, the pedicel is much more enlarged and the transition in the flagellar series occurs between segments 12 and 13, with segments 3 to 12 each bearing a whorl of very greatly elongated, erectile verticils forming a more or less dense plume. The presence of one to several minute hyaline sensory discs ringed by dense tufts of very short setae at the apices of certain flagellar segments is a character recently found to be extremely useful in the recognition of species or of species groups. The relative lengths of the segments are also useful in classification, and the antennal ratio, obtained by dividing the combined lengths of the last five segments by the combined lengths of the preceding eight, is a convenient way of expressing the most basic relation.

The mouthparts are well developed, stronger in the female than in the male, and in most species those of the female are especially fitted for piercing and blood-sucking. They are enclosed in an elongated proboscis often as long as the head capsule itself. Internally the sucking apparatus consists of a cibarial and a pharyngeal pump; no characters of the sclerotized parts of the pharyngeal apparatus have yet been found to have taxonomic value such as those described as the "buccopharyngeal apparatus" in other nematocerous families. The labium of the female is fleshy, with scattered hairs, enclosing the six other parts, which are slender, distally toothed, sclerotized blades of subequal lengths. These parts consist of a strong, distally toothed labrum, a pair of distally toothed mandibles, a pair of maxillae represented by the bladelike laciniae, and a tubular hypopharynx also bearing distal teeth. The number of teeth on the mandible has been found to be especially useful in differentiation of closely related species. The maxillary palpus is 5-segmented and the third segment is more or less swollen and bears on the mesal surface a specialized sense organ, the nature of which is a very valuable specific character. The mouthparts of the male are similar to those of the female, but much more poorly developed, without distal teeth, and not fitted for piercing.

Thorax: The thorax is moderately broad and very convex above, arched anteriorly, and projecting very slightly over the head. The pronotum is divided into lateral halves by the anterior development of the mesonotum and lies partly hidden just below the humeri. The mesonotum bears in this and in a few related genera a pair of small sensory pits sublaterally on the humeral corners near the 
anterior margin, with a pair of almost invisible, slightly depressed lines, the pseudosutural foveae, extending from the pits caudad to near the sides of the scutellum. The mesonotum is clothed with short hairs, which may be somewhat enlarged in rows along the foveae. When a color pattern or pattern of pruinose markings is present, the sublateral markings usually have their mesal margins at the foveae and their greatest breadth is usually at lateral extensions toward the mesonotal or lateral suture, which extends midway on each side from the lateral margins of the mesonotum a short distance mesad. The prescutellar area of the mesonotum is more or less flattened and bears a submedian pair of sensory areas. The scutellum is transverse, with a median caudal expansion and bears a number of strong bristles and short hairs. The postscutellum is arched and bare, with a small, deep, glandular depression. The pleura are bare, each divided into a number of sclerites, with a broad membranous cleft on the anepisternum of the mesopleuron, with an anterior spiracle located in the membrane just behind the pronotum and the posterior spiracle located on the metapleural membrane just below the halter.

The legs are moderately slender, the femora sometimes slightly swollen, not bearing modified spines or scales. At the apex of the fore tibia are a small spur and a tuft of modified hairs, and at the apex of the hind tibia are an anterior spur and two transverse rows of modified spinose hairs. The term "hind tibial comb" includes only the long spines in the distal row and is sometimes useful in classification. The tarsal ratio is the length of the hind basitarsus divided by the length of the second tarsomere, but we have not found it to be of much taxonomic value in this genus. The fourth tarsomere on all legs is usually cylindrical, but in the subgenus Macfiella Fox it is cordiform. The claws are small and equal on all legs, simple in the female and divided at the apices in the male; the empodium is vestigial.

The wings possess dense microtrichia, and the macrotrichia or long hairs may range from numerous to absent. There is usually a pattern of pale and dark spots or bands, which is of prime importance in classification. The costa extends from the base of the wing to half or more than three-fourths of the wing length. There are with rare exceptions two complete radial cells formed by the heavily sclerotized radial branches. The radial cells are usually of subequal lengths, and the second or distal one is usually broader than the first, which may frequently be slitlike. We use the Tillyard modification of the Comstock-Needham system of wing venation, whereby the branches of the anterior fork are called $M_{1}$ and $M_{2}$ and those of the posterior fork $\mathrm{M}_{3+4}$ and $\mathrm{Cu}_{1}$, from front to back. We 
employ an exact measurement of the wing length, comprising the distance from the basal arculus to the tip of the wing, which is about a tenth less than the measurement to the basal attachment of the wing commonly employed by other authors. The color of the halter is frequently of taxonomic importance.

Abdomen: The female abdomen is relatively stout, the apex somewhat tapered, with a pair of small, rounded cerci visible below the ninth tergum. Internally the female usually possesses sclerotized spermathecae which are usually spherical to pyriform, sometimes with the bases of the ducts sclerotized a short distance. The number of completely formed, sclerotized spermathecae varies from none to three; all the known Panama species have one or two. 'The spermathecae are joined by nonsclerotized ducts to a common duct, and at the juncture there is sometimes a small sclerotized ring. In some species with two functional spermathecae the small rudimentary third one is also sclerotized. In our descriptions we make no mention of this third rudimentary spermathecae and ring. We measure the length of the spermatheca in the axis of the base of the duct and include the sclerotized portion of the duct.

The male abdomen is very slender and bears terminally the prominent genitalia, which are of primary importance in group classification and species identification. The ninth segment is in the form of an irregular sclerotized ring consisting of the fused tergum and sternum. The ninth tergum is in the form of an expanded lobe or plate, convex externally and hollowed out mesad and bearing the anus flanked by a pair of membranous setose anal lobes or cerci on the ventromesal face. The hind corners of the ninth tergum are frequently expanded as a pair of apicolateral processes. The ninth sternum is much shorter than the tergum, usually with a caudomedian excavation on its hind margin, at the lateral corners of which the base of the aedeagus articulates. The forceps-like genital appendages, or gonopods, arise laterally at the base of the tergum and are 2-segmented. The enlarged basal segment (basistyle or side piece) bears two internal processes at the base, a mesally directed ventral root and an anteriorly directed dorsal root, the latter articulating directly with the base of the paramere. The distal segment (dististyle or clasper) is hairy and slightly swollen at the base, slender and nearly bare distally, with an incurved point, and when not extended is folded mesad from the apex of the basistyle across the mesal face of the ninth tergum. The aedeagus is usually a $Y$-shaped structure with the stem directed ventrocaudad, forming the sclerotized support on the ventral surface of the male genital duct. The distal portion of the aedeagus is less sclerotized than the basal arms or arch, is usually shallowly U-shaped in cross section and may be variously ornamented or modified distally 
and laterally. The basal arch of the aedeagus is connected to the posterior excavation of the ninth sternum by a hyaline membrane which in a few species is partially covered with spinules or spicules. The parameres are usually a pair of sclerotized internal rodlike sclerites with knobbed bases and ventrally directed distal points, but they are subject to great modifications in the shape and direction of the basal knob, the middle stem, or the distal point. In some groups of species the parameres may fuse mesad and become platelike.

\section{Systematic Discussion}

The modern classification of the genus Culicoides had its beginnings as recently as 1937, when Root and Hoffman grouped the North American species according to the characters of the male genitalia supported by a number of external characters. Edwards followed and enlarged upon this system in 1939 with a grouping of the Palaearctic species. In 1948 Fox erected the subgenus Hoffmania for a number of Neotropical species which he differentiated from Culicoides, s. str. Ortiz (1950) accepted and strengthened Fox's concept of the subgenus Hoffmania. Wirth (1952a) attempted only to follow Root and Hoffman's outline in assigning the California species to groups without respect to subgenera. None of the recent regional revisionssuch as those by Causey (1938, Siam), Fiedler (1951, South Africa), Gutsevitch (1952, Russia), Lee and Reye (1953, Australia), and Foote and Pratt (1954, eastern United States) - attempt any grouping of species.

The first important attempt to bring the genus Culicoides into a phylogenetic system was by Khalaf (1954), who placed the species of the world in four subgenera-Culicoides, s. str., Oecacta Poey, Selfia Khalaf, and Monoculicoides Khalaf-assigning all the species whose genitalic characters had been figured in the literature to five complexes and 21 groups within these subgenera. Although Khalaf's concept of important phylogenetic characters was basically sound, he was hindered by the limited information available in the literature. In a genus whose taxonomy is expanding so rapidly we may expect numerous reshufflings of groups as new species are described and our knowledge of the older species improves. Vargas' (1953a) proposal of the subgenus Beltranmyia for species of the crepuscularis group and Fox's (1955a) erection of the subgenera Avaritia for the obsoletus group and Macfiella for the phlebotomus group furnish badly needed subgeneric names, but numerous species will probably pass through various taxa before being assigned to their correct phylogenetic niches.

We believe that in a genus as large and compact as Culicoides the number of subgenera will eventually have to be increased fourfold 
or fivefold, but until a considerable portion of the species from each region are well described and a general fund of taxonomic characters is made available to work with, no system of classification should be attempted which would be more than a convenient way to think flexibly in terms of groups of related species. We believe that the literature and generic synonymies will be more easily handled in later years if our first attempts to group the species phylogenetically are done in terms of taxa outside the rules of priority and nomenclatural bookkeeping. As certain groups become comparatively well known and the relations of the species are worked out on a natural basis, the groupings can be formalized with subgeneric names. For these reasons we are proposing a tentative framework of taxonomic groups of the Panama species, utilizing subgeneric names for some when these are already available and appropriate, but refraining from proposing any new subgenera at this time.

Our proposed classification of the Panama species (table 4) serves as a systematic check list of species and a convenient summary of the most important quantitative characters used. The species numbers in this table agree with the species numbers in the crossheads throughout the text. An alphabetical list of species and synonyms is presented on page 474 .

TABLE 4.-Systematic arrangement of Panama species of Culicoides with certain quantitative characters

(NotE: Except for segments having sensoria, mean values are shown. Asterisk denotes doubtful position of species in group. Parentheses enclosing segment numbers indicate these segments sometimes have sensoria)

\begin{tabular}{|c|c|c|c|c|c|c|}
\hline Subgenera, groups, and species & $\begin{array}{l}\text { Wing } \\
\text { length } \\
(\mathrm{mm} .)\end{array}$ & $\begin{array}{l}\text { Costal } \\
\text { ratio }\end{array}$ & $\begin{array}{l}\text { An- } \\
\text { tennal } \\
\text { ratio }\end{array}$ & $\begin{array}{c}\text { Segments having } \\
\text { sensoria }\end{array}$ & $\begin{array}{l}\text { No. } \\
\text { mandib- } \\
\text { ular } \\
\text { teeth }\end{array}$ & $\begin{array}{l}\text { No. } \\
\text { tibial } \\
\text { spines }\end{array}$ \\
\hline \multicolumn{7}{|l|}{ Culicoides (Hoffmania) } \\
\hline The hylas group & & & & & & \\
\hline 1. heliconiae & 1. 46 & 0. 68 & 1. 06 & $3,11-15$ & 23 & 6 \\
\hline 2. hylas & 1. 19 & 0.68 & 1. 12 & $3,11-15$ & 19 & 6 \\
\hline 3. verecundus & 1. 31 & 0.70 & 1. 10 & $3,11-15$ & 23 & 6 \\
\hline \multicolumn{7}{|l|}{ The guttatus group } \\
\hline 4. diabolicus & 1. 03 & 0.67 & 1. 14 & $3,11-15$ & 15 & 5 \\
\hline 5. foxi & 1. 21 & 0.68 & 1. 10 & $3,11-15$ & 16 & 6 \\
\hline 6. insignis & 1. 11 & 0.65 & 1. 32 & $\begin{array}{c}3,5,7,9 \\
11-15 .\end{array}$ & 21 & 6 \\
\hline 7. trinidadensis & 1. 12 & 0.66 & 1. 22 & $\begin{array}{c}3,5,7,9 \\
11-15 .\end{array}$ & 17 & 5 \\
\hline \multicolumn{7}{|l|}{ Culicoides (Avaritia) } \\
\hline 8. pusilloides & 0. 69 & 0.57 & 1. 12 & $3,12-15$ & 13 & 5 \\
\hline 9. pusillus & 0.64 & 0.53 & 1. 18 & $3,13-15$ & 14 & 5 \\
\hline
\end{tabular}


TABLE 4.-Systematic arrangement of Panama species of Culicoides with certain quantitative characters - Continued

(Note: Except for segments having sensoria, mean values are shown. Asterisk denotes doubtful position of species in group. Parentheses enclosing segment numbers indicate these segments sometimes have sensoria)

\begin{tabular}{|c|c|c|c|c|c|c|}
\hline Subgenera, groups, and species & $\begin{array}{r}\text { Wing } \\
\text { length } \\
(\mathrm{mm} .)\end{array}$ & $\begin{array}{l}\text { Costal } \\
\text { ratio }\end{array}$ & $\begin{array}{l}\text { An- } \\
\text { tennal } \\
\text { ratio }\end{array}$ & 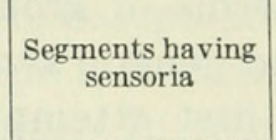 & $\begin{array}{c}\text { No } \\
\text { mandib- } \\
\text { ular } \\
\text { teeth }\end{array}$ & $\begin{array}{l}\text { No. } \\
\text { tibial } \\
\text { spines }\end{array}$ \\
\hline \multicolumn{7}{|l|}{ Culicoides (Culicoides) } \\
\hline The pulicaris group & & & & & & \\
\hline 10. elutus & 1. 14 & 0.65 & 0.93 & $3,11-15$ & 16 & 6 \\
\hline 11. luteovenus & 1. 35 & 0.60 & 0.99 & $3,11-15$ & 14 & 6 \\
\hline \multicolumn{7}{|l|}{ The covagarciai group } \\
\hline 12. efferus & 1. 49 & 0.67 & 0.93 & $3,11-15$ & 24 & 6 \\
\hline 13. rostratus & 1. 13 & 0.68 & 0.98 & $3,11-15$ & 20 & 6 \\
\hline 14. marshi & 1. 18 & 0.68 & 1. 18 & $3,11-15$ & 27 & 5 \\
\hline 15. covagarciai & 1. 19 & 0.67 & 1. 09 & $3,11-15$ & 15 & 6 \\
\hline 16. metagonatus & 1. 02 & 0.63 & 0.95 & $3,11-15$ & 15 & 6 \\
\hline \multicolumn{7}{|l|}{ The nigrigenus group } \\
\hline 17. nigrigenus & 1. 11 & 0.64 & 2. 00 & $3-15$ & 13 & 4 \\
\hline 18. lutealaris & 1. 56 & 0.58 & 1. 30 & $3-15$ & 14 & 4 \\
\hline 19. chrysonotus & 1. 66 & 0.60 & 2. 10 & $3,8-15$ & 14 & 4 \\
\hline \multicolumn{7}{|l|}{ Culicoides (Oecacta) } \\
\hline The daedalus group & & & & & & \\
\hline 20. antefurcatus & 0. 79 & 0.58 & 1. 16 & $3,11-15$ & 14 & 4 \\
\hline 21. crescentis & 0.95 & 0.62 & 1. 48 & $3,11-15$ & 13 & 4 \\
\hline 22. daedalus & 1. 01 & 0.62 & 1. 34 & $3,11-15$ & 13 & 4 \\
\hline 23. commatis & 1. 02 & 0.58 & 1. 19 & $\begin{array}{c}3,5,7,9 \\
11-15 .\end{array}$ & 12 & 4 \\
\hline 24. pampoikilus & 1. 25 & 0.59 & 1. 39 & $\begin{array}{c}3,5,7,9 \\
11-15 .\end{array}$ & 14 & 4 \\
\hline 25. phaeonotus & 1. 06 & 0.61 & 1. 63 & $\begin{array}{c}3,5,7,9 \\
11-15 .\end{array}$ & 12 & 4 \\
\hline 26. dunni & 1. 12 & 0.56 & 1. 13 & $\begin{array}{l}3,4,6,7,9 \\
11-15\end{array}$ & 18 & 4 \\
\hline 27. daedaloides* & 1. 0 & 0.63 & 1. 48 & $3,8-10$ & 12 & 4 \\
\hline \multicolumn{7}{|l|}{ The copiosus group } \\
\hline 28. pilosus & 0. 99 & 0. 59 & 1. 56 & $3-9,11-15$ & 17 & 4 \\
\hline 29. panamensis & 0.87 & 0.55 & 1. 12 & $3,11-15$ & 10 & 4 \\
\hline 30. poikilonotus & 0.83 & 0.61 & 1. 26 & $3,11-15$ & 10 & 4 \\
\hline 31. jamaicensis & 0.97 & 0.57 & 1. 21 & $3-15$ & 15 & 4 \\
\hline \multicolumn{7}{|l|}{ The iriartei group } \\
\hline 32. evansi & 1. 17 & 0.57 & 1. 02 & $3,7-10$ & 13 & 4 \\
\hline 33. iriartei & 0.93 & 0.61 & 1. 42 & $3,7-10$ & 11 & 4 \\
\hline \multicolumn{7}{|l|}{ The scopus group } \\
\hline 34. scopus & 1. 34 & 0.58 & 1. 65 & $3,8,10-15$ & 15 & 4 \\
\hline \multicolumn{7}{|l|}{ The limai group } \\
\hline 35. galindoi & 0.83 & 0.62 & 0.95 & $3,7-10$ & 14 & 4 \\
\hline 36. limai & 0.80 & 0.63 & 1. 06 & $3,7-10$ & 13 & 4 \\
\hline 37. tenuilobus & 0.89 & 0.62 & 1. 13 & $3,7-10$ & 13 & 4 \\
\hline 38. camposi & 0.86 & 0.59 & 1. 18 & $3,7-10$ & $13-14$ & \\
\hline
\end{tabular}


TABLE 4.-Systematic arrangement of Panama species of Culicoides with certain quantitative characters - Continued

(NotE: Except for segments having sensoria, mean values are shown. Asterisk denotes doubtful position of species in group. Parentheses enclosing segment numbers indicate these segments sometimes have sensoria)

Subgenera, groups, and species
Culiciodes (Oecacta) - Con
The limai group-Con

39. carpenteri*

40. magnipalpis*

The acotylus group

41. wokei

42. carsiomelas

43. acotylus

44. guyanensis

45. venezuelensis

46. lanei

The reticulatus group

47. azureus

48. mojingaensis

49. paucienfuscatus

50. pifanoi

51. dicrourus

52. volcanensis

53. lyrinotatus

54. reticulatus

55. macrostigma*

The furens group

56. alahialinus

57. barbosai

58. gorgasi

59. furens

The fluvialis group

60. fluvialis

61. tetrathyris

62. propriipennis

63. balsapambensis

64. castillae

65. leopoldoi

The transferrans group

66. patulipalpis

67. rangeli

68. transferrans

The leoni group

69. fieldi

70. glabellus

\begin{tabular}{|c|c|c|c|c|c|}
\hline $\begin{array}{l}\text { Wing } \\
\text { length } \\
\text { (mm.) }\end{array}$ & $\begin{array}{l}\text { Costal } \\
\text { ratio }\end{array}$ & $\begin{array}{l}\text { An- } \\
\text { tennal } \\
\text { ratio }\end{array}$ & $\begin{array}{c}\text { Segments having } \\
\text { sensoria }\end{array}$ & $\begin{array}{l}\text { No. } \\
\text { mandib- } \\
\text { ular } \\
\text { teeth }\end{array}$ & $\begin{array}{l}\text { No. } \\
\text { tibial } \\
\text { spines }\end{array}$ \\
\hline 0. 99 & 0.61 & 1. 22 & $3,11-14$ & 14 & 4 \\
\hline 1. 07 & 0.60 & 0.91 & $3,11-15$ & 13 & 4 \\
\hline 0.78 & 0.61 & 0.95 & $3-10$ & 14 & 4 \\
\hline 0. 99 & 0.65 & 0.96 & $3,7-10$ & 13 & 4 \\
\hline 1. 05 & 0.70 & 0.78 & $3,6(7)-10$ & 15 & 5 \\
\hline 0.99 & 0.58 & 1. 00 & $3,6-10$ & 15 & 4 \\
\hline 1. 37 & 0.58 & 1. 19 & $\begin{array}{r}3,(5-10) \\
11-14 .\end{array}$ & 13 & 5 \\
\hline 1. 02 & 0.66 & 0.72 & $3,7-10$ & 13 & 4 \\
\hline 1. 04 & 0.63 & 1. 18 & $3,7-10$ & $14-15$ & 4 \\
\hline 0.96 & 0.66 & 1. 32 & $3,(7) 8-10$ & 14 & 4 \\
\hline 1. 02 & 0.63 & 1. 18 & $3,7-10$ & 12 & 4 \\
\hline 0. 79 & 0.60 & 0. 91 & $3,7-10$ & 14 & 4 \\
\hline 1. 14 & 0.65 & 1. 04 & $3,6-10$ & 13 & 4 \\
\hline 1. 45 & 0.61 & 1. 07 & $3,7-10$ & 13 & 4 \\
\hline 1. 17 & 0.68 & 1. 01 & $3,8-10$ & 12 & 4 \\
\hline 0. 96 & 0.65 & 1. 10 & $3,8-10$ & 21 & 4 \\
\hline 0.91 & 0.71 & 1. 97 & $3,8-10$ & 11 & 4 \\
\hline 0.96 & 0.64 & 1. 01 & $3,8-10$ & 15 & 4 \\
\hline 0.88 & 0.58 & 0. 93 & $3,7-10$ & 16 & 4 \\
\hline 1. 04 & 0.64 & 0.99 & $3,7(8)-10$ & 17 & 4 \\
\hline 0.91 & 0.58 & 1. 28 & $3,7-10$ & 15 & 4 \\
\hline 0.78 & 0.61 & 1. 07 & $3,8-10$ & 13 & 4 \\
\hline 0.85 & 0.70 & 1. 09 & $3,8-10$ & 14 & 4 \\
\hline 0. 85 & 0.63 & 0.97 & $3,8-14$ & 15 & 4 \\
\hline 0.72 & 0.70 & 0.84 & $3,8-10$ & 14 & 4 \\
\hline 0.84 & 0.64 & 1. 09 & $3,8-11$ & 15 & 4 \\
\hline 0.85 & 0.61 & 1. 21 & $3,7-10$ & 13 & 4 \\
\hline 0.98 & 0.64 & 1. 85 & $3,10-14$ & 14 & 4 \\
\hline 1. 01 & 0.65 & 1. 63 & $3,10-14$ & 16 & 4 \\
\hline 0.98 & 0.64 & 1. 43 & $3,11-14$ & 15 & 4 \\
\hline 0. 72 & 0.60 & 0.85 & $3,8-10$ & 12 & 4 \\
\hline 0. 68 & 0.56 & 0.88 & $3,8-10$ & 12 & 4 \\
\hline
\end{tabular}


TABLE 4.-Systematic arrangement of Panama species of Culicoides with certain quantitative characters-Continued

(NOTE: Except for segments having sensoria, mean values are shown. Asterisk denotes doubtful position of species in group. Parentheses enclosing segment numbers indicate these segments sometimes have sensoria)

\begin{tabular}{|c|c|c|c|c|c|c|}
\hline Subgenera, groups, and species & $\begin{array}{l}\text { Wing } \\
\text { length } \\
\text { (mm.) }\end{array}$ & $\begin{array}{l}\text { Costal } \\
\text { ratio }\end{array}$ & $\begin{array}{l}\text { An- } \\
\text { tennal } \\
\text { ratio }\end{array}$ & $\underset{\text { sensoria }}{\text { Segments having }}$ & $\underset{\substack{\text { No. } \\
\text { mandib- } \\
\text { ular } \\
\text { teeth }}}{\mid}$ & $\begin{array}{l}\text { No. } \\
\text { tibial } \\
\text { spines }\end{array}$ \\
\hline \multicolumn{7}{|l|}{$\begin{array}{l}\text { Culicoides (Oecacta)-Con. } \\
\text { The debilipalpis group }\end{array}$} \\
\hline 71. gabaldoni & 0.65 & 0.62 & 0. 91 & $3,8-10$ & 11 & 4 \\
\hline 72. spurius & 0. 72 & 0.58 & 0.84 & $3,8-10$ & 13 & 4 \\
\hline 73. hoffmani & 0.76 & 0.59 & 0. 79 & $3,8-10$ & 14 & 4 \\
\hline 74. imitator & 0.68 & 0.53 & 0. 91 & $3,8-10$ & 13 & 4 \\
\hline 75. paraensis & 0.78 & 0.59 & 0.77 & $3,8-10$ & 15 & 4 \\
\hline 76. debilipalpis & 0.80 & 0.65 & 0.83 & $3,8-10$ & 15 & 4 \\
\hline 77. mirsae & 0.78 & 0.61 & 0.70 & $3,8-10$ & 16 & 4 \\
\hline 78. aureus & 0.89 & 0.63 & 0. 76 & $3,7-10$ & 18 & 4 \\
\hline 79. ginesi & 0. 80 & 0.62 & 0.74 & $3,7-10$ & 17 & 4 \\
\hline 80. glabrior & 1. 02 & 0.68 & 0.89 & $3,7-10$ & 15 & 4 \\
\hline \multicolumn{7}{|l|}{ The pachymerus group } \\
\hline 81. almirantei & 0. 79 & 0.69 & 1. 25 & $3,8-10$ & 15 & 4 \\
\hline 82. caprilesi & 0.83 & 0. 78 & 0.61 & $3,8-10$ & $16-17$ & 4 \\
\hline 83. pachymerus & 0.72 & 0.71 & 0. 66 & $3,8(9)-10$ & 14 & 4 \\
\hline 84. uniradialis & 0.94 & 0.79 & 0.65 & $3,8-10$ & 16 & 4 \\
\hline \multicolumn{7}{|l|}{ The arubae group } \\
\hline 85. arubae & 1. 17 & 0.52 & 0.87 & $3-10$ & 15 & 7 \\
\hline The stigmalis gro & & & & & & \\
\hline 86. stigmalis & 0.90 & 0. 64 & 0.91 & $3,8-10$ & 14 & 4 \\
\hline \multicolumn{7}{|l|}{ Culicoides (Macfiella) } \\
\hline 87. phlebotomus & 1. 03 & 0.55 & 1. 19 & $3,6-10$ & 15 & 7 \\
\hline 88. willistoni & 0.92 & 0.55 & 1. 06 & $3-10$ & 14 & 6 \\
\hline
\end{tabular}

\section{Key to the Panama Species of Culicoides}

\section{(Primarily for Females)}

1. Second radial cell wholly or mainly included in a light spot . . . . 2 Second radial cell wholly included in a very dark spot . . . . . . 22

2. Base of cell $\mathrm{M}_{4}$ pale bordering veins $\mathrm{M}_{3+4}$ and $\mathrm{Cu}_{1}$ or apices of veins $\mathrm{M}_{1}$ and $\mathrm{M}_{2}$ pale... . . . . . . . . . . . . . . . . . . . 3

Base of cell $\mathrm{M}_{4}$ and adjacent veins in a dark area; apices of veins $\mathrm{M}_{1}$ and $\mathrm{M}_{2}$ not pale . . . . . . . . . . . . . . . . . . . . 9

3. Cell $R_{5}$ with a separate pale spot present anterior to base of vein $M_{1}$. 4

Cell $R_{5}$ without a separate pale spot present anterior to base of vein $M_{1}$, pale area continuous from $r-m$ crossvein to borders of vein $M_{1}$. . 6 
4. Hind femur dark to apex; apices of veins $\mathrm{M}_{3+4}$ and $\mathrm{Cu}_{1}$ usually pale . 5

Hind femur with subapical yellow band; apices of veins $\mathrm{M}_{3+4}$ and $\mathrm{Cu}_{1}$ dark; third palpal segment slender, without pit; mesonotum yellow in middle with dark brown sublateral vittae; wing $1.3 \mathrm{~mm}$. long.

verecundus Macfie (p. 278)

5. Midknee broadly yellow at the joint; mesonotum dark gray in middle, nearly unicolorous blackish; third palpal segment slender, without pit; wing $1.5 \mathrm{~mm}$. long . . . heliconiae Fox and Hoffman (p. 274)

Midknee black with narrow pale rings on each side; mesonotum yellow in middle with dark brown sublateral vittae; third palpal segment swollen with a shallow, subdivided pit; wing $1.2 \mathrm{~mm}$. long.

hylas Macfie (p. 276)

6 (3). Cell $M_{1}$ with two pale spots distal to the double spot straddling vein $\mathrm{M}_{2}$; palpal pit with regular margins present; halter knob pale or dark . . . . . . . . . . . . . . . . 7

Cell $\mathrm{M}_{1}$ with only one pale spot distal to the double spot straddling vein $\mathrm{M}_{2}$; palpal pit irregular or absent; halter knob brown . . . . 8

7. Small black spot present on vein $R_{4+5}$ near end of second radial cell; halter knob dark; larger species (wing $1.2 \mathrm{~mm}$. long). foxi Ortiz (p.283)

No small black spot on vein $\mathrm{R}_{4+5}$ near end of second radial cell; halter knob usually pale; smaller species (wing $1.0 \mathrm{~mm}$. long).

diabolicus Hoffman (p. 280)

8 (6). Vein $R_{4+5}$ blackened into adjacent distal pale area up to a point where vein turns abruptly forward to meet the costa; mesonotum with prominent pattern; third palpal segment with definite, irregular sensory pit . . . . . . . . . . . . . . insignis Lutz (p. 285)

Vein $\mathrm{R}_{4+5}$ not blackened into adjacent distal pale area; mesonotum uniformly grayish brown pruinose; third palpal segment without sensory pit . . . . . . . . trinidadensis Hoffman (p. 287)

9 (2). Very small species, wing $0.64-0.69 \mathrm{~mm}$. long; costa short, extending only $0.53-0.57$ of distance to wing tip; second radial cell short; mesonotum bluish black with faint sublateral black vittae . . . . 10

Larger species, wing $0.72-1.66 \mathrm{~mm}$. long; costa longer, reaching $0.58-0.79$ of distance to wing tip; second radial cell usually long; mesonotum yellowish to brown (or if blackish there are gray patches present and the legs are dark) . . . . . . . . . . . . . . . . . . . . . 11

10. Second radial cell pale only on extreme distal end; wing pattern very faint; legs pale except for dark knee spots; pit of third palpal segment faint or absent; spermathecae oval and subequal.

pusillus Lutz (part) (p. 292)

Second radial cell on distal half; wing pattern prominent; legs brown with pale bands; palpal pit deep; spermathecae subspherical and very unequal . . . . . . pusilloides Wirth and Blanton (p. 290)

11 (9). Legs stout, fore and hind femora greatly swollen, subapical pale rings present on all femora; mesonotum dull, tawny, yellowish brown; distal sensory tufts absent on antennal segments $\mathrm{XI}-\mathrm{XV}$. . . . . . 12

Legs slender, femora slender, yellow with dark knees or dark with pale knees, never with subapical pale rings; mesonotum if yellow then subshining; distal sensory tufts present on antennal segments $\mathrm{xI}^{-}$ $\mathrm{xv}$. . . . . . . . . . . . . . 13 
12. Only one radial cell present; wing $0.94 \mathrm{~mm}$. long; costa long, extending to 0.79 of wing length; wing entirely without macrotrichia.

uniradialis Wirth and Blanton (p. 462)

Two radial cells present; wing $0.72 \mathrm{~mm}$. long; costa extending to 0.71 of wing length; wing with a few macrotrichia on distal fourth.

pachymerus Lutz (p. 459)

13 (11). Legs black, at most with small pale spots; mesonotum blackish, entirely dull gray pruinose or dark brown with gray pruinose pattern . . 14

Legs yellow or with knees broadly yellow-banded; mesonotum yellow to brown, usually subshining . . . . . . . . . . . . . . . . 15

14. Mesonotum with pattern of interconnected, subshining, dark brown patches . . . . . . . . luteovenus Root and Hoffman (p. 297)

Mesonotum uniformly dark pruinose brown, without pattern.

elutus Macfie (p. 295)

15 (13). Proboscis longer than height of head; legs pale including knees; wing pale with effect of narrow, irregular, transverse bands . . . . . 16

Proboscis shorter than height of head; legs pale with black knee spots or brown with knees broadly pale; third palpal segment more or less swollen. . . . . . . . . . . . . . . . . . . . . . . . . . 18

16. Legs brown with knees and apex of hind tibia broadly yellow; third palpal segment long and slender with a small pit; mandible with 27 teeth . . . . . . . . marshi Wirth and Blanton (p. 302)

Legs pale including knees; mandible with 20-24 teeth . . . . . . 17

17. Third palpal segment long and slender with small pit.

Third palpal segment swollen with open sensory area.

efferus Fox (p. 299)

rostratus Wirth and Blanton (p. 301)

18 (15). Knees pale; legs brownish with broad pale bands including knees on apices of fore and mid femora, bases of all tibia and apex of hind tibia . . . . . . . . . . . covagarciai Ortiz (p. 304)

Knees with a black spot, at least on hind pair; legs otherwise, mostly yellowish . . . . . . . . . . . . . . . . . 19

19. All knees with black spots; femora more or less brownish with subapical pale bands; third palpal segment with small sensory pit; basal antennal segments moniliform, the 11 th segment $2-3$ times as long as tenth . . . . . . . . . . . . . . 20

Legs yellow, only hind knee with black spots; third palpal segment without sensory pit; 11th antennal segment not markedly longer than 10th . . . . . metagonatus Wirth and Blanton (p. 306)

20. Distal pale spot in cell $\mathrm{M}_{1}$ not attaining wing margin; pale spot straddling vein $M_{1}$ separate from the pale spot in cell $R_{5}$ at end of second radial cell; pale spot straddling vein $\mathrm{M}_{2}$ in form of a double, more or less quadrate spot; femora blackish from near base to past middle; third palpal segment slightly swollen; wing $1.66 \mathrm{~mm}$. long.

chrysonotus Wirth and Blanton (p. 312)

Distal pale spot in cell $\mathrm{M}_{1}$ continuous anteriorly with the pale spot in cell $R_{5}$ at the end of second radial cell; third palpal segment greatly swollen . . . . . . . . . . . . . . . . . . . 21

21. All femora dark brown from near base to past middle; tibiae brownish with narrow subbasal pale band; wing $1.56 \mathrm{~mm}$. long.

lutealaris Wirth and Blanton (p. 310) 
Fore and mid femora pale brown on basal portions, hind femur with a broad median darker brown band; wing $1.11 \mathrm{~mm}$. long.

nigrigenus Wirth and Blanton (p. 308)

22 (1). Pale spots at periphery of wing very faint . . . . . . . . . . . 23

Pale spots at periphery of wing well defined; macrotrichia of wing more or less abundant . . . . . . . . . . . . . . . . . . 25

23. Wing practically bare of macrotrichia; stigmal spot blackish; mesonotum blackish . . . . . . . . . . . . . . . . . . . 24

Wing with sparse but widely distributed macrotrichia; stigmal spot scarcely darker than rest of wing; mesonotum pale brown with faint pattern of punctiform brown dots . . alahialinus Barbosa (p. 398)

24. Small species, wing $0.65 \mathrm{~mm}$. long; second radial cell short, costa ending at 0.53 of distance to wing tip; halter yellowish; legs yellow except for dark knee spots; mesonotum with bluish pruinosity and a sublateral pair of narrow blackish bands.

pusillus Lutz (part) (p. 292)

Large species, wing $0.90 \mathrm{~mm}$. long; second radial cell long, costa extending to 0.64 of distance to wing tip; halter dark; legs dark, faint pale bands at base of hind tibia; mesonotum uniformly dull, dark brown . . . . . . . . . . . . stigmalis Wirth (p. 467)

25 (22). Wing with a pale spot straddling middle of vein $\mathrm{M}_{2}$, or veins $\mathrm{M}_{1}$ and $\mathrm{M}_{2}$ entirely pale-margined, including this area . . . . . . . . . 26

Wing with no pale spot straddling vein $\mathrm{M}_{2}$, this vein usually dark to apex . . . . . . . . . . . . . . . . . . . 54

26. Wing with pale markings extensive, interconnected . . . . . . . 27

Wing dark with well-separated pale spots . . . . . . . . . . . . 32

27. Halter knob pale; mesonotum with prominent pattern of large patches or lines; anterior margin of wing with one very dark spot over second radial cell; cell $R_{5}$ with two pale areas between end of costa and wing tip . . . . . . . . . . . . . . . . . 28

Halter knob dark; mesonotum with a pattern of punctiform dots; anterior margin of wing with three very dark spots, cell $R_{5}$ with three pale areas between end of costa and wing tip.

arubae Fox and Hoffman (p. 464)

28. Cell $\mathrm{M}_{1}$ with distal spot not or very narrowly reaching wing margin . 29

Cell $M_{1}$ with distal pale spot broadly reaching wing margin; mesonotum yellowish with dark brown sublateral bands . . . . . . . . . 30

29. Cell $\mathrm{M}_{1}$ with distal pale spot shorter than dark area between it and wing margin; cell $R_{5}$ with poststigmatic pale spot not enclosing a dark spot behind second radial cell; mesonotum yellowish with dark brown sublateral bands ......... . . . pifanoi Ortiz (p. 384)

Cell $\mathrm{M}_{1}$ with distal pale spot longer than dark area between it and wing margin; poststigmatic pale spot in cell $R_{5} U$-shaped, enclosing a small dark spot behind second radial cell; mesonotum grayish pruinose with three narrow dark longitudinal lines.

paucienfuseatus Barbosa (p. 381)

30 (28). Hind femur and tibia dark on apices.

galindoi Wirth and Blanton (part) (p. 349)

Hind femur with subapical pale ring; hind tibia with apex broadly pale . . . . . . . . . . . . . . . . . 31 
31. Slender species, discal area of wing mostly pale; pale area definitely straddling base of vein $\mathrm{M}_{2}$; abdomen whitish on basal half above; antenna with sensoria present on segments III, XI-XIV.

carpenteri Wirth and Blanton (p. 358)

Stockier species, discal area of wing with dark markings at least as extensive as the pale ones, pale mark in base of cell $\mathrm{M}_{1}$ rarely straddling vein $\mathrm{M}_{2}$; abdomen blackish; antenna with sensoria present on segments III, vII-X . . . . . . . . . . limai Barretto (part) (p. 352)

32 (26). Vein $M_{1}$ with pale spot present straddling basal or middle portion . 33

Vein $\mathrm{M}_{1}$ without pale spot straddling basal or middle portion . . . 37

33. Crossvein $\mathrm{r}-\mathrm{m}$ with dark spot in center of pale area; mesonotum uniformly pruinose brown. . . . scopus Root and Hoffman (p. 347)

Crossvein $\mathrm{r}-\mathrm{m}$ pale; mesonotum with a prominent pattern . . . . 34

34. Anal cell with two pale spots in distal portion . . . . . . . . . 35

Anal cell with one pale spot in distal portion; mesonotum brown with three darker longitudinal bands; apices of veins $M_{1}, M_{2}$ and $M_{3+4}$ dark . . . . . . . panamensis Barbosa (part) (p. 334)

35. Pale spot straddling vein $\mathrm{M}_{1}$ located near base of the vein; apices of veins $\mathrm{M}_{1}, \mathrm{M}_{2}$ and $\mathrm{M}_{3+4}$ with pale spots; wing very hairy; mesonotum brown with three broad, darker, longitudinal bands narrowly bordered with whitish pruinosity; cell $\mathrm{R}_{5}$ with distal pale spot divided or hourglass-shaped and broadly meeting wing margin.

jamaicensis Edwards (p. 339)

Pale spot straddling vein $\mathrm{M}_{1}$ located at midlength of vein; apices of veins $\mathrm{M}_{1}, \mathrm{M}_{2}$ and $\mathrm{M}_{3+4}$ dark; mesonotum yellowish with brown markings; cell $R_{5}$ with distal pale spot round and not reaching wing margin . . . . . . . . . . . . . . . . . . . . . . . . 36

36. Mesonotum on anterior half brown with yellow patches, posteriorly yellow; cell $R_{5}$ with poststigmatic pale spot angulate, distal one small and round; wing nearly bare; legs with broad pale bands.

camposi Ortiz and Leon (p. 356)

Mesonotum yellowish brown with brownish sublateral bands; cell $R_{5}$ with both pale spots quadrate, large; wing hairy to base, legs with narrow pale rings . . . . . . . dunni, new species (part) (p. 328)

37 (32). Anal cell with a single pale spot in distal portion . . . . . . . . . 38

Anal cell with two pale spots, which may be partly coalesced, in distal portion . . . . . . . . . . . . . . . . . . . . . . . . . 44

38. Cell $\mathrm{R}_{5}$ with one or two small elongate pale spots present lying adjacent to vein $\mathrm{M}_{1}$ on its basal or midportion . . . . . . . . . . . 39

Cell $R_{5}$ without pale spot lying adjacent to vein $M_{1}$. . . . . . . 40

39. Cell $R_{5}$ with two pale spots lying adjacent to vein $M_{1}$, one proximad and one distad of level of the posterior poststigmatic pale spot; apices of viens $\mathrm{M}_{1}, \mathrm{M}_{2}, \mathrm{M}_{3+4}$ and $\mathrm{Cu}_{1}$ with pale spots at wing margin, veins $\mathrm{M}_{3+4}$ and $\mathrm{Cu}_{1}$ pale bordered in base of cell $\mathrm{M}_{4}$.

iriartei Fox (p. 344)

Cell $R_{5}$ with one pale spot lying adjacent to vein $M_{1}$, at level of anterior poststigmatic pale spot; apices of veins $M_{1}$ to $C_{1}$ dark; veins $M_{3+4}$ and $\mathrm{Cu}_{1}$ not pale bordered in base of cell $\mathrm{M}_{4}$.

panamensis Barbosa (part) (p. 334)

40 (38). Cell $R_{5}$ without pale spot lying between poststigmatic and distal pale spots; mesonotum with prominent pattern of brown lines or patches; fourth tarsomere cylindrical 
Cell $R_{5}$ with a small round distal pale spot lying between the poststigmatic pale spot and the distal pale spot; cell $\mathrm{M}_{1}$ with distal pale spot located far from wing margin; mesonotum grayish green pollinose, without pattern or with small brown punctiform dots, fourth tarsomere cordiform . . . . . . . . . . . . . . . . . . . . 43

41. Cell $R_{5}$ with distal pale spot filling apex of cell; cell $M_{1}$ with distal pale spot broadly reaching wing margin.

tenuilobus new species (p. 354)

Cell $R_{5}$ with distal pale spot transverse, located far from apex of cell; cell $\mathrm{M}_{1}$ with distal pale spot lying far from wing margin . . . . 42

42. Mesonotum grayish pruinose with dark brown patches; anal cell with distal pale spot not double; hind femur dark at apex.

evansi, new species (p. 342)

Mesonotum yellowish brown pruinose with $\mathrm{H}$-shaped marking of brown lines; anal cell with distal pale spot double; hind femur with subapical pale ring. . . . daedaloides, new species (part) (p. 330)

43 (40). Mesonotum with pattern of prominent punctiform brown dots.

willistoni Wirth and Blanton (p. 471)

Mesonotum uniformly grayish green pollinose, sometimes with a pair of faint, brownish, sublateral longitudinal lines.

phlebotomus (Williston) (p. 469)

44 (37). Cell $M_{1}$ with two pale spots past the pale spot straddling vein $M_{2}$; cell $R_{5}$ with six small round pale spots.

venezuelensis Ortiz and Mirsa (part) (p. 372)

Cell $M_{1}$ with only one distal pale spot; cell $R_{5}$ with less than four pale spots . . . . . . . . . . . . . . . . 45

45. Cell $R_{5}$ with a small, elongate pale spot present lying adjacent to vein $\mathrm{M}_{1}$ on its midportion . . . . . . . . . . . . . . . . . . . 46

Cell $R_{5}$ without pale spot lying adjacent to vein $M_{1}$ on its midportion .. . . . . . . . . . . . . . . 48

46. Apices of veins $\mathrm{M}_{1}, \mathrm{M}_{2}$ and $\mathrm{M}_{3+4}$ with a pale spot at wing margin; cell $R_{5}$ with pale spot lying in front of vein $M_{1}$ located between poststigmatic and distal pale spots . . . . . . . . . . . . . 47

Apices of veins $M_{1}, M_{2}$ and $M_{3+4}$ dark; cell $R_{5}$ with pale spot lying in front of vein $\mathrm{M}_{1}$ located at same level as poststigmatic pale spot.

dunni, new species (part) (p. 328)

47. Cell $\mathrm{R}_{5}$ with distal pale spot crescent-shaped, concave on distal side; mesonotum with pattern of three broad, longitudinal bands and associated small brown dots; hind femur and tibia dark.

crescentis, new species (p. 317)

Cell $\mathrm{R}_{5}$ with distal pale spot transversely oval, not concave on distal side; mesonotum with pattern of narrow, reticulated brown lines; hind femur with subapical and hind tibia with apical pale rings.

poikilonotus Macfie (part) (p. 337)

48 (45). Cell $\mathrm{M}_{1}$ with distal pale spot lying far from wing margin . . . . . . 49

Cell $\mathrm{M}_{1}$ with distal pale spot nearly or quite reaching wing margin . 50

49. Anal cell with distal pale spots well separated and obliquely located; hind femur dark at apex; poststigmatic pale spots in cell $R_{5}$ fused; wing very hairy to base . . . . . . . . . daedalus Macfie (p. 319)

Anal cell with distal pale spots fused in a transverse double spot; hind femur with subapical pale ring; poststigmatic pale spots in cell $R_{5}$ separated; wing with sparse hairs on distal third.

daedaloides, new species (part) (p. 330) 
50. Cell $\mathrm{R}_{5}$ with distal pale spot comma-shaped, bearing a small distal extension from posterior side . . . . . . . . . . . . . . 51

Cell $R_{5}$ with distal pale spot not appendiculate but quadrate to round or oval in shape . . . . . . . . . . . . . . . . . . . 52

51. Cell $\mathrm{R}_{5}$ with main body of distal pale spot small and transverse; veins $\mathrm{M}_{3+4}$ and $\mathrm{Cu}_{1}$ pale margined in cell $\mathrm{M}_{4}$; pale spot present in cell $\mathrm{M}_{2}$ behind medial fork; larger (wing $1.25 \mathrm{~mm}$. long).

pampoikilus Macfie (p. 324)

Cell $R_{5}$ with main body of distal pale spot large and rounded; veins $\mathrm{M}_{3+4}$ and $\mathrm{Cu}_{1}$ not pale margined in cell $\mathrm{M}_{4}$; pale spot absent in cell $\mathrm{M}_{2}$ behind medial fork; smaller (wing $1.02 \mathrm{~mm}$. long).

commatis, new species (p. 321)

52 (50). Cell $R_{5}$ with distal pale spot filling cell to apex.

antefurcatus, new species (p. 315)

Cell $\mathrm{R}_{5}$ with distal pale spot rounded or quadrate, not extending to apex of cell. . . . . . . . . . . . . . . . . . 53

53. Mesonotum yellowish brown with dark , brown pattern; antenna with sensoria present on segments III to IX and XI to $\mathrm{XV}$.

pilosus, new species (p. 332)

Mesonotum dark brown with darker brown pattern; antenna with sensoria present on segments III, v, vII, IX and XI to XV.

phaeonotus, new species (p. 326)

54 (25). Cell $\mathrm{M}_{1}$ with three pale spots . . . . . . . . . . . . . . . . . 55

Cell $\mathrm{M}_{1}$ with two pale spots . . . . . . . . . . . . . . . . . 60

55. Cell $R_{5}$ with three small pale spots arranged in a triangle with apex at end of costa and distad with a large, subapical, double spot; cell $\mathrm{M}_{1}$ with small distal pale spot very small at wing margin and usually narrowly connected to large spot in middle of cell; mesonotum with pattern of small punctiform brown dots; branches of media palebordered . . . . . . . . . . . furens (Poey) (p. 404)

Cell $R_{5}$ with pale spots arranged differently. . . . . . . . . . . 56

56. Cell $\mathrm{R}_{5}$ with three small, rounded pale spots arranged in a triangle in distal half of cell . . . . . . . . . . . . . . . . . . . 57

Cell $R_{5}$ with two pale spots in distal half . . . . . . . . . . . . 58

57. Cell $R_{5}$ with three small round pale spots in a triangle at end of second radial cell similar to the triangle in distal half of cell; mesonotum with pattern of punctiform brown dots.

venezuelensis Ortiz and Mirsa (part) (p. 372)

Cell $\mathrm{R}_{5}$ with two small round pale spots, often partially fused, at end of and behind second radial cell; mesonotum with pattern of large patches . . . . . . guyanensis Floch and Abonnenc (p. 370)

58 (56). Cell $R_{5}$ with four small, round pale spots arranged in a rhomboid in midregion; no small pale spot at apex of cell $\mathrm{R}_{5}$; anal cell with two distal pale spots; mesonotum with prominent pattern; halter knob dark . . . . . . . . . . . propriipennis Macfie (p. 412)

Cell $R_{5}$ with a small round pale spot at apex, as well as other proximal pale spots . . . . . . . . . . . . . . . . . . . . . . 59

59. Cell $R_{5}$ with subapical pale spot round or reniform, not attaining wing margin; a double pale spot at end of second radial cell; anal cell with one distal pale spot; mesonotum without prominent pattern.

paraensis (Goeldi) (p. 440)

Cell $R_{5}$ with subapical pale spot irregular, usually extending to anterior wing margin; three small round spots beyond and behind second 
radial cell; anal cell with two distal pale spots; mesonotum with prominent pattern . . . . . . . . . . . . . . . lanei Ortiz (p. 374)

60 (54). Cell $M_{2}$ with one pale spot distal to level of base of mediocubital fork, not counting any spot lying immediately anterior to base of fork . 61

Cell $\mathrm{M}_{2}$ with two (or one with at least part of a second) pale spots lying distal to level of mediocubital fork . . . . . . . . . . 77

61. Cell $R_{5}$ with a $U$-shaped pale spot (sometimes reduced to two separate, round spots) enclosing a small, round, dark spot just behind second radial cell; crossvein $\mathrm{r}-\mathrm{m}$ usually dark; mesonotum uniformly dark brown . . . . . . . . . . . . . . . . . acotylus Lutz (p. 367)

Cell $R_{5}$ without pale area enclosing a round, dark spot behind second radial cell; crossvein $\mathrm{r}-\mathrm{m}$ pale. . . . . . . . . . . . . . . . 62

62. Distal pale spot in cell $\mathrm{M}_{1}$ not attaining wing margin . . . . . . 63

Distal pale spot in cell $\mathrm{M}_{1}$ broadly attaining wing margin; distal pale spot in cell $\mathrm{R}_{5}$ large, filling apex of cell; wing very hairy; third palpal segment bulbous; one pale spot at apex of anal cell

magnipalpis Wirth and Blanton (p. 360)

63. Anal cell with two distal pale spots . . . . . . . . . . . . . . 64

Anal cell with one distal pale spot. . . . . . . . . . . . . . . . 67

64. Crossvein $\mathrm{r}-\mathrm{m}$ with pale spot small and lying entirely on distal side of vein, not reaching anterior wing margin; cell $R_{5}$ with one small transverse pale spot distal to the poststigmatic pale spots.

mirsae Ortiz (p. 446)

Crossvein r-m lying entirely within a pale spot which reaches anterior wing margin . . . . . . . . . . . . . . . . . . . . . . . 65

65. Halter knob dark (only at base in tetrathyrus); no pale spots lying next to anterior sides of veins $\mathrm{M}_{1}$ and $\mathrm{M}_{2}$ near bases . . . . . . 66

Halter entirely pale; small, elongate pale spots present adjoining anterior sides of veins $M_{1}$ and $M_{2}$ near bases; cell $R_{5}$ with an oblique double poststigmatic pale spot and a single large round pale spot past it in middle of cell; hind femur with subapical ring and hind tibia with broad apex pale. . poikilonotus Macfie (part) (p. 337)

66. Cell $R_{s}$ with four, small, round pale spots arranged in a rhomboid in midregion; $r-m$ crossvein pale; apices of hind femur and tibia dark.

tetrathyris, new species (p. 409)

Cell $R_{s}$ with three small, round, pale spots arranged in a triangle in midregion; $r-m$ crossvein dark; hind femur with subapical ring and hind tibia with apex pale lyrinotatus Wirth and Blanton (p. 391)

67 (63). Mesonotum with prominent pattern of punctiform brown dots; three small round, equidistant pale spots in a triangle in cell $R_{5}$; halter knob dark at base; two spermathecae; eye bare; antennal segments in a continuous series, sensoria on segments III, VII-X.

ginesi Ortiz (p. 450)

Mesonotum with prominent pattern of large patches or without prominent pattern . . . . . . . . . . . . . . . . . . . . . . 68

68. Smaller species (wing $0.65 \mathrm{~mm}$. long); distal pale spot in cell $\mathrm{R}_{5}$ large and rounded, nearly filling cell from wing margin to vein $\mathrm{M}_{1}$; macrotrichia sparse, only a few in apices of cells $R_{3}, M_{1}$ and $M_{2}$; antennal segment $\mathrm{XI}$ shorter than $\mathrm{X}$. . . . . . . . . . . . . . . . . . 69

Larger species (wing 0.8-1.4 mm. long); distal pale spot in cell $\mathrm{R}_{\mathrm{s}}$ usually transverse, not nearly filling breadth of cell; macrotrichia more numerous, present at least on distal half of wing; antennal

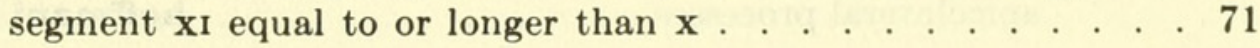


69. Poststigmatic pale spots in cell $R_{5}$ usually fused and extending nearly to vein $\mathrm{M}_{1}$, the posterior portion at same level with or extending slightly distad of the anterior part; macrotrichia present on extreme apex of wing . . . . . . . . . . . . . . . . . . . 70

Poststigmatic pale spots in cell $R_{5}$ usually small and distinctly separated, the posterior one located distinctly proximad of the anterior spot; macrotrichia present on distal third of wing; one spermatheca present; male genitalia with well-developed ventral lobe on paramere.

fieldi, new species (p. 427)

70. One spermatheca present; legs darker; male genitalia with stem of paramere gradually curved at base, swollen near apex of straight portion and abruptly narrowed to filiform tip.

glabellus Wirth and Blanton (p. 429)

Two spermathecae present; legs paler; male genitalia with stem of paramere abruptly bent and swollen near base, gradually tapered to fine tip . . . . . . . . . . . . . gabaldoni Ortiz (p. 431)

71 (68). Large species (wing $1.45 \mathrm{~mm}$. long), with narrow convex mesonotum with prominent yellowish and brown patches; antennal ratio 1.07, sensoria present on segments III, vII-X.

volcanensis, new species (part) (p. 389)

Smaller species (wing $0.72-1.02 \mathrm{~mm}$. long) with broader mesonotum; antennal ratio $0.79-0.89$ or 1.85 . . . . . . . . . . . . . . . 72

72. Second radial cell unusually broad; pale spot at end of costa well separated from spot behind second radial cell, farther from it than from the distal pale spot in cell $R_{5}$ which is narrow and transverse; pale distal spot in anal cell elongated, extending caudad nearly to wing margin; eye bare; antennal sensoria on segments III, vII-x; larger species (wing $1.02 \mathrm{~mm}$. long) . . . . . . glabrior Macfie (p. 452)

Second radial cell not unusually broad; antennal sensoria present on segments III, VIII-X or on III, $\mathbf{x}$-XIV . . . . . . . . . . . . . 73

73. One spermatheca present; antennal ratio 1.85 , last five segments greatly elongated, sensoria present on segments III, $\mathrm{x}-\mathrm{xIV}$; mesonotum brownish without definite pattern.

patulipalpis, new species (p. 421)

Two spermathecae present; antennal ratio about 0.8 , last five segments not much longer than preceding series, sensoria present on segments III, viII-X; mesonotum blackish with prominent pattern . . . . . 74

74. Wing with macrotrichia extending in two rows to base of cell $\mathrm{M}$; poststigmatic pale spots in cell $R_{5}$ lying closer together with the posterior one located slightly proximad of the other; third palpal segment long and slender, about 2.2 times as long as broad, with a small, deep pit. . . . . . . . . . . debilipalpis Lutz (p. 442)

Wing with macrotrichia confined to distal half; poststigmatic pale spots in cell $R_{5}$ usually well separated and situated at same level; third palpal segment short and swollen, 1.6 times as long as broad . 75

75. Pale spot present in front of mediocubital fork; third palpal segment with a deep round pit . . . . . . . . . . . . . . . . . 76

Pale spot absent in front of mediocubital fork; third palpal segment without pit, the sensoria scattered on surface . imitator Ortiz (p. 438)

76. Eyes separated by a wedge-shaped space; antennal ratio 0.79 ; third palpal segment 1.6 times as long as broad; 14 mandibular teeth; male aedeagus with three subequal distal lobes, ninth tergum with large apicolateral processes . . . . . . . . hoffmani Fox (p. 436) 
Eyes separated by a parallel-sided space; antennal ratio 0.84 ; third palpal segment 1.8 times as long as broad; 13 mandibular teeth; male aedeagus with truncated, simple apex, ninth tergum with small apicolateral processes . . . . . . spurius, new species, (p. 433)

77 (60). Distal pale spot in cell $\mathrm{M}_{1}$ broadly reaching wing margin . . . . . 78

Distal pale spot in cell $\mathrm{M}_{1}$ not reaching wing margin, or if connected to margin by a narrow pale line, the mesonotum with punctiform brown dots. . . . . . . . . . . . . . . . . . . 83

78. Distal part of anal cell with one definite pale spot located far from wing margin; mesonotum uniformly pruinose brown, without prominent pattern . . . . . . . . . . . . . . . . . . . . . . . . . 79

Distal part of anal cell with two, partially coalesced pale spots, the posterior one broadly meeting wing margin; mesonotum with or without pattern . . . . . . . . . . . . . . . . . . . . . . 80

79. Femora stout; second radial cell long with broad lumen, over twice as broad as long; costa extending to 0.78 of wing length; antennal ratio 0.61 . . . . . . . . . . . . . . . . . . . caprilesi Fox (p. 456)

Femora slender; second radial cell short, costa extending to 0.61 of wing length; antennal ratio 0.95 . . . . . . . wokei Fox (p. 363)

80. Small pale brown species with poorly marked wing, mesonotum and legs; femora stout; second radial cell long with broad lumen, over twice as long as broad; costa extending to 0.69 of wing length; antennal ratio 1.25 . . . . . almirantei, new species (p. 454)

Well-marked, yellow and dark brown species with femora slender; second radial cell less than 1.5 times as long as broad . . . . . 81

81. Cell $\mathrm{R}_{5}$ with a large $U$-sháped poststigmatic pale spot cutting off an isolated small round dark spot behind second radial cell; large, slender, yellowish brown species with conspicuous brown mesonotal pattern with large yellowish patches (wing $1.14 \mathrm{~mm}$. long)

dicrourus Wirth and Blanton (part) (p. 386)

Cell $R_{5}$ without an isolated small, round dark spot behind second radial cell; smaller, stouter species with yellowish mesonotum bearing a pair of brown bands (wing $0.80-0.83 \mathrm{~mm}$. long) . . . . . . . . . 82

82. Hind femur with narrow subapical and hind tibia with broad apical pale rings . . . . . . . . . . limai Barretto (part) (p. 352)

Hind femur and tibia entirely dark on apices

galindoi Wirth and Blanton (part) (p. 349)

83 (77). Cell $R_{5}$ with a $U$-shaped pale spot enclosing a small round dark spot behind second radial cell and larger, irregularly rounded, pale subapical spot broadly attaining wing margin; mesonotum bluish pruinose on sides; halter knob dark . . . . . . . . . . . . . 84

Cell $\mathrm{R}_{5}$ without complete $U$-shaped pale spot enclosing a small round dark spot behind second radial cell; veins $M_{1}$ and $M_{2}$ entirely dark except possibly for small pale spots at wing margin or a line bordering distal fourth of vein $\mathrm{M}_{1}$ only . . . . . . . . . . . . . . . . 85

84. Veins $\mathrm{M}_{1}$ and $\mathrm{M}_{2}$ both pale bordered on distal fourth; mesonotum with submedian anterior pale spots contrasting yellowish, lateral spots bluish . . . . . . . mojingaensis Wirth and Blanton (p. 379)

Vein $\mathrm{M}_{1}$ only with a pale border on distal fourth, vein $\mathrm{M}_{2}$ dark to apex; mesonotum with submedian as well as the lateral spots bluish pruinose . . . . . . . . . . azureus, new species (p. 377) 
85 (83). Anal cell with one distal pale spot. . . . . . . . . . . . . . . 86

Anal cell with two distal pale spots, which may be more or less coalesced in a double spot . . . . . . . . . . . . . . . . . . . . . 88

86. Cell $\mathrm{R}_{5}$ with five separate pale spots, the distal one lying far from wing margin; mesonotum with a prominent pattern of punctiform brown dots; legs largely pale . . . . . . . aureus Ortiz (p. 447)

Cell $R_{5}$ with three pale spots, the distal one nearly or quite broadly attaining wing margin; mesonotum without pattern or with pattern of large patches; legs dark . . . . . . . . . . . . . . . . . 87

87. Cell $R_{5}$ with distal pale spot in form of an oblique double spot broadly meeting wing margin anteriorly; $r-m$ crossvein pale; mesonotal pattern of large pale and dark patches . . . . fluvialis Macfie (p. 407)

Cell $R_{5}$ with distal pale spot rounded with narrower pale extension barely attaining wing margin anteriorly; r-m crossvein with a prominent dark spot; mesonotum rusty red, without prominent pattern.

carsiomelas Wirth and Blanton (p. 365)

88 (85). Cell $R_{5}$ with one or more pale spots in distal half, past the poststigmatic pale spots; second radial cell short as usual; crossvein r-m pale . . 89

Cell $\mathrm{R}_{5}$ without pale spot in distal half; with two round poststigmatic pale spots, one anterior to the other, and two smaller pale spots behind the greatly elongated second radial cell.

macrostigma Wirth and Blanton (p. 395)

89. Mesonotum with pattern of punctiform brown dots; distal pale spot in cell $\mathrm{M}_{1}$ often with very narrow extension to wing margin; distal pale spot in cell $R_{5}$ with an oblique, narrow extension to wing margin . 90

Mesonotum uniformly dark brown or with pattern of large dark and pale patches; distal pale spot in cell $\mathrm{M}_{1}$ never connected to wing margin; distal pale spot in cell $\mathrm{R}_{5}$ otherwise . . . . . . . . . . . 91

90. Mesonotal pattern obscure, center of mesonotum not yellowish; antennal segment viI with sensoria.

barbosai Wirth and Blanton (p. 400)

Mesonotal pattern well defined, center of mesonotum yellowish; antennal s gment viI without sensoria.

gorgasi Wirth and Blanton (p. 402)

91 (89). Cell $R_{5}$ with a separate fourth or fifth pale spot meeting the anterodistal wing margin in full breadth and which may be narrowly connected (in leopolr'oi) to a pale spot lying in front of vein $\mathrm{M}_{1}$ past middle of cell; apices of veins $\mathrm{M}_{1}, \mathrm{M}_{2}$ and $\mathrm{M}_{3+4}$ ending in a pale spot; mesonotum with conspicuous pattern . . . . . . . . . . . . . . . 92

Cell $R_{5}$ without a separate fourth pale spot past the usual pale spot in middle of cell, or if present it meets the wing margin rarely and not in full breadth; apices of veins $\mathrm{M}_{1}$ (except in castillae and balsapambensis), $\mathrm{M}_{2}$ and $\mathrm{M}_{3+4}$ dark; mesonotum with or without pattern . . 93

92. Cell $R_{5}$ with discal pale spot small and round and never with extension to the anterior poststigmatic pale spot or to the distal spot at wing margin; dienal mesonotum pattern of four pale spots arranged in a four-leaf clover design . . . . . . . reticulatus Lutz (p. 393)

Cell $R_{5}$ with discal poststigmatic pale spot irregular in shape with connections always to the distal spot at wing margin and of ten an extension to a fifth small pale spot near vein $\mathrm{M}_{1}$ lying behind the anterior poststigmatic pale spot; discal mesonotal pattern with principal pale areas arranged in a transverse row, each pale area containing a few small brown punctiform dots . . . . . leopoldoi Ortiz (p. 418) 
93 (91). Vein $M_{1}$ with small pale spot at wing margin; antennal sensoria present on segments III, vII-x; two sepermathecae present; distal pale spot in $\mathrm{R}_{5}$ with narrow extension to wing margin.

volcanensis, new species (part) (p. 389)

Vein $\mathrm{M}_{1}$ dark to apex or pale margined on distal half . . . . . . 94

94. Vein $M_{1}$ pale margined on its distal half; cell $R_{5}$ with distal pale spot entire, not appearing double or divided; antenna with five distal segments not elongated or bearing sensoria; one or two spermathecae.

95

Vein $M_{1}$ dark to apex; cell $R_{5}$ with distal pale spot transverse or divided more or less into two separate spots; antenna with five distal segments elongated and bearing sensoria; one spermatheca . . . . 96

95. Cell $\mathrm{M}_{2}$ with apical and preapical pale spots broadly connected along posterior edge of vein $\mathrm{M}_{2}$; cell $\mathrm{R}_{5}$ with distal pale spot extending broadly to wing margin; two spermathecae.

balsapambensis Ortiz and Leon (p. 414)

Cell $\mathrm{M}_{2}$ with apical and preapical pale spots not connected; cell $\mathrm{R}_{5}$ with distal pale spot not attaining wing margin; one spermatheca.

castillae Fox (p. 4i6)

96 (94). Cell $R_{5}$ with distal pale spot oblique and double or completely divided into two separate spots; palpus with round pit; antennal segment $\mathrm{x}$ without sensoria; wing not so hairy, base of cell $\mathrm{M}_{2}$ bare.

transferrans Ortiz (p. 424)

Cell $\mathrm{R}_{5}$ with distal pale spot transverse and entire; posterior poststigmatic pale spot greatly reduced; palpus with irregular pit; antennal segment $\mathrm{x}$ with sensoria; wing very hairy, with dense long hairs extending to base of cell $\mathrm{M}_{2}$. . . rangeli Ortiz and Mirsa (p. 423)

\section{Subgenus Culicoides (Hoffmania) Fox}

Culicoides (Hoffmania) Fox, 1948, Proc. Biol. Soc. Washington, vol. 16, p. 21.Ortiz, 1950, Rev. Sanid. Asist. Soc., vol. 15, p. 437.-Wirth and Blanton, 1956, Proc. Ent. Soc. Washington, vol. 58, p. 305. (Type: Culicoides inamollae Fox and Hoffman, by original designation.)

Species with the second radial cell ending in a pale area; base of cell $\mathrm{M}_{4}$ pale where it borders the veins at the base of the mediocubital fork or with apices of veins $\mathrm{M}_{1}, \mathrm{M}_{2}, \mathrm{M}_{3+4}$ and $\mathrm{Cu}_{1}$ pale; r-m crossvein often more or less darkened; antennal sensoria present on segments III, $\mathrm{XI}-\mathrm{Xv}$ or III, v, VII, IX, $\mathrm{xI}^{-} \mathrm{xv}$; tibial comb with 5-6 spines; male genitalia with the apicolateral processes small or absent, dorsal and ventral roots of the basistyle undeveloped; ardeagus with a proximal barlike sclerotization or marginal band and usually a distal pegw ith a spherical tip.

There are two distinct groups of this subgenus in Panama: the hylas group (below) and the guttatus group (p. 280).

\section{The hylas group}

This group consists of large to medium-sized species with base of cell $\mathrm{M}_{4}$ dark where it borders the bases of veins $\mathrm{M}_{3+4}$ and $\mathrm{Cu}_{1}$, pale 
spot present anterior to base of vein $M_{1}$; apices of veins $M_{1}$ and $M_{2}$ and usually of veins $\mathrm{M}_{3+4}$ and $\mathrm{Cu}_{1}$ pale; antennal sensoria present on segments III, XI-XV; six spines in hind tibial comb; male parameres fused basally for over half their lengths, the bases joined in a broad, platelike structure.

Panama species: Three: heliconiae Fox and Hoffman, hylas Macfie, and verecundus Macfie.

\section{Culicoides heliconiae Fox and Hoffman}

\section{Figure 4}

Culicoides sp. Fox, 1942, Puerto Rico Journ. Pub. Health Trop. Med., vol. 17, p. 418 (pupa; Venezuela; fig. respiratory horn, anal segment).

Culicoides heliconiae Fox and Hoffman, 1944, Puerto Rico Journ. Pub. Health Trop. Med., vol. 20, p. 108 (male, female; Maracay, Venezuela; reared from bromeliads; fig. wing).-Fox, 1948, Proc. Biol. Soc. Washington, vol. 61, p. 22 (male, female; fig. palpus, male aedeagus, parameres; Trinidad, Honduras).-Ortiz, 1950, Rev. Sanid. Asist. Soc., vol. 15, p. 450 (discussion).Wirth and Blanton, 1956a, Journ. Washington Acad. Sci., vol. 46, p. 95 (male, female; fig. wing, palpus, spermathecae, male genitalia; synonym, rozeboomi).

Culicoides rozeboomi Barbosa, 1947, Anais Soc. Biol. Pernambuco, vol. 7, p. 26 (male, female; Trinidad, Peru, Panama; fig. palpus, mesonotum, wing, male genitalia).

Culicoides verecundus Macfie of Ortiz, 1942, Rev. Sanid. Asist. Soc., vol. 17, p. 259 (male, female; Miranda, Venezuela; fig. female antenna, spermathecae, wing, male palpus, genitalia; verecundus Macfie [=palpalis Macfie], ?= heliconiae Fox and Hoffman).

Female: Length of wing $1.46(1.22-1.68, \mathrm{n}=26) \mathrm{mm}$.

Head.-Eyes bare, contiguous. Antenna with flagellar segments in proportion of $22: 20: 20: 20: 20: 20: 20: 20: 25: 26: 32: 34: 48$, antennal ratio 1.04-1.09; distal sensory tufts present on segments III, $\mathrm{XI}-\mathrm{Xv}$. Clypeus much elongated, bases of palpi arising far below level of ventral eye margin. Palpal segments in proportion of $6: 21: 30: 15: 12$, third segment slender, $3.3(2.8-5.7, \mathrm{n}=18)$ times as long as greatest breadth, without sensory pit. Mandible with 23 $(18-26, \mathrm{n}=26)$ teeth.

Thorax.-Blackish, mesonotum with large median area and other small areas dark pruinose gray, lateral margins and a sublateral pair of short bands velvety black; humeri whitish. Legs black; mid knee narrowly pale on each side of joint, fore femur with subapical, fore tibia with subbasal and hind tibia with basal and apical, narrow pale rings; hind tibial comb with 6 spines, the second from the spur the longest.

Wing.-Pattern as figured, apices of veins $\mathrm{M}_{3+4}$ and $\mathrm{Cu}_{1}$ usually pale, the pale spot in cell $\mathrm{M}_{4}$ continued proximad along vein $\mathrm{M}_{3+4}$ to base of fork. Macrotrichia sparse in apices of cells $R_{5}, M_{1}$ and $M_{2}$; 

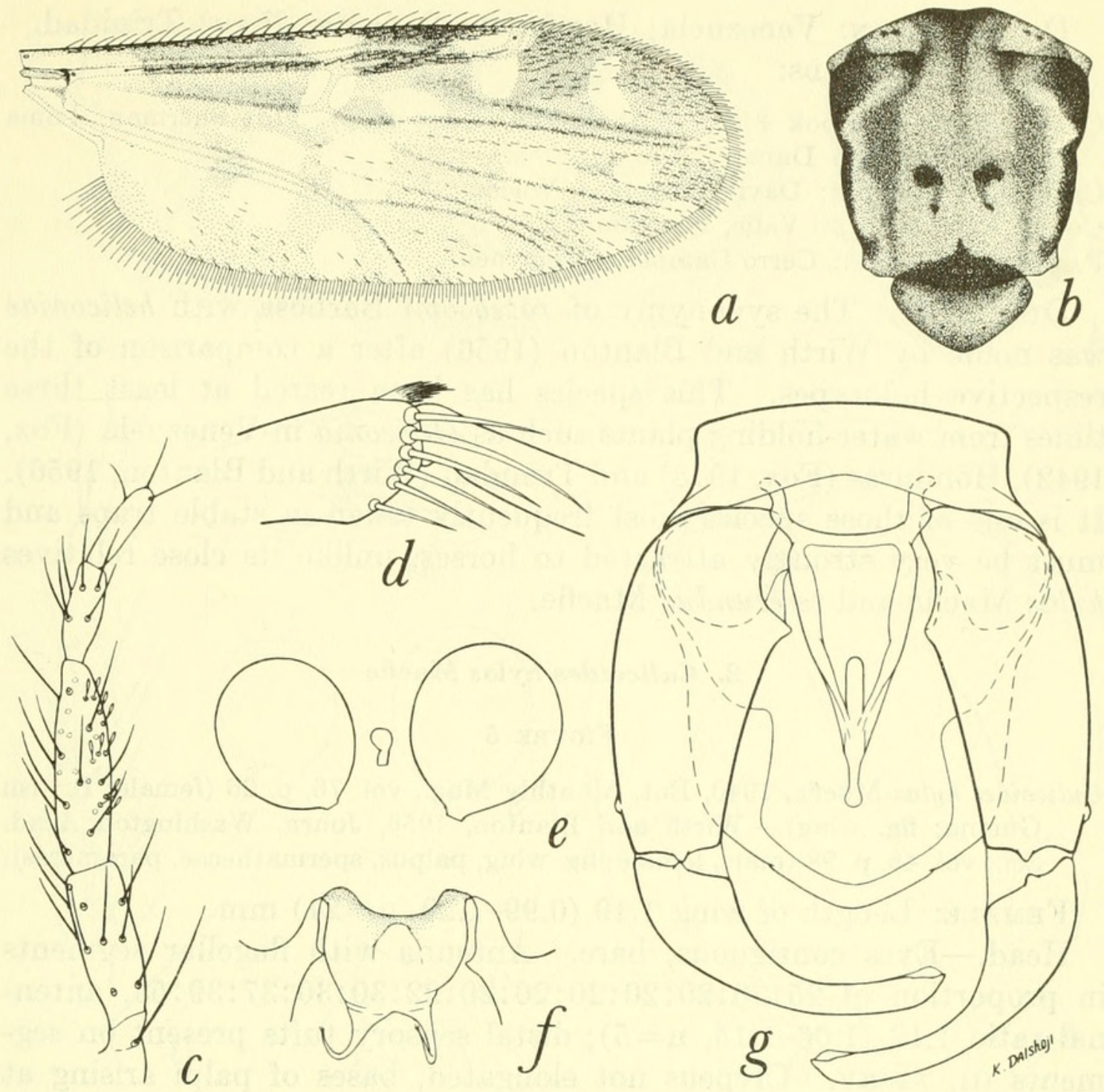

Figure 4.-Culicoides heliconiae Fox and Hoffman. $a-e$, Female: $a$, wing; $b$, thoracic pattern; $c$, palpus; $d$, tibial ccmb; $e$, spermathecae. $f, g$, Male: $f$, parameres; $g$, genitalia, parameres removed.

costa extending to 0.68 of distance to wing tip. Halter yellowish white.

Abdomen.-Black, cerci yellowish. Spermathecae two, slightly ovoid, unequal, measuring 0.065 by $0.053 \mathrm{~mm}$. and 0.051 by 0.042 $\mathrm{mm}$.

Male genitalia: Ninth sternum with very shallow caudomedian excavation; ninth tergum rounded caudad, without apicolateral processes. Basistyle with ventral and dorsal roots not developed, mesal margin without spinose setae. Aedeagus twice as long as basal width, transverse sclerotized band strong, apex with internal peg and slender, spherical tip. Parameres fused on basal two-thirds, fused part slightly broader than long, bases of free portions widely separated, free portions extremely slender, almost filiform and minutely pubescent at their tips. 
Distribution: Venezuela; Honduras; Panama; Peru; Trinidad. PANAMA RECORDS:

Canal Zone: Albrook Field, Fort Kobbe (horse trap), Fort Sherman, Loma Boracho, Madden Dam.

Chiriquí Province: David, Tortugas, Volcán.

Coclé Province: El Valle, Penonomé.

Panamá Province: Cerro Campana, Tocumen.

Discussion: The synonymy of rozeboomi Barbosa with heliconiae was made by Wirth and Blanton (1956) after a comparison of the respective holotypes. This species has been reared at least three times from water-holding plants such as Heliconia in Venezuela (Fox, 1942), Honduras (Fox, 1948) and Trinidad (Wirth and Blanton, 1956). It is one of those species most frequently taken in stable traps and must be very strongly attracted to horses, unlike its close relatives hylas Macfie and verecundus Macfie.

\section{Culicoides hylas Macfie}

FiguRE 5

Culicoides hylas Macfie, 1940, Ent. Monthly Mag., vol. 76, p. 26 (female; British Guiana; fig. wing).-Wirth and Blanton, 1956, Journ. Washington Acad.

Sci., vol. 46, p. 98 (male, female; fig. wing, palpus, spermathecae, parameres).

Female: Length of wing $1.19(0.99-1.29, \mathrm{n}=24) \mathrm{mm}$.

Head.-Eyes contiguous, bare. Antenna with flagellar segments in proportion of $25: 20: 20: 20: 20: 20: 20: 22: 30: 30: 37: 39: 53$, antennal ratio $1.12(1.06-1.15, \mathrm{n}=5)$; distal sensory tufts present on segments III, $\mathbf{x I}-\mathbf{x v}$. Clypeus not elongated, bases of palpi arising at level of ventral eye margins. Palpal segments in proportion of $8: 30: 50: 23: 17$, third segment slightly swollen, $3.1(2.6-3.6, \mathrm{n}=17)$ times as long as greatest breadth, with shallow subdivided pit, which is often completely divided into two, small, separate, round pits. Mandible with $19(17-21, \mathrm{n}=26)$ teeth.

Thorax.-Dark brown, mesonotum with median area yellow and a pair of brownish black, broad, sublateral vittae; humeri blackish. Legs brownish black; fore and mid knee spots black, with adjacent narrow yellow rings on femora and tibiae, hind femur entirely dark, hind tibia with narrow pale rings at base and apex; hind tibial comb with six spines, the second from the spur longest.

Wing.-Pattern as figured, apices of veins $\mathrm{M}_{1}$ and $\mathrm{M}_{2}$ and in some specimens ends of veins $\mathrm{M}_{3+4}$ and $\mathrm{Cu}_{1}$ pale, and pale spot in cell $\mathrm{M}_{4}$ not continued proximad along vein $\mathrm{M}_{3+4}$, extent of other pale markings somewhat variable. Macrotrichia fairly numerous in apices of cells $\mathrm{R}_{5}, \mathrm{M}_{1}$ and $\mathrm{M}_{2}$ and very sparse in cell $\mathrm{M}_{4}$ and anal cell; costa extending to 0.68 of distance to wing tip. Halter whitish. 

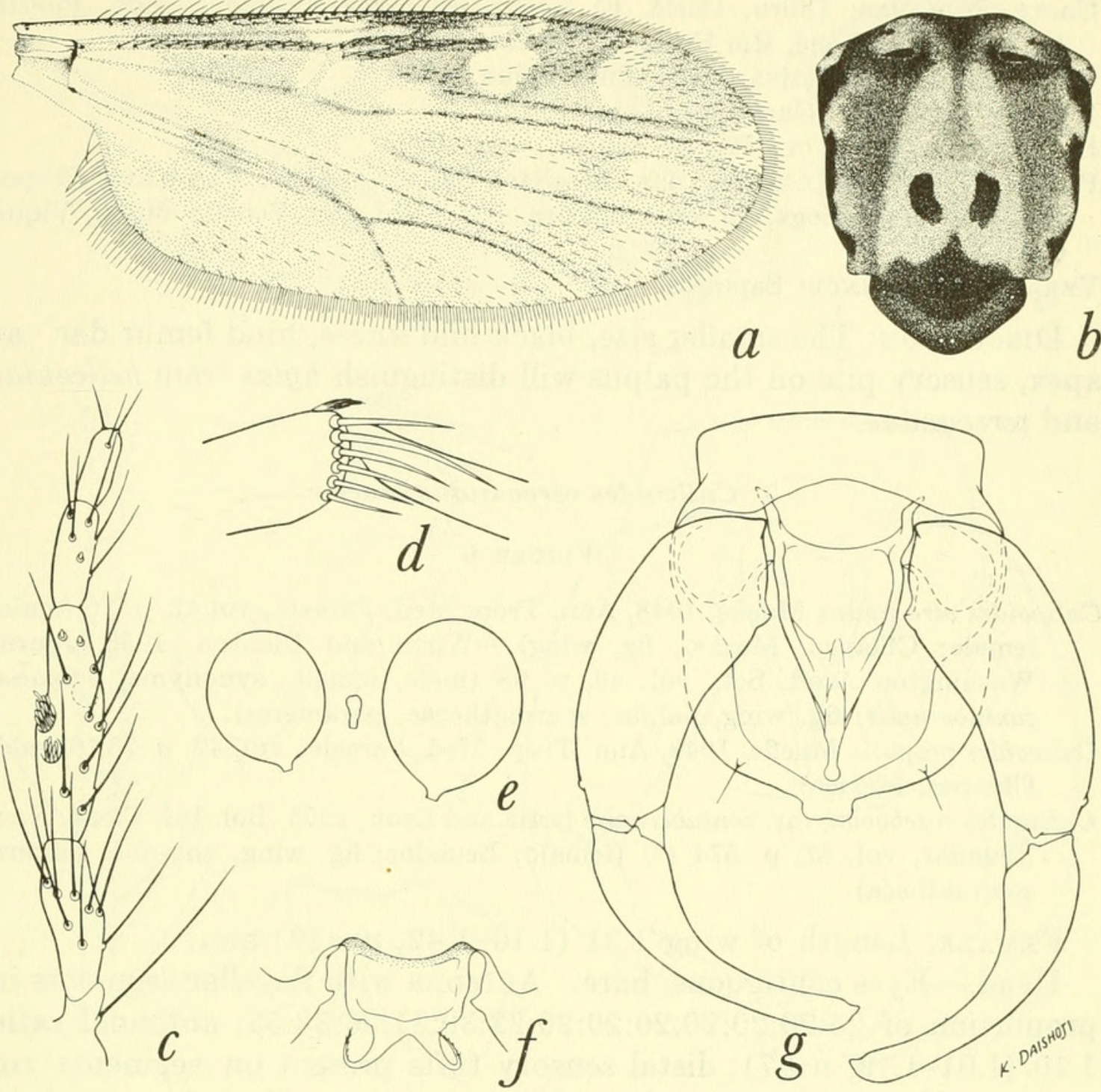

Figure 5.-Culicoides hylas Macfie. $a-e$, Female: $a$, wing; $b$, thoracic pattern; $c$, palpus; $d$, tibial comb; $e$, spermathecae. $f, g$, Male: $f$, parameres; $g$, genitalia, parameres removed.

Abdomen.-Blackish, cerci yellow. Spermathecae two, slightly ovoid, unequal, measuring 0.057 by 0.044 and 0.044 by $0.038 \mathrm{~mm}$.

Male genitalia: Indistinguishable from those of heliconiae, except for the shape of the base of the parameres, which in hylas is much shorter and more quadrate, about twice as broad as long.

Distribution: British Guiana; Honduras; Nicaragua; Panama; Peru.

\section{Panama RECORDS:}

Bocas del Toro Province: Almirante.

CANAL ZoNe: Albrook Field, Balboa, Barro Colorado Island (bred from Calathea violacea), Cabima, Fort Clayton, Fort Davis, Fort Kobbe, Fort San Lorenzo, Fort Sherman, Galeta Point, Gamboa, Huile Sia Clara (?), Loma Boracho, Madden Dam, Mindi Dairy, Mojinga Swamp.

Chiriquf Province: Algarrobo, Chiriquí, Concepción, David, Tortugas. 
Coclé Province: Chiru, Coclé, El Retiro, El Valle, Puerto Pasado, Puerto Farallón, Penomoné, Río Hato, La Venta.

Colón Province: Cativá, Pilón, Piña, Salud.

Darién Province: Garachiné, Jaqué.

Los Santos Province: Pan de Azucar.

Panamá Province: Alcalde Diaz, Arraiján, Camarón, Cerro Campana, Chepo,

El Coco, Isla Taboga, La Jolla, Pacora, Río Las Lajas, Venado Beach, Vique Cove.

Veraguas Province: Sapotilla.

Discussion: The smaller size, black mid knees, hind femur dar at apex, sensory pits on the palpus will distinguish hylas from heliconiae and verecundus.

\section{Culicoides verecundus Macfie}

\section{FIgURE 6}

Culicoides verecundus Macfie, 1948, Ann. Trop. Med. Parasit., vol 42, p. 76 (male, female; Chiapas, Mexico; fig. wing).-Wirth and Blanton, 1956, Journ. Washington Acad. Sci., vol. 46, p. 98 (male, female; synonyms, palpalis, contubernalis; fig. wing, palpus, spermathecae, parameres).

Culicoides palpalis Macfie, 1948, Ann. Trop. Med. Parasit,. vol. 42, p. 78 (female, Chiapas, Mexico).

Culicoides rozeboomi var. contubernalis Ortiz and Leon, 1955, Bol. Inf. Cient. Nac. Ecuador, vol. 67, p. 574 (?) (female; Ecuador; fig. wing, antenna, palpus, spermatheca).

Female: Length of wing $1.31(1.16-1.42, \mathrm{n}=19) \mathrm{mm}$.

Head.-Eyes contiguous, bare. Antenna with flagellar segments in proportion of $25: 20: 20: 20: 20: 20: 20: 22: 30: 31: 36: 38: 53$, antennal ratio $1.10(1.01-1.19, \mathrm{n}=7)$; distal sensory tufts present on segments III, $\mathrm{XI}-\mathrm{Xv}$. Clypeus elongated, palpus arising much below level of ventral eye margins. Palpal segments in proportion of 10:50:57:25:20, third segment very slender, $4.2(3.2-5.2, \mathrm{n}=15)$ times as long as greatest breadth, without sensory pit. Mandible with 23 (22-27, $\mathrm{n}=19)$ teeth.

Thorax.-Mesonotum dark brown, yellowish medially, with subshining brown sublateral vittae, and blackish along anterior and lateral margins; humeri whitish. Scutellum, postscutellum and pleuron dark brown. Legs dark brown; fore and hind knee spots blackish, their femora with broad subapical pale bands and their tibiae with broad basal pale bands; mid femur with apex and mid tibia with base broadly yellow, sometimes a very small black spot on apex of mid femur; hind tibia with apex narrowly pale; hind tibial comb with six spines, the second from the spur longest.

Wing.-Pattern as figured; pale markings more extensive than in hylas and heliconiae, but apices of veins $\mathrm{M}_{3+4}$ and $\mathrm{Cu}_{1}$ always dark, pale spot in cell $\mathrm{M}_{4}$ continued proximad along vein $\mathrm{M}_{3+4}$ to base of 

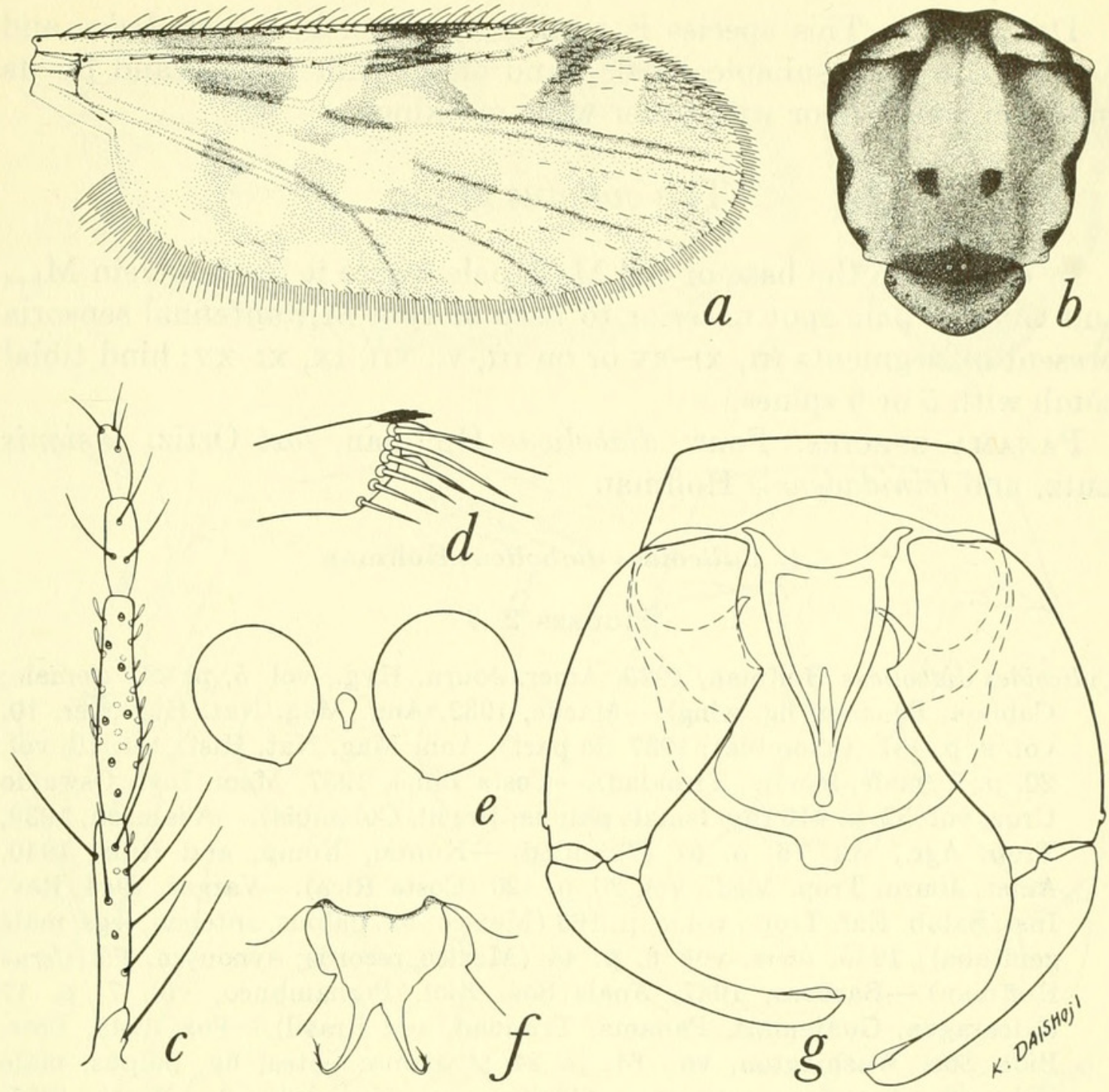

Figure 6.-Culicoides verecundus Macfie. $a-e$, Female: $a$, wing; $b$, thoracic pattern; $c$, palpus; $d$, tibial comb; $e$, spermathecae. $f, g$, Male: $f$, parameres; $g$, genitalia, parameres removed.

fork. Macrotrichia sparse in apices of cells $\mathrm{R}_{5}$ and $\mathrm{M}_{1}$; costa extending to 0.70 of distance of wing tip. Halter whitish.

Abdomen.-Blackish, cerci yellow. Spermathecae two, slightly ovoid, unequal, measuring 0.053 by $0.044 \mathrm{~mm}$. and 0.044 by $0.037 \mathrm{~mm}$.

Male genitalia: As in heliconiae, but parameres with fused basal portion about as broad as long and the distal free portions not so broadly separated at their bases, which are shorter than in heliconiae.

Distribution: Mexico ; Ecuador; Honduras; Nicaragua; Panama.

PANAMA RECORDS:

Bocas del Toro Province: Almirante.

CANAL Zone: Barro Colorado Island (from bracket fungus), Mojinga Swamp.

Chiriquí Province: David, Volcán.

Cocle Province: El Valle.

Panamá Province: Cerro Campana, Pacora. 
Discussion: This species is readily distinguished from hylas and heliconiae by the subapical pale band on the hind femur and by its more brownish color with paler wing markings.

\section{The guttatus group}

In this group the base of cell $\mathrm{M}_{4}$ is pale where it borders vein $\mathrm{M}_{3+4}$ and $\mathrm{Cu}_{1}$; no pale spot anterior to base of vein $\mathrm{M}_{1}$; antennal sensoria present on segments III, XI-XV or on III, V., VII, IX, XI-XV; hind tibial comb with 5 or 6 spines.

Panama species: Four: diabolicus Hoffman, foxi Ortiz, insignis Lutz, and trinidadensis Hoffman.

\section{Culicoides diabolicus Hoffman}

\section{Figures 2,7}

Culicoides diabolicus Hoffman, 1925, Amer. Journ. Hyg., vol. 5, p. 294 (female; Cabima, Panama; fig. wing).--Macfie, 1932, Ann. Mag. Nat. Hist., ser. 10, vol. 9, p. 487 (Colombia) ; 1937 (in part), Ann. Mag. Nat. Hist., ser. 10, vol. 20 , p. 7 (male, female; Trinidad).-Costa Lima, 1937, Mem. Inst. Oswaldo Cruz, vol. 32, p. 416 (fig. female palpus; Brazil, Colombia).-Adamson, 1939, Trop. Agr., vol. 16, p. 81 (Trinidad).-Kumm, Komp, and Ruiz, 1940, Amer. Journ. Trop. Med., vol. 20, p. 420 (Costa Rica).-Vargas, 1944, Rev. Inst. Salub. Enf. Trop., vol. 5, p. 163 (Mexico; fig. palpus, antenna, legs, male genitalia); 1945, idem. vol. 6, p. 44 (Mexico records; synonym, filariferus Hoffman).-Barbosa, 1947, Anais Soc. Biol. Pernambuco, vol. 7, p. 17 (Nicaragua, Guatemala, Panama, Trinidad, and Brazil).--Fox, 1948, Proc. Biol. Soc. Washington, vol. 61, p. 24 (Panama; notes; fig. palpus, male aedeagus, parameres; synonyms, filariferus, pseudodiabolicus).-Wirth, 1955, Proc. Ent. Soc. Washington, vol. 57, p. 109 (Guatemala).-Wirth and Blanton, 1956, Proc. Ent. Soc. Washington, vol. 58, p. 316 (synonyms, bimaculatus, ocumarensis).

Culicoides filariferus Hoffman, 1939, Puerto Rico Journ. Pub. Health Trop. Med., vol. 15, p. 172 (female; Chiapas, Mexico; fig. mesonotum, wing, palpus).

Culicoides bimaculatus Floch and Abonnenc, 1942, Inst. Pasteur Guyane Publ., vol. 49, p. 3 (female; Cayenne, French Guiana; fig. wing, palpus).

Culicoides pseudodiabolicus Fox, 1946, Ann. Ent. Soc. Amer., vol. 39, p. 256 (female; Cumuto Village, Trinidad; fig. wing).

Culicoides ocumarensis Ortiz, 1950, Rev. Sanid. Asist. Soc., vol. 15, p. 455 (male, female; Ocumare, Venezuela; fig. wing, mesonotum, antenna, palpus, spermathecae, male genitalia).-Ortiz and Leon, 1955, Bol. Inf. Cient. Nac., No. 67 , p. 571 (Ecuador; notes; fig. wing, palpus, male genitalia).

Culicoides guttatus of authors (misident., not Coquillett).-Macfie, 1940, Ent. Monthly Mag., vol. 76, p. 25 (British Guiana); 1948, Ann. Trop. Med. Parasit., vol. 42, p. 74 (Chiapas, Mexico).-Barbosa, 1952, Novos subsidios . . . Culicoides Neotrópicos, p. 15 (Ecuador; discussion).-Gibson and Ascoli, 1952, Journ. Parasit., vol. 38, p. 315 (Guatemala).-Forattini, 1955, Fol. Clin. Biol., vol. 23, p. 103 (Brazil, redescription, figs.). 

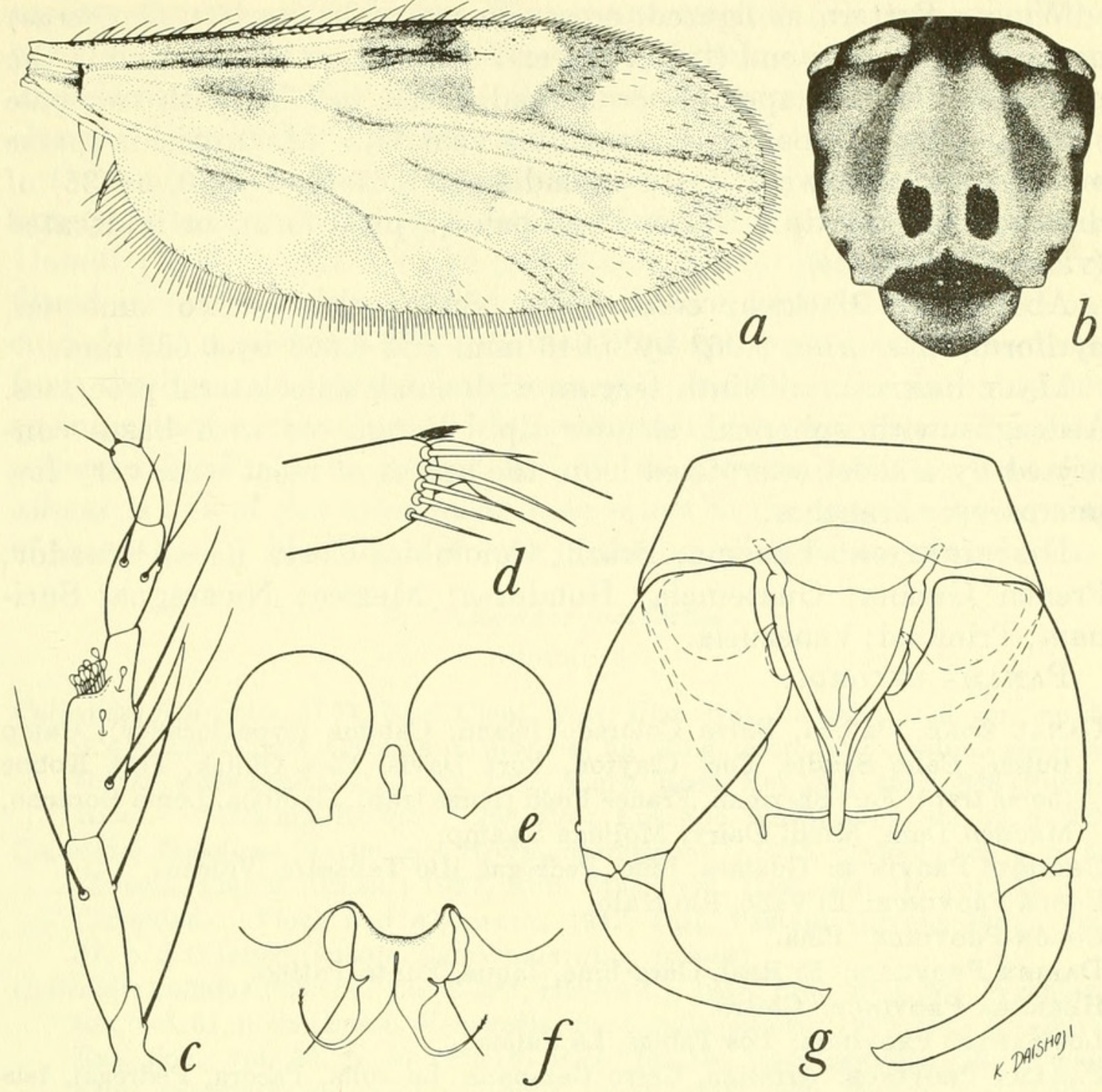

Figure 7.-Culicoides diabolicus Hoffman. $a-e$, Female: $a$, wing; $b$, thoracic pattern; $c$, palpus; $d$, tibial comb; $e$, spermathecae. $f, g$, Male: $f$, parameres; $g$, genitalia, parameres removed.

Female: Length of wing $1.03(0.92-1.22, \mathrm{n}=35) \mathrm{mm}$.

Head.-Eyes contiguous, bare. Antenna with flagellar segments in proportion of $20: 15: 15: 15: 15: 15: 15: 16: 22: 22: 26: 30: 45$, antennal ratio $1.14(1.09-1.17, \mathrm{n}=4)$; distal sensory tufts present on segments III, XI-XV. Palpal segments in proportion of $9: 23: 30: 13: 12$, third segment $3.0(2.4-3.7, \mathrm{n}=29)$ times as long as greatest breadth, with a broad, shallow, sensory pit. Mandible with $15 \quad(14-18, \mathrm{n}=34)$ teeth.

Thorax.-Mesonotum with a prominent pattern, yellowish in center, with a pair of prominent blackish sublateral vittae. Legs brown, fore and mid knees broadly yellow on femora and tibiae, hind femur dark to apex; hind tibia with broad basal and apical yellowish bands; hind tibial comb with five spines. 
Wing.-Pattern as figured, crossvein r-m pale (variety filariferus) or dark on anterior end (typical form), vein $R_{4+5}$ not infuscated in the pale area over the apex of second radial cell, cell $\mathrm{M}_{1}$ with two pale spots distal to the pale spot straddling vein $\mathrm{M}_{2}$. Macrotrichia sparse on distal third of wing; costa extending to $0.67(0.61-0.70, \mathrm{n}=35)$ of distance to wing tip. Halter knob pale (typical form) or infuscated (variety filariferus).

Abdomen.-Blackish, cerci pale. Spermathecae two, unequal, pyriform, measuring 0.062 by $0.046 \mathrm{~mm}$. and 0.053 by $0.039 \mathrm{~mm}$.

Male Genitalia: Ninth tergum with small apicolateral processes. Aedeagus with spherical, slender tip. Parameres with bases connected by a short sclerotized loop, the apices at most with very few microscopic branches.

Distribution: Panama; Brazil; Colombia; Costa Rica; Ecuador; French Guiana; Guatemala; Honduras: Mexico; Nicaragua; Surinam; Trinidad; Venezuela.

PANAMA RECORDS:

Canal Zone: Balboa, Barro Colorado Island, Cabima (type locality), Camp Butler, Caño Saddle, Fort Clayton, Fort Davis, Fort Gulick, Fort Kobbe (horse trap), Fort Sherman, France Field (horse trap), Gamboa, Loma Boracho, Madden Dam, Mindi Dairy, Mojinga Swamp.

Chiriquí Province: Gualaca, Lino, Pedregal, Río Tabasara, Volcán.

Cocle Province: El Valle, Río Hato.

Colon Province: Piña.

Darien Province: El Real, Garachiné, Jaqué, Punta Patiño.

Herrera Province: Chitré.

Los Santos Province: Los Tablas, La Palma.

Panamá Province: Arraiján, Cerro Campana, La Jolla, Pacora, Pedregal, Isla Taboga, Tocumen, Vique Cove.

Veraguas Province: Río Santa María, Sapotilla.

Discussion: This species is distinguished from its close relatives by its smaller size, presence of mesonotal pattern, wings with the pale markings sharp and rather extensive, vein $R_{4+5}$ not infuscated on the portion in the pale area at apex of second radial cell, and two pale spots in cell $M_{1}$ distal to the pale spot straddling vein $M_{2}$. Species with which it has been confused are: foxi Ortiz, which has a black spot on vein $\mathrm{R}_{4+5}$ near the apex of the second radial cell; insignis Lutz, which has vein $R_{4+5}$ infuscated basally in the pale area over second radial cell to the point where it turns abruptly forward to meet the costa and only one pale spot in cell $\mathrm{M}_{1}$ distal to the pale spot straddling vein $\mathrm{M}_{2}$; and guttatus (Coquillett), which has no mesonotal pattern and is larger. There is some variation in the wing markings of diabolicus; rarely the distal spot in cell $\mathrm{M}_{1}$ is obliterated, the crossvein $r-m$, which is normally pale, may be dark on the anterior end, and the halter knob, which is normally infuscated, may be pale in the 
variety filariferus Hoffman. The proportion of this variety in the population is quite high in Venezuela (where it was described as ocumarensis by Ortiz) and in the Central American highlands, but elsewhere, including Panama, it seems to be relatively rare.

Culicoides diabolicus is apparently one of the commonest species annoying to man in Latin America, outside the coastal salt marshes. Dampf (1936) found it to be parasitized by developmental forms of filarid larvae in Chiapas, Mexico, but Gibson and Ascoli (1952) concluded that on account of the rarity of this species in biting collections from the human onchocerciasis zone of Guatemala, it is probably not an important vector there. Material received recently from Trinidad collected by T. H. G. Aitken and W. G. Downs indicates that diabolicus is one of the commonest man-biters in the mountainous parts of that island. Nothing is known of the breeding habits of diabolicus.

\section{Culicoides foxi Ortiz}

Figure 8

Culicoides foxi Ortiz, 1951, Nov. Cient. Mus. Hist. Nat. La Salle, zool. ser., no. 5, p. 4 (male, female; Caracas, Venezuela; fig. wing, mesonotum, palpus, spermathecae, male genitalia).-Fox, 1953, Journ. Econ. Ent., vol. 45, p. 888 (Puerto Rico).-Wirth and Blanton, 1956, Proc. Ent. Soc. Washington, vol. 58, p. 309. Culicoides diabolicus Macfie (not Hoffman, misident.), 1935, Stylops, vol. 4, p. 54 (Tutoia, Piauhi, Brazil); 1937, Ann. Mag. Nat. Hist., ser. 10, vol. 20, p. 7 (Trinidad).-Floch and Abonnenc, 1942, Inst. Pasteur Guyane Publ., vol. 37, p. 2 (French Guiana; fig. female wing, palpus).

Culicoides guttatus Fox (not Coquillett, misident.), 1948, Proc. Biol. Soc. Washington, vol. 61, p. 23 (Brazil, Venezuela; fig. female palpus); 1949, Bull. Brooklyn Ent. Soc., vol. 44, p. 31 (Puerto Rico; female, male genitalia; fig. female wing, spermathecae, male aedeagus, parameres); 1950, Puerto Rico Journ. Pub. Health Trop. Med., vol. 25, p. 342 (Puerto Rico).

Female: Length of wing $1.21(1.01-1.33, \mathrm{n}=15) \mathrm{mm}$.

Head.--Eyes contiguous, bare. Antenna with flagellar segments in proportion of $22: 17: 17: 18: 18: 18: 18: 20: 25: 26: 30: 32: 48$, antennal ratio 1.10; distal sensory tufts present on segments III, XI-Xv. Palpal segments in proportion of $10: 25: 38: 20: 14$, third segment $3.2(2.5-3.6$, $\mathrm{n}=9$ ) times as long as greatest breadth, with a broad, shallow, sensory pit. Mandible with $16(14-17, \mathrm{n}=16)$ teeth.

Thorax.-Mesonotum with prominent pattern, yellowish in center, with two distinct, sublateral, blackish, longitudinal vittae. Legs brown with distinct pale bands at midlength and narrow blackish rings before apex on fore and mid femora, fore and mid knees narrowly pale, hind tibia with basal and apical pale bands; hind tibial comb with six spines.

Wing.-Pattern as figured, two pale spots in cell $\mathrm{M}_{1}$ past the pale spot straddling middle of vein $\mathrm{M}_{2}$, crossvein $\mathrm{r}-\mathrm{m}$ blackish and a small blackish spot behind apex of second radial cell. Macrotrichia sparse 

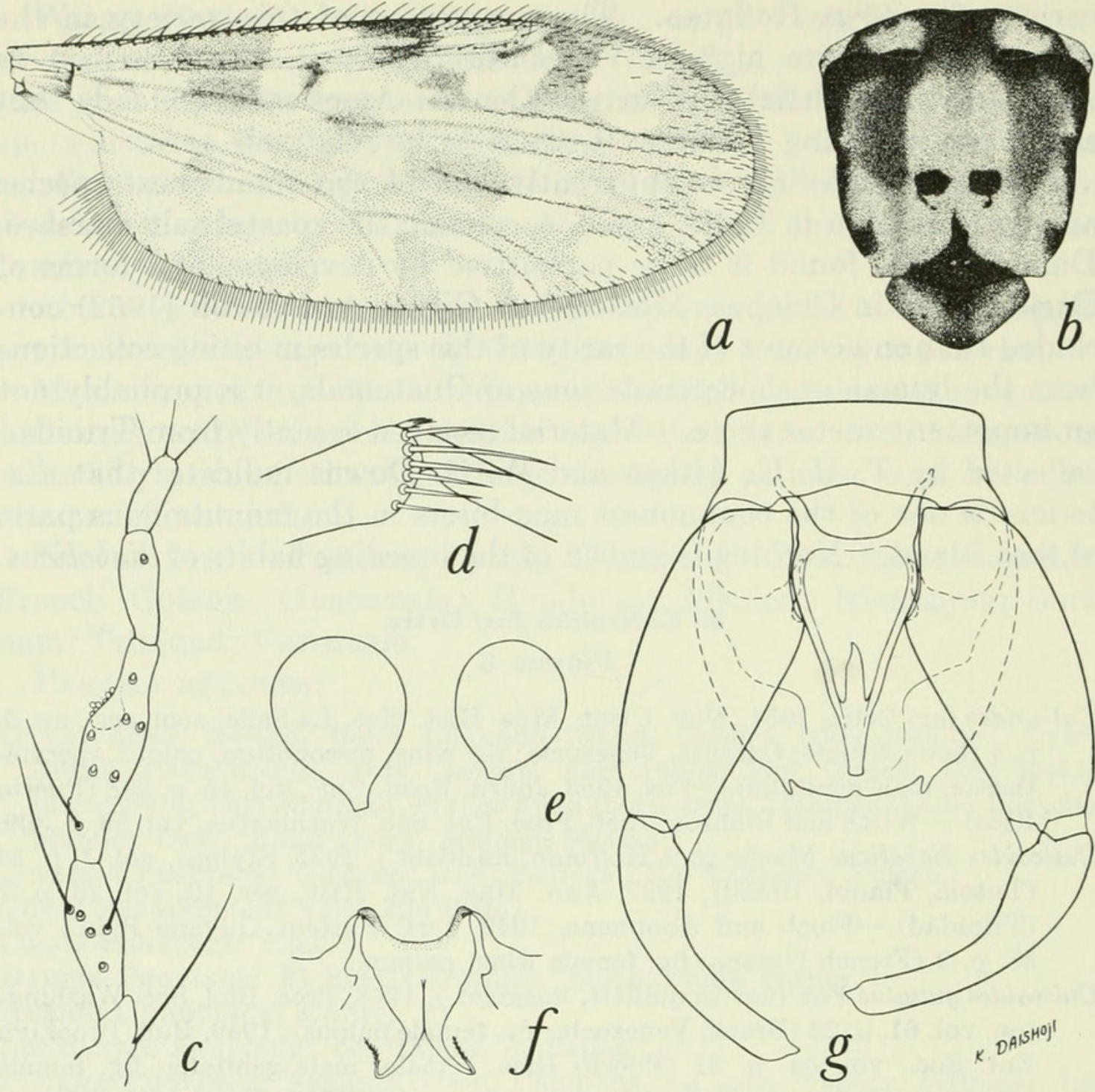

Figure 8.-Culicoides foxi Ortiz. $a-e$, Female: $a$, wing; $b$, thoracic pattern; $c$, palpus; $d$. tibial comb; $e$, spermathecae. $f, g$, Male: $f$, parameres; $g$, genitalia, parameres removed.

near distal wing margin; eosta extending to $0.68(0.67-0.71, \mathrm{n}=15)$ of distance to wing tip near distal wing margin. Halter knob blackish.

Abdomen.-Blackish, cerci pale. Spermathecae two, pyriform, unequal, measuring 0.063 by $0.049 \mathrm{~mm}$. and 0.053 by $0.043 \mathrm{~mm}$., with bases of ducts sclerotized a short distance.

Male genitalia: Ninth sternum with shallow caudomedian excavation; ninth tergum rounded caudad, with very small apicolateral processes. Aedeagus elongate, sides convexly swollen, apex truncate rather than spherical. Parameres fused on basal fourth, apices with short hairs.

Distribution: Venezuela; Brazil; Honduras; Nicaragua; Panama; Puerto Rico. 


\section{PANAMA RECORDS:}

Bocas del Toro Province: Almirante (Río Banana), Torres.

Canal Zone: Albrook Field, Barro Colorado Island, Cabima, Fort Clayton, Fort Gulick, Fort Kobbe (horse trap), Fort Sherman, France Field, Loma

Boracho, Madden Dam, Mandinga River, Mindi Dairy, Mojinga Swamp.

Chiriquí Province: Pedregal, Volcán.

Coclé Province: Aguadulce.

Colón Province: Piña.

Darién Province: El Real, Punta Patiño.

Herrera Province: Chitré.

Panamá Province: Arraiján, La Jolla, Tocumen.

Discussion: The small, isolated dark spot near the tip of vein $\mathrm{R}_{4+5}$ will readily separate this species from its relatives in the subgenus Culicoides (Hoffmania).

\section{Culicoides insignis Lutz}

FIGURE 9

Culicoides insignis Lutz, 1913, Mem. Inst. Oswaldo Cruz, vol. 5, p. 50 (male, female, pupa; Rio de Janeiro and Bahia, Brazil; fig. female wing).-Costa Lima, 1937, Mem. Inst. Oswaldo Cruz, vol. 32, p. 415 (fig. female palpus).Floch and Abonnenc, 1942, Inst. Pasteur Guyane Terr. l'Inini, publ. 49, p. 1 (French Guiana; fig. wing, palpus).-Barbosa, 1947, Anais Soc. Biol. Pernambuco, vol. 7, p. 20 (notes on genitalia of male in Lutz collection; fig. male genitalia from Rio de Janeiro).-Macfie, 1948, Ann. Trop. Med. Parasit., vol. 42, p. 75 (Chiapas, Mexico).-Fox, 1948, Proc. Biol. Soc. Washington, vol. 61, p. 25 (notes on female characters).-Barbosa, 1952, Novos Subsidios . . . Culicoides Neotrópicos, p. 16 (Ceara, Brazil; notes on Lutz collection).-Wirth and Blanton, 1956, Proc. Ent. Soc. Washington, vol. 58, p. 319 (synonyms, inamollae, painteri).

Culicoides guttatus Lutz (misident., not Coquillett), 1913, Mem. Inst. Oswaldo Cruz, vol. 5, p. 58 (fig. wing).-Beck, 1952, Florida Ent., vol. 35, p. 102 (Florida records).

Culicoides inamollae Fox and Hoffman, 1944, Puerto Rico Journ. Pub. Health Trop. Med., vol. 20, p. 110 (male, female; Puerto Rico; fig. wing).-Fox, 1948, Proc. Biol. Soc. Washington, vol. 61, p. 25 (Florida; fig. male aedeagus, parameres, female palpus); 1950, Puerto Rico Journ. Pub. Health Trop. Med., vol. 25, p. 342.-Foote and Pratt, 1954, Pub. Health Monogr. no. 18, p. 25 (United States records; fig. wing, mesonotum, palpus, male genitalia).Fox, 1955, Journ. Agr. Univ. Puerto Rico, vol. 39, p. 242 (synonyms, painteri Fox, oliveri Fox and Hoffman [sic]).

Culicoides painteri Fox, 1946, Ann. Ent. Soc. Amer., vol. 39, p. 257 (female; Honduras; fig. wing); 1948, Proc. Biol. Soc. Washington, vol. 61, p. 26 (fig. male parameres, aedeagus, female palpus).

Female: Length of wing $1.11(0.89-1.25, \mathrm{n}=24) \mathrm{mm}$.

Head.-Eyes bare, contiguous. Antenna with flagellar segments in proportion of $20: 14: 14: 14: 14: 14: 14: 15: 24: 25: 26: 29: 44$, antennal ratio 1.32; distal sensory tufts present on segments III, V, VII, IX, 
$\mathrm{XI}-\mathrm{Xv}$. Palpal segments in proportion of $9: 23: 33: 13: 17$, third segment $2.8(2.5-3.5, \mathrm{n}=19)$ times as long as greatest breadth, sensory pit broad and shallow, more or less subdivided into small pitted areas. Mandible with $21(20-23, \mathrm{n}=20)$ teeth.

Thorax.-Mesonotum with prominent pattern, yellowish in center, two dark sublateral vittae. Legs dark brown with pale rings on fore
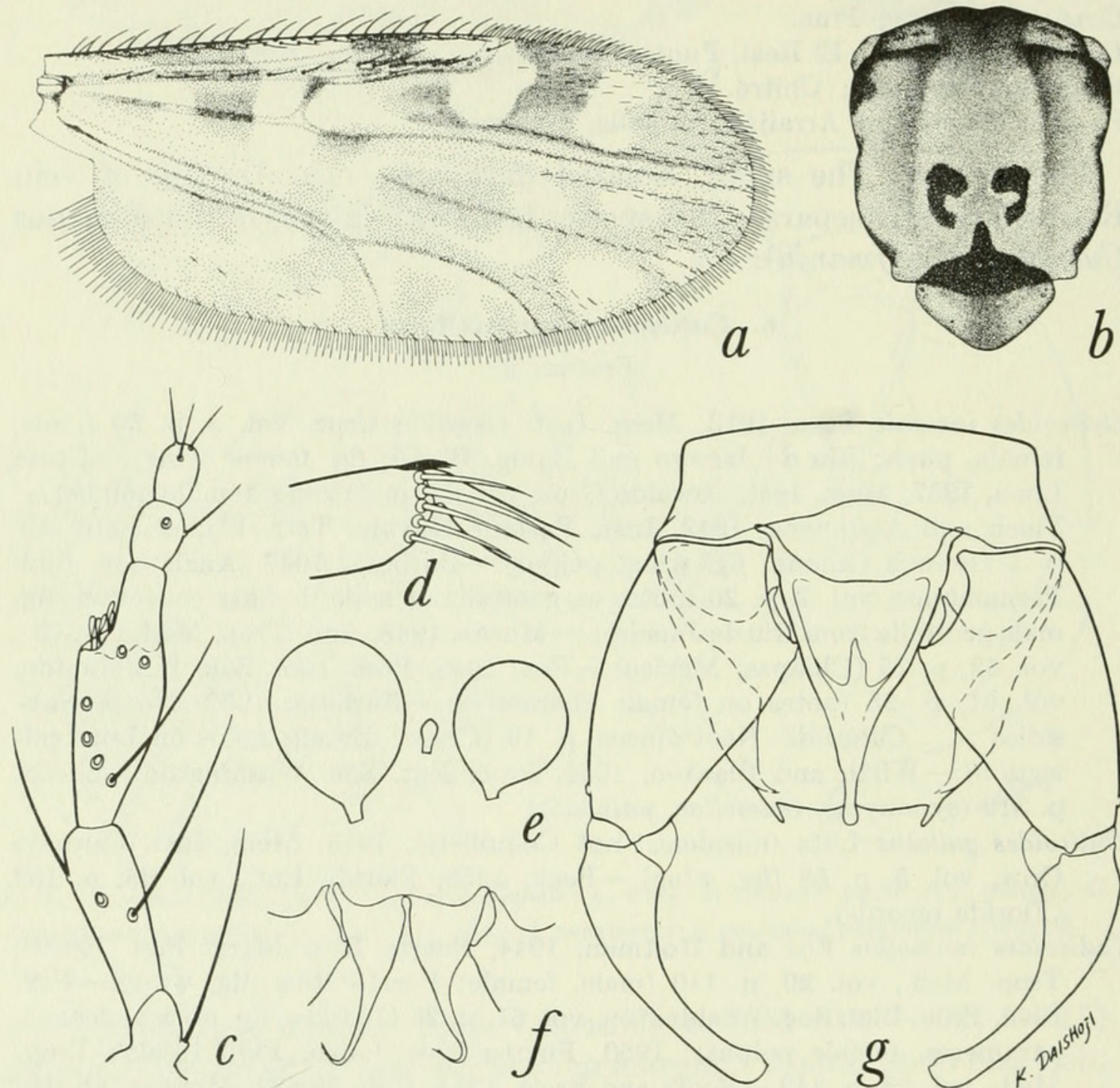

$a$

Figure 9.-Culicoides insignis Lutz. $a-e$, Female: $a$, wing; $b$, thoracic pattern; $c$, palpus; $d$, tibial comb; $e$, spermathecae. $f, g$, Male: $f$, parameres; $g$, genitalia, parameres removed.

and mid knees and at base and apex of hind tibia; hind tibial comb with six spines.

Wing.-Pattern as figured, one pale spot in cell $\mathrm{M}_{1}$ distal to the pale spot straddling vein $\mathrm{M}_{2}$; crossvein $\mathrm{r}-\mathrm{m}$ dark, vein $\mathrm{R}_{4+5}$ dark up to the point where it turns abruptly forward to meet the costa. Macrotrichia sparse on distal half of wing and in anal cell; costa extending to $0.65(0.63-0.68, \mathrm{n}=24)$ of distance to wing tip. Halter knob dark. 
Abdomen.-Blackish, cerci paler. Spermathecae two, subspherical to pyriform, unequal, measuring 0.063 by $0.049 \mathrm{~mm}$. and 0.052 by $0.041 \mathrm{~mm}$.

Male Genitalia: Ninth tergun with small apicolateral processes; basistyle with well-developed spinose setae on mesal margin. Aedeagus A-shaped, with slender, spherical tip. Parameres with main bodies connected at bases by a short loop, the tips bare.

Distribution: Puerto Rico; Brazil; Colombia; Florida; French Guiana; Honduras; Jamaica; Mexico; Nicaragua ; Panama; Surinam; Trindidad; Venezuela.

Panama ReCORDS:

Canal Zone: Balboa, Fort Davis, Fort Gulick, Loma Boracho, Mindi Dairy, Mojinga Swamp.

Chiriquí Province: Gualaca, Volcán.

Coclé Province: Aguadulce, El Cristo, El Vallé, Natá, Puerto Farallón, Puerto Obaldia, Río Hato.

Darién Province: El Real, Jaqué, Punta Patiño.

Herrere Province: Chitré.

Los Santos Province: Guararé, Las Tablas.

Panamí Province: Arraiján, Cerro Campana, La Jolla, Pacora, San Carlos, Isla Taboga, Tocumen.

We have sunk inamollae and painteri in the synonymy of insignis after a comparison of the holotypes of these two species, kindly loaned to us by Dr. Fox, with syntypes of insignis loaned to us by Dr. Costa Lima (Wirth and Blanton, 1956). We have designated a male syntype of insignis from the Instituto Oswaldo Cruz collection as the lectotype of insignis.

The females of insignis are quite easily recognized by the wing markings, only one pale spot in cell $\mathrm{M}_{1}$ past the pale spot straddling vein $M_{2}, r-m$ crossvein is dark and vein $R_{4+5}$ is dark extending well into the pale area over the second radial cell and usually dark to the point where it bends forward abruptly toward the costa.

In Panama, insignis reaches its greatest abundance in muddy cowpastures as at Aguadulce and Tocumen, where it usually outnumbers all other species of Culicoides.

\section{Culicoides trinidadensis Hoffman}

Figure 10

Culicoides trinidadensis Hoffman, 1925, Amer. Journ. Hyg., vol. 5, p. 286 (female; Trinidad; fig. wing).-Fox, 1946, Ann. Ent. Soc. Amer., vol. 39, p. 256 (Stubal's Bay, Trinidad); 1948, Proc. Biol. Soc. Washington, vol. 61, p. 23 (fig. female palpus).-Wirth and Blanton, 1956, Proc. Ent. Soc. Washington, vol. 58, p. 324 (synonyms, oliveri, diminutus).

Culicoides oliveri Fox and Hoffman, 1944, Puerto Rico Journ. Pub. Health Trop. Med., vol. 20, p. 108 (Haiti; male, female; fig. male aedeagus, parameres).Fox, 1948, Proc. Biol. Soc. Washington, vol. 61, p. 23 (discussion). 
Culicoides wokei Barbosa (in part, not Fox, June 1947), November 1947, Anais Soc. Biol. Pernambuco, vol. 7, p. 28 (male, female; Balboa, Panama; fig. male genitalia, female palpus).

Culicoides diminutus Barbosa, 1951, Proc. Ent. Soc. Washington, vol. 53, p. 163 (new name for wokei Barbosa not Fox).-Woke, 1954, Ann. Ent. Soc. Amer., vol. 47 , p. 68,71 (biological notes).

Female: Length of wing $1.12(1.06-1.19, \mathrm{n}=14) \mathrm{mm}$.

Head.-Eyes contiguous, bare. Antenna with flagellar segments in proportion of $23: 15: 15: 15: 15: 15: 15: 16: 27: 29: 32: 33: 43$, antennal ratio $1.22(1.15-1.30, \mathrm{n}=5)$; distal sensory tufts present on segments III, V, VII, IX, XI-XV. Palpal segments in proportion of $10: 27: 45: 15: 18$; third segment $3.4(2.8-3.9, \mathrm{n}=15)$ times as long as greatest breadth, without sensory pit, the sensoria scattered on surface. Mandible with $17(16-20, \mathrm{n}=17)$ teeth.
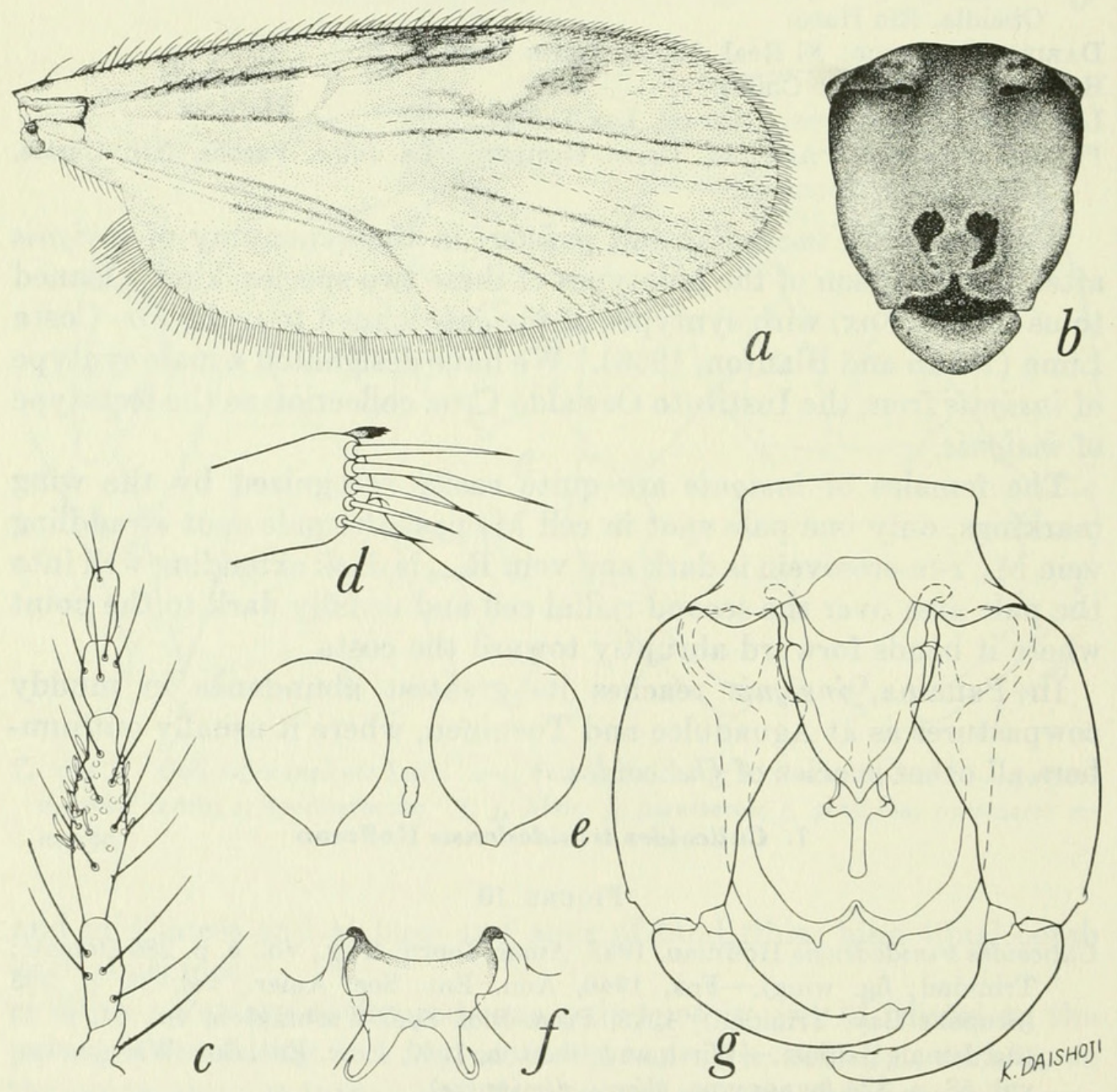

Figure 10.-Culicoides trinidadensis Hoffman. $a-e$, Female: $a$, wing; $b$, thoracic pattern; $c$, palpus; $d$, tibial comb; $e$, spermathecae. $f, g$, Male: $f$, parameres; $g$, genitalia, parameres removed. 
Thorax.-Mesonotum and scutellum uniformly dull brown, without pattern. Legs dark brown, trace of pale spots on fore and mid knees and pale bands at base and apex of hind tibia; hind tibial comb with five $(n=17)$ spines.

Wing pattern as figured, grayish brown with pattern of small, dull, grayish white spots, crossvein dark on anterior end, vein $R_{4+5}$ not darkened past the dark area over base of second radial cell, cell $\mathrm{M}_{1}$ with only one pale spot distal to the pale spot straddling vein $\mathrm{M}_{2}$. Macrotrichia sparse but present in all marginal cells of wing; costa extending to $0.66(0.63-0.70, \mathrm{n}=14)$ of distance to wing tip. Halter dark.

Abdomen.-Blackish, cerci paler. Spermathecae two, subpsherical to pyriform, subequal, measuring 0.058 by $0.046 \mathrm{~mm}$.

Male genitalia: Ninth tergum with distinct caudomedian cleft and small, not widely separated, apicolateral processes. Aedeagus stout, with a pair of peculiar, subapical projections extending ventrolaterad, the shape of the apex resembling a fleur-de-lis. Parameres with main bodies fused on basal half, apices filiform and bare.

Distribution: Trinidad; Bahama Islands, Haiti, Nicaragua, Panama.

Panama Records:

Canal Zone: Balboa (type locality of wokei Barbosa), Fort Kobbe, Galita

Point, Loma Boracho, Mojinga Swamp.

Bocas del Toro Province: Almirante.

Chiriquí Province: Alanje, Río Tabasará.

Coclé Province: Puerto Farallón, Puerto Obaldía, Río Hato.

Darién Province: Garachiné, Jaqué, Punta Patiño.

Herrera Province: Puerto Chitré.

Los Santos Province: Las Tablas.

Panamá Province: Arraiján, Bayano, Chame, Pedregal, Puerto de Chorrera,

Río Las Lajas, Tocumen, Viqué Cove.

Archipiélago de las Perlas: Isla del Rey.

Discussion: This species is known only from localities near coastal salt marshes. It greatly resembles the Brazilian species, maruim Lutz, with its unmarked mesonotum, wing pattern with dark crossvein, undarkened vein $R_{4+5}$ and only one distal pale spot in cell $M_{1}$, dark halter, and third palpal segment without sensory pit, but maruim is a paler species with a more yellowish wing on which the macrotrichia are very scanty, lacks the sensoria on antennal segments v, vII and Ix, the male aedeagus lacks the fleur-de-lis-like apex and the parameres are fused only a short distance at bases and taper more gradually to stouter, bare apices.

Woke (1954) reported this species (as diminutus Barbosa) from biting collections on man, and from emergence traps on the tidal 
marsh at Balboa, Canal Zone. Woke's collections formed part of the type series of diminutus (=wokei Barbosa, not Fox).

\section{Subgenus Culicoides (Avaritia) Fox}

Culicoides (Avaritia) Fox, 1955, Puerto Rico Journ Agr., vol. 39, p. 218.

Small species with bluish black mesonotum and pale legs; antenna with sensoria on segments III, XII or XIII to $\mathrm{Xv}$; tibial comb with 5 spines; male genitalia with ninth tergum rounded, apicolateral processes absent, inner margin of basistyle without spinose setae; aedeagus without basal barlike sclerotization or ball-like tip, but with distal peg; parameres separate and short with simple tips.

TYPE: Ceratopogon obsoletus Meigen, by original designation.

Panama species: Two: pusilloides Wirth and Blanton and pusillus Lutz. These species belong to a group distinct from the Holarctic obsoletus group and we will call this the pusillus group.

\section{Culicoides pusilloides Wirth and Blanton}

Figure 11

Culicoides pusilloides Wirth and Blanton, 1955, Bull. Brooklyn Ent. Soc., vol. 50, p. 104 (male, female; Panama; fig. wing, palpus, spermathecae, male genitalia)

Female: Length of wing $0.69(0.63-0.73, \mathrm{n}=10) \mathrm{mm}$.

Head.-Eyes bare, broadly contiguous. Antenna with flagellar segments in proportion of $14: 9: 10: 11: 11: 11: 12: 13: 15: 16: 16: 18: 28$, antennal ratio $1.12(0.98-1.43, \mathrm{n}=8)$; distal sensory tufts present on segments III, XII-Xv. Palpal segments in proportion of $5: 11: 13: 5: 7$, third segment slightly swollen, $1.9(1.6-2.2, \mathrm{n}=9)$ times as long as greatest breadth, with a small, deep sensory pit. Mandible with $13(12-15, \mathrm{n}=8)$ teeth.

Thorax.-Mesonotum blackish, anterior margin and two broad sublateral vittae extending the entire length of mesonotum intense black, a broad median band and sides of mesonotum behind level of humeral pits densely bluish gray pruinose. Scutellum, postscutellum and pleuron black. Legs brown, fore and mid femora with broad apical pale rings; fore tibia with narrow and mid tibia with broad, basal pale rings, hind tibia and most of tarsi yellowish; hind tibial comb with five spines, the one next to the spur longest.

Wing.-Pattern as figured, with four incomplete bands of large, diffuse, pale spots, the dark areas of wing less extensive than the pale areas, distal half of second radial cell in a pale area, each band in cell $R_{5}$ about half as broad as the pale areas on each side. Macrotrichia nearly absent, only a few along wing margin in cells $R_{5}$ and $M_{1}$; costa extending to 0.57 of distance to wing tip. Halter pale yellowish. 

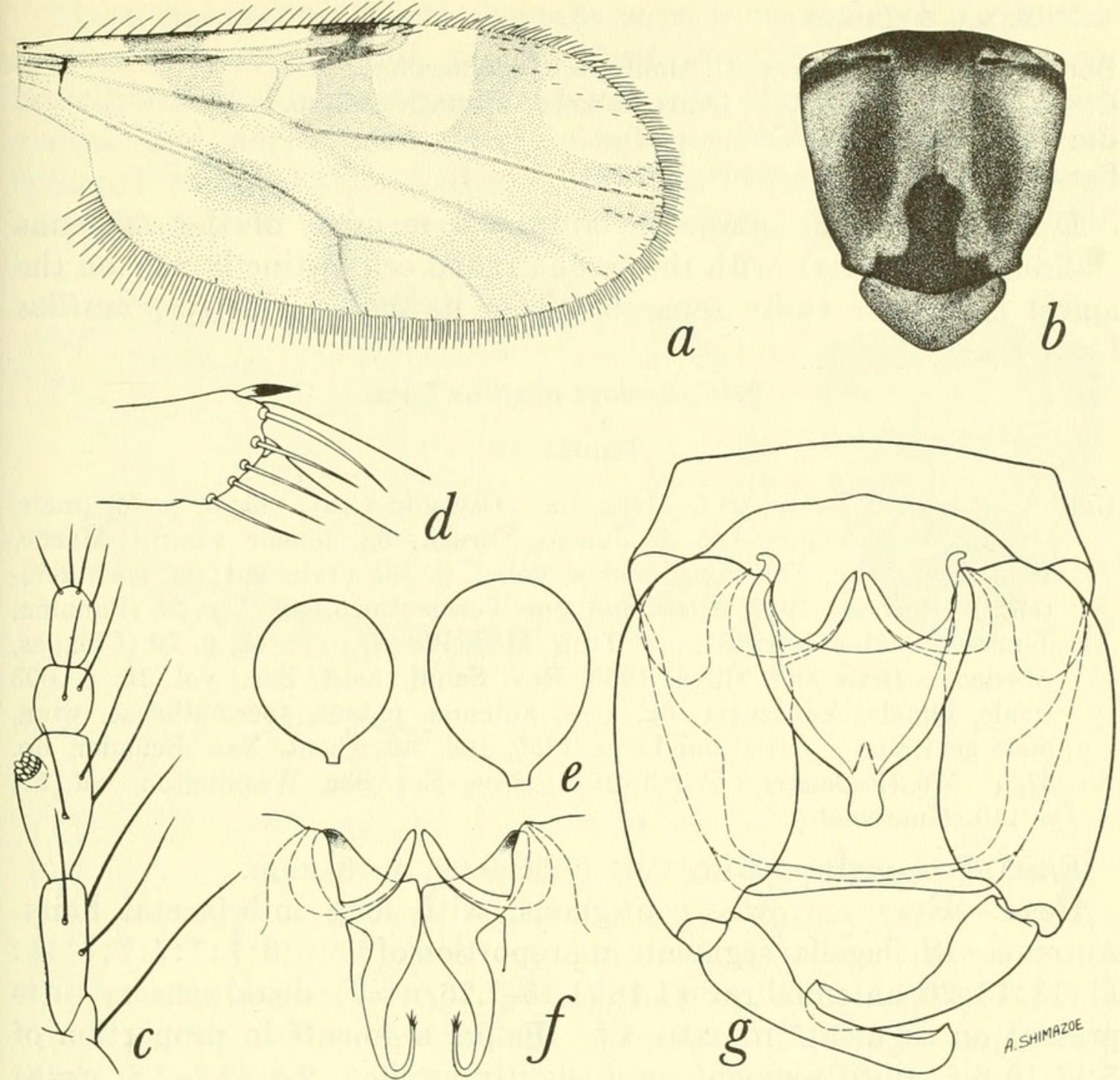

Figure 11.-Culicoides pusilloides Wirth and Blanton. $a-e$, Female: $a$, wing; $b$, thoracic pattern; $c$, palpus; $d$, tibial comb; $e$, spermathecae. $f, g$, Male: $f$, parameres; $g$, genitalia, parameres removed.

Abdomen.-Pale brown, darker toward apex. Spermathecae two, slightly ovoid, very unequal, measuring 0.042 by $0.034 \mathrm{~mm}$. and 0.033 by $0.026 \mathrm{~mm}$.

Male genitalia: Ninth sternum narrow, ribbonlike; ninth tergum broader than long, slightly convex caudally, without apicolateral processes, median notch or lobes. Basistyle with ventral root long and slender, dorsal root about half as long as ventral root, pointed; dististyle with slightly expanded apex. Aedeagus 1.4 times as long as basal breadth, with basal arch reaching about 0.4 of total length, distal portion with a peglike internal sclerotization, apex papilliform. Parameres separate, each with very stout base, bulbous stem. apex very slender and recurved, with a few very fine hairs.

Distribution: Panama; Guatemala; Honduras; Nicaragua. 
PanAMA RECORDS:

Bocas del Toro Province: Almirante (type locality).

Canal Zone: Fort Kobbe, Loma Boracho, Mojinga Swamp.

Chiriquí Province: La Concepción.

Panamá Province: Camarón, Pedregal.

Discussion: This species is a typical member of the subgenus Culicoides (Avaritia), with the second radial cell distinctly pale on the apical half, thus easily separable from its closest relative, pusillus Lutz.

\section{Culicoides pusillus Lutz}

Figure 12

Culicoides pusillus Lutz, 1913, Mem. Inst. Oswaldo Cruz, vol. 5, p. 52 (male, female; Manguinhos, Rio de Janeiro, Brazil; fig. female wing).-Macfie, 1938, Proc. Roy. Ent. Soc. London, vol. 7, p. 165 (Trinidad; fig. male genitalia).-Barbosa, 1947, Anais Biol. Soc. Pernambuco, vol. 7, p. 25 (Panama, Jamaica).-Macfie, 1948, Ann. Trop. Med. Parasit., vol. 42, p. 79 (Chiapas, Mexico).-Ortiz and Mirsa, 1952, Rev. Sanid. Asist. Soc., vol. 16, p. 603 (male, female; Venezuela; fig. eyes, antenna, palpus, spermathecae, wing, male genitalia).--Ortiz and Leon, 1955, Bol. Inf. Cient. Nac. Ecuador, no. 67, p. 570 (Ecuador).-Wirth, 1955, Proc. Ent. Soc. Washington, vol. 57, p. 110 (Guatemala).

Female: Length of wing $0.64(0.56-0.69, \mathrm{n}=8) \mathrm{mm}$.

Head.-Eyes narrowly contiguous, with long interfacetal hairs. Antenna with flagellar segments in proportion of $11: 6: 6: 7: 7: 7: 7: 7: 11$ : $11: 13: 13: 20$, antennal ratio $1.18(1.15-1.26, \mathrm{n}=7)$; distal sensory tufts present on segments III, XIII-Xv. Palpal segments in proportion of $5: 17: 19: 8: 8$, third segment only slightly swollen, $2.6(2.2-2.8, \mathrm{n}=8)$ times as long as greatest breadth, with a small, deep sensory pit. Mandible with $14(13-15, \mathrm{n}=10)$ teeth.

Thorax.-Mesonotum blackish, densely bluish to greenish gray pruinose, with two narrow, longitudinal sublateral black vittae. Scutellum, postscutellum and pleuron blackish. Legs pale brown, knee spots blackish; fore and mid femora with subapical, all tibiae with subbasal and hind tibia with apical, broad pale bands; hind tibial comb with five $(n=5)$ spines, the one next to the spur longest.

Wing.-Pattern as figured; large quadrate pale spots at anterior wing margin over $r-m$ crossvein and past end of second radial cell, remainder of wing without distinct pale spots, but obscurely paler between the veins. Macrotrichia absent, costa extending to 0.53 $(0.52-0.53, \mathrm{n}=8)$ of distance to wing tip. Halter whitish.

Abdomen.-Pale brown. Spermathecae two, slightly ovoid, subequal, measuring 0.043 by $0.031 \mathrm{~mm}$., the bases of the ducts sclerotized a very short distance. 
MALE Genitalia: Ninth sternum with a broad, shallow, caudomedian excavation; ninth tergum short, rounded caudad with two broadly rounded lobes, apicolateral processes absent. Basistyle with ventral and dorsal roots short, slender, subequal; dististyle with enlarged, rounded tip. Aedeagus with main body triangular, basa] arms short, basal arch low and rounded, extending to about a fourth
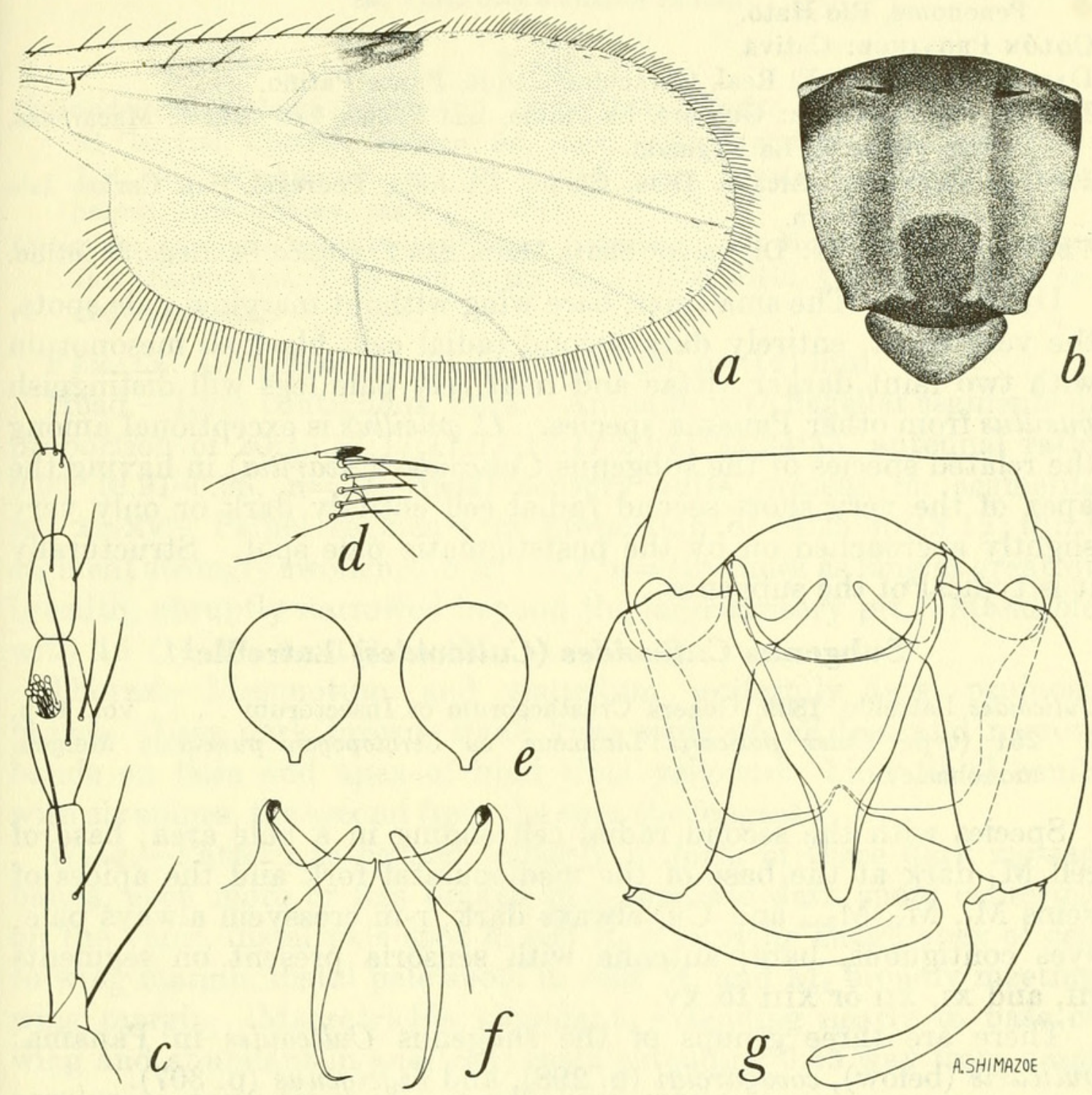

Figure 12.-Culicoides pusillus Lutz. $a-e$, Female: $a$, wing; $b$, thoracic pattern; $c$, palpus; $d$, tibial comb; $e$, spermathecae. $f, g$, Male: $f$, parameres; $g$, genitalia, parameres removed.

of total length of aedeagus, distal portion slender with a rounded apex, a distinct internal, basally projecting, sclerotized peg present. Parameres separate, each with slender anterolateral arm, base of stem stout, stem tapering to curved, filiform, simple apex.

Distribution: Brazil; Ecuador; French Guiana; Guatemala; Mexico; Panama; Trinidad; Venezuela; West Indies. 


\section{Panama Records:}

Bocas del Toro Province: Almirante.

Canal Zone: Fort Clayton, Fort Davis, Fort Kobbe, France Field, Loma Boracho, Mandinga River, Mindi Dairy, Mojinga Swamp.

Chiriquí Province: Algarrobo, Boca Chica, Chiriquí, Chirú, Concepción Horconcitos, Río Tabasará, Tortugas.

Coclé Province: Aguadulce, Antón, Coclé, El Cristo, El Valle, La Venta, Penonomé, Río Hato.

Colón Province: Cativá.

Darien Province: El Real, Garachiné, Jaqué, Punta Patiño.

Los Santos Province: Guararé, La Palma, Las Tablas, Los Cruces, Macaracas, Puerto Mensabé, La Yeguada.

Panamá Province: Alcalde Diaz, Chepo, La Jolla, Pedregal, San Carlos, Isla Taboga, Tocumen.

Veraguas Province: Divisa, Río Santa María, San Francisco, Santiago, Sapotillo.

Discussion: The small size, bare wing without marginal pale spots, the very short, entirely dark second radial cell, blackish mesonotum with two faint darker vittae and relatively pale legs will distinguish pusillus from other Panama species. C. pusillus is exceptional among the related species of the subgenus Culicoides (Avaritia) in having the apex of the very short second radial cell entirely dark or only very slightly encroached on by the poststigmatic pale spot. Structurally it is typical of the subgenus.

\section{Subgenus Culicoides (Culicoides) Latreille}

Culicoides Latreille, 1809, Genera Crustaceorum et Insectorum . . . , vol. 4, p. 251 (type: Culex pulicaris Linnaeus, as Ceratopogon punctatus Meigen, monobasic).

Species with the second radial cell ending in a pale area; base of cell $\mathrm{M}_{4}$ dark at the base of the mediocubital fork and the apices of veins $\mathrm{M}_{1}, \mathrm{M}_{2}, \mathrm{M}_{3+4}$ and $\mathrm{Cu}_{1}$ always dark; $\mathrm{r}-\mathrm{m}$ crossvein always pale; eyes contiguous, bare; antenna with sensoria present on segments III, and XI, XII or XIII to Xv.

There are three groups of the subgenus Culicoides in Panama: pulicaris (below), covagarciai (p. 298), and nigrigenus (p. 307).

\section{The pulicaris group}

Large species with black legs, at most with small pale knee spots; mesonotum blackish, entirely dull gray pruinose or with gray pruinose pattern; antenna with sensoria present on segments III, $\mathbf{X I}-\mathbf{X v}$; tibial comb with six spines; male genitalia with ninth tergum rounded caudally and bearing a low median lobe, the apicolateral processes small; basistyle with mesal surface more or less spinose; aedeagus without basal sclerotized band, distal peg or spherical tip; parameres separate, with bent bases and slender, pubescent tips. 
This group and the obsoletus group of the subgenus Culicoides (Avaritia) reach their highest development in the Holarctic Region with numerous North American and Eurasian species, particularly in the far north.

Panama Species: Two: elutus Macfie and luteovenus Root and Hoffman.

\section{Culicoides elutus Macfie}

\section{Figure 13}

Culicoides elutus Macfie, 1948, Ann. Trop. Med. Parasit., vol. 42, p. 75 (female; El Carrizal, Chiapas, Mexico; fig. wing).-Wirth and Blanton, 1956, Proc. Ent. Soc. Washington, vol. 58, p. 212 (male, female: Panama; fig. wing, palpus, spermatheca, male genitalia).

Culicoides cockerelli tristriatulus Vargas (misident., not Hoffman), 1945, Rev. Inst. Salub. Enf. Trop., vol. 6, pp. 45, 48 (Camotlán, Oaxaca, Mexico; fig. male genitalia).

Female: Length of wing $1.14(1.02-1.25, \mathrm{n}=14) \mathrm{mm}$.

Head.-Eyes contiguous, bare. Antenna with flagellar segments in proportion of $20: 15: 17: 17 \cdot 17: 17: 17: 17: 20: 21: 23: 24: 35$, antennal ratio $0.93(0.91-0.96, \mathrm{n}=2)$; distal sensory tufts present on segments III, XI-XV. Palpal segments in proportion of 10:26:30:12:12; third segment strongly swollen, $2.5(2.1-2.7, \mathrm{n}=10)$ times as long as greatest breadth, abruptly narrowed beyond the large sensory pit. Mandible with $16(14-17, \mathrm{n}=14)$ teeth.

Thorax.-Mesonotum and scutellum uniformly dark pruinose brown. Legs dark brown, small knee spots on all legs and narrow bands on base and apex of hind tibia yellowish; hind tibial comb with six spines, the second from the spur the longest.

Wing.-Pattern as figured, roughly in form of three dark zig-zag bands, each more or less broken into separate dark spots centering on the veins, distal pale spot in cell $R_{5}$ occupying entire apex of cell to wing margin, distal pale spots in cells $\mathrm{M}_{1}$ and $\mathrm{M}_{2}$ broadly meeting wing margin. Macrotrichia abundant, extending nearly to base of wing and abundant in anal cell; costa extending 0.65 way from basal arculus to wing tip. Halter yellowish white.

Abdomen.-Blackish. Spermathecae two, subequal, suboval, each measuring 0.083 by $0.053 \mathrm{~mm}$.

Male genitalia: Ninth sternum with deep caudomedian excavation; ninth tergum rounded caudally with moderately developed apicolateral processes and a well-developed, hyaline, uncleft, caudomedian lobe. Basistyle with dense, dark, spinose setae on mesal face, dorsal and ventral roots well developed; dististyle with expanded tip. Aedeagus massive, distal portion stout with a short, more slender, caudomedian lobe. Parameres separate, slender, each with 


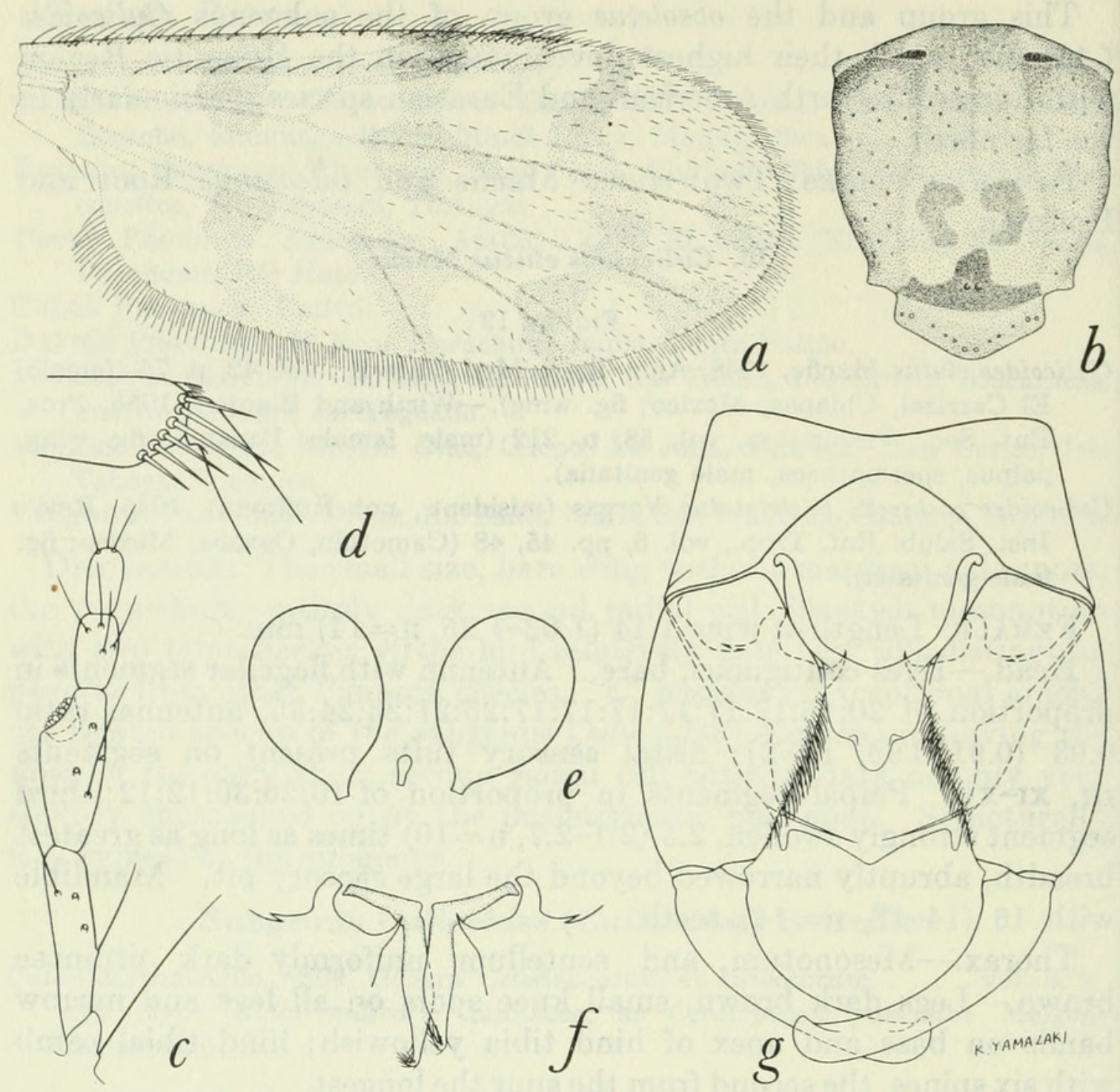

Figure 13.-Culicoides elutus Macfie. $a-e$, Female: $a$, wing; $b$, thoracic pattern; $c$, palpus; $d$, tibial comb; $e$, spermathecae. $f, g$, Male: $f$, parameres; $g$, genitalia, parameres removed.

base abruptly bent laterad, nearly straight stem and hairy, ventrally bent apex.

Distribution: Mexico; Panama.

PANAMA RECORDS:

Bocas del Toro Province: Almirante.

Chiriquí Province: Boquete, Volcán.

Panamá Province: Cerro Azul, Pacora.

Discussion: This species is confined to the Chiriquí highlands and the adjacent jungle area at Almirante, country similar in ecology to the Chiapas highland area of Mexico from which it was originally described. Its closest Neotropical relative is luteovenus Root and Hoffman, a Nearctic species which follows the Central American highlands into Panama. 


\section{Culicoides luteovenus Root and Hoffman}

FIGURE 14

Culicoides luteovenus Root and Hoffman, 1937, Amer. Journ. Hyg., vol. 25, p. 156 (male, female; San Jacinto, D. F., Mexico; fig. wing, male genitalia).Macfie, 1948, Ann. Trop. Med. Parasit., vol. 42, p. 76 (Chiapas, Mexico).Wirth, 1952, Univ. California Publ. Ent., vol. 9, p. 175 (male, female; California, Washington, Utah; fig. wing, mesonotum, palpus); 1955, Proc. Ent. Soc. Washington, vol. 57, p. 110 (Guatemala).-Wirth and Blanton, 1956, Proc. Ent. Soc. Washington, vol. 58, p. 214 (male, female; Panama; fig. wing, mesonotum, palpus, spermathecae, male genitalia).

Female: Length of wing $1.35(1.29-1.42, \mathrm{n}=4) \mathrm{mm}$.

Head.-Eyes contiguous, bare. Antenna with flagellar segments in proportion of $22: 18: 18: 19: 20: 20: 20: 21: 25: 26: 28: 32: 41$, antennal ratio $0.99(0.95-1.03, \mathrm{n}=5)$; distal sensory tufts present on segments
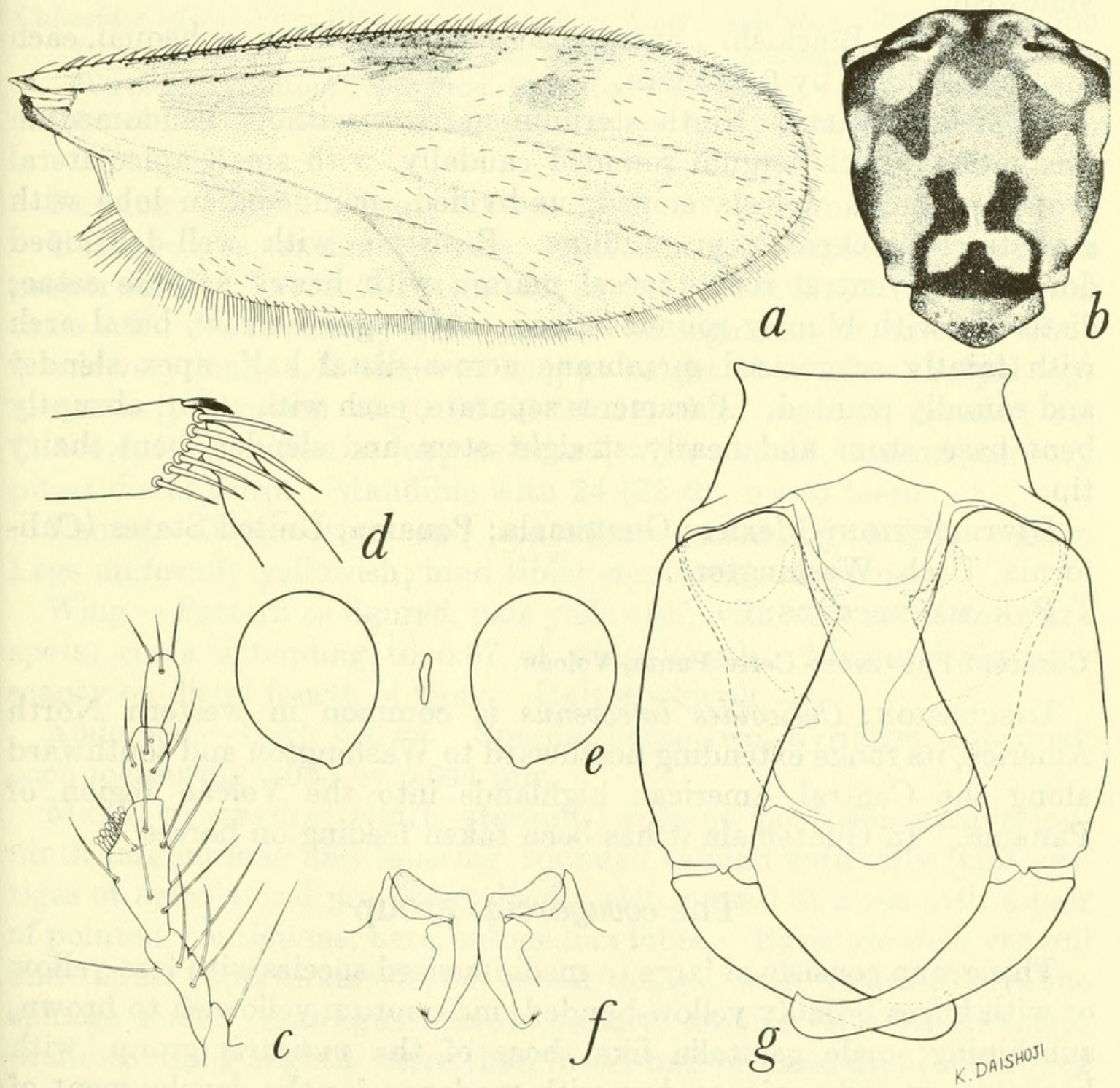

Figure 14.-Culicoides luteovenus Root and Hoffman. a-e, Female: $a$, wing; $b$, thoracic pattern; $c$, palpus; $d$, tibial comb; $e$, spermathecae. $f, g$, Male: $f$, parameres; $g$, genitalia, parameres removed. 
III, XI-XV. Palpal segments in proportion of $10: 25: 34: 11: 14$; third segment slightly swollen, $2.45(2.3-2.6, \mathrm{n}=2)$ times as long as broad, with a broad, shallow, sensory pit. Mandible with $14(13-17, \mathrm{n}=7)$ teeth.

Thorax.-Mesonotum pruinose gray, with a prominent pattern of interconnected, subshining dark brown areas on anterior and lateral portions. Scutellum gray pruinose; postscutellum and pleuron shining dark brown. Legs dark brown, knees narrowly yellowish; base and apex of hind tibia with narrow pale rings; hind tibial comb with six spines, the second from the spur longest.

Wing.-Pattern as figured, the pale areas milky white to yellowish hyaline; distal pale spot in cell $R_{5}$ gradually evanescent towards wing tip. Macrotrichia numerous on distal half of wing, sparse in cell $\mathbf{M}_{4}$ and in anal cell; costa extending to 0.60 of wing length. Halter yellowish.

Abdomen.-Blackish. Spermathecae two, pyriform, subequal, each measuring 0.061 by $0.045 \mathrm{~mm}$.

Male Genitalia: Ninth sternum narrow, without caudomedian excavation; ninth tergum rounded caudally, with small apicolateral processes and a well-developed, undivided, caudomedian lobe with a distinct thickening on midline. Basistyle with well-developed dorsal and ventral roots, mesal margin with heavy spinose setae; dististyle with bluntly rounded apex. Aedeagus narrow, basal arch with faintly sclerotized membrane across distal half, apex slender and roundly pointed. Parameres separate, each with stout, abruptly bent base, stout and nearly straight stem and slender, bent, hairy tip.

Distribution: Mexico; Guatemala; Panama; United States (California, Utah, Washington).

Panama RECORDS:

Chiriquí Province: Cerro Punta, Volcán.

Discussion: Culicoides luteovenus is common in western North America, its range extending northward to Washington and southward along the Central American highlands into the Volcán region of Panama. In Guatemala it has been taken feeding on horses.

\section{The covagarciai group}

This group consists of large to medium-sized species with legs yellow or with knees broadly yellow-banded; mesonotum yellowish to brown, subshining; male genitalia like those of the pulicaris group, with basistyles mesally spinose, but with tendency for the development of long apicolateral processes and a caudomedian cleft on the ninth tergum, a basal sclerotized band and distal peg and spherical tip on 
the aedeagus, together with a fusion of the parameres, all characters resembling those of the subgenus Culicoides (Hoffmania).

In systematic position and geographic development this group is intermediate between the subgenus Culicoides (Hoffmania) and the more typical Culicoides (Culicoides). When better investigated by further intensive collecting, the extraordinary speciation of this group and the nigrigenus group in Central America and the southern Caribbean fringe may shed important clues on the biogeographic history of the connections between North and South America.

Panama species: Five: covagarciai Ortiz, efferus Fox, marshi Wirth and Blanton, metagonatus Wirth and Blanton, and rostratus Wirth and Blanton.

\section{Culicoides efferus Fox}

FIGURE 15

Culicoides efferus Fox, 1952, Ann. Ent. Soc. Amer., vol. 45, p. 365 (female; Río Charape, Peru; fig. wing, palpus, tibial comb, spermathecae, antenna).Wirth and Blanton, 1956, Proc. Ent. Soc. Washington, vol. 58, p. 217 (male, female; Peru, Panama, Nicaragua, Honduras; fig. wing, palpus, spermathecae, male genitalia).

Female: Length of wing $1.49(1.35-1.62, \mathrm{n}=6) \mathrm{mm}$.

Head.-Eyes contiguous, bare. Antenna with flagellar segments in proportion of $25: 22: 24: 24: 24: 24: 24: 24: 25: 25: 28: 38: 52$, antennal ratio 0.93 ; distal sensory tufts present on segments III, XI-Xv. Proboscis very long, 1.42 times as long as height of an eye. Palpal segments in proportion of $10: 38: 43: 25: 21$, third segment slender, 3.9 $(3.5-4.4, \mathrm{n}=6)$ times as long as broad, with a small, shallow, sensory pit at distal third. Mandible with $24(22-26, \mathrm{n}=8)$ teeth.

Thorax.-Mesonotum and scutellum subshining bright yellow. Legs uniformly yellowish; hind tibial comb with six spines.

Wing.-Pattern as figured, pale yellowish, with very restricted dark spots; costa extending to 0.67 of wing length. Macrotrichia very scanty on distal fourth of wing. Halter whitish.

Abdomen.-Dark brown. Spermathecae two, pyriform, subequal, each measuring 0.053 by $0.041 \mathrm{~mm}$.

Male genitalia: Ninth sternum without posterior excavation; ninth tergum long and tapering, rounded caudad with only faint vestiges of apicolateral processes, deeply cleft mesad at apex with a pair of pointed, contiguous, bare, submedian lobes. Basistyle with ventral and dorsal roots undeveloped, mesal margin with yellowish hyaline spinose setae. Aedeagus narrow basally, anterior sclerotized membrane covering slightly more than distal half of basal arch; distal peg and apical spherical tip very slender. Parameres fused more than halfway to apices, the free portions very slender, pointed, hairy, the common basal portion not greatly expanded laterally. 
Distribution: Peru; Honduras; Nicaragua; Panama.

PanAma ReCORDS:

Chiriquí Province: Cerro Punta, Volcán.

Discussion: The large size, yellow color, long proboscis, and slender, long third palpal segment with small round sensory pit will readily
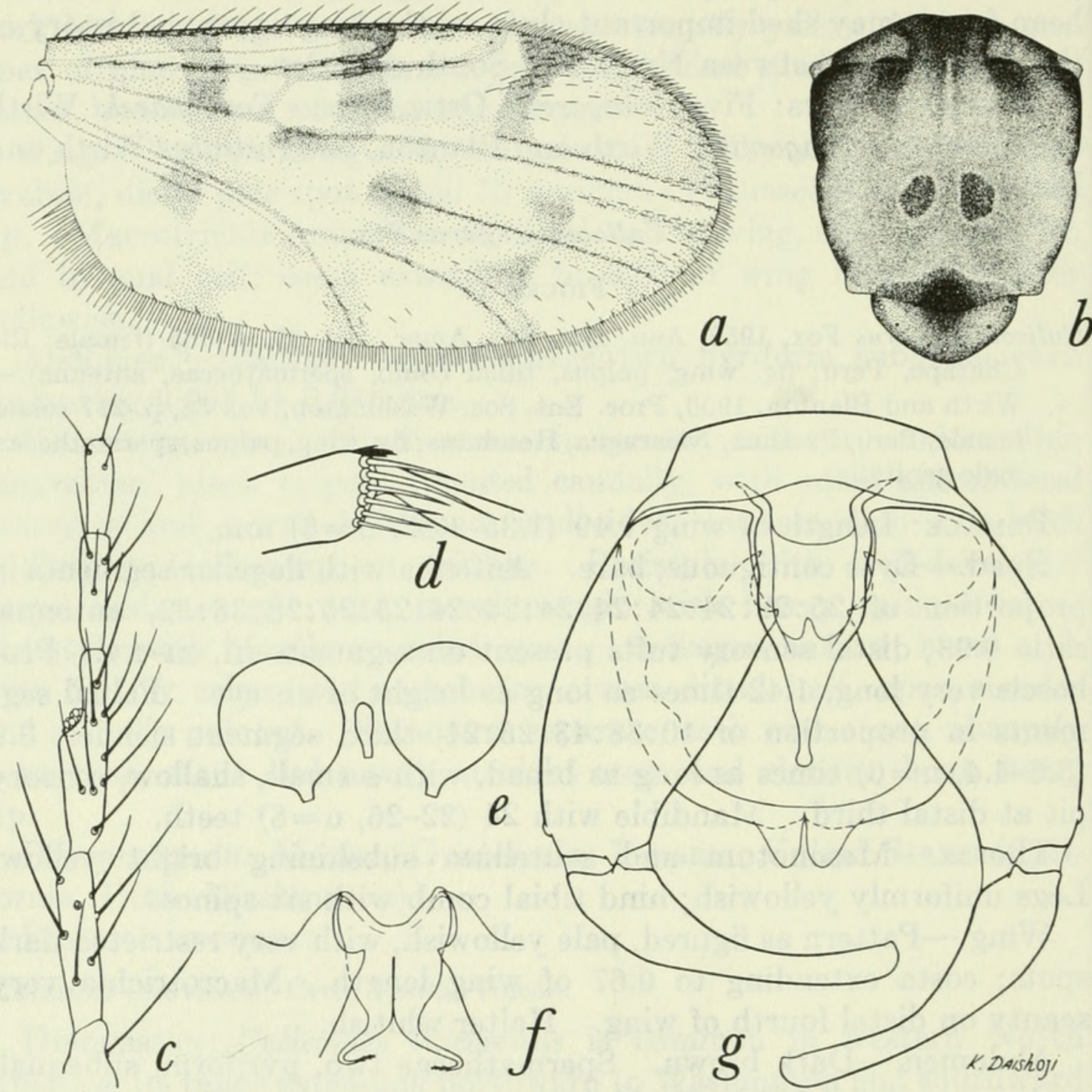

Figure 15.-Culicoides efferus Fox. $a-e$, Female: $a$, wing; $b$, thoracic pattern; $c$, palpus; $d$, tibial comb; $e$, spermathecae. $f, g$, Male: $f$, parameres; $g$, genitalia, parameres removed.

distinguish this species. The caudally rounded tergum of the male genitalia is probably indicative of close relation to the species of the pulicaris group, but the long proboscis, brilliant yellow color, Hoffmania-like aedeagus and fused parameres are indicative of great evolutionary specialization. 


\section{Culicoides rostratus Wirth and Blanton}

Figure 16

Culicoides rostratus Wirth and Blanton, 1956, Proc. Ent. Soc. Washington, vol. 58, p. 219 (male, female; Panama; fig. wing, palpus, spermatheca, male genitalia).

Female: Length of wing $1.13(1.06-1.19, \mathrm{n}=9) \mathrm{mm}$.

Head.-Eyes contiguous, bare. Antenna with flagellar segments in proportion of $25: 17: 17: 19: 19: 19: 19: 19: 24: 24: 26: 32: 45$, antennal ratio 0.98 ; distal sensory tufts present on segments III, $\mathrm{XI}-\mathrm{XV}$. Proboscis elongate, its length to base of palpi about 1.2 times height of an eye. Palpal segments in proportion of $8: 32: 43: 17: 17$, second segment long and fairly stout, third segment moderately swollen on proximal two-thirds, $2.6(2.3-3.1, \mathrm{n}=8)$ times as long as broad, with
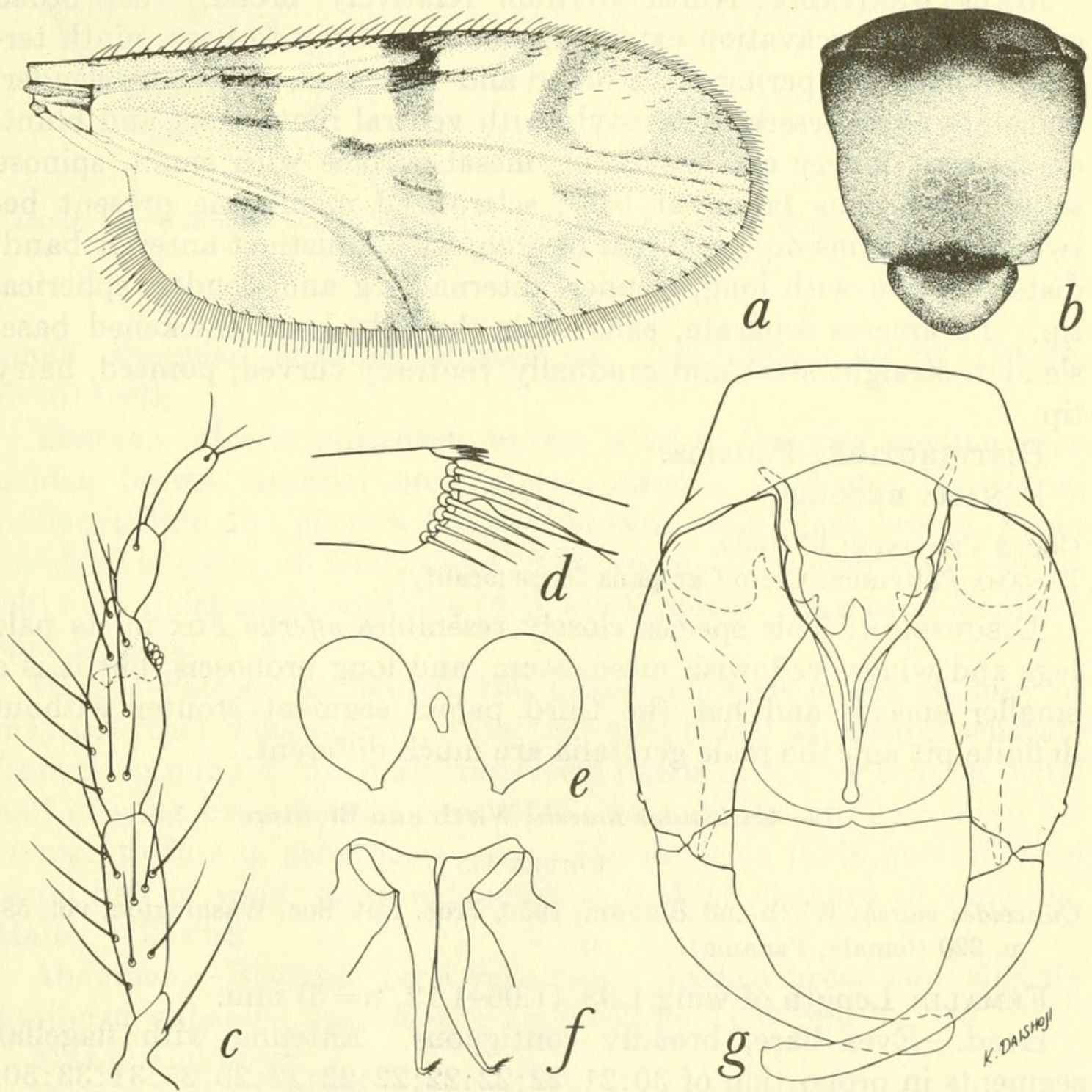

Figure 16.-Culicoides rostratus Wirth and Blanton. a-e, Female: $a$, wing; $b$, thoracic pattern; $c$, palpus; $d$, tibial comb; $e$, spermathecae. $f, g$, Male: $f$, parameres; g, genitalia, parameres removed. 
a hollowed, open, sensory area on the distal tapering portion. Mandible with $20(19-21, \mathrm{n}=8)$ teeth.

Thorax.-Mesonotum yellowish brown, becoming blackish at anterior margin. Scutellum concolorous with mesonotum; postscutellum and pleuron brown. Legs yellow, broad base of fore femur and apex of fore tibia brownish; hind tibial comb with six spines, the second from the spur longest.

Wing.-Pattern as figured, appearing pale yellowish with restricted dark spots and areas, pale spots in apices of cells $R_{5}$ and $M_{1}$ not meeting wing margin. Macrotrichia confined to a few in apices of cells $\mathrm{R}_{5}, \mathrm{M}_{1}$ and $\mathrm{M}_{2}$; costa extending to 0.68 of wing length. Halter yellowish white.

Abdomen.-Dark brown. Spermathecae two, pyriform, subequal, each measuring 0.058 by $0.043 \mathrm{~mm}$.

Male Genitalia: Ninth sternum relatively broad, with broad caudomedian excavation extending about halfway to base; ninth tergum short and tapering, apex broad and truncated, with long, slender, apicolateral processes. Basistyle with ventral roots short and blunt, dorsal root longer and slenderer, mesal surface with small, spinose setae. Aedeagus broad at base, sclerotized membrane present between basal arms on distal half of arch, with indistinct anterior band; distal portion with long, slender, internal peg and slender, spherical tip. Parameres separate, each with abruptly bent, thickened base, slender, straight stem and gradually ventrally curved, pointed, hairy tip.

Distribution: Panama.

PANAMA RECORDS:

Coclé Province: El Valle.

Panamá Province: Cerro Campana (type locality).

Discussion: This species closely resembles efferus Fox in its pale legs and wings, yellowish mesonotum, and long proboscis, but it is a smaller species and has the third palpal segment stouter without definite pit and the male genitalia are much different.

\section{Culicoides marshi Wirth and Blanton}

FigURE 17.

Culicoides marshi Wirth and Blanton, 1956, Proc. Ent. Soc. Washington, vol. 58, p. 220 (female; Panama).

Female: Length of wing $1.08(1.06-1.12, \mathrm{n}=5) \mathrm{mm}$.

Head.-Eyes bare, broadly contiguous. Antenna with flagellar segments in proportion of $30: 21: 22: 22: 22: 22: 22: 22: 25: 25: 31: 33: 50$, antennal ratio 1.18; distal sensory tufts present on segments III, XI-XV. Palpal segments in proportion of $10: 31: 40: 16: 13$, third segment very slender, $3.5(3.1-3.9, \mathrm{n}=2)$ times as long as greatest breadth, with 


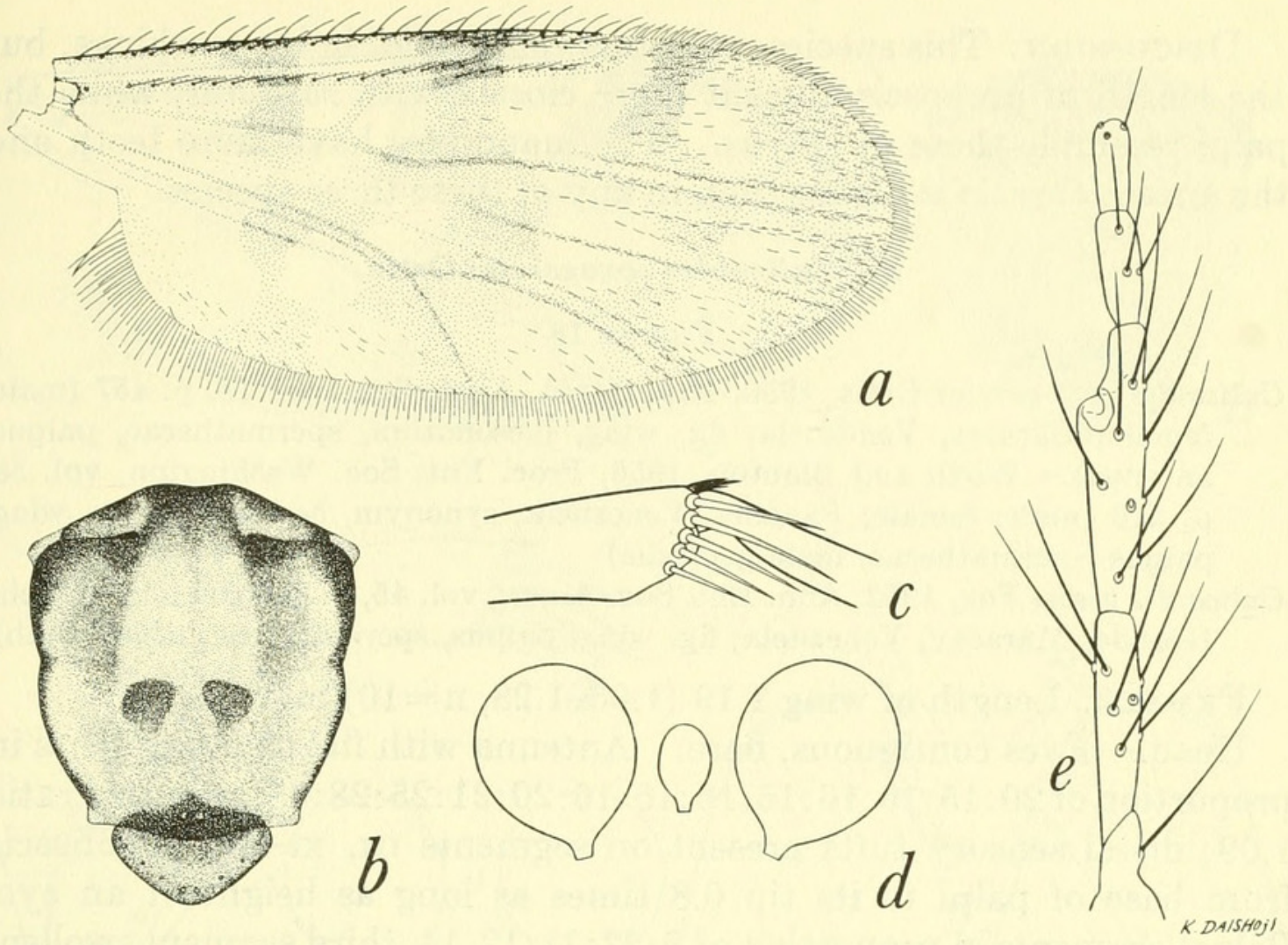

Figure 17.-Culicoides marshi Wirth and Blanton. Female: $a$, wing; $b$, thoracic pattern; $c$, tibial comb; $d$, spermathecae; $e$, palpus.

small, irregular, shallow, sensory pit. Mandible with 27 (26-28, $\mathrm{n}=5$ ) teeth.

Thorax.-Mesonotum dark brown with a pruinose median area golden brown, anterior and lateral margins blackish. Scutellum, postscutellum and pleuron blackish brown. Legs dark brown, broad bands at knees on all femora and tibiae and apex of hind tibia yellowish; hind tibial comb with five $(4-5, \mathrm{n}=4)$ spines, the second from the spur longest.

Wing.-Pattern as figured, the distal pale spot in cell $R_{5}$ may or may not reach wing margin, distal pale spot in cell $\mathrm{M}_{1}$ always separate from wing margin, the dark transverse bands of the pattern on distal half of wing irregular but connected, the pale spots rarely extensive enough to fuse in paler specimens. Macrotrichia fairly abundant on distal half of wing; costa extending to 0.68 of distance to wing tip. Halter yellowish.

Abdomen.-Blackish, cerci yellowish. Spermathecae two, slightly pyriform, subequal, each measuring 0.050 by $0.039 \mathrm{~mm}$.

MALE: Unknown.

Distribution: Panama.

PANAMA RECORDS:

Bocas del Toro Province: Almirante (type locality). 
Discussion: This species resembles covagarciai in leg markings, but the length of proboscis allies it more closely with rostratus, while the palpi resemble those of efferus. The mandibles have more teeth and the antennal ratio is higher than in any of these three species.

\section{Culicoides covagarciai Ortiz}

Figure 18

Culicoides cova-garciai Ortiz, 1950, Rev. Sanid. Asist. Soc., vol. 15, p. 457 (male, female; Caracas, Venezuela; fig. wing, mesonotum, spermathecae, palpus, antenna).-Wirth and Blanton, 1956, Proc. Ent. Soc. Washington, vol. 58, p. 216 (male, female; Panama, Venezuela; synonym, beebei Fox; fig. wing, palpus, spermathecae, male genitalia).

Culicoides beebei Fox, 1952, Ann. Ent. Soc. Amer., vol. 45, p. 366 (female; Rancho Grande, Maracay, Venezuela; fig. wing, palpus, spermathecae, tibial comb).

Female: Length of wing $1.19(1.06-1.28, \mathrm{n}=10) \mathrm{mm}$.

Head.-Eyes contiguous, bare. Antenna with flagellar segments in proportion of $20: 15: 16: 16: 16: 16: 16: 16: 20: 21: 25: 28: 38$, antennal ratio 1.09 ; distal sensory tufts present on segments III, XI-Xv. Proboscis from base of palpi to its tip 0.8 times as long as height of an eye. Palpal segments in proportion of $8: 22: 31: 12: 14$, third segment swollen, $2.4(2.1-2.7, \mathrm{n}=9)$ times as long as greatest breadth, with a broad, shallow, sensory pit. Mandible with $15(15-16, \mathrm{n}=10)$ teeth.

Thorax.-Mesonotum uniformly yellowish brown, varying from a golden yellow to a darker brown, scutellum somewhat darker. Legs brown, bases of femora, apices of fore and mid femora, bases of all tibiae, and apex of hind tibia broadly yellowish; hind tibial comb with six spines.

Wing.-Pattern as figured, all of second radial cell except extreme base in a yellow area, wing predominantly pale marked, with irregular, broken, transverse dark bands. Macrotrichia very sparse on distal fourth of wing; costa extending 0.67 way to wing tip. Halter pale.

Abdomen.-Dark brown. Spermathecae two, slightly ovoid, subequal, each measuring 0.050 by $0.043 \mathrm{~mm}$.

Male Genitalia: Ninth sternum with moderately deep caudomedian excavation; ninth tergum with truncated caudal margin bearing long, slender, apicolateral processes. Basistyle with ventral root short and blunt, dorsal root longer and slender, heavy spinose setae present on mesal surface. Aedeagus long, narrow at base, a sclerotized transverse membrane near base of arch, a distinct internal peglike sclerotization at base of distal stem, latter with spherical tip. Parameres separated at bases, each with abruptly bent stout basal portion; straight tapering stem and pointed, slender, hairy tip. 

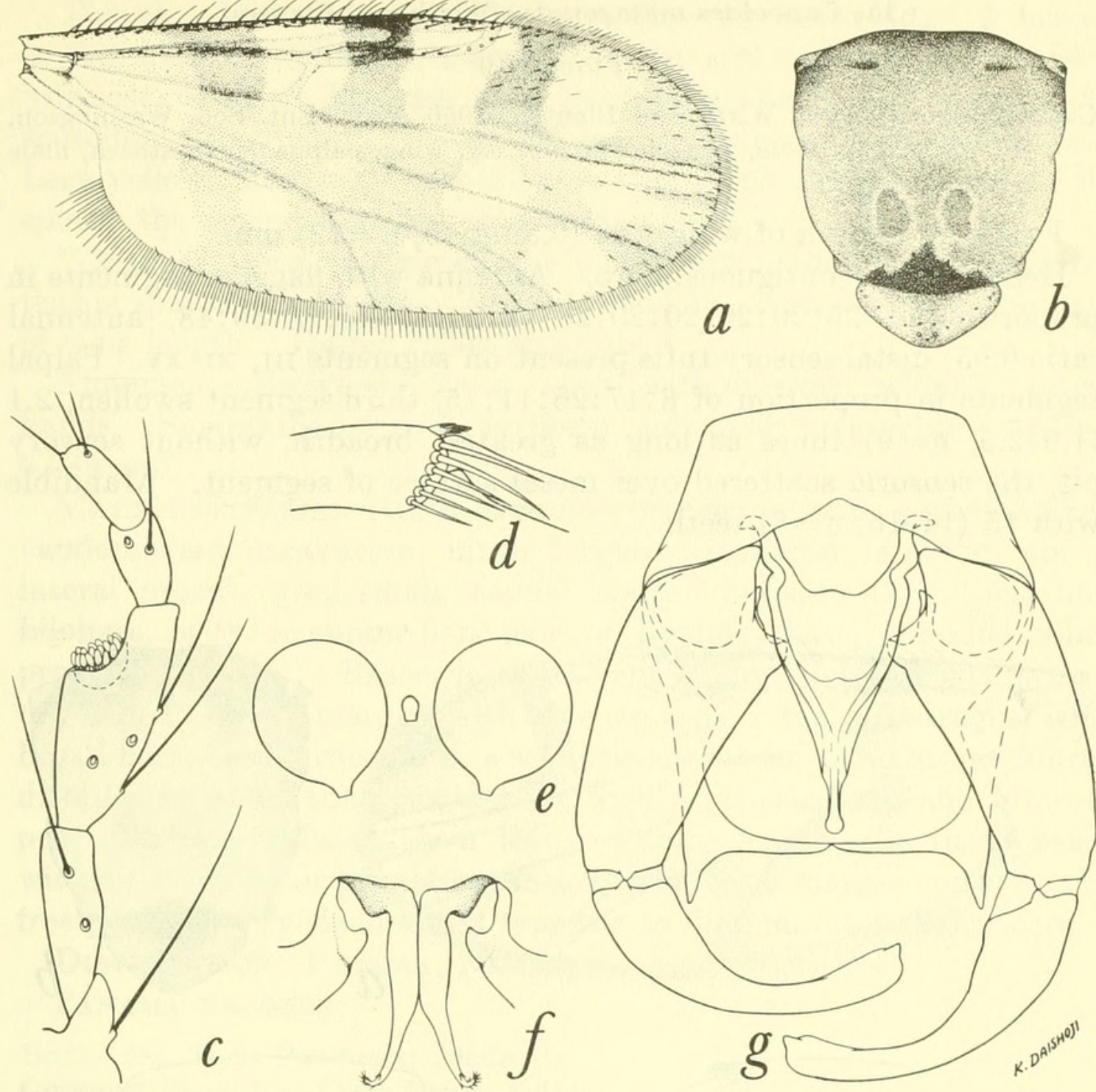

Frgure 18.-Culicoides covagarciai Ortiz. $a-e$, Female: $a$, wing; $b$, thoracic pattern; $c$, palpus; $d$, tibial comb; $e$, spermathecae. $f, g$, Male: $f$, parameres; $g$, genitalia, parameres removed.

Distribution: Venezuela; Panama.

PANAMA RECORDS:

Bocas del Toro Province: Almirante.

Chiriquf Province: Boquete, Cerro Punta, Volcán.

Coclé Province: El Valle.

Panamá Province: Cerro Campana.

Discussion: This species is easily recognized by its dark wings with well-isolated pale areas, its dark brown legs with broadly pale knees, the short proboscis and swollen third palpal segment with broad sensory pit. 


\section{Culicoides metagonatus Wirth and Blanton}

Figure 19

Culicoides metagonatus Wirth and Blanton, 1956, Proc. Ent. Soc. Washington, vol. 58, p. 221 (male, female; Panama; fig. wing, palpus, spermatheca, male genitalia).

Female: Length of wing $1.02(0.89-1.19, \mathrm{n}=12) \mathrm{mm}$.

Head.-Eyes contiguous, bare. Antenna with flagellar segments in proportion of $25: 20: 20: 20: 20: 20: 20: 20: 25: 25: 28: 30: 48$, antennal ratio 0.95 ; distal sensory tufts present on segments III, XI-xv. Palpal segments in proportion of $8: 17: 26: 11: 15$, third segment swollen, 2.1 $(1.9-2.5, \mathrm{n}=9)$ times as long as greatest breadth, without sensory pit, the sensoria scattered over mesal surface of segment. Mandible with $15(14-16, \mathrm{n}=8)$ teeth.
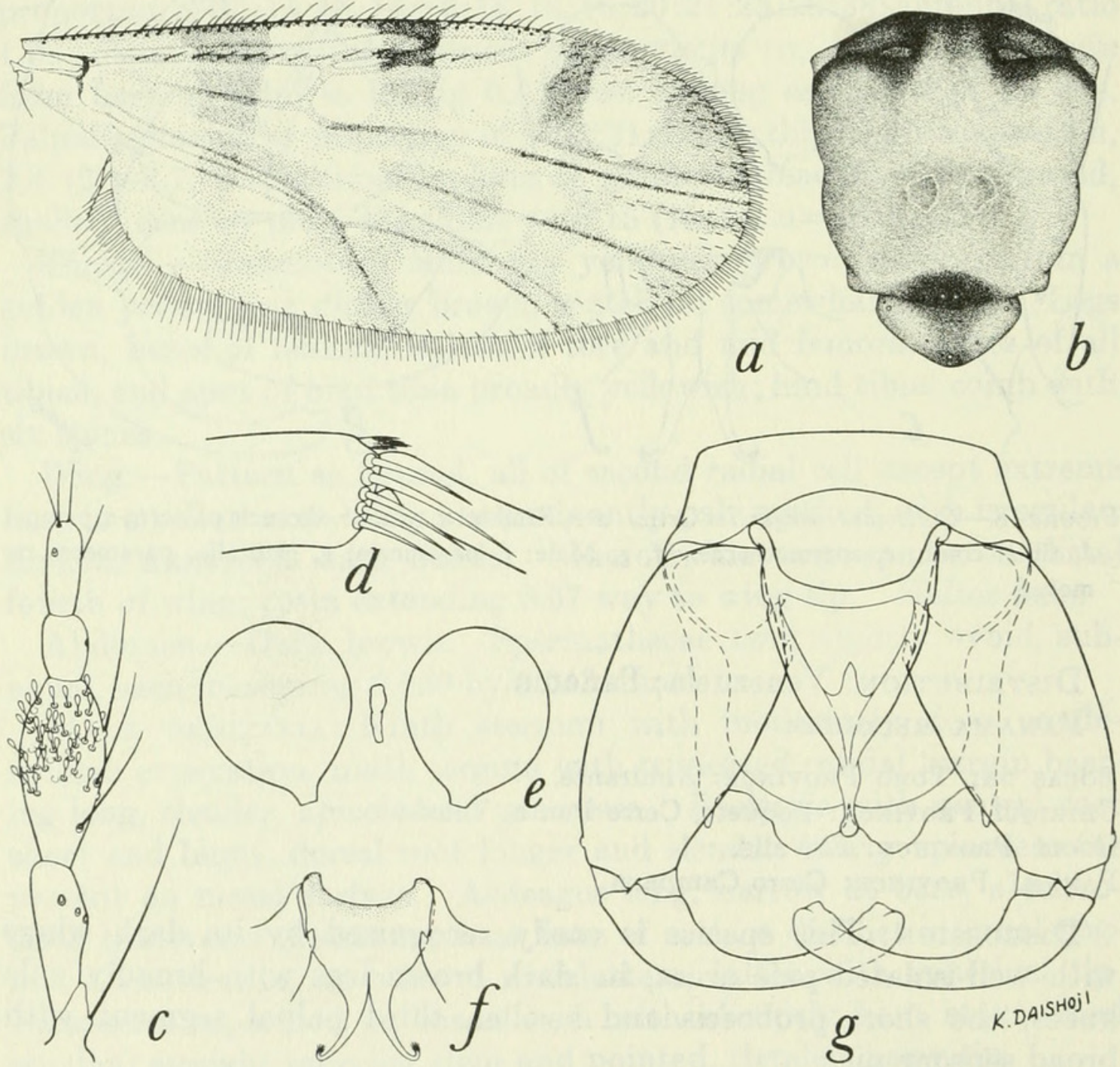

Figure 19.--Culicoides metagonatus Wirth and Blanton. $a-e$, Female: $a$, wing; $b$, thoracic pattern; $c$, palpus; $d$, tibial comb; $e$, spermathecae. $f, g$, Male: $f$, parameres; $g$, genitaila parameres removed. 
Thorax.-Mesonotum subshining, yellowish brown, darker brown to blackish on anterior margin, humeri and sensory pits whitish pruinose, a small blackish spot present medially just anterior to scutellum. Scutellum, postscutellum and pleura yellowish brown. Legs yellow, hind knee with a black spot; hind tibial comb with six spines, the second from the spur longest.

Wing.-Pattern as figured, the pale areas predominant. Macrotrichia sparse in apices of cells $\mathrm{R}_{5}, \mathrm{M}_{1}$ and $\mathrm{M}_{2}$; costa extending to 0.63 of wing length. Halter yellowish white.

Abdomen.-Brownish black; terga with narrow, whitish, apical bands. Spermathecae two, pyriform, subequal, measuring 0.048 by $0.039 \mathrm{~mm}$.

Male Genitalia: Ninth sternum very narrow, with a very shallow caudomedian excavation; ninth tergum short and tapering, apicolateral process very small, caudal margin between them cleft and bilobate, with a submedian pair of hyaline, bare, rounded lobes produced caudad. Basistyle with ventral and dorsal roots poorly developed, mesal margin with fine spinose setae. Aedeagus with broad base, basal arms stout, a sclerotized anterior band at one-fourth distance to apex, the apex slender with a spherical tip and internal peg. Parameres fused for a third of total length, the fused bases without winglike or lateral expansions, the basal margin concave, the free portions very slender and tapering to fine, minutely hairy tips.

Distribution: Panama; Nicaragua.

PANAMA RECORDS:

Bocas del Toro Province: Almirante.

Chiriquí Province: Cerro Punta, Volcán.

Cocle Province: El Retiro, El Valle, Penonomé.

Darien Province: Jaqué.

Panamá Province: Cerro Campana (type locality).

Discussion: Related to covagarciai in wing and mesonotal pattern, the short proboscis and unmodified antenna, but unique in having the third palpal segment swollen without sensory pit, only hind knee black, and the male genitalia with mesally cleft, bilobate tergum and fused parameres.

\section{The nigrigenus group}

This group consists of large species with knees black-spotted and legs mostly yellowish; mesonotum dull grayish to brownish; palpus with a large, deep, sensory pit; male genitalia with basistyle mesally spinose, apicolateral processes well developed, aedeagus without basal barlike sclerotization or ball-like tip, parameres separate with well-developed basal knob. Differs from the covagarciai group by having moniliform proximal antennal segments (antennal ratio, 
1.3-2.1), sensoria present on segments $\mathrm{III}-\mathrm{XV}$ or $\mathrm{III}, \mathrm{vIII}-\mathrm{XV}$, and only four tibial spines.

This group is intermediate between typical Culicoides (Culicoides) and the daedalus group of the subgenus Culicoides (Oecacta). Culicoides decor (Williston), known only from the island of St. Vincent in the West Indies, belongs to this group (see remarks under nigrigenus). There are three Panama species-chrysonotus Wirth and Blanton, lutealaris Wirth and Blanton, and nigrigenus Wirth and Blanton.

\section{Culicoides nigrigenus Wirth and Blanton}

\section{Figure 20}

Culicoides nigrigenus Wirth and Blanton, 1956, Proc. Ent. Soc. Washington, vol 58, p. 222 (male, female; Panama; fig. wing, palpus, spermathecae, male genitalia).

Female: Length of wing $1.11(1.02-1.25, \mathrm{n}=8) \mathrm{mm}$.

Head.-Eyes bare, contiguous. Antenna with flagellar segments in proportion of $20: 15: 15: 15: 15: 15: 15: 15: 47: 50: 50: 50: 55$, antennal ratio 2.0; distal sensory tufts present on segments III-Xv. Palpal segments in proportion of $10: 20: 30: 10: 10$, third segment greatly swollen, $1.9(1.7-2.1, \mathrm{n}=6)$ times as long as greatest breadth, with a broad, deep sensory pit. Mandible with $13(10-15, \mathrm{n}=10)$ teeth.

Thorax.-Mesonotum yellowish brown, with grayish pruinosity becoming very prominent in some specimens, anterior margin narrowly dark brown, dark brown spot present just anterior to scutellum. Scutellum concolorous with mesonotum, postscutellum and pleuron dark brown. Legs yellow, fore and mid femora pale brown on basal halves, hind femur with broad median brown band and distal twothirds of fore tibia brownish; prominent knee spot on all legs and the narrow apex of hind tibia blackish; hind tibial comb with four spines, the one nearest the spur longest.

Wing.-Pattern as figured, with pale markings predominant, the dark markings rarely extensive enough on distal half of wing to be interconnected. Macrotrichia very numerous on distal half of wing and extending to near base in anal cell and cell $\mathrm{M}_{2}$; costa extending to 0.64 of distance to wing tip. Halter yellowish white.

Abdomen.-Brownish, the terga whitish. Spermathecae two, pyriform, subequal, each measuring 0.057 by $0.044 \mathrm{~mm}$.

Male Genitalia: Ninth sternum narrow, with a broad, shallow, caudomedian excavation; ninth tergum with large, triangular, apicolateral processes, the caudal margin between them truncated, with a slight mesal notch. Basistyle with ventral and dorsal roots small and simple, no spinose setae on mesal surface. Aedeagus V-shaped, without anterior transverse marginal band or distal peglike internal sclerotization, apex slender and rounded but not spherical. Para- 


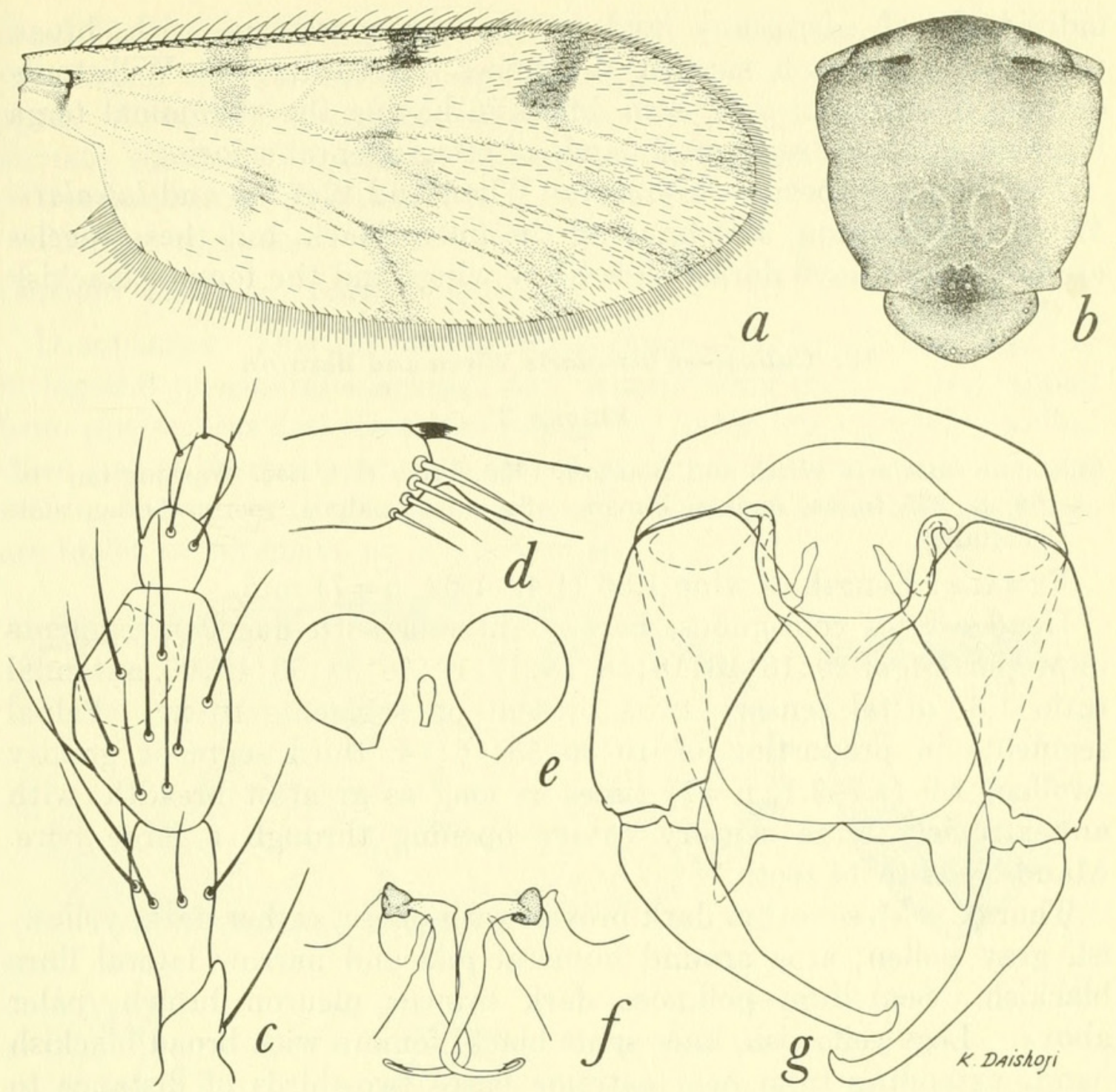

Figure 20.-Culicoides nigrigenus Wirth and Blanton. $a-e$, Female: $a$, wing; $b$, thoracic pattern; $c$, palpus; $d$, tibial comb; $e$, spermathecae. $f, g$, Male: $f$, parameres; $g$, genitalia, parameres removed.

meres separate, each with abruptly bent, knobbed base, nearly straight, slender stem and slender pointed apex abruptly bent laterad, thence ventromesad.

Distribution: Panama; Honduras, Nicaragua.

PANAMA RECORDS:

Bocas del Toro Province: Almirante (type locality).

Panamá Province: Cerro Campana.

Discussion.-This species is similar to Culicoides decor (Williston), which is known only from the type female from the island of St. Vincent. According to notes on the type made by the senior author at the British Museum (Natural History) in July 1957, decor differs from nigrigenus in having the pale wing markings more restricted, in the form of discrete rounded spots which are smaller than in the darkest 
individuals of nigrigenus, and in the leg markings, with broad pale bands on each side of the knees. According to Williston's original description, decor also differs in having the abdominal terga blackish with pale segmental bands of integumental coloring.

Two Panama species, chrysonotus Wirth and Blanton and lutealaris Wirth and Blanton, also have all the knees black, but these species are larger and have darker, less hairy wings and the femora blackish at the bases.

\section{Culicoides lutealaris Wirth and Blanton}

FIGURE 21

Culicoides lutealaris Wirth and Blanton, 1956, Proc. Ent. Soc. Washington, vol. 58 , p. 225 (male, female; Panama; fig. wing, palpus, spermathecae, male genitalia).

Female: Length of wing $1.56(1.49-1.62, \mathrm{n}=7) \mathrm{mm}$.

Head.-Eyes contiguous, bare. Antenna with flagellar segments in proportion of $20: 18: 18: 18: 18: 18: 18: 19: 38: 38: 38: 42: 60$, antennal ratio 1.3; distal sensory tufts present on segments III-xv. Palpal segments in proportion of $10: 30: 55: 16: 14$, third segment greatly swollen, $1.9(1.7-2.1, \mathrm{n}=7)$ times as long as greatest breadth, with an extremely large sensory cavity opening through a large pore. Mandible with 14 teeth.

Thorax.-Mesonotum dark brown, with dense, rather dark, yellowish gray pollen; area around humeral pits and narrow lateral lines blackish. Scutellum pollinose dark brown; pleuron brown, paler above. Legs yellowish, knee spots black; femora with broad blackish bands extending from near extreme bases two-thirds of distance to apices, fore tibia brownish except at extreme base, mid and hind tibiae with fainter infuscation on distal halves, narrow apex of hind tibia blackish; hind tibial comb with four spines, the one nearest the spur longest.

Wing.-Pattern as figured, distal pale spot in cell $\mathrm{M}_{1}$ broadly meeting wing margin. Macrotrichia abundant, extending nearly to base of anal cell; costa extending to $0.58(0.57-0.62, \mathrm{n}=7)$ of distance to wing tip. Halter yellowish.

Abdomen.-Dark brown, terga with indistinct sublateral blackish areas; distal apical integumental bands and faint pollen on entire dorsum whitish, cerci yellowish. Spermathecae two, pyriform, subequal, each measuring 0.060 by $0.048 \mathrm{~mm}$.

Male genitalia: Ninth sternum narrow, with a broad, shallow, caudomedian excavation; ninth tergum. with long, pointed, apicolateral processes, the caudal margin between them distinctly notched medially. Basistyle with ventral and dorsal roots long and slender; mesal margin without spinose setae. Aedeagus with heavily sclero- 
tized basal arms forming a narrow basal arch, anterior sclerotized membrane absent; distal stem tapering to a very slender, pointed apex. Parameres separate, each with bent, knobbed base, slightly sinuate, slender stem and very slender, recurved, simple, pointed apex.

Distribution: Panama.

PANAMA RECORDS:

Chiriquí Province: Volcán (type locality).

Discussion: This species resembles chrsyonotus Wirth and Blanton in leg and mesonotal markings and general wing pattern, but differs from chrysonotus and resembles nigrigenus in having a greatly swollen third palpal segment, sensoria on all proximal antennal flagellar segments, and more extensive pale wing markings, although markings are never so extensive as in nigrigenus.
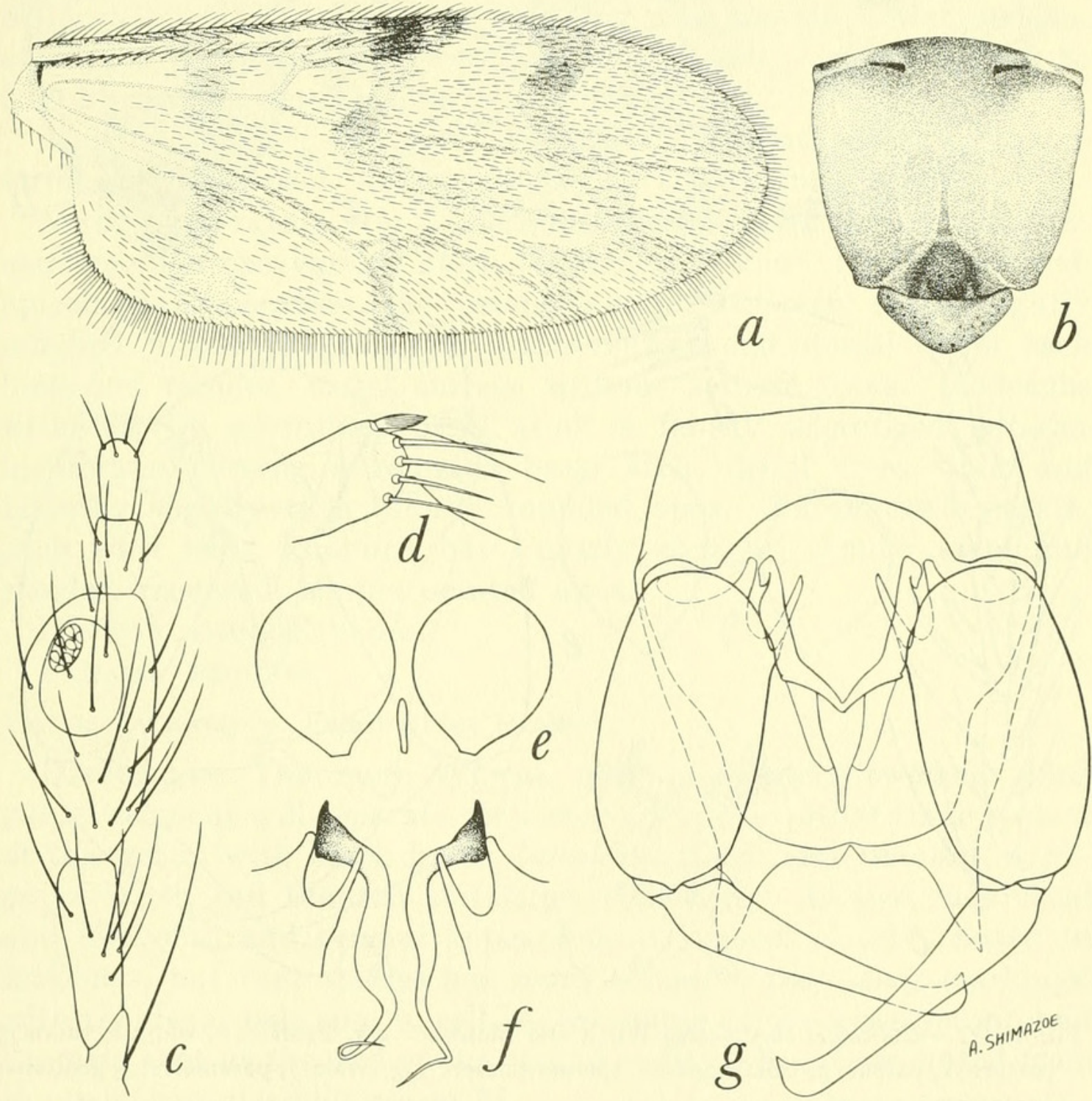

FigURE 21.-Culicoides lutealaris Wirth and Blanton. $a-e$, Female: $a$, wing; $b$, thoracic pattern; $c$, palpus; $d$, tibial comb; $e$, spermathecae. $f, g$, Male: $f$, parameres; g, genitalia, parameres removed. 


\section{Culicoides chrysonotus Wirth and Blanton}

Figure 22

Culicoides chrysonotus Wirth and Blanton, 1956, Proc. Ent. Soc. Washington, vol. 58, p. 226 (male, female; Panama; fig. wing, palpus, spermathecae, male genitalia).

Female: Length of wing $1.66(1.58-1.75, \mathrm{n}=7) \mathrm{mm}$.

Head-Eyes contiguous, bare. Antenna with flagellar segments in proportion of $20: 15: 15: 15: 15: 16: 16: 17: 48: 48: 50: 50: 72$, antennal ratio 2.1 ; sensoria present on segments III, VIII-Xv. Palpal segments in
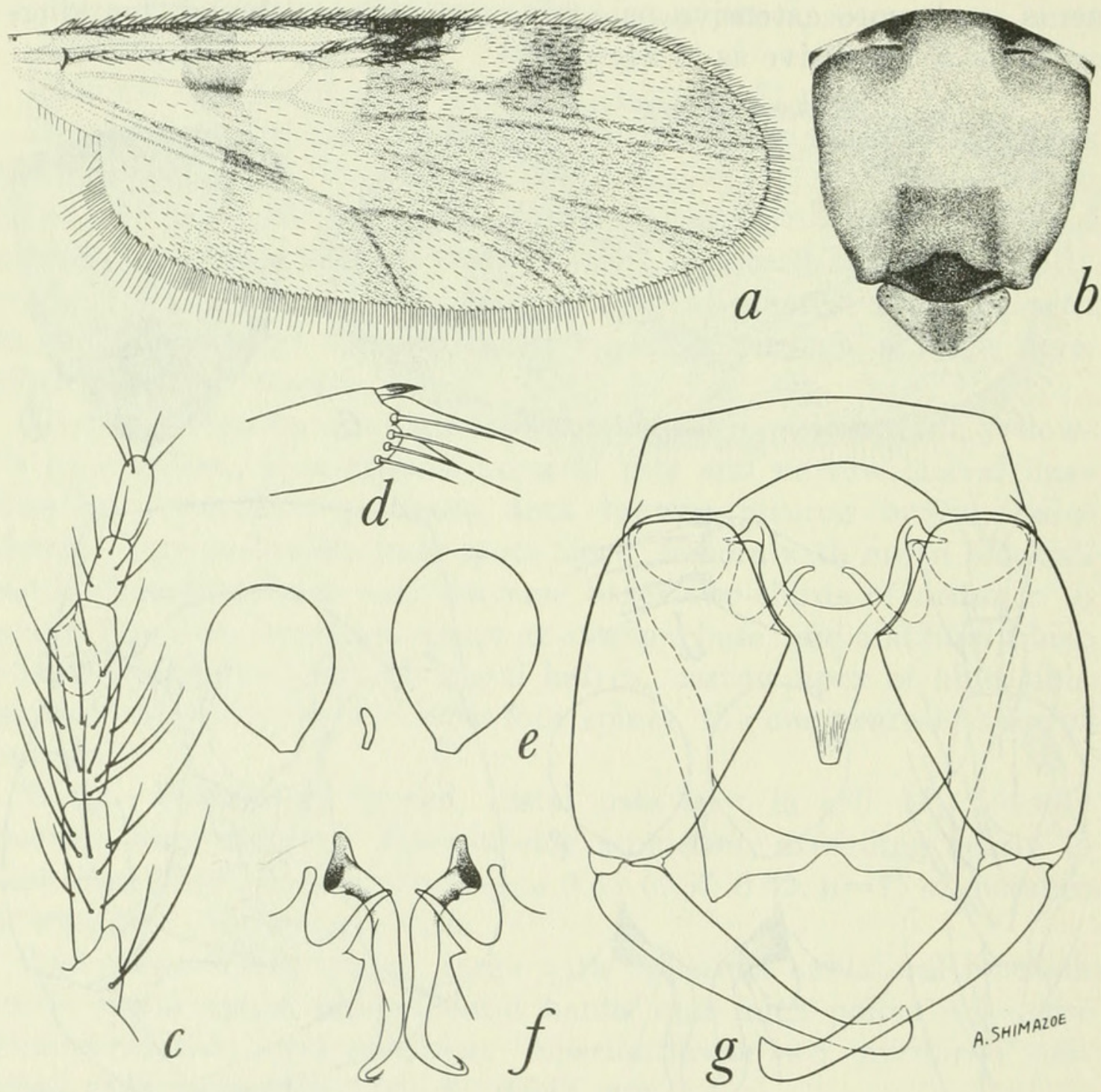

Figure 22.-Culicoides chrysonotus Wirth and Blanton. $a-e$, Female: $a$, wing; $b$, thoracic pattern; $c$, palpus; $d$, tibial comb; $e$, spermathecae. $f, g$, Male: $f$, parameres; $g$, genitalia, parameres removed. 
proportion of 15:35:50:20:20, third segment moderately swollen, 1.91 times as long as greatest breadth, sensory pit deep, with broad opening near apex of segment. Mandible with $14(13-14, n=6)$ teeth.

Thorax-Mesonotum dark brown with dense golden brown pollen, anterolateral corners broadly blackish. Scutellum dark brown, pleuron blackish. Legs yellowish, narrow knee spots black; femora with broad blackish bands extending from near extreme bases to two-thirds of distance to apices, fore tibia brownish except at extreme base, mid and hind tibiae with fainter infuscation on distal halves, narrow apex of hind tibia blackish; hind tibial comb with four spines, the one nearest the spur longest.

Wing-Pattern as figured, appearing dark with large, more or less isolated, rounded yellow spots, pale spot straddling vein $\mathrm{M}_{1}$ separated from pale spot at end of second radial cell by a narrow dark area, distal pale spot in cell $\mathrm{M}_{1}$ not attaining wing margin. Macrotrichia abundant, extending nearly to base of anal cell, costa extending to 0.60 of wing length. Halter pale yellowish.

Abdomen-Blackish, cerci yellowish. Spermathecae two, pyriform, subequal, each measuring 0.072 by $0.052 \mathrm{~mm}$.

Male genitalia: Ninth sternum narrow, with broad, shallow, caudomedian excavation; ninth tergum with short, bluntly pointed, apicolateral processes, the caudal margin between them slightly notched medially. Basistyle with ventral and dorsal roots each long and slender, mesal surface without spinose setae. Aedeagus with heavily sclerotized basal arms, a faintly sclerotized anterior membrane forming a rounded basal arch, distal stem stout and tapering slightly to a bluntly rounded apex. Parameres separate, each with bent, knobbed base, nearly straight, slender stem and slender, recurved, simple pointed apex.

Distribution: Panama.

PANAMA RECORDS:

Chiriquí Province: Volcán (type locality).

Discussion: The more typical, only moderately swollen, third palpal segment will separate chrysonotus from the other three species of this group with black knees, lutealaris Wirth and Blanton, nigrigenus Wirth and Blanton and decor (Williston). In size, mesonotal and leg color, and general appearance it is most clearly related to lutealaris, but that species has more extensive pale wing markings, with the distal pale spot in cell $\mathrm{M}_{1}$ extending to the wing margin and the pale spot at the end of the second radial cell not separated from the pale spot straddling vein $\mathrm{M}_{1}$. 


\section{Subgenus Culicoides (Oecacta) Poey}

Oecacta Poey, 1851, Mem. Hist. Nat. Isla Cuba, vol. 1, p. 236. (Type: Oecacta furens Poey, monobasic.)

Psychophaena Philippi, 1865, Verh. Zool.-Bot. Ges. Wien, vol. 15, p. 628.-

Wirth, 1955, Rev. Chilena Ent., vol. 4, p. 234. (Type: Culicoides venezuelensis Ortiz, as Psychophaena pictipennis Philippi, monobasic.)

Haematomyidium Goeldi, 1905, Mem. Mus. Goeldi, vol. 4, p. 137. (Type: Haematomyidium paraense Goeldi, monobasic.)

Species with the second radial cell usually entirely dark; wing usually with prominent pattern; male parameres separate; basistyle with well-developed, foot-shaped or pointed, ventral root; ninth tergum with well developed apicolateral processes; spermathecae usually two, rarely one; hind tibial comb with four (rarely five or seven) spines.

This subgenus has undergone a tremendous development in the Neotropical region, with the evolution of numerous groups of related species. Groups of this subgenus found in Panama are daedalus, copiosus (p. 332), iriartei (p. 342), scopus (p. 347), limai (p. 349), acotylus (p. 362), reticulatus (p. 376), furens (p. 397), fluvialis (p. 407), transferrans (p. 420), leoni (p. 426), debilipalpis (p. 431), pachymerus (p. 454), arubae (p. 464), and stigmalis (p. 466).

\section{The daedalus group}

This group consists of medium-sized species with very hairy wing; male genitalia with ventral root of basistyle slender, short and pointed, paramere with the base not directed laterad, with a long anterior process on the basal knob and with simple twisted tip and aedeagus simple, $V$-shaped or $Y$-shaped and slender at the apex; wing with a pale spot present straddling vein $\mathrm{M}_{2}$, a pale spot lying adjacent to the anterior side of vein $\mathbf{M}_{1}$ only in crescentis; female antenna with sensoria present on segments III, XI-XV or on III, v, VII, IX, and $\mathbf{x I}-\mathbf{x v}$; female palpal pit broad and shallow or deep and opening by a small pore.

\section{PaNAMA SPECIES:}

The species of this group are most numerous in western Panama at Almirante or in the Upper Tropical Zone at Cerro Campana and El Valle, only a few species ranging to the Canal Zone. There are seven or eight Panama species: antefurcatus, new species; commatis, new species; crescentis, new species; daedalus Macfie; dunni, new species; pampoikilus Macfie, and phaeonotus, new species. Culicoides daedaloides, new species, is provisionally referred here but its position is uncertain. 


\section{Culicoides antefurcatus, new species}

Figure 23

Female: Length of wing $0.79(\mathrm{n}=2) \mathrm{mm}$.

Head-Eyes narrowly separated, bare. Antenna with flagellar segments in proportion of $14: 13: 13: 14: 15: 15: 15: 16: 22: 22: 27: 28: 34$, antennal ratio $1.16(n=2)$; distal sensory tufts present on segments III, XI-Xv. Palpal segments in proportion of 9:21:26:6:7, third segment only slightly swollen, $2.0(1.9-2.2, \mathrm{n}=2)$ times as long as greatest breadth, with a broad, shallow sensory pit. Mandible with 14 $(n=2)$ teeth.
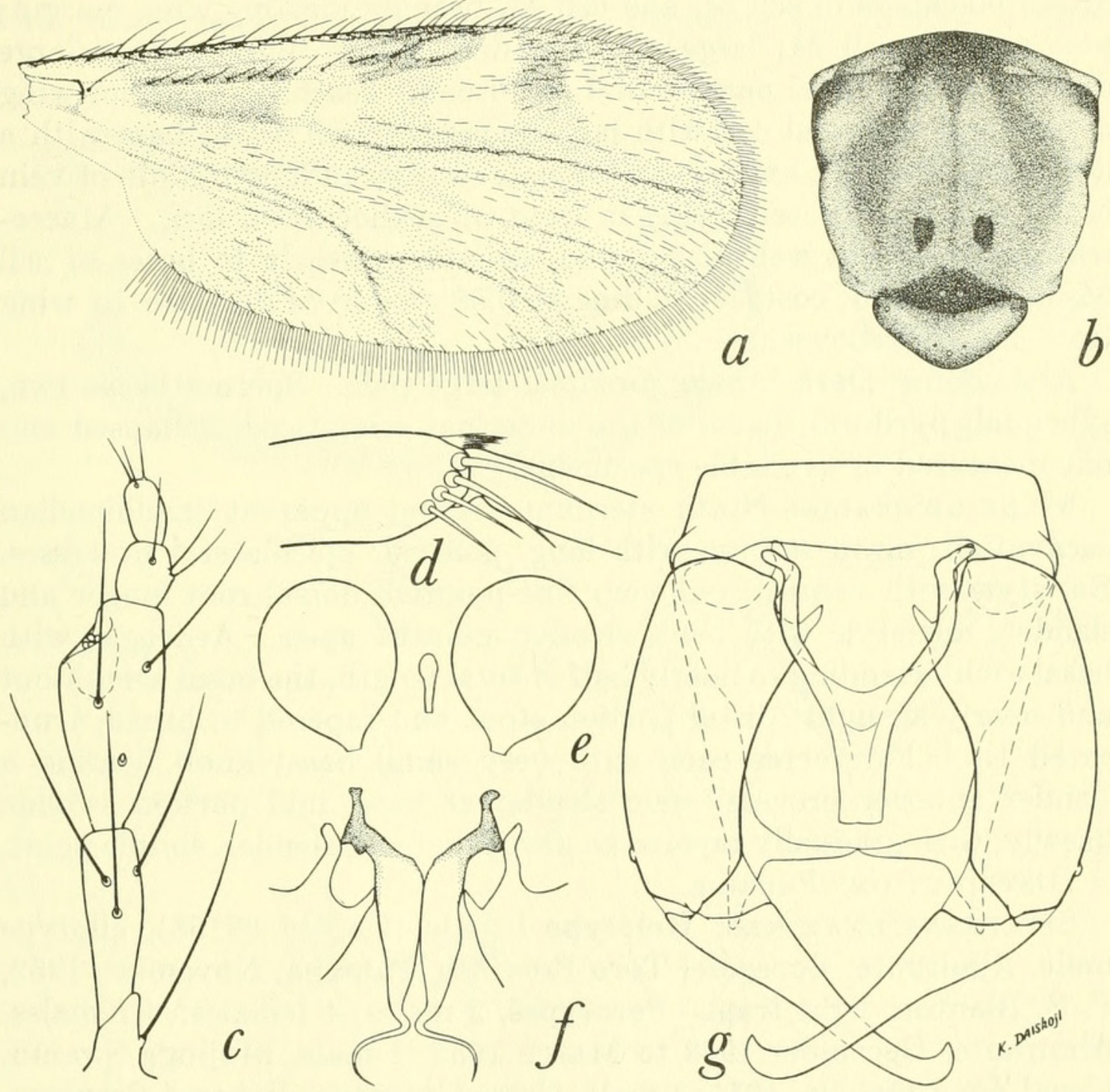

FigURE 23.-Cuticoides antefurcatus, new species. $a-e$, Female: $a$, wing; $b$, thoracic pattern; $c$, palpus; $d$, tibial comb; $e$, spermathecae. $f, g$, Male: $f$, parameres; $g$, genitalia, parameres removed. 
Thorax.-Mesonotum pruinose yellowish gray, with a brown pattern consisting of a very fine median line from anterior margin to scutellum and a pair of sublateral longitudinal bands. Scutellum brown; postscutellum and pleuron dark brown. Legs dark brown; fore and mid femora with subapical and all tibiae with subbasal narrow pale rings; hind tibial comb with $4-5(\mathrm{n}=2)$ spines, the one nearest the spur longest.

Wing.-Pattern as figured, second radial cell only moderately dark; pale spot over r-m crossvein large, broadly meeting costal margin; poststigmatic pale spot in cell $R_{5}$ double and oblique, the posterior part slightly larger; distal pale spot in cell $R_{5}$ elongate longitudinally, filling apex of cell $\mathrm{R}_{5}$; pale spot present straddling middle of vein $\mathrm{M}_{2}$; distal pale spots in cell $\mathrm{M}_{1}$ and cell $\mathrm{M}_{2}$ broadly meeting wing margin; pale spot in cell $\mathrm{M}_{4}$ large and rounded, nearly filling cell; a large double spot in distal part of anal cell broadly reaching posterior wing margin, base of anal cell with large pale area; cell $\mathrm{M}_{2}$ at base with a linear streak which extends to the pale spot straddling middle of vein $\mathrm{M}_{2}$, a pale spot present lying in front of mediocubital fork. Macrotrichia sparse but well distributed, extending nearly to bases of cell $\mathrm{M}_{2}$ and anal cell; costa extending to $0.58(\mathrm{n}=2)$ of distance to wing tip. Halter yellowish.

Abdomen.-Dark brown, proximal terga pale. Spermathecae two, subequal, pyriform, bases of the ducts not sclerotized, collapsed and not measured in available specimens.

Male Genitalia: Ninth sternum without apparent caudomedian excavation; ninth tergum with long, pointed, apicolateral processes. Basistyle with ventral root very fine-pointed, dorsal root longer and slender; dististyle with bent, slender, pointed apex. Aedeagus with basal arch extending to nearly half of total length, the basal arms stout and nearly straight; distal portion stout and tapered to broad, truncated tip. Parameres each with very small basal knob bearing a slender anterior process, stem slender at base, mid portion swollen basally, then gradually tapered to abruptly bent, slender, simple point.

Distribution: Panama.

Specimens examined: Holotype female (USNM 63158), allotype male, Almirante, Bocas del Toro Province, Panama, November 1952, F. S. Blanton, light trap. Paratypes, 2 males, 4 females: 4 females, Almirante, December 1952 to March 1953; 1 male, Mojinga Swamp, Canal Zone, Oct. 24, 1951; 1 male, Cerro Campana, Panamá Province, September 1952.

Discussion: This species superficially resembles tenuilobus, new species, in general facies and wing markings, both having a large apical pale spot in cell $R_{5}$, a pale spot at wing margin in cell $M_{1}$ and a pale spot straddling vein $\mathrm{M}_{2}$, but tenuilobus belongs to the limai 
group near galindoi on the basis of antennal sensorial pattern and male genitalic structure, on external characters it can readily be distinguished from antefurcatus by its subapical pale rings on the hind femur, swollen third palpal segment, only one pale spot in the distal portion of the anal cell and no pale spot in cell $\mathrm{M}_{2}$ in front of the mediocubital fork.

\section{Culicoides crescentis, new species}

Figure 24

Female: Length of wing $0.95(0.86-1.02, \mathrm{n}=8) \mathrm{mm}$.

Head.-Eyes narrowly separated, bare. Antenna with segments in proportion of $17: 10: 11: 10: 11: 10: 10: 11: 23: 23: 25: 26: 36$, antennal ratio 1.48; distal sensory tufts present on segments III, XI-Xv. Palpal
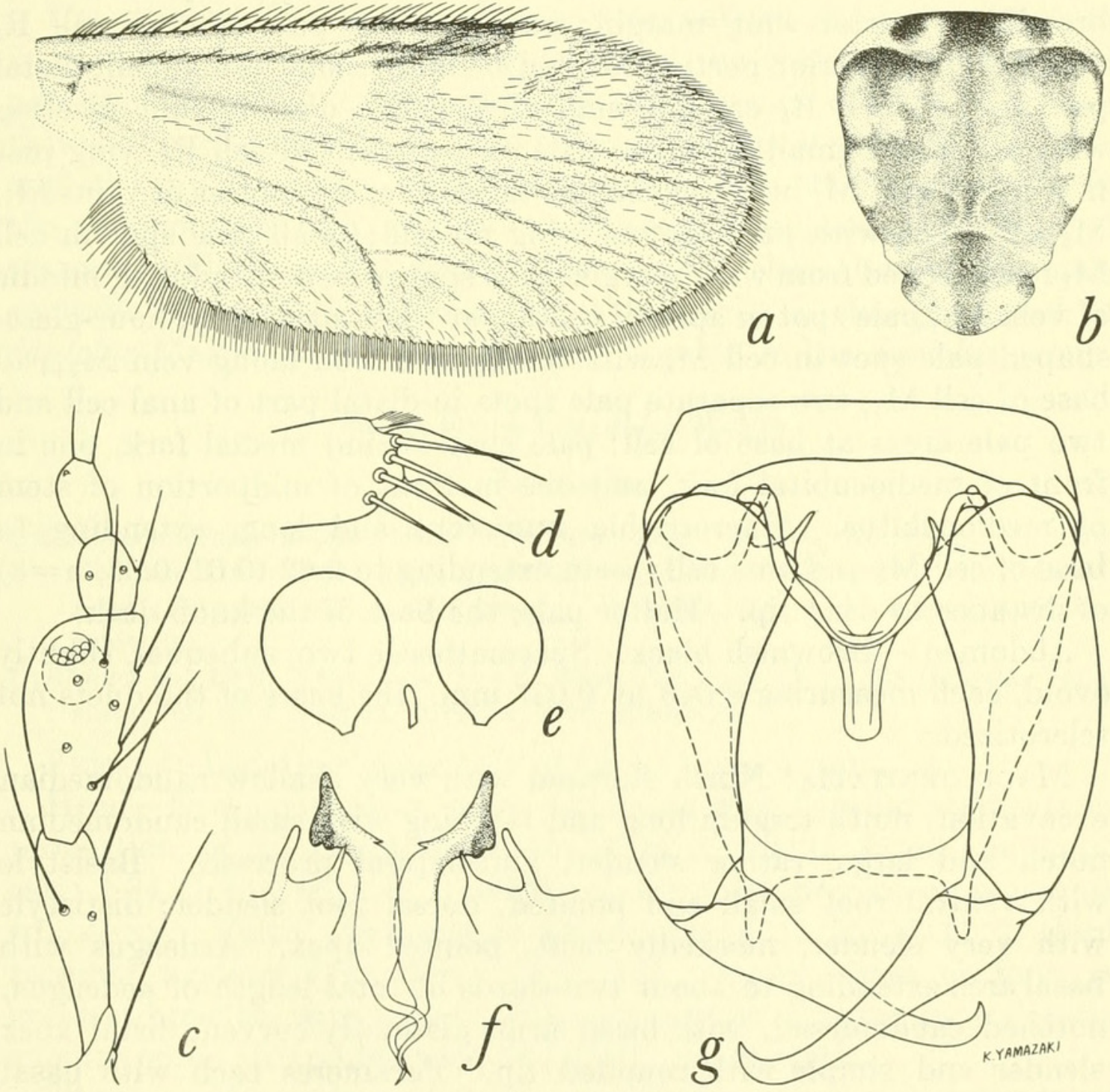

Figure 24.-Culicoides crescentis, new species. $a-e$, Female: $a$, wing; $b$, thoracic pattern; $c$, palpus; $d$, tibial comb; $e$, spermathecae. $f, g$, Male: $f$, parameres; $g$, genitalia, parameres removed. 
segments in proportion of 10:18:25:9:9, third segment moderately swollen, $1.8(1.5-2.0, \mathrm{n}=8)$ times as long as greatest breadth, with a large, deep sensory pit opening by a small distal pore. Mandible with $13(12-14, \mathrm{n}=8)$ teeth.

Thorax.--Mesonotum yellowish brown, with prominent pattern of dark brown patches as figured, consisting principally of a broad median anterior band and two lateral posterior bands associated with numerous, more or less interconnected, smaller dark brown dots. Scutellum yellowish brown, narrowly dark brown in middle and on extreme sides; postscutellum and pleuron dark brown. Legs dark brown; fore and mid femora with subapical and all tibiae with subbasal narrow pale rings; hind tibial comb with four $(4-5, \mathrm{n}=7)$ spines, the two nearest the spur longest, subequal.

Wing.-Pattern as figured, small pale spot present over basal arculus and over $\mathrm{r}-\mathrm{m}$ crossvein, the latter indistinctly continued broadly to costal wing margin; poststigmatic pale spot in cell $R_{5}$ double, the posterior portion located behind second radial cell; distal pale spot in cell $R_{5}$ crescent-shaped, concave distally, not meeting wing margin; a small, elongate pale spot present in cell $R_{5}$ lying just in front of vein $M_{1}$ between the two anterior spots; apices of veins $M_{1}$, $\mathrm{M}_{2}$ and $\mathrm{M}_{3+4}$ with pale spot at wing margin; small pale spot in cell $\mathrm{M}_{1}$ far removed from wing margin; pale spot present straddling middle of vein $\mathrm{M}_{2}$; pale spot in apex of cell $\mathrm{M}_{2}$ at wing margin; an hour-glassshaped pale spot in cell $\mathrm{M}_{4}$ with linear extension along vein $\mathrm{M}_{3+4}$ to base of cell $\mathrm{M}_{4}$; two separate pale spots in distal part of anal cell and two pale areas at base of cell; pale spot behind medial fork, one in front of mediocubital fork, and one in front of midportion of stem of mediocubitus. Macrotrichia numerous and long, extending to base of cell $\mathrm{M}_{2}$ and anal cell; costa extending to $0.62(0.61-0.65, \mathrm{n}=8)$ of distance to wing tip. Halter pale, the base of the knob dark.

Abdomen.-Brownish black. Spermathecae two, subequal, slightly ovoid, each measuring 0.045 by $0.037 \mathrm{~mm}$., the bases of the ducts not sclerotized.

Male Genitalia: Ninth sternum with very shallow caudomedian excavation; ninth tergum long and tapering with small caudomedian notch and large, rather slender, apicolateral processes. Basistyle with ventral root small and pointed, dorsal root slender; dististyle with very slender, markedly bent, pointed apex. Aedeagus with basal arch extending to about two-thirds of total length of aedeagus, notched caudomesad, with basal arms distinctly curved; distal apex slender and simple with rounded tip. Parameres each with basal knob bearing a long anterior projection; stem slender and bent at base, midportion moderately swollen, straight; distal portion abruptly narrowed to slender, simple, filiform tip with a corkscrew twist. 


\section{Distribution: Panama; Mexico, Nicaragua.}

Specimens examined: Holotype female, Mojinga Swamp, Canal Zone, Dec. 11, 1951, F. S. Blanton, light trap (USNM 63159). Allotype male, Las Palmas, Veraguas Province, July 1953, F. S. Blanton. Paratypes, 2 males, 23 females: Panama: 7 females, Mojinga Swamp, Canal Zone, Aug. 28, Oct. 24, 1951, May 7, 1952; 1 male, 1 female, Loma Boracho, Canal Zone, Oct. 23, 1951, July 1952; 6 females, Almirante, Bocas del Toro Province, November 1952 to January 1953; 1 female, El Valle, Coclé Province, Dec. 22, 1953; 1 male, Río Hato, Coclé Province, Aug. 3, 1952; 1 female, Piña, Colón Province, Jan. 18, 1954; 1 female, Punta Patiño, Darién Province, July 1952; 3 females, Isla Taboga, Panamá Province, Dec. 10, 11, 1953; 1 female, Las Palmas, Veraguas Province, July 1953. Mexico: 1 female, Tapachula, Chiapas, Sept. 20, 1944; B. Brookman, light trap. NicaraGUA : 1 female, Villa Somoza, July 14, 1953, P. Galindo, light trap.

Discussion: This species has a wing pattern similar to that of iriartei Fox, but can be distinguished by the crescent-shaped distal pale spot in cell $R_{5}$ of the wing, by the presence of only one small pale spot bordering vein $\mathrm{M}_{1}$, two pale spots in the distal portion of the anal cell, by the brown mottlings in addition to the large patches in the mesonotal pattern, and by the different arrangement of antennal sensoria. The sensorial distribution and the characters of the male genitalia of crescentis indicate that this species is closely related to daedalus Macfie and antefurcatus, new species, in the daedalus group.

\section{Culicoides daedalus Macfie}

Figure 25

Culicoides daedalus Macfie, 1948, Ann. Trop. Med. Parasit., vol. 42, p. 83 (male; Chiapas, Mexico; fig. wing, genitalia).-Ortiz and Mirsa, 1952, Rev. Sanid. Asist. Soc., vol. 17, p. 277 (male; Venezuela; fig. wing, palpus, antenna, genitalia).

Culicoides sp., Ortiz, 1951, Rev. Sanid. Asist. Soc., vol. 16, p. 583 (female; Venezuela; fig. wing, palpus, antenna, spermathecae).

Female: Length of wing $1.01(0.92-1.09, \mathrm{n}=5) \mathrm{mm}$.

Head-Eyes contiguous, bare. Antenna with flagellar segments in proportion of $20: 17: 15: 14: 15: 14: 14: 15: 31: 32: 32: 35: 45$, antennal ratio $1.34(1.30-141, \mathrm{n}=3)$; distal sensory tufts present on segments III, XI-XV. Palpal segments in proportion of $12: 25: 30: 11: 9$, third segment moderately swollen, $2.0(1.9-2.1, \mathrm{n}=6)$ times as long as greatest breadth, with a large, deep, sensory pit opening by a slightly smaller pore. Mandible with $13(12-13, \mathrm{n}=5)$ teeth.

Thorax.-Mesonotum pruinose gray with a prominent, reticulated pattern of blackish brown patches consisting of a narrow median anterior band, a pair of sublateral bands and irregular marks near 

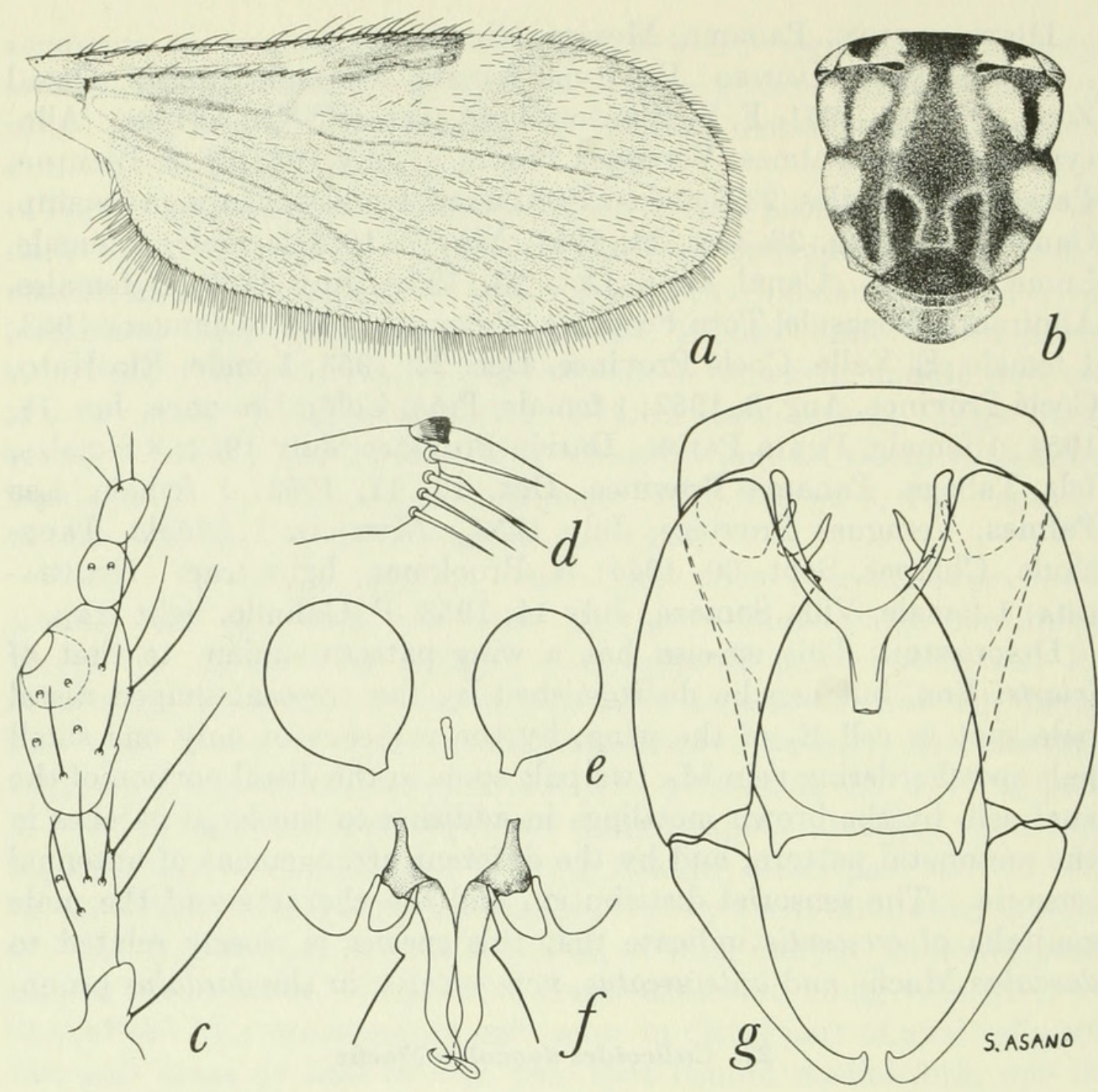

Figure 25.-Culicoides daedalus Macfie. $a-e$, Female: $a$, wing; $b$, thoracic pattern; $c$, palpus; $d$, tibial comb; $e$, spermathecae. $f, g$, Male: $f$, parameres; $g$, genitalia, parameres removed.

humeral pits and lateral margins. Scutellum narrowly dark brown in middle, yellowish on sides; postscutellum and pleuron blackish brown. Legs dark brown; fore and mid femora with subapical and all tibiae with subbasal, narrow pale rings, subapical rings on hind femur and apex of hind tibia very obscurely pale; hind tibial comb with four $(n=5)$ spines, the two nearest the spur longest.

Wing.-Pattern as figured, second radial cell very dark; pale spot over $\mathrm{r}-\mathrm{m}$ crossvein broadly continued to costal margin; poststigmatic pale spot in cell $R_{5}$ double. the posterior part only slightly displaced proximad; distal pale spot in cell $R_{5}$ quadrate, not reaching anterior wing margin; pale spot in cell $\mathrm{M}_{1}$ lying far removed from wing margin; pale spot present straddling middle of vein $\mathrm{M}_{2}$; distal pale spot in cell $\mathrm{M}_{2}$ round and lying adjacent to wing margin; pale spot in cell $\mathrm{M}_{4}$ ex- 
tending its full breadth from wing margin to posterior side of vein $\mathrm{M}_{3+4}$; two well separated round pale spots in distal part of anal cell and a third near hind wing margin at base of cell; cell $\mathrm{M}_{2}$ with small pale spot lying in front of mediocubital fork and one lying behind medial fork; pale spot present straddling middle of stem of mediocubitus. Macrotrichia long and numerous, extending to base of wing in cell $\mathrm{M}_{2}$ and anal cell; costa extending to $0.62(0.59-0.64, \mathrm{n}=5)$ of distance to wing tip. Halter pale.

Abdomen.-Dark brown. Spermathecae two, slightly unequal; pyriform, measuring 0.058 by 0.046 and 0.050 by $0.038 \mathrm{~mm}$., the bases of the ducts sclerotized a short distance.

Male Genitalia: Ninth sternum with very shallow, broad, caudomedian excavation; ninth tergum tapering with large, triangular, apicolateral processes. Basistyle with very small, pointed, ventral root; dorsal root longer and slender; dististyle slender and slightly curved, with bent, pointed tip. Aedeagus with basal arch extending to about three-fourths of total length of aedeagus, the basal arms slender and nearly straight; distal portion short and slender with simple tip. Parameres each with large basal knob bearing a long anterior process; stem slender and gently curved at base, nearly straight and slightly swollen in midportion, distal portion gradually narrowed to slender twisted tip.

Distribution: Mexico; Venezuela; Panama; Honduras (Lancetilla).

PanAMA RECORDS:

Bocas del Toro Province: Almirante.

Discussion: This species is closely related to crescentis, new species, and antefurcatus, new species, but can easily be separated from the first by the lack of the small pale spot lying in front of vein $\mathrm{M}_{1}$ and from the second by the location of the distal pale spot in cell $\mathrm{M}_{1}$ far from the wing margin. The wing pattern of daedalus is closest to that of daedaloides, but in daedaloides the distal pale spots in the anal cell are fused, there is a subapical pale ring on the hind femur and the wing is only sparsely hairy.

\section{Culicoides commatis, new species}

Figure 26

Female: Length of wing $1.02 \mathrm{~mm}$.

Head.-Eyes narrowly separated, bare. Antenna with flagellar segments in proportion of $16: 12: 14: 13: 15: 14: 14: 15: 28: 27: 29: 29: 42$, antennal ratio 1.19; distal sensory tufts present on segments III, v, VII, IX, XI-Xv. Palpal segments in proportion of $12: 21: 26: 9: 8$, third segment markedly swollen, 1.53 times as long as greatest breadth, with very large, deep sensory pit. Mandible with 12 teeth. 
Thorax.-Mesonotum dark pruinose grayish brown, with moderately prominent dark brown pattern, consisting of a median anterior longitudinal band, a pair of transverse marks over humeral pits and a larger triangular pair of marks at the sutural level. Scutellum black-
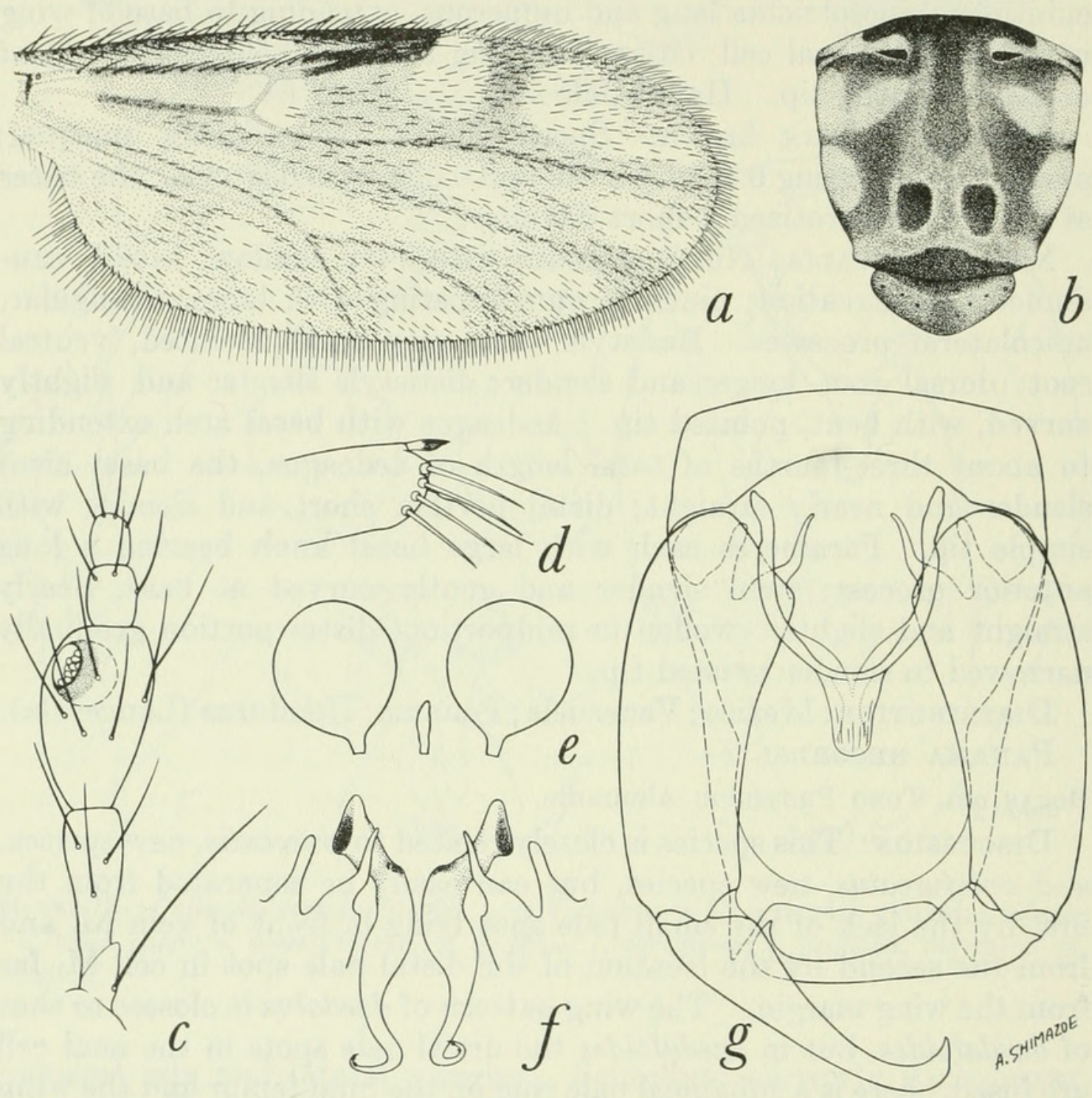

FigURE 26.-Culicoides commatis, new species. $a-e$, Female: $a$, wing; $b$, thoracic pattern; $c$, palpus; $d$, tibial comb; $e$, spermathecae. $f, g$, Male: $f$, parameres; $g$, genitalia, parameres removed.

ish in middle, dark brown on sides; postscutellum and pleuron blackish. Legs dark brown; fore and mid femora with subapical and all tibiae with subbasal narrow pale rings; hind tibial comb with four spines, the second from the spur longest.

Wing.-Pattern as figured; second radial cell very dark; pale spot over $\mathrm{r}-\mathrm{m}$ crossvein rounded, meeting costal margin in reduced breadth; 
poststigmatic pale spot in cell $R_{5}$ not double, but transverse; distal pale spot in cell $R_{5}$ round, not meeting anterior wing margin, with a linear distal pale appendage extending from posterior side of spot nearly to wing tip in apex of cell $\mathrm{R}_{5}$; distal pale spot in cell $\mathrm{M}_{1}$ broadly meeting wing margin; pale spot present straddling middle of cell $\mathrm{M}_{2}$; no pale marks on vein $\mathrm{M}_{1}$ or at apices of medial branches; pale spot at apex of cell $\mathrm{M}_{2}$ broadly meeting wing margin; pale spot in cell $\mathrm{M}_{4}$ extending in full breadth from wing margin to vein $\mathrm{M}_{3+4}$, without pale border on veins $\mathrm{M}_{3+4}$ or $\mathrm{Cu}_{1}$ in base of cell $\mathrm{M}_{4}$, two pale spots in distal portion and one pale spot near base of anal cell, cell $\mathrm{M}_{2}$ with pale spot present in front of mediocubital fork, none present behind medial fork. Macrotrichia numerous and long over entire wing; costa extending to 0.58 of distance to wing tip. Halter dull yellowish.

Abdomen.-Brownish black. Spermathecae two, subequal, pyriform, collapsed in type specimen and not measurable, with the bases of the ducts sclerotized a short distance.

Male Genitalia: Ninth sternum with broad, shallow, caudomedian excavation; ninth tergum long and slightly tapering with long pointed apicolateral processes, the caudal margin not notched. Basistyle with ventral root long and pointed, dorsal root slender; dististyle slender with bent, pointed tip. Aedeagus with moderately broad, pointed, basal arch, the basal arms well sclerotized and curved; distal portion with nearly parallel sides and bluntly rounded, moderately stout tip. Parameres each with large basal knob; stem sinuate, basal portion distinctly swollen, tapered distad to bent, pointed tip bearing a few minute hairs.

Distribution: Panama.

Specimens eXamined: Holotype female (USNM 63160) and allotype male, Almirante, Bocas del Toro Province, Panama, December 1952, F. S. Blanton, light trap. Paratypes: 2 males, 1 female, same data except dates October to December 1952, and Apr. 27, 1953.

Discussion: The wing markings, antennal sensoria, and structure of the male genitalia ally commatis with pampoikilus Macfie, but pampoikilus is larger (wing $1.25 \mathrm{~mm}$. long), with distal antennal segments longer (antennal ratio, 1.39), the main body of the distal pale spot in cell $R_{5}$ not round, veins $\mathrm{M}_{3+4}$ and $\mathrm{Cu}_{1}$ pale margined in base of cell $\mathrm{M}_{4}$ and a pale spot present behind the medial fork. The male genitalia of pampoikilus differ mainly in the greater development of the apicolateral processes with a deep notch between their bases on the caudal margin of the ninth tergum. 


\section{Culicoides pampoikilus Macfie}

Figure 27

Culicoides pampoikilus Macfie, 1948, Ann. Trop. Med. Parasit., vol. 42, p. 79 (female; Chiapas, Mexico; fig. wing).

Culicoides dominicii Ortiz, 1951, Nov. Cient. Mus. Hist. Nat. LaSalle, zool. ser., no. 5, p. 7 (male, Ocumare, Venezuela; fig. male palpus, wing, genitalia).-Mirsa and Ortiz, 1952, Bol. Lab. Clin. Luis Razetti, vol. 12, p. 476 (female; Los Chorros, Venezuela; fig. wing, mesonotum, antenna, palpus, spermathecae). New synonymy.

Female: Length of wing $1.25 \mathrm{~mm}$.

Head-Eyes narrowly separated, bare. Antenna with flagellar segments in proportion of $18: 14: 16: 16: 17: 15: 16: 17: 30: 32: 34: 35: 46$, antennal ratio 1.39 ; distal sensory tufts present on segments III, v. vII. IX, XI-XV. Palpal segments in proportion of $10: 22: 32: 9: 9$, third
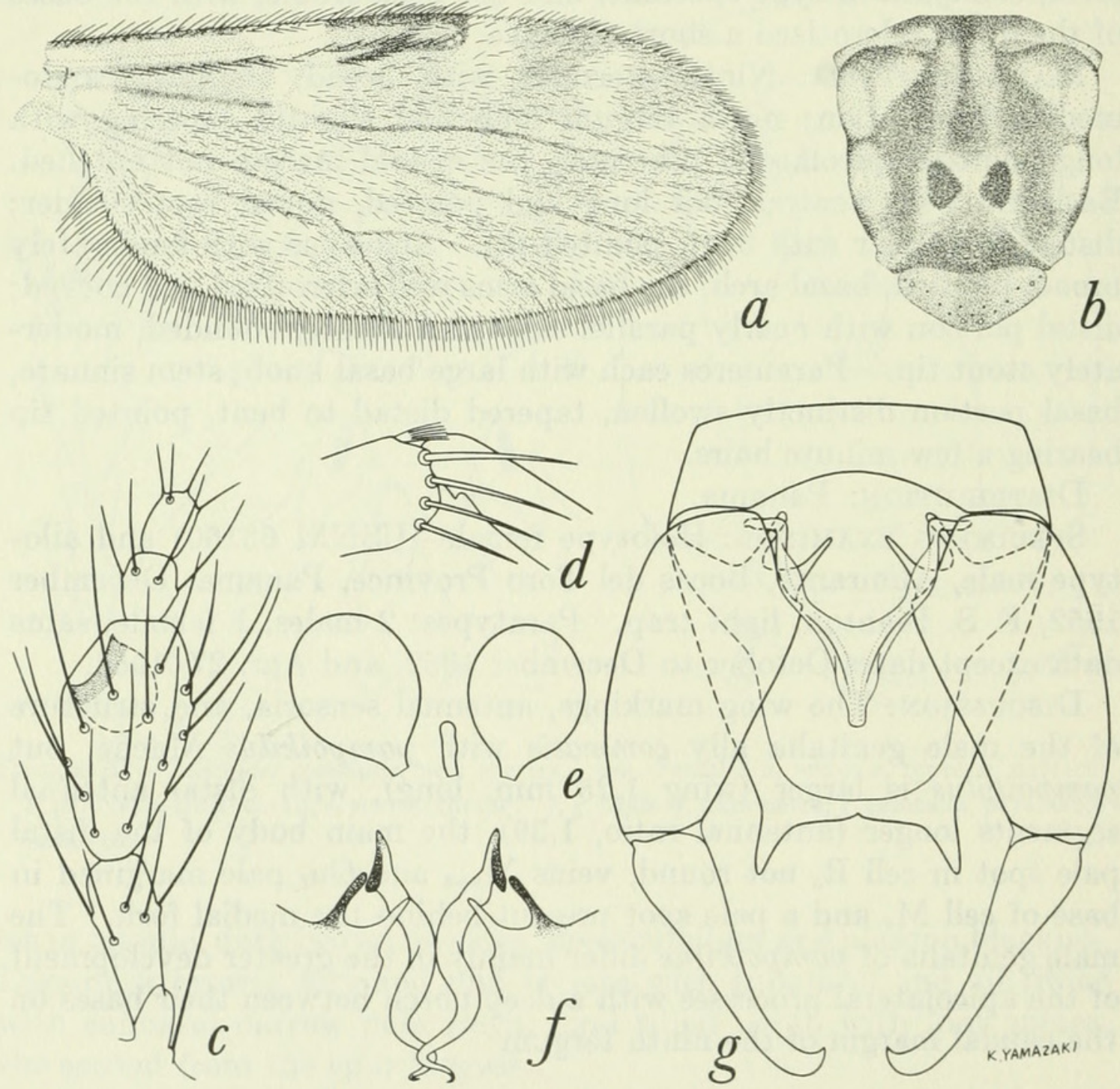

Figure 27.-Culicoides pampoikilus Macfie. $a-e$, Female: $a$, wing; $b$, thoracic pattern; $c$, palpus; $d$, tibial comb; $e$, spermathecae. $f, g$, Male: $f$, parameres; $g$, genitalia, parameres removed. 
segment greatly swollen, 1.8 times as long as greatest breadth, with a large, deep, sensory pit opening by a small pore. Mandible with 14 teeth.

Thorax.-Mesonotum with prominent pattern as figured, consisting of a pair of sublateral dark brown broad longitudinal bands, with a pair of small anterior submedian spots and several lateral pairs of small spots, pruinose yellowish gray. Scutellum narrowly dark brown in middle, pale on sides; postscutellum and pleuron dark brown. Legs dark brown, knee spots blackish; fore and mid femora with subapical and all tibiae with subbasal narrow pale rings; hind tibial comb with four spines, the second from the spur longest.

Wing.-Pattern as figured; pale spot over $\mathrm{r}-\mathrm{m}$ crossvein broadly reaching costal margin; cell $R_{5}$ with single, transverse, poststigmatic pale spot and a small pale spot in middle of cell, the posterior margin of which is connected by a somewhat obscure, narrow pale line near posterior margin of cell to a smaller pale spot at wing margin in apex of cell; cell $\mathrm{M}_{1}$ with an elongate pale spot at wing margin; vein $\mathrm{M}_{2}$ straddled by a pale spot near its base; cell $\mathrm{M}_{2}$ with a pale spot at wing margin; cell $\mathrm{M}_{4}$ with a pale spot at wing margin connected anteriorly to a narrow pale line along posterior margin of vein $\mathrm{M}_{3+4}$ (Mirsa and Ortiz' figure shows this line also extending down distal margin of vein $\mathrm{Cu}_{1}$ ); anal cell with two distal pale spots; cell $\mathrm{M}_{2}$ with a pale spot lying in front of mediocubital fork and another lying behind medial fork; a small pale area at basal arculus and another lying on base of mediocubital stem. Macrotrichia dense and long, extending to bases of medial and anal cells; costa extending to 0.59 of distance to wing tip. Halter pale.

Abdomen.-Dark brown, cerci yellowish. Spermathecae two, oval, slightly unequal, measuring 0.043 by $0.034 \mathrm{~mm}$. and 0.038 by 0.031 $\mathrm{mm}$., the bases of the ducts sclerotized a short distance.

Male Genitalia: Ninth sternum with scarcely perceptible caudomedian exacavation, ninth tergum tapered with large caudomedian notch and large, triangular, apicolateral processes. Basistyle with dorsal and ventral roots subequal, simple and slender; dististyle slender with hooked tip. Aedeagus with pointed basal arch extending to half of total length of aedeagus; distal portion tapered to simple, slender tip. Parameres each with slender anterior process on basal knob; stem rather stout and sinuate, tapered distally to simple, filiform tip abruptly bent ventrad.

Distribution: Mexico; Venezuela; Panama.

PanAMA RECORDS:

Chiriquí Province: Cerro Punta, Volcán.

Panamí Province: Cerro Campana. 
Discussion: This species is closely related to commatis, new species; for characters of separation see discussion under that species.

\section{Culicoides phaeonotus, new species}

Figure 28

F emale: Length of wing $1.06(0.96-1.09, \mathrm{n}=7) \mathrm{mm}$.

Head.-Eyes narrowly separated, bare. Antenna with flagellar segment in proportion of $18: 14: 14: 14: 14: 14: 14: 15: 35: 35: 38: 36: 49$, antennal ratio $1.63(1.56-1.77, \mathrm{n}=6)$ : distal sensory tufts present on segments III, V, VII, IX, XI-XV. Palpal segments in proportion of $9: 24: 24: 10: 8$, third segment short and greatly swollen, $2.0(1.9-2.2$, $\mathrm{n}=7$ ) times as long as greatest breadth, with a broad, deep sensory pit. Mandible with $12(12-13, \mathrm{n}=6)$ teeth.
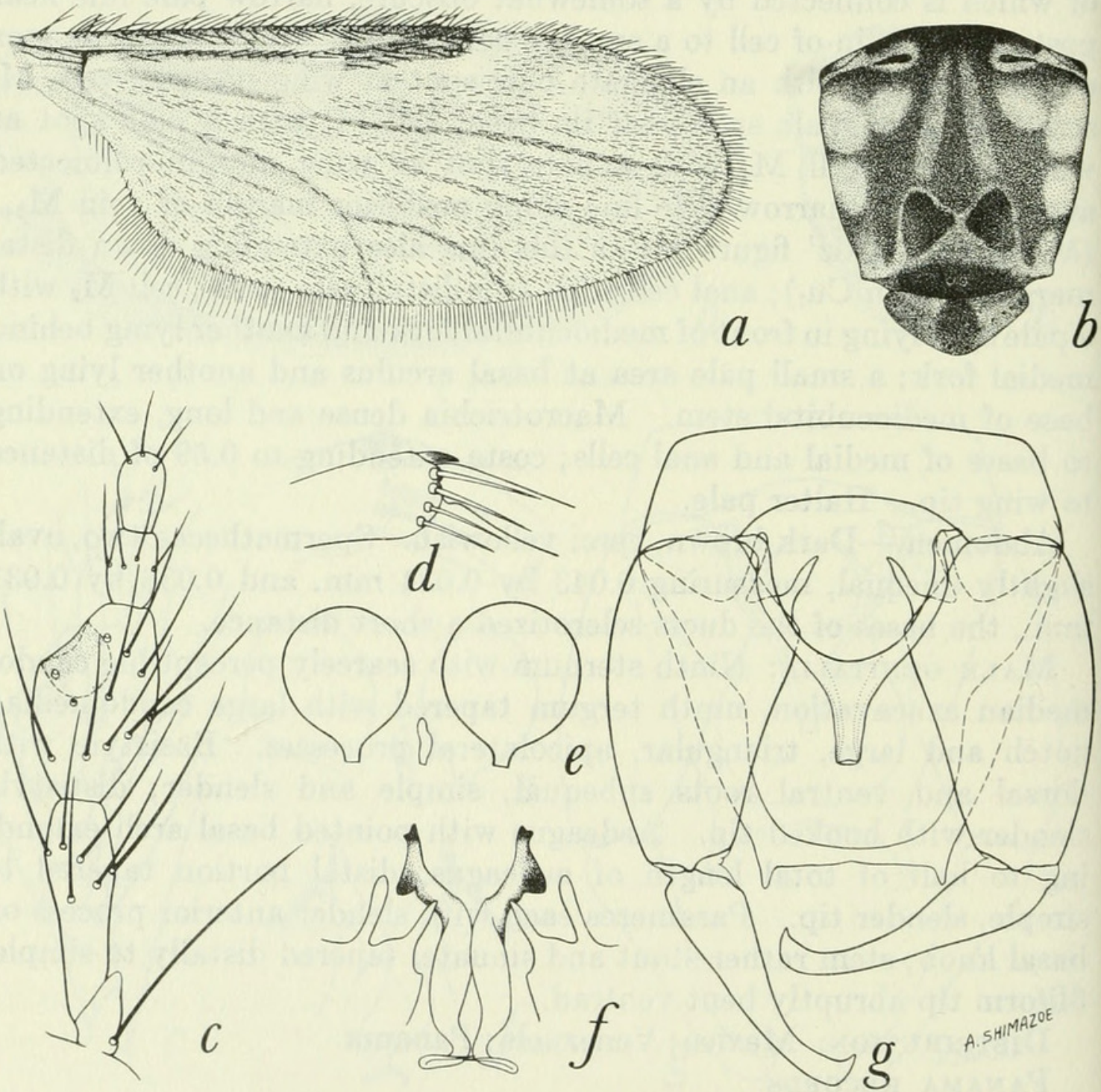

FigURE 28.-Culicoides phaeonotus, new species. $a-\ell$, Female: $a$, wing; $b$, thoracic pattern; $c$, palpus; $d$, tibial comb; $e$, spermathecae. $f, g$, Male: $f$, parameres; $g$, genitalia, parameres removed. 
Thorax.-Mesonotum dark brown with prominent pattern of pruinose, grayish brown patches; a pair of very narrow, elongate, submedian anterior ones, and four pairs of small, rounded, lateral ones. Scutellum dark brown in middle, light brown on sides; postscutellum and pleuron dark brown. Legs dark brown; fore and mid femora with subapical and all tibiae with subbasal narrow pale rings; hind tibial comb with four $(n=7)$ spines, the one nearest the spur longest.

Wing.-Pattern as figured; pale spots relatively small and indistinct; small pale spot over $\mathrm{r}-\mathrm{m}$ crossvein broadly reaching costal margin; a small, oblique, poststigmatic pale spot in cell $\mathrm{R}_{5}$; distal pale spot in cell $R_{5}$ small and rounded, not meeting wing margin; no pale spots bordering vein $\mathrm{M}_{1}$; pale spot in cell $\mathrm{M}_{1}$ indistinctly approaching wing margin, elongate; small pale spot straddling middle of vein $\mathrm{M}_{2}$; small pale spots at the wing margin in cells $\mathrm{M}_{2}$ and $\mathrm{M}_{4}$, the one in cell $\mathrm{M}_{4}$ broadly extending to vein $\mathrm{M}_{3+4}$ but not continued along that vein; two small, separated pale spots in distal portion of anal cell; pale spots present in cell $\mathrm{M}_{2}$, one in front of mediocubital fork and another behind medial fork. Macrotrichia very numerous and long, extending to base of wing in cell $\mathrm{M}_{2}$ and anal cell; costa extending to $0.61(0.59-0.66, \mathrm{n}=7)$ of distance to wing tip. Halter brownish yellow.

Abdomen.-Brownish black. Spermathecae two, subspherical, subequal, measuring 0.038 by $0.034 \mathrm{~mm}$. and 0.036 by $0.031 \mathrm{~mm}$.

Male genitalia: Ninth sternum with a broad, shallow, caudomedian excavation; ninth tergum long and tapering with short, triangular, pointed, apicolateral processes. Basistyle with ventral root short, slender and pointed, dorsal root longer and slender; dististyle very slender with markedly hooked, pointed tip. Aedeagus with basal arch reaching to two-thirds of total length, the basal arms bent in midportions; distal portion short and simple with moderately slender, truncated apex. Parameres each with basal knob bearing a long anterior process; stem slender at base, moderately bent before the moderately stout, nearly straight midportion, without ventral lobe, with distal portion twisted, only moderately narrowed to simple pointed tip.

Distribution: Panama.

Specimens examined: Holotype female (USNM 63161), Almirante, Bocas del Toro Province, Panama, November 1952, F. S. Blanton, light trap. Allotype male and 10 male and 50 female paratypes, same data except dates October 1952 to March 1953.

Discussion: This species is closely related to daedalus Macfie, which differs in having the pale spot in cell $\mathrm{M}_{1}$ located far from the wing margin, in having a third basal pale spot in anal cell, and in 
lacking sensoria on any of antennal segments iv to x. Pilosus, new species, of the copiosus group has a nearly identical wing pattern but differs in having a paler, more yellowish mesonotal pattern and sensoria present on all of segments III to IX.

\section{Culicoides dunni, new species}

Figure 29

Female: Length of wing $1.12(\mathrm{n}=2) \mathrm{mm}$.

Head.-Eyes narrowly separated, bare. Antenna with flagellar segments in proportion of $18: 14: 15: 15: 15: 15: 15: 15: 21: 24: 27: 28: 38$, antennal ratio 1.13, distal sensory tufts present on segments III, IV, VI, VII, IX and XI-XV on one antenna and on segments III, VI-IX (segments $\mathrm{XI}-\mathrm{Xv}$ missing) on other antenna of the single specimen available. Palpal segments in proportion of $11: 21: 36: 8: 9$, third segment very large and swollen, 2.06-2.25 $(\mathrm{n}=2)$ times as long as greatest breadth, with a large deep pit opening by a small pore. Mandible with 18 teeth.

Thorax.-Mesonotum yellowish brown, blackish on anterior and lateral margins, with a moderately distinct, dark brown pattern consisting of a very narrow median anterior line and two short, broad, sublateral vittae at sutural level. Scutellum dark brown in middle, yellowish brown on sides; postscutellum and pleuron blackish. Legs

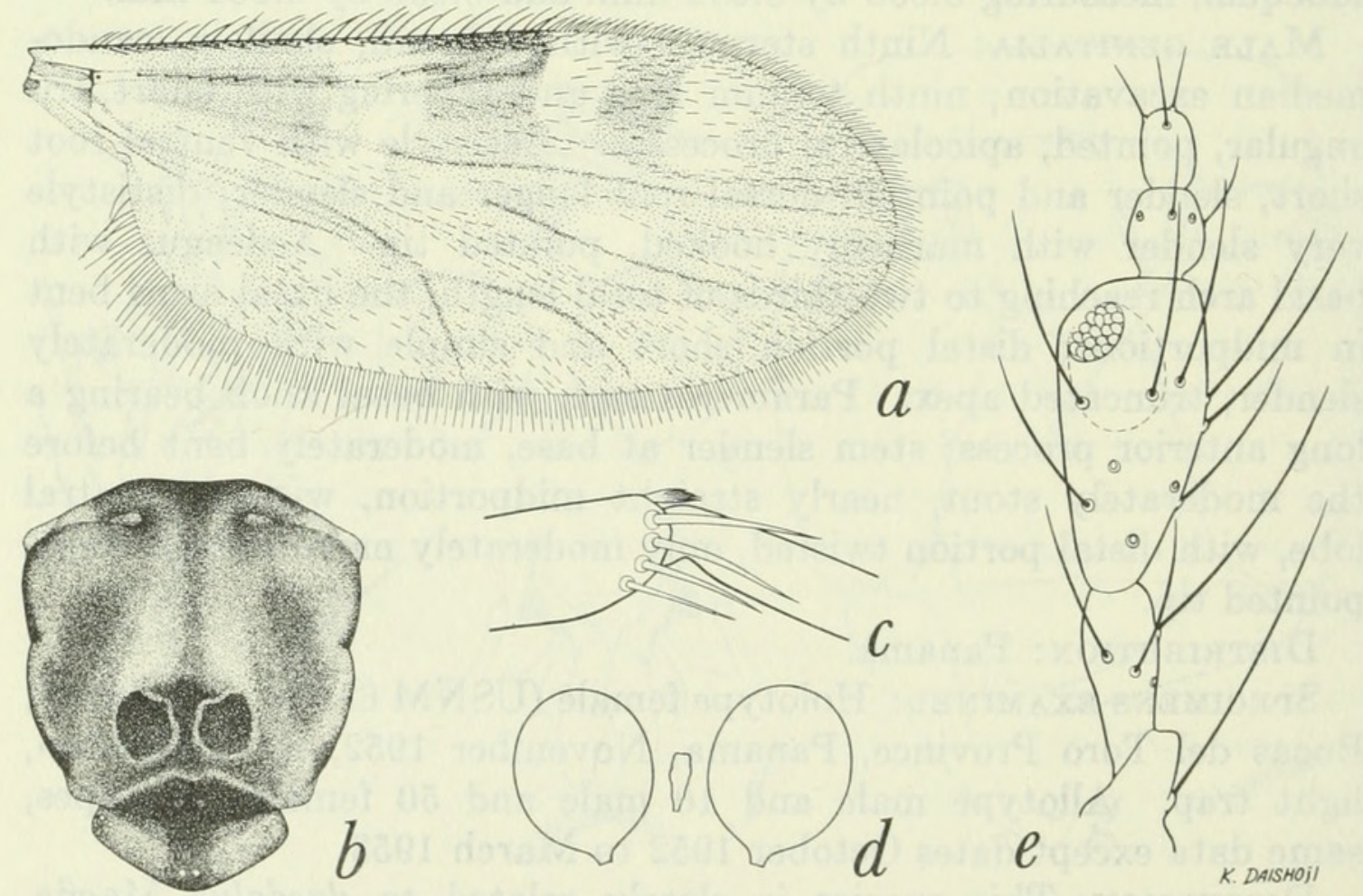

Figure 29.-Culicoides dunni, new species. Female: $a$, wing; $b$, thoracic pattern; $c$, tibial comb; $d$, spermathecae; $e$, palpus. 
blackish brown; fore and mid femora with subapical and all tibiae with subbasal, narrow pale rings; hind tibial comb with four spines, the two nearest the spur longest, subequal.

Wing.-Pattern as figured; three relatively dark anterior spots, the second entirely covering second radial cell; pale spot over r-m crossvein large, extending broadly to costal margin and through half the width of cell $\mathrm{M}_{2}$; poststigmatic pale spot narrow, transverse, quadrate in shape, distal pale spot in cell $R_{5}$ of same size and shape or slightly shorter, a very dark spot in cell $R_{5}$ of the same size and shape between the pale spots; vein $\mathrm{M}_{1}$ with an elongate pale spot lying on anterior side of vein or extending over it slightly into cell $\mathrm{M}_{2}$, at level of the poststigmatic pale spot in cell $\mathrm{R}_{5}$; distal pale spot in cell $\mathrm{M}_{1}$ lying far from wing margin; apices of veins without pale spots; a large pale spot straddling middle of vein $\mathrm{M}_{2}$; distal pale spot in cell $\mathrm{M}_{2}$; distal pale spot in cell $\mathrm{M}_{2}$ not meeting wing margin; pale spot in cell $\mathrm{M}_{4}$ broadly meeting wing margin and with narrow extension anteriorly to vein $\mathrm{M}_{3+4}$; anal cell with two pale spots in distal portion, the posterior one broadly meeting wing margin, one posterior spot far from wing margin in basal part of cell and a fourth pale area extending across mediocubital stem to halfway across base of cell $\mathrm{M}_{2}$; cell $\mathrm{M}_{2}$ also with a small pale spot lying in front of mediocubital fork and a very small one behind medial fork. Macrotrichia numerous and long on entire wing, extending to base of cell $\mathrm{M}_{2}$ and anal cell; costa extending to 0.56 of wing length. Halter yellowish.

Abdomen.-Brownish black, cerci dull yellowish. Spermathecae two, subspherical, subequal, small, measuring 0.046 by $0.036 \mathrm{~mm}$., the bases of the ducts sclerotized a very short distance.

MALE: Unknown.

Distribution: Panama.

Specimens examined: Holotype female (USNM 63162), Volcán, Chiriquí Province, Panama, December 1952, F. S. Blanton, light trap. Paratypes, 4 females, same data except three with dates Apr. 4, 1954.

Discussion: Culicoides propinquus Macfie from Chiapas, Mexico, has a similar wing pattern which differs in having the pale spot lying in front of vein $M_{1}$ not crossing over the vein and lying distal to the level of the poststigmatic pale spot in cell $\mathrm{R}_{5}$. C. propinquus is known only from the male, whose genitalia place it definitely in the copiosus group near poikilonotus Macfie. The sensorial pattern of ảunni allies it with the species of the daedalus group.

This species is dedicated to Dr. Lawrence H. Dunn, for many years medical entomologist and assistant director of the Gorgas Memorial Laboratory, in honor of his contributions to science in Panama. 


\section{Culicoides daedaloides, new species}

Figure 30

Female: Length of wing $0.92-1.09(\mathrm{n}=2) \mathrm{mm}$.

Head.-Eyes contiguous, bare. Antenna with flagellar segments in proportion of $18: 14: 12: 13: 13: 13: 12: 14: 28: 28: 31: 32: 43$, antennal ratio $1.48-1.49(\mathrm{n}=2)$; distal sensory tufts present on segments III, viII-X. Palpal segments in proportion of $9: 12: 19: 6: 7$, third segment short and swollen, $1.83-1.90(\mathrm{n}=2)$ times as long as greatest breadth, with a very broad and shallow sensory pit. Mandible with 12 teeth.

Thorax.-Mesonotum pruinose yellowish brown, with a prominent pattern of brown lines in the form of $\mathrm{H}$-shaped marking, the longitudinal lines extending from the humeral pits to the sides of scutellum,
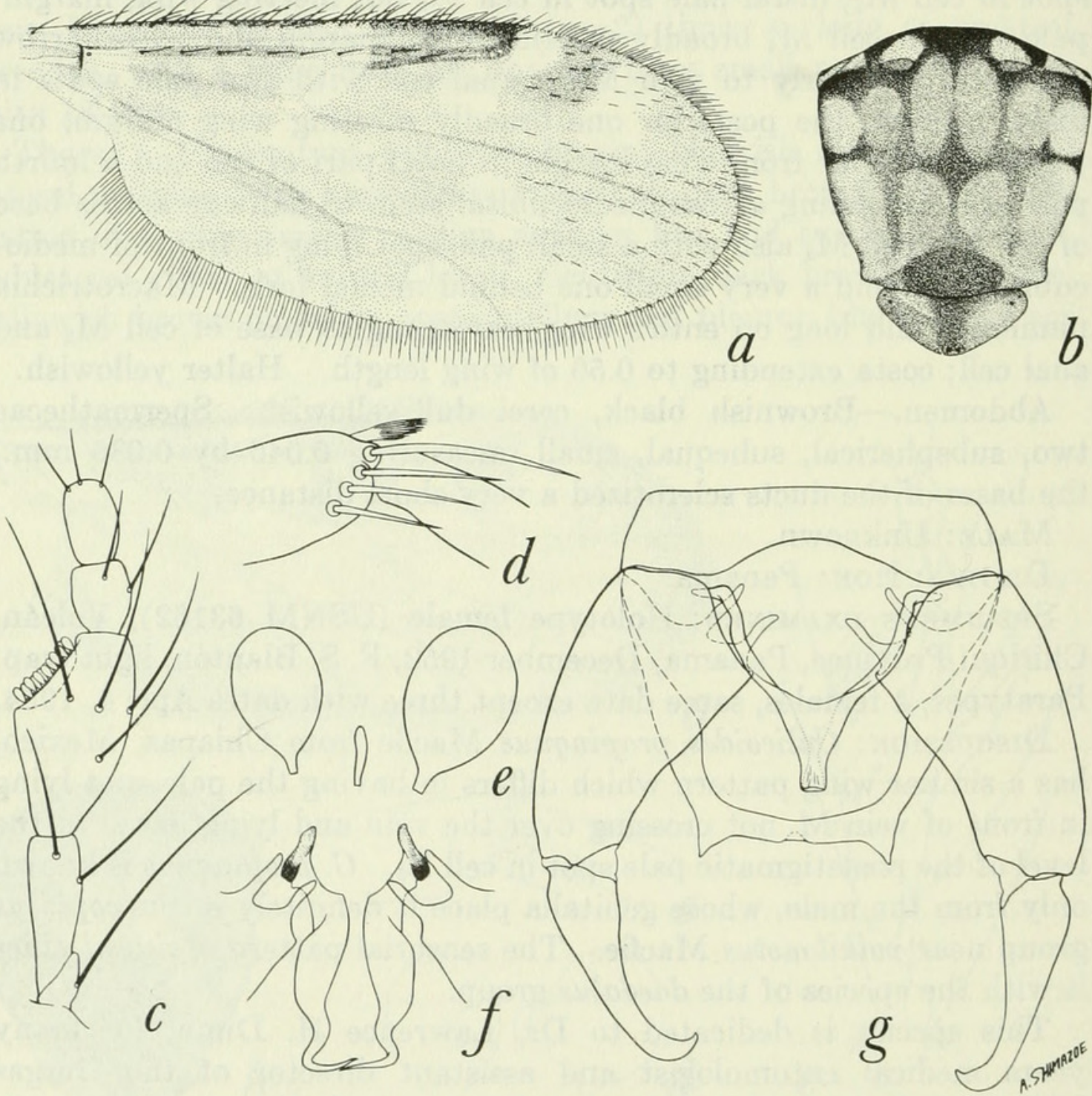

Figure 30.-Culicoides daedaloides, new species. $a-e$, Female: $a$, wing; $b$, thoracic pattern; $c$, palpus; $d$, tibial comb; $e$, spermathecae. $f, g$, Male: $f$, parameres; $g$, genitalia, parameres removed. 
the transverse line located at level of lateral sutures. Scutellum narrowly brown in middle, yellowish on sides; postscutellum and pleuron brownish. Legs brown; knee spots blackish, femora with subapical, tibiae with subbasal and hind tibiae with apical narrow pale rings; hind tibial comb with four $(n=2)$ spines, the one nearest the spur longest, very long, 0.4 as long as basitarsus.

Wing.-Pattern as figured, second radial cell moderately dark; pale spot over r-m crossvein continued in full breadth to costal margin; poststigmatic pale spots in cell $R_{5}$ separate, round, the one behind second radial cell larger; distal pale spot in cell $R_{5}$ double, transverse, reaching anterior wing margin in full breadth; distal pale spot in cell $\mathrm{M}_{1}$ oval, located far from wing margin; pale spot present straddling middle of vein $\mathrm{M}_{2}$; one pale spot at the wing margin in distal part of cell $\mathrm{M}_{2}$; pale spot in cell $\mathrm{M}_{4}$ the same breadth from wing margin to posterior side of vein $\mathrm{M}_{3+4}$; a transverse, double pale spot in distal part of anal cell, a small pale spot over anal vein near base of anal cell; pale spot absent in front of mediocubital fork; pale spot behind medial fork and at basal arculus of wing. Macrotrichia very sparse on distal third of wing, none in cell $\mathrm{M}_{4}$ and anal cell; costa extending to $0.63(n=2)$ of distance to wing tip. Halter whitish.

Abdomen.-Dark brown. Spermathecae two, slightly unequal, pyriform, the larger measuring 0.053 by $0.036 \mathrm{~mm}$. in holotype, the smaller collapsed in available specimens, bases of the ducts sclerotized a considerable distance.

Male Genitalia: Ninth sternum with broad, very shallow, caudomedian excavation; ninth tergum tapering with short, triangular, apicolateral processes. Basistyle with ventral and dorsal roots slender, simple, the ventral root pointed; dististyle with slender, hooked, pointed apex. Aedeagus with basal arch reaching 0.6 of total length of aedeagus, rounded mesally, the basal arms slender and curved, the distal portion tapered to slender, simple tip. Parameres each with basal knob bearing a long anterior process, stem narrow at extreme base, stout on midportion and sinuate, apparently (?) bearing a very low, extensive ventral lobe, distal points simple, with a long twist ventromesad.

Distribution: Panama.

Specimens examined: Holotype female (USNM 63163), Almirante, Bocas del Toro Province, Panama, Apr. 29, 1953, F. S. Blanton, light trap. Allotype male, same data except date November 1952. Paratypes, 1 male, 3 females: 1 male, 2 females, Cerro Campana, Panamá Province, July 2, Sept. 19, 1951; 1 female, Mojinga Swamp, Canal Zone, January 1952.

Discussion: Culicoides daedalus Macfie has a similar wing pattern and male genitalia, but has the wing much hairier with the post- 
stigmatic pale spots fused and the distal pale spot in cell $R_{5}$ not reaching wing margin and the pale spots in anal cell well separated, the mesonotum is dark brown and the hind femur is dark to the tip. The presence in daedaloides of antennal sensory tufts on segments viII-x, the broad, shallow palpal pit, the transverse distal pale spot in anal cell and the sparsely hairy wings would exclude this species from the daedalus group and thus its true relations are still unknown.

\section{The copiosus group}

This group consists of small species with very hairy wing; the wing pattern of well-defined, rounded pale spots, a pale spot usually present straddling middle of vein $\mathrm{M}_{2}$ or lying just in front of this vein and often with a similar spot on vein $\mathrm{M}_{1}$; pale spot in cell $\mathrm{M}_{4}$ usually widened toward vein $\mathrm{M}_{3+4}$, crossvein $\mathrm{r}-\mathrm{m}$ never darkened; female palpus with third segment greatly swollen and bearing a deep sensory pit usually opening by a smaller pore; spermathecae two; four tibial spines; male genitalia with dorsal and ventral roots of the basistyle simple, the ventral root never foot-shaped, parameres short with basal knob directed laterad, stem swollen at base, without ventral lobe, the apex slender, simple and often twisted, aedeagus usually short and broad, the basal arch usually low, the basal arms stout.

PANAMA SPECIES: Four: jamaicensis Edwards; panamensis Barbosa; pilosus, new species; and poikilonotus Macfie. (Other Neotropical species belonging to this group include borinqueni Fox and Hoffman, copiosus Root and Hoffman, loughnani Edwards and propinquus Macfie. Ryckman and Ames (1953) reared copiosus from rotting stems of cactus in Arizona.)

\section{Culicoides pilosus, new species}

Figure 31

Female: Length of wing $0.99(n=3) \mathrm{mm}$.

Head.-Eyes broadly separated, bare. Antenna with flagellar segments in proportion of $18: 12: 12: 12: 13: 13: 13: 14: 28: 28: 32: 33: 46$, antennal ratio 1.56 ; distal sensory tufts present on segments III-IX and $\mathrm{XI}-\mathrm{Xv}$. Palpal segments in proportion of $10: 20: 30: 9: 10$, third segment greatly swollen, $2.0(1.9-2.1, \mathrm{n}=3)$ times as long as greatest breadth, with a large, very deep, sensory pit opening by a small pore. Mandible with $17(16-18, \mathrm{n}=3)$ teeth.

Thorax.-Mesonotum yellowish brown, with a moderately prominent pattern of large dark brown patches; a narrow median anterior line and a pair of lateral, broad bands at sutural level the most prominent; prescutellar area and anterior lateral margins also dark. Scutellum dark brown in middle, yellowish brown on sides; postscutellum 

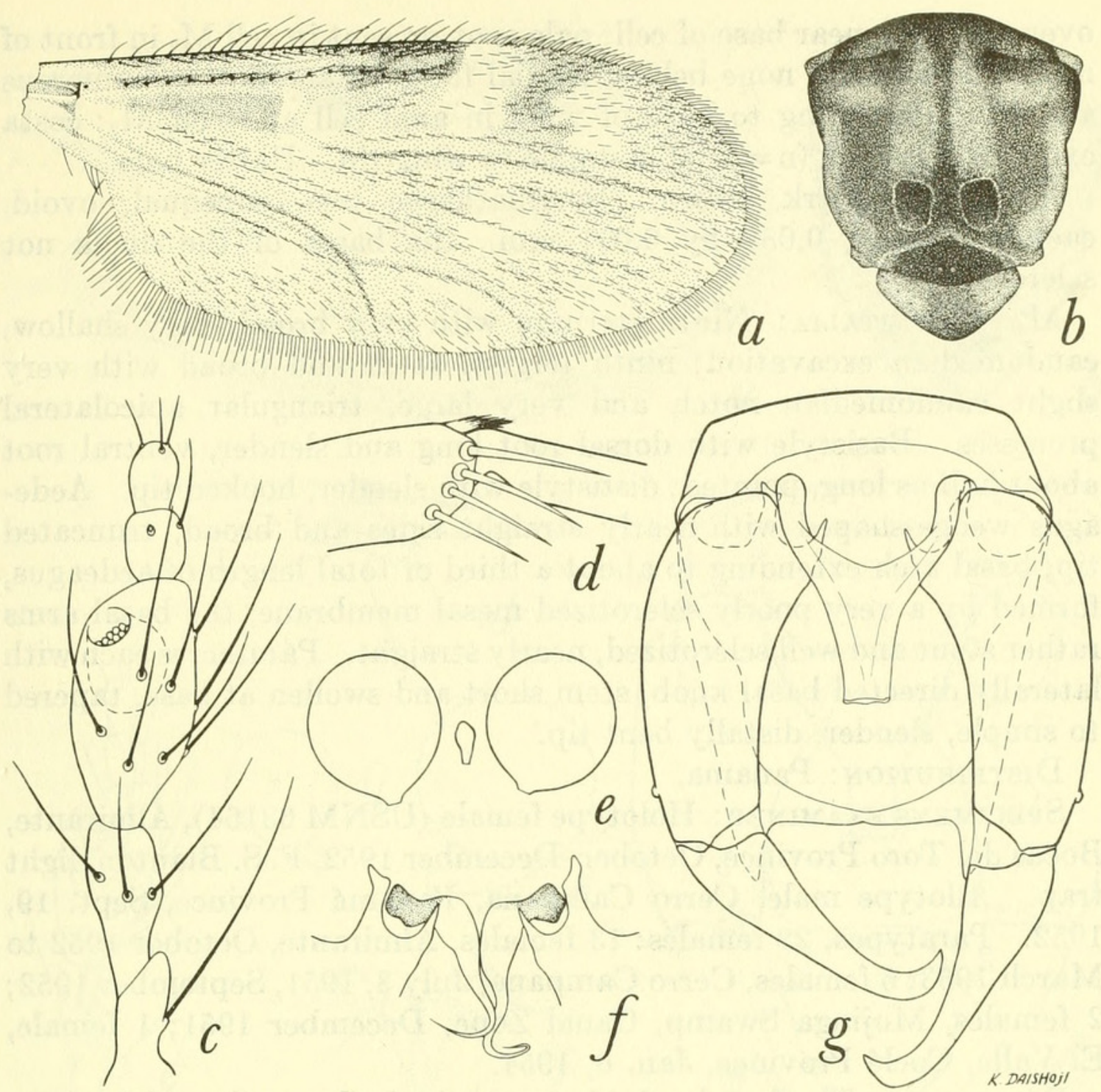

Figure 31.-Culicoides pilosus, new species. a-e, Female: $a$, wing; $b$, thoracic pattern; $c$, palpus; $d$, tibial comb; $e$, spermathecae. $f, g$, Male: $f$, parameres; $g$, gentalia, parameres removed.

and pleuron dark brown. Legs dark brown; fore and mid femora with subapical and all tibiae with subbasal narrow pale rings; hind tibial comb with four $(n=3)$ spines, the one nearest the spur longest.

Wing.-Pattern as figured; pale spot over r-m crossvein large, broadly but with reduced intensity reaching costal margin; poststigmatic pale spot in cell $R_{5}$ large, nearly transverse; distal pale spot in cell $R_{5}$ irregularly rounded, not reaching wing margin, dark area between the two pale spots in cell $R_{5}$, the area over second radial cell and the area proximad of $\mathrm{r}-\mathrm{m}$ crossvein very dark brown; no pale spots on vein $\mathrm{M}_{1}$; pale spot in cell $\mathrm{M}_{1}$ elongate, reaching distal wing margin; pale spot present straddling middle of vein $\mathrm{M}_{2}$; pale spots present at wing margin in cells $\mathrm{M}_{2}$ and $\mathrm{M}_{4}$, the latter broadened and extended proximad a short distance along posterior side of vein $\mathrm{M}_{3+4}$; two separate spots in distal portion of anal cell and a third spot lying 
over anal vein near base of cell; pale spot present in cell $\mathrm{M}_{2}$ in front of mediocubital fork, none behind medial fork. Macrotrichia numerous and long, extending to base of wing in anal cell and cell $\mathrm{M}_{2}$; costa extending to $0.59(\mathrm{n}=3)$ of distance to wing tip. Halter pale.

Abdomen.-Dark brown. Spermathecae two, subequal, ovoid, each measuring 0.036 by $0.031 \mathrm{~mm}$., the bases of the ducts not sclerotized.

Male genitalia: Ninth sternum with very broad, very shallow, caudomedian excavation; ninth tergum short and broad with very slight caudomedian notch and very large, triangular apicolateral processes. Basistyle with dorsal root long and slender, ventral root about half as long, pointed; dististyle with slender, hooked tip. Aedeagus wedge-shaped with nearly straight sides and broad, truncated tip; basal arch extending to about a third of total length of aedeagus, formed by a very poorly sclerotized mesal membrane, the basal arms rather stout and well sclerotized, nearly straight. Parameres each with laterally directed basal knob, stem short and swollen at base, tapered to simple, slender, distally bent tip.

Distribution: Panama.

Specimens examined: Holotype female (USNM 63164), Almirante, Bocas del Toro Province, October-December 1952, F. S. Blanton, light trap. Allotype male, Cerro Campana, Panamá Province, Sept. 19, 1952. Paratypes, 22 females: 13 females, Almirante, October 1952 to March 1953; 6 females, Cerro Campana, July 3, 1951, September 1952; 2 females, Mojinga Swamp, Canal Zone, December 1951; 1 female, El Valle, Coclé Province, Jan. 6, 1954.

Discussion: The female of this species is similar to that of daedalus Macfie and phaeonotus, new species; for characters of separation see the discussion under phaeonotus. The male genitalia of pilosus are nearly identical with those of panamensis Barbosa, but in panamensis the basal knob and the basal swelling of the stem of the parameres are not so well developed, the aedeagal arch is usually higher and broader and the apicolateral processes are somewhat longer and more diverging.

\section{Culicoides panamensis Barbosa}

Figure 32

Culicoides panamensis Barbosa, 1947, Anais Soc. Biol. Pernambuco, vol. 7, p. 22 (male, female; Barro Colorado Island, Canal Zone; fig. palpus, male genitalia).-Wirth, 1955, Proc. Ent. Soc. Washington, vol. 57, p. 114 (Guatemala; descriptive notes; fig. palpus, male genitalia; synonym, alambiculorum Macfie).

Culicoides alambiculorum Macfie, 1948, Ann. Trop. Med. Parasit., vol. 42, p. 81 (female; Chiapas, Mexico; fig. wing).

Female: Length of wing $0.87(0.76-1.06, \mathrm{n}=10) \mathrm{mm}$.

Head.-Eyes narrowly separated, bare. Antenna with flagellar 

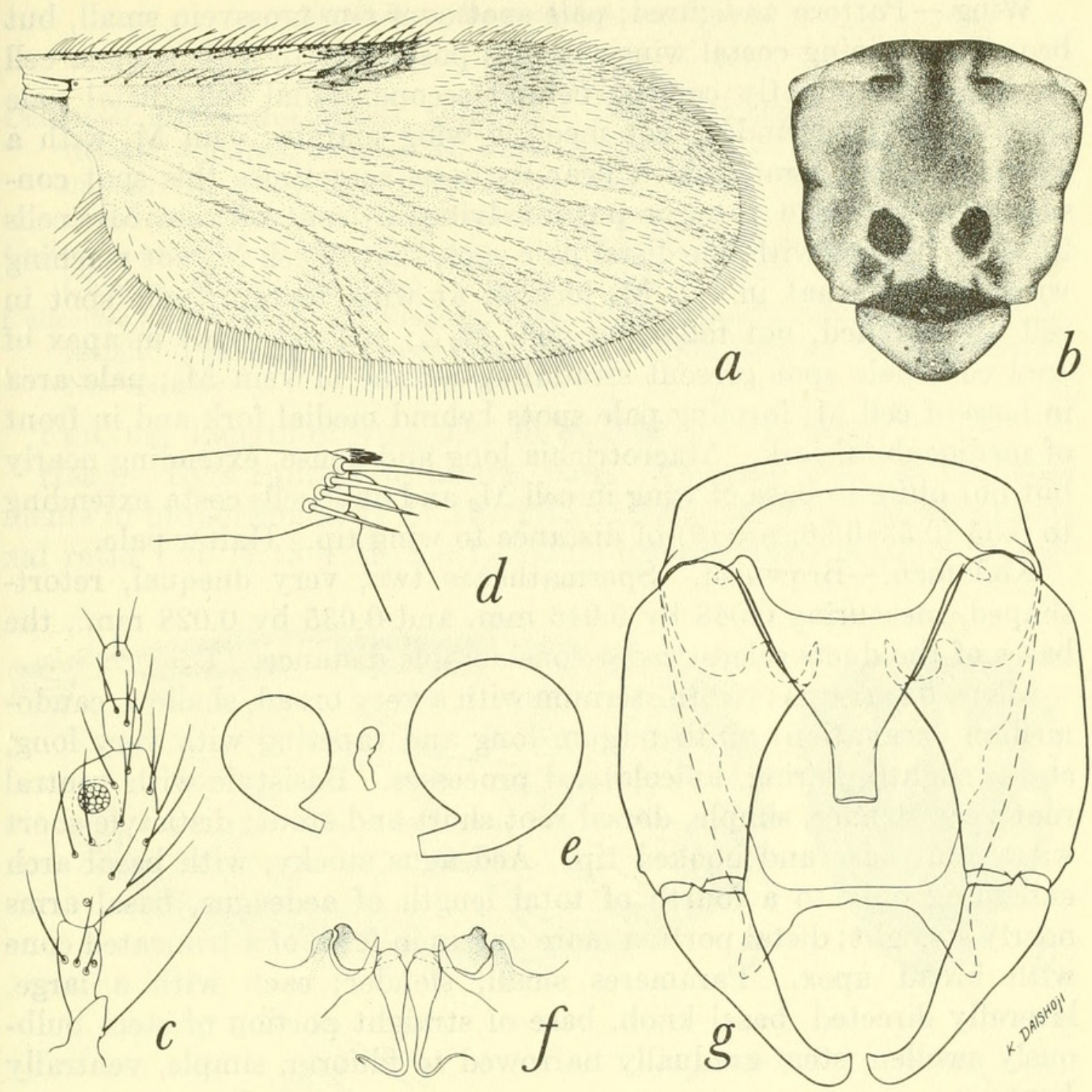

Figure 32.-Culicoides panamensis Barbosa. a-e, Female: $a$, wing; $b$, thoracic pattern; $c$, palpus; $d$, tibial comb; $e$, spermathecae. $f, g$, Male: $f$, parameres; $g$, genitalia, parameres removed.

segments in proportion of $16: 10: 10: 11: 11: 11: 11: 12: 18: 18: 19: 20: 28$, antennal ratio $1.12(1.06-1.15, \mathrm{n}=6)$; distal sensory tufts present on segments III, XI-Xv. Palpal segments in proportion of $7: 12: 30: 10: 10$, third segment greatly swollen, $2.0(1.8-2.1, \mathrm{n}=9)$ times as long as greatest breadth, with a large, deep pit opening through a very small pore. Mandible with $10(n=3)$ teeth, very poorly developed, the teeth practically vestigial.

Thorax.-Mesonotum grayish brown pruinose, with three dark brown longitudinal bands, a median anterior one and two sublateral ones, each broadest in midportion. Scutellum, postscutellum, and pleuron dark brown. Legs dark brown, fore and mid femora with subapical and all tibiae with subbasal narrow pale rings; hind tibial comb with four $(n=10)$ spines, the one nearest the spur longest. 
Wing.-Pattern as figured; pale spot over r-m crossvein small, but broadly attaining costal wing margin; poststigmatic pale spot in cell $\mathrm{R}_{5}$ extending slightly caudad behind second radial cell, distal pale spot in cell $R_{5}$ rounded, not meeting wing margin; vein $M_{1}$ with a small pale spot straddling it near its base, sometimes this spot consisting only of the anterior portion lying in front of vein $\mathrm{M}_{1}$; cells $\mathrm{M}_{1}$ and $\mathrm{M}_{2}$ each with one distal pale spot, that in cell $\mathrm{M}_{1}$ not reaching wing margin, that in cell $\mathrm{M}_{2}$ located at wing margin; pale spot in cell $\mathrm{M}_{4}$ rounded, not following vein $\mathrm{M}_{3+4}$; one pale spot in apex of anal cell; pale spot present straddling middle of vein $\mathrm{M}_{2}$; pale area in base of cell $\mathrm{M}_{2}$ forming pale spots behind medial fork and in front of mediocubital fork. Macrotrichia long and dense, extending nearly but not quite to base of wing in cell $\mathrm{M}_{2}$ and anal cell; costa extending to $0.55(0.53-0.56, \mathrm{n}=10)$ of distance to wing tip. Halter pale.

Abdomen.-Brownish. Spermathecae two, very unequal, retortshaped, measuring 0.048 by $0.046 \mathrm{~mm}$. and 0.035 by $0.028 \mathrm{~mm}$., the bases of the ducts sclerotized a considerable distance.

Male Genitalia: Ninth sternum with a very broad, shallow, caudomedian excavation; ninth tergum long and tapering with very long, stout, slightly flaring, apicolateral processes. Basistyle with ventral root very slender, simple, dorsal root short and stout; dististyle short with stout base and hooked tip. Aedeagus stocky, with basal arch extending only to a fourth of total length of aedeagus, basal arms nearly straight; distal portion more or less in form of a truncated cone with broad apex. Parameres small, slender; each with a large, laterally directed, basal knob, base of straight portion of stem bulbously swollen, stem gradually narrowed to filiform, simple, ventrally bent tip.

Distribution: Panama; Guatemala; Mexico.

\section{PanAMA RECORDS:}

Canal Zone: Barro Colorado Island (type locality).

Chiriquí Province: Volcán.

Coclé Province: El Valle.

Los Santos Province: La Palma.

Discussion: The reduced mandibles, remarkably enlarged third palpal segment with very deep pit and small pore, and retort-shaped spermathecae are distinctive features of this species. Culicoides copiosus Root and Hoffman from Mexico closely resembles panamensis, but has the distal pale spot in cell $\mathrm{M}_{1}$ extending to the wing margin. 


\section{Culicoides poikilonotus Macfie}

\section{Figure 33}

Culicoides poikilonotus Macfie, 1948, Ann. Trop. Med. Parasit., vol. 42, p. 82 (female; Chiapas, Mexico; fig. wing).-Wirth, 1955, Proc. Ent. Soc. Washington, vol. 57, p. 115 (Guatemala; male, female, descriptive notes; fig. mesonotum, palpus, male genitalia; synonym, cacozelus Macfie).

Culicoides cacozelus Macfie, 1948, Ann. Trop. Med. Parasit., vol. 42, p. 85 (female; Chiapas, Mexico; fig. wing).

Culicoides hertigi Wirth and Blanton, 1953, Journ. Parasit., vol. 39, p. 229 (male, female; Panama; fig. wing, mesonotal pattern, palpus, male genitalia). New synonymy.

Female: Length of wing $0.83(0.76-0.92, \mathrm{n}=12) \mathrm{mm}$.

Head.-Eyes contiguous above, bare. Antenna with flagellar segments in proportion of $17: 11: 12: 12: 12: 12: 12: 13: 23: 23: 23: 24: 34$, antennal ratio $1.26(1.18-1.32, \mathrm{n}=4)$; distal sensory tufts present on seg-
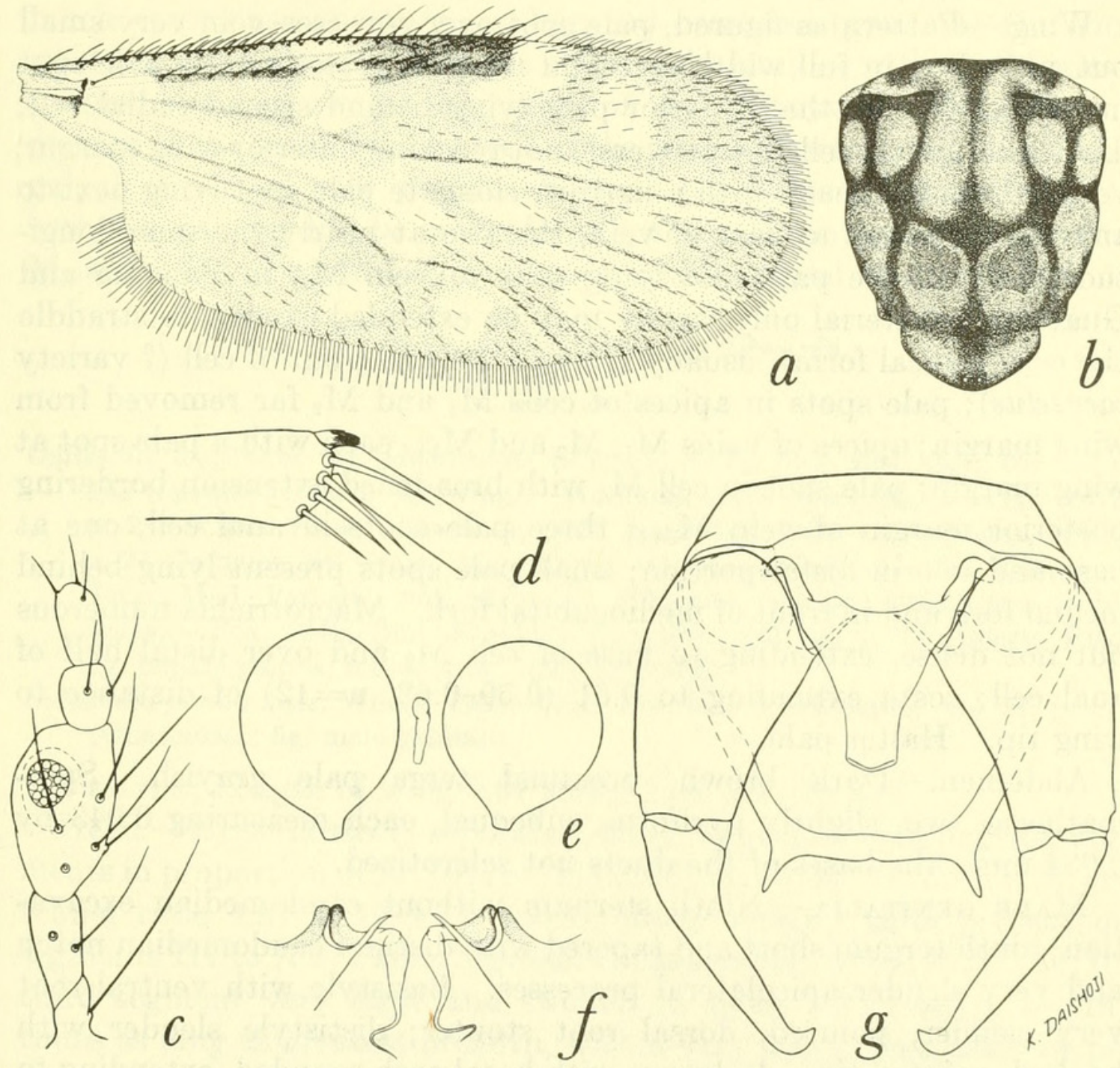

Figure 33.-Culicoides poikilonotus Macfie. $a-e$, Female: $a$, wing; $b$, thoracic pattern; $c$, palpus; $d$, tibial comb; $e$, spermathecae. $f, g$, Male: $f$, parameres; $g$, genitalia, parameres removed. 
ments III, XI-XV. Palpal segments in proportion of $7: 14: 20: 7: 9$, third segment short and swollen, $1.6(1.4-1.8, \mathrm{n}=9)$ times as long as greatest breadth, with a very deep, large sensory pit opening by a very small distal pore. Mandible with $10(10-11, \mathrm{n}=3)$ very small, almost vestigial teeth.

Thorax.-Mesonotum yellowish brown with a prominent pattern of narrow, darker brown bands as figured, principally a very narrow median longitudinal line extending from anterior margin to scutellum and a transverse band across sutural level with short, broader, anterior and posterior, lateral longitudinal extensions. Scutellum yellowish, narrowly dark brown in middle and on extreme ends; postscutellum brownish; pleuron yellowish, dark brown transversely across middle. Legs brownish, all femora with subapical, all tibiae with subbasal and hind tibia with apical narrow pale rings; hind tibial comb with four $(n=12)$ spines, the one nearest the spur longest.

Wing.-Pattern as figured, pale spot over $r-m$ crossvein very small but extending in full width to costal margin; poststigmatic pale spot in cell $R_{5}$ double, the posterior part lying behind second radial cell; distal pale spot in cell $\mathrm{R}_{5}$ transverse, not reaching anterior wing margin; veins $M_{1}$ and $M_{2}$ each with a narrow, elongate pale spot lying next to anterior side next to base of vein, the two at nearly the same longitudinal level, the pale spot lying next to vein $\mathrm{M}_{2}$, in Panama and Guatemala material only, rarely may be extended caudad to straddle the cell (typical form), usually lying entirely in front of cell (? variety cacozelus); pale spots in apices of cells $\mathrm{M}_{1}$ and $\mathrm{M}_{2}$ far removed from wing margin; apices of veins $\mathrm{M}_{1}, \mathrm{M}_{2}$ and $\mathrm{M}_{3+4}$ each with a pale spot at wing margin; pale spot in cell $\mathrm{M}_{4}$ with broadened extension bordering posterior margin of vein $\mathrm{M}_{3+4}$; three pale spots in anal cell, one at base and two in distal portion; small pale spots present lying behind medial fork and in front of mediocubital fork. Macrotrichia numerous but not dense, extending to base of cell $\mathrm{M}_{2}$ and over distal half of anal cell; costa extending to $0.61(0.59-0.62, \mathrm{n}=12)$ of distance to wing tip. Halter pale.

Abdomen.-Dark brown, proximal terga pale grayish. Spermathecae two, slightly pyriform, subequal, each measuring 0.043 by $0.034 \mathrm{~mm}$., the bases of the ducts not sclerotized.

Male Genitalia. - Ninth sternum without caudomedian excavation; ninth tergum short and tapered with distinct caudomedian notch and very slender apicolateral processes. Basistyle with ventral root very slender, pointed, dorsal root stouter; dististyle slender with hooked, pointed tip. Aedeagus with basal arch rounded, extending to about a third of total length of aedeagus; posterior portion tapered to a relatively stout, truncated tip. Parameres each with large, lat- 
erally directed, basal knob; base of stem not greatly swollen, stem gradually tapered to very slender, filiform, simple, twisted tip.

Distribution: Mexico; Guatemala; Honduras (Lancetilla); Nicaragua (Villa Somoza); Panama.

Panama Records:

Bocas del Toro Province: Almirante.

Canal Zone: Fort Davis, Fort Sherman, Mindi Dairy, Mojinga Swamp.

Coclé Province: El Valle, Río Hato (type locality of hertigi).

Los Santos Province: La Palma, Las Tablas.

Panamá Province: Cerro Campana, Isla Taboga.

Discussion: Except for the difference in the extent of the pale spot in front of (cacozelus) or straddling (poikilonotus) the base of vein $\mathrm{M}_{2}$, cacozelus seems to be identical with poikilonotus. A few specimens with poikilonotus wing markings are present in the series from Almirante as well as the series studied from Yepocapa, Guatemala, along with the much commoner and more widespread cacozelus type. At the time we described hertigi we were not sufficiently familiar with the Mexican species, but we now are convinced of the synonymy. The great reduction in the mandibles, as well as the wing pattern and antennal and palpal structure, ally poikilonotus with panamensis Barbosa, which, however, can readily be recognized by the pale spots straddling veins $\mathrm{M}_{1}$ and $\mathrm{M}_{2}$ and by the very unequal, retort-shaped spermathecae.

\section{Culicoides jamaicensis Edwards}

\section{Figure 34}

Culicoides loughnani var. jamaicensis Edwards, 1922, Bull. Ent. Res., vol. 13, p. 165 (female; Jamaica; fig. wing).- - Hoffman, 1925, Amer. Journ. Hyg., vol. 5, p. 283 (Canal Zone).-Barbosa, 1947, Anais Soc. Biol. Pernambuco, vol. 7, p. 21 (Jamaica, St. Croix, Panama; fig. male genitalia).-Macfie, 1948, Ann. Trop. Med. Parasit., vol. 42, p. 80 (Chiapas, Mexico; female descriptive notes).-Fox, 1949, Bull. Brooklyn Ent. Soc., vol. 44, p. 32 (Puerto Rico; fig. female palpus, mesonotum, male genitalia).

Culicoides jamaicensis, Wirth, 1955, Proc. Ent. Soc. Washington, vol. 57, p. 112 (Guatemala; fig. male genitalia).

Female: Length of wing $0.97(0.89-1.06, \mathrm{n}=16) \mathrm{mm}$.

Head.-Eyes narrowly separated, bare. Antenna with flagellar segments in proportion of $16: 10: 11: 12: 12: 13: 14: 14: 20: 21: 21: 22: 30$, antennal ratio $1.21(1.12-1.32, \mathrm{n}=8)$; distal sensory tufts present on segments III to XV. Palpal segments in proportion of $10: 20: 37: 10: 10$, third segment very large and swollen to apex, $2.2(1.9-2.3, \mathrm{n}=16)$ times as long as greatest breadth, with a very large, deep, sensory pit 

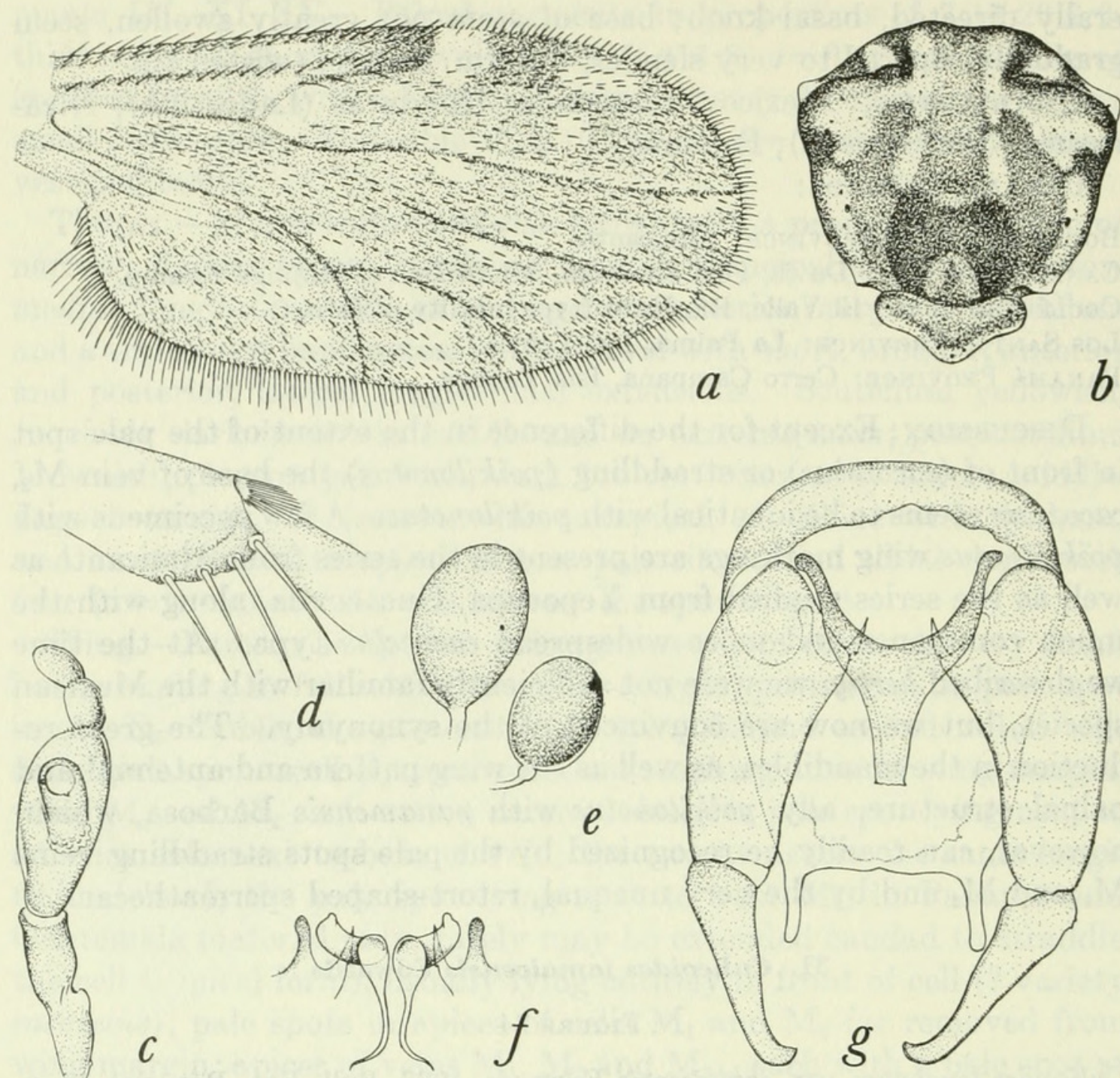

FIGURE 34.-Culicoides jamaicensis Edwards. $a-e$, Female: $a$, wing; $b$, thoracic pattern; $c$, palpus; $d$, tibial comb; $e$, spermathecae. $f, g$, Male: $f$, parameres; $g$, genitalia, parameres removed.

opening by a small distal pore. Mandible with $15(14-17, \mathrm{n}=9)$ teeth. Thorax.-Mesonotum with pattern as figured, dark pruinose gray, with three broad, dark brown bands, the median band extending from anterior margin to prescutellar depression and the lateral bands from behind humeral pits to ends of scutellum; these three bands bordered by conspicuous, narrow, whitish pruinose lines. Scutellum dark brown in middle, gray on sides; postscutellum and pleuron dark brown. Legs dark brown; femora pale at bases, femora with subapical and tibiae with subbasal narrow pale rings; hind tibial comb with four $(n=15)$ spines, the second from the spur very slightly the longest.

Wing.-Pattern as figured, pale spot over r-m crossvein small but broadly reaching costal margin; cell $R_{5}$ with four pale spots arranged in a rhomboid, the proximal and distal pairs each sometimes fused into oblique, double spots, the anterior portions of which lie at anterior 
wing margin; small, double pale spots present straddling base of vein $\mathrm{M}_{1}$ and middle of vein $\mathrm{M}_{2}$; one pale spot in apex of cell $\mathrm{M}_{1}$ and one in cell $\mathrm{M}_{2}$, well removed from wing margin; pale spot in cell $\mathrm{M}_{4}$ broadest along posterior margin of vein $\mathrm{M}_{3+4}$; two pale spots in apex and one at base of anal cell; pale spot at wing base and one straddling middle of stem of mediocubitus; pale spots at wing margin at apices of veins $\mathrm{M}_{1}, \mathrm{M}_{2}$ and $\mathrm{M}_{3+4}$. Macrotrichia very dense, covering entire wing; costa extending to $0.57(0.54-0.59, \mathrm{n}=16)$ of distance to wing tip. Halter pale.

Abdomen.-Brownish black. Spermathecae two, oval, unequal, measuring 0.046 by 0.037 and 0.037 by $0.031 \mathrm{~mm}$., the bases of the ducts not sclerotized.

Male Genitalia: Ninth sternum with scarcely perceptible caudomedian excavation; ninth tergum tapered, with extremely long and slender apicolateral processes. Basistyle with ventral and dorsal roots slender and simple, the ventral roots pointed apically; dististyle short and tapered to slender, hooked apex. Aedeagus with round basal arch extending nearly to half of total length, basal arms stout and curved; distal portion stout and tapered to rather broad, truncated apex. Parameres small, each with stout lateral arms at base, stem swollen bulbously at base, tapered very rapidly to very slender, simple tip abruptly bent ventrolaterad.

Distribution: Jamaica, Puerto Rico, Virgin Islands, Trinidad (Port Delgada), Venezuela, Panama, Honduras (Lago Yojoa, Tela), Nicaragua (Tela, Villa Somoza), Guatemala, Mexico, United States (Kerrville, Texas).

PanAMA RECORDS:

Bocas del Toro Province: Almirante.

Canal Zone: Ancón, Gamboa, Loma Boracho, Mojinga Swamp.

Chiriquí Province: Chirú.

Coclé Province: Penonomé, Puerto Farallón, Río Hato, Tranquilla.

Darién Province: Garachiné, Punta Patiño.

Herrera Province: Puerta Chitré.

Los Santos Province: Guararé, La Palma, Pan de Azucar, San José.

Panamá Province: Camarón, Chepo, El Coco, La Jolla, Río Las Lajas, Isla Toboga, Tocumen.

Veraguas Province: Rio Santa María, San Francisco.

Discussion: This species is widely distributed around the Caribbean from Texas to Venezuela and Trinidad. It was long called a variety of loughnani Edwards from Jamaica (from whence both species were described at the same time) and Florida (Foote and Pratt, 1954), but no loughnani specimens, with their extensive pale wing markings and long male apicolateral processes and parameres, have been seen from the Central American jamaicensis localities, and we believe there are two distinct species. Culicoides bakeri Vargas from Mexico 
is also closely related to jamaicensis, but bakeri has the pale spot at the end of vein $\mathrm{M}_{1}$ continued proximad as a pale border to the vein to the pale spot straddling this vein near its base, there is no pale spot at the apex of vein $\mathrm{M}_{3+4}$ and the male parameres are spinose at the tips.

\section{The iriartei group}

This group consists of small to medium-sized species with moderately hairy wings; wing with pale spot present straddling middle of vein $\mathrm{M}_{2}$ and usually with one or two linear pale spots lying in front of vein $\mathrm{M}_{1}$ toward its base; female antenna with sensoria present on segments III, VII-X; four spines in tibial comb; two spermathecae; male genitalia with ventral root of the basistyle long and curved and foot-shaped with a prominent basal hook, parameres with large basal knob, the base not directed laterad, the apex with fringing spines; aedeagus with bladelike projections on the caudolateral margin of the arch.

Panama species: Two: evansi, new species, and iriartei Fox.

$(C$. blantoni Vargas and Wirth from Mexico and C. baueri Hoffman from the United States also belong to this group.)

\section{Culicoides evansi, new species}

Figure 35

Female: Length of wing $1.17(1.12-1.23, \mathrm{n}=10) \mathrm{mm}$.

Head.-Eyes narrowly separated, bare. Antenna with flagellar segments in proportion of $18: 13: 13: 14: 15: 14: 14: 15: 20: 20: 22: 24: 38$, antennal ratio $1.02(0.90-1.09, \mathrm{n}=3)$; distal sensory tufts present on segments III, VII-X. Palpal segments in proportion of $10: 17: 31$ : $10: 10$, third segment greatly swollen, $2.0(1.8-2.3, \mathrm{n}=10)$ times as long as greatest breadth, with a very broad, moderately deep, sensory pit. Mandible with $13(12-14, \mathrm{n}=8)$ teeth.

Thorax.-Mesonotum rich chocolate brown, with prominent pattern of pruinose gray patches, consisting mainly of a submedian anterior pair of elongate spots, a pair of similar shape and position in flattened prescutellar area, and several small spots over humeral pits and along lateral margins. Scutellum dark brown in middle, pruinose gray on sides; postscutellum and pleuron dark brown. Legs dark brown; fore and mid femora with subapical, all tibiae with subbasal, and hind tibia with apical, narrow pale rings; hind tibial comb with four $(n=10)$ spines, the one nearest the spur longest.

Wing.-Pattern as figured, pale spot over $r-m$ crossvein narrow but broadening as it reaches costal margin; cell $R_{5}$ with two double, transverse pale spots, both broadly meeting anterior wing margin, each of these sometimes separated into two distinct small rounded 

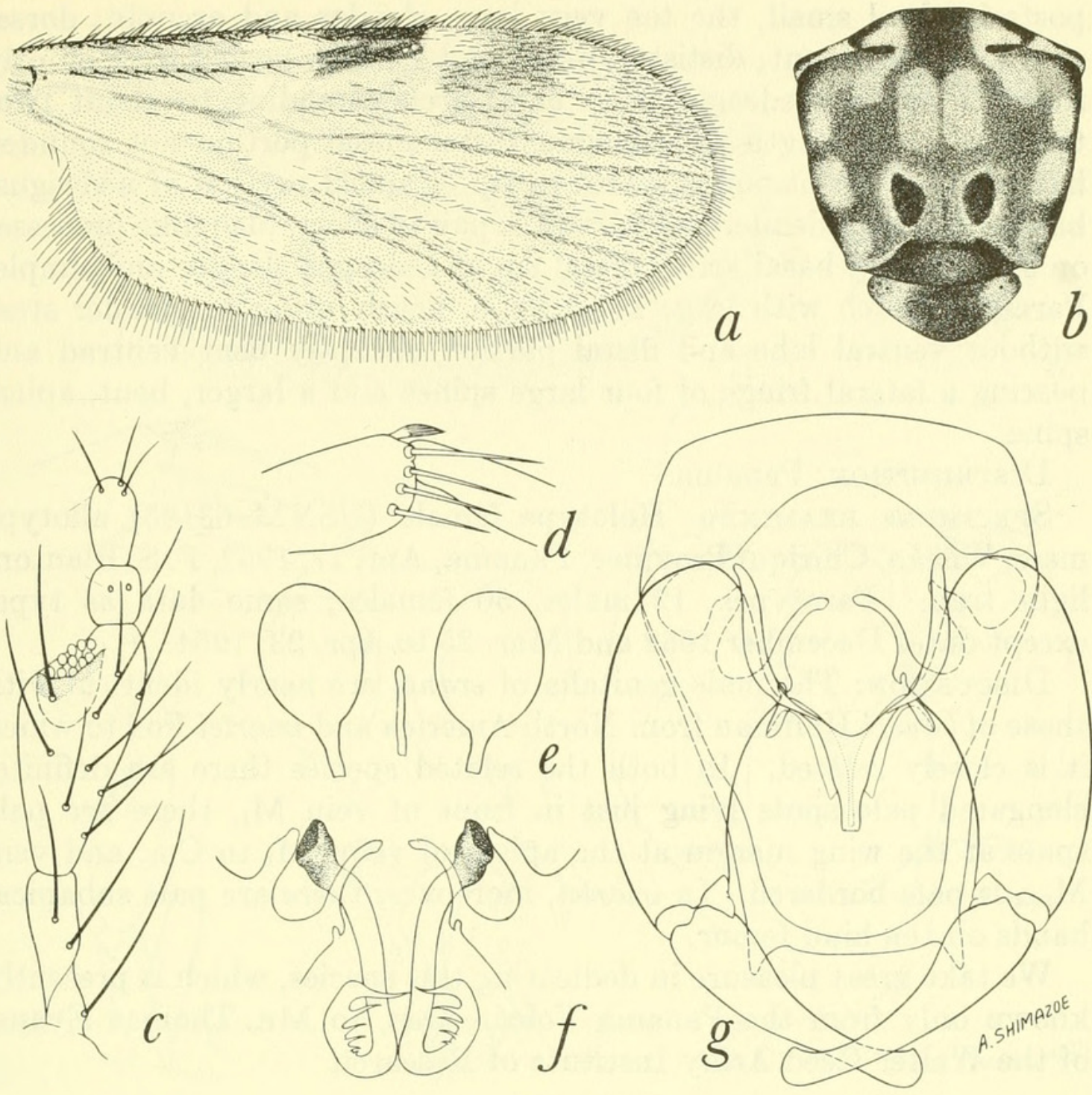

Figure 35--Culicoides evansi, new species. $a-e$, Female: $a$, wing; $b$, thoracic pattern; $c$, palpus; $d$, tibial comb; $e$, spermathecae. $f, g$, Male: $f$, parameres; $g$, genitalia, parameres removed.

spots; no pale spots or areas straddling or lying next to vein $\mathrm{M}_{1}$; cell $\mathrm{M}_{1}$ with a small round pale spot lying far from wing margin; a pale spot straddling middle of vein $\mathrm{M}_{2}$, a small pale spot lying near wing margin in apex of cell $\mathrm{M}_{2}$ and another in cell $\mathrm{M}_{4}$; only one pale spot in apex of anal cell and a small pale spot lying behind medial fork. Macrotrichia dense and very long over entire wing; costa extending to $0.57(0.55-0.58, \mathrm{n}=10)$ of distance to wing tip. Halter pale.

Abdomen.-Blackish brown. Spermathecae two, subequal, pyriform, measuring 0.071 by $0.047 \mathrm{~mm}$. and 0.072 by $0.041 \mathrm{~mm}$., the bases of the ducts sclerotized a considerable distance.

Male genitalia: Ninth sternum with a broad, deep, caudomedian excavation; ninth tergum long and tapering with small apicolateral processes. Basistyle with ventral root foot-shaped, very slender, the 
posterior heel small, the toe very long, slender and arcuate; dorsal root relatively stout; dististyle stout and slightly curved with bluntly rounded apex. Aedeagus with basal arch extending to about twothirds of total length of aedeagus, distal mesal portion not rounded but with cleft continuing nearly to tip of apical portion of aedeagus; basal arms very slender and curved, a pair of short, bladelike processes on shoulders of basal arms; distal tip of aedeagus slender and simple. Parameres each with large basal knob, nearly straight, slender stem without ventral lobe and distal portion abruptly bent ventrad and earing a lateral fringe of four large spines and a larger, bent, apical spine.

Distribution: Panama.

Specimens examined: Holotype female (USNM 63165), allotype male, Volcán, Chiriquí Province, Panama, Apr. 17, 1952, F. S. Blanton, light trap. Paratypes, 12 males, 50 females; same data as type, except dates December 1952 and Mar. 25 to Apr. 23, 1954.

Discussion: The male genitalia of evansi are nearly identical with those of baueri Hoffman from North America and iriartei Fox to which it is closely related. In both the related species there are definite, elongated pale spots lying just in front of vein $\mathrm{M}_{1}$, there are pale spots at the wing margin at the apices of veins $\mathrm{M}_{1}$ to $\mathrm{Cu}_{1}$, and vein $\mathrm{M}_{3+4}$ is pale bordered. In iriartei, moreover, there are pale subapical bands on the hind femur.

We take great pleasure in dedicating this species, which is presently known only from the Panama Volcán area, to Mr. Thomas Evans, of the Walter Reed Army Institute of Research.

\section{Culicoides iriartei Fox}

Figure 36

Culicoides iriartei Fox, 1952, Ann. Ent. Soc. Amer., vol. 45, p. 368 (female; La Salina, Venezuela; fig. wing, palpus, spermathecae, tibial comb); 1955, Journ. Agr. Univ. Puerto Rico, vol. 39, p. 243 (synonym, vargasi Wirth and Blanton).

Culicoides baueri Ortiz and Mirsa (misident,, not Hoffman), 1952, Rev. Sanid. Asist. Soc., vol. 16, p. 599 (male, female; Ocumare, Venezuela; fig. palpus, spermathecae, wing, male genitalia).

Culicoides vargasi Wirth and Blanton, 1953, Journ. Washington Acad. Sci., vol. 43, p. 74 (male, female; Panama; fig. wing, mesonotum, palpus, male genitalia).

Female: Length $0.93(0.89-0.92, \mathrm{n}=10) \mathrm{mm}$.

Head.-Eyes nearly contiguous, bare. Antenna with flagellar segments in proportion of $15: 12: 12: 12: 12: 12: 12: 12: 20: 22: 25: 28: 36$, antennal ratio $1.42(1.36-1.46, \mathrm{n}=7)$; distal sensory tufts present on segments III, vII-X. Palpal segments in proportion of $8: 15: 25: 9: 11$, third segment swollen, $2.0(1.9-2.2, \mathrm{n}=9)$ times as long as greatest 


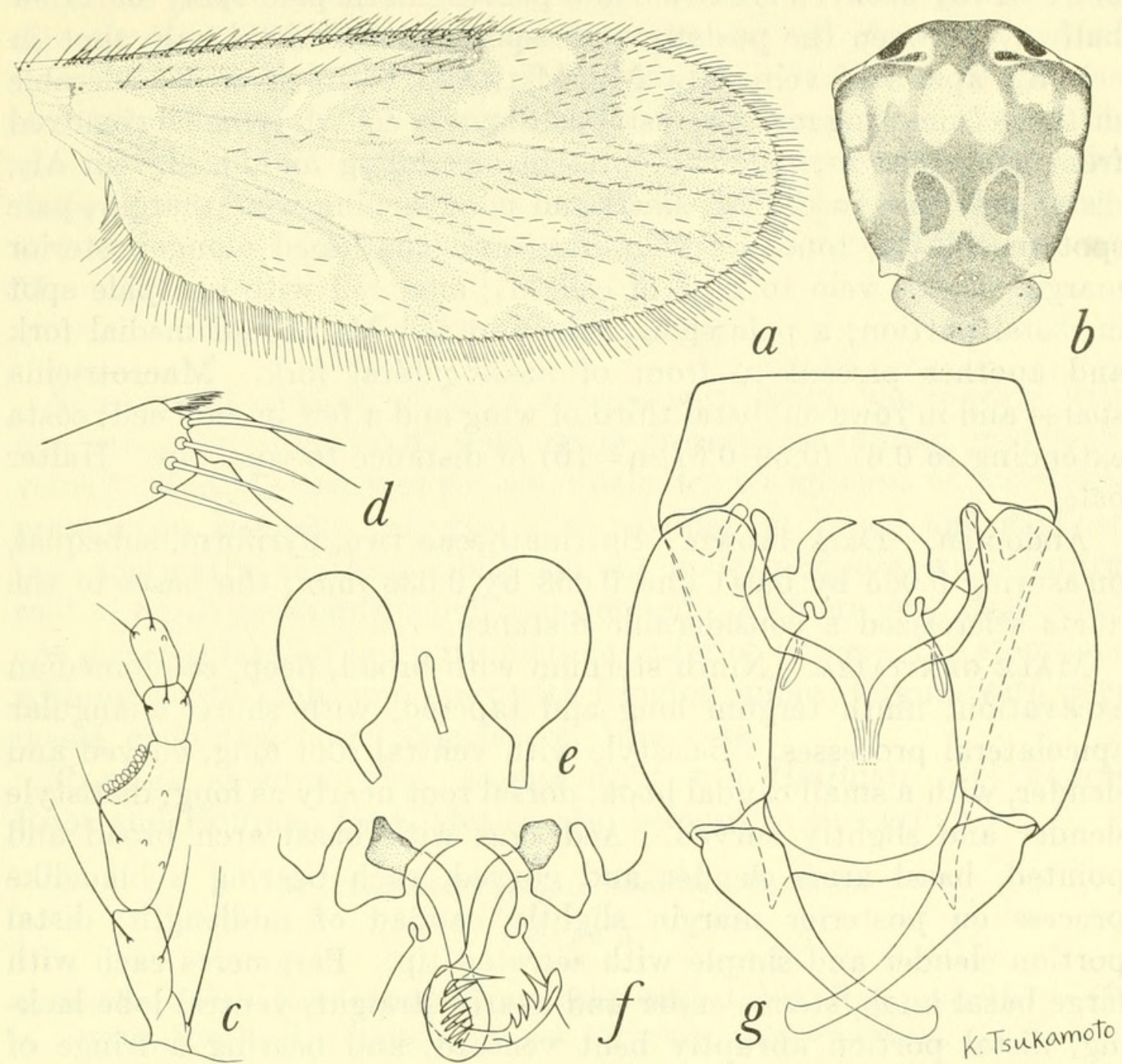

FigURE 36.-Culicoides iriartei Fox. $a-e$, Female: $a$, wing; $b$, thoracic pattern; $c$, palpus; $d$, tibial comb; $e$, spermathecae. $f, g$, Male: $f$, parameres; $g$, genitalia, parameres removed.

breadth, with a broad, shallow sensory pit. Mandible with 11 (11-12, $\mathrm{n}=9$ ) teeth.

Thorax.-Mesonotum dark brown, with prominent pattern of large pruinose gray patches as figured, including a submedian anterior pair of large oval spots and several pairs of spots along lateral margins. Scutellum gray, brown in middle. Postscutellum and pleuron dark brown. Legs dark brown; femora with subapical, tibiae with basal and hind tibia with apical narrow pale rings; hind tibial comb with four $(n=8)$ spines, the one nearest the spur longest.

Wing.-Pattern as figured, second radial cell in a very dark spot; pale spot over crossvein $r-m$ broadly continued to costal margin; cell $\mathrm{R}_{5}$ with two, oblique to transverse, double spots reaching anterior wing margin, one at apex of second radial cell, the other subapical; two small, elongate pale spots in cell $R_{5}$ lying adjacent to vein $M_{1}$, 
one halfway between crossvein and poststigmatic pale spot, the other halfway between the poststigmatic spot and the distal pale spot in cell $\mathrm{R}_{5}$; apices of veins $\mathrm{M}_{1}, \mathrm{M}_{2}, \mathrm{M}_{3+4}$ and $\mathrm{Cu}_{1}$ pale a considerable distance from wing margin; distal pale spot in cell $\mathrm{M}_{1}$ lying far removed from wing margin; pale spot present straddling middle of vein $\mathrm{M}_{2}$; distal pale spot in cell $\mathrm{M}_{2}$ small and not reaching wing margin; pale spot in cell $\mathrm{M}_{4}$ touching vein $\mathrm{M}_{3+4}$ and continued along posterior margin of this vein to base of cell $\mathrm{M}_{4}$; anal cell with one pale spot in distal portion; a pale spot present in cell $\mathrm{M}_{2}$ behind medial fork and another present in front of mediocubital fork. Macrotrichia sparse and in rows on distal third of wing and a few in anal cell; costa extending to $0.61(0.59-0.61, \mathrm{n}=10)$ of distance to wing tip. Halter pale.

Abdomen.-Dark brown. Spermathecae two, pyriform, subequal, measuring 0.065 by 0.041 and 0.058 by $0.036 \mathrm{~mm}$., the bases of the ducts sclerotized a considerable distance.

Male genitalia. Ninth sternum with broad, deep, caudomedian excavation; ninth tergum long and tapered, with short, triangular apicolateral processes. Basistyle with ventral root long, curved and slender, with a small caudal hook, dorsal root nearly as long; dististyle slender and slightly curved. Aedeagus with basal arch broad and pointed, basal arms slender and curved, each bearing a bladelike process on posterior margin slightly caudad of midlength; distal portion slender and simple with serrated tip. Parameres each with large basal knob, stem slender and nearly straight, ventral lobe lacking, distal portion abruptly bent ventrad, and bearing a fringe of 4-6 sharp spines and a strong, bent distal spine.

Distribution. Venezuela; Honduras (Lancetilla); Panama.

PANAMA RECORDS:

Bocas del Toro Province: Almirante.

CANal Zone: Fort San Lorenzo, Fort Sherman, Loma Boracho, Madden Dam, Mojinga Swamp.

Chiriquí Province: Concepción.

Coclé Province: Antón, Aguadulce, Coclé, El Valle, Penonomé, Pocrí, Puerto Farallon, Río Hato.

Colón Province: Espino, Piña.

Darién Province: El Real, Garachiné.

Herrera Province: Ocú, Pesé, Puerto Chitré.

Los Santos Province: Guararé, La Palma, Las Cruces, Las Lajas, Las-Tablas (type locality of vargasi), Los Santos, Macaracas, Puerto Mensabe, Quemado, San José.

Panamá Province: Bayano, Naranjal.

Veraguas Province: Río Santa María, Santiago.

Discussion: $C$. iriartei is closely related to $C$. baueri Hoffman from the United States, C. blantoni Vargas and Wirth from Mexico, and $C$. evansi, new species, from Panama. C.baueri differs in having 
only one pale line bordering the anterior side of vein $\mathrm{M}_{1}$ and lying directly behind the poststigmatic pale spot in cell $R_{5}$, and the hind femora and tibiae lack the distal pale bands. The female of blantoni is nearly identical with iriarte $i$ but the male paramere has a long ventral pouch. $C$. evansi has male genitalia almost identical with those of iriartei, but is a much larger species (wing $1.17 \mathrm{~mm}$. ong) and there are no pale spots lying adjacent to the anterior side of vein $\mathrm{M}_{1}$.

\section{The scopus group}

This group consists of large species with hairy wing; wing with $r-m$ crossvein infuscated, pale spots present straddling middle of veins $M_{1}$ and $M_{2}$, apices of veins not pale; female antenna with sensoria present on segments III, viII, $\mathrm{x}-\mathrm{xv}$; palpal pit broad and shallow; two spermathecae; four tibial spines; male genitalia with ventral root of basistyle simple, small and pointed, paramere with basal knob not directed laterad but with distinct anterior process, the stem long without ventral lobe and apex with fringing spines; tergum with deep mesal cleft and large apicolateral processes.

Panama species: One: scopus Root and Hoffman. (C. dampfi Root and Hoffman from Mexico also belongs to this group.)

\section{Culicoides scopus Root and Hoffman}

FIGURE 37

Culicoides scopus Root and Hoffman, 1937, Amer. Journ. Hyg., vol. 25, p. 170 (male, female; San Jacinto, Mexico; fig. wing, male genitalia).

Female: Length of wing $1.34(1.15-1.78, \mathrm{n}=12) \mathrm{mm}$.

Head.-Eyes narrowly separated, bare. Antenna with flagellar segments in proportion of $17: 12: 13: 13: 13: 13: 14: 14: 30: 30: 32: 32: 50$, antennal ratio $1.65(1.57-1.76, \mathrm{n}=3)$; distal sensory tufts present on segments III, VIII, $\mathrm{X}-\mathrm{Xv}$. Palpal segments in proportion of 10:25: $31: 10: 12$, third segment swollen toward apex, $2.1 \quad(1.7-2.5, \mathrm{n}=9)$ times as long as greatest breadth, with a broad, shallow, sensory pit. Mandible with $15(14-16, \mathrm{n}=9)$ teeth.

Thorax.-Mesonotum golden brown pruinose, without prominent pattern. Scutellum, postscutellum and pleuron dark brown. Legs dark brown; knees blackish; fore and mid femora with subapical and all tibiae with subbasal narrow pale rings; hind tibial comb with four $(n=10)$ spines, the one nearest the spur longest.

Wing.-Pattern as figured; large pale area over wing base; $r-m$ crossvein blackish, in the middle of a large round pale spot broadly meeting costal margin and extending past vein $\mathrm{M}_{1+2}$ into cell $\mathrm{M}_{2}$; small round pale spot distal to end of costa at wing margin in cell $R_{5}$, distal pale spot in cell $R_{5}$ transversely rectangular, extending from 

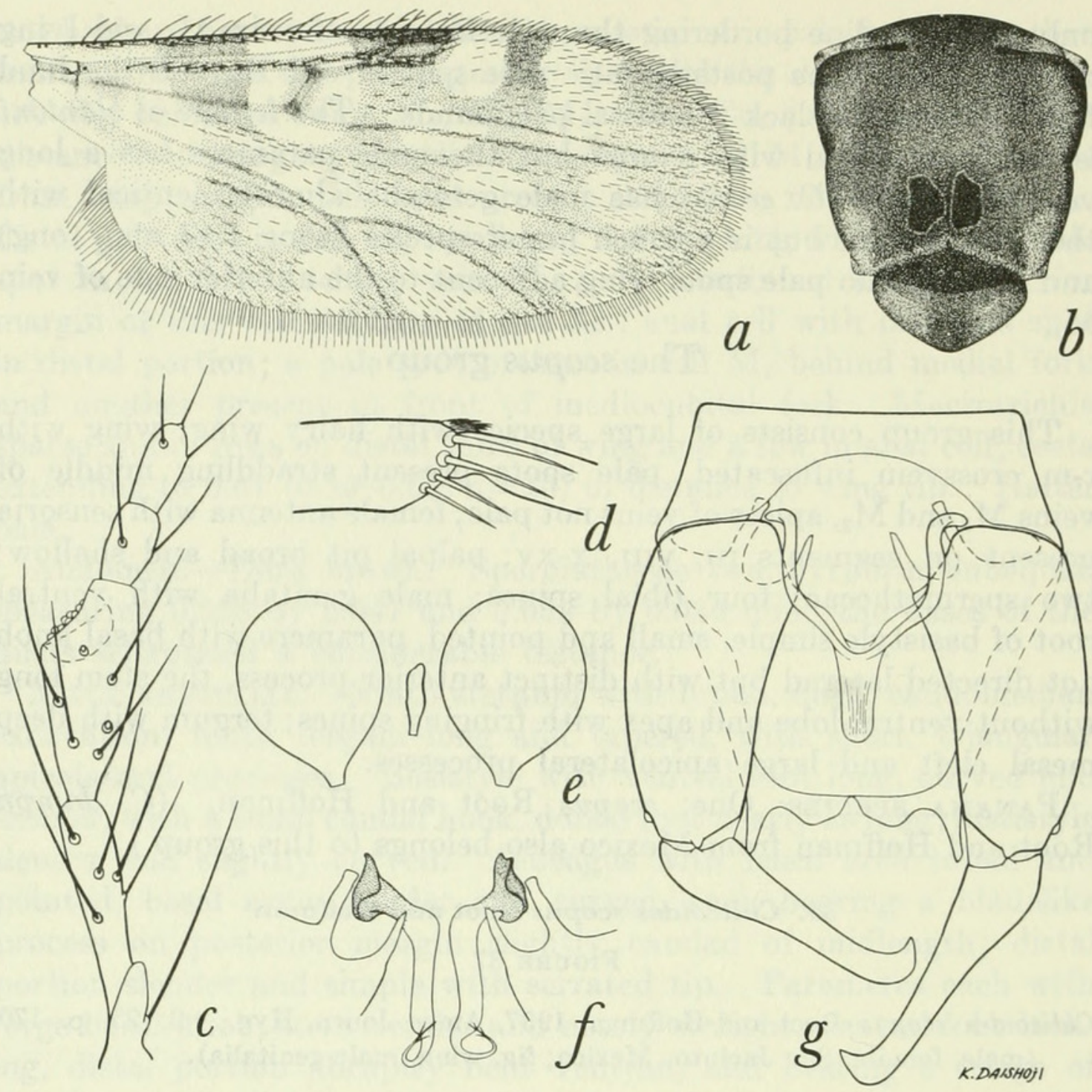

Figure 37.-Culicoides scopus Root and Hoffman. $a-e$, Female: $a$, wing; $b$, thoracic pattern; $c$, palpus; $d$, tibial comb; $e$, spermathecae. $f, g$, Male: $f$, parameres; $g$, genitalia, parameres removed.

wing margin to anterior side of vein $\mathrm{M}_{1}$; pale spot straddling base of vein $\mathrm{M}_{1}$, a larger pale spot straddling middle of vein $\mathrm{M}_{2}$; a round subapical pale spot in cell $\mathrm{M}_{1}$, a spot at wing margin in apices of cells $\mathrm{M}_{2}$ and $\mathrm{M}_{4}$; two round, well separated pale spots in distal part of anal cell and a long pale spot lying in front of mediocubital fork. Macrotrichia long, numerous and well distributed, extending to base of wing; costa extending to $0.58(0.51-.062, \mathrm{n}=12)$ of distance to wing tip. Halter pale.

Abdomen.-Dark brown. Spermathecae two, subequal, pyriform, measuring 0.053 by $0.038 \mathrm{~mm}$. and 0.050 by $0.041 \mathrm{~mm}$., the bases of the ducts sclerotized a very short distance.

Male genitalia: Ninth sternum with a broad, relatively deep, caudomedian excavation; ninth tergum long and tapered, with very large, triangular, apicolateral processes and distinct caudomedian 
notch. Basistyle with ventral and dorsal roots subequal, slender, simple; dististyle slender, sinuate with distinctly hooked apex. Aedeagus with rounded basal arch extending to about half of total length of aedeagus, the basal arms distinctly curved; distal portion simple, slender, tapered to rounded apex. Paramere with large basal knob, base of stem slender, abruptly bent, then swollen on sinuate midportion, no ventral lobe, apex slender and bent ventromesad with a few subapical, very fine hairs.

Distribution: Mexico; Panama.

PANAMA RECORDS:

Bocas del Toro Province: Almirante.

Chiriquí Province: Volcán.

Coclé Province: Hermita.

Discussion: This species has no close Panama relatives, but belongs to a distinct Central American group along with the Mexican species dampf Root and Hoffman, both species having a similar wing pattern with $\mathrm{r}-\mathrm{m}$ crossvein darkened and pale spots straddling both veins $\mathrm{M}_{1}$ and $\mathrm{M}_{2}$, and similar male genitalia. C. dampfi has much more extensive wing spots than scopus and the stems of the male parameres are straight.

\section{The limai group}

This group consists of small species with wing pattern of large pale spots filling the cells, pale spots present straddling veins $M_{1}$ and $M_{2}$ in some species; female antenna with sensoria present on segments III, vII-X (present on XI-XIV only in the doubtful species carpenteri); four tibial spines; two spermathecae; male genitalia with ventral root of the basistyle foot-shaped; paramere with simple basal knob, apex fringed, stem straight, ventral lobe present or absent; aedeagus $Y$ shaped with simple tip; ninth tergum with narrow apex and short apicolateral processes.

Panama species: Four, possibly six: camposi Ortiz and Leon, galindoi Wirth and Blanton, limai Barretto, and tenuilobus, new species. Two species, carpenteri Wirth and Blanton and magnipalpis Wirth and Blanton, are provisionally referred here but their group position is uncertain.

\section{Culicoides galindoi Wirth and Blanton}

Figure 38

Culicoides galindoi Wirth and Blanton, 1953, Journ. Washington Acad. Sci., vol. 43 , p. 73 (male, female; Panama; fig. wing, mesonotum, palpus, spermathecae, male genitalia).

Female: Length of wing $0.83(0.73-0.89, \mathrm{n}=15) \mathrm{mm}$.

Head.-Eyes contiguous, bare. Antenna with flagellar segments in proportion of $17: 12: 14: 15: 15: 14: 14: 15: 18: 20: 22: 20: 30$, antennal ratio 

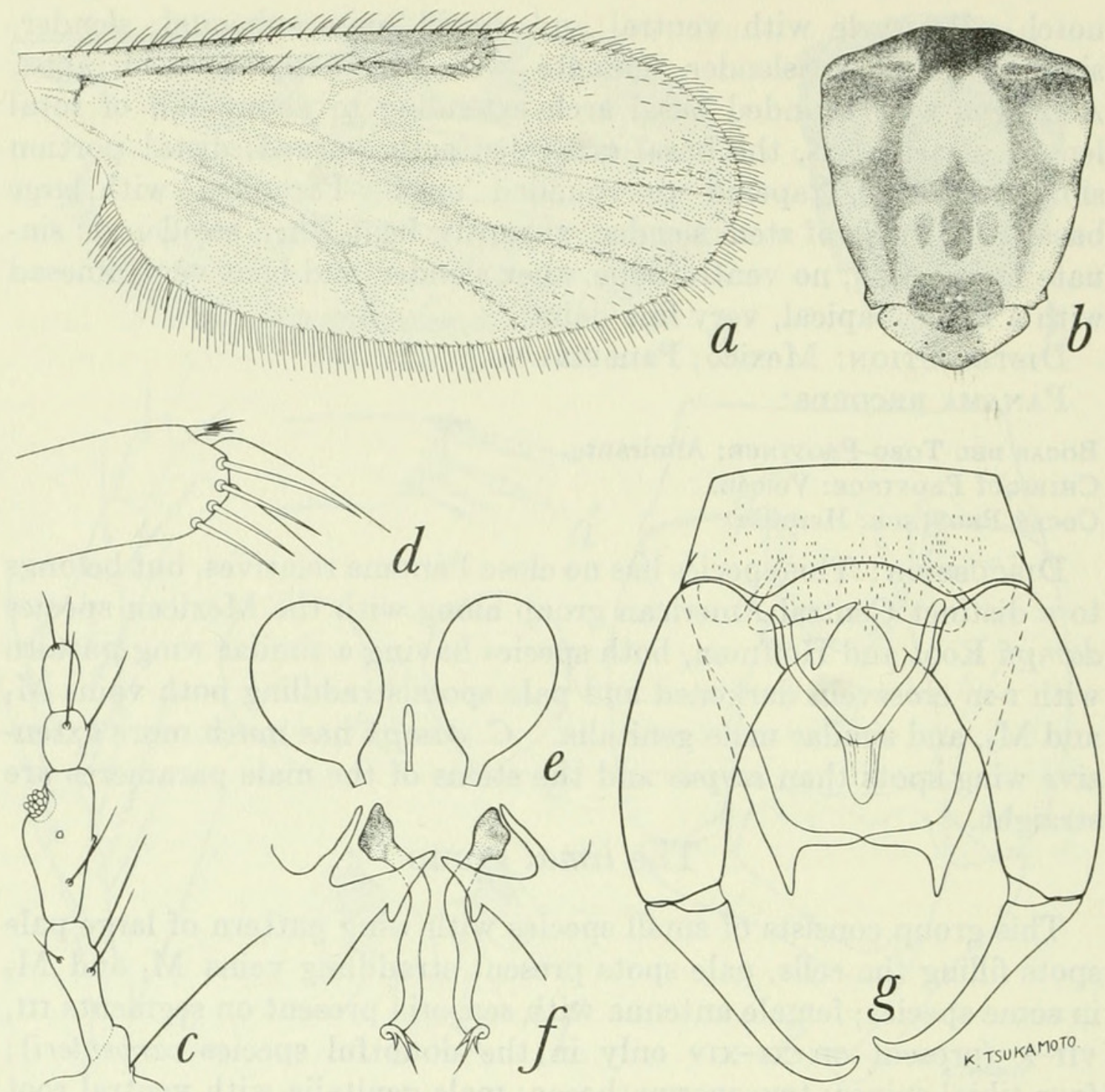

Figure 38.-Culicoides galindoi Wirth and Blanton. $a-e$, Female: $a$, wing; $b$, thoracic pattern; $c$, palpus; $d$, tibial comb; $e$, spermathecae. $f, g$, Male: $f$, parameres; $g$, genitalia, parameres removed.

$0.95(0.91-1.00, \mathrm{n}=10)$; distal sensory tufts present on segments III, viI-X. Palpal segments in proportion of $8: 18: 20: 9: 10$, third segment slightly swollen, $2.1(2.0-2.3, \mathrm{n}=14)$ times as long as greatest breadth, with a small, shallow, sensory pit. Mandible with $14(12-15, \mathrm{n}=14)$ teeth.

Thorax.-Mesonotum dark brown with extensive, pruinose, yellowish patches as figured, principally two elongate submedian anterior marks, two pairs of lateral spots and extensive pale prescutellar area; postscutellum and pleuron dark brown, pleuron yellowish on dorsal half. Legs dark brown, fore and mid femora with subapical and all tibiae with subbasal pale rings; hind tibial comb with four $(\mathrm{n}=14)$ spines, the one nearest the spur longest.

Wing.-Pattern as figured, ends of cells $R_{5}, M_{1}, M_{2}$ and anal cell with large pale areas extending broadly to wing margin, ends of the 
branches of media and cubitus dark, two pale spots in cell $\mathrm{M}_{2}$ beyond the pale spot in front of mediocubital fork, the proximal spot in cell $\mathrm{M}_{1}$ completely filling the space between veins $\mathrm{M}_{1}$ and $\mathrm{M}_{2}$ but usually not appearing to straddle these veins, distal pale spot in anal cell consisting of two broadly fused spots. Macrotrichia sparse in apices of cells $\mathrm{R}_{5}, \mathrm{M}_{1}$ and $\mathrm{M}_{2}$; costa extending to 0.62 of distance to wing tip. Halter pale.

Abdomen.-Dull brownish black. Spermathecae two, pyriform, subequal, measuring 0.048 by $0.032 \mathrm{~mm}$. and 0.043 by $0.029 \mathrm{~mm}$.

Male genttalia: Ninth sternum with shallow caudomedial excavation, the posterior membrane spiculate; ninth tergum short and strongly tapered, with well developed, triangular, apicolateral processes. Basistyle with dorsal and ventral roots relatively short, the ventral root foot-shaped with long heel and sharp-pointed toe; dististyle with slender, bent apex. Aedeagus with broad, rounded basal arch, the basal arms slender and curved; distal stem short and rounded apically. Parameres each with basal knob, stem abruptly bent near base, slender and sinuate distad, without ventral lobe, apex sharp with two or three lateral barbs.

Distribution: Panama.

PANAMA RECORDS:

Bocas del Toro Province: Almirante.

Canal Zone: Fort Clayton, Fort Davis, Fort San Lorenzo, Huile Sia Clara(?),

Loma Boracho, Madden Dam, Mojinga Swamp (type locality).

Chiriquí Province: Rio Tabasará, Tortugas.

Coclé Province: Espiño.

Colón Province: Piña.

Darien Province: Jaqué.

Panamá Province: Camarón, Cerro Campana, Chepo, El Coco, La Jolla, Pacora, Pedregal, Isla Taboga, Tocumen, Viqué Cove.

Veraguas Province: Río Santa María, Sapotilla.

Discussion: Typical specimens of galindoi from Mojinga Swamp, Fort Sherman, and Loma Boracho have the pale distal spot in cell $\mathrm{R}_{5}$ rounded distally, leaving a small dark area in apex of cell as figured in our 1953 paper. More common in Panama, however, is the form having the apex of cell $R_{5}$ entirely pale. Structurally, typical galindoi has the costal ratio longer (0.55), the antennal ratio greater (1.08), resembling limai, and the spermathecae more nearly equal in size. In the atypical galindoi (as well as in tenuilobus, new species) the antennal segments gradually increase in length to the seventh segment, then segment eight is shorter and the segments increase in length again, while in the typical specimens the segments gradually increase in length up to the tenth segment.

Culicoides limai is very closely related, having a wing pattern like the atypical specimens discussed in the paragraph above, but 
limai can be readily distinguished by its smaller size, the subapical pale band on the hind femur and pale apex of the hind tibia, the much broader third palpal segment, and the presence of a small ventral lobe on the male parameres.

\section{Culicoides limai Barretto}

Figure 39

Culicoides limai Barretto, 1944, Anais Fac. Med. Univ. São Paulo, vol. 20, p. 99 (male; Est. São Paulo, Brazil; fig. genitalia, antenna, palpus, mesonotum, wing).--Ortiz and Mirsa, 1951, Rev. Sanid. Asist. Soc., vol. 16, p. 597 (male; Venezuela; fig. mesonotal pattern, palpus, spermatheca, wing, male genitalia); 1952 , idem., vol. 17, p. 265 (female; Venezuela; fig. wing, antenna, palpus, spermathecae). Forattini; 1954, Fol. Clin. Biol., vol. 22, p. 224 (male, female; Brazil, Colombia; fig. wing, palpus, eyes, mesonotum, antenna,
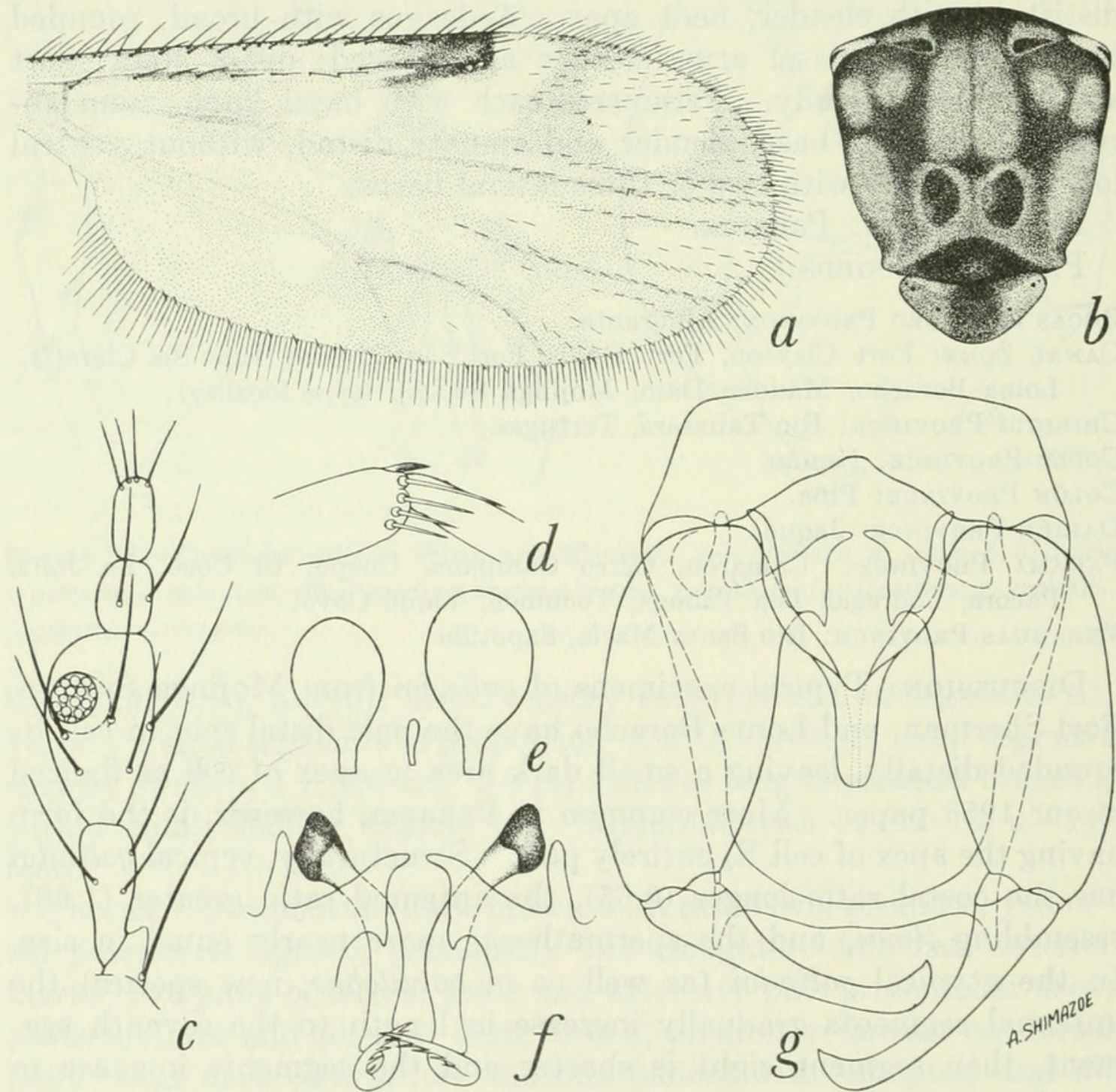

Figure 39.-Culicoides limai Barretto. $a-e$, Female: $a$, wing; $b$, thoracic pattern; $c$, palpus; $d$, tibial comb; e, spermathedae. $f, g$, Male: $f$, parameres; $g$, genitalia, parameres removed. 
male genitalia).-Ortiz and Leon, 1955, Inf. Cient. Nac. Eduador, no. 67, p. 577 (Ecuador).

Female: Length of wing $0.80(0.79-0.82, \mathrm{n}=5) \mathrm{mm}$.

Head.-Eyes nearly continguous, bare. Antenna with flagellar segments in proportion of $15: 10: 11: 12: 13: 13: 13: 13: 17: 18: 19: 20: 32$, antennal ratio 1.06; distal sensory tufts present on segments III, viI-x. Palpal segments in proportion of $8: 15: 20: 6: 7$, third segment considerably swollen up to the apex, $1.8(1.7-1.8, \mathrm{n}=5)$ times as long as greatest breadth, with a moderately broad, shallow sensory pit. Mandible with $13(12-14, \mathrm{n}=5)$ teeth.

Thorax.-Mesonotum dark brown with extensive, pruinose, yellowish patches as figured, principally two elongate submedian anterior marks, two pairs of lateral spots and extensive prescutellar areas. Scutellum narrowly dark brown in middle, yellowish on sides; postscutellum and pleuron dark brown. Legs dark brown, all femora with subapical, all tibiae with subbasal, and hind tibia with broad apical pale rings; hind tibial comb with four $(n=5)$ spines, the one next to the spur longest.

Wing.-Pattern as figured, closely resembling that of galindoi but with the distal pale spot in cell $R_{5}$ shortened and rounded distally, and extending obliquely to the anterior wing margin, not following vein $\mathrm{M}_{1}$ to the wing tip. Macrotrichia sparse on distal fourth of wing; costa extending to 0.63 of distance to wing tip. Halter pale.

Abdomen.-Brownish black; cerci yellowish. Spermathecae two, slightly unequal, pyriform, measuring 0.059 by $0.042 \mathrm{~mm}$. and 0.055 by $0.046 \mathrm{~mm}$.

Male Genitalia: Ninth sternum with shallow caudomedian excavation; ninth tergum tapering, with small, triangular apicolateral processes. Basistyle with ventral root foot-shaped, dorsal root slender; dististyle slender, with bent apex. Aedeagus with rounded basal arch, the basal arms slender and curved, distal stem slender and tapering to bluntly rounded apex, the ventral side appearing channellike. Parameres each with knobbed base, slender, bent stem with distinct ventral lobe, apical portion tapered to fine point with sublateral barbs.

Distribution: Brazil; Ecuador; Honduras (Lancetilla); Panama; Trinidad (Tucker Valley); Venezuela.

PANAMA RECORDS:

Canal Zone: Fort Sherman, Mojinga Swamp.

Panamá Province: Arraiján, Cerro Campana.

Discussion: This widely distributed Neotropical species is rare in Panama. It is readily distinguished from the closely related Panama species, galindoi Wirth and Blanton, by the presence of the 
subapical pale ring on the hind femur, the pale apex of the hind tibia, and the presence of a distinct ventral lobe on the male paramere.

\section{Culicoides tenuilobus, new species}

Figure 40

Female: Length of wing $0.89(0.86-0.92, \mathrm{n}=7) \mathrm{mm}$.

Head.-Eyes contiguous, bare. Antenna with flagellar segments in proportion of $17: 12: 12: 13: 14: 12: 12: 12: 19: 19: 22: 24: 34$, antennal ratio $1.13(1.04-1.19, n=4)$; distal sensory tufts present on segments III, VII-x. Palpal segments in proportion of $8: 13: 27: 8: 7$, third segment greatly swollen, $1.86(1.76-1.93, \mathrm{n}=6)$ times as long as greatest breadth, with a large deep sensory pit opening by a small pore. Mandible with $13(12-13, \mathrm{n}=5)$ teeth.
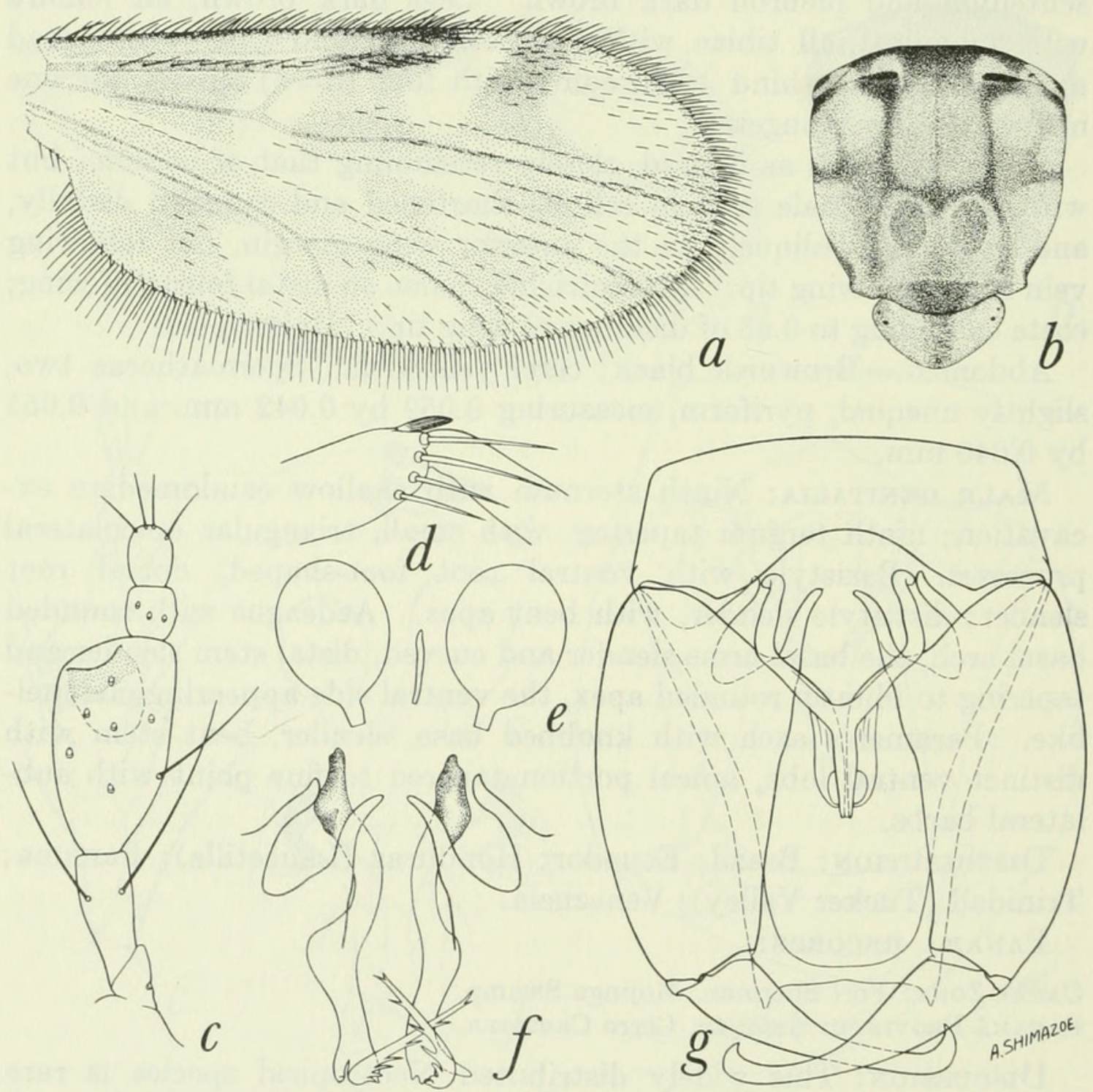

Figure 40.-Culicoides tenuilobus, new species. $a-e$, Female: $a$, wing; $b$, thoracic pattern; $c$, palpus; $d$, tibial comb; $e$, spermathecae. $f, g$, Male: $f$, parameres; $g$, genitalia, parameres removed. 
Thorax.-Mesonotum pruinose grayish brown with the anterior and lateral margins blackish; a moderately prominent pattern of narrow dark brown lines forming an $\mathrm{H}$-shaped mark on the disc from the humeral pits to the sides of the scutellum. Scutellum dark brown in middle, yellowish on sides; postscutellum and pleuron dark brown. Legs dark brown, knee spots blackish; all femora with subapical, tibiae with subbasal and hind tibia with apical narrow pale rings; hind tibia with four $(n=6)$ spines, the two nearest the spur longest, subequal.

Wing.-Pattern as figured; second radial cell in a moderately dark spot; pale spot over $\mathrm{r}-\mathrm{m}$ crossvein continued in full breadth to costal margin; poststigmatic pale spot in cell $R_{5}$ double, the posterior portion slightly larger and located slightly proximad of the anterior portion; distal pale spot in cell $R_{5}$ suboval, broadly meeting anterior wing margin its full length, filling all but extreme caudodistal corner of cell; distal pale spot in cell $\mathrm{M}_{1}$ elongate, broadly meeting wing margin; pale spot present straddling middle of vein $\mathrm{M}_{2}$; pale spots in apices of cells $\mathrm{M}_{2}$ and $\mathrm{M}_{4}$ broadly meeting wing margin, the one in cell $\mathrm{M}_{4}$ broadly rounded, nearly filling apex of cell; one pale spot, which may nearly meet wing margin as a posterior point, in distal portion of anal cell; a small pale spot in basal portion of anal cell; cell $\mathrm{M}_{2}$ without pale spot lying in front of mediocubital fork, but a large pale spot lying behind medial fork and joined broadly to the pale spot over $\mathrm{r}-\mathrm{m}$ crossvein. Macrotrichia sparse on distal half of wing and a few in anal cell; costa extending to $0.62(0.60-0.64)$ of distance to wing tip. Halter dull yellowish.

Abdomen.-Brownish black. Spermathecae two, ovoid, subequal, measuring 0.056 by $0.036 \mathrm{~mm}$., the bases of the ducts sclerotized a short distance.

Male genitalia: Ninth sternum with a broad, moderately shallow, caudomedian excavation; ninth tergum very long and narrow distad, with short apicolateral processes. Basistyle with ventral and dorsal roots subequal, long and slender; dististyle very slender and bent at tip. Aedeagus with basal arch pointed at mesal apex, basal arms strong and curved; distal portion with well sclerotized slender median point flanked by a pair of sclerotized incurve processes nearly as long. Parameres each with large basal knob, stem sinuate and somewhat swollen beyond midlength and bearing a long, slender ventral lobe or process at the subapical bend; distal portion with sharp point and a lateral fringe of fine spines.

Distribution: Panama.

Specimens eXamined: Holotype female (USNM 63166), Almirante, Bocas del Toro Province, Oct. 28, 1952, F. S. Blanton, light trap. Allotype male, same data except dates October-December 1952. 
Paratypes, 6 males, 33 females: 4 males, 31 females, Almirante, October 1952 to March 1953; 1 male, Fort Sherman, Canal Zone, Sept. 28, 1953; 1 male, Mojinga Swamp, Canal Zone, February 1952; 2 females, Piña, Colón Province, Jan. 18, 1954.

Discussion: This species is most closely related to galindoi Wirth and Blanton and limai Barretto, although vein $\mathrm{M}_{2}$ is straddled by a pale spot, as in the species of the copiosus, daedalus, and iriartei groups. The wing markings are closest to those of antefurcatus, new species, which differs however in having only one pale spot in the anal cell, no pale spot in front of the mediocubital fork, and the hind femora with subapical pale rings. The ventral lobe of the male paramere is more extremely developed, into a rodlike process, in tenuilobus than in any species of Culicoides known to us.

\section{Culicoides camposi Ortiz and Leon}

Figure 41

Culicoides camposi Ortiz and Leon, 1955 (January-February), Bol. Inf. Cient. Nac. Ecuador, no. 67, p. 580 (female; Ecuador; fig. wing, mesonotum, palpus, antenna).

Culicoides fairchildi Wirth and Blanton, 1955 (October), Bull. Brooklyn Ent. Soc., vol. 50, p. 103 (male, female; Panama; fig. wing, palpus, spermathecae; male genitalia). New synonymy.

Female: Length of wing $0.86(0.79-0.96, \mathrm{n}=3) \mathrm{mm}$.

Head.-Eyes narrowly separated, bare. Antenna with flagellar segments in proportion of $16: 10: 12: 13: 11: 11: 12: 13: 20: 21: 22: 21: 41$, antennal ratio $1.18(1.10-1.27, \mathrm{n}=2)$; distal sensory tufts present on segments III, VII-X. Palpal segments in proportion of $6: 13: 17: 10: 8$, third segment swollen, 2.1 times as long as greatest breadth, with a broad, shallow, irregular sensory pit. Mandible with 13-14 $(\mathrm{n}=2)$ teeth.

Thorax.-Mesonotum dark brown on anterior half with a prominent pattern of yellowish patches, consisting of a submedian pair of large elongate spots, just laterad of which is another pair of very small round spots; humeri, a small area around each sensory pit, and entire posterior half of mesonotum yellowish. Scutellum dark brown in middle and yellowish on sides; postscutellum dark brown; pleuron yellow on upper half and dark brown below. Legs dark brown; knee spots blackish; fore and mid femora with very broad subapical bands, all tibiae with very broad basal bands and broad apex of hind tibia, yellowish; hind tibial comb with four $(n=2)$ spines, the one nearest the spur longest.

Wing.-Pattern as figured; second radial cell very dark; pale spot over $\mathrm{r}-\mathrm{m}$ crossvein broadly reaching costal margin; poststigmatic pale spot in cell $R_{5}$ extended proximad behind second radial cell; 

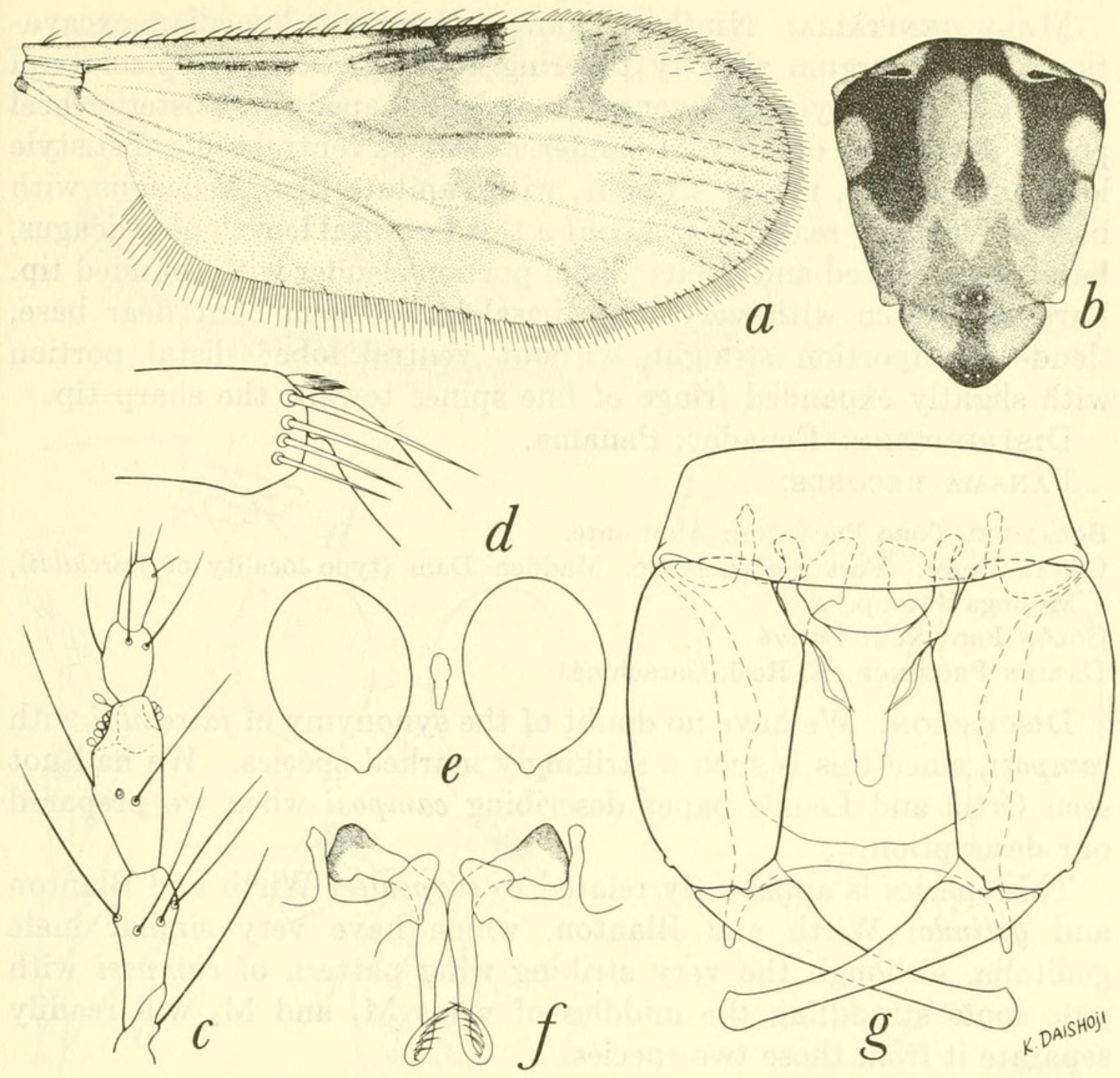

Figure 41.-Culicoides camposi Ortiz and Leon. $a-e$, Female: $a$, wing; $b$, thoracic pattern; $c$, palpus; $d$, tibial comb; $e$, spermathecae. $f, g$, Male: $f$, parameres; $g$, genitalia, parameres removed.

distal pale spot in cell $R_{5}$ rounded, almost reaching anterior wing margin; a pale spot present in center of wing straddling middle of veins $M_{1}$ and $M_{2}$ and usually filling the intervening space in cell $M_{1}$; distal pale spot in cell $\mathrm{M}_{1}$ elongate and nearly reaching wing margin; pale spots present at wing margin in apices of cells $\mathrm{M}_{2}$ and $\mathrm{M}_{4}$; two pale spots, which may be more or less fused, in distal part of anal cell; base of anal cell pale; cell $\mathrm{M}_{2}$ with a small pale spot lying in front of mediocubital fork and a pale area extending from behind medial fork to base of wing. Macrotrichia sparse in apices of cells $R_{5}, M_{1}$ and $\mathrm{M}_{2}$, none proximad; costa extending to $0.59(0.58-0.60, \mathrm{n}=2)$ of distance to wing tip. Halter yellowish.

Abdomen.-Blackish on sides, grayish pruinose above. Spermathecae two, pyriform, subequal, very small, each measuring 0.029 by $0.019 \mathrm{~mm}$., the bases of the ducts not sclerotized. 
Male genitalia: Ninth sternum without caudomedian excavation; ninth tergum slightly tapering to long, slender, apicolateral processes. Basistyle with ventral root foot-shaped, the posterior heel poorly developed, dorsal root slender, as long as ventral root; dististyle long and slender, nearly straight, with capitate tip. Aedeagus with basal arch short, reaching to about a third of total length of aedeagus, basal arms curved and stout; distal portion slender with rounded tip. Parameres each with very large basal knob, stem bent near base, slender, midportion straight, without ventral lobe; distal portion with slightly expanded fringe of fine spines toward the sharp tip.

Distribution: Ecuador; Panama.

PANAMA RECORDS:

Bocas del Toro Province: Almirante.

Canal Zone: Fort San Lorenzo, Madden Dam (type locality of fairchildi), Mojinga Swamp.

Colón Province: Cativá.

Darién Province: El Real, Garachiné.

Discussion: We have no doubt of the synonymy of fairchildi with camposi, since this is such a strikingly marked species. We had not seen Ortiz and Leon's paper describing camposi when we prepared our description.

This species is apparently related to carpenteri Wirth and Blanton and galindoi Wirth and Blanton, which have very similar male genitalia, although the very striking wing pattern of camposi with pale spots straddling the middles of veins $\mathrm{M}_{1}$ and $\mathrm{M}_{2}$ will readily separate it from those two species.

\section{Culicoides carpenteri Wirth and Blanton}

\section{Figure 42}

Culicoides carpenteri Wirth and Blanton, 1953, Journ. Washington Acad. Sci., vol. 43, p. 72 (male, female; Panama; fig. wing, mesonotum, palpus, male genitalia).

Female: Length of wing $0.99(0.96-1.02, \mathrm{n}=10) \mathrm{mm}$.

Head.-Eyes narrowly separated, bare. Antenna with flagellar segments in proportion of $20: 14: 15: 15: 15: 14: 15: 15: 26: 27: 33: 31: 43$, antennal ratio $1.22(1.17-1.30, \mathrm{n}=8)$; distal sensory tufts present on segments III, XI-XIV. Palpal segments in proportion of 10:20:25:10:10, third segment scarcely swollen, $2.4(2.2-2.7, \mathrm{n}=10)$ times as long as greatest breadth, with a broad, shallow, sensory pit. Mandible with $14(13-14, \mathrm{n}=10)$ teeth.

Thorax.-Mesonotum elongate, color yellowish brown, anterior portion except humeri darker brown and a narrow median line and a sublateral pair of broader longitudinal bands of brown extending caudad to about middle of mesonotum, or sometimes to scutellum: 

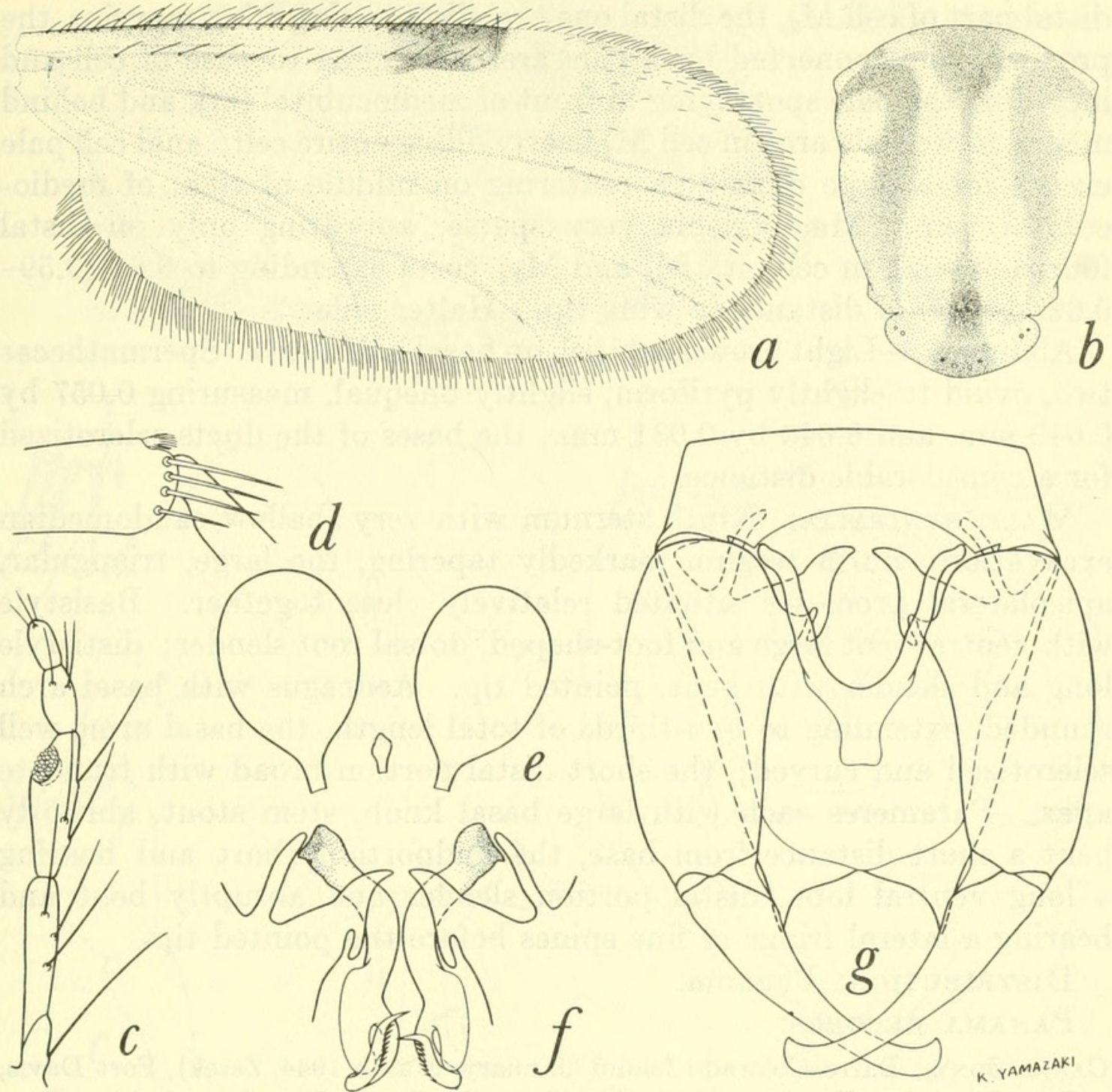

Figure 42.-Culicoides carpenteri Wirth and Blanton. $a-e$, Female: $a$, wing; $b$, thoracic pattern; $c$, palpus; $d$, tibial comb; $e$, spermathecae. $f, g$, Male: $f$, parameres; $g$, genitalia, parameres removed.

Scutellum dark in middle, sides yellowish; postscutellum and pleuron dark brown. Legs brown, all femora with basal and subapical, tibiae with subbasal, and hind tibia with apical wide pale bands; hind tibial comb with four $(n=10)$ spines, the one nearest the spur longest.

Wing.-Pattern as figured; pale areas extensive but comparatively faint; second radial cell very dark; large pale area over r-m crossvein; poststigmatic pale area in cell $R_{5}$ extensive, extending from anterior wing margin around second radial cell and sometimes fusing with pale spot over crossvein; distal pale spot in cell $R_{5}$ extensive, broadly extending across cell near apex from anterior wing margin to vein $\mathrm{M}_{1}$; apices of veins $\mathrm{M}_{1}, \mathrm{M}_{2}, \mathrm{M}_{3+4}$ and $\mathrm{Cu}_{1}$ dark; cell $\mathrm{M}_{1}$ with a long basal area extending across veins $M_{1}$ and $M_{2}$ to fuse with poststigmatic pale spot in cell $R_{5}$ and subapical pale spot in cell $\mathrm{M}_{2}$, distal pale spot in cell $M_{1}$ broadly meeting wing margin; two pale spots in 
distal part of cell $\mathrm{M}_{2}$, the distal one broadly meeting wing margin; the proximal one connected by a pale area extending to base of cell and including the pale spots lying in front of mediocubital fork and behind medial fork; pale area in cell $\mathrm{M}_{4}$ nearly filling entire cell; anal cell pale except for a large dark area centering on middle of stem of mediocubital vein. Macrotrichia very sparse, appearing only on distal fourth of wing in cells $\mathrm{R}_{5}, \mathrm{M}_{1}$ and $\mathrm{M}_{2}$; costa extending to 0.61 (0.59$0.62, \mathrm{n}=10$ ) of distance to wing tip. Halter pale.

Abdomen.- Light brown, whitish on basal half above. Spermathecae two, ovoid to slightly pyriform, slightly unequal, measuring 0.057 by $0.042 \mathrm{~mm}$. and 0.046 by $0.031 \mathrm{~mm}$., the bases of the ducts sclerotized for a considerable distance.

Male Genitalia: Ninth sternum with very shallow caudomedian excavation; ninth tergum markedly tapering, the large, triangular, apicolateral processes situated relatively close together. Basistyle with ventral root large and foot-shaped, dorsal root slender; dististyle long and slender with bent, pointed tip. Aedeagus with basal arch rounded, extending to two-thirds of total length, the basal arms well sclerotized and curved; the short distal portion broad with truncate apex. Parameres each with large basal knob, stem stout, abruptly bent a short distance from base, the midportion short and bearing a long ventral lobe, distal portion slender and abruptly bent and bearing a lateral fringe of fine spines before the pointed tip.

Distribution: Panama.

PANAMA RECORDS:

Canal Zone: Barro Colorado Island (January-March 1944, Zetek), Fort Davis, Fort Sherman, Gamboa, Huile Sia Clara (?), Loma Boracho, Madden Dam (type locality), Mandinga River, Mojinga Swamp.

Panamá Province: El Coco, Pedregal.

Veraguas Province: Río Santa María.

Discussion: By wing pattern, general appearance, and structure of the male genitalia, carpenteri appears to be related to camposi Ortiz and Leon, galindoi Wirth and Blanton, and limai Barretto, but the sensorial pattern, with sensoria present on segments III, XI-XIV, does not resemble that of any of these species, and the true relation of carpenteri thus remains obscure.

\section{Culicoides magnipalpis Wirth and Blanton}

Figure 43

Culicoides magnipalpis Wirth and Blanton, 1953, Journ. Washington Acad. Sci., vol. 43, p. 76 (male, female; Panama; fig. wing, antenna, spermathecae, male genitalia).

Female: Length of wing $1.07(1.06-1.09, \mathrm{n}=2) \mathrm{mm}$.

Head.-Eyes narrowly separated, bare. Antenna with flagellar segments in proportion of $19: 17: 18: 17: 18: 17: 17: 18: 23: 23: 23: 23: 32$, 

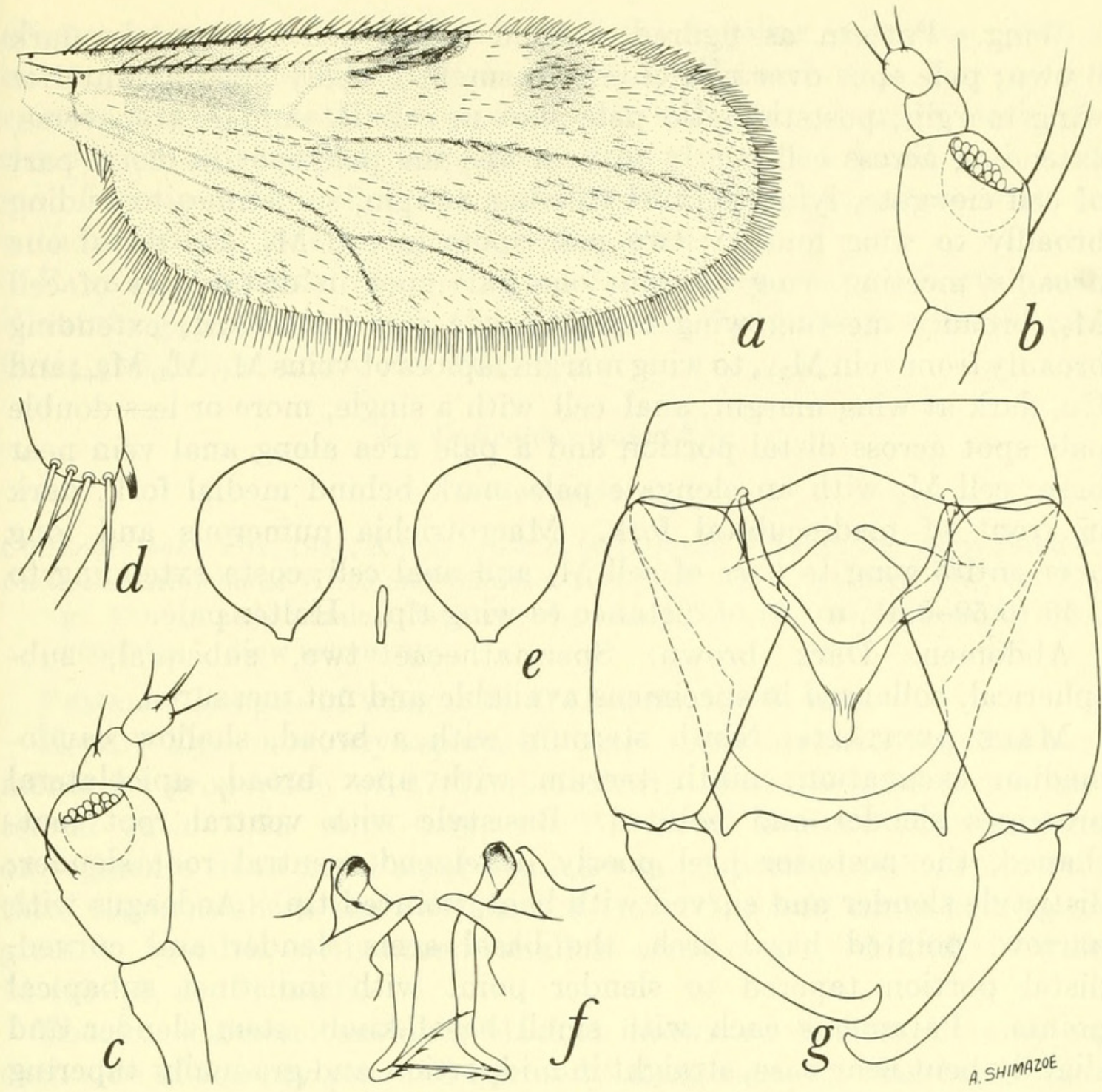

Figure 43.-Culicoides magnipalpis Wirth and Blanton. $a-e$, Female: $a$, wing; $b, c$, palpus; $d$, tibial comb; $e$, spermathecae. $f, g$, Male: $f$, parameres; $g$, genitalia, parameres removed.

antennal ratio $0.91(0.88-0.94, \mathrm{n}=2)$; distal sensory tufts present on segments III, XI-XV. Palpal segments in proportion of 10:20:30:8:7, third segment remarkably bulbously swollen, 1.3 times as long as broad, with a broad, deep sensory pit on distal half. Mandible with 13 teeth.

Thorax.-Mesonotum tawny yellowish brown, a contiguous pair of faint, paler yellowish, oval, submedian, anterior spots on disc; humeral corners with a pair of small whitish spots; area between these spots and humeral pits blackish. Scutellum yellowish, darker in middle; postscutellum and pleuron blackish, pleuron pale on upper half. Legs brown; femora with subapical and tibiae with subbasal narrow pale rings; hind tibial comb with $4(n=2)$ spines, the two nearest the comb subequal, longest. 
Wing.-Pattern as figured; second radial cell moderately dark brown; pale spot over $\mathrm{r}-\mathrm{m}$ crossvein small, broadly meeting anterior wing margin; poststigmatic pale spot in cell $R_{5}$ simple, transverse, extending across cell nearly to vein $\mathrm{M}_{1}$, the pale spot in distal part of cell elongate, lying parallel to wing margin, sometimes extending broadly to wing margin; two pale spots in cell $\mathrm{M}_{1}$, the distal one broadly meeting wing margin; one pale spot in distal part of cell $\mathrm{M}_{2}$, broadly meeting wing margin; pale spot in cell $\mathrm{M}_{4}$ extending broadly from vein $\mathrm{M}_{3+4}$ to wing margin; apices of veins $\mathrm{M}_{1}, \mathrm{M}_{2}, \mathrm{M}_{3+4}$ and $\mathrm{Cu}_{1}$ dark at wing margin; anal cell with a single, more or less double pale spot across distal portion and a pale area along anal vein near base; cell $\mathrm{M}_{2}$ with an elongate pale mark behind medial fork, dark in front of mediocubital fork. Macrotrichia numerous and long over entire wing to base of cell $\mathrm{M}_{2}$ and anal cell; costa extending to $0.60(0.59-0.61, \mathrm{n}=2)$ of distance to wing tip. Halter pale.

Abdomen.-Dark brown. Spermathecae two, subequal, subspherical, collapsed in specimens available and not measured.

Male genitalia: Ninth sternum with a broad, shallow caudomedian excavation; ninth tergum with apex broad, apicolateral processes slender and pointed. Basistyle with ventral root footshaped, the posterior heel poorly developed, ventral root slender; dististyle slender and curved with bent, pointed tip. Aedeagus with narrow, pointed basal arch, the basal arms slender and curved, distal portion tapered to slender point with indistinct subapical points. Parameres each with small basal knob, stem slender and slightly bent near base, straight in midportion and gradually tapering to ventrally curved, points with a subapical fringe of very fine spines.

Distribution: Panama.

PanAMA RECORDS:

Chiriqui Province: Volcán.

Panamá Province: Cerro Campana (type locality).

Discussion: This species is provisionally placed in the limai group near galindoi Wirth and Blanton on the basis of wing pattern and male genitalic structure, but the sensorial pattern and very hairy wing would indicate possible affinities with the daedalus group.

\section{The acotylus group}

This is a heterogeneous group of species, placed here more for convenience than because of any definitely close relation. Moderate sized to large species with very prominent wing pattern of numerous round spots, cells $R_{5}$ and $M_{1}$ with pale spots in apices of cells or with poststigmatic pale spots clustering around a small dark spot behind second radial cell; r-m crossvein often dark; antenna with sensoria 
always present on some of the proximal flagellar segments, absent on the last five except in venezuelensis; tibial comb with four or five spines; two spermathecae present; ventral root of male basistyle slender or foot-shaped; aedeagus often with stout basal arch and modified tip with well developed lateral points; parameres with or without ventral lobe or distal fringing spines.

Panama species: Six: acotylus Lutz, carsiomelas Wirth and Blanton, guyanensis Floch and Abonnenc, lanei Ortiz, venezuelensis Ortiz and Mirsa, and wokei Fox.

\section{Culicoides wokei Fox}

FigURE 44

Culicoides wokei Fox, 1947, Kuba, vol. 3, p. 90 (female; Panama; fig. wing, palpus). Culicoides aethionotus Wirth and Blanton, 1955, Bull. Brooklyn Ent. Soc., vol. 50, p. 121 (male, female; Panama; fig. wing, palpus, spermathecae, male genitalia). New synonymy.

Female: Length of wing $0.78(0.75-0.84, \mathrm{n}=9) \mathrm{mm}$.

Head.-Eyes narrowly separated, bare. Antenna with flagellar segments in proportion of $17: 13: 13: 13: 13: 13: 13: 13: 16: 17: 18: 20: 30$, antennal ratio $0.95(0.93-0.96, \quad \mathrm{n}=2)$; distal sensory tufts present on segments III to $\mathrm{x}$. Palpal segments in proportion of $8: 16: 20: 8: 10$, third segment short and swollen, $1.6(1.5-1.7, \mathrm{n}=8)$ times as long as greatest breadth, with broad, shallow sensory pit. Mandible with $14(13-15, \mathrm{n}=7)$ teeth.

Thorax.-Mesonotum dull, blackish brown on humeri, broadly on each side of sensory pits and narrowly along sides to wing bases, disc uniformly dark grayish to coppery pruinose. Scutellum uniformly pruinose brown; postscutellum and pleuron blackish. Legs dark brown, all femora pale at bases; fore and mid femora with subapical and all tibiae with subbasal narrow pale rings; hind tibial comb with four $(n=5)$ spines, the one nearest the spur longest.

Wing.-Pattern as figured; pale spots whitish and extensive, in a framework of narrow, connected dark linear markings, principally along the veins; second radial cell dark; pale spot over r-m crossvein very broad, a large pale area over base of wing, the dark area between these pale areas quite short; cell $R_{5}$ with three pale spots, a small one at end of second radial cell, an elongate one behind second radial cell sometimes narrowly meeting the pale spot over crossvein and the anterior poststigmatic pale spot, and the third pale spot extensive, nearly filling apex of cell $\mathrm{R}_{5}$, broadly meeting anterior wing margin and continuing along the margin as a narrow pale appendage nearly to end of cell $M_{1}$; two elongate, pale, streak-like spots in cell $M_{1}$, the distal one broadly meeting wing margin; two pale spots in distal part of cell $\mathrm{M}_{2}$, the distal one broadly meeting wing margin; pale spot in 

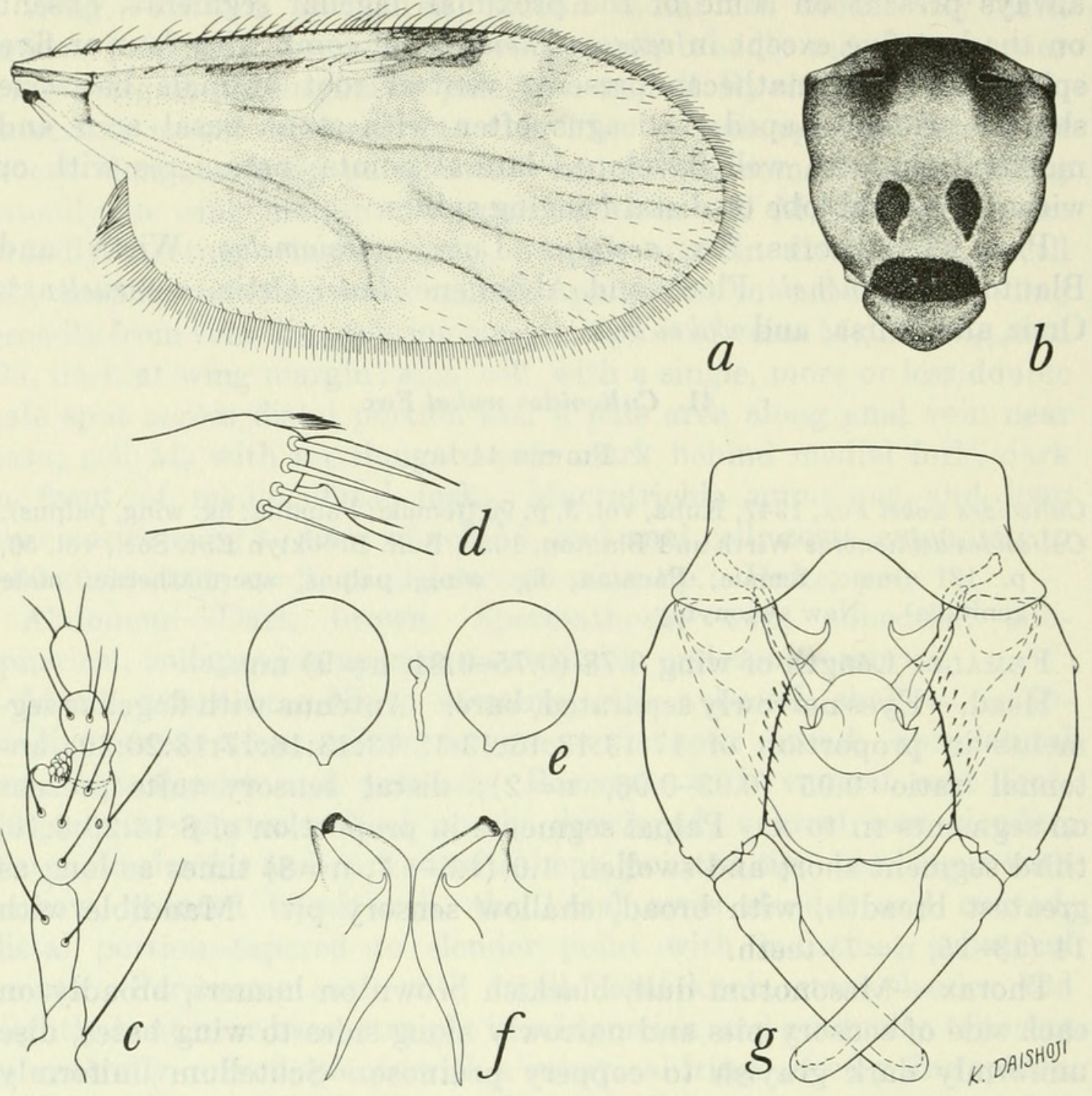

Figure 44.-Culicoides wokei Fox. $a-e$, Female: $a$, wing; $b$, thoracic pattern; $c$, palpus; $d$, tibial comb; $e$, spermathecae. $f, g$, Male: $f$, parameres; $g$, genitalia, parameres removed.

cell $\mathrm{M}_{4}$ continued in full breadth across cell from vein $\mathrm{M}_{3+4}$ to wing margin, one pale spot in distal part of anal cell; Cell $\mathrm{M}_{2}$ with a small pale spot lying in front of mediocubital fork and one lying behind medial fork. Macrotrichia sparse on distal third of wing; costa extending to $0.61(0.60-0.64, \mathrm{n}=9)$ of distance to wing tip. Halter pale.

Abdomen.-Dull brownish black. Spermathecae two, large and heavily sclerotized, slightly ovoid, slightly unequal, measuring 0.062 by $0.047 \mathrm{~mm}$. and 0.051 by $0.043 \mathrm{~mm}$., the bases of the ducts not sclerotized.

Male Genitalia: Ninth sternum with moderately deep caudomedian excavation; ninth tergum rounded caudal, the apicolateral processes not developed. Basistyle short and broad with mesal mar- 
gin densely setose, ventral and dorsal roots short and pointed, slender, subequal in length, and joined together by a dark sclerotization; dististyle longer than basistyle, moderately stout and straight, with blunt apex. Aedeagus with a broad basal arch extending to two-thirds of total length, the basal arms nearly straight; distal portion very broad and heavily sclerotized with the apex in the form of a mushroomshaped cap. Parameres each with long, heavily sclerotized, rodlike, laterally directed basal processes, abruptly bent at the base of the stem which is somewhat swollen at the base of the straight midportion and gradually narrowed and only slightly curved to a slender simple tip.

Distribution: Panama.

PANAMA RECORDS:

Canal Zone: Balboa (West Bank, June 26, 1942, P. A. Woke 1021, at light; holotype of wokei Fox), Galeta Point, Loma Boracho, Mindi Dairy, Mojinga Swamp.

Chiriquf Province: Alanje, Chiriquí.

Coclé Province: Puerto Farallón, Río Hato.

Darién Province: Garachiné, Jaqué, Punta Patiño (type locality of aethionotus). Herrera Province: Puerto Chitré.

Panamá Province: Bayano, Chepo, Pedregal, San Carlos, Isla Taboga. Archipiélago de las Perlas: Isla del Rey.

Discussion: We are sinking aethionotus in the synonymy under wokei as the result of a direct comparison of the respective holotypes, that of wokei having kindly been loaned to us by Dr. Irving Fox.

The wing pattern of wokei is very similar to that of galindoi and limai, but the antennal sensorial pattern and structure of the male genitalia make it seem likely that wokei is more closely related to the species of the acotylus group.

\section{Culicoides carsiomelas Wirth and Blanton}

FIGURE 45

Culicoides carsiomelas Wirth and Blanton, 1955, Bull. Brooklyn Ent. Soc., vol. 50, p. 100 (male, female; Panama; fig. wing, palpus, spermathecae, male genitalia).

Female: Length of wing $0.99(0.96-1.02, \mathrm{n}=6) \mathrm{mm}$.

Head.-Eyes narrowly separated, bare. Antenna with flagellar segments in proportion of 19:14:14:15:16:16:15:15:20:21:23:23:32, antennal ratio 0.96 ; distal sensory tufts present on segments III, vII-X. Palpal segments in proportion of 10:19:22:7; 8 , third segment broadly swollen, $1.8(1.6-2.0, n=5)$ times as long as greatest breadth, with a large, very deep, sensory pit. Mandible with $13(12-14, n=5)$ teeth.

Thorax.-Mesonotum without prominent pattern, the sides and entire anterior margin to sensory pits dark brown; median area from 

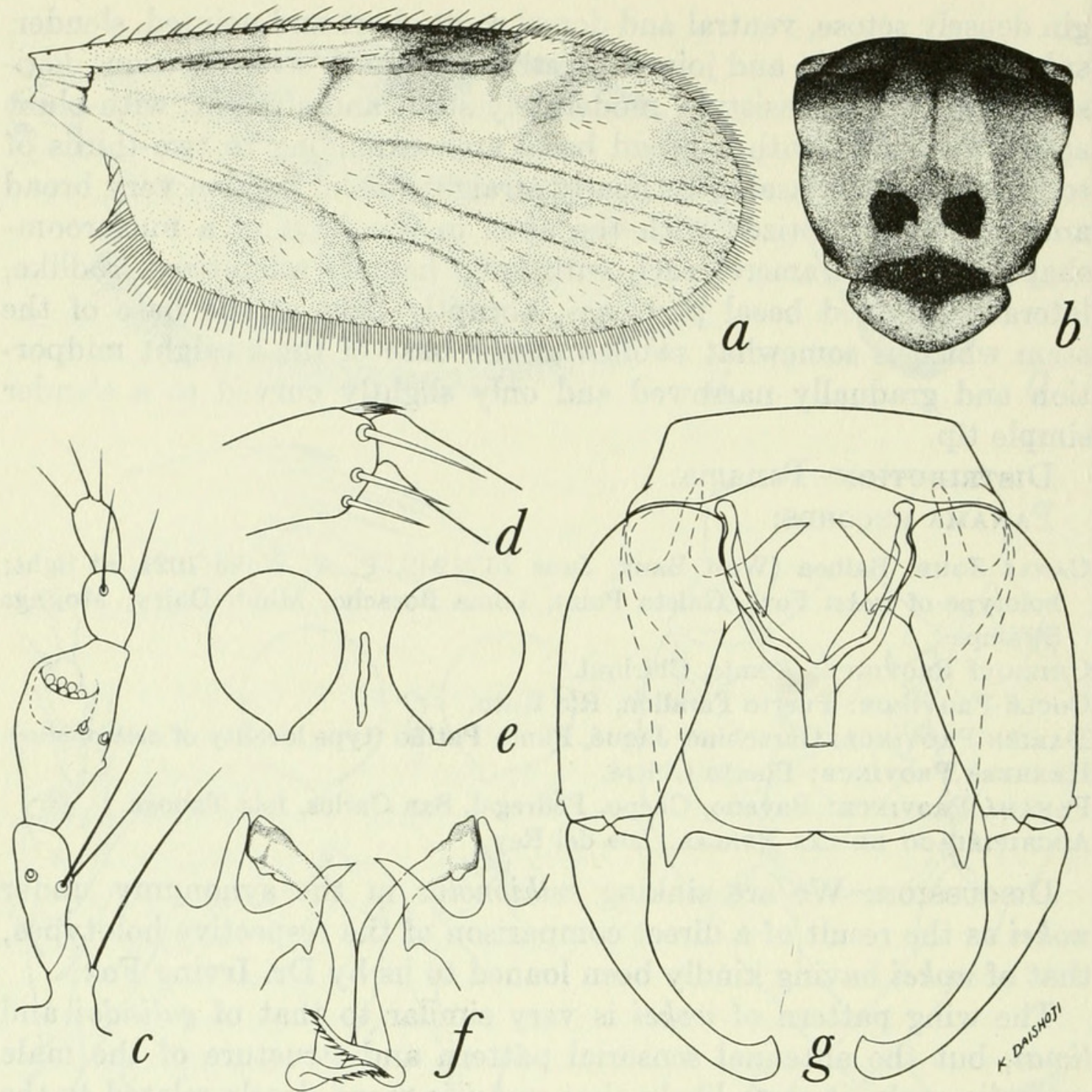

Figure 45.-Culicoides carsiomelas Wirth and Blanton. $a-e$, Female: $a$, wing; $b$, thoracic pattern; $c$, palpus; $d$, tibial comb; $e$, spermathecae. $f, g$, Male: $f$, parameres; $g$, genitalia, parameres removed.

pits to prescutellar depression and wing bases brownish yellow. Scutellum yellowish, brown in middle on anterior margin; postscutellum and pleuron brownish black. Legs brown, fore and mid femora with subapical, all tibia with subbasal and hind tibia with apical narrow pale rings; hind tibial comb with four $(3-5, n=6)$ spines, the one nearest the spur longest.

Wing.-Pattern as figured; second radial cell moderately dark, very broad, subequal in length to the first; $r-m$ crossvein infuscated, lying in a broad pale spot which broadly reaches costal margin; cell $R_{5}$ with three pale spots, the proximal one a flattened $U$-shaped spot lying behind second radial cell, second spot lying on anterior wing margin just distad of end of costa, third spot occupying middle of distal part of cell,-sometimes attaining anterior wing margin; apices 
of veins $\mathrm{M}_{1}, \mathrm{M}_{2}$ and $\mathrm{M}_{3+4}$ with small pale spots at wing margin; cell $\mathrm{M}_{1}$ with two elongate pale spots, the distal one lying far from wing margin; two pale spots in distal part of cell $\mathrm{M}_{2}$, the distal one not reaching wing margin; a small pale spot present in center of cell $\mathrm{M}_{4}$; distal portion of anal cell with one small round pale spot; cell $\mathrm{M}_{2}$ with a small pale spot lying in front of mediocubital fork and one lying behind medial fork; base of wing broadly pale. Macrotrichia sparse but scattered over wing, including anal cell and base of cell $\mathrm{M}_{2}$; costa extending to $0.65(0.64-0.67, \mathrm{n}=6)$ of distance to wing tip. Halter knob infuscated.

Abdomen.-Dull blackish, cerci yellowish. Spermathecae two, large, unequal, pyriform, measuring 0.061 by $0.043 \mathrm{~mm}$. and 0.040 by 0.029 $\mathrm{mm}$., the bases of the ducts sclerotized a short distance.

Male Genitalia: Ninth sternum with a very shallow caudomedian excavation; ninth tergum broad apically with short, pointed apicolateral processes. Basistyle with ventral root foot-shaped, dorsal root long and slender; dististyle slender with narrow, curved apex. Aedeagus with broad, pointed basal arch extending to three-fourths of total length, the basal arms curved and stout; distal apex slender with truncated tip. Parameres each with large basal knob, stem slightly curved basally, straight and fairly stout on midportion with a well-developed ventral lobe, distal portion slender with fine lateral spines.

Distribution: Panama.

PANAMA RECORDS:

Bocas del Toro Province: Almirante.

Canal Zone: Fort San Lorenzo, Fort Sherman, Mojinga Swamp (type locality). Darien Province: El Real.

Discussion: This species bears a close superficial resemblance to acotylus Lutz, with its infuscated crossvein, unmarked brownish mesonotum and general wing pattern. However, acotylus can be readily distinguished by the presence of two pale spots in the distal part of the anal cell, by the presence of five rather than three pale spots in cell $R_{5}$, by the presence of only one pale spot in the apex of cell $\mathrm{M}_{2}$, and by the absence of a palpal pit.

\section{Culicoides acotylus Lutz}

Figure 46

Culicoides acotylus Lutz, 1913, Mem. Inst. Oswaldo Cruz, vol. 5, p. 69 (female; Rio Tapajos, Mato Grosso, Brazil; fig. wing, palpus).-Barbosa, 1947, Anais Soc. Biol. Pernambuco, vol. 7, p. 10 (Mato Grosso, Brazil).-Ortiz, 1952, Rev. Sanid. Asist. Soc., vol. 17, p. 257 (female; Falcón and Guarica, Venezuela; fig. palpus, spermathecae, wing; synonym, panamericanus Fox). Culicoides panamericanus Fox, 1947, Kuba vol. 3, p. 90 (female; Mexico; fig. wing, palpus). 

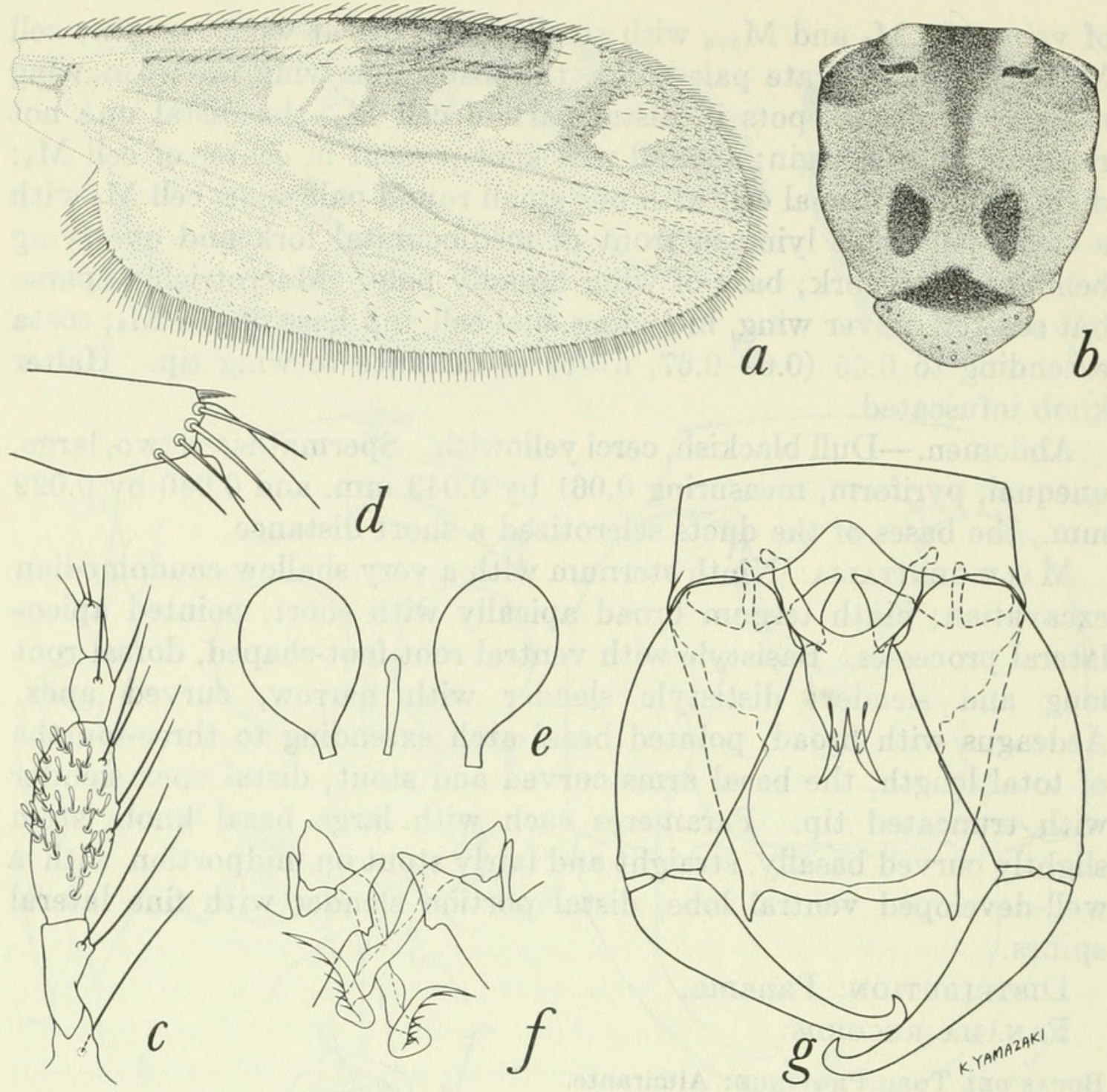

Figure 46.-Culicoides acotylus Lutz. $a-e$, Female: $a$, wing; $b$, thoracic pattern; $c$, palpus; $d$, tibial comb; $e$, spermathecae. $f, g$, Male: $f$, parameres; $g$, genitalia, parameres removed.

Female: Length of wing $1.05(0.96-1.11, \mathrm{n}=9) \mathrm{mm}$.

Head.-Eyes contiguous, bare. Antenna with flagellar segments in proportion of $24: 19: 19: 20: 20: 20: 20: 20: 22: 22: 22 \cdot 22: 37$, antennal ratio $0.78(0.74-0.80, \mathrm{n}=4)$; distal sensory tufts present on segments III and from vi or viI to $\mathrm{x}$. Palpal segments in proportion of 10:16:32:10:9, third segment moderately swollen, $2.3(2.1-2.8, \mathrm{n}=9)$ times as long as greatest breadth, without sensory pit, the sensoria scattered on surface of segment. Mandible with $15(14-15, \mathrm{n}=7)$ teeth.

Thorax.-Mesonotum and scutellum dark brown, without prominent pattern, in some specimens paler brown in midportion. Postscutellum and pleuron brownish black. Legs dark brown, narrow pale rings at bases of all tibiae and at apex of hind pair; hind tibial comb with five $(4-5, \mathrm{n}=7)$ spines, the second from the spur longest. 
Wing.-Pattern as figured; second radial cell very dark; radial cells broad, the second very broad, the first about twice as long as the second; r-m crossvein blackish, in the center of a large pale spot which broadly reaches costal margin; cell $R_{5}$ with five definite pale spots, one resting on anterior side of vein $\mathrm{M}_{1}$ near base of cell, the next three arranged in an arc behind and around the apex of second radial cell and the fifth spot lying in middle of distal portion of cell $R_{5}$, not reaching wing marcin; two pale spots in cell $\mathrm{M}_{1}$, the distal one lying far from wing margin; apices of veins $M_{1}$ and $M_{2}$ pale margined a short distance; one pale spot each in apex of cell $\mathrm{M}_{2}$ and cell $\mathrm{M}_{4}$, neither attaining wing margin; two pale spots in distal portion of anal cell and two in basal portion of this cell; cell $\mathrm{M}_{2}$ with a pale spot lying in front of mediocubital fork, one lying behind medial fork and another lying across cell about halfway from these spots and wing base. Macrotrichia sparse on distal third of wing; costa extending to 0.70 $(0.69-0.72, \mathrm{n}=8)$ of distance to wing tip. Halter pale.

Abdomen.-Brownish black, cerci whitish. Spermathecae two, pyriform, slightly unequal, measuring 0.063 by $0.043 \mathrm{~mm}$. and 0.059 by $0.042 \mathrm{~mm}$., the bases of the ducts sclerotized a short distance.

Male Genitalia: Ninth sternum with a shallow caudomedian excavation; ninth tergum quadrate, with large, triangular apicolateral processes. Basistyle with ventral root large, foot-shaped; ventral root slender; dististyle long and slightly curved with pointed, bent tip. Aedeagus with rounded basal arch extending to a third of total length, the basal arms stout and curved; distal portion with four long, tapering pointed branches, the median pair cleft about half the distance from their apices to the arch, the lateral pair arising nearer to arch. Parameres each with very large basal knob, stem curved near base, only slightly swollen on curved portion, midportion of stem slightly sinuate, slender, without ventral lobe, the distal apex with a lateral fringe of long spines.

Distribution: Brazil; Mexico; Panama; Venezuela.

Panama Records:

Bocas del Toro Province: Almirante.

Canal Zone: Fort Davis, Fort San Lorenzo, Fort Sherman, Loma Boracho, Mojinga Swamp.

Darién Province: El Real, Jaqué.

Panamá Province: Arraiján, La Jolla.

Discussion: Culicoides carsiomelas Wirth and Blanton resembles acotylus in having an unmarked brownish mesonotum, darkened crossvein and the same general wing pattern, but can be readily distinguished by the presence of only one pale spot in the distal part of the anal cell, by the presence of two distal pale spots in cell $\mathrm{M}_{2}$, and the presence of five rather than three pale spots in cell $R_{5}$. 


\section{Culicoides guyanensis Floch and Abonnenc}

Figure 47

Culicoides guyanensis Floch and Abonnenc, 1942, Inst. Pasteur Guyane Terr. l'Inini, no. 37, p. 5 (male, female; Cayenne, French Guiana; fig. male, female wings, antenna, palpus, male genitalia).-Barbosa, 1947, Anais Soc. Biol. Pernambuco, vol. 7, p. 19 (Panama, Trinidad, Brazil; fig. male genitalia; synonyms, recifensis Barbosa, stubalensis Fox).

Culicoides stellifer Macfie (not Coquillett, misident.), 1937, Ann. Mag. Nat. Hist., vol. 20, p. 12 (female; Trinidad).

Culicoides recifensis Barbosa, 1943, Rev. Bras. Biol., vol. 3, p. 261 (female; Brazil; fig. wing).

Culicoides stubalensis Fox, 1946, Ann. Ent. Soc. Amer., vol. 39, p. 254 (female; Trinidad; fig. wing, mesonotum).

Female: Length of wing $0.99 \mathrm{~mm}$.

Head.-Eyes narrowly separated, bare. Antenna with flagellar segments in proportion of $16: 14: 14: 15: 15: 15: 15: 15: 20: 20: 22: 25: 34$, antennal ratio $1.0(0.99-1.1, \mathrm{n}=2)$; distal sensory tufts present on segments III, VI-X. Palpal segments in proportion of $9: 23: 27: 10: 13$, third segment moderately swollen, $2.4(2.1-2.6, n=3)$ times as long as greatest breadth, with a broad, shallow sensory pit. Mandible with 15 teeth.

Thorax.-Mesonotum densely pruinose gray, with a prominent pattern consisting mainly of a sublateral pair of broad brownish bands; a median area on anterior margin between humeral pits blackish. Scutellum narrowly brown in middle, yellowish on sides; postscutellum and pleuron dark brown. Legs brown; femora with bases broadly pale; all femora with subapical, tibiae with subbasal and hind tibia with apical narrow pale rings; hind tibial comb with four spines, the one nearest the spur longest.

Wing.-Pattern as figured; second radial cell very dark; yellowish area over r-m crossvein extending broadly to costal margin; cell $R_{5}$ with five small round, separate, pale spots spread from base to apex of cell; apices of veins $\mathrm{M}_{1}, \mathrm{M}_{2}$ and $\mathrm{M}_{3-4}$ with a small pale spot at wing margin; three pale spots in cell $\mathrm{M}_{1}$, the distal one meeting wing margin; two pale spots in distal part of cell $\mathrm{M}_{2}$, the distal one meeting wing margin; pale spot in cell $\mathrm{M}_{4}$ broadly meeting wing margin; one small round pale spot in distal portion of anal cell and a large pale area anteriorly at base of cell; cell $\mathrm{M}_{2}$ with a pale spot behind medial fork and one at half the length of the mediocubital stem; pale spot just distad of basal arculus. Macrotrichia fairly numerous on distal half of wing and a few in anal cell; costa extending to 0.58 of distance to wing tip. Halter with base of knob brownish.

Abdomen.-Dark brown, cerci yellowish. Spermathecae two, pyriform, subequal, measuring 0.050 by $0.034 \mathrm{~mm}$. and 0.050 by $0.029 \mathrm{~mm}$., the bases of the ducts sclerotized a considerable distance. 

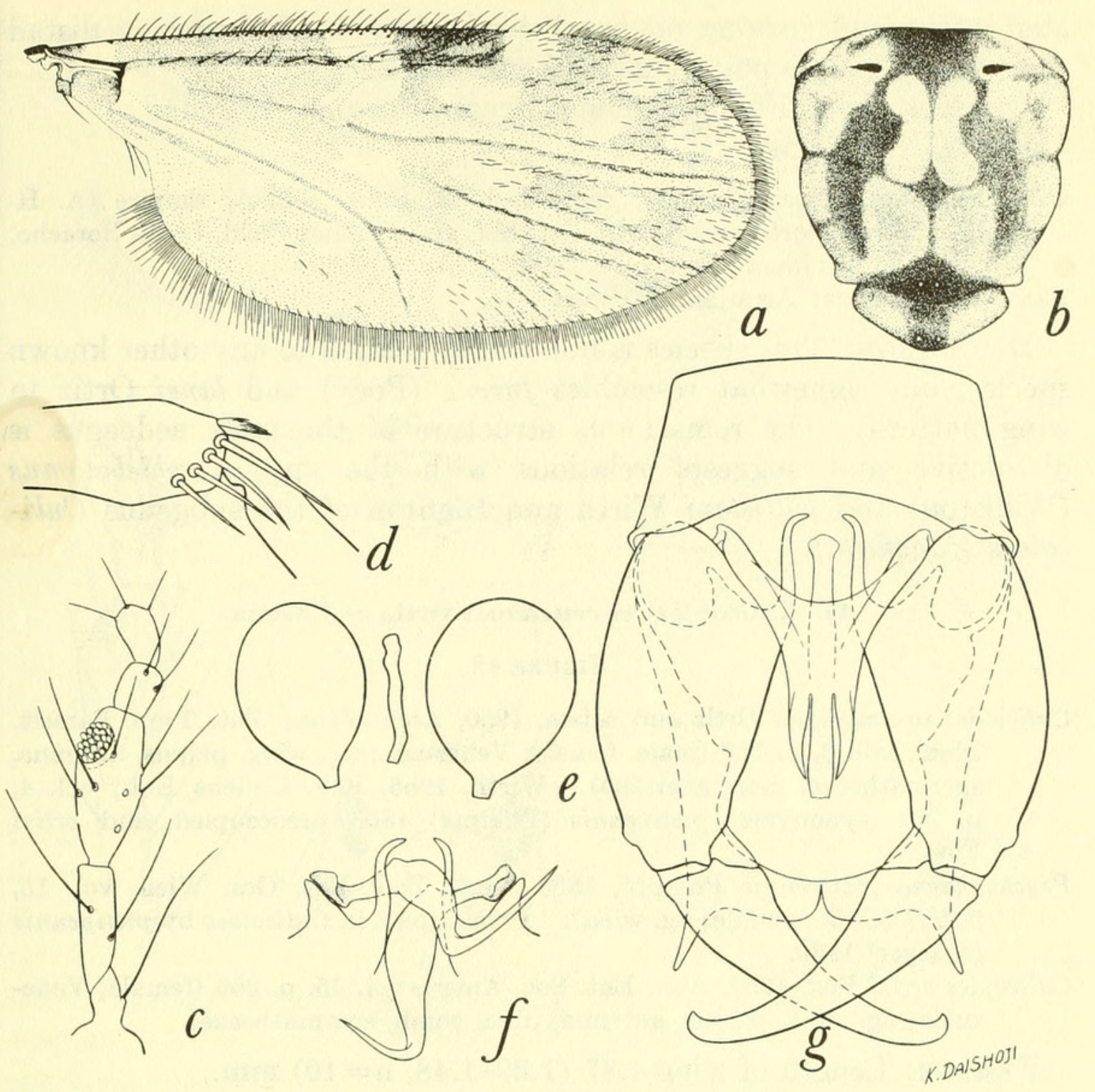

Figure 47.-Culicoides guyanensis Floch and Abonnenc. $a-e$, Female: $a$, wing; $b$, thoracic pattern; $c$, palpus; $d$, tibial comb; e, spermathecae. $f, g$, Male: $f$, parameres; $g$, genitalia, parameres removed.

Male genitalia: Ninth sternum remarkably long, without appreciable caudomedian excavation; ninth tergum quadrate, with slender, pointed, apicolateral processes. Basistyle with ventral root long and slender, dorsal root shorter and stouter; dististyle tapered to slender pointed tip. Aedeagus remarkably modified: basal arch broad and round, extending to half of total length, the basal arms curved and strongly sclerotized; distal portion with the long, slender median lobe detached at the base, its base curving dorsad of the arch and its proximal end lying free a short way between basal arms; a pair of slender, pointed, lateral lobes nearly as long as median lobe arising from basal arch on each side of median lobe. Parameres separate, each with basal lobe bearing a slender anterior process; 
stem stout and curving on basal portion, gradually tapering distad to a slender simple point curving ventromesally.

Distribution: French Guiana; Brazil; Panama; Trinidad.

PANAMA RECORDS:

Canal Zone: Balboa (June 23, Sept. 4, 1942, P. A. Woke), Empire (A. H Jennings, coll.), Fort San Lorenzo, Fort Sherman, France Field, Loma Boracho, Mindi Dairy, Mojinga Swamp.

Panamá Province: Arraiján, Bayano.

Discussion: This species is not closely related to any other known species, but somewhat resembles furens (Poey) and lanei Ortiz in wing pattern. The remarkable structure of the male aedeagus is distinctive and suggests relations with the species phlebotomus (Williston) and willistoni Wirth and Blanton of the subgenus Culicoides (Macfiella).

\section{Culicoides venezuelensis Ortiz and Mirsa}

Figure 48

Culicoides venezuelensis Ortiz and Mirsa, 1950, Arch. Venez. Pat. Trop. Parasit. Med., vol. 2, p. 137 (male, female; Venezuela; fig. wing, palpus, antenna, spermathecae, male genitalia).-Wirth, 1955, Rev. Chilena Ent., vol. 4, p. 234 (synonyms, pictipennis (Philippi) 1865 preoccupied, and ortizi Fox).

Psychophaena pictipennis Philippi, 1865, Verh. Zool.-Bot. Ges. Wien, vol. 15, p. 628 (Chile; female; fig. wing). Preoccupied in Culicoides by pictipennis (Staeger) 1839.

Culicoides ortizi Fox, 1952, Ann. Ent. Soc. Amer., vol. 45, p. 366 (female; Venezuela; fig. wing, palpus, antenna, tibial comb, spermathecae).

Female: Length of wing $1.37(1.29-1.48, \mathrm{n}=10) \mathrm{mm}$.

Head.-Eyes narrowly separated, bare. Antenna with flagellar segments in proportion of $20: 15: 15: 15: 16: 16: 16: 16: 26: 26: 28: 30: 37$, antennal ratio $1.19(1.13-1.26, \mathrm{n}=4)$; distal sensory tufts present on segments III, XI-XIV always, and also variably on segments $\mathrm{v}$ to $\mathrm{x}$. Palpal segments in proportion of $11: 22: 36: 8: 15$, third segment moderately swollen, $2.1(1.9-2.2, \mathrm{n}=10)$ times as long as greatest breadth, with a broad, shallow, sensory pit. Mandible with 13 $(13-14, \mathrm{n}=9)$ teeth.

Thorax.-Mesonotum densely grayish pruinose, with a prominent pattern of numerous punctiform brown dots at the seta bases, those in midline and on sublateral rows more or less coalescing to form indistinct vittae. Scutellum pruinose gray, narrowly brown in middle and on extreme sides; postscutellum dark brown with pruinose gray patches, pleuron dark brown. Legs dark brown; fore and mid femora with subapical, all tibiae with subbasal and hind tibia with apical narrow pale rings; hind tibial comb with five $(n=9)$ spines, the second from the spur longest. 

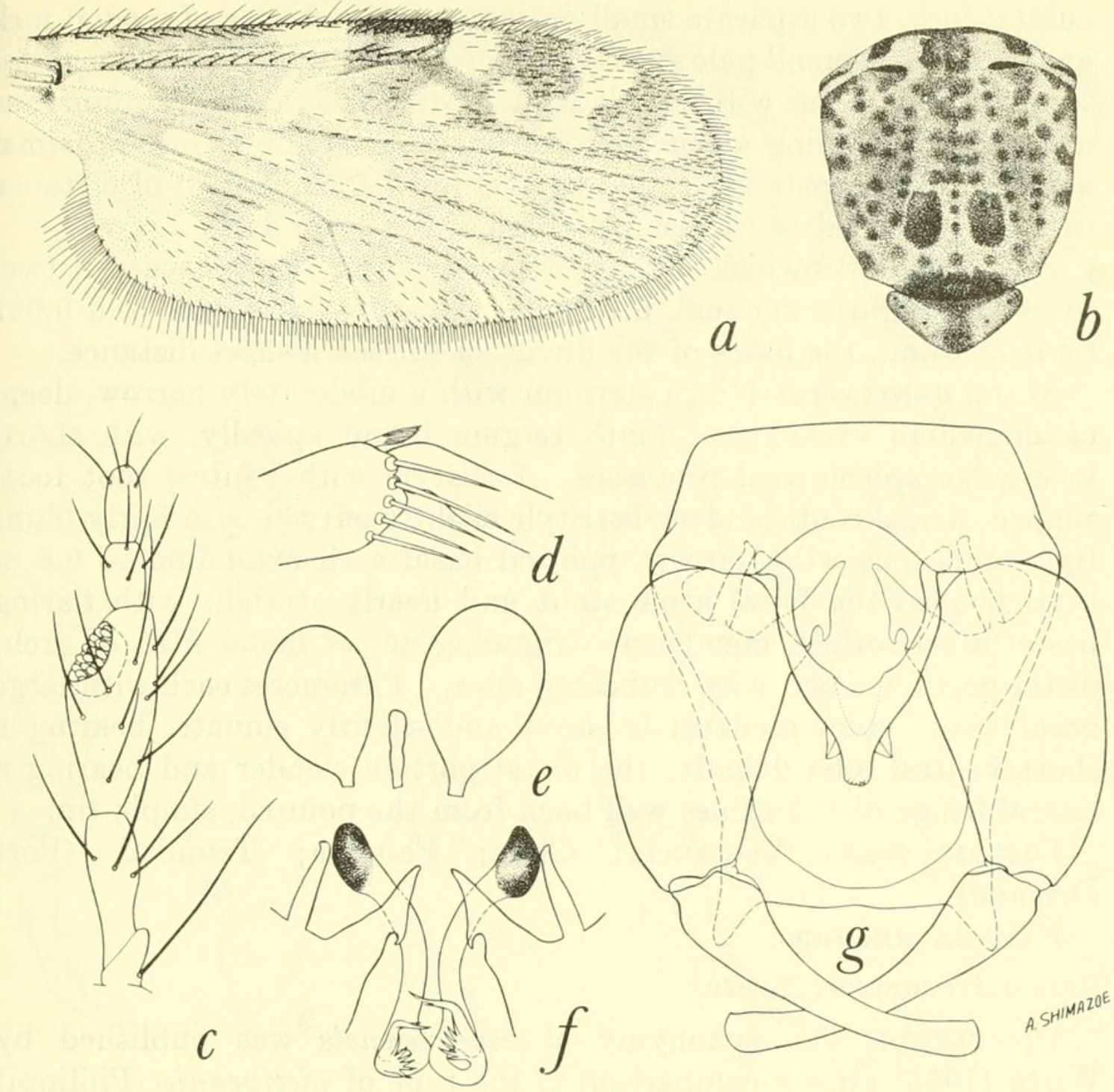

FigURE 48.-Culicoides venezuelensis Ortiz and Mirsa. $a-e$, Female: $a$, wing; $b$, thoracic pattern; $c$, palpus; $d$, tibial comb; $e$, spermathecae. $f, g$, Male: $f$, parameres; $g$, genitalia, parameres removed.

Wing.-Pattern as figured; anterior margin of wing, including second radial cell, very dark; pale spot over $r-m$ crossvein; cell $R_{5}$ pale at base next to $\mathrm{r}-\mathrm{m}$ crossvein, distally with six small round pale spots arranged in two triangular groups of three each, the proximal group at level of end of costa, the distal group near apex of cell; apices of veins $\mathrm{M}_{1}, \mathrm{M}_{2}, \mathrm{M}_{3+4}$ and $\mathrm{Cu}_{1}$ with small pale spots at wing margin; three pale spots in cell $\mathrm{M}_{1}$, the proximal one with a pale extension across middle of vein $\mathrm{M}_{2}$ and joining with the subapical pale spot in cell $\mathrm{M}_{2}$; the distal spot in cell $\mathrm{M}_{1}$ not reaching wing margin; two pale spots in distal portion of cell $\mathrm{M}_{2}$, the distal one separate from wing margin; round pale spot present in center of cell $\mathrm{M}_{4}$; anal cell with two round pale spots in distal portion, two irregular pale areas at base, a faint pale streak in cell $\mathrm{M}_{2}$ in front of medio- 
cubital fork, two separate small pale spots behind base of medial fork and a proximal small pale spot lying in front of middle of mediocubital stem; base of wing with a pale spot. Macrotrichia fairly numerous over wing, including all of anal cell but not extending into proximal half of cell $\mathrm{M}_{2}$; costa extending to $0.58(0.56-0.59, \mathrm{n}=10)$ of distance to wing tip. Halter whitish, the base of the knob dark.

Abdomen.-Brownish black; cerci yellowish. Spermathecae two, pyriform, slightly unequal, measuring 0.064 by $0.044 \mathrm{~mm}$. and 0.057 by $0.038 \mathrm{~mm}$., the bases of the ducts sclerotized a short distance.

Male genitalia: Ninth sternum with a moderately narrow, deep, caudomedian excavation; ninth tergum broad apically, with short, triangular apicolateral processes. Basistyle with ventral root footshaped, dorsal root slender; dististyle slightly curved with fairly blunt tip. Aedeagus with narrow, pointed basal arch extending to 0.8 of total length, the basal arms stout and nearly straight with flaring bases, a sclerotized membrane extending across distal fifth of arch; distal portion short, with truncated apex. Parameres each with large basal knob, stem moderately stout and slightly sinuate, bearing a short ventral lobe distally, the distal portion slender and bearing a lateral fringe of 4-5 spines well back from the pointed, simple tip.

Distribution: Venezuela; Chile; Panama; Trinidad (Port Delgada).

Panama Records:

Chiriqué Province: Volcán.

Discussion: The synonymy of venezuelensis was published by Wirth (1955) after a comparison of the type of pictipennis (Philippi) from Santiago, Chile, with paratype material of venezuelensis from Venezuela.

\section{Culicoides lanei Ortiz}

FIGURE 49

Culicoides lanei Ortiz, 1950, Rev. Sanid. Asist. Soc., vol. 15, p. 431 (male; Cerro Sefa, Panama; fig. wing, mesonotum, palpus, genitalia); 1951, idem., vol. 16 , p. 577 (notes; fig. wing, mesonotum, palpus, genitalia of male).

Female: Length of wing $1.02(0.96-1.12, \mathrm{n}=7) \mathrm{mm}$.

Head.-Eyes narrowly separated, bare. Antenna with flagellar segments in proportion of $21: 17: 20: 20: 20: 20: 20: 21: 19: 21: 20: 20: 33$, antennal ratio 0.72 ; distal sensory tufts present on segments III, vII-X. Palpal segments in proportion of $10: 15: 23: 9: 10$, third segment moderately swollen, $1.8(1.6-2.1, \mathrm{n}=6)$ times as long as greatest breadth, with a small, deep, sensory pit. Mandible with 13 (12-14), $\mathrm{n}=4$ ) teeth.

Thorax.-Mesonotum dark brown, with a prominent pattern of round or oval, yellowish gray pruinose patches as figured. Scutellum 

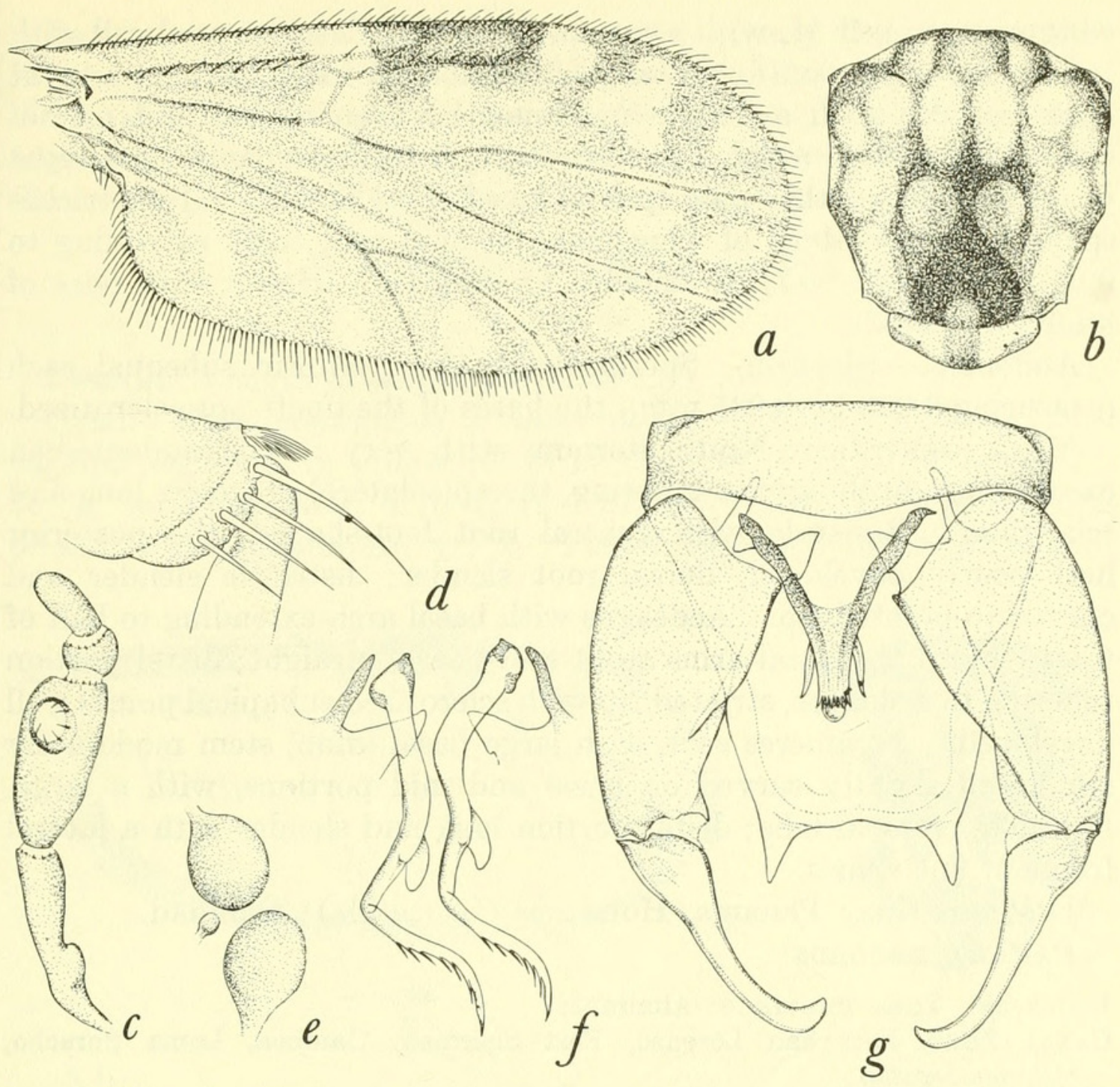

Figure 49.-Culoicoides lanei Ortiz. $a-e$, Female: $a$, wing; $b$, thoracic pattern; $c$, palpus; $d$, tibial comb; $e$, spermathecae. $f, g$, Male: $f$, parameres; $g$, genitalia, parameres removed.

narrowly dark brown in middle, yellowish on sides; postscutellum and pleuron dark brown. Legs dark brown, fore and mid femora with subapical and all tibiae with subbasal narrow pale rings; hind tibial comb with four $(n=7)$ spines, the one nearest the spur longest.

Wing.-Pattern as figured; second radial cell dark brown, more than twice as long as broad; pale spot over r-m crossvein narrow; cell $R_{5}$ with five definite pale spots; a small round one at end of costa and two, usually more or less confluent, in a longitudinal line behind second radial cell, these three more or less delimiting a small dark spot behind second radial cell; subapical pale spot in cell $R_{5}$ of irregular shape, usually with a narrow anterior connection to wing margin; a small round pale spot in apex of cell $R_{5}$; nearly all of vein $M_{1}$ and distal half of veins $M_{2}$ and $M_{3+4}$ pale margined; three pale spots in cell $\mathrm{M}_{1}$, the distal one nearly reaching wing margin; cell $\mathrm{M}_{2}$ with two pale spots in distal portion, the apical one nearly touching 
wing margin; cell $\mathrm{M}_{4}$ with a round pale spot in center; anal cell with two round pale spots in distal portion and an irregular pale area at base; cell $\mathrm{M}_{2}$ with a double pale spot between medial and mediocubital forks, with a pale line connecting it to the subapical pale spot in cell and to another pale spot in basal third of cell. Macrotrichia sparse on distal third of wing, none in anal cell; costa extending to $0.66(0.63-0.68, \mathrm{n}=7)$ of distance to wing tip. Halter with base of knob infuscated.

Abdomen.-Blackish. Spermathecae two, pyriform, subequal, each measuring 0.050 by $0.035 \mathrm{~mm}$., the bases of the ducts not sclerotized.

Male genitalia: Ninth sternum with very small caudomedian excavation: ninth tergum tapering, the apicolateral processes long and triangular. Basistyle with ventral root foot-shaped, the posterior heel poorly developed, dorsal root slender; dististyle slender and curved to pointed tip. Aedeagus with basal arch extending to half of total length, the basal arms stout and nearly straight; distal portion tapering to a slender, striated tip with sclerotized subapical points well developed. Parameres each with large basal knob, stem moderately stout and slightly curved on basal and mid portions, with a large, bladelike, ventral lobe; distal portion long and slender with a lateral fringe of fine spines.

Distribution: Panama; Honduras (Lancetilla); Trinidad.

Panama Records:

Bocas del Toro Province: Almirante.

Canal Zone: Fort San Lorenzo, Fort Sherman, Gamboa, Loma Boracho, Mojinga Swamp.

Discussion: Ortiz described this species from a male specimen collected by Fairchild at Cerro Sefa, Panama, 2,300 feet elevation, and sent to John Lane at the University of São Paulo, Brazil, where the type is now deposited.

\section{The reticulatus group}

This group consists mostly of medium-sized species, the wings usually with extensive pale markings, either veins $M_{1}$ and $M_{2}$ pale margined or pale spots at ends of veins (except in macrostigma); many species with a basic pattern of four pale spots in cell $R_{5}$ with the proximal three forming a ring around the second radial cell leaving a small dark spot just behind this cell; female antenna with sensoria present on segments III, and VI, viI or vill to $\mathrm{x}$; four tibial spines; two spermathecae; male genitalia with ventral root foot-shaped (except in macrostigma); paramere with simple basal knob, the stem very long and slender without ventral lobe, the apex simple or fringed; aedeagus with arch-high and pointed, subapical points usually present. 
Panama SPECIES: Eight or nine: azureus, new species; dicrourus Wirth and Blanton, lyrinotatus Wirth and Blanton; mojingaensis Wirth and Blanton; paucienfuscatus Barbosa; pifanoi Ortiz; reticulatus Lutz; and volcanensis, new species. Macrostigma Wirth and Blanton is provisionally referred here but its position is doubtful.

\section{Culicoides azureus, new species}

\section{Figure 50}

Female: Length of wing $1.04(1.02-1.09, \mathrm{n}=4) \mathrm{mm}$.

Head.-Eyes contiguous a short distance, bare. Antenna with flagellar segments in proportion of $17: 13: 14: 14: 14: 15: 15: 16: 24: 24: 25$ : $24: 38$, antennal ratio $1.18(1.15-1.21, \mathrm{n}=2)$; distal sensory tufts present on segments III, viI-x. Palpal segments in proportion of
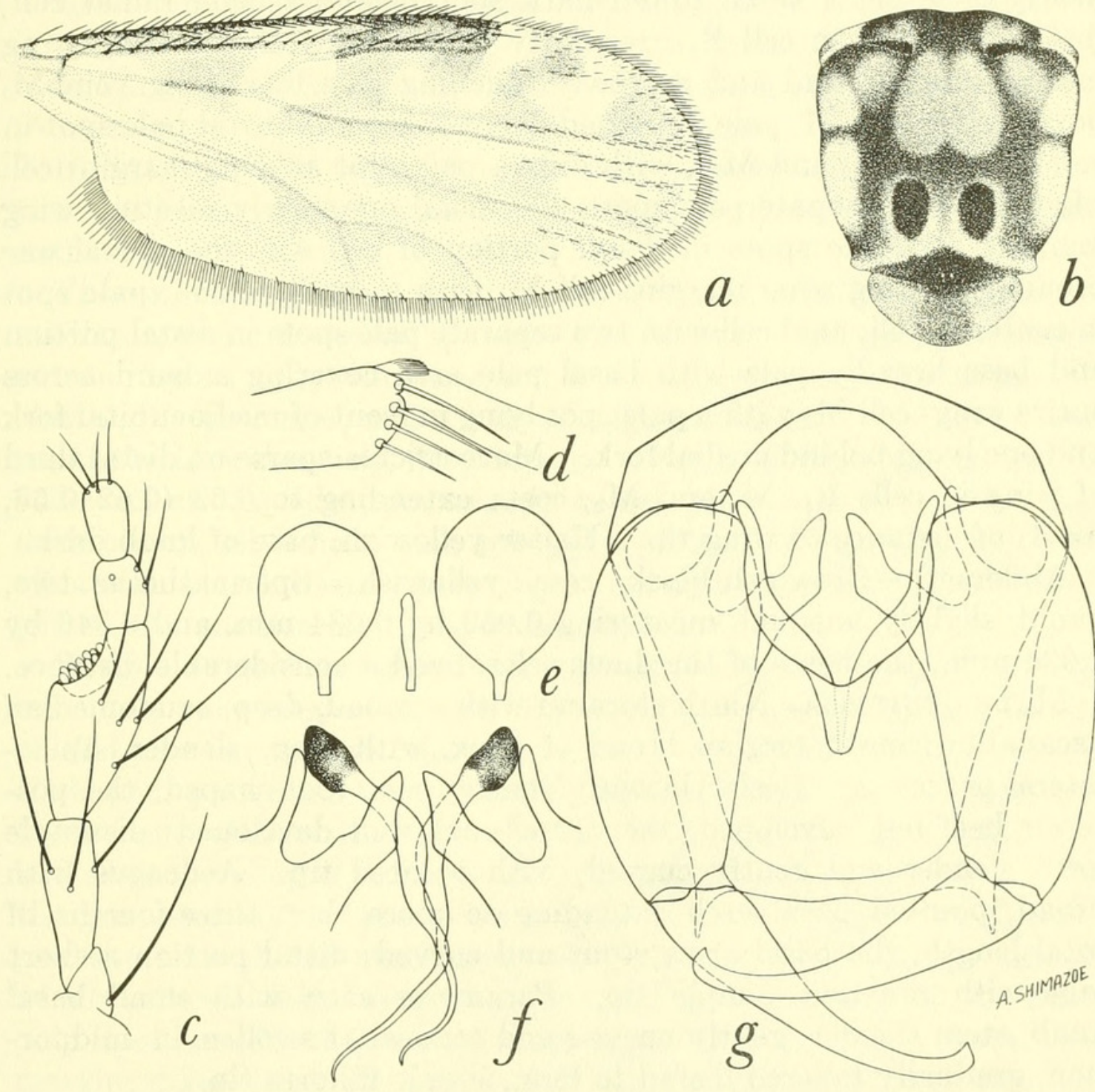

Figure 50.-Culicoides azureus, new species. $a-e$, Female: $a$, wing; $b$, thoracic pattern; $c$, palpus; $d$, tibial comb; $e$, spermathecae. $f, g$, Male: $f$, parameres; $g$, genitalia, parameres removed. 
$8: 16: 23: 9: 9$, third segment moderately swollen, 2.18 (2.09-2.27, $\mathrm{n}=2$ ) times as long as greatest breadth, with a broad, shallow, sensory pit. Mandible with 14-15 $(\mathrm{n}=2)$ teeth.

Thorax.-Mesonotum a rich, dark, brownish black with a prominent pattern of bluish gray patches, consisting mainly of a submedian, anterior, elongate pair and three lateral pairs of irregularly rounded, smaller spots. Scutellum brownish black in middle, grayish pruinose on sides; postscutellum and pleuron brownish black. Legs dark brownish black, femora with subapical and tibiae with subbasal, narrow pale rings; hind tibial comb with four $(n=5)$ spines, the one nearest the spur longest.

Wing.-Pattern as figured; second radial cell moderately dark, markedly elongated; pale spot over r-m crossvein very large, extending well into cell $\mathrm{M}_{2}$; poststigmatic pale spot in cell $\mathrm{R}_{5}$ 3-lobed, L-shaped, nearly isolating a small round dark spot behind second radial cell; distal pale spot in cell $R_{5}$ irregularly shaped, broadly meeting wing margin anterodistad and narrowly touching pale line along vein $\mathbf{M}_{1}$ posteriorly; vein $M_{1}$ pale margined distal to level of distal pale spot in cell $R_{5}$, veins $M_{2}$ and $M_{3+4}$ with only a pale spot at wing margin; cell $M_{1}$ with two elongate pale spots, the distal one nearly meeting wing margin; two pale spots in distal portion of cell $\mathrm{M}_{2}$, the apical one broadly meeting wing margin; cell $\mathrm{M}_{4}$ with a small, round, pale spot in center of cell; anal cell with two separate pale spots in distal portion and base broadly pale with basal pale area covering a band across entire wing; cell $\mathrm{M}_{2}$ with a pale spot lying in front of mediocubital fork and one lying behind medial fork. Macrotrichia sparse on distal third of wing in cells $R_{5}, M_{1}$ and $M_{2}$; costa extending to $0.63(0.62-0.68$, $\mathrm{n}=3$ ) of distance to wing tip. Halter yellowish, base of knob dark.

Abdomen.-Brownish black, cerci yellowish. Spermathecae two, ovoid, slightly unequal, measuring 0.050 by $0.034 \mathrm{~mm}$. and 0.046 by $0.034 \mathrm{~mm}$., the bases of the ducts sclerotized a considerable distance.

Male genitalia: Ninth sternum with a broad, deep, caudomedian excavation; ninth tergum broad at apex, with long, slender, apicolateral processes. Basistyle with ventral root foot-shaped, the posterior heel not developed, the dorsal root well developed; dististyle long, slender and gently curved, with pointed tip. Aedeagus with broad, pointed basal arch extending to more than three-fourths of total length, the basal arms stout and curved; distal portion a short lobe with rounded, simple tip. Parameres each with small basal knob, stem slender, gently curved and somewhat swollen in midportion, gradually tapered distad to long, simple filiform tip.

Distribution: Panama.

Specimens examined: Holotype female (USNM 63167), allotype male, Almirante, Bocas del Toro Province, December 1952, F. S. 
Blanton, light trap. Paratypes, 1 male, 7 females, same data except dates November and December 1952.

Discussion: This species is very closely related to mojingaensis Wirth and Blanton, but can readily be distinguished by the submedian mesonotal spots being bluish instead of bright yellowish, vein $\mathrm{M}_{2}$ not extensively pale margined distally, the distal pale spot in cell $M_{1}$ nearly meeting the wing margin, the apex of the male aedeagus stouter, and the tips of the parameres much slenderer.

\section{Culicoides mojingaensis Wirth and Blanton}

Figure 51

Culicoides mojingaensis Wirth and Blanton, 1953, Journ. Parasit., vol. 39, p. 232 (male [sic], female; wing, mesonotum, palpus, spermathecae, male genitalia [sic]).

Female: Length of wing $0.96(0.89-1.02, \mathrm{n}=5) \mathrm{mm}$.

Head.-Eyes contiguous, bare. Antenna with flagellar segments in proportion of $16: 10: 11: 12: 13: 14: 14: 15: 22: 23: 25: 27: 43$, antennal ratio $1.32(1.31-1.33, \mathrm{n}=2)$, distal sensory tufts present on segments III, viII-x, rarely present on viI. Palpal segments in proportion of $9: 16: 24: 9: 9$, third segment moderately swollen, $2.1(1.8-2.3, \mathrm{n}=5)$ times as long as broad, with a broad, shallow, sensory pit. Mandible with $14(\mathrm{n}=4)$ teeth.

Thorax.-Mesonotum with a conspicuous 4-colored pattern; a median anterior marginal spot blackish; a pair of elongate submedian anterior spots yellowish; irregular lateral spots and prescutellar area bluish gray pollinose; and a pair of angular, sublateral bands, broadest at the lateral suture, deep brown. Scutellum brownish in middle, yellowish on the sides; postscutellum and pleuron dark brown. Legs dark brown, all femora with subapical, tibiae with subbasal and hind tibia with apical, narrow pale rings; hind tibial comb with four $(n=7)$ spines, the one nearest the spur longest.

Wing.-Pattern as figured; second radial cell very dark; r-m crossvein in a very large pale spot extending from costal margin to half of distance across cell $\mathrm{M}_{2}$; cell $\mathrm{R}_{5}$ with two pale spots, a narrow, $\mathrm{U}$-shaped, poststigmatic area which isolates a small, round, dark spot behind end of second radial cell, the distal pale spot in cell $R_{5}$ large and diamond-shaped, broadly meeting wing margin anterodistad and the posterior corner joined with pale line bordering vein $\mathrm{M}_{1}$; two pale spots in cell $\mathrm{M}_{1}$, each fusing with the pale line bordering vein $\mathrm{M}_{1}$ which extends distad from the proximal pale spot in cell $\mathrm{M}_{1}$, distal pale spot in cell $\mathrm{M}_{1}$ located more than its own length from wing margin; distal third of vein $\mathrm{M}_{2}$ pale-margined; cell $\mathrm{M}_{2}$ with two pale spots in distal part, the distal one small and round and not quite meeting wing margin; apex of vein $\mathrm{M}_{3+4}$ with a pale spot at wing margin; cell $\mathrm{M}_{4}$ with a large round pale spot in middle of cell, barely 

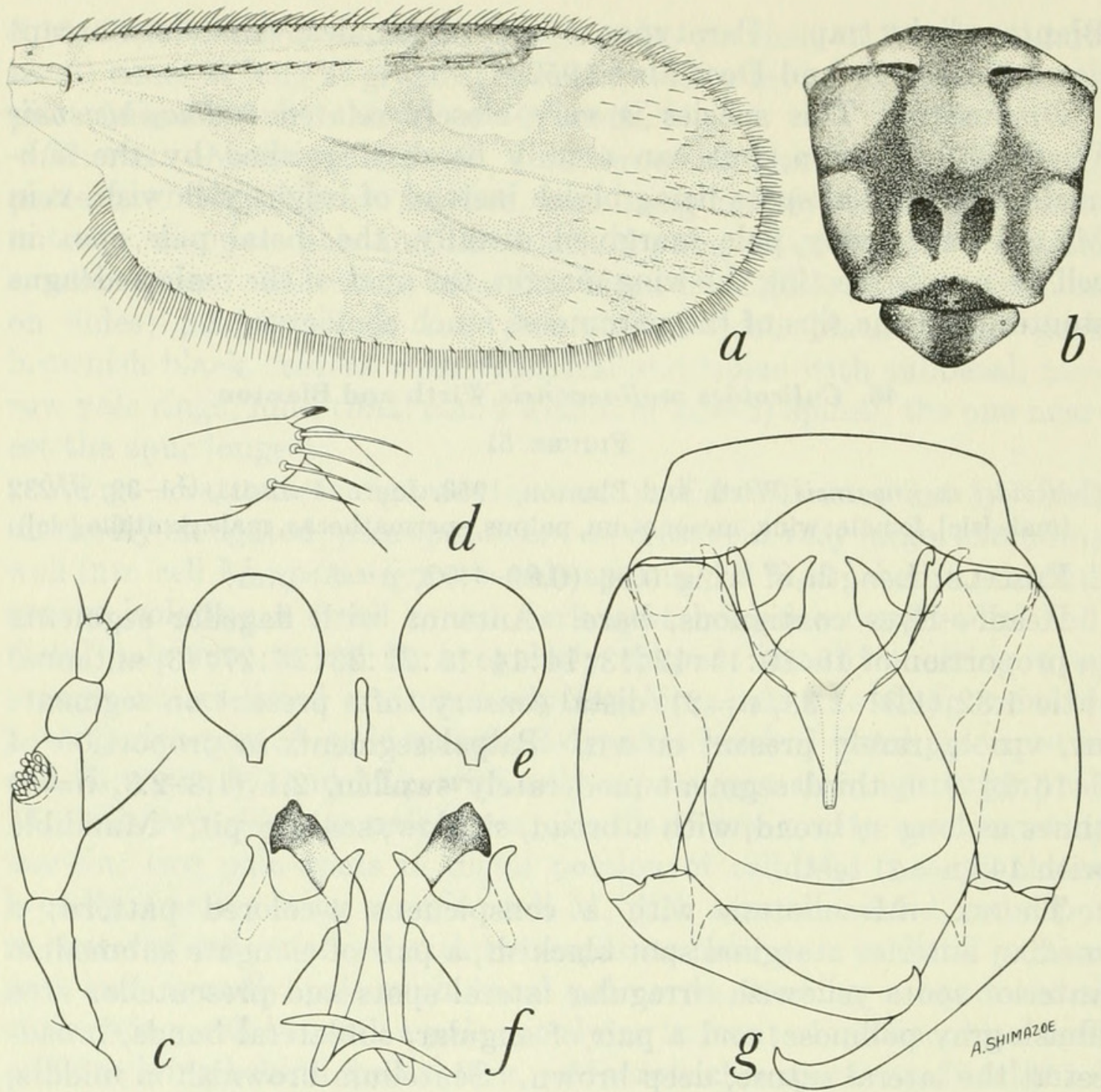

FIGURE 51.-Culicoides mojingaensis Wirth and Blanton. $a-e$, Female: $a$, wing; $b$, thoracic pattern: $c$, palpus; $d$, tibial comb; $e$, spermathecae. $f, g$, Male: $f$, parameres; $g$, genitalia, parameres removed.

meeting wing margin; two small round pale spots in distal part of anal cell; cell $\mathrm{M}_{2}$ with a small pale spot present in front of mediocubital fork and one present behind medial fork; base of wing with large pale area extending into base of anal cell. Macrotrichia sparse on distal third of wing, none in cell $\mathrm{M}_{4}$ or anal cell, costa extending to $0.66(0.63-0.68, \mathrm{n}=5)$ of distance to wing tip. Halter pale, base of the knob dark.

Abdomen.-Brownish black, cerci yellowish. Spermathecae two, oval, slightly unequal, measuring 0.049 by 0.038 and 0.039 by 0.034 $\mathrm{mm}$., the bases of the ducts sclerotized a very short distance.

Male Genitalia.- Ninth sternum with a relatively narrow, deep, caudomedian excavation; ninth tergum broad at the apex with slender, pointed, apicolateral processes. Basistyle with ventral root footshaped, the posterior heel not developed, dorsal root slender; disti- 
style slender, with bent, pointed apex. Aedeagus with pointed basal arch extending to half of total length, the basal arms slender and curved, distal portion tapered to very slender distal point. Parameres each with large basal knob, stem gently curving and moderately stout on basal portion, midportion slender and straight, ventral lobe absent, abruptly curved to relatively stout, long simple tip.

Distribution: Panama.

PANAMA RECORDS:

Bocas del Toro Province: Almirante.

Canal Zone: Fort Davis, Fort San Lorenzo, Fort Sherman, Loma Boracho, Mojinga Swamp (type locality).

Los Santos Province: Pan de Azucar.

Panamá Province: Arraiján.

Discussion: Our original description of the male genitalia of mojingaensis was based on a misidentified specimen of paucienfuscatus. We have seen correctly associated males from most of the above localities, and on these the present description of the male is based.

This species is related to paucienfuscatus Barbosa, bricenoi Ortiz, and azureus, new species, all of which have the distal pale spot in cell $\mathrm{M}_{1}$ nearly attaining wing margin. Paucienfuscatus and bricenoi have the pale wing spots much more extensive with the pale margins of veins $\mathrm{M}_{1}$ and $\mathrm{M}_{2}$ connected extensively to the discal pale wing spots. In azureus vein $\mathrm{M}_{2}$ is pale only on a small apical spot at the wing margin and the parameres are slenderer, while in bricenoi the parameres have remarkable spatulate tips. Bricenoi is known only from Venezuela and Ecuador.

\section{Culicoides paucienfuscatus Barbosa}

FIGURE 52

Culicoides paucienfuscatus Barbosa, 1947, Anais Soc. Biol. Pernambuco, vol. 7, p. 23 (female; Brazil, Panama; fig. wing, palpus).

Culicoides mojingaensis Wirth and Blanton, 1953, Journ. Parasit., vol. 39, p. 232 (in part, male allotype was misdetermined).

Female: Length of wing $1.02(0.84-1.16, \mathrm{n}=13) \mathrm{mm}$.

Head.-Eyes narrowly separated, bare. Antenna with flagellar segments in proportion of $16: 14: 14: 14: 13: 14: 13: 13: 21: 21: 23: 23: 36$, antennal ratio $1.18(1.02-1.34, \mathrm{n}=8)$; distal sensory tufts present on segments III, VII-X, rarely absent on VII. Palpal segments in proportion of $11: 26: 28: 9: 12$, third segment moderately swollen, 2.21 $(1.80-2.73, \mathrm{n}=13)$ times as long as greatest breadth, with a moderately large, deep, sensory pit. Mandible with $12(11-15, \mathrm{n}=12)$ teeth.

Thorax.-Mesonotum pruinose blackish brown on anterior and lateral margins, midportion grayish brown pruinose, with pattern of elongate, longitudinal oval patches delimited by three narrow dark 

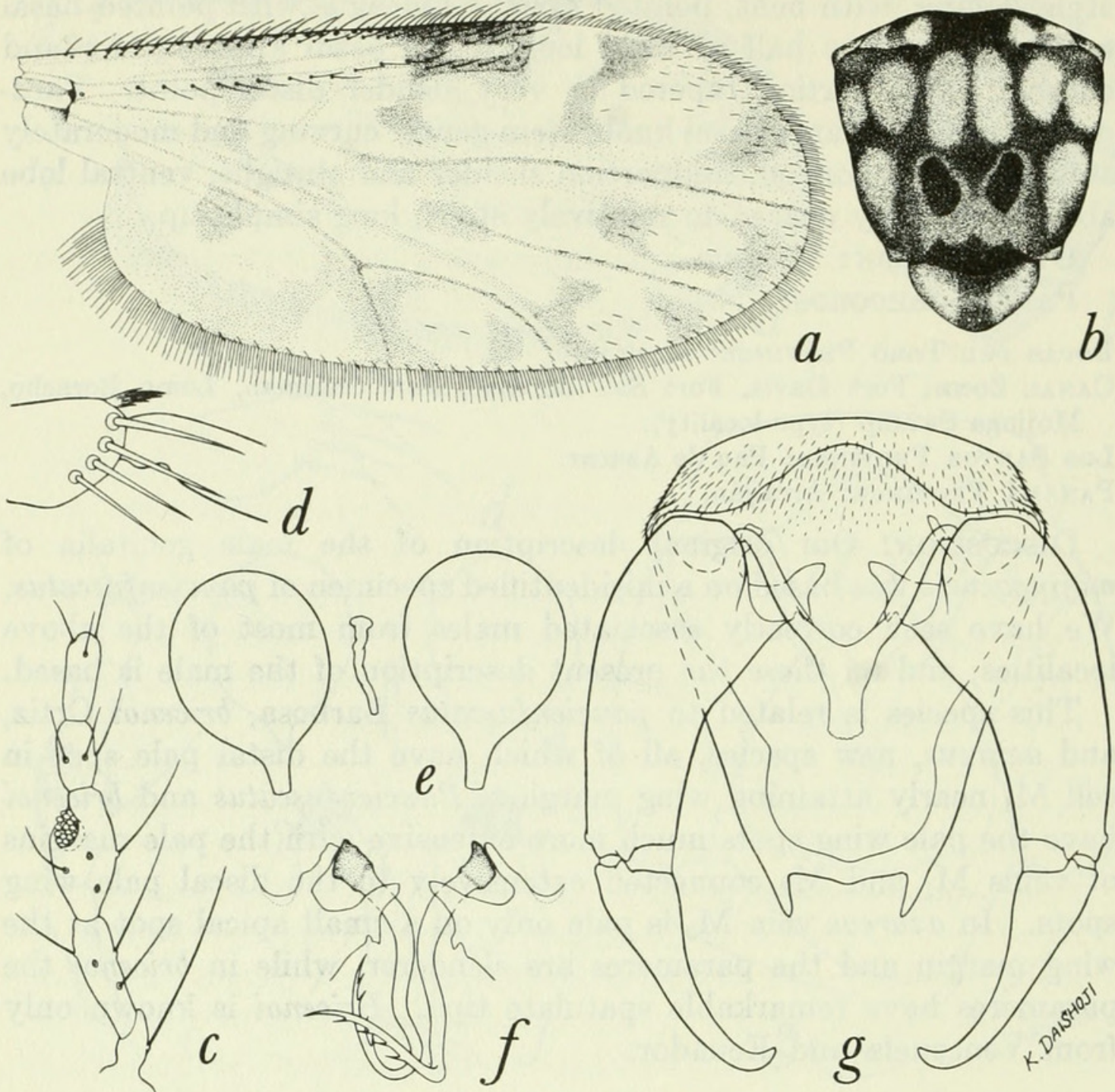

FIGURE 52.-Culicoides paucienfuscatus Barbosa. $a-e$, Female: $a$, wing; $b$, thoracic pattern; $c$, palpus; $d$, tibial comb; $e$, spermathecae. $f, g$, Male: $f$, parameres; $g$, genitalia, parameres removed.

brown longitudinal lines with a transverse line at level of lateral suture. Scutellum narrowly blackish in middle, yellowish on sides; postscutellum and pleuron blackish. Legs dark brown; all femora with subapical, tibiae with subbasal and hind tibia with apical, narrow pale rings; hind tibial comb with four $4(n=12)$ spines, the two nearest the spur longest, subequal.

Wing.-Pattern as figured; second radial cell very dark; very large pale spot over r-m crossvein, broadly reaching costal margin and extending through half the breadth of cell $\mathrm{M}_{2}$; wing pattern appearing as limited dark spots on a pale ground due to extensive fusion of the pale spots; pale spots at post-stigmatic level continued as an unbroken band to hind wing margin, distad of this band veins $M_{1}, M_{2}$ and $M_{3+4}$ are pale margined; cell $\mathrm{R}_{5}$ with a $\mathrm{C}$-shaped pale poststigmatic pale spot 
isolating a small round black spot behind apex of second radial cell; distal pale spot in cell $R_{5}$ quadrate, broadly extending across cell from anterior wing margin to vein $\mathrm{M}_{1}$; two pale spots present in cell $\mathrm{M}_{1}$, the proximal one merged into transverse band of wing, the distal one failing by less than its length to meet wing margin; two pale spots in distal part of cell $\mathrm{M}_{2}$, the distal one meeting wing margin; pale spot in cell $\mathrm{M}_{4}$ large and broadly meeting wing margin; two pale spots in distal portion of anal cell; cell $\mathrm{M}_{2}$ with small pale spot in front of mediocubital fork and a pale spot behind medial fork; base of wing broadly pale. Macrotrichia numerous on distal half of wing, a few in cell $\mathrm{M}_{4}$ and anal cell; costa extending to $0.63(0.60-0.66, \mathrm{n}=12)$ of distance to wing tip. Halter yellowish.

Abdomen.-Dark brown; cerci pale. Spermathecae two, pyriform, slightly unequal, measuring 0.055 by $0.038 \mathrm{~mm}$. and 0.050 by $0.036 \mathrm{~mm}$., the bases of the ducts sclerotized a considerable distance.

Male Genitalia: Ninth sternum with a moderately deep caudomedian excavation, the ventral membrane spiculate; ninth tergum long and tapering, the apicolateral processes long and pointed. Basistyle with ventral root foot-shaped, dorsal root slender; dististyle long and slender, moderately curved. Aedeagus with rounded basal arch extending to about half of total length, the basal arms curved and slender, the distal apex slender and rounded with fine distal spinules. Parameres each with large basal knob, stem gently curved on basal portion, slender, distally slightly sinuate, without ventral lobe, very long, with pointed tip bearing a lateral fringe of fine spines.

Distribution: Brazil; Panama; Trinidad (Tucker Valley).

Panama Records.

Canal Zone: Camp Piña, Fort Davis, Fort San Lorenzo, Fort Sherman, Loma Boracho, Madden Dam, Mojinga Swamp.

Colón Province: Nuevo Chagres, Piña.

Darién Province: El Real, Jaqué, Punta Patiño.

Panamá Province: La Jolla, Pacora, Pedregal, Río Trinidad (Busck, coll.), Tocumen.

Veraguas Province: Río Santa María.

Discussion: Barbosa described paucienfuscatus from two cotype specimens in the U. S. National Museum: a pinned female from Manaus, Amazonas, Brazil, June 1931, R. C. Shannon, which we are here designating the lectotype, and a female (paratype), mounted on a slide, from Río Trinidad, Panama, June 9, 1912, A. Busck.

This species, while remaining remarkably constant in color and wing pattern characters and male genitalic structure, exhibits an interesting type of variation in structural characters which we suspect may lead to the recognition of subspecies when more distributional records are obtained. For example, the Panama specimens from near the Canal Zone have a much stouter third palpal segment (1.64-2.09 times as 
long as broad) and an antennal ratio of 1.07-1.12. A series of specimens measured from Trinidad, B. W. I., have the palpal ratio 2.15 to 2.64 and the antennal ratio 1.28-1.34. Furthermore, specimens from Jaqué in Darién Province and Río Santa María in Veraguas have an even slenderer palpus (2.4-2.73) and shorter distal antennal segments (antennal ratio, 1.02-1.19).

The extreme development and confluence of the pale areas of the wing and the unicolorous grayish brown mesonotum with a pattern of narrow dark brown lines will readily separate paucienfuscatus from the related species, mojingaensis and azureus.

\section{Culicoides pifanoi Ortiz}

\section{Figure 53}

Culicoides pifanoi Ortiz, 1951, Rev. Sanid. Asist. Soc., vol. 16, p. 588 (male, female; San Felipe, Yaracuy, Venezuela; fig. wing, mesonotum, palpus, antenna, spermathecae, male genitalia); 1954, Arch. Venezolana Patol. Trop. Parasit. Med., vol. 2, p. 225 (female; fig. wing, palpus, spermathecae, antenna).-Fox, 1955, Journ. Agr. Univ. Puerto Rico, vol. 39, p. 251 (synonym, tricoloratus Wirth and Blanton).

Culicoides tricoloratus Wirth and Blanton, 1953, Journ. Parasit., vol. 39, p. 233 (male, female; Panama, Florida; fig. wing, mesonotum, palpus, male genitalia).

Female: Length of wing $0.79(0.73-0.89, \mathrm{n}=9) \mathrm{mm}$.

Head.-Eyes narrowly separated, bare. Antenna with flagellar segments in proportion of $14: 10: 11: 13: 12: 12: 13: 13: 14: 16: 16: 16: 26$, antennal ratio $0.91(0.84-0.97, \mathrm{n}=6)$; distal sensory tufts present on segments III, VII-X. Palpal segments in proportion of $7: 16: 16$ : $7: 7$, third segment moderately swollen, $1.8(1.6-1.9, \mathrm{n}=8)$ times as long as greatest breadth, with a large, shallow sensory pit. Mandible with $14(12-15, \mathrm{n}=6)$ teeth.

Thorax.-Mesonotum dark brown with a pair of elongate, submedian, yellowish spots on disc and two sublateral pairs of irregularly rounded, bluish pruinose light spots. Scutellum narrowly dark brown in middle, sides paler. Postscutellum dark brown, pleuron light brown, darker across middle transversely. Legs dark brown; fore and mid femora with subapical (a faint trace of subapical pale ring on hind femur of some specimens), all tibiae with subbasal and hind tibia with apical, narrow pale rings; hind tibial comb with four $(n=9)$ spines, the one nearest the spur longest.

Wing.-Pattern as figured, pale spot over r-m crossvein extensive; poststigmatic pale spot consisting of a single spot extending from anterior wing margin around end and posterior side of second radial cell and narrowly connected proximad to the pale spot over r-m crossvein; distal pale spot in cell $R_{5}$ more or less quadrate in outline with one side meeting wing margin and one corner nearly meeting the pale 

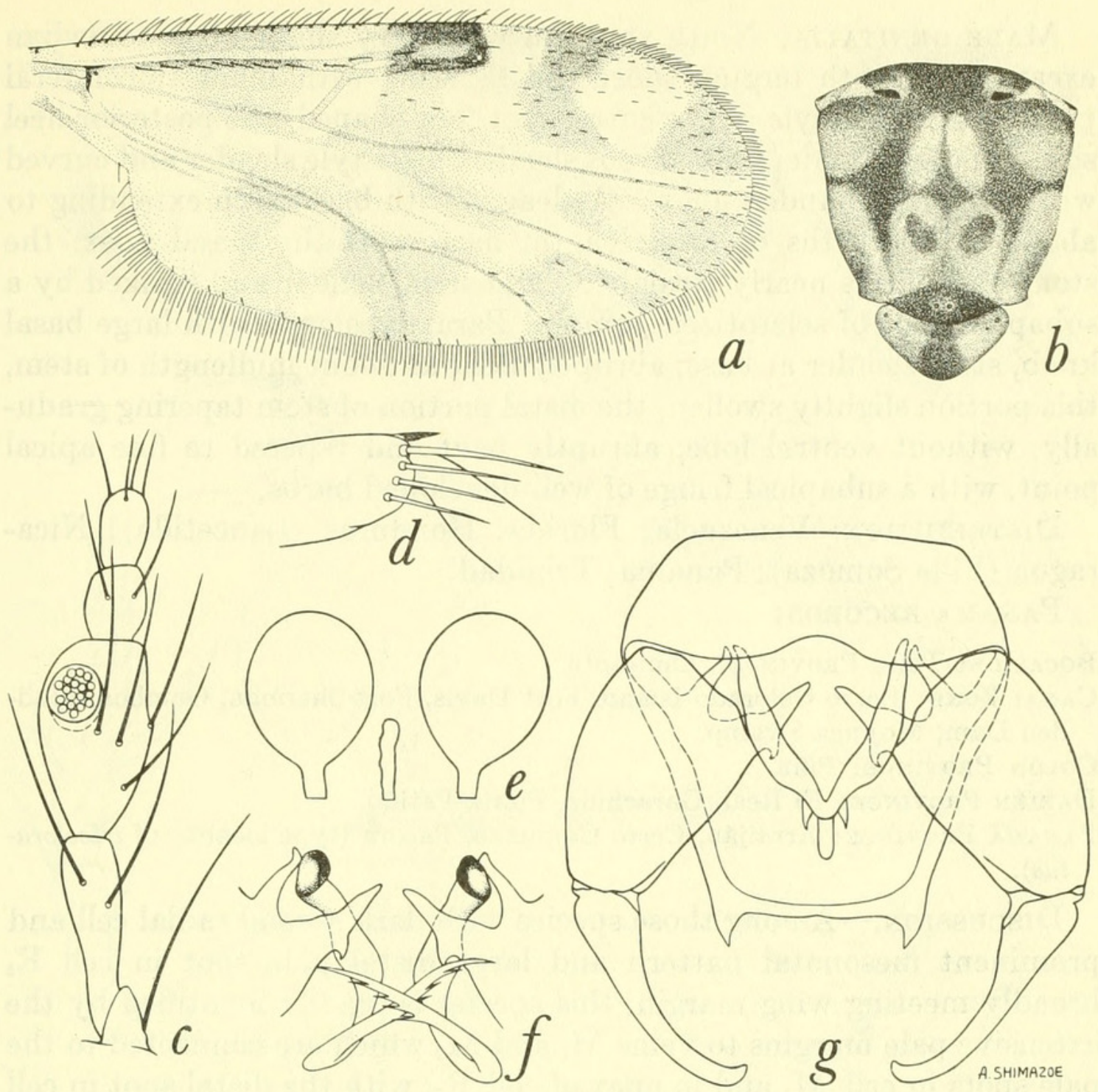

Figure 53.-Culicoides pifanoi Ortiz. a-e, Female: $a$, wing; $b$, thoracic pattern; $c$, palpus; $d$, tibial comb; $e$, spermathecae. $f, g$, Male: $f$, parameres; $g$, genitalia, parameres removed.

line along vein $\mathrm{M}_{1}$; veins $\mathrm{M}_{1}$ and $\mathrm{M}_{2}$ pale margined on their distal halves, the basal pale spot in cell $\mathrm{M}_{1}$ joined to these pale lines, the distal pale spot in cell $\mathrm{M}_{1}$ far removed from wing margin; the two distal pale spots in cell $\mathrm{M}_{2}$ not connected; cell $\mathrm{M}_{4}$ with large pale spot; two pale spots in distal part of anal cell; pale spots lying ahead of mediocubital fork and behind medial fork joined by a pale area extending to base of wing; proximal fifth of wing pale from costal margin to anal angle of anal cell. Macrotrichia scanty, only a few in cells $R_{5}$ and $M_{1}$; costa extending to $0.60(0.58-0.62, \mathrm{n}=9)$ of distance to wing tip. Halter pale.

Abdomen.-Brown, terga more or less pale; cerci pale. Spermathecae two, ovoid, unequal, measuring 0.049 by $0.046 \mathrm{~mm}$. and 0.038 by $0.026 \mathrm{~mm}$., the bases of the ducts sclerotized for a distance of about a fourth the length of spermathecae. 
Male Genitalia: Ninth sternum with very shallow caudomedian excavation; ninth tergum short and tapering with small apicolateral processes. Basistyle with ventral root foot-shaped, the posterior heel small, the toe slender, dorsal root slender; dististyle slender and curved with slightly expanded apex. Aedeagus with basal arch extending to about three-fourths of total length, narrow at the mesal apex, the stout basal arms nearly straight; distal stem slender and flanked by a subapical pair of sclerotized points. Parameres each with large basal knob, stem slender at base, abruptly bent at about midlength of stem, this portion slightly swollen, the distal portion of stem tapering gradually, without ventral lobe, abruptly bent and tapered to fine apical point, with a subapical fringe of well-developed barbs.

Distribution: Venezuela; Florida; Honduras (Lancetilla); Nicaragua (Villa Somoza); Panama; Trinidad.

\section{PANAMA RECORDS:}

Bocas del Toro Province: Almirante.

Canal Zone: Barro Colorado Island, Fort Davis, Fort Sherman, Gamboa, Madden Dam, Mojinga Swamp.

Colón Province: Piña.

Darien Province: El Real, Garachiné, Punta Patiño.

Panamá Province: Arraiján, Cerro Campana, Pacora (type locality of tricoloratus).

Discussion.-Among those species with dark second radial cell and prominent mesonotal pattern and large distal pale spot in cell $R_{5}$ broadly meeting wing margin, this species is readily identified by the extensive pale margins to veins $\mathrm{M}_{1}$ and $\mathrm{M}_{2}$ which are connected to the pale spots in cell $M_{1}$ and in apex of cell $R_{5}$, with the distal spot in cell $M_{1}$ much smaller than its distance from the wing margin. In some specimens the bluish pruinosity of the lateral pale areas of the mesonotum is not evident and in some there is an indication of a subapical pale band on the hind femur.

\section{Culicoides dicrourus Wirth and Blanton}

\section{Figure 54}

Culicoides dicrourus Wirth and Blanton, 1955, Bull. Brooklyn Ent. Soc., vol. 50, p. 123 (male, female; Panama; fig. wing, palpus, spermathecae, male genitalia).

Female: Length of wing $1.14(1.02-1.25, \mathrm{n}=10) \mathrm{mm}$.

Head.-Eyes narrowly separated, bare. Antenna with flagellar segments in proportion of $19: 16: 16: 16: 17: 17: 17: 17: 23: 25: 27: 27: 41$, antennal ratio $1.04(0.98-1.07, \mathrm{n}=4)$; distal sensory tufts present on segments III, VI-X. Palpal segments in proportion of 10:22:28:10:10, third segment swollen, $2.1(1.9-2.3, \mathrm{n}=8)$ times as long as greatest 


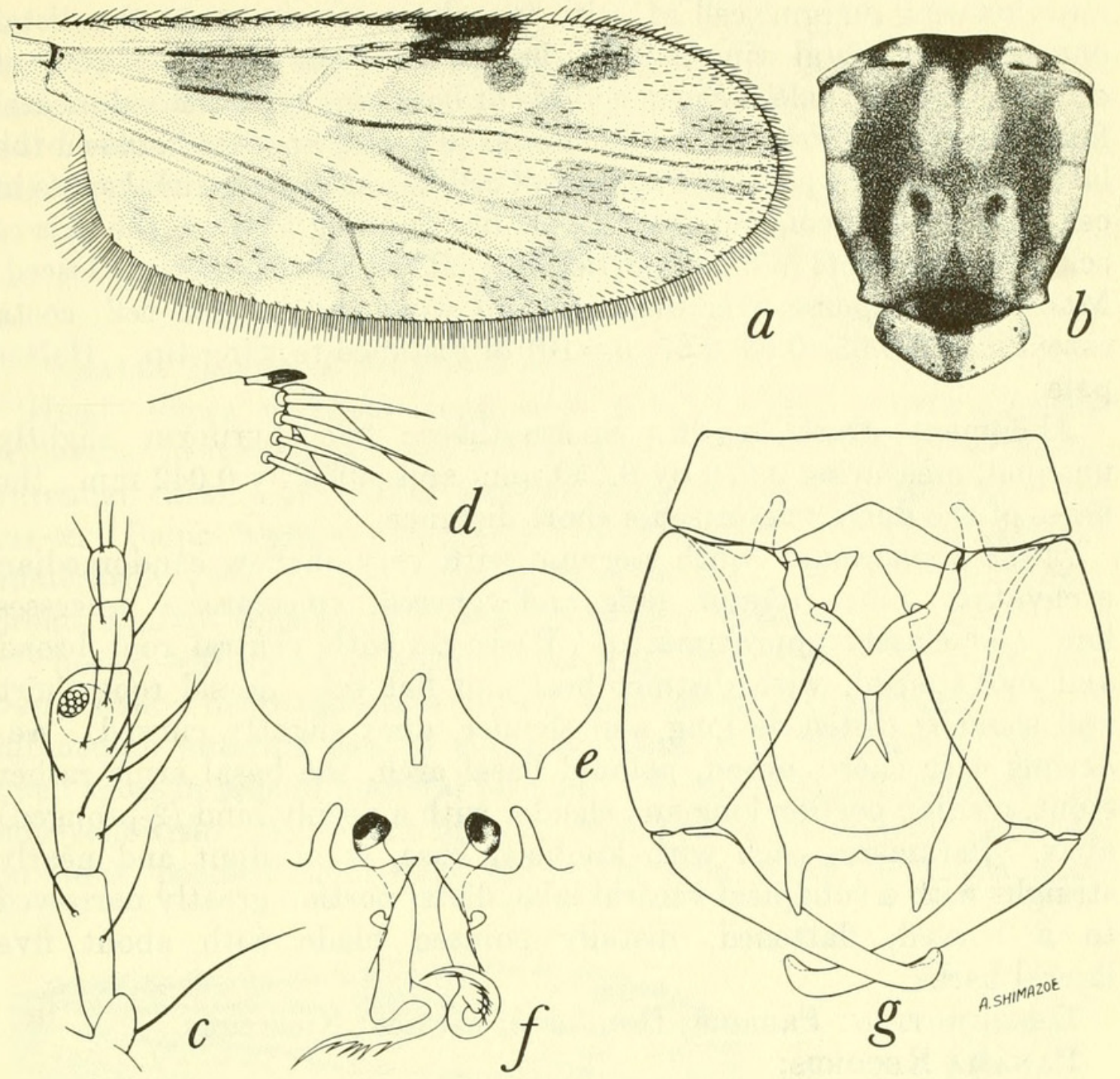

Figure 54.-Culicoides dicrourus Wirth and Blanton. $a-e$, Female: $a$, wing; $b$, thoracic pattern; $c$, palpus; $d$, tibial comb; $e$, spermathecae. $f, g$, Male: $f$, parameres; $g$, genitalia, parameres removed.

breadth, with a large sensory pit opening by a slightly smaller pore. Mandible with $13(12-14, \mathrm{n}=11)$ teeth.

Thorax.-Mesonotum elongated, dark brown, with a prominent pattern of yellowish patches as figured. Scutellum narrowly dark in middle, yellowish on sides. Legs dark brown, all femora with subapical, tibiae with subbasal and hind tibia with apical, broad yellowish bands: four distal tarsomeres pale; hind tibial comb with four $(n=9)$ spines, the two adjacent to the spur longest, subequal.

Wings.-Pattern as figured, large yellow spots at base of wing and over $r-m$ crossvein; cell $R_{5}$ with two large pale marks, the poststigmatic spot roughly in the form of an incomplete circle isolating a small black round spot just behind end of second radial cell, distal pale spot in cell $R_{5}$ oblique and hourglass-shaped, very broadly meeting the 
anterior wing margin; cell $\mathrm{M}_{1}$ with two elongate pale spots, the distal one attaining distal wing margin; large pale spots present in ends of cells $\mathrm{M}_{2}$ and $\mathrm{M}_{4}$, pale areas in cell $\mathrm{M}_{2}$ at base, one lying behind medial fork, one lying in front of mediocubital fork and another between the latter two and the pale spot at apex of cell $\mathrm{M}_{2}$, all the proximal spots in cell $\mathrm{M}_{2}$ narrowly connected by a pale line running through the axis of cell; two pale spots in distal portion of anal cell more or less coalesced. Macrotrichia sparse over distal half of wing and in anal cell; costa extending to $0.65(0.63-0.67, \mathrm{n}=10)$ of distance to wing tip. Halter pale.

Abdomen.-Dark brown. Spermathecae two, pyriform, slightly unequal, measuring 0.070 by $0.050 \mathrm{~mm}$. and 0.062 by $0.042 \mathrm{~mm}$., the bases of the ducts sclerotized a short distance.

Male genitalia: Ninth sternum with very shallow caudomedian excavation; ninth tergum long and tapered, apicolateral processes long and closely approximated. Basistyle with ventral root broad and foot-shaped, with distinct heel and flat sole, dorsal root short and slender; dististyle long and slender, apex slightly curved. Aedeagus with short, broad, pointed basal arch, the basal arms rather stout, median portion long and slender with a deeply bifid (2-pronged) apex. Parameres each with knobbed base, stem stout and nearly straight with a subapical ventral lobe, distal portion greatly narrowed to a curved, flattened, distally pointed blade with about five lateral barbs.

Distribution: Panama; Honduras; Mexico; Nicaragua.

Panama ReCORds:

Bocas del Toro Province: Almirante.

Canal Zone: Atlantic side; Fort Clayton, Fort Davis, Fort Gulick; Fort Sherman, France Field, Huile Sia Clara(?), Loma Boracho (type locality), Madden Dam, Mindi Dairy, Mojinga Swamp, Tabernilla.

Chiriquí Province: Concepción, David, Tortugas.

Colón Province: Cativá, Piña.

Darién Province: El Real, Garachiné, Jaqué.

Panamá Province: Arraiján, Capitana, La Jolla, Pedregal, Isla Taboga, Tocumen.

Veraguas Province: Río Santa María, Las Palmas.

Discussion: Two species from Venezuela, discrepans Ortiz and Mirsa and avilaensis Ortiz and Mirsa, are closely related to dicrourus. The former species is larger (wing $1.9 \mathrm{~mm}$. long), wing with the pale spot at the end of the costa entire, not broken into two more or less separate spots and the lower portion not bending around $U$-shaped proximad toward vein $R_{4+5}$ and not isolating a separate black spot behind end of second radial cell, the three discal pale spots in cell $\mathrm{M}$ are discrete and not connected by a long pale line, there are 
antennal sensoria only on segments III, VIII-X, palpal segments IV and $\mathrm{v}$ combined are only 0.88 as long as III and the sensory pit on the third palpal segment is deeper with a narrower opening. C. avilaensis has the pale wing spots even more reduced than in discrepans.

\section{Culicoides volcanensis, new species}

\section{Figure 55}

Female: Length of wing $1.45 \mathrm{~mm}$.

Head.-Eyes narrowly separated, bare. Antenna with flagellar segments in proportion of $30: 24: 24: 25: 25: 26: 24: 24: 33: 35: 41: 43: 65$, antennal ratio 1.07; distal sensory tufts present on segments III, viI-X. Palpal segments in proportion of $9: 15: 30: 7: 10$, third segment moderately swollen, 2.1 times as long as greatest breadth, with a broad, shallow sensory pit. Mandible with 13 teeth.

Thorax.-Mesonotum slender and long, very convex on front portion; color a deep chocolate brown, anterior margin blackish, with a submedian anterior pair of elongate spots, a prescutellar area, two small spots in area of humeral pit and three small lateral spots on each side yellowish. Scutellum broadly dark brown in middle, yellowish on sides; postscutellum dark brown, pleuron yellowish above, dark
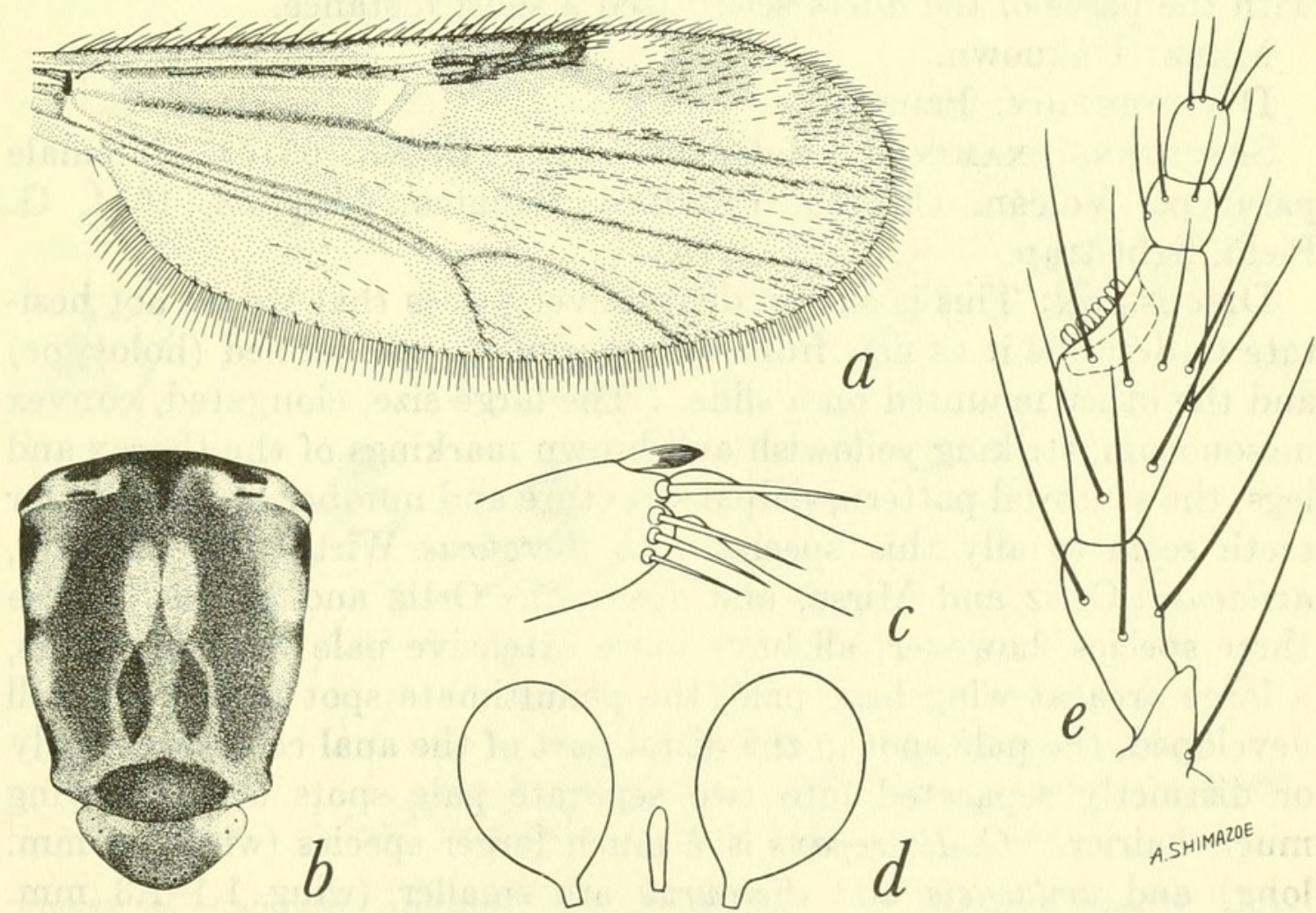

Figure 55.-Culicoides volcanensis, new species. Female: $a$, wing; $b$, thoracic pattern; $c$, tibial comb; $d$, spermathecae; $e$, palpus. 
brown below. Legs dark brown, femora with subapical, tibiae with subbasal and hind tibia with apical, narrow pale rings; knee spots blackish; hind tibial comb with four spines, the one nearest the spur longest.

Wing.-Very long and narrow, four times as long as broad; with pattern as figured; pale areas of wing few and not prominent; second radial cell very dark; pale area over $\mathrm{r}-\mathrm{m}$ crossvein continued in full breadth to costal margin; two well-separated, round, pale, poststigmatic spots in cell $R_{5}$, the posterior one located slightly proximad of the other; distal pale spot in cell $R_{5}$ small and oblique, meeting wing margin in slightly reduced breadth; apex of vein $\mathrm{M}_{1}$ with a pale spot at wing margin; cell $\mathrm{M}_{1}$ with two small pale spots, the distal one elongate and not quite meeting wing margin; two pale spots in distal portion of cell $\mathrm{M}_{2}$, the proximal one very small and faint, the distal one lying at wing margin; large pale spot in cell $\mathrm{M}_{4}$; a single, large double pale spot in distal portion of anal cell; a pale spot in cell $\mathbf{M}_{2}$ lying in front of mediocubital fork and one lying behind medial fork; a pale spot over basal arculus. Macrotrichia sparse over distal half of wing and a few in middle of anal cell; costa extending to 0.61 of distance to wing tip. Halter yellowish, base of the knob infuscated.

Abdomen.-Dark brown. Spermathecae two, collapsed in single slide specimen and not measured, apparently subequal and pyriform, with the bases of the ducts sclerotized a short distance.

MaLE: Unknown.

Distribution: Panama.

Specimens examined: Holotype female (USNM 63168); 1 female paratype, Volcán, Chiriquí Province, Panama, May 28, 1954, G. Field, light trap.

Discussion: This is such a distinctive species that we do not hesitate to describe it as new from two specimens, one pinned (holotype) and the other mounted on a slide. The large size, elongated, convex mesonotum, striking yellowish and brown markings of the thorax and legs, the sensorial pattern, palpal structure and number of mandibular teeth seem to ally this species with dicrourus Wirth and Blanton, avilaensis Ortiz and Mirsa, and discrepans Ortiz and Mirsa. These three species, however, all have more extensive pale wing markings, a large area at wing base pale, the penultimate spot in cell $\mathbf{M}_{2}$ well developed, the pale spot in the distal part of the anal cell more nearly or distinctly separated into two separate pale spots and the wing much hairier. C. discrepans is a much larger species (wing $1.9 \mathrm{~mm}$. long) and avilaensis and dicrourus are smaller (wing $1.1-1.3 \mathrm{~mm}$. long) than volcanensis. 


\section{Culicoides lyrinotatus Wirth and Blanton}

Figure 56

Culicoides lyrinotatus Wirth and Blanton, 1955, Bull. Brooklyn Ent. Soc., vol. 50, p. 126 (male, female; Panama; fig. wing, palpus, spermathecae, male genitalia).

Female: Length of wing $1.17(1.12-1.22, \mathrm{n}=2) \mathrm{mm}$.

Head-Eyes narrowly separated, bare. Antenna with flagellar segments in proportion of $28: 24: 24: 26: 24: 25: 25: 25: 26: 27: 35: 37: 58$, antennal ratio 1.01; distal sensory tufts present on segments III, viII-X. Palpal segments in proportion of $8: 20: 20: 10: 10$, third segment swollen, 2.27 times as long as greatest breadth, with a very broad, shallow, sensory pit. Mandible with 12 teeth.

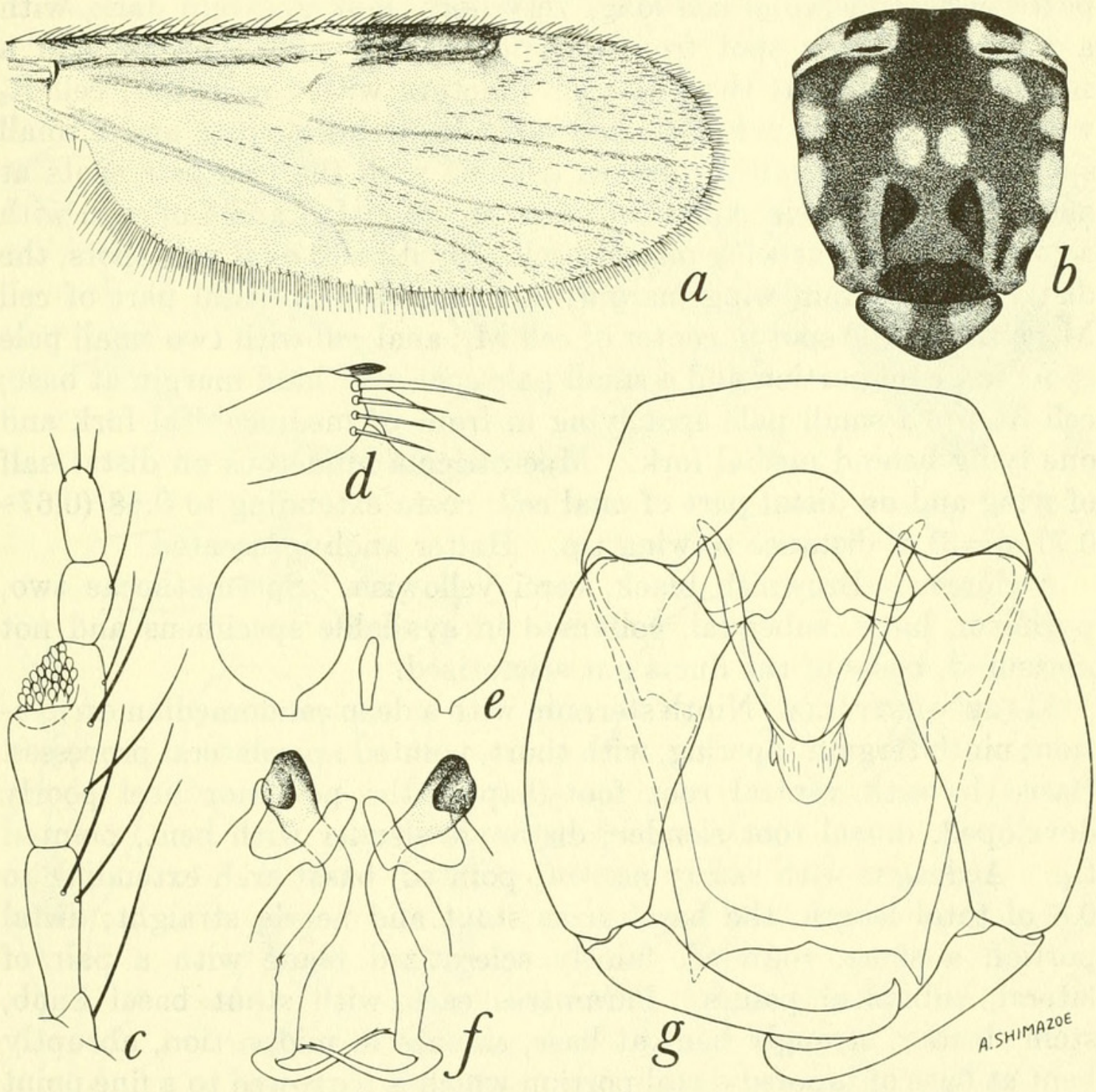

Figure 56.-Culicoides lyrinotatus Wirth and Blanton. a-e, Female: $a$, wing; $b$, thoracic pattern; c, palpus; $d$, tibial comb; $e$, spermathecae. $f, g$, Male: $f$, parameres; $g$, genitalia, parameres removed. 
Thorax.-Mesonotum dark brown, with prominent pattern of small, yellowish-white spots arranged as follows: a pair on humeri; two pairs of elongate submedian spots, one at suture, the other in the prescutellar depression; five pairs of very small spots in a pair of lyre-shaped, curving lines, the anteriormost pair covering sensory pits, the second pair behind and slightly laterad, third and fourth pairs on lateral margins on each side of suture and the fifth pair above the wing bases. Scutellum broadly black in the middle, yellowish on sides, extreme sides narrowly black. Postscutellum and pleuron dark brown. Legs dark brown, femora with subapical, tibiae with subbasal, and hind tibia with apical, narrow pale rings; hind tibial comb with four $(n=2)$ spines, the one nearest the spur longest.

Wing.-Pattern as figured, the distal wing spots forming a wheel-like pattern; second radial cell long, very dark; r-m crossvein dark, with a very small pale spot from anterior end to costal margin and a smaller pale spot at the posterior juncture with the media; cell $R_{5}$ with three small round spots in a triangle at end of costa and a small spot near base of cell forming a triangle with the two pale spots at ends of $\mathrm{r}-\mathrm{m}$ crossvein; apices of veins $\mathrm{M}_{1}, \mathrm{M}_{2}, \mathrm{M}_{3+4}$ and $\mathrm{Cu}_{1}$ each with a small pale spot at wing margin; cell $\mathrm{M}_{1}$ with two oval pale spots, the distal one far from wing margin; one pale spot in distal part of cell $\mathrm{M}_{2}$; a small pale spot in center of cell $\mathrm{M}_{4}$; anal cell with two small pale spots in distal portion and a small pale spot near hind margin at base; cell $\mathrm{M}_{2}$ with small pale spot lying in front of mediocubital fork and one lying behind medial fork. Macrotrichia numerous on distal half of wing and on distal part of anal cell; costa extending to $0.68(0.67-$ $0.71, \mathrm{n}=3$ ) of distance to wing tip. Halter knob infuscated.

Abdomen.-Brownish black, cerci yellowish. Spermathecae two, pyriform, large, subequal, collapsed in available specimens and not measured, bases of the ducts not sclerotized.

Male Genitalia: Ninth sternum with a deep caudomedian excavation; ninth tergum tapering, with short, pointed apicolateral processes. Basistyle with ventral root foot-shaped, the posterior heel poorly developed, dorsal root slender; dististyle slender with bent, pointed tip. Aedeagus with rather narrow, pointed, basal arch extending to 0.8 of total length, the basal arms stout and nearly straight; distal portion a short, rounded, faintly sclerotized blade with a pair of lateral, subapical points. Parameres each with stout basal knob, stem slender, strongly bent at base, sinuate in midportion, abruptly bent at base of tapered distal portion which is narrowed to a fine point with a few very minute, subapical spines.

Distribution: Panama; Nicaragua (Villa Somoza).

Panama Records:

Bocas del Toro Province: Almirante (type locality). 
Discussion: This species and reticulatus Lutz belong in the group with paucienfuscatus Barbosa on structural features in spite of the reduction of the wing markings to numerous small round pale spots. The distinctive arrangement of these spots in a wheel-like pattern on the distal part of the wing and the dark crossvein with small pale spots on each end will readily serve to identify lyrinotatus.

\section{Culicoides reticulatus Lutz}

FIGURE 57

Culicoides reticulatus Lutz, 1913, Mem. Inst. Oswaldo Cruz, vol. 5, p. 49 (male, female; Santos, Rio de Janeiro, and Bahia, Brazil; biology, larvae in crab holes in mangrove edge; fig. wing, palpus, male).-Barbosa, 1943, Rev. Brasil. Biol., vol. 3, p. 261 (Brazil; fig. wings, palpus, male genitalia).Forattini and Galvao, 1955, Rev. Brasileira Malariologia, vol. 7, p. 229 (male, female; Brazil, Panama; fig. wing, mesonotum, palpus, antenna, male genitalia).
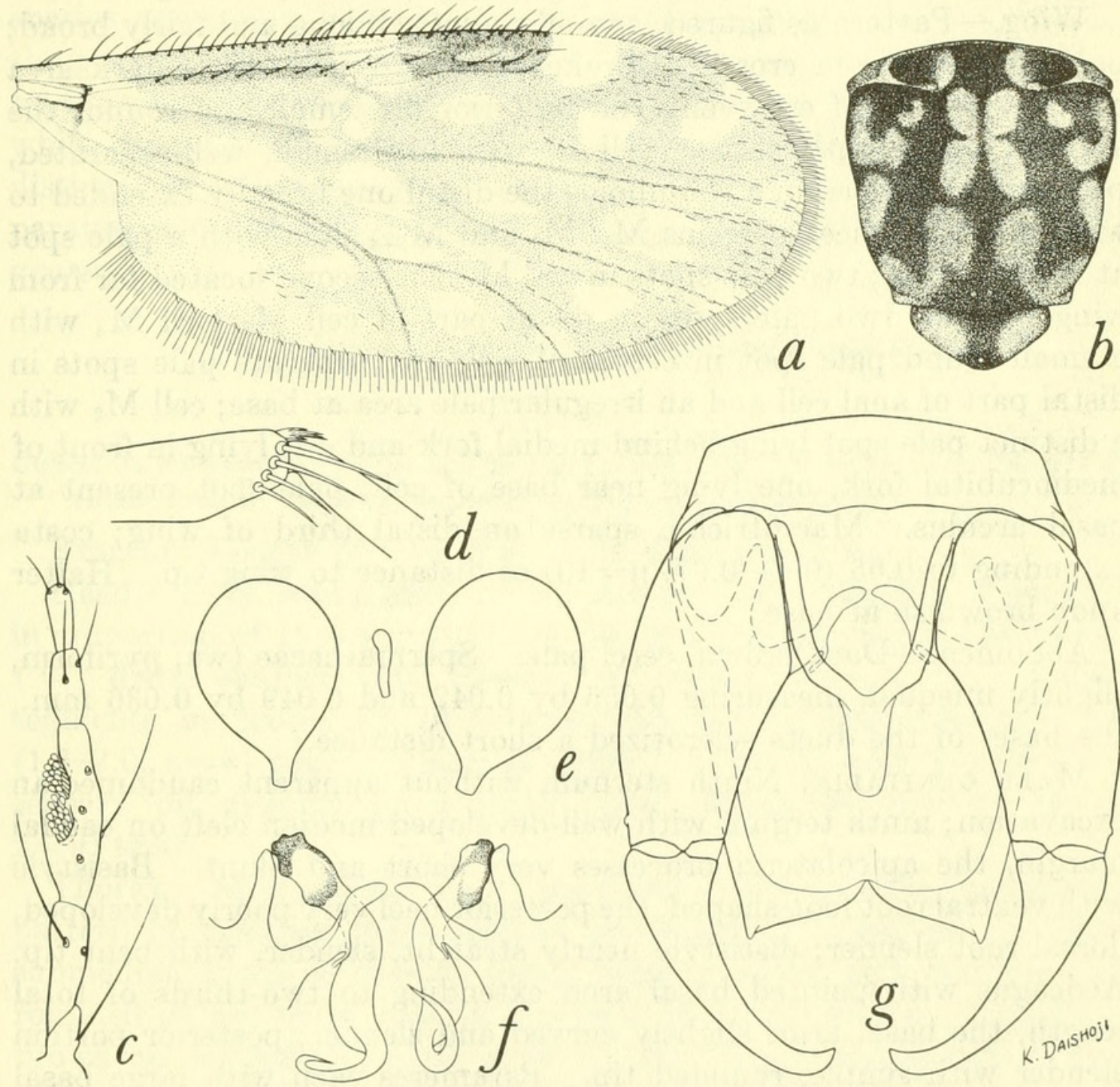

FigURE 57.-Culicoides reticulatus Lutz. $a-e$, Female: $a$, wing; $b$, thoracic pattern; $c$, palpus; $d$, tibial comb; $e$, spermathecae. $f, g$, Male: $f$, parameres; $g$, genitalia, parameres removed. 


\section{Female: Length of wing $0.96(0.89-1.06, \mathrm{n}=10) \mathrm{mm}$.}

Head--Eyes narrowly separated, bare. Antenna with flagellar segments in proportion of $19: 14: 15: 16: 16: 16: 16: 16: 22: 24: 26: 26: 44$, antennal ratio $1.10(1.08-1.11, \mathrm{n}=3)$; distal sensory tufts present on segments III, viII-X. Palpal segments in proportion of $10: 22: 34: 13: 15$, third segment extremely long, slightly swollen, $2.8 \quad(2.4-3.3, \mathrm{n}=1)$ times as long as greatest breadth, with a very large, shallow, irregular, generally double sensory pit. Mandible with $21(20-22, \mathrm{n}=7)$ teeth.

Thorax.-Mesonotum dark brown with a very prominent pattern of yellowish patches, median anterior area with four spots arranged in a four-leaf-clover design, lateral areas with 4-5 small pale spots, prescutellar depression pale. Scutellum narrowly brown in middle, yellowish on sides; postscutellum and pleuron dark brown. Legs dark brown, bases of femora pale; femora with subapical, tibiae with subbasal and hind tibia with apical, narrow pale rings; hind tibial comb with four $(n=9)$ spines, the one nearest the spur longest.

Wing.-Pattern as figured; second radial cell long and fairly broad; pale spot over r-m crossvein broken into two spots by a dark area at anterior end of crossvein, the posterior one small and round, the anterior one slightly larger; cell $R_{5}$ with four small, well-separated, pale spots arranged in a rhomboid, the distal one broadly extended to wing margin; apices of veins $\mathrm{M}_{1}, \mathrm{M}_{2}$ and $\mathrm{M}_{3+4}$ each with a pale spot at wing margin; two pale spots in cell $\mathrm{M}_{1}$, the second located far from wing margin; two pale spots in distal part of cell $\mathrm{M}_{2}$; cell $\mathrm{M}_{4}$ with a small round pale spot in center of cell; two separate pale spots in distal part of anal cell and an irregular pale area at base; cell $\mathrm{M}_{2}$ with a distinct pale spot lying behind medial fork and one lying in front of mediocubital fork, one lying near base of cell; pale spot present at basal arculus. Macrotrichia sparse on distal third of wing; costa extending to $0.65(0.64-0.67, \mathrm{n}=10)$ of distance to wing tip. Halter knob brownish at base.

Abdomen.-Dark brown, cerci pale. Spermathecae two, pyriform, slightly unequal, measuring 0.056 by 0.042 and 0.049 by $0.036 \mathrm{~mm}$., the bases of the ducts sclerotized a short distance.

Male genitalia: Ninth sternum without apparent caudomedian excavation; ninth tergum with well-developed median cleft on caudal margin, the apicolateral processes very short and blunt. Basistyle with ventral root foot-shaped, the posterior heel very poorly developed, dorsal root slender; dististyle nearly straight, slender, with bent tip. Aedeagus with pointed basal arch extending to two-thirds of total length, the basal arms slightly curved and slender; posterior portion slender with simple, rounded tip. Parameres each with large basal knob, stem moderately stout, bent near base, midportion slightlv 
swollen with very low ventral lobe, distal portion tapered to relatively stout, pointed, simple apex.

Distribution: Brazil; Panama.

PANAMA RECORDS:

Bocas del Toro Province: Almirante.

Canal Zone: Fort San Lorenzo, Fort Snerman, France Field, Galeta Point, Loma Boracho, Mojinga Swamp.

Chiriquf Province: Alanje.

Coclé Province: Puerto Farallón, Puerto Obaldía.

Colón Province: Cativá, Piña.

Darién Province: El Real, Garachiné, Punta Patiño.

Los Santos Province: Guararé, La Palma, Las Tablas, Puerto Mensabé.

Panamá Province: Arraiján, Camarón, Panamá Vieja, Pedregal, Venado Beach, Viqué Cove.

Discussion: This species is closely related to lyrinotatus Wirth and Blanton, both species having the distinctive division of the pale spot over the r-m crossvein into two separate pale spots. The two species agree also in many other less conspicuous details including the general wing pattern, but lyrinotatus can readily be distinguished by the wheel-like design of the pale wing spots and the dark crossvein, while the four-leaf-clover design of the anterior mesonotal spots will distinguish reticulatus from all other known species. The male parameres of reticulatus greatly resemble those of mojingaensis and azureus.

\section{Culicoides macrostigma Wirth and Blanton}

Figure 58

Culicoides macrostigma Wirth and Blanton, 1953, Journ. Parasit., vol. 39, p. 230 (male, female; Panama; fig. wing, palpus, male genitalia).

Female: Length of wing $0.91(0.83-0.96, \mathrm{n}=9) \mathrm{mm}$.

Head.-Eyes contiguous, bare. Antenna with flagellar segments in proportion of $15: 8: 9: 9: 10: 10: 11: 12: 28: 28: 29: 29: 48$, antennal ratio 1.97 ; distal sensory tufts present on segments III, viII-X. Palpal segments in proportion of $9: 14: 20: 9: 10$, third segment swollen, 1.8 $(1.6-2.0, n=8)$ times as long as greatest breadth, with a large deep sensory pit opening by a small pore. Mandible with 11 (9-12, $\mathrm{n}=9$ ) teeth.

Thorax.-Mesonotum dark chocolate brown, with prominent pattern of pruinose gray patches consisting of a pair of elongate, submedian spots, a pair of small humeral spots, and two pairs of rounded lateral spots, one on each side of lateral suture. Scutellum brown in middle, pruinose gray on the sides; postscutellum and pleuron dark brown. Legs dark brown; fore and mid femora with 


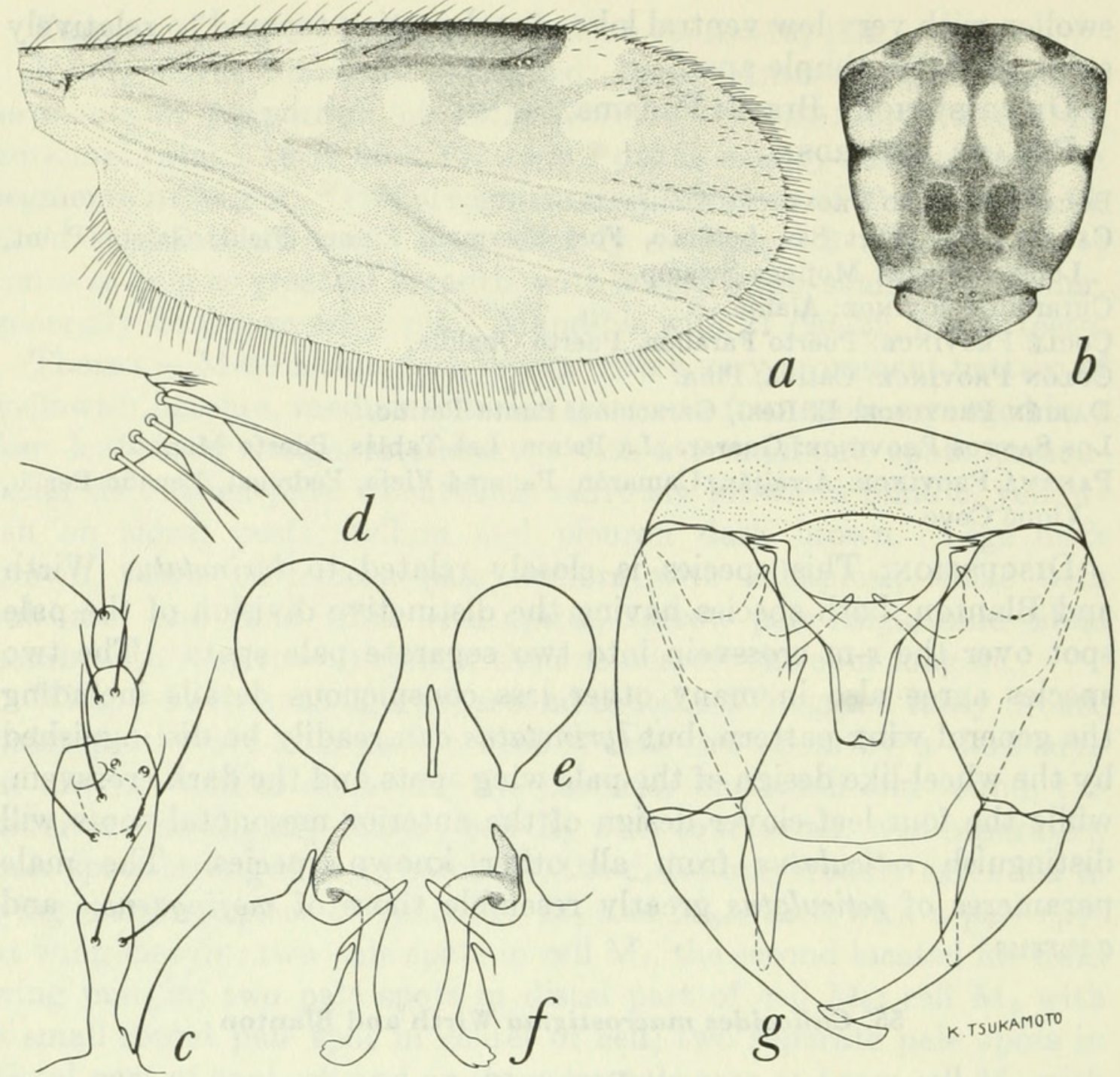

FIGURE 58.-Culicoides macrostigma Wirth and Blanton. $a-e$, Female: $a$, wing; $b$, thoracic pattern; $c$, palpus; $d$, tibial comb; $e$, spermathecae. $f, g$, Male: $f$, parameres ; $g$, genitalia, parameres removed.

subapical and all tibiae with subbasal narrow pale rings; hind tibial comb with four $(n=8)$ spines, the one nearest the spur longest.

Wing.--Pattern as figured; second radial cell dark, quite broad and very long, over twice as long as first; pale spot over r-m crossvein continued broadly to costal margin; cell $\mathrm{R}_{5}$ with four well-separated, small pale spots, two in a longitudinal row behind second radial cell, one at wing margin at end of costa and the distal one located in middle of cell toward the apex, the distal side of the last spot concaved; two pale spots in cell $\mathrm{M}_{1}$, the second located far from wing margin; two pale spots in distal part of cell $\mathrm{M}_{2}$, the apical one rounded and located at wing margin; one pale spot in cell $\mathrm{M}_{4}$, not touching the veins or wing margin; two pale spots in distal portion of anal cell; a pale spot in cell $\mathrm{M}_{2}$ lying in front of mediocubital fork and another behind medial fork; a pale spot at basal arculus of wing; 
a very narrow transverse pale mark across extreme apex of wing. Macrotrichia very scanty, only a few in apices of cells $R_{5}$ and $M_{1}$; costa extending to $0.71(0.70-0.74, \mathrm{n}=9)$ of distance to wing tip. Halter pale.

Abdomen.-Brownish black. Spermathecae two, pyriform, unequal, measuring 0.063 by $0.039 \mathrm{~mm}$. and 0.052 by $0.038 \mathrm{~mm}$., the bases of the ducts sclerotized a very short distance.

Male genitalia: Ninth sternum with very broad, shallow, caudomedian excavation, the posterior membrane spiculate; ninth tergum short and tapered, with very long, slender, fingerlike, closely approximated, apicolateral processes. Basistyle with ventral root very slender, long and pointed, dorsal root stouter and about half as long; dististyle curved, tapered to slender point. Aedeagus with basal arch about 1.5 times as broad as high, basal arms very short and curved; distal portion very broad, about twice as long as broad, with truncated apex. Parameres each with very broadly expanded, laterally directed basal knob bearing a distinct anterior process, stem very short, swollen at base, stout on distal portion with extreme tip expanded and abruptly bent laterad in the shape of a beak.

Distribution: Panama.

PANAMA RECORDS:

Bocas Del Toro Province: Almirante.

Canal Zone: Fort Davis, Fort Sherman, Loma Boracho, Mojinga Swamp (type locality).

Darien Province: Punta Patiño.

Panamá Province: Tocumen.

Discussion: The relations of macrostigma are uncertain, but this species is probably related to mojingaensis Wirth and Blanton and bricenoi Ortiz. Features which support its assignment to the group with these two species are the basic arrangement of the four pale spots in cell $R_{5}$ with two spots behind the second radial cell, the sensorial pattern with sensoria present on segments III, viII-x, the shape of the male aedeagus, the long male apicolateral processes and the spiculate membrane on the ninth sternum. The male parameres are bluntly expanded apically as in bricenoi, but in a different shape. The shape of the basal knob of the paramere as well as the long slender simple ventral root of the male basistyle are quite different, however, and prevent macrostigma from being assigned to this group with any degree of confidence.

\section{The furens group}

This group consists of small to medium-sized species, frequently with pale spots at the extreme apices of cells $R_{5}$ and $M_{1}$ and a mesonotal pattern of small punctiform brown dots; female antenna with sensoria 
present on segments III, vII or viII to $\mathrm{x}$; four tibial spines; two spermathecae; male genitalia with ventral root of basistyle foot-shaped; paramere with basal knob simple, ventral lobe usually present and well developed and apex with fringing spines; aedeagus usually V-shaped with pointed basal arch and distal portion with subapical points.

Panama species: Four: alahialinus Barbosa, barbosai Wirth and Blanton, furens (Poey), and gorgasi Wirth and Blanton.

\section{Culicoides alahialinus Barbosa}

Figure 59

Culicoides alahialinus Barbosa, 1952, Nov. Subs. Conhec. Culicoides Neotr., p. 11 (female; Limones, Esmeraldas, Ecuador; fig. wing, palpus).-Ortiz and Leon, 1955, Bol. Inf. Cient. Nac., vol. 67, p. 571 (Ecuador, female redescribed; fig. wing, palpus, antenna, spermathecae).

Female: Length of wing $0.96(0.89-1.02, \mathrm{n}=10) \mathrm{mm}$.

Head.-Eyes narrowly separated, bare. Antenna with flagellar segments in proportion of $20: 14: 14: 14: 14: 14: 14: 14: 20: 20: 22: 22: 34$, antennal ratio $1.01(0.94-1.11, \mathrm{n}=9)$; distal sensory tufts present on segments III, viII-X. Palpal segments in proportion of $9: 21: 24$ : $10: 12$, third segment moderately swollen, $2.2(2.0-2.4, \mathrm{n}=8)$ times as long as greatest breadth, with moderately large, shallow, sensory pit. Mandible with $15(15-16, \mathrm{n}=7)$ teeth.

Thorax.-Mesonotum slightly shining brown, with faint grayish pollen, punctiform brown dots scattered at insertions of mesonotal hairs, no discal pale area apparent. Scutellum dark brown in middle, paler on sides; postscutellum and pleuron dark brown. Legs pale brown, knees blackish; fore and mid femora with subapical, all tibiae with subbasal and hind tibia with apical, very faint, narrow pale rings; hind tibial comb with four $(n=10)$ spines, the one nearest the spur longest.

Wing.-With very faint pattern as figured, appearing grayish; yellowish pale area at wing base and over r-m crossvein; very faint indications of pale spots in cells on distal part of wing located as in gorgasi. Macrotrichia sparse but well distributed on distal half of wing and in anal cell; costa extending to $0.64(0.61-0.68, \mathrm{n}=10)$ of distance to wing tip. Halter infuscated.

Abdomen.-Blackish, cerci pale. Spermathecae two, slightly pyriform, slightly unequal, measuring 0.055 by $0.036 \mathrm{~mm}$. and 0.048 by $0.036 \mathrm{~mm}$., the bases of the ducts not sclerotized.

Male genitalia: Ninth sternum with a deep caudomedian excavation; ninth tergum long, broad at apex with slender apicolateral processes. Basistyle with ventral root foot-shaped, dorsal root slender; dististyle Iong and curving to pointed tip. Aedeagus with 

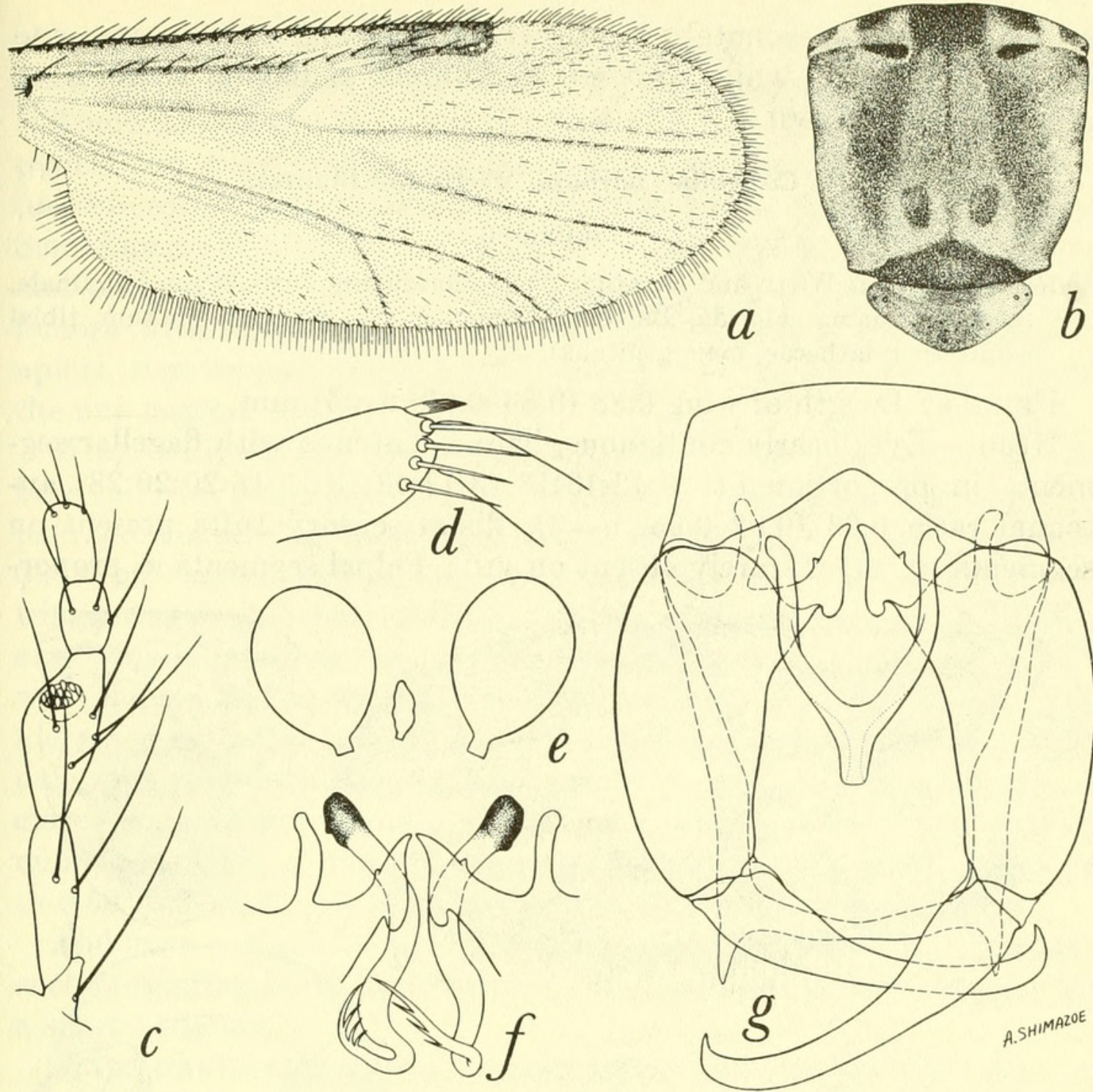

Figure 59.-Culicoides alahialinus Barbosa. $a-e$, Female: $a$, wing; $b$, thoracic pattern; $c$, palpus; $d$, tibial comb; $e$, spermathecae. $f, g$, Male: $f$, parameres; $g$, genitalia, parameres removed.

basal arch extending to about two-thirds of total length of aedeagus, basal arms curved, distal portion with rounded apex and indistinct subapical lateral points. Parameres each with basal knob, stem bent near base, slightly sinuate in midportion, without ventral lobe, distal portion abruptly bent and twisted ventrad, the sharp tip with several fine subapical hairs.

Distribution: Ecuador; Panama.

PANAMA RECORDS:

Canal Zone: Balboa, Fort Davis, Fort Randolph, Fort San Lorenzo, Fort Sherman, France Field, Loma Boracho (biting man), Mindi Dairy, Mojinga Swamp.

Discussion: Culicoides gorgasi Wirth and Blanton and C. barbosai Wirth and Blanton are closely related to this species but they have a distinct wing pattern; gorgasi also differs from alahialinus in having 
a more distinct mesonotal pattern with a yellowish median area and by its larger size, while barbosai also differs in having sensoria on antennal segment viI.

\section{Culicoides barbosai Wirth and Blanton}

\section{Figure 60}

Culicoides barbosai Wirth and Blanton, 1956, Florida Ent., vol. 39, p. 161 (male, female; Panama, Florida, Bahamas, Ecuador; fig. wing, mesonotum, tibial comb, spermathecae, male genitalia).

Female: Length of wing $0.88(0.83-0.92, \mathrm{n}=5) \mathrm{mm}$.

Head.-Eyes nearly contiguous, bare. Antenna with flagellar segments in proportion of $18: 13: 13: 13: 13: 13: 13: 13: 15: 18: 20: 20: 28$, antennal ratio $0.93(0.92-0.95, \mathrm{n}=3)$; distal sensory tufts present on segments III, VII-X, rarely absent on vir. Palpal segments in propor-

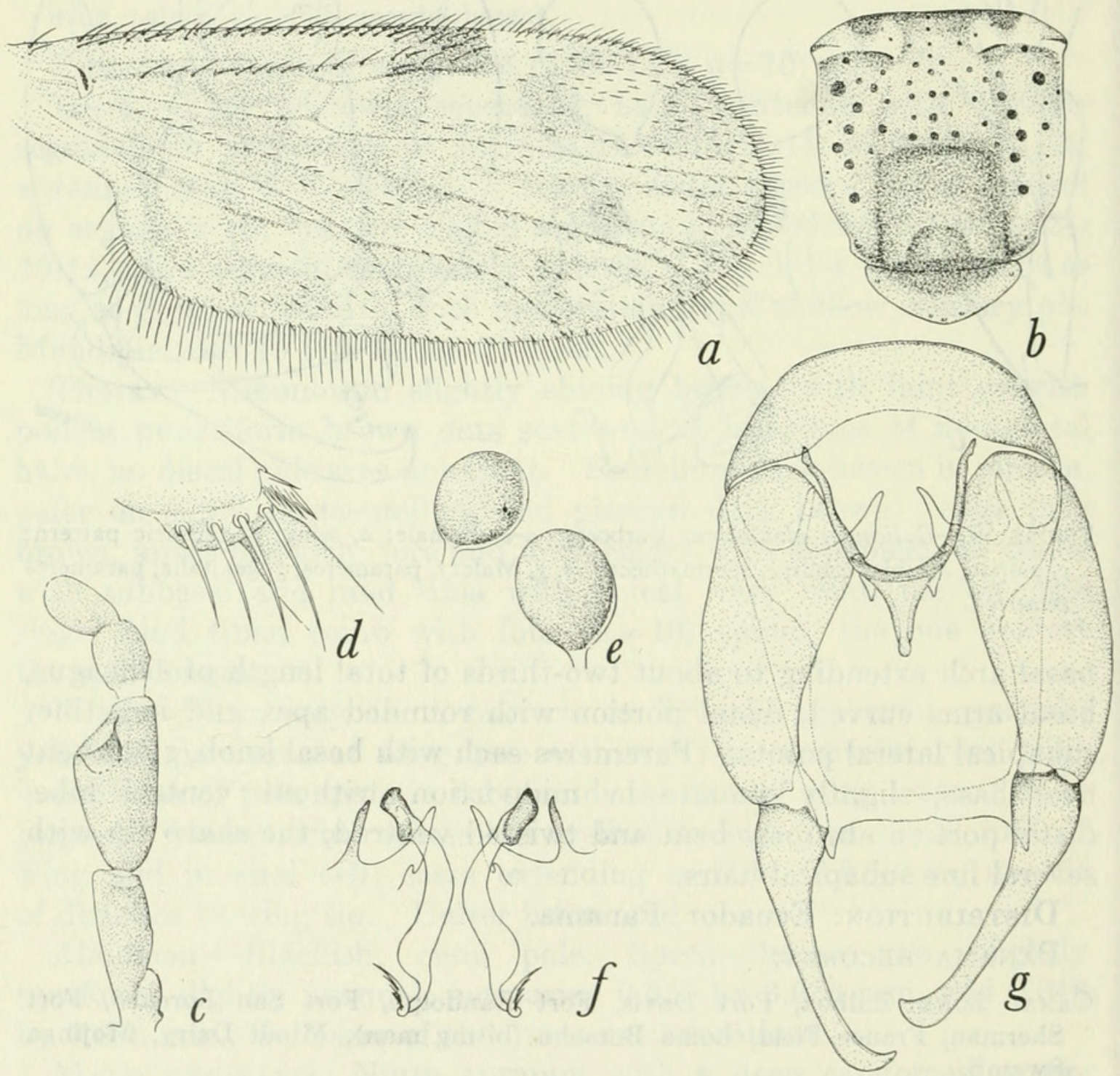

Figure 60.-Culicoides barbosai Wirth and Blanton. $a-e$, Female: $a$, wing; $b$, thoracic pattern; $c$, palpus; $d$, tibial comb; $e$, spermathecae. $f, g$, Male: $f$, parameres; $g$, genitalia, parameres removed. 
tion of $9: 17: 21: 8: 8$, third segment moderately swollen, 2.2 (1.8-2.3, $\mathrm{n}=3$ ) times as long as greatest breadth, with a small, deep sensory pit.

Thorax.-Mesonotum pruinose gray with pattern of dark brown punctiform dots at bases of mesonotal hairs, these dots irregularly fused in some areas, principally in two sublateral, longitudinal bands. Scutellum narrowly dark in middle, yellowish on sides. Postscutellum and pleuron dark brown. Legs dark brown; knee spots blackish, all femora with subapical, all tibia with subbasal and hind tibia with apical, narrow pale rings; hind tibial comb with four $(\mathrm{n}=5)$ spines, the one nearest the spur longest.

Wing.-Pattern as figured, large yellowish anterior spots at wing base and over r-m crossvein; two longitudinally elongate poststigmatic pale spots in cell $R_{5}$, narrowly fused to form an hourglass-shaped spot; distal pale spot in cell $R_{5}$ large, rounded and broadly meeting anterior wing margin; two pale spots in cell $\mathrm{M}_{1}$, the proximal one streaklike and lying adjacent to vein $\mathrm{M}_{2}$, the distal one usually connected by a narrow pale line to wing margin; veins $\mathrm{M}_{1}$ and $\mathrm{M}_{2}$ very faintly pale margined on distal halves; a pale line running through cell $\mathrm{M}_{2}$ to the pale spot at apex of cell $\mathrm{M}_{2}$; large pale spot in cell $\mathrm{M}_{4}$; two pale spots, more or less coalesced, in distal part of anal cell. Macrotrichia numerous on distal half of wing and a few in anal cell; costa extending to $0.58(0.57-0.59, \mathrm{n}=5)$ of distance to wing tip. Halter dark.

Abdomen.-Dark brown, cerci pale. Spermathecae two, subequal, each measuring 0.045 by $0.030 \mathrm{~mm}$., the bases of the ducts sclerotized a short distance.

Male genitalia: Ninth sternum with broad caudomedian excavation; ninth tergum long, the apicolateral processes moderately long and slender. Basistyle with slender, foot-shaped ventral root, dorsal root slender; dististyle long and very slender, with bent apex. Aedeagus with basal arch extending to about 0.7 of total length of aedeagus, basal arms slender and slightly curved, distal portion tapered to slender, rounded point with an indistinct lateral pair of pointed hyaline processes near juncture with the arch. Parameres each with strongly sclerotized basal knob, stem slender and curved near base, distal portion gradually more swollen, until there arises a distinct low ventral lobed area beyond which the distal portion is quite slender, tapering to fine point with a few minute lateral barbs.

Distribution: Panama; Bahamas; United States (Florida).

PanAMA RECORDS:

Canal Zone: Balboa (Apr. 28, 1942, P. A. Woke, biting man; including 3 paratypes of wokei Barbosa not Fox); Fort Randolph, Fort Sherman, Loma Boracho, Mojinga Swamp (type locality).

Discussion: Like the closely related alahialinus Barbosa, this species is apparently restricted in Panama to localities with saline 
environments in the Canal Zone. It superficially resembles furens (Poey) in wing and mesonotal markings but the relationship to furens is not so close as to alahialinus and gorgasi Wirth and Blanton. Culicoides alahialinus differs in having a very faint wing pattern and fainter mesonotal pattern and lacking the sensoria on segment vil of the antenna; gorgasi differs in its larger size, more prominent mesonotal pattern with yellowish center and also lacking the sensoria on antennal segment vir. Barbosai at times is fairly abundant at some localities in the Bahamas and extreme southern Florida, where it has been confused with furens.

\section{Culicoides gorgasi Wirth and Blanton}

\section{Figure 61}

Culicoides gorgasi Wirth and Blanton, 1953, Journ. Parasit., vol. 39, p. 232 (male, female; Panama; fig. wing, mesonotum, palpus, male genitalia).

Female: Length of wing $1.04(0.96-1.09, \mathrm{n}=10) \mathrm{mm}$.

Head.-Eyes nearly contiguous, bare. Antenna with flagellar segments in proportion of $23: 17: 17: 17: 17: 16: 16: 16: 24: 24: 26: 26: 37$, antennal ratio $0.99(0.94-1.03, \mathrm{n}=5)$; distal sensory tufts present on segments III, VIII-X, rarely on vir. Palpal segments in proportion of $9: 24: 25: 10: 12$, third segment moderately swollen, 2.1 (1.9-2.4) times as long as broad, with a small, deep sensory pit. Mandible with $17(15-19, \mathrm{n}=12)$ teeth.

Thorax.-Mesonotum pruinose gray-brown with prominent pattern on dark brown punctiform dots at bases of mesonotal hairs, these dots irregularly fused in some areas, principally in two sublateral longitudinal bands; an elongate pair of submedian anterior spots yellowish brown. Scutellum narrowly brown in middle, dark brown on sides; postscutellum and pleuron dark brown. Legs dark brown; knee spots blackish; all femora with subapical, all tibiae with subbasal and hind tibia with apical, narrow pale rings; hind tibial comb with four $(n=10)$ spines, the one nearest the spur longest.

Wing.-Pattern as figured; large yellowish areas at wing base and over $\mathrm{r}-\mathrm{m}$ crossvein; two longitudinal, elongate poststigmatic pale spots in cell $R_{5}$, the anterior one situated entirely distad of the posterior one and sometimes connected to it by a very narrow pale space, distal pale spot in cell $R_{5}$ usually narrowly connected obliquely distad to anterior wing margin; two small, narrow, elongate pale spots in cell $\mathrm{M}_{1}$, the distal one sometimes connected by a narrow pale line to a trace of a small pale spot at wing margin; a large pale spot at wing margin in cell $\mathrm{M}_{2}$ and one in cell $\mathrm{M}_{4}$; two pale spots in distal portion of anal cell; cell $\mathrm{M}$ with a pale line from base connected to a pale spot behind medial fork and a pale spot lying ahead of broadest portion of cell $\mathrm{M}_{4}$. Macrotrichia numerous on distal portion of wing and in anal cell and 

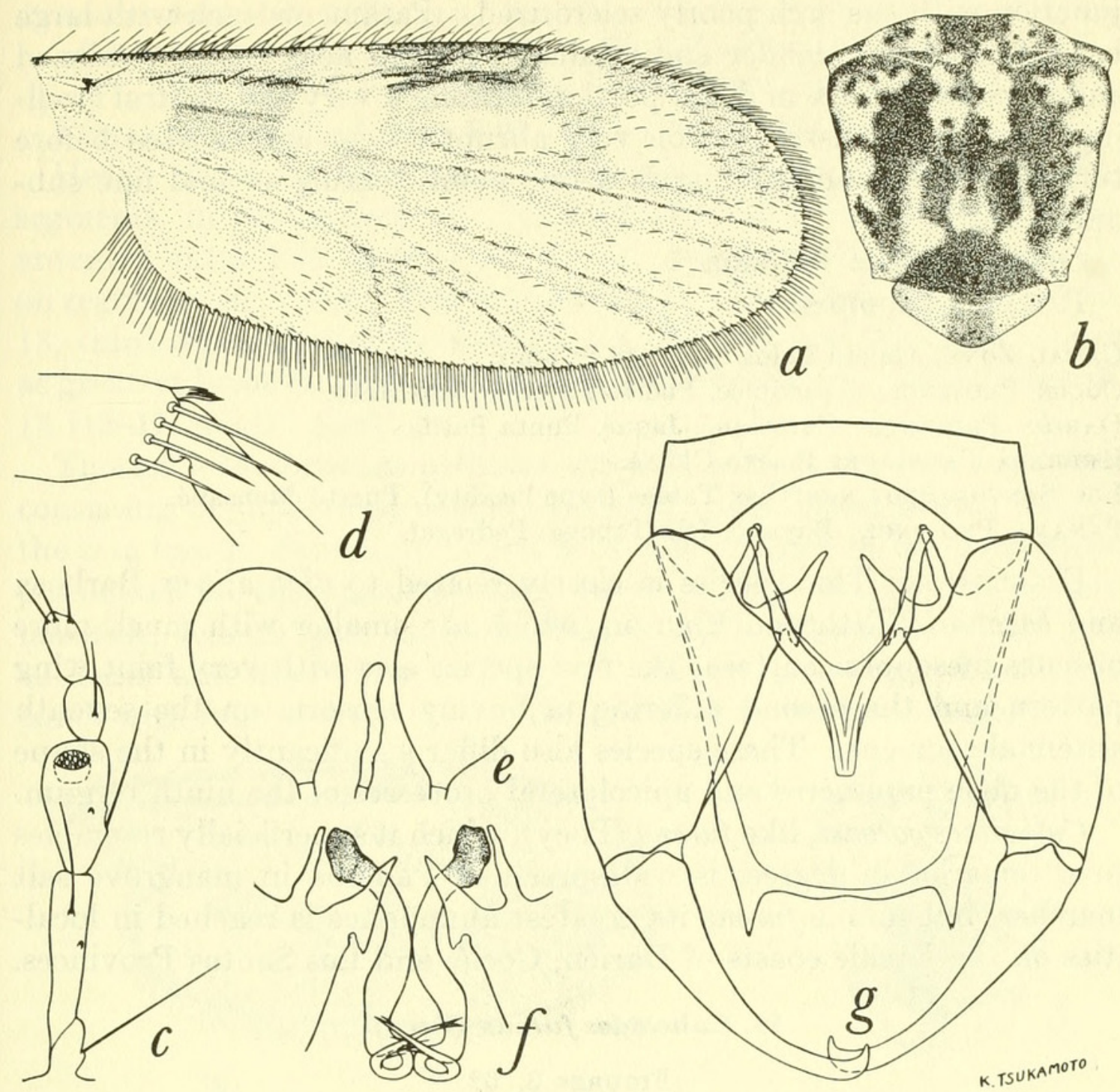

Figure 61.-Culicoides gorgasi Wirth and Blanton. $a-e$, Female: $a$, wing; $b$, thoracic pattern; $c$, palpus; $d$, tibial comb; $e$, spermathecae. $f, g$, Male: $f$, parameres; $g$, genitalia, parameres removed.

extending nearly to base of cell $\mathrm{M}$; costa extending to 0.64 (0.61-0.67, $\mathrm{n}=10$ ) of distance to wing tip. Halter knob infuscated.

Abdomen.-Dark brown, cerci pale. Spermathecae two, ovoid, slightly unequal, measuring 0.054 by $0.039 \mathrm{~mm}$. and 0.049 by 0.036 $\mathrm{mm}$., the bases of the ducts sclerotized a short distance.

Male Genitalia.- Ninth sternum with broad, shallow, caudomedian excavation; ninth tergum long with long, triangular, apicolateral processes. Basistyle with ventral root foot-shaped, the posterior heel well developed, dorsal root slender; dististyle long and slender with hooked apex. Aedeagus with basal arch extending to three-fourths of total length of aedeagus, basal arms well sclerotized and nearly straig ht, the basal arch narrow caudomedially; distal portion short and simple, with moderately broad, truncate apex, the subapical, lateral points at 
junction with the arch poorly sclerotized. Parameres each with large basal knob, stem slender and gradually curved near base, broadened and bowed ventrally in distal portion forming a very low ventral swelling, the slender distal portion very abruptly bent and twisted before turning ventrad and ending in a fine point bearing several fine subapical hairs.

\section{Distribution: Panama.}

PanAma RECORDS:

Canal Zone: Galeta Point, Mojinga Swamp.

Coclé Province: Aguadulce, Puerto Farallón, Río Hato.

Darién Province: Garachiné, Jaqué, Punta Patiño.

Herrera Province: Puerto Chitré.

Los Santos Province: Las Tablas (type locality), Puerto Mensabé.

Panamá Province: Bayano, Isla Taboga, Pedregal.

Discussion: This species is closely related to alahialinus Barbosa and barbosai Wirth and Blanton, which are smaller with much more obscure mesonotal pattern; the first species also with very faint wing pattern and the second differing in having sensoria on the seventh antennal segment. These species also differ significantly in the shape of the male parameres and apicolateral processes of the ninth tergum.

Culicoides gorgasi, like furens (Poey), which it superficially resembles to a remarkable degree, is widespread in Panama in mangrove salt marshes, but unlike furens its greatest abundance is reached in localities on the Pacific coasts of Darién, Coclé, and Los Santos Provinces.

\section{Culicoides furens (Poey)}

Figures 3,62

Oecacta furens Poey, 1853, Mem. Hist. Nat. Isla de Cuba, vol. 1, p. 236 (female; Cuba; fig. female, wing, head, antenna, mouthparts).

Culicoides furens, Lutz, 1912, Mem. Inst. Oswaldo Cruz, vol. 4, p. 16.-Hoffman, 1925, Amer. Journ. Hyg., vol. 5, p. 287.-Macfie, 1937, Ann. Mag. Nat. Hist., ser. 10, vol. 20, p. 10 (male, female; Trinidad; fig. male genitalia; synonyms, dovei Hall, maculithorax Williston).--Root and Hoffman, 1937, Amer. Journ. Hyg., vol. 25, p. 162 (male, female; United States; fig. male genitalia).-Barretto, 1944, Anais Fac. Med. Univ. Sao Paulo, vol. 20, p. 89 (male; Brazil; fig. wing, palpus, .antenna and genitalia of male).-Barbosa, 1947, Anais Soc. Biol. Pernambuco, vol. 7, p. 15 (distribution and notes; fig. male genitalia).-Wirth, 1952, Florida Ent., vol. 35, p. 91 (Florida; fig. larva, pupa).-Foote and Pratt, 1954, Pub. Health Monogr., vol. 18, p. 21 (male, female; United States records; fig. wing, mesonotum, palpus, male genitalia).-Ortiz and Leon, 1955, Bol. Inf. Cient. Nac., no. 67, p. 572 (female; Ecuador; fig. wing, palpus).-Wirth and Blanton, 1956, Florida Ent., vol. 39, p. 159 (redescription, distribution, figs.).

Ceratopogon maculithorax Williston, 1896, Trans. Ent. Soc. London, vol. 3, p. 277 (female; St. Vincent; fig. wing).-Lutz, 1913, Mem. Inst. Oswaldo Cruz, vol. 5, p. 53 (male, female; Brazil; fig. wing).-Floch and Abonnenc, 1942, Inst. Pasteur Guyane Terr. l'Inini, publ. 49, p. 1 (female; Guadaloupe; fig. wing, palpus). 
Culicoides dovei Hall, 1932, Proc. Ent. Soc. Washington, vol. 34, p. 88 (male, female; Georgia; fig. male genitalia); Dove, Hall and Hull, 1932, Ann. Ent. Soc. Amer., vol. 25, p. 505 (biology, United States; fig. all stages).

Female: Length of wing $0.91(0.88-0.99, \mathrm{n}=16) \mathrm{mm}$.

Head.-Eyes narrowly separated, bare. Antenna with flagellar segments in proportion of $16: 12: 12: 12: 12: 12: 12: 12: 20: 22: 24: 25: 35$, antennal ratio $1.28(1.09-1.51, \mathrm{n}=7)$; distal sensory tufts present on segments III, VII-X. Palpal segments in proportion of $11: 24: 28: 10$ : 13 , third segment slightly swollen, $2.4(2.1-2.9, \mathrm{n}=16)$ times as long as greatest breadth, with a small, shallow, sensory pit. Mandible with $15(12-17, \mathrm{n}=16)$ teeth.

Thorax.-Mesonotum pollinose grayish, with a prominent pattern consisting of numerous, evenly scattered, punctiform brown dots at the seta bases. Scutellum brown in middle, grayish pruinose on sides; postscutellum and pleuron dark brown. Legs brown, knee spots blackish; femora pale at bases, femora with subapical, tibiae witb subbasal and hind tibia with apical, narrow pale rings; hind tibial comb with four $(n=15)$ spines, the one next to the spur longest.
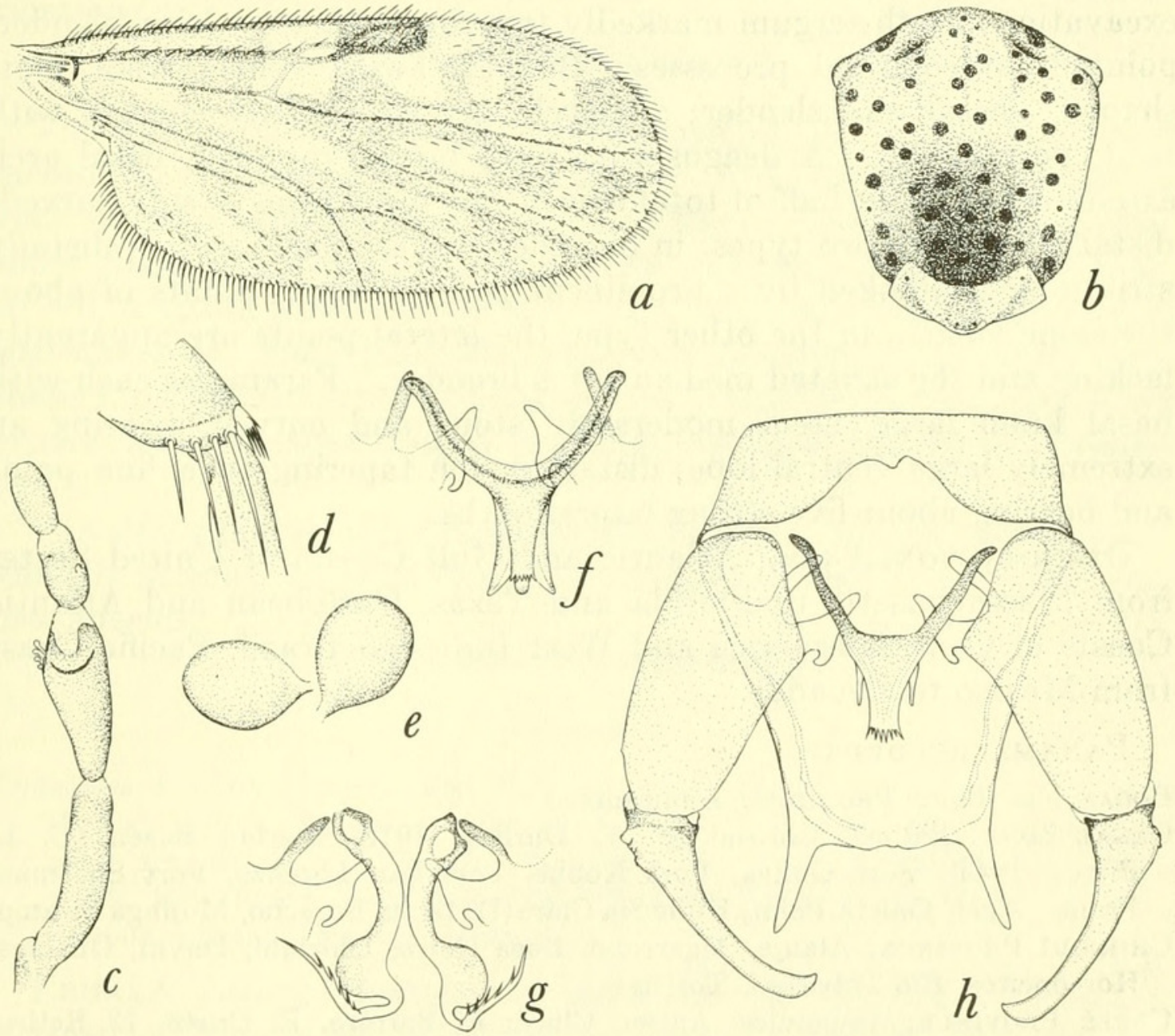

Figure 62.-Culicoides furens (Poey). $a-e$, Female: $a$, wing; $b$, thoracic pattern; $c$, palpus; $d$, tibial comb; $e$, spermathecae. $f-h$, Male: $f$, aedeagus, variation; $g$, parameres; $h$, genitalia, parameres removed. 
Wing.-Pattern as figured; second radial cell blackish; pale spot over $r-m$ crossvein quite broad; cell $R_{5}$ with three small round poststigmatic spots in a triangle, the two next to the second radial cell more or less fused, a large, oblique, double spot broadly meeting wing margin in distal part of cell; vein $\mathrm{M}_{1}$ pale margined from apex nearly to its base, veins $M_{2}$ and $M_{3+4}$ pale margined on distal portions; cell $M_{1}$ with three pale spots, the distal one located at the wing margin; cell $\mathrm{M}_{2}$ with two pale spots in distal part, the distal one broadly meeting wing margin; cell $\mathrm{M}_{4}$ with a large pale spot; two small round pale spots in distal part of anal cell; pale area at base of anal cell narrowly connected to the large pale area over wing base; pale spot present in cell $\mathrm{M}_{2}$ behind medial fork. Macrotrichia fairly numerous on distal half of wing and in anal cell; costa extending to 0.58 (0.56-0.61, $\mathrm{n}=16$ ) of distance to wing tip. Halter pale.

Abdomen.-Dark brown, cerci yellowish. Spermathecae two, pyriform, subequal, each measuring 0.057 by $0.037 \mathrm{~mm}$., the bases of the ducts sclerotized a considerable distance.

Male genitalia: Ninth sternum with broad, deep, caudomedian excavation; ninth tergum markedly tapering with very long, slender, pointed, apicolateral processes. Basistyle with ventral root footshaped, dorsal root slender; dististyle slender, slightly curved, with bent, pointed tip. Aedeagus with very broad, rounded, basal arch extending to about half of total length, the basal arms evenly curved; distal portion of two types: in one the very slender, median, distally striate tip is flanked by a prominent pair of lateral points of about the same length; in the other type, the lateral points are apparently lacking and the striated median tip is broader. Parameres each with basal knob large, stem moderately stout and curved, bearing an extremely large ventral lobe; distal portion tapering to a fine point and bearing about five strong lateral barbs.

Distribution: Cuba; Atlantic and Gulf Coasts of United States from Massachusetts to Florida and Texas, Caribbean and Atlantic Coasts of Central America and West Indies to Brazil, Pacific Coast from Mexico to Ecuador.

\section{PANAMA RECORDS:}

Bocas del Toro Province: Almirante.

Canal Zone: Balboa, Corozal (S. T. Darling, 1912), Farfan Beach (C. L. Pierce, 1944), Fort Gulick, Fort Kobbe, Fort San Lorenzo, Fort Sherman, France Field, Galeta Point, Huile Sia Clara(?), Loma Boracho, Mojinga Swamp.

Chiriquf Province: Alanje, Algarrobo, Boca Chica; Chiriquí, David, Gualaca, Horconcitos, Río Tabasará, Tortugas.

Coclé Province: Aguadulce, Antón, Chirú, El Barrero, El Cristo, El Retiro, El Salado, Espiño, Natá, Pocrí, Puerto Farallón, Puerto Obaldía, Puerto Posado, Río Hato.

Colón Province: Cativá, Piña, Salud. 
Darien Province: Garachiné, Jaqué, Punta Patiño.

Herrera Province: Ocú, Puerto Chitré.

Los Santos Province: Guararé, La Palma, Peña Blanca, Puerto Mensabé, Río Estibaná, San José, Santo Domingo.

Panamá Province: Arraiján, Bayano, Camarón, Capitana, Chepo, El Espino, La Jolla, Pacora, Panamá Vieja, Pedregal, Río Las Lajas, San Carlos, Tocumen, Viqué Cove.

Veraguas Province: Divisa.

Archipiélago de las Perlas: Isla del Rey.

Discussion: Except for the differences in the tip of the aedeagus, this widely distributed and abundant salt marsh species is fairly constant in its characters. Males from the United States, Bahamas, and from most of the Panama localities have the lateral apical points of the aedeagus lacking, while males from Trinidad and from Aguadulce, Garachiné, Puerto Mensabé, and Tocumen and part of the series from Río Hato have these points well developed. The latter form might well prove to be a subspecies for which the name maculithorax (Williston) is available, but a distributional study of males from many Caribbean localities would be necessary to establish this relationship.

\section{The fluvialis group}

This group consists of small to medium-sized species with prominent mesonotal pattern, wing pattern usually of definite small pale spots, vein $M_{1}$ pale-margined distally or the apices of veins $M_{1}, M_{2}$ and sometimes $\mathrm{M}_{3+4}$ pale; female antenna with sensoria present on segments III, vIl or vIII to $\mathrm{x}$ and rarely to XI or XIV; four tibial spines; one or two spermathecae; male genitalia with ventral root of basistyle footshaped, paramere with simple basal knob, stem short, with or without ventral lobe, the apex fringed or simple; aedeagus usually with simple tip.

Panama sPecies: Six: balsapambensis Ortiz and Leon, castillae Fox, fluvialis Macfie, leopoldoi Ortiz, propriipennis Macfie, and tetrathyris, new species.

\section{Culicoides fluvialis Macfie}

Figure 63

Culicoides fluvialis Macfie, 1940, Ent. Monthly Mag., vol. 76, p. 75 (female; British Guiana; fig. wing).-Ortiz, 1951, Nov. Cient. Mus. Hist. Nat. LaSalle, zool. ser., no. 5, p. 2 (female; Venezuela; fig. wing, palpus, spermathecae); 1952, Rev. Sanid. Asist. Soc., vol. 17, p. 264 (male; Venezuela; fig. wing, palpus, genitalia, fig. female wing).

Female: Length of wing $0.76(0.73-0.79, \mathrm{n}=10) \mathrm{mm}$.

Head.-Eyes narrowly separated, bare. Antenna with flagellar segments in proportion of $15: 11: 11: 11: 11: 12: 12: 12: 17: 18: 18: 19: 29$, antennal ratio $1.07(1.05-1.11, \mathrm{n}=6)$; distal sensory tufts present on 

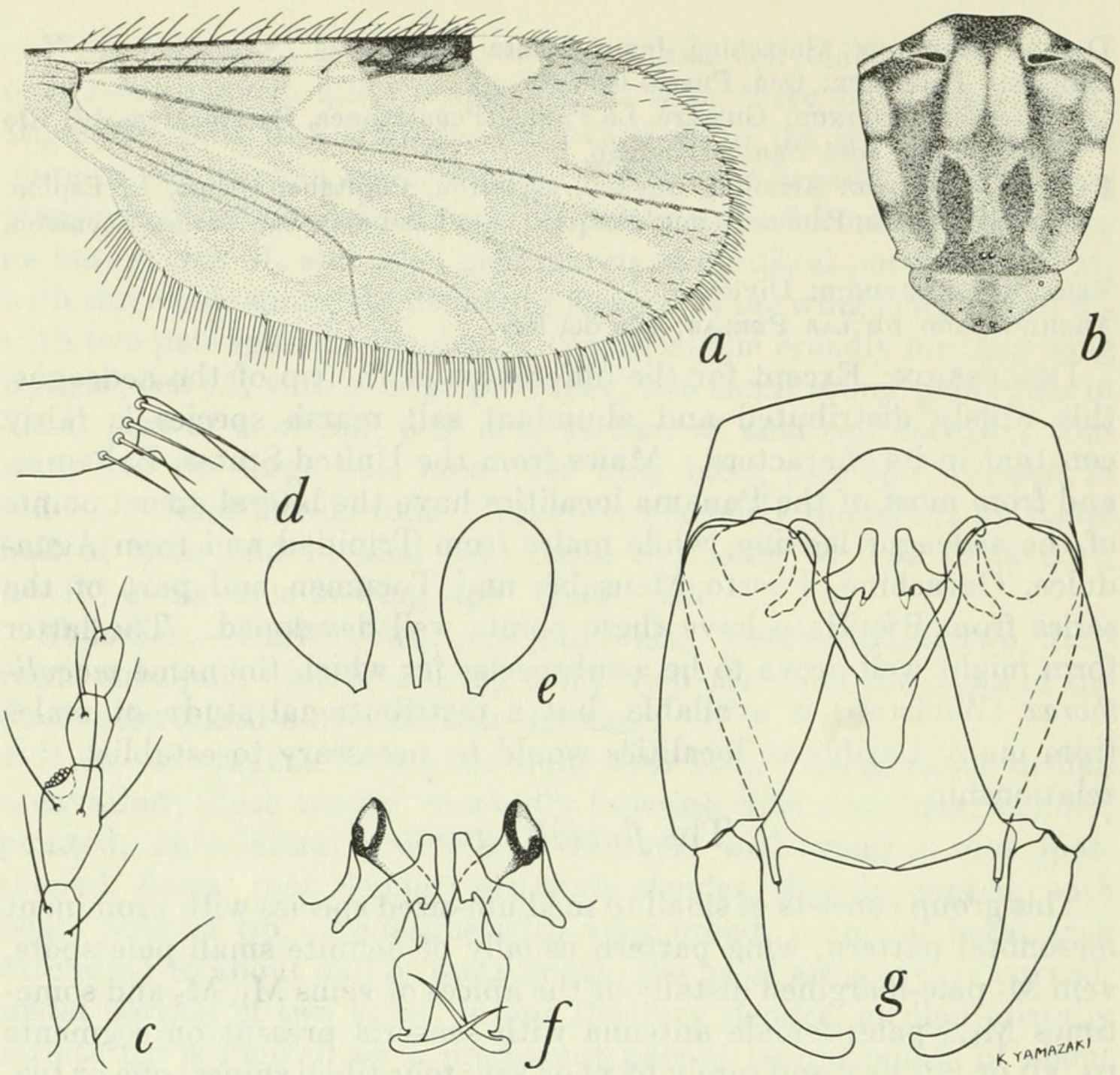

FiguRE 63.-Culicoides fuvialis Macfie. $a-e$, Female: $a$, wing; $b$, thoracic pattern; $c$, palpus; $d$, tibial comb; $e$, spermathecae. $f, g$, Male; $f$, parameres; $g$, genitalia, parameres removed.

segments III, viII-X. Palpal segments in proportion of $6: 15: 16: 7: 7$, third segment short and slightly swollen, $1.8(1.7-1.9, \mathrm{n}=9)$ times as long as greatest breadth, with a small, deep sensory pit. Mandible with $13(12-15, \mathrm{n}=7)$ teeth.

Thorax.-Mesonotum grayish pruinose, blackish between the humeral pits, with a prominent pattern consisting mainly of a sublateral pair of brown bands, widest at level of the lateral suture, leaving a median anterior pair of elongated yellowish gray spots. Scutellum brown in middle, yellowish gray on sides; postscutellum and pleuron dark brown. Legs brown; knee spots blackish; all femora with subapical and all tibiae with subbasal narrow pale rings; femora pale at bases; hind tibial comb with four $(n=7)$ spines, the one nearest the spur longest.

Wing.-Pattern as figured; second radial cell moderately dark; a small pale spot over $\mathrm{r}-\mathrm{m}$ crossvein; cell $\mathrm{R}_{5}$ with two separate, round, poststigmatic pale spots, the posterior one located behind second 
radial cell; distal pale spot in cell $R_{5}$ hourglass-shaped, oblique, broadly meeting wing margin; apices of veins $\mathrm{M}_{1}$ and $\mathrm{M}_{2}$ with a small pale spot at wing margin; cell $\mathrm{M}_{1}$ with two pale spots, the distal one located far from wing margin; two distal pale spots in cell $\mathrm{M}_{2}$, the apical one located at the wing margin; cell $\mathrm{M}_{4}$ with a round pale spot almost meeting wing margin; only one small round pale spot in distal part of anal cell; cell $\mathrm{M}_{2}$ with no pale spot lying in front of mediocubital fork, a small pale spot present lying behind medial fork. Macrotrichia sparse and in rows on distal fourth of wing in cells $R_{5}, M_{1}$ and $\mathrm{M}_{2}$; costa extending to $0.61(0.59-0.62, \mathrm{n}=10)$ of distance to wing tip. Halter pale.

Abdomen.-Dull blackish. Spermathecae two, oval, slightly unequal, measuring 0.046 by $0.029 \mathrm{~mm}$. and 0.040 by $0.026 \mathrm{~mm}$., the bases of the ducts sclerotized a short distance.

Male genitalia: Ninth sternum with a moderately deep caudomedian excavation; ninth tergum broad apically with long, extremely slender, apicolateral processes. Basistyle with ventral root footshaped, dorsal root short and slender; dististyle slender and markedly curved to pointed tip. Aedeagus with broad, pointed basal arch extending to two-thirds of total length, the basal arms slender and curved; distal portion short and stout with bluntly rounded tip. Parameres each with large basal knob, stem stout, markedly bent at midportion, the part distad stout with a low, flat, extensive, ventral lobe, the apex narrowed to simple sharp point.

Distribution: British Guiana; Honduras (Lancetilla); Panama; Venezuela.

\section{Panama RECORDS:}

Bocas del Toro Province: Almirante.

Canal Zone: Fort Sherman, Loma Boracho, Mojinga Swamp.

Panamá Province: Isla Taboga.

Discussion: Ortiz (1954) has described fernandezi from Venezuela, a species very similar to fluvialis but differing mainly in having the poststigmatic pale spots in cell $R_{5}$ narrowly fused, lacking the pale spot at wing margin at the apex of vein $\mathrm{M}_{2}$, having a pale spot present in front of the mediocubital fork, having sensoria present on segments III, vII-X and being slightly larger, wing $1.0 \mathrm{~mm}$. long.

\section{Culicoides tetrathyris, new species}

FIGURE 64

Female: Length of wing $0.85(0.69-0.87, \mathrm{n}=12) \mathrm{mm}$.

Head.-Eyes nearly contiguous, bare. Antenna with flagellar segments in proportion of $15: 12: 13: 14: 14: 14: 14: 14: 19: 20: 21: 20: 34$, antennal ratio $1.09(1.04-1.14, \mathrm{n}=4)$; distal sensory tufts present on 

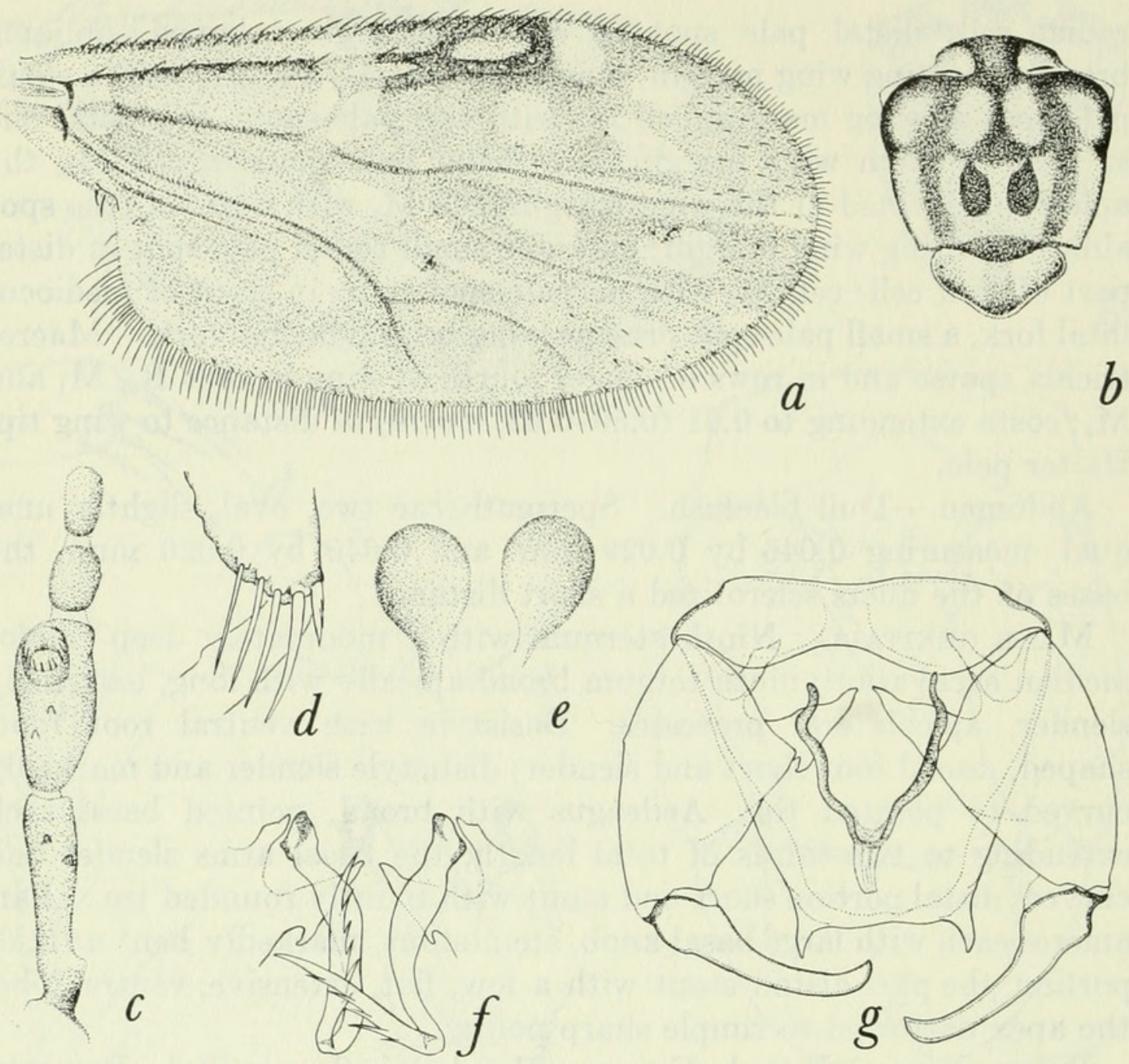

FigURE 64.-Culicoides tetrathyris, new species. $a-e$, Female: $a$, wing; $b$, thoracic pattern; $c$, palpus; $d$, tibial comb; $e$, spermathecae. $f, g$, Male: $f$, parameres; $g$, genitalia, parameres removed.

segments III, viII-X. Palpal segments in proportion to $7: 21: 22: 9: 9$, third segment moderately swollen to apex, $1.9(1.5-2.1, \mathrm{n}=12)$ times as long as greatest breadth, with a moderately large and deep sensory pit. Mandible with $14(12-15, \mathrm{n}=13)$ teeth.

Thorax.-Mesonotum blackish, with a prominent pattern of pruinose bluish gray patches as figured, the submedian anterior pair yellowish when viewed from above and behind. Scutellum narrowly dark brown in middle, sides broadly pale yellowish; postscutellum and pleuron blackish. Legs blackish; fore and mid femora with subapical, and all tibiae with sub-basal, narrow whitish rings; hind tibial comb with four $(4-5, n=12)$ long spines, the one next to the spur longest, a third as long as basitarsus.

Wing.-Pattern as figured, cell $R_{5}$ with four small, round, pale spots arranged in a trapezoid, two pale spots each in cell $\mathrm{M}_{1}$ and apex 
of anal cell, only one pale spot in distal portion of cell $\mathrm{M}_{2}$, a pale spot behind medial fork and another in front of mediocubital fork, ends of veins $\mathrm{M}_{1}, \mathrm{M}_{2}$ and $\mathrm{M}_{3+4}$ with pale spot at wing margin. Macrotrichia sparse on distal fourth of wing; costa extending to 0.70 of distance to wing tip. Halter pale.

Abdomen.-Blackish, cerci yellowish. Spermathecae two, subequal, pyriform, each measuring 0.045 by $0.030 \mathrm{~mm}$.

Male genitalia: Ninth sternum with small but distinct caudomedian excavation; ninth tergum tapering, the apicolateral processes moderately long with slender points. Basistyle with ventral and dorsal roots of subequal lengths, the ventral root foot-shaped with distinct heel and long toe; dististyle slender, curved to pointed apex. Aedeagus with high basal arch, the mesal apex of arch narrow; distal stem slender with rounded point. Parameres each with knobbed base, swollen toward base of stem, stem abruptly bent at base but straight in midportion, ventral lobe absent, distal portion somewhat flattened with lateral fringe of sharp barbs, tapering to a needle-like point.

Distribution: Panama; Honduras.

Specimens examined: Holotype female (USNM 63169), allotype male, Almirante, Bocas del Toro Province, Panama, November 1952, F. S. Blanton, light trap. Paratypes, 19 males, 80 females: Panama: Bocas del Toro Province: 8 males, 49 females, same data as type except dates October 1952 to March 1953. Canal Zone: 2 males, 1 female, Fort Davis, Oct. 7, 1953; 2 females, Loma Boracho, Oct. 29, 1951; 1 male, 1 female, Mindi Dairy, Dec. 17, 1951, Aug. 22, 1952; 2 males, 4 females, Mojinga Swamp, Jan. 2, Sept. 4, Dec. 4, 1951. Coclé Province: 1 female, Penonomé, Nov. 28, 1952; 1 female, Río Hato, Sept. 24, 1951. Panamá Province: 1 female, Pacora, June 4, 1951. Honduras: 5 males, 20 females, Lancetilla, July 2, 1953 to Feb. 12, 1954, P. Galindo; 1 male, Tela, June 10, 1953, P. Galindo.

Discussion: This species closely resembles propriipennis Macfie in wing pattern, mesonotal and leg markings, structural characters, and male genitalia, but propriipennis differs by having the sides of the mesonotum brownish instead of bluish pruinose, a third pale spot in cell $M_{1}$ at the wing margin, the pale spots in cell $R_{5}$ arranged in a rhomboid instead of a trapezoid, distal sensory tufts on antennal segments III, IX-XIv, and the pit on the third palpal segment broader. The male genitalia of the two species are practically identical, but in propriipennis the stem of the paramere is stouter and not bent near the base. 


\section{Culicoides propriipennis Macfie}

Figure 65

Culicoides propriipennis Macfie, 1948, Ann. Trop. Med. Parasit., vol. 42, p. 84 (female; Chiapas, Mexico; fig. wing).-Ortiz and Mirsa, 1952, Rev. Sanid. Asist. Soc., vol. 17, p. 262 (male; Venezuela; fig. wing, palpus, genitalia).Wirth, 1955, Proc. Ent. Soc. Washington, vol. 57, p. 116 (male, female; Guatemala; fig. palpus, male genitalia).

Female: Length of wing $0.85(0.79-0.89, \mathrm{n}=8) \mathrm{mm}$.

Head.-Eyes narrowly separated, bare. Antenna with flagellar segments in proportion of $16: 11: 13: 14: 14: 14: 14: 15: 19: 19: 20: 20: 32$, antennal ratio $0.97(0.91-1.02, \mathrm{n}=4)$; distal sensory tufts present on segments III, vIII-XIv. Palpal segments in proportion of $8: 18: 20: 9: 9$, third segment slightly swollen, $1.9 \quad(1.7-2.1, \quad \mathrm{n}=8)$ times as long as greatest breadth, with a very broad, shallow, sensory pit. Mandible with $15(15-16, \mathrm{n}=4)$ teeth.

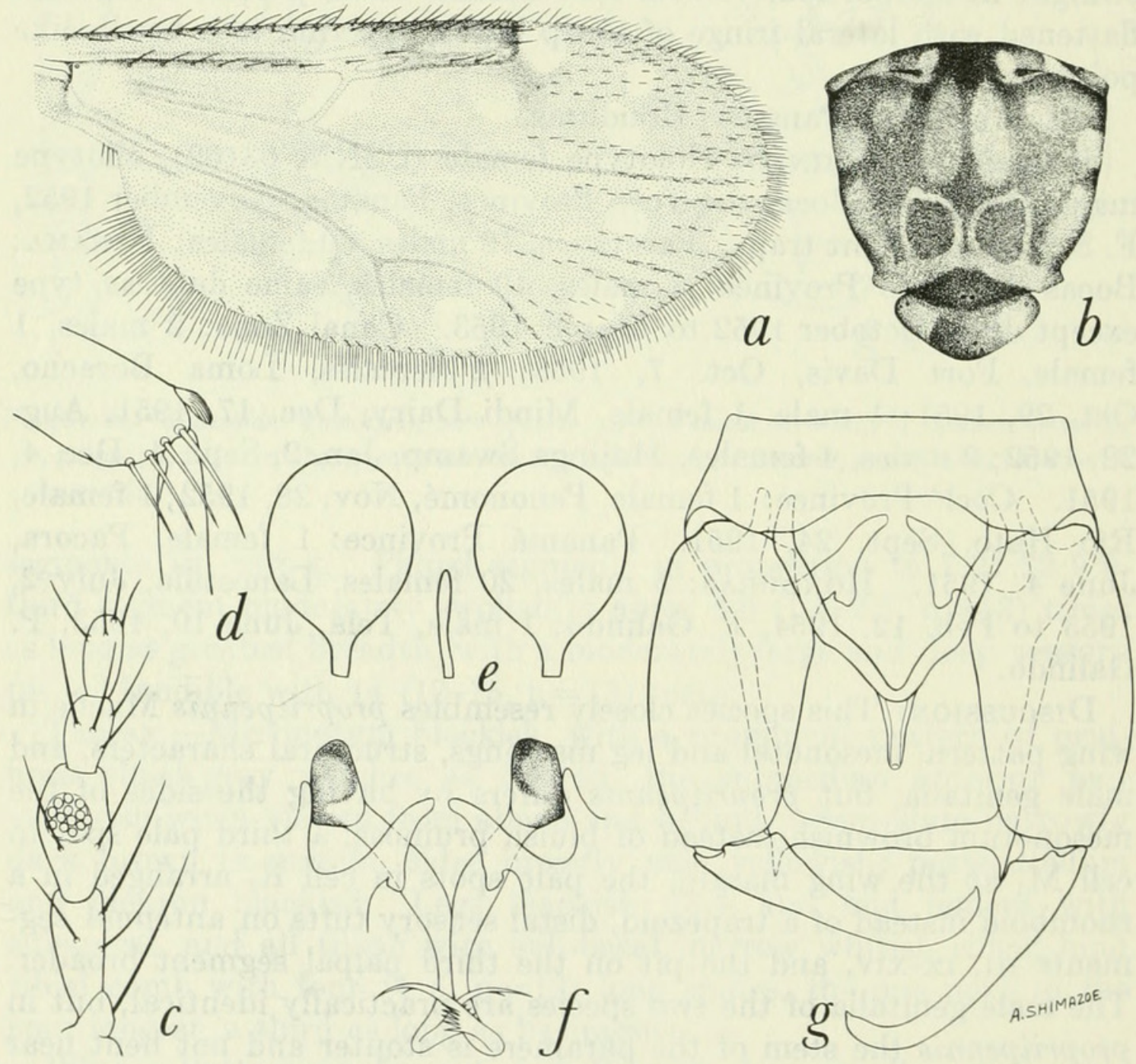

Figure 65.-Culicoides propriipennis Macfie. $a-e$, Female: $a$, wing; $b$, thoracic pattern; $c$, palpus; $d$, tibial comb; $e$, spermathecae. $f, g$, Male: $f$, parameres; $g$, genitalia, parameres removed. 
Thorax.-Mesonotum dark brown with a prominent pattern of pale spots and patches; a submedian anterior pair of elongate yellowish spots and several smaller pruinose yellowish gray spots around lateral margins. Scutellum dark brown in middle, yellowish on sides; postscutellum and pleuron dark brown, pleuron yellowish above. Legs dark brown, fore and mid femora with subapical and all tibiae with subbasal, narrow pale rings; hind tibial comb with four $(n=6)$ spines, the one nearest the spur longest.

Wing.-Pattern as figured; second radial cell very dark; pale spot over $\mathrm{r}-\mathrm{m}$ crossvein extensive; cell $\mathrm{R}_{5}$ with four small well-separated round pale spots distributed in a rhomboidal pattern, the two anterior spots situated distad of the posterior ones; apex of vein $M_{1}$ with a pale spot at wing margin; three pale spots in cell $\mathrm{M}_{1}$, the distal one located at the wing margin and sometimes faint; two pale spots in distal part of cell $\mathrm{M}_{2}$; small round pale spot in center of cell $\mathrm{M}_{4}$; two well-separated, small round pale spots in distal part of anal cell, a faint, irregular, pale area at base of anal cell; cell $\mathrm{M}_{2}$ with a pale spot lying behind medial fork, one lying in front of mediocubital fork and a faint one near base of cell; a pale area distad of basal arculus. Macrotrichia sparse on distal third of wing; costa extending to $0.63(0.62-0.65$, $\mathrm{n}=8$ ) of distance to wing tip. Halter with base of knob brownish.

Abdomen.-Dark brown, cerci yellowish. Spermathecae two, ovoid, subequal, measuring 0.055 by $0.039 \mathrm{~mm}$. and 0.050 by $0.031 \mathrm{~mm}$., the bases of the ducts sclerotized a short distance.

Male genitalia: Ninth sternum with a broad caudomedian excavation; ninth tergum short and tapered, with short apicolateral processes. Basistyle with ventral root foot-shaped, dorsal root short and tapered; dististyle slender and curved with bent tip. Aedeagus $V$-shaped, the basal arch pointed caudad, extending to three-fourths of total length, the basal arms straight, the posterior portion slender with simple tip. Parameres each with large basal knob, stem slender near base, slightly swollen in midportion, gradually tapered distally to slender tip with a subapical fringe of spines, the portion at the base of the fringe slightly expanded.

Distribution: Mexico; Guatemala; Nicaragua (Villa Somoza); Venezuela.

PanAMA RECORDS:

Bocas del Toro Province: Almirante,

Canal Zone: Fort San Lorenzo, Huile Sia Clara (?), Loma Boracho, Mojinga Swamp.

Chiriquí Province: Concepción.

Cocle Province: Penomoné.

Darien Province: Garachiné.

Panamá Province: Pacora. 
Discussion: This species is closely related to tetrathyris, new species, but propriipennis can easily be distinguished by the presence of a third pale spot at the wing margin in cell $\mathrm{M}_{1}$, by the second pale spot in the distal portion of cell $\mathrm{M}_{2}$, and by the presence of distal sensory tufts on segments XI-XIV as well as on III, VIII-X.

\section{Culicoides balsapambensis Ortiz and Leon, new status}

\section{FiguRE 66}

Culicoides pifanoi var. balsapambensis Ortiz and Leon, 1955, Bol. Inf. Cient.

Nac. Ecuador, no. 67, p. 579 (female; Balsapamba, Bolívar, Ecuador; fig. wing, palpus).

Female: Length of wing $0.72(0.66-0.76, \mathrm{n}=5) \mathrm{mm}$.

Head.-Eyes narrowly separated, with long interfacetal hairs. Antenna with flagellar segments in proportion of $15: 12: 12: 14: 14: 13: 14$ : $15: 15: 15: 16: 17: 26$, antennal ratio $0.84(0.81-0.86, \mathrm{n}=2)$; distal sensory
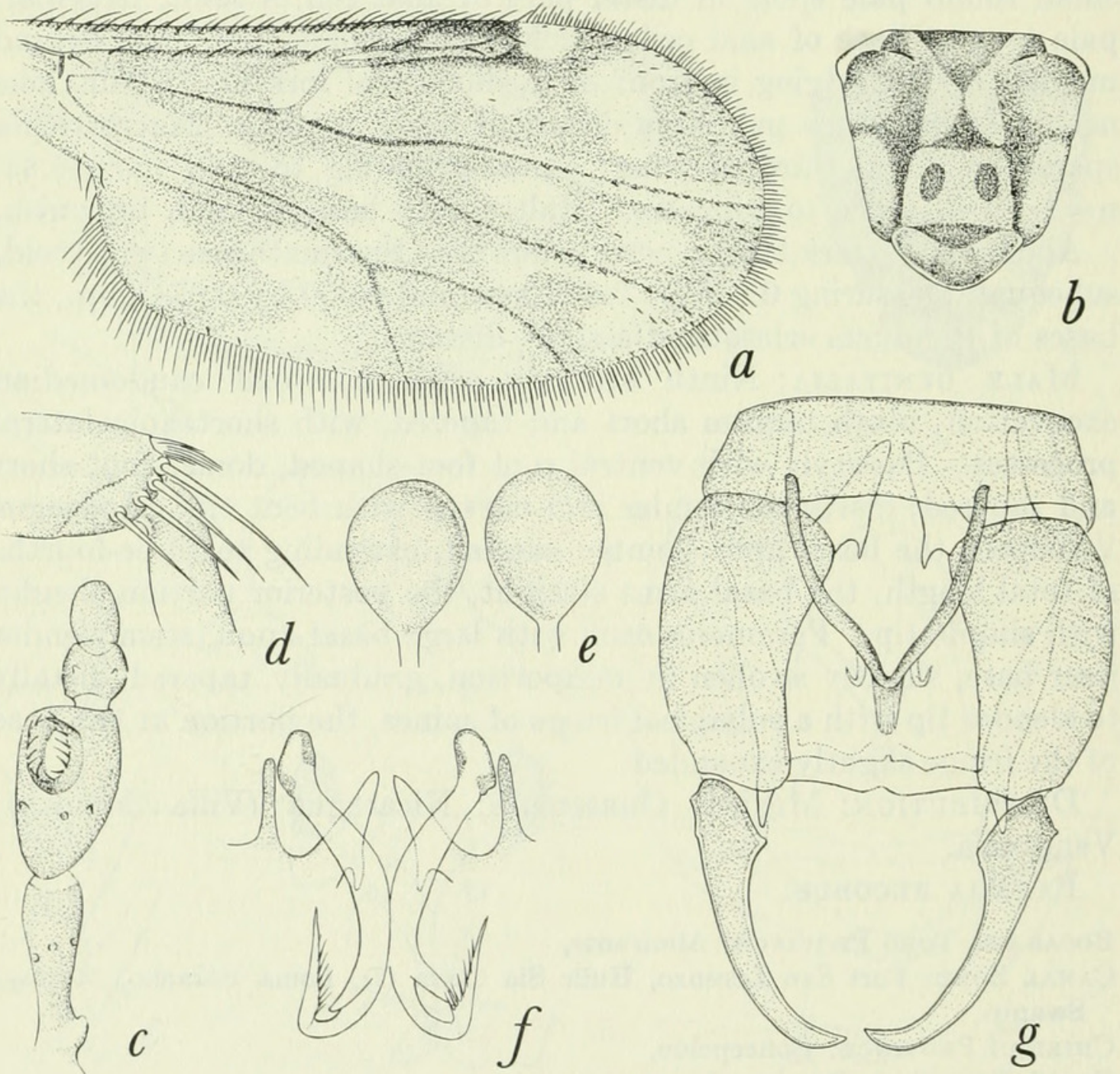

Figure 66.-Culicoides balsapambensis Ortiz and Leon. a-e, Female: $a$, wing; $b$, thoracic pattern; $c$, palpus; $d$, tibial comb; $e$, spermathecae. $f, g$, Male: $f$, parameres; $g$, genitalia, parameres removed. 
tufts present on segments III, viII-X. Palpal segments in proportion of $6: 17: 20: 7: 7$, third segment moderately swollen, 1.8 (1.7-1.9, $\mathrm{n}=6$ ) times as long as greatest breadth, with broad, deep, sensory pit. Mandible with $14(13-14, \mathrm{n}=5)$ teeth.

Thorax.-Mesonotum bluish gray pollinose, with two prominent, jet black, sublateral, longitudinal patches, widest at the mesonotal suture. Scutellum narrowly dark brown in middle, pale on sides; postscutellum and pleuron dark brown. Legs dark brown; fore and mid femora with subapical and all tibiae with subbasal narrow pale rings; hind tibial comb with four $(n=5)$ spines, the one nearest the spur longest.

Wing.-Pattern as figured; pale spot over r-m crossvein large and meeting anterior wing margin; poststigmatic pale spots in cell $R_{5}$ small, distinctly separated, the posterior one located slightly proximad of the anterior one, its diameter longest in the longitudinal axis of wing; distal pale spot in cell $\mathrm{R}_{5}$ reniform, broadly meeting anterior wing margin anterodistad; vein $\mathrm{M}_{1}$ pale-margined on distal half; two pale spots in cell $\mathrm{M}_{1}$, the distal one far removed from wing margin; two pale spots in distal portion of cell $\mathrm{M}_{2}$, connected narrowly by a pale line bordering posterior margin of vein $\mathrm{M}_{2}$; pale spot in cell $\mathrm{M}_{4}$ large; two pale spots in distal portion of anal cell; pale spots present in front of mediocubital fork and behind medial fork, base of wing pale from costal margin to the proximal fourth of anal cell. Macrotrichia very sparse on distal fourth of wing and extending along posterior margin to distal part of cell $\mathrm{M}_{4}$; costa extending to $0.70(0.68-$ $0.72, \mathrm{n}=5$ ) of distance to wing tip. Halter pale.

Abdomen.-Dark brown, cerci yellowish. Spermathecae two, slightly unequal, ovoid, measuring 0.048 by $0.031 \mathrm{~mm}$. and 0.045 by $0.028 \mathrm{~mm}$., the bases of the ducts sclerotized a considerable distance.

Male genitalia: Ninth sternum with very shallow caudomedian excavation; ninth tergum short, very broad and truncate apically with slender apicolateral processes. Basistyle with ventral root footshaped, the posterior heel sharp, the toe long and pointed, dorsal root slender; dististyle long and slender, markedly curved to a pointed apex. Aedeagus with basal arch extending to three-fourths of total length, pointed at mesal apex, the basal arms curved; distal apex simple, with slender, rounded point. Parameres each with welldeveloped basal knob, stem gradually curved to the well-developed, pointed, ventral lobe, distal portion slender and tapered to apical point with a lateral fringe of fine barbs.

Distribution: Ecuador; Panama.

PANAMA RECORDS:

Bocas del Toro Province: Almirante.

Canal Zone: Fort Davis, Loma Boracho. 
Discussion: The resemblance of this species to pifanoi Ortiz, which led Ortiz and Leon to describe it as a variety of that species, is only a superficial one of the wing and mesonotal markings. The wing markings are much more like those of castillae Fox, differing only in the broad extension of the distal pale spot in cell $R_{5}$ to the wing margin, while the presence of only one spermatheca in castillae provides an additional quick separation.

\section{Culicoides castillae Fox}

\section{Figure 67}

Culicoides castillae Fox, 1946, Ann. Ent. Soc. Amer., vol. 39, p. 251 (female; Puerto Castilla, Honduras; fig. mesonotum, wing).

Culicoides dasyophrus Barbosa (misident., not dasyophrus Macfie), 1947, Anais Soc. Biol. Pernambuco, vol. 7, p. 14 (Panama; fig. male genitalia).

Culicoides lichyi Ortiz and Mirsa (misident., not Floch and Abonnenc), 1951, Rev. Sanid. Asist. Soc., vol. 16, p. 601 (female; Venezuela; fig. mesonotum, palpus, spermatheca, wing).

Culicoides flochabonnenci Ortiz and Mirsa, 1952, Rev. Sanid. Asist. Soc., vol. 17, p. 267 (female; Venezuela; fig. palpus, spermatheca, wing).-Ortiz, 1953. idem., vol. 18, p. 801 (in key).-Ortiz and Leon, 1955, Bol. Inf. Cient. Nac. Ecuador, no. 67, p. 574 (male, female; Ecuador; fig. wing, palpus, spermatheca, antenna). New synonymy.

Culicoides gibsoni Wirth, 1952, Journ. Parasit., vol. 38, p. 246 (female; Guatemala; fig. wing, palpus, spermatheca); 1955, Proc. Ent. Soc. Washington, vol. 57 , p. 111 (Guatemala; male, female; fig. male Genitalia). New synonymy.

Female: Length of wing $0.84(0.79-0.89, \mathrm{n}=9) \mathrm{mm}$.

Head.-Eyes moderately separated, with short interfacetal hairs. Antenna with flagellar segments in proportion of $15: 10: 12: 12: 13: 13$ : $13: 14: 18: 19: 21: 22: 30$, antennal ratio $1.09(1.02-1.15, \mathrm{n}=9)$; distal sensory tufts present on segments III, viII-XI. Palpal segments in proportion of $6: 18: 22: 7: 8$, third segment slightly swollen, $2.2(2.0-2.3$, $\mathrm{n}=10$ ) times as long as greatest breadth, with a small, shallow, sensory pit. Mandible with $15(14-16, \mathrm{n}=7)$ teeth.

Thorax.-Mesonotum very dark brown with a prominent pattern as figured, the submedian elongate spots yellowish, the sublateral bands intense black. Scutellum brown in middle, yellowish on sides. Legs dark brown, fore and mid femora with subapical, and all tibiae with subbasal, narrow white rings; hind tibial comb with four $(n=9)$ spines, the one nearest the spur longest, a third as long as basitarsus.

Wing.-Pattern as figured, the three pale spots in cell $R_{5}$ arranged in a triangle and well separated, the distal spot often irregularly $\mathrm{V}$-shaped; distal half of vein $\mathrm{M}_{1}$ pale-margined, two pale spots in cell $\mathrm{M}_{1}$ and in apices of cells $\mathrm{M}_{2}$ and anal cell. Macrotrichia sparse in apices of cells $\mathrm{R}_{5}, \mathrm{M}_{1}$ and $\mathrm{M}_{2}$; costa extending to 0.64 of distance to wing tip. Halter pale, base of the knob darkened. 

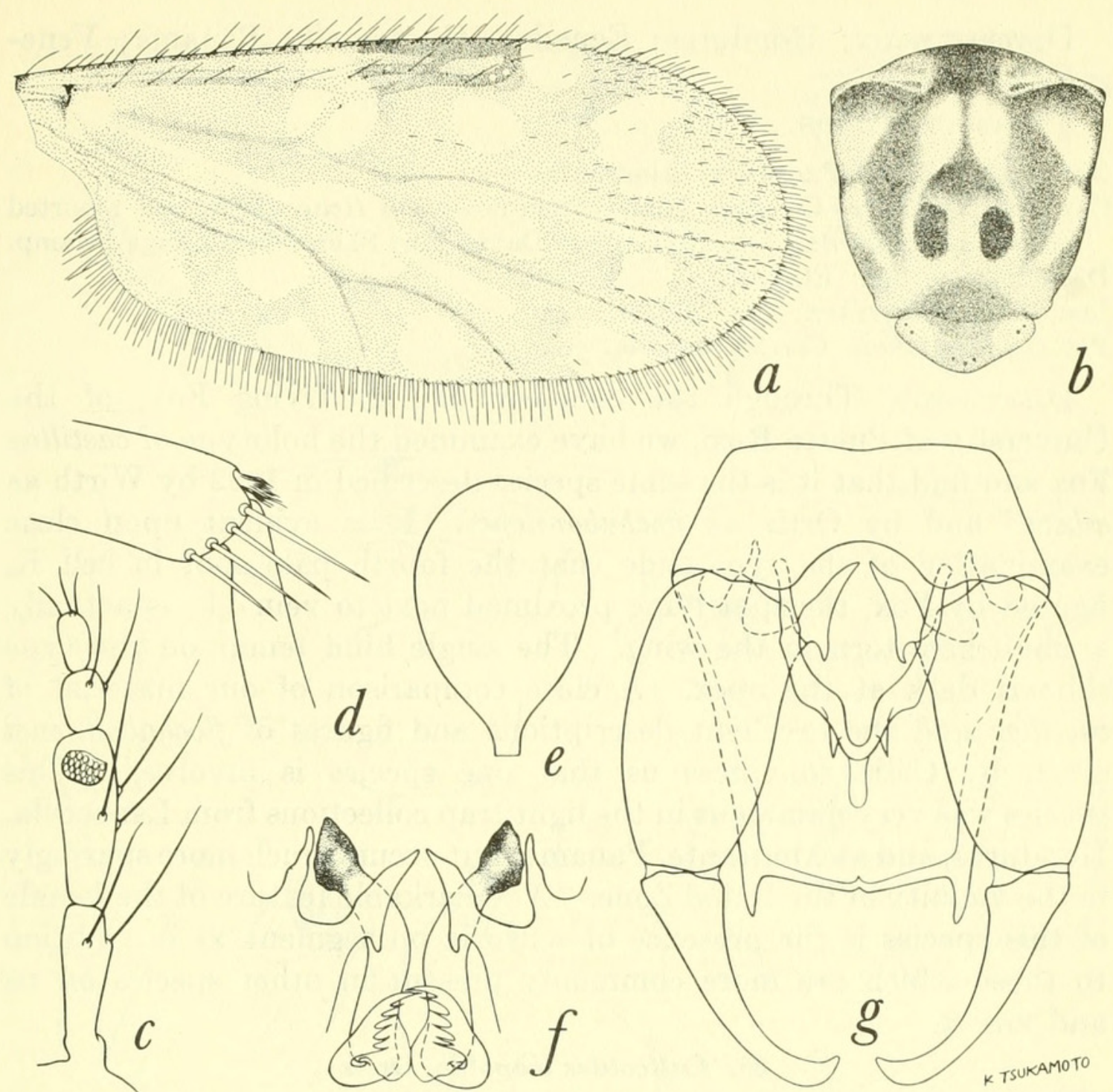

Figure 67.-Culicoides castillae Fox. $a-e$, Female: $a$, wing; $b$, thoracic pattern; $c$, palpus; $d$, tibial comb; $e$, spermatheca. $f, g$, Male: $f$, parameres; $g$, genitalia, parameres removed.

Abdomen.-Dull brownish black. Spermatheca one, pyriform, the base of the duct sclerotized, spermathica measuring 0.052 by 0.037 $\mathrm{mm}$.

Male genitalia: Ninth sternum with shallow caudomedian excavation; ninth tergum tapering, with short, pointed, apicolateral processes. Basistyle with ventral root foot-shaped with a distinct posterior heel; dististyle slender and slightly curved to pointed apex. Aedeagus with basal arch extending to two-thirds of total length, basal arms curved and slender, posterior stem slender and pointed, with a pair of subapical projections arising on sides at juncture with the arch. Parameres each with knobbed base, stem slightly swollen and distinctly bent at midlength, with a small ventral lobe and apex pointed with a fringe of fine barbs. 
Distribution: Honduras; Ecuador; Guatemala; Panama; Venezuela.

PANAMA RECORDS:

Bocas del Toro Province: Almirante.

Canal Zone: Barro Colorado Island (from flowers of Heliconia mariae, reported as dasyophrus by Barbosa, 1947); Fort Davis, Fort Sherman, Mojinga Swamp. Darién Province: El Real.

Los Santos Province: Las Tablas.

Panamá Province: Cerro Campana.

Discussion: Through the courtesy of Dr. Irving Fox, of the University of Puerto Rico, we have examined the holotype of castillae Fox and find that it is the same species described in 1952 by Wirth as gibsoni and by Ortiz as flochabonnenci. It is evident upon close examination of the type slide that the fourth pale spot in cell $R_{5}$ figured by Fox, the spot lying proximad next to vein $\mathrm{M}_{1}$, is actually a small hole torn in the wing. The single hind femur on the type slide is dark at the apex. A close comparison of our material of castillae and the excellent descriptions and figures of flochabonnenci given by Ortiz convinces us that one species is involved. This species was very numerous in the light trap collections from Lancetilla, Honduras, and at Almirante, Panama, but occurs much more sparingly in the vicinity of the Canal Zone. A remarkable feature of the female of this species is the presence of sensoria on segment XI in addition to those which are more commonly present in other species on III and VIII-X.

\section{Culicoides leopoldoi Ortiz}

\section{Figure 68}

Culicoides leopoldoi Ortiz, 1952, Rev. Sanid. Asist. Soc., vol. 16, p. 579 (female; Ocumare del Tuy, Venezuela; fig. palpus, antenna, wing, mesonotal pattern); 1952, Acta Cient. Venezolana, vol. 3, p. 127 (female; Panama record; fig. spermatheca, wing, palpus, antenna).-Ortiz and Mirsa, 1952, Rev. Sanid. Asist. Soc., vol. 16, p. 596 (male; fig. palpus, wing, genitalia).

Female: Length of wing $0.85(0.74-0.96, \mathrm{n}=11) \mathrm{mm}$.

Head.-Eyes contiguous, bare. Antenna with flagellar segents in proportion of $17: 11: 12: 12: 13: 13: 13: 13: 21: 22: 23: 23: 37$, antennal ratio $1.21(1.12-1.26, \mathrm{n}=7)$; distal sensory tufts present on segments III, viI-X. Palpal segments in proportion of $8: 14: 16: 8: 8$, third segment very short and swollen, $1.8(1.6-1.9, \mathrm{n}=10)$ times as long as greatest breadth, with a large, shallow, irregular sensory pit. Mandible with $12(12-13, \mathrm{n}=12)$ teeth.

Thorax.-Mesonotum yellowish gray pruinose, with a prominent pattern consisting of an $\mathrm{H}$-shaped dark-brown patch, as well as a few small brown punctiform dots between and on each side of the anterior arms of the $\mathrm{H}$. Scutellum dark brown narrowly in middle, 

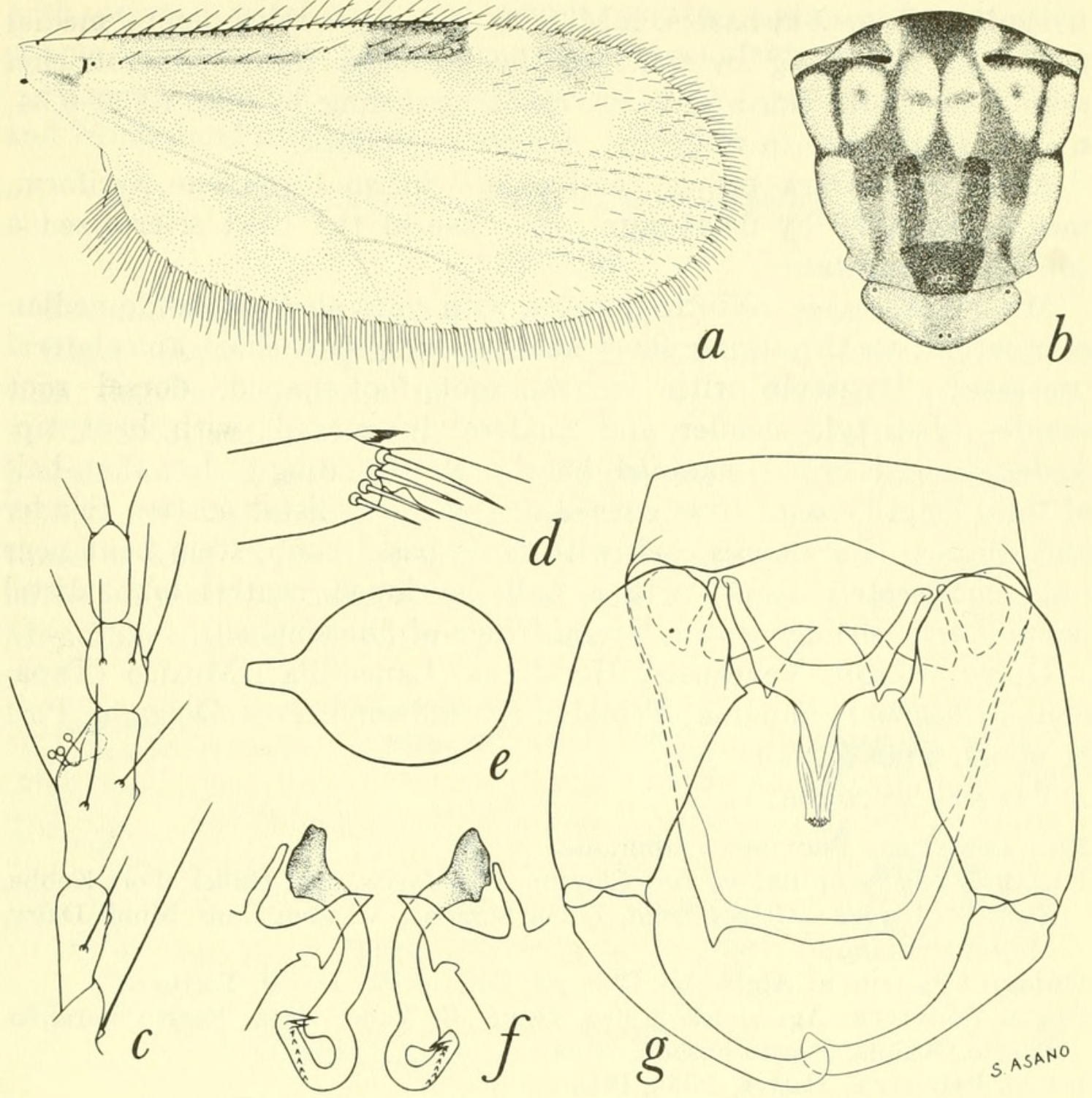

Figure 68.-Culicoides leopoldoi Ortiz. $a-e$, Female: $a$, wing; $b$, thoracic pattern; $c$, palpus; $d$, tibial comb; $e$, spermatheca. $f, g$, Male: $f$, parameres; $g$, genitalia, parameres removed.

yellowish gray on the sides; postscutellum and pleuron dark brown. Legs dark brown; all femora with subapical, all tibiae with subbasal, and hind tibiae with apical, narrow pale rings; hind tibial comb with four $(n=11)$ spines, the one nearest the spur longest.

Wing.-Pattern as figured; second radial cell very dark, pale spot over $\mathrm{r}-\mathrm{m}$ crossvein extensive, broadly meeting anterior wing margin; cell $\mathrm{R}_{5}$ with four pale spots, the anterior poststigmatic spot moderate in size and separated from the two, small, longitudinally aligned, poststigmatic spots, distal pale spot in cell $R_{5}$ large, meeting wing margin broadly and bearing a narrow proximal extension; veins $\mathrm{M}_{1}, \mathrm{M}_{2}$ and $\mathrm{M}_{3+4}$ each with pale spot at wing margin; cell $\mathrm{M}_{1}$ with two pale spots, the second located far from wing margin; two pale spots in distal part of cell $\mathrm{M}_{2}$; pale spot in cell $\mathrm{M}_{4}$ small and round and not meeting wing margin; anal cell with two round pale spots in distal part, a large, 
irregular pale area at base; cell $\mathrm{M}_{2}$ with a pale spot lying behind medial fork and one lying in front of mediocubital fork. Macrotrichia scanty on distal third of wing; costa extending to 0.61 (0.59-0.64, $\mathrm{n}=11$ ) of distance to wing tip. Halter knob dark.

Abdomen.-Dark brown, cerci pale. Spermatheca one, pyriform, measuring 0.070 by $0.046 \mathrm{~mm}$., the base of the duct sclerotized a considerable distance.

Male genitalia: Ninth sternum with very shallow caudomedian excavation; ninth tergum short and tapering with short apicolateral processes. Basistyle with ventral root foot-shaped, dorsal root slender; dististyle slender and moderately curved, with bent tip. Aedeagus with broad, rounded, basal arch extending to less than half of total length, basal arms curved and slender, distal portion slender and simple. Parameres each with large basal knob, stem bent near base, moderately stout, with a well developed ventral lobe, distal portion very slender with a lateral fringe of fine spines.

Distribution: Venezuela; Honduras (Lancetilla); Mexico (Tapachula, Chiapas); Panama; Trinidad (Grandwood, Port Delgada, Port of Spain, Tucker Valley).

PANAMA RECORDS:

Bocas del Toro Province: Almirante.

Canal Zone: Camp Butler, Fort Clayton, Fort Davis, Fort Gulick, Fort Kobbe,

Fort San Lorenzo, Galeta Point, Loma Boracho, Madden Dam, Mindi Dairy, Mojinga Swamp.

Chiriqui Province: Algarrobo, Chiriquí, Concepción, David, Tortugas.

Coclé Province: Aguadulce, Chirú, Coclé, El Valle, Natá, Puerto Farallón,

Puerto Obaldía, Puerto Posado.

Colón Province: Cativá, Pilón, Piña.

Darién Province: El Real, Garachiné, Punta Patiño.

Los Santos Province: Pan de Azucar, Puerto Mensabé, Las Tablas.

Panamá Province: Alcalde Diaz, Arraiján, Capitana, Chepo, Juan Diaz, La Jolla, Naranjal Pacora, Pedregal, Tapagra, Tocumen, Venado Beach, Vique Cove.

Archipiélago de las Perlas: Isla del Rey.

Veraguas Province: Divisa, Rio Santa Maria, Sapotilla.

Discussion: This species is related to castillae Fox, which also is unusual in this group in having only one spermatheca.

\section{The transferrans group}

This group consists of medium-sized brownish species with small, round, pale wing spots; two pale spots in apex of anal cell; five distal antennal segments much elongated, (antennal ratio, 1.43-1.85); distal sensory tufts present on segments III, $\mathrm{x}$ or XI to XIV; four or five tibial spines, only one spermatheca present; male genitalia of patulipalpis similar to those of debilipalpis, with foot-shaped ventral root, aedeagus 
with pointed basal arch and simple pointed apex; paramere with simple basal knob, prominent ventral lobe and fringed tip.

Panama species: Three: patulipalpis, new species; rangeli Ortiz and Mirsa; and transferrans Ortiz.

\section{Culicoides patulipalpis, new species}

Figure 69

Female: Length of wing $0.98(0.90-1.01, \mathrm{n}=6) \mathrm{mm}$.

Head.-Eyes contiguous, with long interfacetal hairs. Antenna with flagellar segments in proportion of $15: 9: 9: 9: 10: 10: 10: 11: 28$ : $31: 32: 38: 43$, antennal ratio $1.85(1.6-2.1, \mathrm{n}=5)$; distal sensory tufts present on segments III, $\mathrm{x}$-XIV. Palpal segments in proportion of $7: 18: 21: 8: 8$; third segment swollen in middle, $2.0 \quad(1.9-2.3, \mathrm{n}=5)$ times as long as greatest breadth, without definite pit, the sensoria borne on mesal, ventral and lateral sides of concaved distal portion. Mandible with $14(14-15, \mathrm{n}=5)$ teeth.
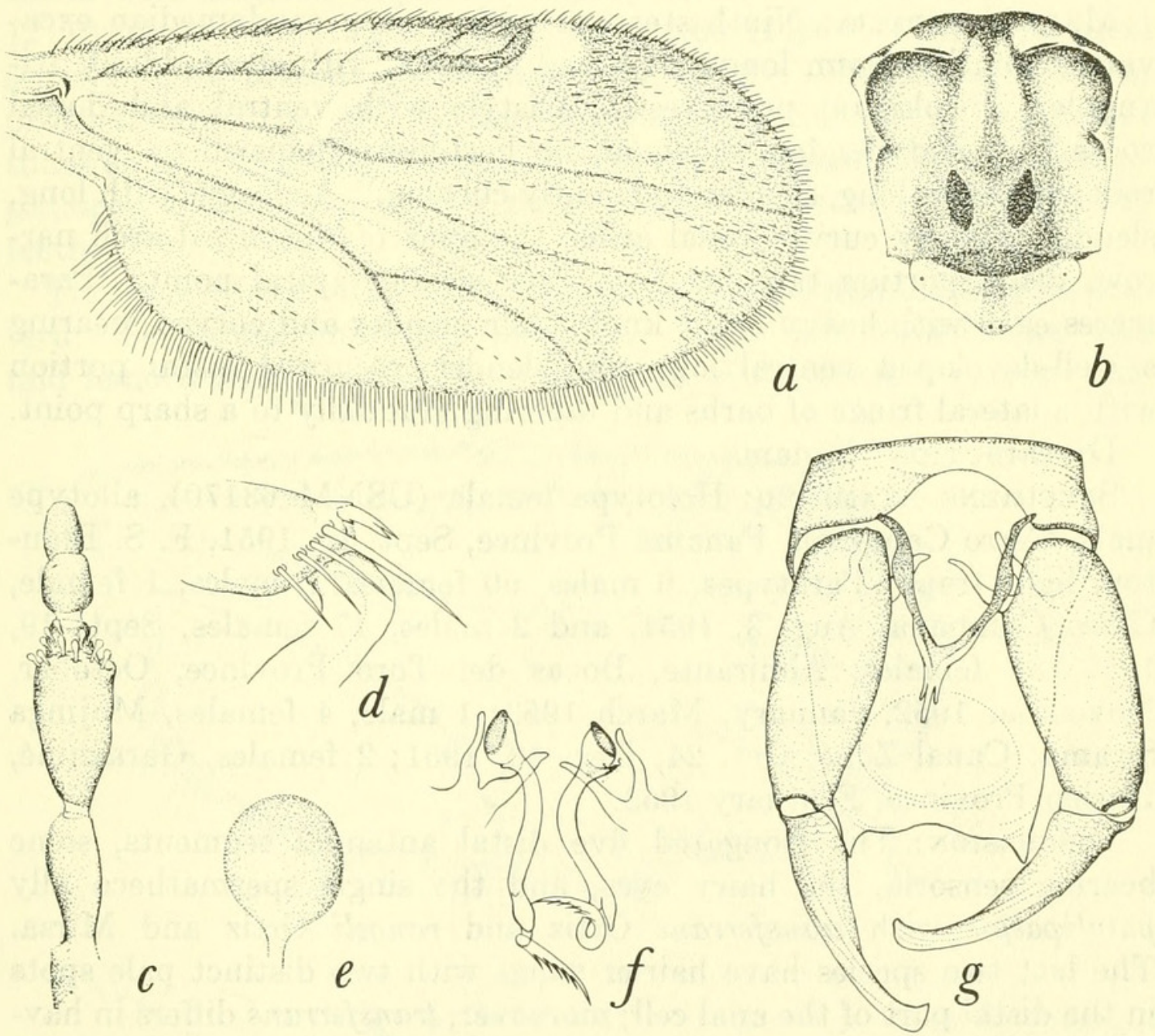

FIGURE 69.-Culicoides patulipalpis, new species. $a-e$, Female: $a$, wing; $b$, thoracic pattern; $c$, palpus; $d$, tibial comb; $e$, spermatheca. $f, g$, Male: $f$, parameres; $g$, genitalia, parameres removed. 
Thorax.-Mesonotum pruinose brown, with large dark brown patches as figured. Scutellum dark brown broadly in middle, sides narrowly yellowish. Legs dark brown; fore and mid femora with subapical and all tibiae with subbasal narrow pale rings; hind tibial comb with four $(n=5)$ spines, the one next to the spur longest, very long, a third as long as basitarsus.

Wing.-Pattern as figured; poststigmatic pale spots broadly connected, the posterior one slightly larger and slightly proximad of the anterior one; pale spot in apex of cell $\mathrm{R}_{5}$ large and transverse, not meeting wing margin; two pale spots in cell $\mathrm{M}_{1}$, only one spot in apex of cell $\mathrm{M}_{2}$, anal cell with single distal pale spot which broadly reaches wing margin, pale spots present lying behind medial fork and in front of mediocubital fork. Macrotrichia long but only moderately dense on distal half of wing, a few in anal cell; costa extending to $0.64(0.61-0.67, \mathrm{n}=6)$ of distance to wing tip. Halter yellowish.

Abdomen.-Dark brown, cerci yellowish. Spermatheca one, pyriform, measuring 0.051 by $0.041 \mathrm{~mm}$.

Male genitalia: Ninth sternum with a deep caudomedian excavation; ninth tergum long and broad at apex, with short, blunt, triangular apicolateral processes. Basistyle with ventral and dorsal roots long and slender, subequal, no heel-like expansion on ventral root; dististyle long, slender and gently curving. Aedeagus with long, slender, slightly curved basal arms, the apex of the mesal arch narrow, distal portion tapering to a very slender apical point. Parameres each with heavy basal knob, stem slender and curved, bearing a well-developed ventral lobe, the slender, recurved distal portion with a lateral fringe of barbs and tapering gradually to a sharp point.

Distribution: Panama.

Spectmens examined: Holotype female (USNM 63170), allotype male, Cerro Campana, Panamá Province, Sept. 19, 1951, F. S. Blanton, light trap. Paratypes, 6 males, 60 females: 3 males, 1 female, Cerro Campana, Aug. 3, 1951, and 2 males, 17 females, Sept. 19, 1951; 36 females, Almirante, Bocas del Toro Province, October, November 1952, January, March 1953; 1 male, 4 females, Mojinga Swamp, Canal Zone, Oct. 24, Dec. 10, 1951; 2 females, Garachiné, Darién Province, February 1953.

Discussion: The elongated five distal antennal segments, some bearing sensoria, the hairy eyes, and the single spermatheca ally patulipalpis with transferrans Ortiz and rangeli Ortiz and Mirsa. The last two species have hairier wings with two distinct pale spots in the distal part of the anal cell; moreover, transferrans differs in having a very contrasting mesonotal pattern, palpus with definite pit, sensoria lacking on antennal segment $\mathrm{x}$ and the pale spots in cell $\mathrm{R}_{5}$ often separated into four separate spots, while rangeli has a palpus 
with an irregular pit, sensoria as in patulipalpis and the spots in cell $R_{5}$ more restricted, the distal one transverse and the posterior poststigmatic spot greatly reduced or often entirely absent.

The male genitalia of patulipalpis are similar to those of debilipalpis Lutz, but in patulipalpis the apicolateral processes of the ninth tergite are stouter, the caudomedian excavation of the ninth sternum is much deeper, the apex of the aedeagus is much more pointed, and the ventroposterior lobe on the parameres is longer.

\section{Culicoides rangeli Ortiz and Mirsa}

Figure 70

Culicoides rangeli Ortiz and Mirsa, 1952, Acta Cient. Venezolana, vol. 3, p. 126 (female; Los Chorros, Miranda, Venezuela; fig. palpus, antenna; spermatheca; wing).

Female: Length of wing $1.01(0.91-1.19, \mathrm{n}=9) \mathrm{mm}$.

Head.-Eyes nearly contiguous, with long interfacetal hairs. Antenna with flagellar segments in proportion of $17: 11: 11: 12: 12: 12$ : $12: 12: 29: 30: 31: 34: 36$, antennal ratio $1.63(1.39-1.79, \mathrm{n}=4)$; distal sensory tufts present on segments III, $\mathrm{x}$-XIv. Palpal segments in proportion of $7: 17: 20: 7: 8$, third segment swollen, $1.9(1.5-2.1, \mathrm{n}=7)$ times as long as greatest breadth, with a very broad, shallow, sensory pit, open and without regular pore. Mandible with $16(14-20, n=7)$ teeth.

Thorax.-Mesonotum blackish, densely hairy, without apparent pattern. Scutellum uniformly blackish. Legs dark brown; fore and mid femora with subapical and all tibiae with subbasal narrow pale
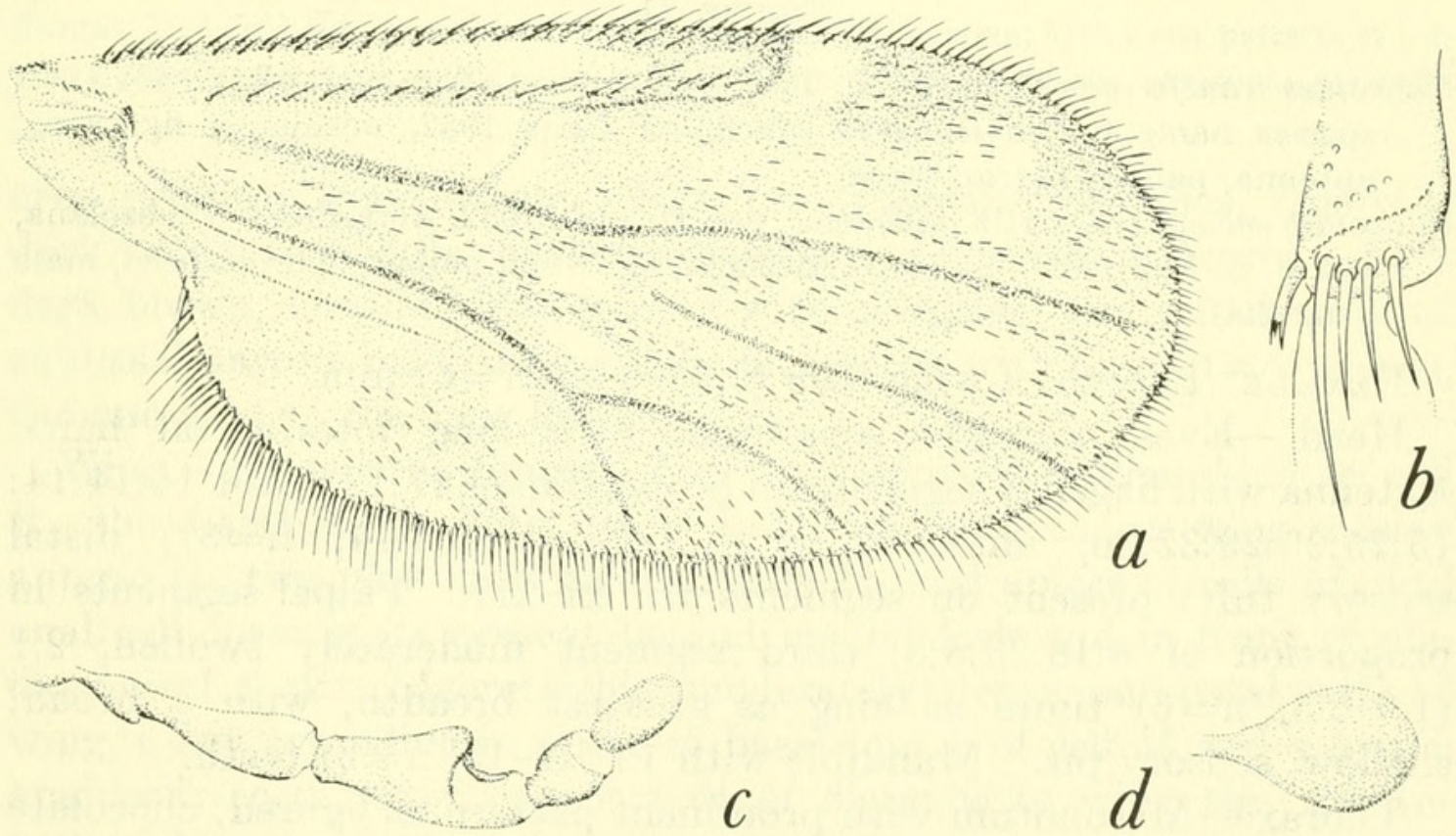

C

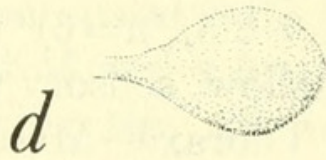

Figure 70.-Culicoides rangeli Ortiz and Mirsa, female: $a$, wing; $b$, tibial comb; $c$, palpus; $d$, spermatheca. 
rings; hind tibial comb with four $(n=9)$ spines, the one next to the spur longest, a third as long as basitarsus.

Wing.-Pattern as figured, posterior poststigmatic pale spot in cell $R_{5}$ very small or entirely absent, distal spot in cell $R_{5}$ transverse and not double, not attaining wing margin; two very small pale spots each in cell $M_{1}$ and in apices of cell $M_{2}$ and anal cell; a pale spot present behind medial fork and another in front of mediocubital fork. Macrotrichia very long and dense, numerous in anal cell and in three or four rows to base of cell $\mathrm{M}$; costa extending to 0.65 of distance to wing tip. Halter pale.

Abdomen.-Dark brown; cerci yellowish. Spermatheca one, pyriform, measuring 0.063 by $0.037 \mathrm{~mm}$., with long sclerotized neck.

Male: Unknown.

Distribution: Venezuela; Panama.

Panama Records:

Bocas del Toro Province: Almirante.

Canal Zone: Las Cruces.

Chiriquí Province: Boquete, Volcán.

Discussion: Characters for the separation of rangeli from the closely related iransferrans Ortiz and patulipalpis Wirth and Blanton are discussed under patulipalpis. According to the original description and figures given by Vargas (1954), donajii Vargas from Chiapas, Mexico, is very close to rangeli, differing in the female by the fusion and extension of the two poststigmatic pale spots in cell $R_{5}$.

\section{Culicoides transferrans Ortiz}

\section{Figure 71}

Culicoides transferrans Ortiz, 1953, Rev. Sanid. Asist. Soc., vol. 18, p. 801 (new species name for eublepharus Macfie of Ortiz 1952, misident.; fig. wing, antenna, palpus, spermatheca).

Culicoides eublepharus Ortiz (misident., not Macfie), 1952, Acta Cient. Venezolana, vol. 3, p. 129 (male, female; Venezuela; fig. wing, palpus, spermatheca, male genitalia).

Female: Length of wing $0.98(0.96-0.99, \mathrm{n}=6) \mathrm{mm}$.

Head.-Eyes narrowly separated, with long interfacetal hairs. Antenna with flagellar segments in proportion of $17: 12: 13: 14: 14: 14: 14$ : $15: 25: 26: 29: 32: 36$, antennal ratio $1.43 \quad(1.24-1.74, \quad \mathrm{n}=3)$; distal sensory tufts present on segments III, XI-xIV. Palpal segments in proportion of $8: 18: 23: 8: 8$, third segment moderately swollen, 2.1 $(1.9-2.3, \mathrm{n}=6)$ times as long as greatest breadth, with a broad, shallow, sensory pit. Mandible with $15(14-15, \mathrm{n}=3)$ teeth.

Thorax.-Mesonotum with prominent pattern as figured, chocolate brown on the disc with an elongate submedian anterior pair of large yellowish spots, two pairs of lateral spots and extensive prescutellar 

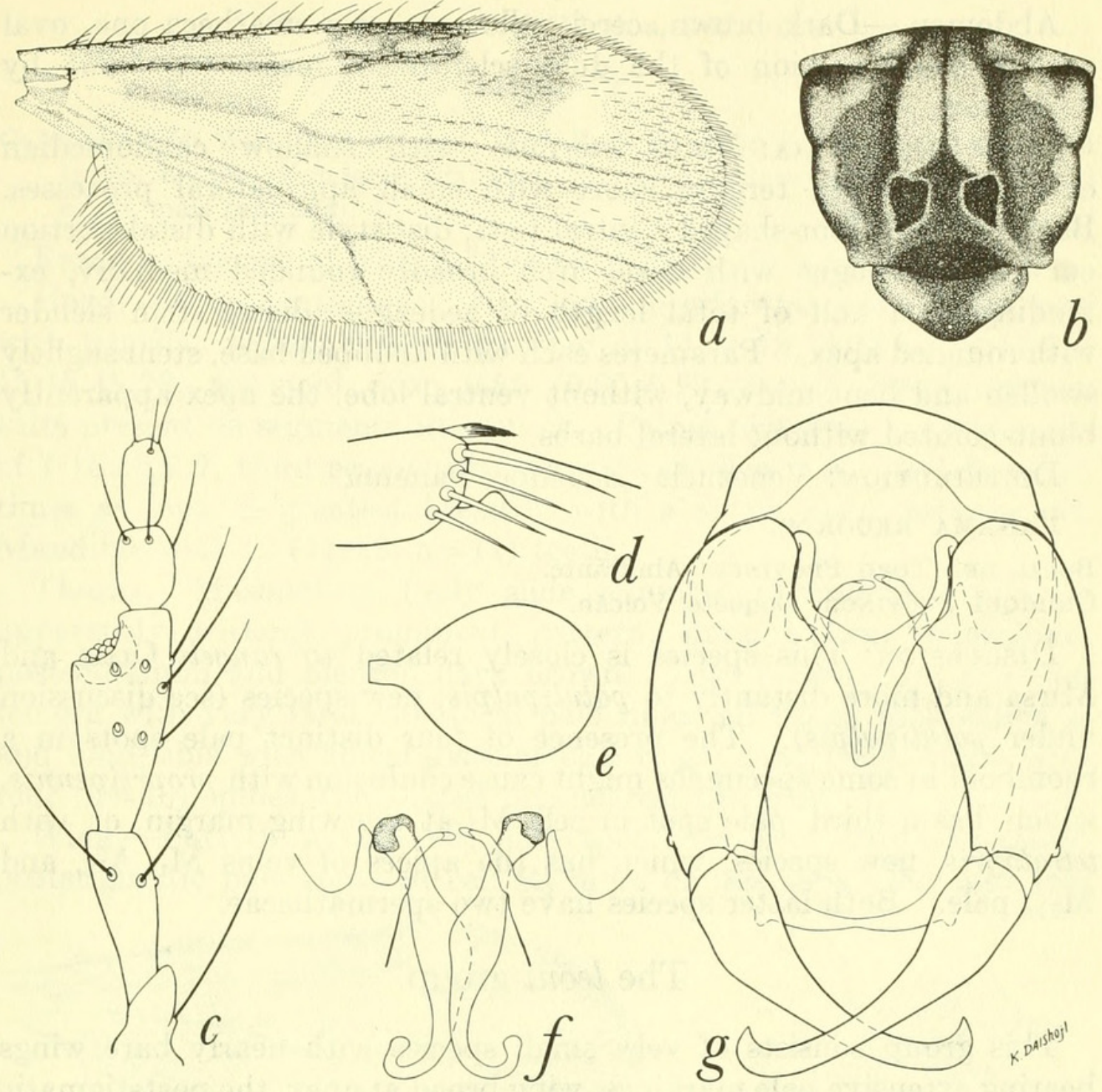

Figure 71.-Culicoides transferrans Ortiz. $a-e$, Female: $a$, wing; $b$, thoracic pattern; $c$, palpus; $d$, tibial comb; $e$, spermatheca. $f, g$, Male: $f$, parameres; $g$, genitalia, parameres removed.

area pruinose gray-brown. Scutellum yellowish on sides, narrowly dark brown in middle; postscutellum and pleuron dark brown. Legs dark brown, fore and mid femora with subapical and all tibiae with subbasal narrow pale rings; hind tibial comb with four $(\mathrm{n}=5)$ spines, the one next to the spur longest.

Wing.- Pattern as figured, four pale spots in a rhomboid in cell $\mathrm{R}_{5}$, the distal pair usually fused and broadly attaining wing margin anteriorly; two pale spots each in cells $M_{1}$ and apices of cells $M_{2}$ and anal cell; pale spots present behind medial fork and in front of mediocubital fork. Macrotrichia moderately dense on distal half of wing, a few extending in a line to basal fourth of cell $\mathrm{M}$ and a few in anal cell; costa extending to 0.64 of distance to wing tip. Halter yellowish. 
Abdomen.-Dark brown, cerci yellowish. Spermatheca one, oval with a short portion of the duct sclerotized, measuring 0.055 by $0.038 \mathrm{~mm}$.

Male Genitalia: Ninth sternum with shallow caudomedian excavation; ninth tergum short with small apicolateral processes. Basistyle with foot-shaped ventral root; dististyle with distal portion curved. Aedeagus with basal arch broadly rounded medially, extending to a half of total length of aedeagus, distal stem slender with rounded apex. Parameres each with knobbed base, stem slightly swollen and bent midway, without ventral lobe, the apex apparently blunt-pointed without lateral barbs.

Distribution: Venezuela; Ecuador; Panama.

PANAMA RECORDS:

Bocas del Toro Province: Almirante.

Chiriquí Province: Boquete, Volcán.

Discussion: This species is closely related to rangeli Ortiz and Mirsa and more distantly to patulipalpis, new species (see discussion under patulipalpis). The presence of four distinct pale spots in a rhomboid in some specimens might cause confusion with propriipennis, which has a third pale spot in cell $\mathrm{M}_{1}$ at the wing margin, or with tetrathyris, new species, which has the apices of veins $\mathrm{M}_{1}, \mathrm{M}_{2}$, and $\mathbf{M}_{3+4}$ pale. Both latter species have two spermathecae.

\section{The leoni group}

This group consists of very small species with nearly bare wings bearing extensive pale markings, wing broad at apex, the poststigmatic pale spots nearly in line transversely and usually broadly fused, the distal pale spot in cell $R_{5}$ round and nearly filling apex of cell; one pale spot each in distal parts of cell $\mathrm{M}_{2}$ and anal cell; antenna of female with flagellar segments in two series, one from III-x, the other from $\mathrm{XI}-\mathrm{Xv}$, in each of which the segments gradually increase in length distally, segment $\mathrm{xI}$ thus shorter than $\mathrm{x}$; distal sensory tufts present on segments III, viI or viII to $\mathrm{x}$; four tibial spines, only one spermatheca present; male genitalia with ventral root of basistyle foot-shaped; paramere with simple basal knob, stem short, with or without ventral lobe, tip simple or with very few fringing spines; ninth tergum short and broad; aedeagus with or without subapical points.

Panama species: Two: fieldi Wirth and Blanton and glabellus Wirth and Blanton. Wirth and Blanton (1956) have recently treated the species in this group which, in addition to the above species, includes benarrochei Ortiz from Venezuela, leoni Barbosa from Ecuador, and reevesi Wirth from California. 


\section{Culicoides fieldi Wirth and Blanton}

\section{FiguRE 72}

Culicoides fieldi Wirth and Blanton, 1956, Bull. Brookłyn Ent. Soc., vol. 51, p. 50 (male, female; Honduras, Panama; fig. wing, palpus, spermatheca, tibial comb, male genitalia).

Female: Length of wing $0.72(0.66-0.76, \mathrm{n}=9) \mathrm{mm}$.

Head.-Eyes contiguous, with long interfacetal hairs. Antenna with flagellar segments in proportion of $14: 11: 13: 14: 13: 13: 14: 17: 15$ : $15: 18: 18: 29$, antennal ratio $0.85(0.80-0.92, \mathrm{n}=6)$; distal sensory tufts present on segments III, VIII-X. Palpal segments in proportion of $7: 15: 15: 7: 7$, third segment moderately swollen, $1.8(1.7-1.9, \mathrm{n}=8)$ times as long as greatest breadth, with a small, deep, sensory pit. Mandible with $12(11-13, \mathrm{n}=11)$ teeth.

Thorax.-Mesonotum (only slide mounted specimens available) apparently without prominent pattern, dark brown. Scutellum, postscutellum and pleuron dark brown. Legs brown, fore and mid femora with very faint subapical pale rings, all tibiae with subbasal and hind tibia with apical distinct pale rings; hind tibial comb with four $(n=10)$ spines, the longest one nearest the spur.

Wing.-Pattern as figured; pale spot over $\mathrm{r}-\mathrm{m}$ crossvein small; poststigmatic pale spots in cell $R_{5}$ more or less separated into two

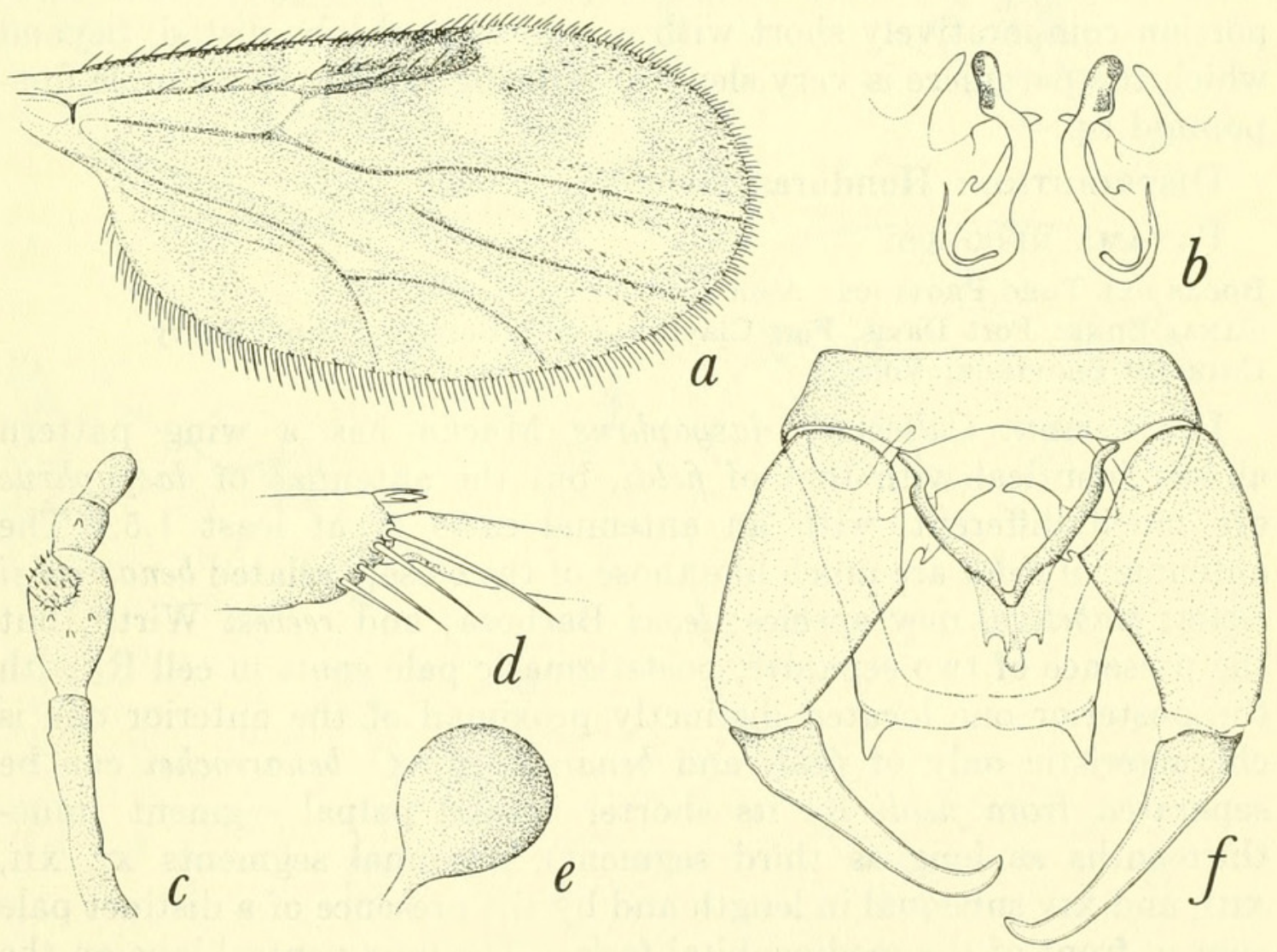

Figure 72.-Culicoides fieldi Wirth and Blanton. $a, c-e$, Female: $a$, wing; $c$, palpus; $d$, tibial comb; $e$, spermatheca. $b, f$, Male: $b$, parameres; $f$, genitalia, parameres removed. 
distinct, small round spots, the posterior one located distinctly proximad of the anterior one; distal pale spot in cell $R_{5}$ small and round, located in center of cell; two pale spots in cell $\mathrm{M}_{1}$; only one pale spot each in apices of cells $\mathrm{M}_{2}, \mathrm{M}_{4}$ and anal cell; pale spot present behind medial fork but no pale spot in front of mediocubital fork. Macrotrichia very sparse on distal fourth of wing, none located proximad of level of end of costa; costa extending to $0.60(0.59$ $0.62, \mathrm{n}=9$ ) of distance to wing tip. Halter infuscated.

Abdomen.-Blackish, cerci yellowish. Spermatheca one, pyriform, measuring 0.057 by $0.038 \mathrm{~mm}$., the base of the duct sclerotized a considerable distance.

Male genitalia: Ninth sternum very narrow, caudomedian excavation not developed, the posterior membrane not spiculate; ninth tergum short with truncate apex, apicolateral processes long and slender. Basistyle with ventral lobe large and foot-shaped, the posterior heel pointed, dorsal root slender; dististyle long and slender with hooked apex. Aedeagus with basal arch extending to more than half of total length, mesal apex of arch narrow, the basal arms nearly straight and well sclerotized; distal portion tapering to a slender rounded tip, with a subapical, lateral pair of sclerotized points arising near juncture with the arch. Parameres each with small basal knob, stem slender, abruptly bent near base, the straight portion comparatively short with a long ventral lobe distad, beyond which the paramere is very slender, tapering rapidly to a simple finepointed tip.

\section{Distribution: Honduras; Panama.}

PANAMA RECORDS:

Bocas del Toro Province: Almirante.

Canal Zone: Fort Davis, Fort Clayton, Loma Boracho, Mindi Dairy. Chiriquí Province: Volcán.

Discussion: Culicoides dasyophrus Macfie has a wing pattern almost identical with that of fieldi, but the antennae of dasyophrus are much different, with an antennal ratio of at least 1.5. The antennae of fieldi are much like those of the closely related benarrochei Ortiz; glabellus, new species; leoni Barbosa; and reevesi Wirth, but the presence of two separate, poststigmatic pale spots in cell $R_{5}$ with the posterior one located distinctly proximad of the anterior one is characteristic only of fieldi and benarrochei. C. benarrochei can be separated from fieldi by its shorter second palpal segment (ninethirteenths as long as third segment), antennal segments XI, XII, XIII, and XIv subequal in length and by the presence of a distinct pale spot in front of the mediocubital fork. The long ventral lobe on the male paramere is diagnostic of fieldi. 
basal and hind tibia with apical, narrow whitish rings; hind tibial comb with four $(n=10)$ spines, the longest one next to the spur.

Wing.-Pattern as figured; poststigmatic pale spot in cell $R_{5}$ only rarely incompletely divided into two separate spots, these located at same distance from base of wing, the spot never extending caudad as far as vein $\mathrm{M}_{1}$; pale spot in apex of cell $\mathrm{R}_{5}$ large and rounded, usually filling most of the space between anterior wing margin and vein $\mathrm{M}_{1}$; two pale spots in cell $\mathrm{M}_{1}$, only one pale spot each in apices of cell $\mathrm{M}_{2}$ and anal cell, pale spots present lying in front of mediocubital fork and behind medial fork. Macrotrichia very sparse in extreme apices of cells $R_{5}, M_{1}$ and $M_{2}$; costa extending to 0.65 of wing length, wing broader than usual on distal half. Halter whitish.

Abdomen.-Dark brown, cerci yellowish. Spermatheca one, pyriform, measuring 0.059 by $0.038 \mathrm{~mm}$., with long sclerotized duct.

Male genitalia: Ninth sternum with very shallow, broad, caudomedian excavation; the posterior membrane bare; ninth tergum short, the apex distinctly notched in middle with prominent, triangular, apicolateral processes. Basistyle with short ventral and dorsal roots, the posterior heel not developed on ventral root; dististyle slender, only slightly curved. Aedeagus with broad, distally rounded, basal arch, the basal arms distinctly curved; distal stem broad at base with a pair of hyaline, sublateral, rounded lobes, the median point slender and rounded at tip. Parameres each with large basal knob, stem slender and gradually curved on basal portion, more swollen toward apex of straight portion, ventral lobe absent, apex abruptly tapered to simple filiform tip directed ventrad.

Distribution: Panama; Honduras; Nicaragua; Trinidad.

PANAMA RECORDS:

Bocas del Toro Province: Almirante (type locality).

Canal Zone: Camp Butler, Mojinga Swamp.

Discussion: In general appearance, size, and wing markings glabellus is practically identical with leoni Barbosa and gabaldoni Ortiz. There are two spermathecae, however, in gabaldoni, and leoni differs in having an antennal ratio of only 0.75 and sensoria present on segment viI as well as on III, VIII-x. All three species have the remarkable repetition of increasing lengths of segments in the antennal series with segment $\mathrm{XI}$ always shorter than $\mathrm{x}$. The male genitalia of glabellus can be readily distinguished by the gradually curving base of the paramere, the stem swollen at the distal part of the straight portion, beyond which the paramere tapers rapidly to a simple, filamentous tip. 


\section{The debilipalpis group}

This group consists of small species with dark brown mesonotum, rarely with prominent pattern; wing with small round spots, one or two in distal part of cells $R_{5}$ and $M_{1}$, and only one spot in distal parts of cell $\mathrm{M}_{2}$ and anal cell, all far from wing margin; apices of veins dark; antenna with flagellar segments in one series of gradually increasing lengths, no break between segments $\mathrm{x}$ and $\mathrm{xI}$, sensoria present on segments III, and vII or VIII to $\mathrm{x}$; four tibial spines; two spermathecae; male genitalia with ventral root of basistyle foot-shaped, paramere with simple basal knob and fringed apex; aedeagus with subapical or apical sclerotized points, these often remarkably developed.

Panama species: Ten: aureus Ortiz, debilipalpis Lutz, gabaldoni Ortiz, ginesi Ortiz, glabrior Macfie, hoffmani Fox, imitator Ortiz, mirsae Ortiz, paraensis (Goeldi), and spurius, new species.

\section{Culicoides gabaldoni Ortiz}

Figure 74

Culicoides gabaldoni Ortiz, 1954, Arch. Venezolana Patol. Trop. Parasit. Med., vol. 2, p. 221 (female; Venezuela; fig. wing, antenna, palpus, spermathecae), Culicoides germanus Wirth (misident., not Macfie), 1955, Proc. Ent. Soc. Washington, vol. 57, p. 111 (male, female; Guatemala; fig. male genitalia).

Female: Length of wing $0.65(0.55-0.79, \mathrm{n}=14) \mathrm{mm}$.

Head.-Eyes broadly separated, with long interfacetal hairs. Antenna with flagellar segments in proportion of 18:9:10:11:11:11:12: $14: 13: 12: 16: 17: 25$, antennal ratio $0.91 \quad(0.85-0.96, n=9)$; distal sensory tufts present on segments III, viII-X. Palpal segments in proportion of $6: 14: 16: 5: 9$, third segment moderately swollen, 1.8 $(1.7-2.1, n=13)$ times as long as greatest breadth, with a small, very deep sensory pit. Mandible with $11(10-15, \mathrm{n}=13)$ teeth.

Thorax.-Mesonotum very dark brown with bluish gray pruinosity, with pattern of two sublateral, narrow, blackish vittae. Scutellum, postscutellum and pleuron dark brown. Legs pale brown, hind femur darker; fore and mid femur with subapical, all tibiae with subbasal and hind tibia with apical, broad pale bands; hind tibial comb with four $(\mathrm{n}=12)$ spines, the one nearest the spur longest.

Wing.-Pattern as figured, the two poststigmatic pale spots in cell $\mathrm{R}_{5}$ fused into a single quadrate pale area extending nearly to vein $\mathrm{M}_{1}$, with the posterior portion of the area usually extending slightly distad of the anterior portion, distal pale spot in cell $R_{5}$ large and rounded, nearly filling space between anterior wing margin and vein $M_{1}$; two pale spots in cell $M_{1}$; one pale spot each in apices of cell $M_{2}$, 

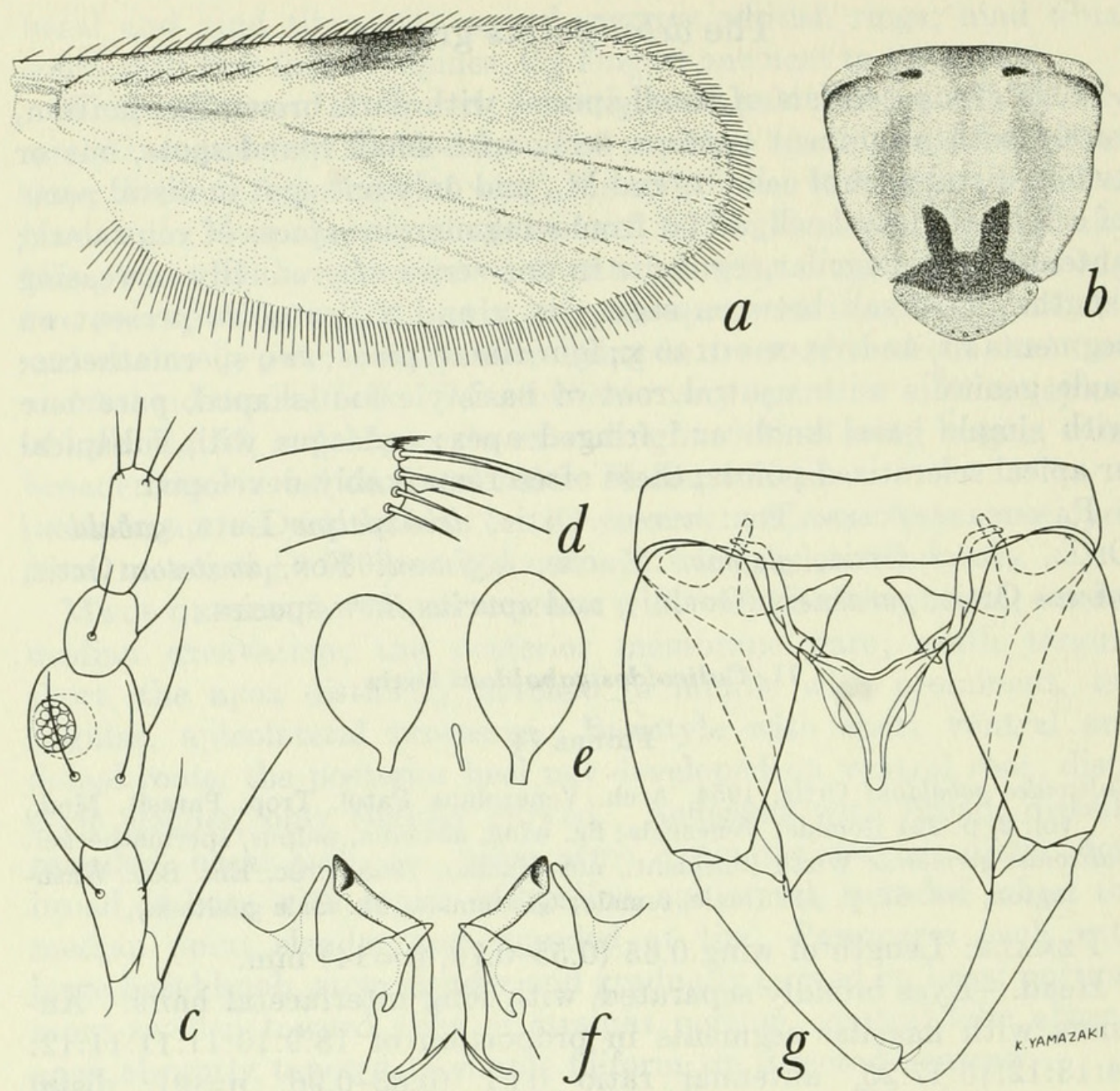

Figure 74.-Culicoides gabaldoni Ortiz. $a-e$, Female: $a$, wing; $b$, thoracic pattern; $c$, palpus; $d$, tibial comb; $e$, spermathecae. $f, g$, Male: $f$, parameres; $g$, genitalia, parameres removed.

cell $\mathrm{M}_{4}$, and anal cell; pale spot in anal cell sometimes extending to wing margin; pale spot present behind medial fork, but no pale spot present in front of mediocubital fork. Macrotrichia practically absent, a few in rows in apices of cells $\mathrm{R}_{5}, \mathrm{M}_{1}$ and $\mathrm{M}_{2}$; costa extending to $0.62(0.59-0.65, \mathrm{n}=14)$ of distance to wing tip. Halter pale.

Abdomen.-Dark brown, cerci yellowish. Spermathecae two, ovoid, slightly unequal, measuring 0.045 by $0.028 \mathrm{~mm}$. and 0.036 by 0.026 $\mathrm{mm}$., the bases of the ducts sclerotized a short distance.

Male genitalia: Ninth sternum with very slight caudomedian excavation; ninth tergum short and tapering, with long, slender apicolateral processes, the caudal margin between the processes straight. Basistyle with foot-shaped ventral root, dorsal root stout and nearly as long; dististyle short and slender, nearly straight with hooked apex. Aedeagus with basal arch attaining one-half to twothirds of total length, rounded mesally, the basal arms stout and 
curved, distal stem tapered to an apical rounded point with a pair of small, sharp, subapical, lateral, sclerotized projections. Parameres each with small basal knob; stem abruptly bent and slightly swollen near base, slender and tapering distad, without ventral lobe; apex tapering to sharp point without lateral barbs.

Distribution: Venezuela; Guatemala; Honduras (Lancetilla, Tela); Nicaragua (Villa Somoza); Panama.

PANAMA RECORDS:

Bocas del Toro Province: Almirante.

Canal Zone: Fort Davis, Loma Boracho, Mojinga Swamp.

Coclé Province: Rí́ Hato.

Darien Province: Punta Patiño.

Los Santos Province: Puerto Mensabé.

Discussion: In pinned material females of gabaldoni are practically inseparable from leoni Barbosa and glabellus Wirth and Blanton, although in gabaldoni the legs are paler and there may be a few more hairs at the apex of the wing, arranged in rows. This resemblance is also borne out in slide-mounted material by the similarity in the series of antennal segments, the 11th and 12 th segments being shorter than the 10th, but leoni differs from the other two in having an antennal ratio of only 0.75 and in having sensoria on segment viI as well as on III and viII-X. Females of leoni and glabellus differ from gabaldoni in having only one spermatheca. The male genitalia of gabaldoni can be recognized readily by the parameres being abruptly bent and slightly swollen at the base, with simple, filamentous apex. Culicoides imitator Ortiz also resembles gabaldoni but has macrotrichia on the distal half of the wing, antennal segment xI is not shorter than $\mathrm{x}$ and the third palpal segment does not bear a definite sensory pit. Culicoides horticola Lutz also has a similar wing pattern but lacks the pale spot lying behind the medial fork as well as the one in front of the mediocubital fork.

\section{Culicoides spurius, new species}

Figure 75

Female: Length of wing $0.72(0.69-0.79, \mathrm{n}=10) \mathrm{mm}$.

Head.-Eyes broadly separated, with short interfacetal hairs, the interocular space not markedly narrowed below. Antenna with flagellar segments in proportion of $14: 10: 12: 13: 13: 13: 13: 13: 13: 14: 16: 15$ : 27 , antennal ratio 0.84 ; distal sensory tufts present on segments III, viI-X. Palpal segments in proportion of $7: 14: 17: 7: 8$, third segment very short and swollen, $1.8(1.6-2.1, \mathrm{n}=10)$ times as long as greatest breadth, with a large, deep sensory pit opening by a small pore. Mandible with $13(12-14, \mathrm{n}=8)$ teeth. 


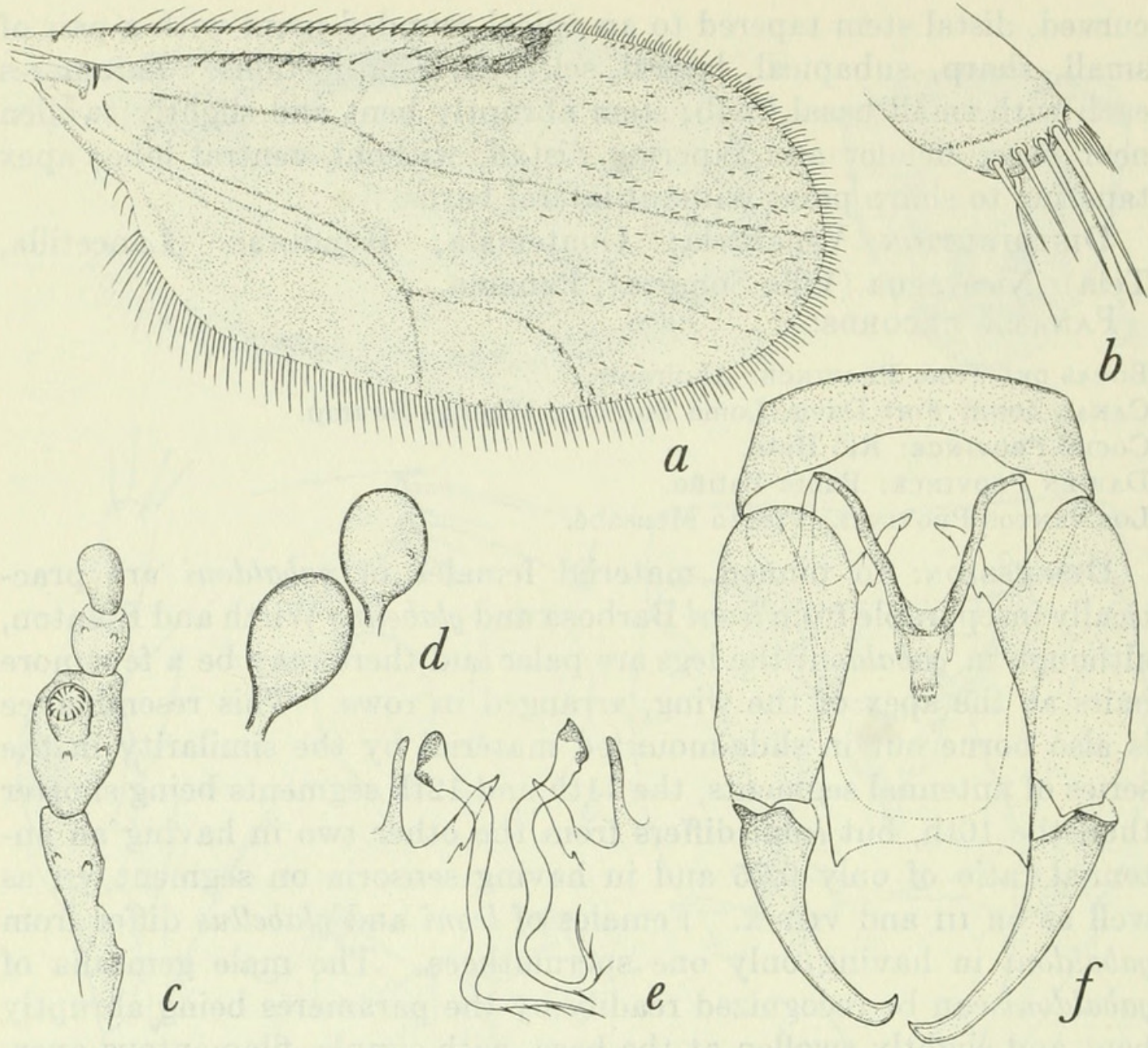

FigURE 75.-Culicoides spurius, new species. $a-d$, Female: $a$, wing; $b$, tibial comb; $c$, palpus; $d$, spermathecae. $e, f$, Male: $e$, parameres; $f$, genitalia, parameres removed.

Thorax.-Mesonotum (only slide-mounted specimens available) apparently without conspicuous pattern, dark brown. Scutellum, postscutellum and pleuron dark brown. Legs dark brown; fore and mid femora with subapical, all tibiae with subbasal and hind tibia with apical, narrow pale rings; hind tibial comb with four $(\mathrm{n}=10)$ spines, the one nearest the spur longest.

Wing.-Pattern as figured; pale spots small, moderately distinct; pale spot over r-m crossvein about as broad as long, poststigmatic pale spots in cell $R_{5}$ small and rounded, well separated, the posterior one slightly larger and located slightly proximad of the anterior one; distal pale spot in cell $R_{5}$ moderately large, rounded; two pale spots in cell $M_{1}$, one pale spot each in apices of cell $\mathrm{M}_{2}, \mathrm{M}_{4}$ and anal cell; definite pale spots present behind medial fork and in front of mediocubital fork. Macrotrichia sparse on distal third of wing, none in cell $\mathrm{M}_{4}$, anal cell 
or base of cell $\mathrm{M}_{2}$; costa extending to $0.58(0.58-0.60, n=10)$ of distance to wing tip. Halter knob infuscated.

Abdomen.-Brownish black, cerci yellowish. Spermathecae two, slightly unequal, pyriform, measuring 0.048 by $0.033 \mathrm{~mm}$. and 0.042 by $0.026 \mathrm{~mm}$., the bases of the ducts sclerotized a very short distance.

Male genitalia: Ninth sternum with broad, shallow, caudomedian excavation; ninth tergum long, tapering, with short, pointed apicolateral processes. Basistyle with ventral root foot-shaped, the posterior heel well developed, dorsal root slender; dististyle long and slender with hooked apex. Aedeagus with basal arch rounded, extending to more than half of total length of aedeagus, basal arms slender and nearly straight; distal portion with a slender, tapering median stem with rounded, distally striated, apical point, flanked by a pair of long, triangular, sharp pointed, poorly sclerotized processes arising from main body of aedeagus near base of distal stem. Parameres each with large basal knob, stem moderately slender, abruptly bent a short distance from base, midportion sinuate and slightly swollen ventrally, distal portion slender, abruptly bent ventrad with pointed apex bearing a few lateral barbs.

\section{Distribution: Panama; Guatemala; Honduras:}

Specimens examined: Holotype female (USNM 63171), allotype, Fort Davis, Canal Zone, Oct. 7, 1953, F. S. Blanton, light trap. Paratypes, 23 males, 17 females: Panama: Bocas del Toro Province: 4 females, Almirante, Nov. 10, 1952, Jan. 18, 1953. Canal Zone: 12 males, 2 females, same data as type; 1 male, 3 females, Huile Sia Clara (?), Oct. 13, 1952; 5 males, 3 females, Loma Boracho, Nov. 27, 1951, June 14, 1952; 2 females, Mojinga Swamp, Nov. 27, 1951, Nov. 15, 1953. Chiriquí Province: 1 male, Pedregal, Sept. 29, 1952. Darién Province: 1 female, El Real, July 1952. Honduras: 3 males, 1 female, Lancetilla, Jan. 5, 1953, Jan. 29, 1953, P. Galindo, light trap; 1 male, Tela, June 10, 1953, P. Galindo, light trap. Guatemala: 1 female, Yepocapa, July 26, 1951, Gibson and Ascoli, at light.

Discussion: C. spurius is similar to hoffmani Fox, but the latter species differs from it in having the antennal ratio about 0.79 , the second palpal segment much shorter than the third $(12: 19)$, the third segment even stouter, 1.6 times as long as broad, the wing larger, averaging $0.76 \mathrm{~mm}$. long, and an average of 14 mandibular teeth. The male genitalia of hoffmani differ markedly - the apicolateral processes on the ninth tergum much larger, the aedeagus with broadly expanded and well-sclerotized apex with three subequal distal processes. C. imitator Ortiz is also closely related, but it has no definite pit on the third palpal segment and the male aedeagus is broad and truncated distally without distal processes. 


\section{Culicoides hoffmani Fox}

\section{Figure 76}

Culicoides hoffmani Fox, 1946, Ann. Ent. Soc. Amer., vol. 39, p. 251 (female; Cumuto Village, Trinidad; biting man; fig. mesonotum, wing); 1949, Bull. Brooklyn Ent. Soc., vol. 44, p. 29 (male, female; Puerto Rico; reared, tree hole; fig. palpus, spermathecae, male aedeagus, parameres).-Wirth and Blanton, 1956, Journ. Washington Acad. Sci., vol. 46, p. 189 (male, female; Trinidad, Puerto Rico, St. Croix; fig. wing, mesonotum, palpus, spermathecae, tibial comb, male genitalia).

Female: Length of wing $0.76(0.73-0.86, \mathrm{n}=9) \mathrm{mm}$.

Head.-Eyes separated, the line of separation broad above but narrowed below, eye with short interfacetal hairs. Antenna with
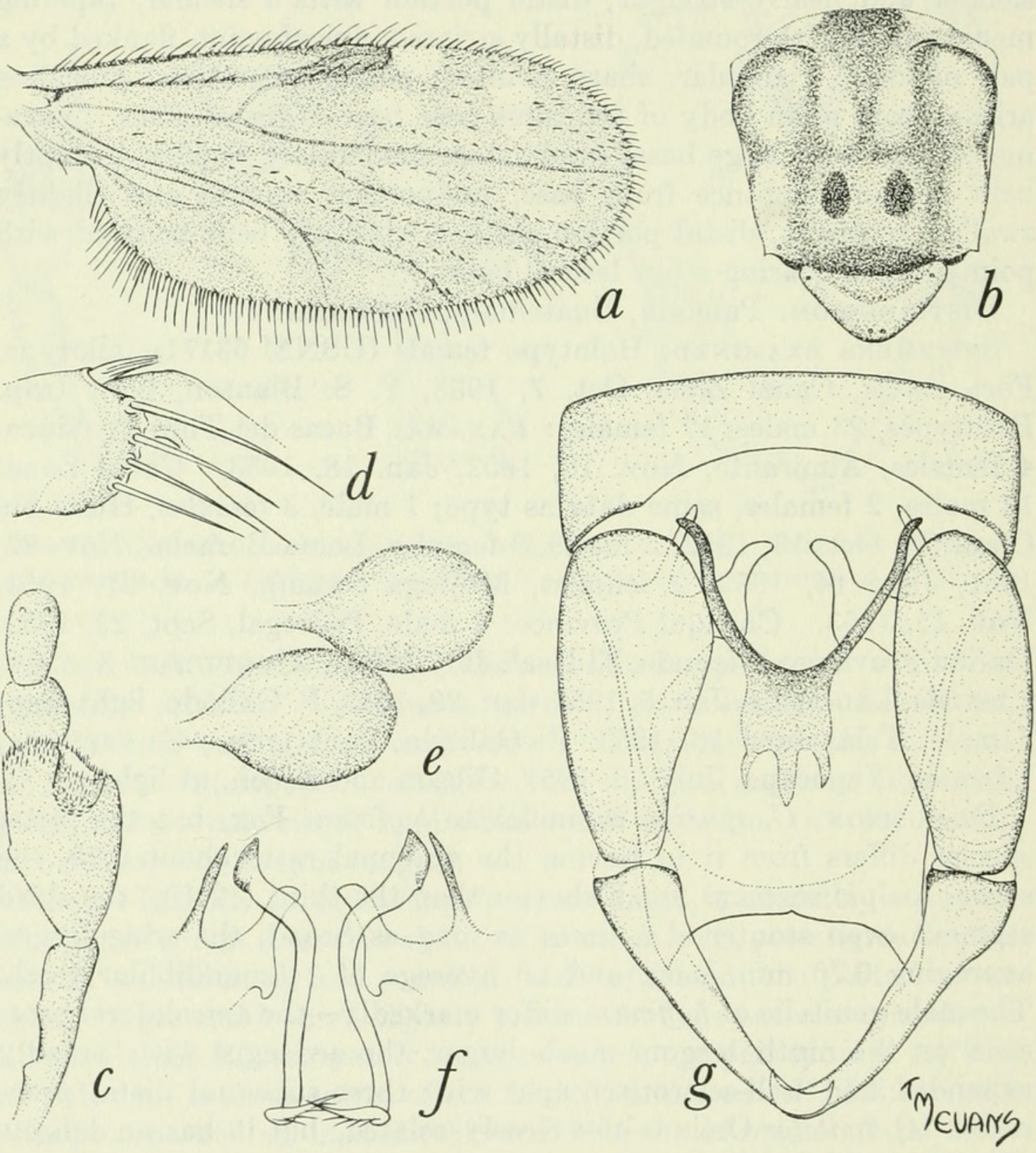

Figure 76.-Culicoides hoffmani Fox. $a-e$, Female: $a$, wing; $b$, thoracic pattern; $c$, palpus; $d$, tibial comb; $e$, spermathecae. $f, g$, Male: $f$, parameres; $g$, genitalia, parameres removed. 
flagellar segments in proportion of $14: 11: 13: 15: 15: 14: 14: 15: 14: 14: 15$ : $15: 25$, antennal ratio $0.79(0.75-0.84, \mathrm{n}=3)$; distal sensory tufts present on segments III, VIII-X. Palpal segments in proportion of $6: 11: 19: 6: 7$, third segment very short and swollen, 1.6 (1.5-1.7, $\mathrm{n}=9$ ) times as long as greatest breadth, with a moderately large and deep sensory pit. Mandible with $14(13-15, \mathrm{n}=5)$ teeth.

Thorax.-Mesonotum pruinose brown with pattern as figured, consisting essentially of a sublateral pair of darker brown patches, widest at midlength; scutellum, postscutellum and pleuron dark brown. Legs dark brown, fore and mid femora with subapical, all tibiae with subbasal and hind tibia with apical, narrow pale rings; hind tibial comb with four $(n=9)$ spines, the one nearest the spur longest.

Wing.-Pattern as figured; two, slightly separated, poststigmatic pale spots in cell $R_{5}$, the posterior one lying only slightly proximad of the anterior one; distal pale spot in cell $R_{5}$ moderately large, rounded; two pale spots in cell $\mathrm{M}_{1}$; one pale spot each in apices of cells $\mathrm{M}_{2}, \mathrm{M}_{4}$ and anal cell, the one in anal cell failing by its own diameter to meet wing margin; a pale spot lying ahead of mediocubital fork and another pale spot lying behind medial fork. Macrotrichia sparse on distal third of wing, none in anal cell, cell $\mathrm{M}_{4}$ or base of cell $\mathrm{M}_{2}$; costa extending to $0.59(0.57-0.62, \mathrm{n}=9)$ of distance to wing tip, second radial cell well developed. Halter brown, the flat end of the knob whitish.

Abdomen.-Blackish, cerci pale. Spermathecae two, pyriform, slightly unequal, measuring 0.048 by $0.034 \mathrm{~mm}$. and 0.043 by $0.031 \mathrm{~mm}$.

Male genitalia: Ninth sternum with very broad and shallow caudomedian excavation; ninth tergum long, with large, triangular, apicolateral processes. Basistyle with ventral root large and footshaped, dorsal root slender; dististyle slender and nearly straight with hooked apex. Aedeagus with basal arch rounded caudad, extending slightly more than half of total length of aedeagus, basal arms slender and curved; distal apex broadly expanded and well sclerotized, with three pointed lobes of subequal lengths. Parameres each with knobbed base, stem abruptly bent near base, very slender, midportion sinuate, no trace of ventral lobe, apex pointed with lateral fringe of fine hairs.

Distribution: Trinidad; Panama; Puerto Rico; Virgin Islands. Panama Records:

Canal Zone: Fort Clayton.

Panamá Province: Isla Taboga.

Discussion: These new Panama records are based on two males, the genitalia of which show the very distinctive characters of hoffmani. 


\section{Culicoides imitator Ortiz}

\section{Figure 77}

Culicoides imitator Ortiz, 1953, Rev. Sanid. Asist. Soc., vol. 18, p. 808 (male, female; Ocumare del Tuy, Venezuela; fig. wing, palpus, antenna, eye, spermathecae).

Female: Length of wing $0.68(0.64-0.73, \mathrm{n}=5) \mathrm{mm}$.

Head.-Eyes narrowly separated, bare. Antenna with flagellar segments in proportion of $13: 8: 8: 10: 10: 10: 10: 10: 11: 11: 14: 15: 21$, antennal ratio 0.91 ; distal sensory tufts present on segments III, vIII-X. Palpal segments in proportion of $8: 16: 16: 7: 8$, third segment slightly swollen, $1.9(1.7-2.1, \mathrm{n}=4)$ times as long as greatest breadth, with a large, irregular, open sensory area on mesal side. Mandible with $13(n=5)$ teeth.
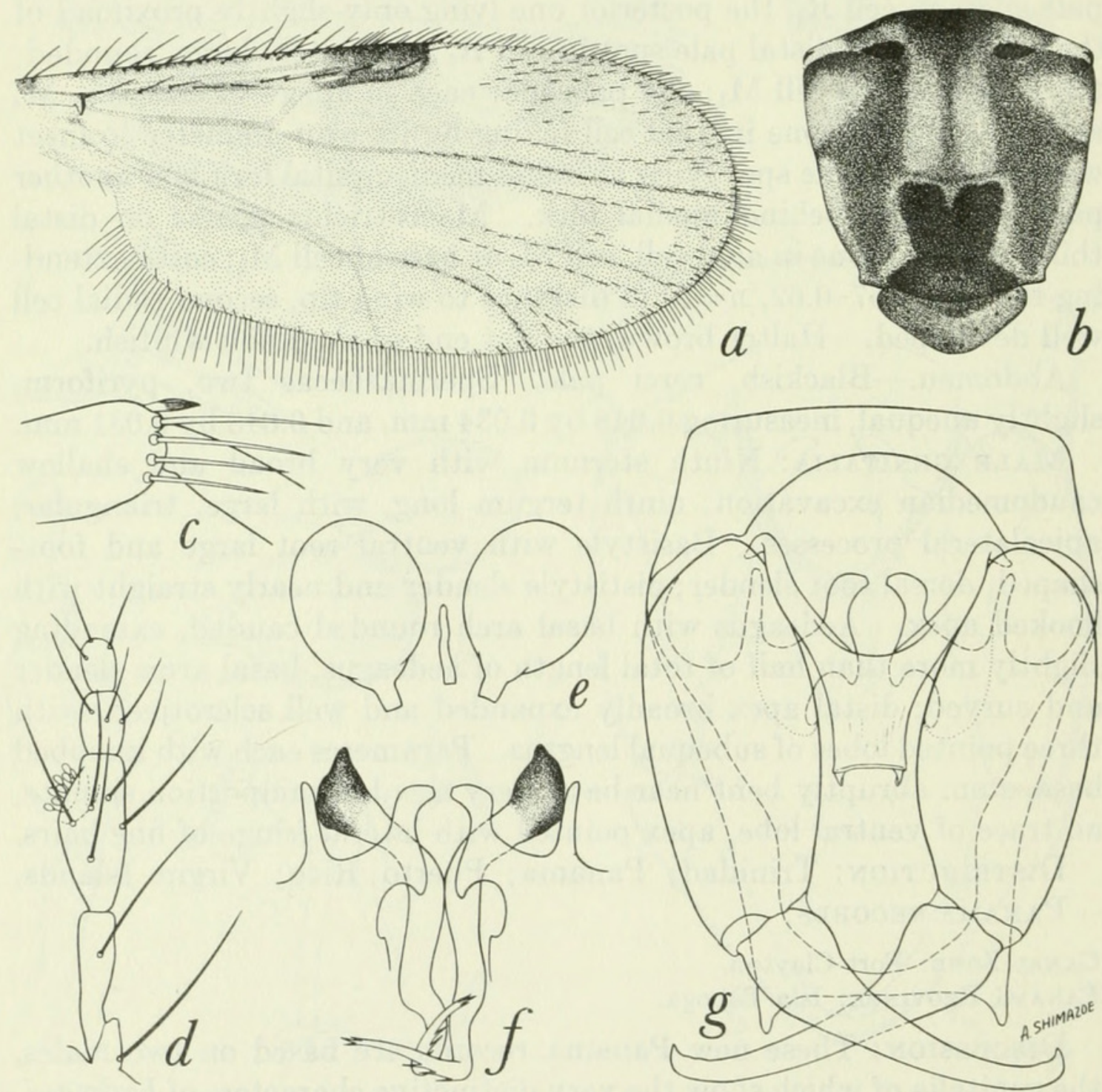

Figure 77.-Culicoides imitator Ortiz. $a-e$, Female: $a$, wing; $b$, thoracic pattern; $c$, tibial comb; $d$, palpus; $e$, spermathecae. $f, g$, Male: $f$, parameres; $g$, genitalia, parameres removed. 
Thorax.-Mesonotum brownish black with pattern as figured, a pair of large, elongate, submedian anterior spots and irregular area on lateral margins pruinose grayish brown. Scutellum, postscutellum and pleuron dark brown. Legs dark brown; fore and mid femora with subapical, all tibiae with subbasal and hind tibia with apical, narrow pale rings; hind tibial comb with four $(n=5)$ spines, the two nearest the spur longest, subequal.

Wing.-Pattern as figured, pale spots small and definite; a small yellowish spot over $r-m$ crossvein to costal wing margin; the poststigmatic pale spots in cell $R_{5}$ small, more or less fused, the two at the same level or the posterior one slightly distad of the other; distal pale spot in cell $R_{5}$ small, rounded and not reaching wing margin; two pale spots in cell $\mathrm{M}_{1}$; one pale spot in apex of cell $\mathrm{M}_{2}$, cell $\mathrm{M}_{4}$ and anal cell; no pale spot lying ahead of mediocubital fork but a distinct pale spot lying behind medial fork. Macrotrichia moderately numerous, situated more or less in rows, on distal portion of wing beyond end of costa, none in anal cell or base of cell $\mathrm{M}_{2}$; costa extending to 0.53 $(0.52-0.55, \mathrm{n}=5)$ of distance to wing tip. Halter pale.

Abdomen.-Dark brown; cerci pale. Spermathecae two, ovoid, subequal, measuring 0.046 by 0.038 and 0.042 by $0.025 \mathrm{~mm}$., the bases of the ducts lightly sclerotized a short distance.

Male Genitalia: Ninth sternum with broad, shallow, caudomedian excavation; ninth tergum moderately long and tapering, with short, pointed, apicolateral processes. Basistyle with ventral root stout, foot-shaped, the posterior heel not prolonged, dorsal root slender; dististyle long and slender, nearly straight with bent, pointed apex. Aedeagus short and stout, basal arch reaching about half of total length, the basal arms stout and heavily sclerotized, distal portion broad and spatulate with truncated apex. Parameres each with large basal knob, stem slender, abruptly bent near base, sinuate in midportion, abruptly bent near apex, ventral lobe only slightly developed, apex pointed with lateral fringe of fine barbs.

Distribution: Venezuela; Panama.

Panama Records:

Canal Zone: Mojinga Swamp.

Los Santos Province: Puerto Mensabé.

Discussion.- This species is closely related to hoffmani Fox, but can be distinguished easily by the open sensory area on the third palpal segment and by the more definite wing markings in which the posterior poststigmatic pale spot is usually slightly distad of the anterior one. The male genitalia of the Panama specimens differ slightly from those of the type figured by Ortiz in having large distal teeth on the aedeagus and the stem of the paramere stouter with small processes. A longer series of males would have to be examined to determine if these differ- 
ences are constant enough to warrant specific recognition.

The female characters closely fit those of the type from Venezuela.

\section{Culicoides paraensis (Goeldi)}

Figure 78

Haematomyidium paraense Goeldi, 1905, Mem. Mus. Goeldi, vol. 4, p. 137 (female; Pará, Brazil; fig. female, wing).

Culicoides paraensis, Lutz, 1913, Mem. Inst. Oswaldo Cruz, vol. 5, p. 55 (male, female; Brazil; fig. wing).-Floch and Abonnenc, 1942, Inst. Pasteur Guyane Terr. l'Inini, publ. 37, p. 4 (French Guiana; fig. wing).-Fairchild, 1943, Amer. Journ. Trop. Med., vol. 23, p. 572 (Chiriquí, Panama).-Barretto, 1944, Anais Fac. Med. Univ. São Paulo, vol. 20, p. 92 (male; Brazil; fig. wing, genitalia).-Ortiz, 1951, Rev. Sanid. Asist. Soc., vol. 16, p. 574 (male, female; Venezuela; fig. wing, palpus, antenna, mesonotal pattern, spermathecae, male aedeagus, parameres).-Fox, 1955, Journ. Agr. Univ. Puerto Rico, vol. 39, p. 250 (extensive synonymy).

Culicoides undecimpunctatus Kieffer, 1917, Ann. Mus. Nat. Hungarici, vol. 15, p. 307 (female; Argentina).

Female: Length of wing $0.78(0.69-0.89, \mathrm{n}=8) \mathrm{mm}$.

Head.-Eyes broadly separated, bare. Antenna with flagellar segments in proportion of $15: 11: 12: 14: 14: 14: 14: 15: 15: 16: 16: 16: 25$, antennal ratio $0.77(0.71-0.81, \mathrm{n}=5)$; distal sensory tufts present on segments III, VIII-X. Palpal segments in proportion of $8: 17: 20: 7: 10$, third segment slightly swollen, $2.1(1.7-2.4, \mathrm{n}=9)$ times as long as greatest breadth, with a small, deep sensory pit. Mandible with 15 $(14-15, \mathrm{n}=6)$ teeth.

Thorax.-Mesonotum dark brown with dark grayish pruinosity, three more or less prominent longitudinal vittae present anteriorly, the lateral ones widened at sutural level. Scutellum, postscutellum, and pleuron brownish black. Legs dark brown, fore and mid femora with subapical, all tibiae with subbasal and hind tibia with apical, narrow pale rings; hind tibial comb with four $(n=9)$ spines, the second from the spur longest.

Wing.-Pattern as figured; second radial cell dark; pale spot over $r-m$ crossvein narrow, extending to coastal margin; cell $R_{5}$ with four small, round pale spots, the two poststigmatic spots well separated and located one behind the other, the posterior one located slightly proximad, apices of veins dark at wing margin; three small pale spots in cell $\mathrm{M}_{1}$; only one pale spot in distal part of cell $\mathrm{M}_{2}$; $\mathrm{a}$ round pale spot in center of cell $\mathrm{M}_{4}$; anal cell with one pale spot in distal portion; cell $\mathrm{M}_{2}$ with a pale spot lying behind medial fork, none in front of mediocubital fork; a pale spot lying just distad of basal arculus. Macrotrichia sparse and in rows on distal half of wing, a few in base of cell $\mathrm{M}_{2}$ and in anal cell; costa extending to 0.59 

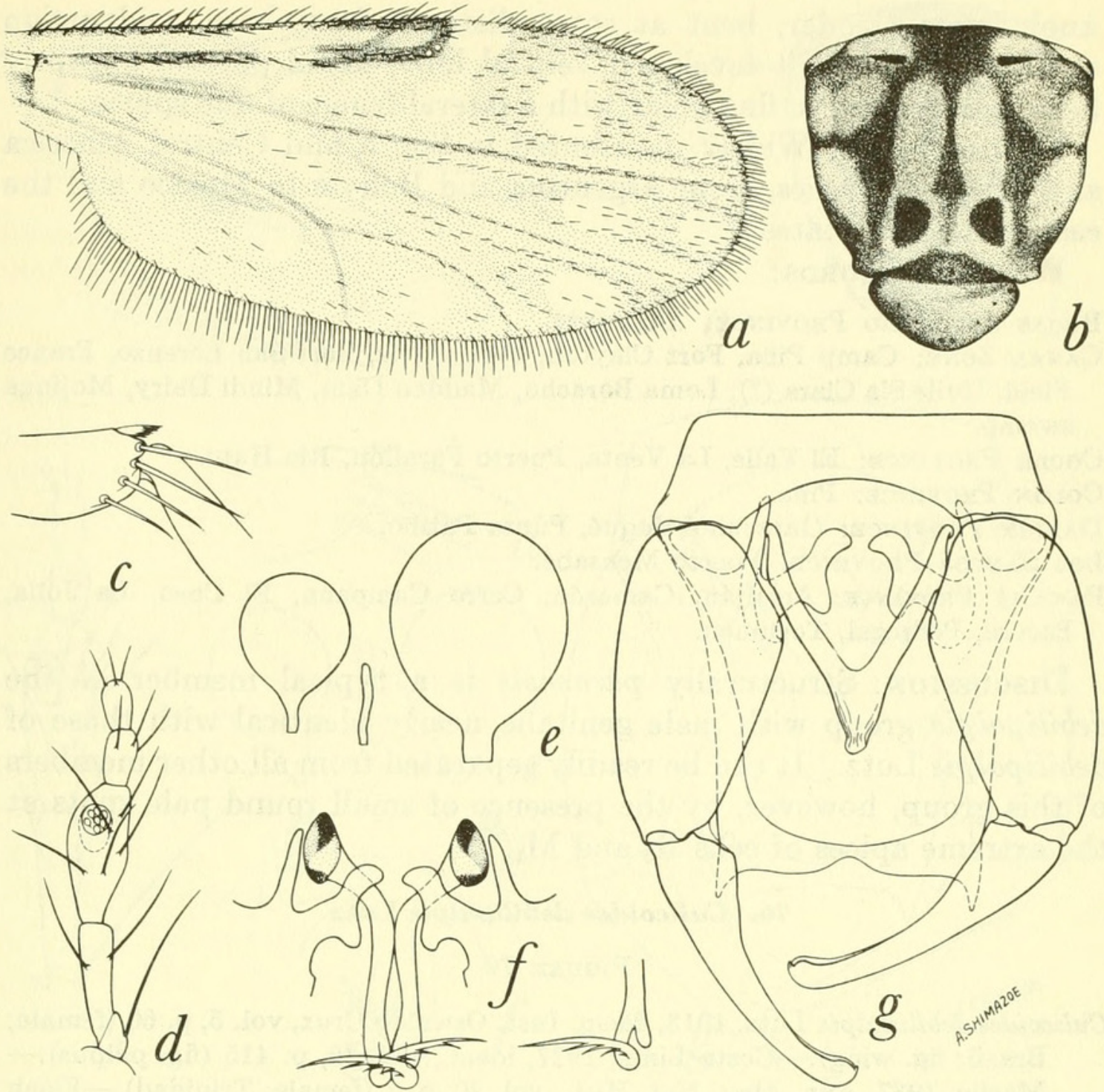

Figure 78.-Culicoides paraensis (Goeldi). $a-e$, Female: $a$, wing; $b$, thoracic pattern; $c$, tibial comb; $d$, palpus; $e$, spermathecae. $f, g$, Male: $f$, parameres; $g$, genitalia, parameres removed.

$(0.56-0.60, \mathrm{n}=8)$ of distance to wing tip. Halter pale, base of knob brownish.

Abdomen.-Dark brown, cerci yellowish. Spermathecae two, pyriform, unequal, measuring 0.057 by $0.037 \mathrm{~mm}$. and 0.048 by 0.029 $\mathrm{mm}$., the bases of the ducts sclerotized a considerable distance.

Male genitalia: Ninth sternum with a broad, shallow, caudomedian excavation; ninth tergum long and tapering with short, pointed, widely separated apicolateral processes. Basistyle with ventral root foot-shaped, and posterior heel well developed, dorsal root short; dististyle slender and curved with bent tip. Aedeagus $V$-shaped, the basal arch pointed and extending to two-thirds of total length, the basal arms straight and moderately stout, the distal portion with simple, rounded tip. Parameres each with large basal 
knob, stem slender, bent at some distance from base, midportion straight with a well-developed ventral lobe, distal portion abruptly bent and tapered to fine point with a lateral fringe of fine spines.

Distribution: Widely distributed in South and Central America and the West Indies, from Argentina and Bolivia to Mexico and the eastern United States.

PANAMA RECORDS:

Bocas del Toro Province: Almirante.

Canal Zone: Camp Piña, Fort Clayton, Fort Davis, Fort San Lorenzo, France

Field, Huile Sia Clara (?), Loma Boracho, Madden Dam, Mindi Dairy, Mojinga swamp.

Coclé Province: El Valle, La Venta, Puerto Farallón, Río Hato.

Colón Province: Piña.

Darién Province: Garachiné, Jaqué, Punta Patiño.

Los Santos Province: Puerto Mensabé.

Panamá Province: Arraiján, Camarón, Cerro Campana, El Coco, La Jolla, Pacora, Pedregal, Tocumen.

Discussion: Structurally paraensis is a typical member of the debilipalpis group with male genitalia nearly identical with those of debilipalpis Lutz. It can be readily separated from all other members of this group, however, by the presence of small round pale spots at the extreme apices of cells $R_{5}$ and $M_{1}$.

\section{Culicoides debilipalpis Lutz}

FIGURE 79

Culicoides debilipalpis Lutz, 1913, Mem. Inst. Oswaldo Cruz, vol. 5, p. 60 (female; Brazil; fig. wing).-Costa Lima, 1937, idem., vol. 32, p. 415 (fig. palpus).Macfie, 1937, Ann. Mag. Nat. Hist., vol. 20, p. 7 (female; Trinidad)._Floch and Abonnenc, 1942, Inst. Pasteur Guyane Terr. l'Inini, publ. 37, p. 3 (French Guiana; fig. wing, palpus).-Barbosa, 1947, Anais Soc. Biol. Pernambuco, vol. 7, p. 14 (St. Croix, Barbados, Venezuela; fig. palpus).-Macfie, 1948, Ann. Trop. Med. Parasit., vol. 42, p. 86 (Chiapas, Mexico, notes).-Barbosa, 1952, Novas Subsidios . . . Culicoides Neotropicos, p. 12 (Argentina, Brazil; fig. palpus).

Female: Length of wing $0.80(0.66-0.92, \mathrm{n}=38) \mathrm{mm}$.

Head.-Eyes broadly separated, with very short interfacetal hairs, appearing bare in profile of eye. Antenna with flagellar segments in proportion of $15: 12: 13: 15: 15: 15: 15: 15: 15: 16: 18: 18: 29$, antennal ratio $0.83(0.76-0.90, \mathrm{n}=13)$; distal sensory tufts present on segments III, viII-X. Palpal segments in proportion of $7: 19: 24: 8: 8$, third segment moderately swollen, $2.2(1.6-2.6, \mathrm{n}=35)$ times as long as greatest breadth, with small, deep sensory pit. Mandible with 15 (12-19, $\mathrm{n}=37$ ) teeth.

Thorax.-Mesono tum pruinose dark grayish brown with moderately strong pattern of subshining, brownish black, consisting of a median anterior triangular marking and a sublateral pair of elongate, tri- 

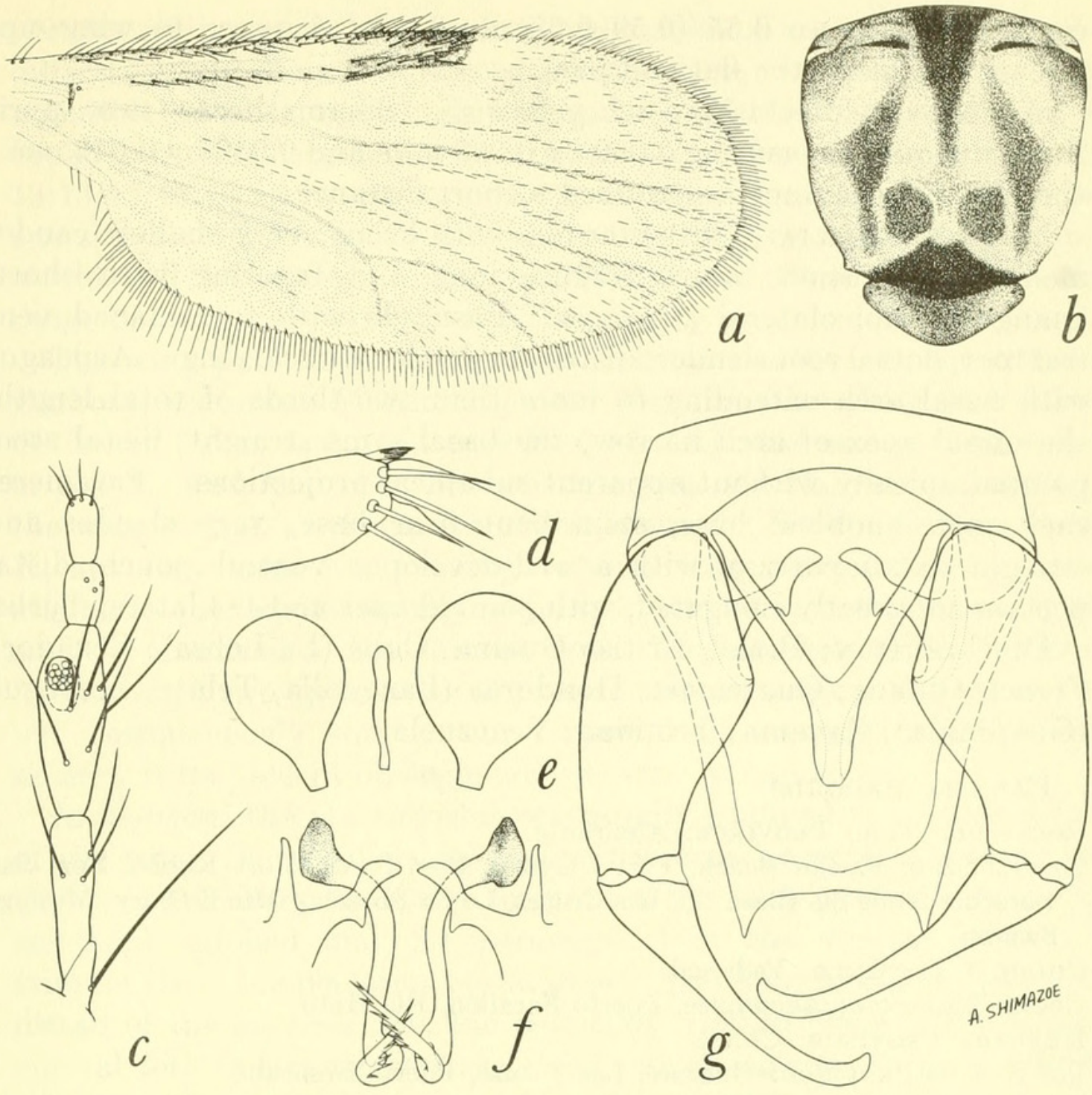

Figure 79.-Culicoides debilipalpis Lutz. $a-e$, Female: $a$, wing; $b$, thoracic pattern; $c$, palpus; $d$, tibial comb; $e$, spermathecae. $f, g$, Male: $f$, parameres; $g$, genitalia, parameres removed.

angular patches, widest at the suture. Scutellum, postscutellum and pleuron brownish black. Legs dark brown; fore and mid femora with subapical, all tibiae with subbasal and hind tibia with apical, narrow pale rings; hind tibial comb with four $(n=37)$ spines, the one next to the spur longest.

Wing.-Pattern as figured; the two poststigmatic pale spots in cell $R_{5}$ usually well separated, the posterior one located slightly proximad of the anterior one; distal pale spot in cell $R_{5}$ usually transverse to slightly reniform; two pale spots in cell $\mathrm{M}_{1}$; one pale spot each in apices of cell $\mathrm{M}_{2}$ and anal cell; pale spots present behind medial fork and in front of mediocubital fork, the latter absent in some specimens. Macrotrichia numerous, extending proximad to base of wing in a double row in cell $\mathrm{M}$ and numerous in anal cell; 
costa extending to $0.65(0.59-0.68, \mathrm{n}=37)$ of distance to wing tip. Halter brownish, the flat end pale.

Abdomen.-Blackish, cerci yellowish. Spermathecae two, pyriform, unequal, measuring 0.060 by $0.039 \mathrm{~mm}$. and 0.050 by $0.032 \mathrm{~mm}$., the bases of the ducts sclerotized a short distance.

Male Genitalia: Ninth sternum with broad, very shallow caudomedian excavation; ninth tergum long and tapering with short, triangular, apicolateral processes. Basistyle with foot-shaped ventral root, dorsal root slender; dististyle slender and curving. Aedeagus with basal arch extending to more than two-thirds of total length, the mesal apex of arch narrow, the basal arms straight; distal stem pointed apically without apparent subapical projections. Parameres each with knobbed base, stem bent near base, very slender and straight in midportion, with a well-developed ventral pouch, distal portion not greatly elongated, with pointed apex and 4-4 lateral barbs.

Distribution: Brazil; British Guiana; Cuba (La Lolisa); Ecuador; French Guiana; Guatemala; Honduras (Lancetilla, Tela); Nicaragua (Guapinula); Panama; Trinidad; Venezuela.

PANAMA RECORDS:

Bocas del Toro Province: Almirante.

Canal Zone: Farfan Beach, Fort Clayton, Fort Davis, Fort Kobbe, Fort San Lorenzo, Huile Sia Clara (?), Las Cruces, Loma Boracho, Mindi Dairy, Mojinga Swamp.

Chiriquí Province: Pedregal.

Coclé Province: Aguadulce, Puerto Farallón, Río Hato.

Herrera Province: Chitré.

Los Santos Province: Guararé, Las Tablas, Puerto Mensabé.

Panamá Province: Isla Taboga, Pacora.

Discussion: Through the courtesy of Dr. A. da Costa Lima, of the Instituto Oswaldo Cruz in Rio de Janeiro, we have been able to examine three slides from the original cotype series of debilipalpis Lutz. On one slide-from Amazonas de Cima, 1913, Lutz-are four females with the following characters: wing length $0.68(0.66-$ $0.69, \mathrm{n}=3$ ) $\mathrm{mm}$., costal ratio 0.62 ; eyes broadly separated, with short interfacetal hairs; antenna with flagellar segments in proportion of $14: 10: 11: 12: 13: 13: 13: 13: 13: 14: 15: 16: 22$, antennal ratio 0.81 , distal sensory tufts present on segments III, viII-X; palpal segments in proportion of $8: 17: 22: 9: 11$, third segment 2.2 times as long as broad with a deep, small pit; mandible with $18,20(n=2)$ teeth; spermathecae measuring 0.050 by $0.034 \mathrm{~mm}$. and 0.043 by $0.037 \mathrm{~mm}$. These specimens conform well to the diagnosis of the species based on our Panama material and give reasonable assurance of the correctness of our determination. The other two slides are of a specimen remounted by Costa Lima for his 1937 paper (slides 2828 and 2829 made from preparation No. 2411), with the wings on one slide and 
the remaining parts on another, no locality given. This specimen differs slightly from the others, being larger, wing $0.83 \mathrm{~mm}$. long; mandible with 21 teeth; third palpal segment 2.5 times as long as broad; antennal segments III-XIII in proportion of 15:13:13:13:13: $13: 13: 15: 16: 16: 18$, sensoria present on segments III and VIII- $\mathbf{x}$ on one side and III, VII-X on the other. We believe that this specimen would still fall within, and extend slightly in some characters, the range of variation found in debilipalpis.

The wing pattern of debilipalpis is similar to that of equatoriensis Barbosa, germanus Macfie, hoffmani Fox, imitator Ortiz, insinuatus Ortiz and Leon, and trilineatus Fox, all with one pale spot in apices of cell $\mathrm{M}_{2}$ and anal cell, two pale spots in cell $\mathrm{M}_{1}$, no pale spots at the wing margin at the apices of the veins, the distal pale spot in cell $R_{5}$ not very large nor meeting anterior wing margin and the post stigmatic pale spots usually separate, with the posterior one lying slightly proximad of the anterior one. These species all have rather hairy wings, two spermathecae present, the antenna with segment $\mathrm{xI}$ not conspicuously shorter nor longer than segment $\mathrm{x}$ and distal sensory tufts present on segments III, VIII, IX and $\mathrm{x}$.

In hoffmani the macrotrichia are usually confined to the distal half of the wing, the third palpal segment is broader with a broader pit, the eyes are more distinctly hairy and the male genitalia have the aedeagus trilobed and the parameres lack the ventral lobes. In imitator Ortiz the posterior poststigmatic pale spot in cell $\mathrm{R}_{5}$ is located distad of the anterior one, the pale spot lying in front of the mediocubital fork is lacking and the third palpal segment lacks a definite sensory pit. Culicoides germanus and insinuatus have a similar wing pattern but the anterior femora are dark in insinuatus and the fore and mid legs are dark in germanus, and in germanus the posterior poststigmatic pale spot lies far proximad of the anterior one and there are sensoria present on antennal segment viI. Culicoides equatoriensis Barbosa from Ecuador resembles hoffmani and germanus in wing markings, in the restriction of the macrotrichia to the distal half of the wing, and in the broad, shallow, palpal pit, but differs from these species and from debilipalpis in having the eyes bare and contiguous and the knees bordered by pale rings on both sides on all three pairs of legs. Culicoides trilineatus has an even hairier wing than debilipalpis, but the pale spots in cell $\mathrm{M}_{1}$ and the distal one in cell $\mathrm{R}_{5}$ are much smaller, the mesonotum has a pattern of narrow dark lines, the third palpal segment is even longer and more slender, the mandible has more teeth (18) and antennal sensoria extend proximad to the fifth or sixth segment.

Other species with similar wing pattern and macrotrichia extending to the base of cell $\mathrm{M}$ are transferrans Ortiz and rangeli Ortiz and Mirsa, 
but these species have one spermatheca, two pale distal spots in the anal cell, and the five distal antennal segments much elongated and bearing sensoria.

\section{Culicoides mirsae Ortiz}

\section{FiguRe 80}

Culicoides mirsae Ortiz, 1953, Rev. Sanid. Asist. Soc., vol. 18, p. 801 (female; Venezuela; fig. wing).

Female: Length of wing $0.78(0.76-0.82, \mathrm{n}=3) \mathrm{mm}$.

Head.-Eyes narrowly separated, with long interfacetal hairs. Antenna with flagellar segments in proportion of $17: 15: 16: 17: 16: 14$ : $15: 15: 15: 15: 17: 16: 25$, antennal ratio 0.70 ; distal sensory tufts present on segments III, VIII-X. Palpal segments in proportion of $7: 17: 21: 7: 8$, third segment moderately swollen, 2.1 times as long as greatest breadth, with a broad, deep sensory pit. Mandible with 16 teeth.

Thorax.-Mesonotum uniformly dark brown without prominent pattern. Scutellum, postscutellum and pleuron dark brown. Legs dark brown; fore and mid femora with subapical, all tibia with subbasal and hind tibia with (3 specimens) or without (2 specimens), narrow distal pale rings; hind tibial comb with four spines, the one next to the spur longest.

Wing.-Pattern as figured, the pale spot at $\mathrm{r}-\mathrm{m}$ crossvein very small and round and lying entirely distad of the crossvein in cell $R_{5}$; the two
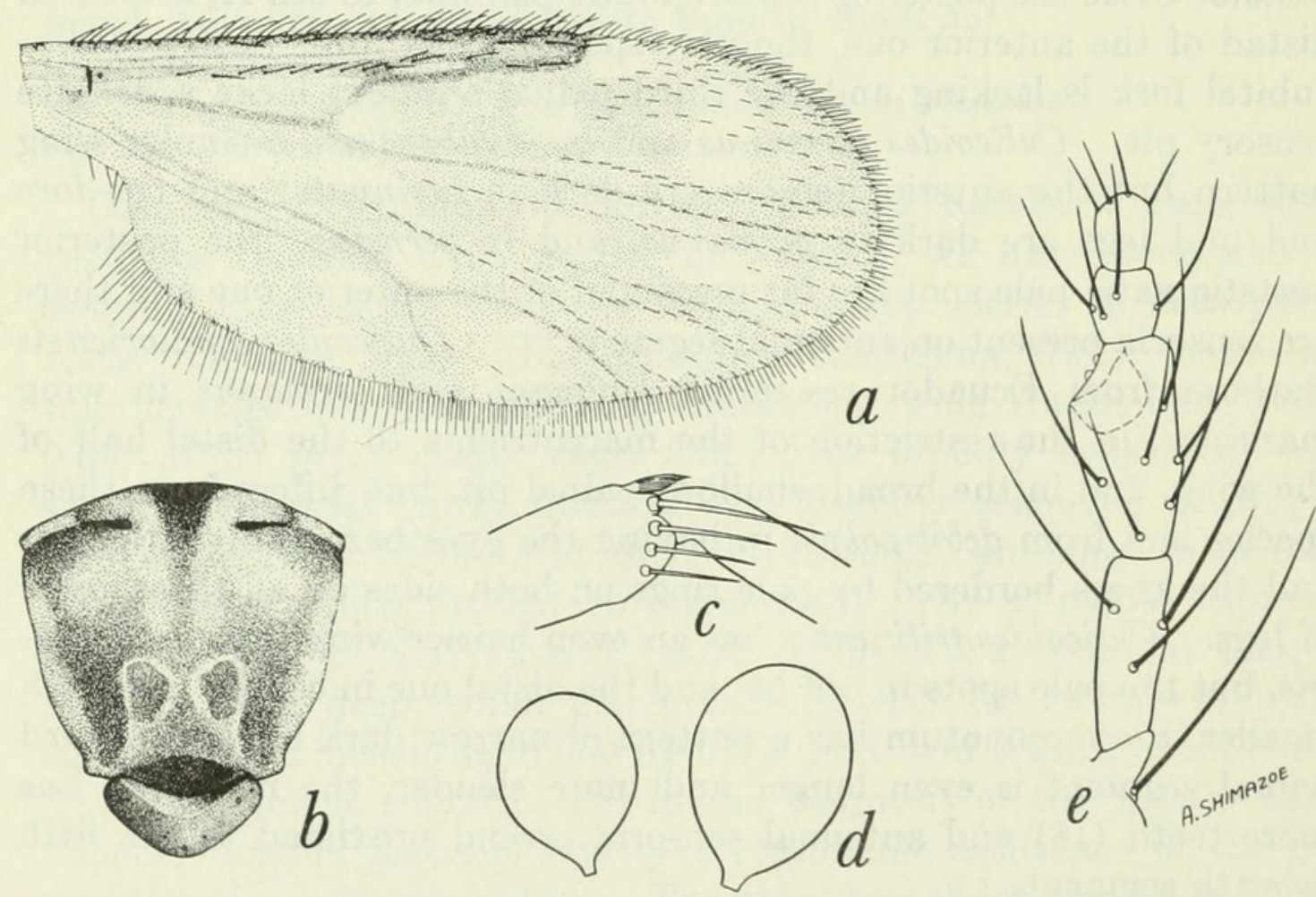

Figure 80.-Culicoides mirsae Ortiz, female: $a$, wing; $b$, thoracic pattern; $c$, tibial comb; $d$, spermathecae; $e$, palpus. 
poststigmatic spots in cell $R_{5}$ small and well separated, the posterior one well proximad of the anterior one, distal pale spot in cell $R_{5}$ small and transverse; two pale spots in cell $\mathrm{M}_{1}$ and two in the apex of anal cell; only one pale spot in distal part of cell $\mathrm{M}_{2}$, a pale spot in cell $\mathrm{M}_{4}$, one lying behind medial fork, and one lying in front of mediocubital fork. Macrotrichia numerous on distal half of wing, in some specimens extending proximad in a double row to base of cell $\mathrm{M}$ and numerous in anal cell; costa extending to $0.60-0.62(n=2)$ of distance to wing tip. Halter dull yellowish, the base of the knob brownish.

Abdomen.-Brownish black; cerci yellowish. Spermathecae two, ovoid, unequal, measuring 0.053 by 0.038 and 0.036 by $0.026 \mathrm{~mm}$., the bases of the ducts not sclerotized.

MALE: Unknown.

Distribution: Venezuela; Panama; Trinidad (St. Patrick Estate).

PANAMA RECORDS:

Bocas del Toro Province: Almirante.

Discussion: The location of the small pale spot, not over the $r-m$ crossvein, but entirely distad of it in cell $R_{5}$, is unique and will readily distinguish mirsae. The wing pattern is similar to that of debilipalpis Lutz, but that species has only one pale distal spot in the anal cell; the wing of castillae Fox is also similar but has the apex of vein $\mathrm{M}_{1}$ pale margined and two pale spots in the distal part of cell $\mathrm{M}_{2}$. Culicoides mirsae is quite rare, our series consisting of only three females from Almirante, taken in light traps in November, December and January, and two females from Trinidad (St. Patrick Estate, Arima), Dec. 24, 31, 1954, Aitken and Downs, collectors, in tree station.

\section{Culicoides aureus Ortiz}

\section{FigURE 81}

Culicoides aureus Ortiz, 1951, Rev. Sanid. Asist. Soc., vol. 16, p. 585 (male; San Felipe, Yaracuy, Venezuela; fig. wing, palpus, mesonotum, genitalia).Fox, 1955, Journ. Agr. Univ. Puerto Rico, vol. 39, p. 228 (synonym, miyamotoi Wirth and Blanton).

Culicoides miyamotoi Wirth and Blanton, 1953, Journ. Parasit., vol. 39, p. 231 (male, female; Panama; fig. wing, mesonotum, palpus, male genitalia).

Female: Length of wing $0.89(0.86-0.92 \mathrm{n}=3) \mathrm{mm}$.

Head.-Eyes narrowly separated, bare. Antenna with flagellar segments in proportion of $17: 14: 15: 16: 16: 15: 16: 17: 16: 16: 18: 19: 27$, antennal ratio 0.76 ; distal sensory tufts present on segments III, VII-x. Palpal segments in proportion of $11: 19: 24: 8: 9$, third segment moderately swollen, $2.1(1.8-2.5, \mathrm{n}=3)$ times as long as greatest breadth, with a large, deep sensory pit opening by a small pore. Mandible with $18(\mathrm{n}=3)$ teeth. 
Thorax.-Mesonotum yellowish brown, with a prominent pattern of punctiform brown dots at the seta-bases, more or less confluent in narrow irregular bands and lines, especially along a pair of sublateral, longitudinal lines. Scutellum narrowly dark brown in middle, yellowish on sides; postscutellum dark brown; pleuron yellowish above,

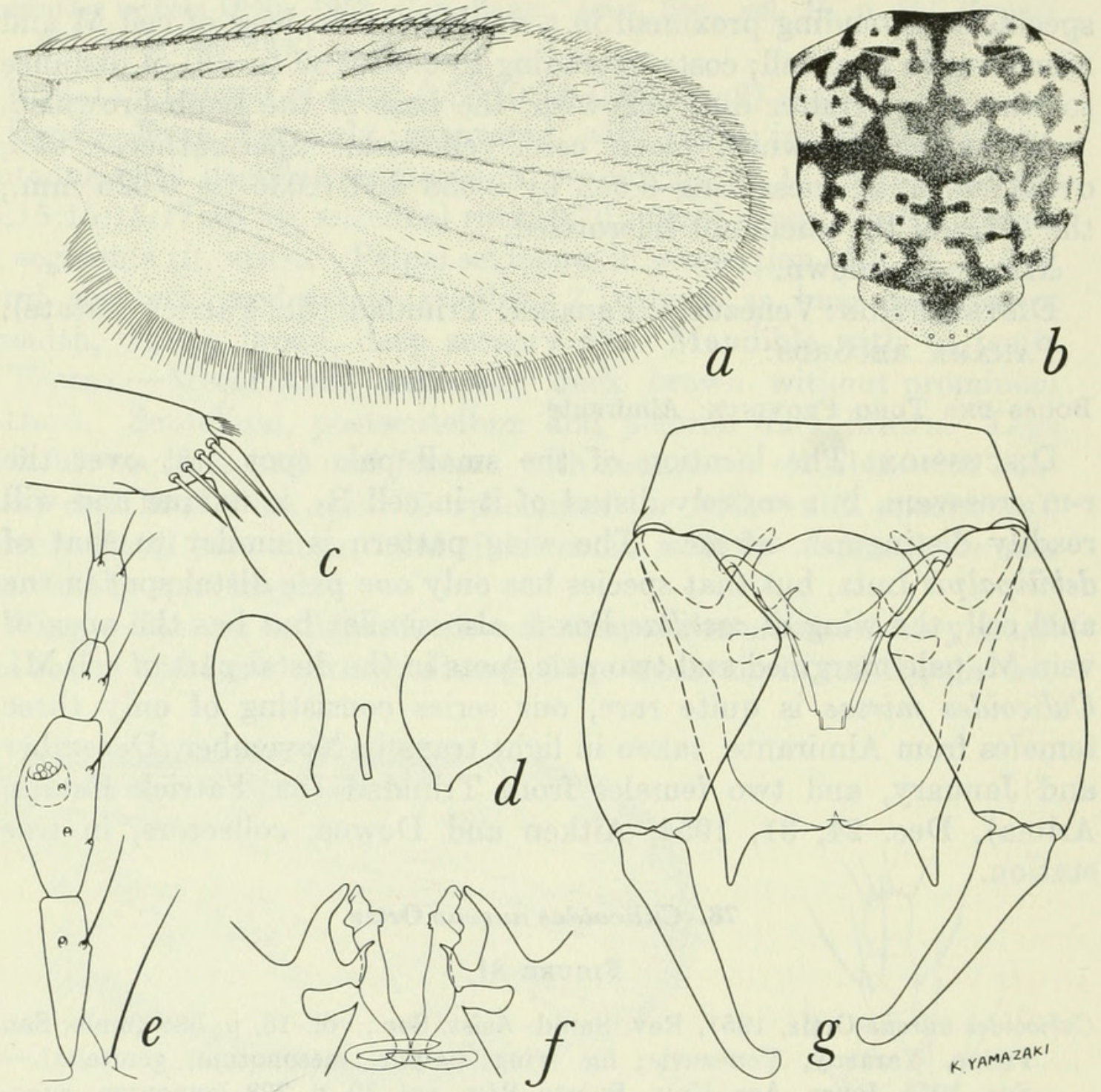

Figure 81.-Culicoides aureus Ortiz. $a-e$, Female: $a$, wing; $b$, thoracic pattern; $c$, tibial comb; $d$, spermathecae; $e$, palpus. $f$, $g$, Male: $f$, parameres; $g$, genitalia, parameres removed.

dark below. Legs brown with knee spots black, broad pale bands at bases and just before apices of femora, at bases of tibiae and at apex of hind tibia; hind tibial comb with four $(n=3)$ spines, the one nearest the spur longest. 
Wing.-Pattern as figured, the membrane grayish with very prominent, small, milky white spots; second radial cell very dark; pale spot over $\mathrm{r}-\mathrm{m}$ crossvein narrow, continued in full breadth to costal margin; cell $R_{5}$ with five small pale spots - one lying on anterior side of vein $\mathrm{M}_{1}$ at base of cell, and four lying in an irregular oval group in middle of cell, of the four, a round one lies at costal margin just beyond second radial cell, two round ones lie behind second radial cell, and a crescent-shaped one, the convex side distad, lies across subapical part of cell; apices of veins $\mathrm{M}_{1}, \mathrm{M}_{2}, \mathrm{M}_{3+4}$ and $\mathrm{Cu}_{1}$ pale; two small round pale spots in cell $\mathrm{M}_{1}$, the distal one lying far from wing margin; pale spot in apex of cell $\mathrm{M}_{2}$ and in cell $\mathrm{M}_{4}$ lying far from wing margin; only one pale spot in distal part of anal cell; cell $\mathrm{M}_{2}$ with a linear spot lying in front of convex part of vein $\mathrm{M}_{3+4}$, a pale spot lying in front of mediocubital fork, one lying behind medial fork, one extending across middle of stem of mediocubitus and one extending to base of wing over base of medial vein. Macrotrichia moderately numerous on distal half of wing, barely extending to apex of anal cell; costa extending to $0.63(n=3)$ of distance to wing tip. Halter pale, anterior side of knob brownish.

Abdomen.-Spermathecae two, subequal, pyriform, with short sclerotized necks.

Male Genitalia: Ninth sternum with a very slightly perceptible caudomedian excavation; ninth tergum slightly tapered, with long, pointed, apicolateral processes. Basistyle with ventral lobe footshaped, the posterior heel not developed, dorsal root longer and slender; dististyle slender, nearly straight with slender rounded tip slightly bent. Aedeagus with low, broad, mesally rounded basal arch extending to a third of total length of aedeagus, basal arms stout, distal portion slightly tapered to a slender, truncated apex. Parameres each with basal knob, stem nearly straight and very slightly swollen to midlength, without ventral lobe, distal portion long and narrowed gradually to simple, recurved, flattened points.

Distribution: Venezuela; Panama.

PANAMA RECORDS:

Bocas del Toro Province: Almirante.

CANaL Zone: Fort Clayton, Fort Davis, Fort Gulick, Fort Sherman, Loma Boracho, Mojinga Swamp.

Discussion: This species closely resembles ginesi Ortiz in mesonotal and wing markings, and the two apparently are closely related, but ginesi has much different male genitalia (similar to those of hoffmani Fox), only three pale spots in a triangle in cell $R_{5}$, and the apices of the wing veins not pale at the wing margin. 


\section{Culicoides ginesi Ortiz}

FIGURE 82

Culicoides ginesi Ortiz, 1952, Rev. Sanid. Asist. Soc., vol. 16, p. 586 (female;

San Felipe, Yaracuy, Venezuela; fig. wing, palpus, antenna, spermatheca).

Female: Length of wing $0.80(0.73-0.89, \mathrm{n}=10) \mathrm{mm}$.

Head.-Eyes nearly contiguous, without interfacetal hairs. Antenna with flagellar segments in proportion of $16: 14: 14: 14: 14: 13: 13$ : $13: 14: 14: 14: 14: 26$, antennal ratio 0.74 ; distal sensory tufts present on segments III, vII-X. Palpal segments in proportion of $7: 15: 22$ : $7: 10$, third segment moderately swollen, $2.0(1.6-2.3, \mathrm{n}=10)$ times as long as greatest breadth, with a small, deep sensory pit. Mandible with $17(16-19, \mathrm{n}=7)$ teeth.
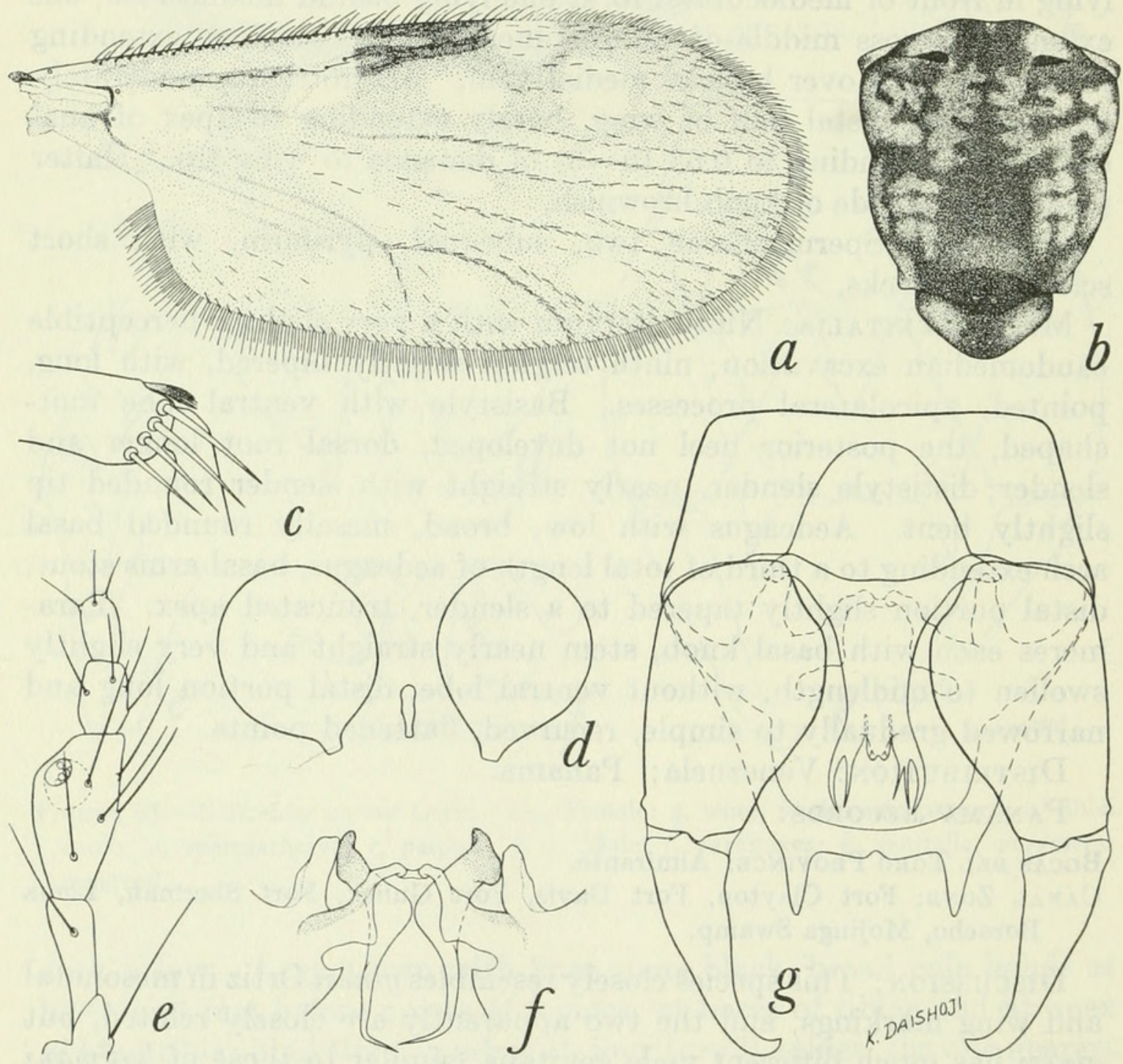

Figure 82.-Culicoides ginesi Ortiz. $a-e$, Female: $a$, wing; $b$, thoracic pattern; $c$, tibial comb; $d$, spermathecae; $e$, palpus. $f, g$, Male: $f$, parameres; $g$, genitalia, parameres removed. 
Thorax.-Mesonotum pruinose yellowish brown, with irregular pattern of dark brown dots at seta bases and splotches from their occasional fusion. Scutellum pale on sides, brown in middle; postscutellum dark brown, pleuron yellowish with a broad, transverse, brown band. Legs brown, femora with broad basal and subapical pale bands, all tibiae with broad subbasal and fore and mid tibiae with broad apical pale bands; tarsi pale, hind tibial comb with four $(n=9)$ spines, the two nearest the spur longest, subequal.

Wing.-Pattern as figured; cell $R_{5}$ with three well-separated spots arranged in a triangle; two pale spots in cell $\mathrm{M}_{1}$, one each in distal portions of cells $\mathrm{M}_{2}, \mathrm{M}_{4}$ and anal cell, all lying distant from wing margin; pale spot present lying behind medial fork and one lying ahead of mediocubital fork. Macrotrichia numerous on distal half of wing and a few extending in a double row to base of cell $\mathrm{M}$ and a few in anal cell; costa extending to $0.62(0.59-0.68, \mathrm{n}=10)$ of distance to wing tip. Halter pale.

Abdomen.-Brown, cerci pale. Spermathecae two, slightly ovoid, subequal, each measuring 0.047 by $0.034 \mathrm{~mm}$., the bases of the ducts not sclerotized.

Male Genitalia: Ninth sternum broad, with a deep caudomedian excavation; ninth tergum short and tapering, with very long, triangular, apicolateral processes. Basistyle with foot-shaped ventral root, the posterior heel not developed, dorsal root shorter and stout; dististyle stout at base, tip slightly bent and slender. Aedeagus with very low basal arch, the basal arms short and stout, distal stem very broad and bearing apically two or three sublateral pairs of long, pointed, sclerotized processes in a distal row. Parameres each with stout basal knob, stem greatly swollen in basal portion, abruptly bent at most swollen portion, without ventral lobe, tapered distally to slender, simple, only slightly curved distal points.

Distribution: Venezuela; Panama.

PANAMA RECORDS:

Bocas del Toro Province: Almirante.

CANal Zone: Fort Clayton, Fort Davis, Fort San Lorenzo, Fort Sherman, Loma

Boracho, Mojinga Swamp.

Coclé Province: Aguadulce.

Los Santos Province: Puerto Mensabé.

Panamá Province: Arraiján, Tocumen.

Discussion: This very characteristic and strikingly marked species takes its place in the debilipalpis group, with wing, mesonotal and leg markings allying it with aureus Ortiz. The male aedeagus of ginesi bears distal processes similar to but more numerous and more extreme in development than those of hoffmani. 


\section{Culicoides glabrior Macfie}

FIGURE 83

Culicoides debilipalpis var. glabrior Macfie, 1940, Ent. Monthly Mag., vol. 76, p. 27 (male, female; British Guiana).

Culicoides grahambelli Forattini, 1956, Proc. Ent. Soc. Washington, vol. 58, p. 35 (female; Cerro Cefa, Panama). New synonymy.

Female: Length of wing $1.02(0.86-1.22, \mathrm{n}=11) \mathrm{mm}$.

Head.-Eyes bare, broadly contiguous. Antenna with flagellar segments in proportion of $20: 15: 15: 15: 16: 16: 16: 16: 18: 19: 21: 22: 36$, antennal ratio $0.89(0.80-0.99, \mathrm{n}=5)$; distal sensory tufts present on segments III, VII-X. Palpal segments in proportion of $7: 13: 23: 8: 8$, third segment broad, $1.9(1.7-2.6, \mathrm{n}=5)$ times as long as greatest breadth, with a very broad, shallow sensory pit; fourth segment much broader than fifth. Mandible with $15(12-16, \mathrm{n}=11)$ teeth.

Thorax.-Mesonotum shining dark brown, with faint pattern of dull, paler brown areas consisting of a median discal area from anterior third to scutellum and two pairs of small spots, one over humeral pits, the other at lateral margins at sutural level. Scutellum, post-

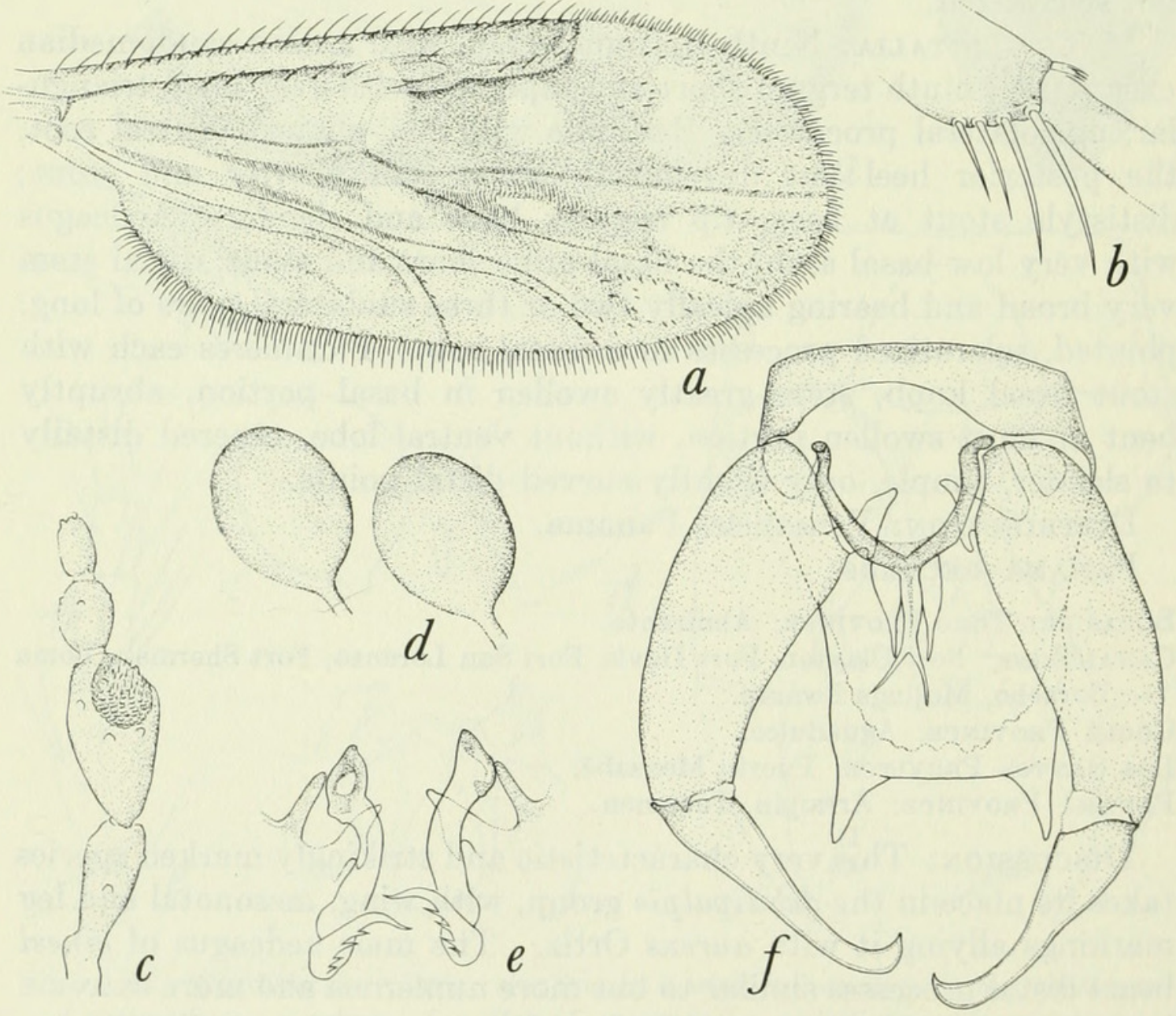

FIGURE 83.-Culicoides glabrior Macfie. $a-d$, Female: $a$, wing; $b$, tibial comb; $c$, palpus $d$, spermathecae. $e, f$, Male: $e$, parameres; $f$, genitalia, parameres removed. 
scutellum and pleuron dark brown. Legs dark brown, femora without pale rings, fore and mid tibiae with basal, and hind tibai with basal and apical, narrow pale rings; hind tibial comb with four $(n=9)$ spines, the one nearest the spur longest.

Wing.-Pattern as figured; second radial cell remarkably broadened, the three pale spots in cell $R_{5}$ arranged in a large triangle, distal spot in cell $R_{5}$ transverse, only one distal spot in cell $\mathrm{M}_{2}$, pale spots present behind medial fork and in front of mediocubital fork, a single pale spot in apex of anal cell transverse, extending nearly to wing margin. Macrotrichia sparse on distal half of wing, a few at base of medial cell and in anal cell; costa extending to 0.68 of distance to wing tip. Halter brown, the end of the knob slightly paler.

Abdomen.-Blackish, cerci yellowish. Spermathecae two, pyriform, subequal, measuring 0.063 by $0.048 \mathrm{~mm}$. and 0.059 by $0.042 \mathrm{~mm}$.

Male Genitalia: Ninth sternum with very shallow caudomedian excavation; ninth tergum long and tapering, the apicolateral processes large, triangular. Basistyle with ventral root foot-shaped, the posterior heel long; dorsal root short; dististyle long and slender, with bent, pointed apex. Aedeagus with short, rounded anterior arch, posterior portion in three parts; a median stem-like lobe with prominently bifurcate apex, and a pair of slender, tapering, pointed lateral lobes about half as long as median one. Parameres stout, each with large basal knob, stout stem gradually expanded to a large, ventral, subapical lobe, beyond which it is greatly narrowed, twisted laterad, ventrad, and then mesad, the distal point flattened with four subapical barbs.

Distribution: British Guiana; Honduras (Lancetilla); Panama. Panama Records:

Bocas del Toro Province: Almirante.

Canal Zone: Camp Piña, Fort Davis, Loma Boracho, Mojinga Swamp.

Panamá Province: Goofy Lake, Pacora.

Discussion: Through the courtesy of Paul Freeman and the trustees of the British Museum (Natural History) we have examined a slide labeled in Macfie's handwriting "Culicoides / debilipalpis Lz. / v. glabrior / क (large specimen) / C. germanus / ᄋ," but not bearing locality or other data. According to Mr. Freeman these are the presumed types of glabrior and germanus, each of which Macfie described from single females from British Guiana. The type of glabrior agrees in all details very closely with our Panama series. Culicoides glabrior can readily be distinguished from all related species by the remarkable breadth of the second radial cell. The unbanded femora are also distinctive.

This species seems to occupy an intermediate position between the fluvialis and debilipalpis groups and its true relations are doubtful. 


\section{The pachymerus group}

This group consists of small species with tawny yellowish mesonotum without prominent pattern, wing with pattern of oblique streaks and spots, with pale poststigmatic pale spot often encroaching on distal half of second radial cell; costa long, extending to $0.69-0.79$ of distance to wing tip, second radial cell long and narrow, in uniradialis fused with the first radial cell; antenna with distal sensory tufts present on segments III, viII-x; third palpal segment slender with small pit; legs stout, the femora markedly swollen; four tibial spines, two spermathecae; male genitalia with ventral root of basistyle footshaped; aedeagus stout; parameres with simple basal knob, long slender stem with or without ventral lobe or subapical spines.

Panama species: Four: almirantei, new species; caprilesi Fox; pachymerus Lutz, and uniradialis Wirth and Blanton. Also, obnoxius Fox from Venezuela apparently belongs to this group.

\section{Culicoides almirantei, new species}

Figure 84

Female: Length of wing $0.79(0.76-0.86, \mathrm{n}=8) \mathrm{mm}$.

Head.-Eyes contiguous, bare. Antenna with flagellar segments in proportion of $15: 10: 9: 9: 10: 11: 12: 13: 16: 17: 20: 24: 31$, antennal ratio $1.25(1.21-1.29, \mathrm{n}=6)$; distal sensory tufts present on segments III, viII-X. Palpal segments in proportion of $7: 16: 24: 8: 7$, third segment moderately swollen, $2.1(2.0-2.4, \mathrm{n}=10)$ times as long as greatest breadth, with a broad, shallow sensory pit. Mandible with 15 (14-16, $\mathrm{n}=5$ ) teeth.

Thorax.-Mesonotum pruinose grayish brown; anterior margin and two narrow longitudinal striae, each with broader lateral extensions at midlength, dark brown. Scutellum pruinose brown, darker narrowly in middle; postscutellum and pleuron dark brown. Legs brown; fore and mid femora with subapical, all tibiae with subbasal and hind tibia with apical, narrow pale rings; hind tibial comb with four $(n=10)$ spines, the one nearest the spur longest.

Wing.-Pattern as figured; large pale spot over $r-m$ crossvein extending broadly to costal margin; poststigmatic pale spot in cell $R_{5}$ with narrow anterior extension to wing margin past second radial cell, greatly expanded and filling cell $\mathrm{R}_{5}$ behind second radial cell to anterior side of vein $\mathrm{M}_{1}$; distal pale spot in cell $\mathrm{R}_{5}$ diamond-shaped, usually extending anterodistally to wing margin, leaving a very narrow, oblique dark mark proximad between it and poststigmatic pale spot; penultimate pale spots in cells $\mathrm{M}_{1}$ and $\mathrm{M}_{2}$ oval, largely filling the space between the adjacent veins; distal pale spot in cell $\mathrm{M}_{1}$ usually broadly attaining wing margin; distal pale spots in cells $\mathrm{M}_{2}$ and $\mathrm{M}_{4}$ 

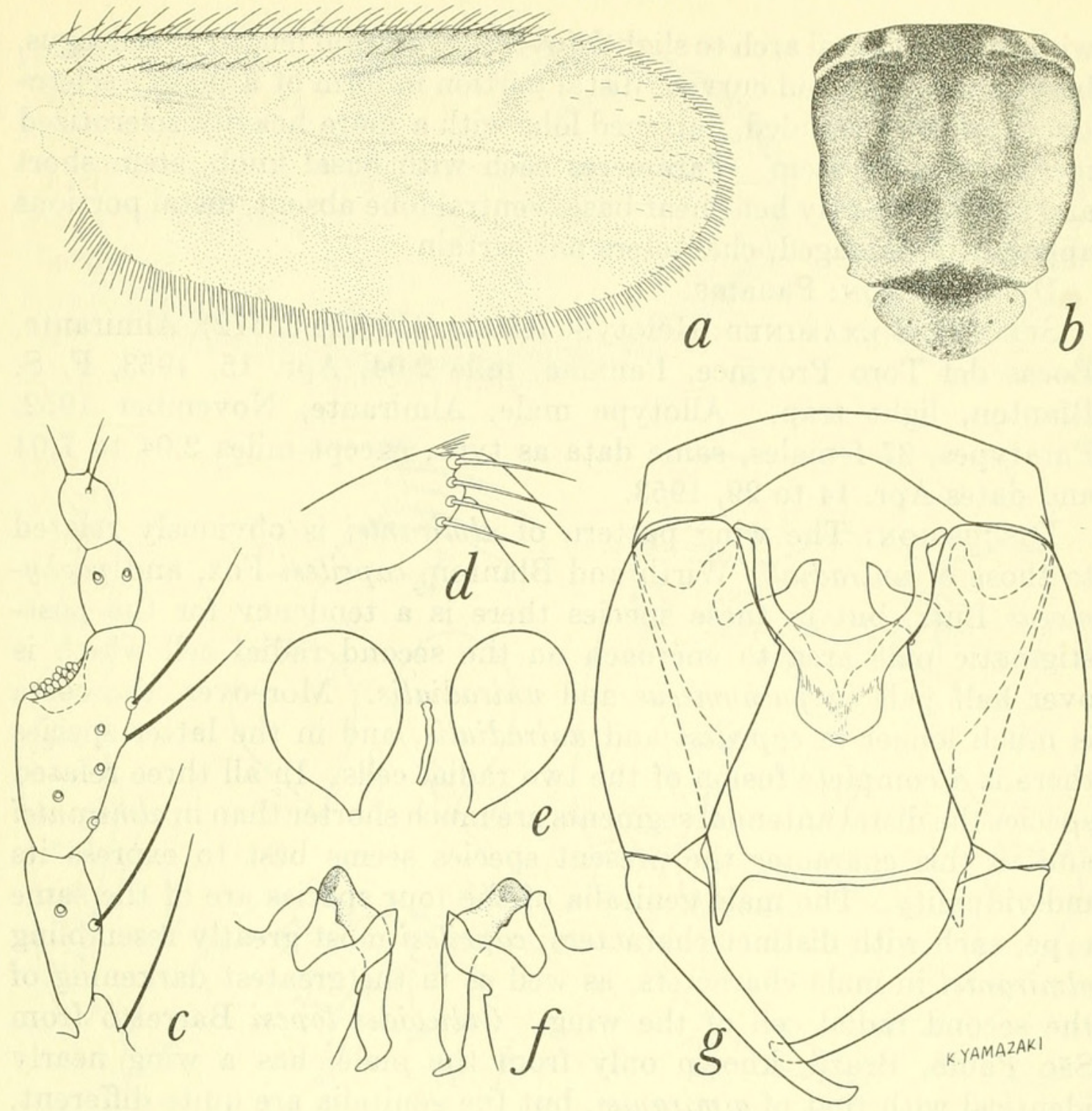

FIgURE 84.--Culicoides almirantei, new species. $a-e$, Female: $a$, wing; $b$, thoracic pattern; $c$, palpus; $d$, tibial comb; $e$, spermathecae. $f, g$, Male: $f$, parameres; $g$, genitalia, parameres removed.

large and broadly attaining wing margin; two pale spots in distal part of anal cell; pale spots present lying in front of mediocubital fork and behind medial fork, connected to the penultimate pale spot in cell $\mathrm{M}_{2}$; base of wing broadly pale from costal margin to base of anal cell. Macrotrichia very sparse in apices of cells $R_{5}$ and $M_{1}$; costa extending to $0.69(0.64-0.74, \mathrm{n}=8)$ of distance to wing tip. Halter yellowish. Abdomen.-Brownish black, cerci pale. Spermathecae two, pyriform, subequal, measuring 0.048 by $0.035 \mathrm{~mm}$., the bases of the ducts not sclerotized.

Male genitalia: Ninth sternum with a broad, shallow, caudomedian excavation; ninth tergum short with broad apex, caudal margin straight, apicolateral processes long and pointed. Basistyle with ventral root foot-shaped, the posterior heel poorly developed, dorsal root stout; dististyle nearly straight with slender tip. Aedeagus 
with rounded basal arch to slightly over half of total length of aedeagus, basal arms stout and curved; distal portion in form of a poorly sclerotized, apically rounded, flattened lobe with a more heavily sclerotized median slender stem. Parameres each with basal knob, stem short and stout, abruptly bent near base, ventral lobe absent, distal portions apparently damaged, characters not certain.

Distribution: Panama.

Specimens examined: Holotype female (USNM 63172), Almirante, Bocas del Toro Province, Panama, mile 2.04, Apr. 15, 1953, F. S. Blanton, light trap. Allotype male, Almirante, November 1952. Paratypes, 37 females, same data as type, except miles 2.04 to 7.04 and dates Apr. 14 to 29, 1953.

Discussion: The wing pattern of almirantei is obviously related to those of uniradialis Wirth and Blanton, caprilesi Fox, and pachymerus Lutz, but in these species there is a tendency for the poststigmatic pale area to encroach on the second radial cell which is over half pale in pachymerus and uniradialis. Moreover, the costa is much longer in caprilesi and uniradialis, and in the latter species there is a complete fusion of the two radial cells. In all three related species the distal antennal segments are much shorter than in almirantei and in this character the present species seems best to express its individuality. The male genitalia of the four species are of the same type, each with distinct characters; caprilesi most greatly resembling almirante $i$ in male characters, as well as in the greatest darkening of the second radial cell of the wing. Culicoides lopesi Barretto from São Paulo, Brazil, known only from the male, has a wing nearly identical with that of almirantei, but the genitalia are quite different, with a tapering ninth tergum, aedeagus with slender basal arms and slender apex, and parameres with a low ventral lobe and subapical barbs. Culicoides obnoxius Fox from Venezuela, known only from the female, has a similar wing pattern also, but in that species the apex of the second radial cell is pale, apex of vein $M_{1}$ is pale, the eyes are widely separated with short interfacetal hairs and the five distal antennal segments are much more elongated.

\section{Culicoides caprilesi Fox}

Figure 85

Culicoides caprilesi Fox, 1952, Ann. Ent. Soc. Amer., vol. 45, p. 364 (female; Mt. Marachuaca, Venezuela; fig. wing, palpus, antenna, eyes, tibial comb, spermathecae).

Culicoides kintzi Wirth and Blanton, 1953, Journ. Washington Acad. Sci., vol. 43, p. 72 (male, female; Panama; fig. wing, palpus, spermathecae, male genitalia). -Wirth, 1955, Proc. Ent. Soc. Washington, vol. 57, p. 114 (notes). New synonymy.

Female: Length of wing $0.83(0.73-0.98, \mathrm{n}=6) \mathrm{mm}$. 

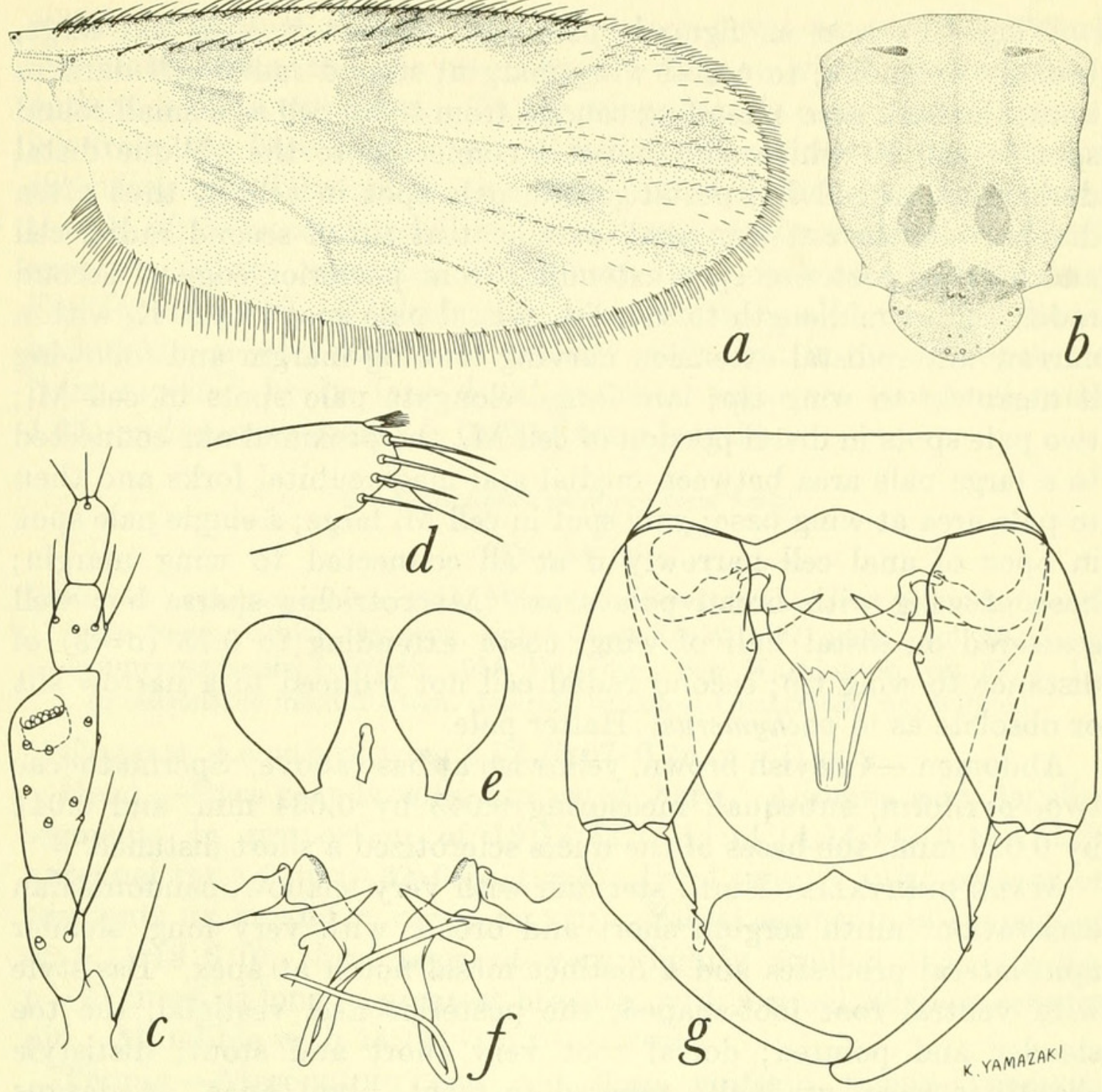

Figure 85.-Culicoiäes caprilesi Fox. $a-e$, Female: $a$, wing; $b$, thoracic pattern; $c$, palpus; $d$, tibial comb; $e$, spermathecae. $f, g$, Male: $f$, parameres; $g$, genitalia, parameres removed.

Head.-Eyes very broadly separated, bare. Antenna with flagellar segments in proportion of $18: 15: 16: 16: 16: 16: 16: 16: 16: 16: 16: 14: 18$, antennal ratio $0.61(0.58-0.65, \mathrm{n}=3)$; distal sensory tufts present on segments III, vIII-X, sometimes absent on viII. Palpal segments in proportion of $7: 15: 20: 8: 10$, third segment very slightly swollen, $2.0(1.6-2.3, \mathrm{n}=4)$ times as long as greatest breadth, with a small, shallow sensory pit. Mandibles with $16-17(n=2)$ teeth.

Thorax.-Mesonotum and scutellum tawny, yellowish brown; mesonotum with irregular anterior areas and three very narrow longitudinal striae brownish. Postscutellum and pleuron brown. Legs yellowish; knee spots and broad median bands on femora and tibiae brownish; hind tibial comb with four $(n=6)$ spines, the one nearest the spur longest. Legs stout, fore and hind femora particularly swollen. 
Wing.-Pattern as figured, pale spot over r-m crossvein large, broadly extending to costal wing margin; second radial cell dark to apex, the dark area extending caudad from tip of cell as a small round spot in cell $R_{5}$ which sometimes is connected to the oblique distal dark mark in cell $R_{5}$; poststigmatic pale spot in cell $R_{5}$ thus often divided into an anterior small pale spot at tip of second radial cell and a large posterior spot extending from posterior edge of second radial cell at midlength to vein $M_{1}$; distal pale spot in cell $R_{5}$ with a narrow anterodistal extension curving to wing margin and following it narrowly to wing tip; two large, elongate pale spots in cell $\mathrm{M}_{1}$; two pale spots in distal portion of cell $\mathrm{M}_{2}$, the proximal one connected to a large pale area between medial and mediocubital forks and then to pale area at wing base; pale spot in cell $\mathrm{M}_{4}$ large; a single pale spot in apex of anal cell narrowly if at all connected to wing margin; base of wing with broad pale area. Macrotrichia sparse but well scattered on distal half of wing; costa extending to $0.78(n=3)$ of distance to wing tip; second radial cell not reduced to a narrow slit or obsolete as in pachymerus. Halter pale.

Abdomen.-Grayish brown, yellowish at base above. Spermathecae two, pyriform, subequal, measuring 0.043 by $0.034 \mathrm{~mm}$. and 0.041 by $0.029 \mathrm{~mm}$., the bases of the ducts sclerotized a short distance.

Male genitalia: Ninth sternum with very shallow, caudomedian excavation; ninth tergum short and broad, with very long, slender apicolateral processes and a distinct mesal notch at apex. Basistyle with ventral root foot-shaped, the posterior heel vestigial, the toe slender and pointed; dorsal root very short and stout; dististyle slightly curved, gradually tapered to stout, blunt apex. Aedeagus stocky, basal arch very low and broad, basal arms stout and abruptly bent, distal portion tapered to bluntly rounded apex. Parameres each with basal knob, stem slender, abruptly bent near base, tapering distally without ventral lobe, the ventrally distal portion very long, tapered to simple, slender point.

Distribution: Venezuela; Panama.

PANAMA RECORDS:

Canal Zone: Fort Sherman, Madden Dam, Mojinga Swamp (type locality of kintzi).

Chiriquí Province: Río Tabasará.

Darién Province: Garachiné, Punta Patiño.

Veraguas Province: Las Palmas.

Discussion: Through the courtesy of Dr. Irving Fox of the University of Puerto Rico we have examined the type slide of caprilesi, which is in good condition, and we have been able to determine by direct comparison that kintzi Wirth and Blanton is a synonym. $C$. caprilesi is closely related to pachymerus Lutz, but can be distinguished 
readily in pinned mounts by the greater development of the dark mesonotal striae, and the much hairier wing on which the dark color pattern is more extensive. On the wing there is a dark mark extending from the base of the second radial cell almost to its apex and extending over into cell $R_{5}$ as a small rounded dark spot just behind the tip of the second radial cell. In some specimens the latter dark spot is narrowly connected to the next distal dark area as figured by Fox for caprilesi. C. almirantei, new species, is also closely related, having the second radial cell entirely dark, but it can be separated from caprilesi by its long distal antennal segments (antennal ratio, 1.25 ) and shorter costa (to 0.69 of wing length).

\section{Culicoides pachymerus Lutz}

\section{Figure 86}

Culicoides pachymerus Lutz, 1914, Mem. Inst. Oswaldo Cruz, vol. 6, p. 83 (female; Rio Negro, Brazil; fig. wing, leg).-Costa Lima, 1937, idem., vol. 32, p. 421 (unrecognizable).-Wirth, 1955, Proc. Ent. Soc. Washington, vol. 57, p. 112 (questionable identification, descriptive notes; Guatemala; fig. palpus).

Female: Length of wing $0.72(0.67-0.76, \mathrm{n}=7) \mathrm{mm}$.

Head.-Eyes very broadly separated, bare. Antenna with flagellar segments in proportion of $16: 13: 13: 14: 14: 14: 14: 14: 14: 13: 14: 13: 22$, antennal ratio $0.66(0.62-0.71, \mathrm{n}=5)$; distal sensory tufts present on segments III, IX and $\mathrm{X}$, rarely on VIII. Palpal segments in proportion of $5: 11: 18: 6: 10$, third segment very slightly swollen, 1.8 (1.6-2.1, $\mathrm{n}=7$ ) times as long as greatest breadth, with a small, shallow sensory pit. Mandible with $14(11-18, \mathrm{n}=8)$ teeth.

Thorax.-Mesonotum and scutellum uniform tawny yellowish brown, with vestiture of short appressed yellowish hairs. Postscutellum and pleuron brownish. Legs yellowish, femora and tibia with very faint, broad, median brownish bands; hind tibial comb with four $(n=6)$ spines, the one nearest the spur longest; legs stout, fore and hind femora greatly swollen, fusiform, slightly flattened laterally.

Wing.-Pattern as figured; pale spot over r-m crossvein large and broadly meeting costal wing margin; poststigmatic pale spot in cell $R_{5}$ including distal half of vein $R_{4+5}$, the extremely long and narrow second radial cell thus appearing pale on distal half; the poststigmatic pale spot narrow in cell $R_{5}$ distal to end of costa, extending obliquely proximad and greatly broadened posteriorly to vein $\mathrm{M}_{1}$ behind second radial cell; distal pale spot in cell $R_{5}$ varying in extent, usually oval in shape and not attaining wing margin, but in some specimens with a narrow anterior extension extending distad to wing tip; two elongated pale spots in cell $\mathrm{M}_{1}$; two pale spots in distal portion of cell $\mathrm{M}_{2}$; pale spot in cell $\mathrm{M}_{4}$ nearly filling cell; anal cell with large pale 
spot filling apex of cell to wing margin; area between medial and mediocubital forks continuously pale, connected by a pale line to broad basal pale area of wing. Costa extending to $0.71(0.69-0.74$, $\mathrm{n}=7$ ) of distance to wing tip; second radial cell extremely long and narrow, appearing obsolete in most specimens; macrotrichia very sparse, confined to a few in apices of cells $R_{5}$ and $M_{1}$. Halter pale.
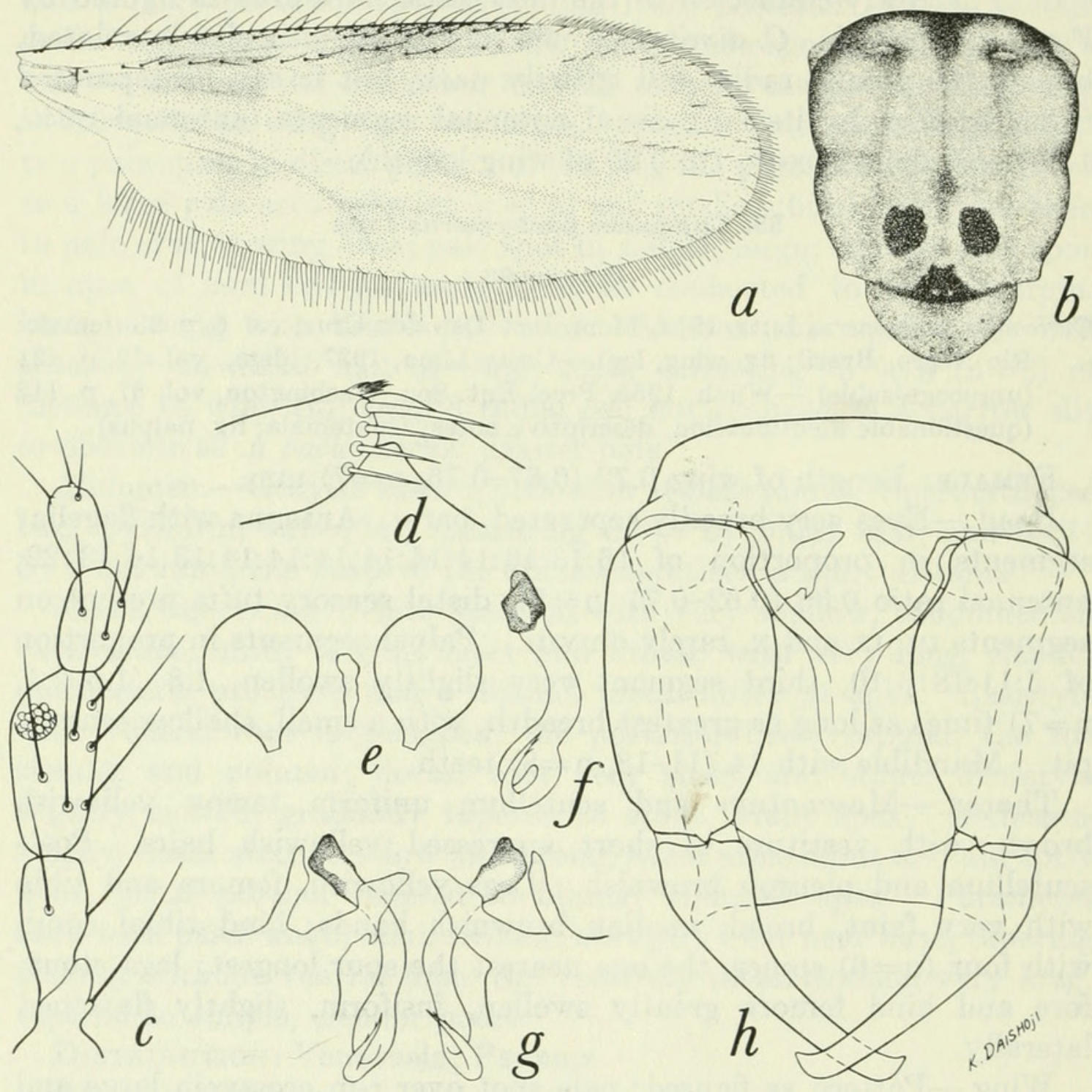

FigUre 86.-Culicoides pachymerus Lutz. $a-e$, Female: $a$, wing; $b$, thoracic pattern; $c$, palpus; $d$, tibial comb; $e$, spermathecae. $f-h$, Male: $f$, paramere, lateral view; $g$, parameres; $h$, genitalia, parameres removed.

Abdomen.- Yellowish with brownish segmental, pleural and tergal spots. Spermathecae two, pyriform, subequal, relatively small, each measuring 0.036 by $0.026 \mathrm{~mm}$., the bases of the ducts not sclerotized.

Male Genitalia: Ninth sternum with very shallow caudomedian excavation; ninth tergum short and quadrate, caudal margin some- 
what indented mesad, the apicolateral processes moderately well developed, bluntly triangular. Basistyle with ventral root footshaped, the posterior heel very poorly developed, dorsal root slender; dististyle moderately stout distad with bluntly pointed apex. Aedeagus with basal arch low and broad, the basal arms bent in midportions, slender; distal apex with relatively slender, rounded tip. Parameres each with basal knob, stem slender and curved in midportion, ventral lobe very long, about two times as long as its diameter, apical portion of paramere very slender, tapered to simple point.

Distribution: Brazil; Guatemala; Panama.

PANAMA RECORDS:

Bocas del Toro Province: Almirante.

CANAL ZoNe: Fort Davis, Fort Sherman, Loma Boracho, Mojinga Swamp.

Chiriqui Province: David.

Darién Province: El Real, Punta Patiño.

Veraguas Province: Las Palmas.

Discussion: Through the courtesy of Dr. A. da Costa Lima we have been able to examine the slide on which are mounted the five cotype specimens of pachymerus described by Lutz from Rio Negro, Amazonas, Brazil. As previously remarked by Lutz and by Costa Lima in the publications cited, the condition of the slide is very poor since the liquid mounting medium has separated for the most part from the specimens, leaving them wet but not immersed in the liquid. The antennae and palpi are missing, as originally stated by Lutz. By dark-field illumination of the wing it is possible to make out something of the venation and color pattern, which agree so far as can be determined with that described above for the specimens from Guatemala and Panama, and are quite distinct from the characters of uniradialis Wirth and Blanton and caprilesi Fox. The wing length measures $0.80 \mathrm{~mm}$. and the costal ratio is 0.69 . We are thus able to conclude with fair assurance that our species is conspecific with Brazilian pachymerus.

Culicoides pachymerus is smaller than uniradialis and caprilesi, its wing is less hairy than that of caprilesi, there is no dark spot or connection immediately posterior to the end of the second radial cell as in caprilesi, and the last segment of the antenna is much longer than the tenth (22:14, compared with 18:16 in caprilesi). The male genitalia of pachymerus closely resemble those of uniradialis, with a long ventral lobe present on the parameres, but differing in having a median notch on the ninth tergum, aedeagal arch much broader with slender basal arms and no barbs on the tips of the parameres. 


\section{Culicoides uniradialis Wirth and Blanton}

\section{FigURE 87}

Culicoides uniradialis Wirth and Blanton, 1953, Journ. Washington Acad. Sci., vol. 43, p. 69 (male, female; Panama; fig. wing, palpus, male genitalia).

Female: Length of wing $0.94(0.89-0.99, \mathrm{n}=5) \mathrm{mm}$.

Head.-Eyes narrowly separated, bare. Antenna with flagellar segments in proportion of $22: 19: 19: 19: 18: 18: 18: 18: 18: 18: 18: 18: 26$, antennal ratio $0.65(0.64-0.66, \mathrm{n}=2)$; distal sensory tufts present on segments III, VIII-X. Palpal segments in proportion of $9: 18: 24: 10: 10$, third segment very slightly swollen, $2.0(1.9-2.2, \mathrm{n}=5)$ times as long as greatest breadth, with a small, shallow sensory pit. Mandible with $16(16-17, \mathrm{n}=4)$ teeth.

Thorax.-Mesonotum rather narrow, color uniformly light tawny brown, with numerous short, appressed, yellowish hairs. Scutellum

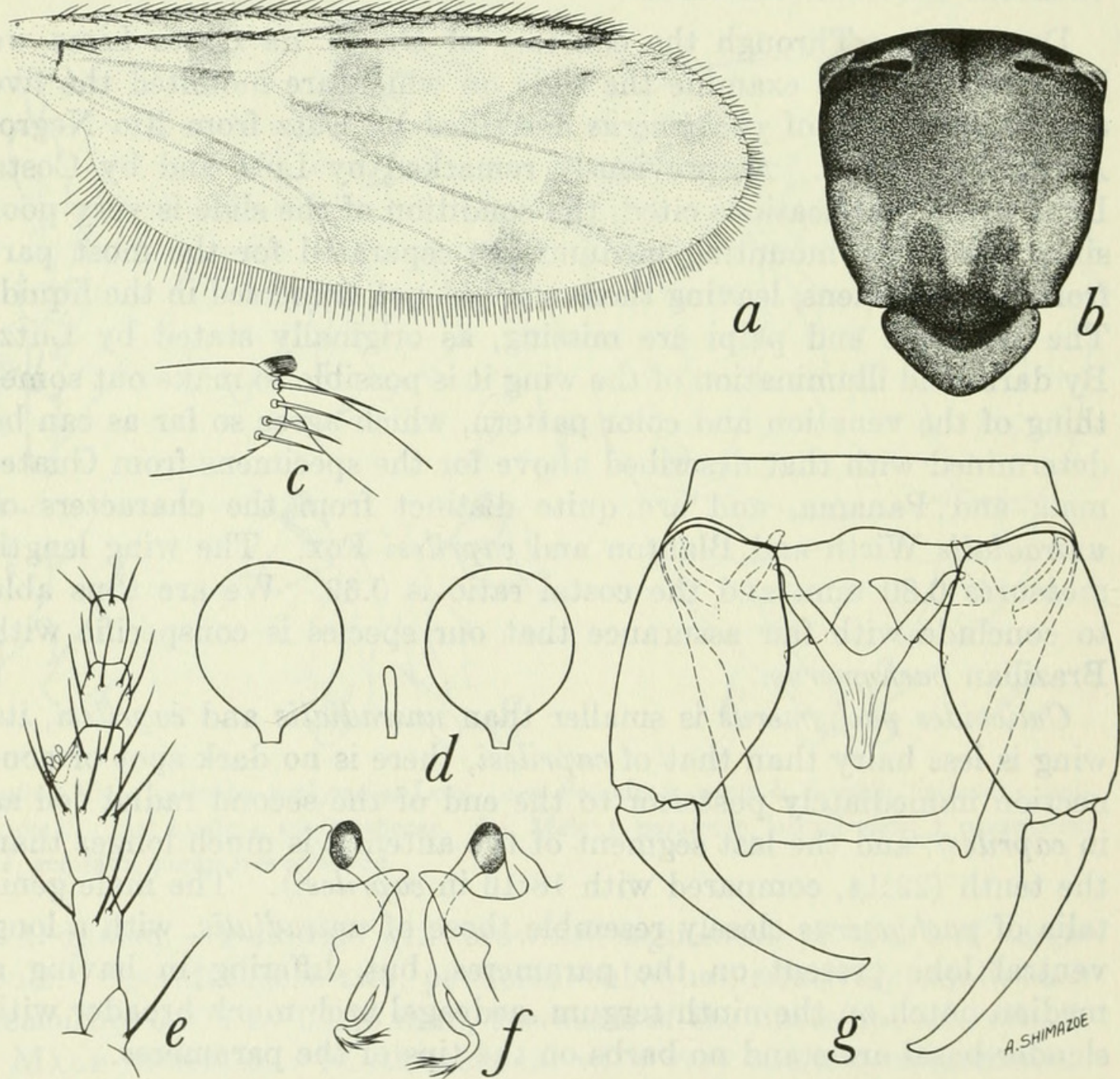

Figure 87.-Culicoides uniradialis Wirth and Blanton. $a-e$, Female: $a$, wing; $b$, thoracic pattern; $c$, tibial comb; $d$, spermathecae; $e$, palpus. $f, g$, Male: $f$, parameres; $g$, genitalia, parameres removed. 
tawny, postscutellum dark brown; pleuron pale with transverse area in middle darker. Legs pale brown, apical bands on all femora, basal and apical bands on tibiae and all of tarsi pale; all femora remarkably stout; hind tibial comb with four $(n=5)$ spines, the one nearest the spur longest.

Wing.-Pattern as figured; only one very elongate radial cell present; pale spots very extensive, interconnected, more than distal half of radial cell in pale area; dark markings of wing arranged in three transverse areas, the proximal one consisting of a dark spot from costa to media and a dark spot over stem of mediocubitus, both located slightly past midlengths of stems of these veins before the forks; second dark band narrower than pale areas on each side, consisting of an anterior spot extending from costa over base of radial cell to include the base of the medial fork, and a posterior spot over mediocubital fork following vein $\mathrm{Cu}_{1}$ broadly to wing margin; third dark band beginning as an oblique, dark mark across middle of cell $\mathrm{R}_{5}$ from wing margin near apex of cell, broadening toward vein $\mathrm{M}_{1}$ and extending along this vein and forming a broad dark mark in front of its apex, continuing broadly across middle of cells $M_{1}$ and $M_{2}$ to apex of vein $\mathrm{M}_{3+4}$ and following vein $\mathrm{M}_{2}$ also to its apex. Macrotrichia entirely absent; costa extending to $0.79(0.78-0.81, \mathrm{n}=5)$ of distance to wing tip. Halter pale.

Abdomen.-Brown. Spermathecae two, small, pyriform, slightly unequal, measuring 0.038 by 0.031 and 0.036 by $0.026 \mathrm{~mm}$., the bases of the ducts sclerotized a very short distance.

Male genitalia: Ninth sternum with very shallow caudomedian excavation; ninth tergum short, quadrate, with very small, widely separated, apicolateral processes. Basistyle with ventral root footshaped, the posterior heel a short, sharp spur, dorsal root short and relatively stout; dististyle nearly straight, gently tapered to tip which is blunt and slender but not bent. Aedeagus short and stout, basal arms stout and forming a $V$-shaped anterior arch to a half of total length of aedeagus; distal apex stout and rounded with faint serrations and apparently a few appressed, sharp, flattened, subapical spines. Parameres each with basal knob, stem slender, curved in midportion with a ventral lobe 1.5 times as long as its diameter, distal portion narrowed and tapered to sharp apical point with three or four subapical lateral barbs.

Distribution: Panama.

PanAMA RECORDS:

Bocas del Toro Province: Almirante.

Canal Zone: Fort Sherman, Loma Boracho, Mojinga Swamp (type locality).

Cólon Province: Piña.

Darien Province: Garachiné. 
Discussion: The remarkable extension of the costa to nearly eight-tenths of the wing length and the presence of only one radial cell which tapers evenly from the linear base to the apex, the absence of macrotrichia, and the larger size will readily separate uniradialis from the closely related pachymerus Lutz and caprilesi Fox.

\section{The arubae group}

This group consists of moderately large, stout species with mesonotal pattern of punctiform dots and black and white speckled wings; costa short, to 0.52 of wing length; a pair of distinct frontal tubercles present between antennal bases; antenna with short segments (antennal ratio, 0.87), distal sensory tufts present on segments iII to $\mathrm{x}$; tibial comb with seven spines, two spermathecae; male genitalia with ventral root of basistyle long and slender; paramere with basal knob directed sharply laterad, stem short and stout, the apex simple; aedeagus short and stout with reflexed basal arms, low basal arch and stout, truncated tip.

This group contains only one species, arubae Fox and Hoffman. It occurs in Panama.

\section{Culicoides arubae Fox and Hoffman}

\section{Figure 88}

Culicoides arubae Fox and Hoffman, 1944, Puerto Rico Journ. Pub. Health Trop. Med., vol. 20, p. 109 (male, female; Aruba, D. W. I.; fig. wing).-Barbosa, 1947, Anais Soc. Biol. Pernambuco, vol. 7, p. 11 (Canal Zone, Venezuela; fig. palpus, male genitalia).-Ortiz and Mirsa, 1952, Rev. Sanid. Asist. Soc., vol. 17, p. 269 (male, female; Venezuela; fig. palpus, spermathecae, male genitalia).

Female: Length of wing $1.17(1.11-1.23, \mathrm{n}=3) \mathrm{mm}$.

Head.-Eyes narrowly separated, bare. Antenna with flagellar segments in proportion of $22: 13: 13: 13: 13: 12: 12: 11: 15: 15: 16: 17: 32$, antennal ratio 0.87 ; distal sensory tufts present on segments III to $\mathrm{x}$. Palpal segments in proportion of $15: 30: 48: 11: 11$, third segment swollen, $2.3(2.1-2.7, \mathrm{n}=3)$ times as long as broad, with a very broad, shallow sensory pit. Mandible with $15(14-16, \mathrm{n}=5)$ teeth.

Thorax.-Mesonotum.very broad and convex; densely pale grayish pruinose; narrow median and two broader sublateral vittae indistinctly yellowish brown fumose; mesonotum with numerous punctiform brown dots at the seta bases. Scutellum narrowly dark brown in middle, yellowish white pollinose on sides; postscutellum grayish pollinose with two lateroposterior blackish spots; pleuron brownish black. Legs dark brown and distinctly annulated; narrow knee joints pale, knees with narrow blackish rings and then narrow pale rings on each side on femora and tibiae, femora narrowly pale at 

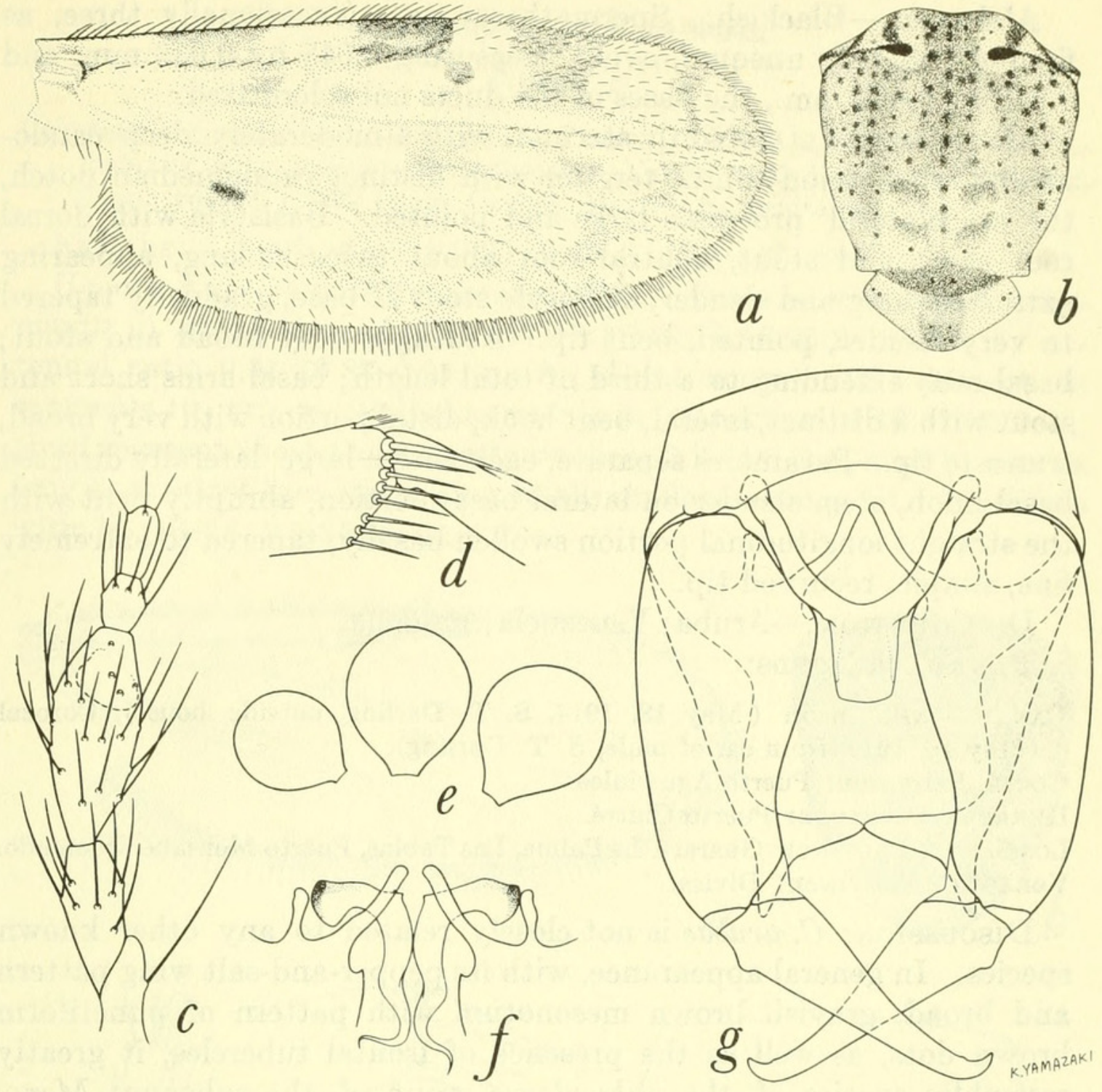

FigUre 88.-Culicoides arubae Fox and Hoffman. $a-e$, Female: $a$, wing; $b$, thoracic pattern; $c$, palpus; $d$, tibial comb; $e$, spermathecae. $f, g$, Male: $f$, parameres; $g$, genitalia, parameres removed.

bases, fore femur with narrow pale ring at midlength; hind tibial comb with 7-8 $(\mathrm{n}=3)$ spines, the one nearest the spur longest.

Wing.-Membrane milky white, with limited dark gray spots as figured, giving the appearance of blackish spots on a whitish ground; second radial cell blackish; veins pale margined; cell $R_{5}$ with a large pale spot surrounding a tiny black spot behind second radial cell, a broad V-shaped mark and a small distal round pale spot in apex of cell; cells $M_{1}$ and $M_{2}$ with three small round pale spots past level of forks; two pale spots in cell $\mathrm{M}_{4}$ and two in distal portion of anal cell; base of wing extensively pale. Macrotrichia sparse but well scattered over wing, including anal cell; costa extending to $0.52(0.51-0.54, \mathrm{n}=3)$ of distance to wing tip. Halter knob blackish. 
Abdomen.-Blackish. Spermathecae two (occasionally three, as figured), slightly unequal, ovoid, measuring 0.043 by $0.038 \mathrm{~mm}$. and 0.038 by $0.029 \mathrm{~mm}$., the bases of the ducts not sclerotized.

Male genitalia: Ninth sternum with a moderately deep caudomedian excavation; ninth tergum with distinct caudomedian notch, the apicolateral processes large and pointed. Basistyle with dorsal root short and stout, ventral root about twice as long, appearing extremely long and slender, dististyle stout at base, gradually tapered to very slender, pointed, bent tip. Aedeagus very broad and stout; basal arch extending to a third of total length; basal arms short and stout with a distinct, lateral, bent hook, distal portion with very broad, truncate tip. Parameres separate, each with a large, laterally directed basal knob, stem slender on lateral basal portion, abruptly bent with the straight longitudinal portion swollen basally, tapered to extremely fine, simple, recurved tip.

Distribution:-Aruba; Venezuela; Panama.

PANAMA RECORDS:

Canal Zone: Ancón (May 18, 1914, S. T. Darling, outside house), Corozal (May 18, 1914, from ear of mule, S. T. Darling).

Coclé Province: Puerto Aguadulce.

Herrera Province: Puerto Chitré.

Los Santos Province: Guararé, La Palma, Las Tablas, Puerto Mensabé, Quemado. Veraguas Province: Divisa.

Discussion: C. arubae is not closely related to any other known species. In general appearance, with its pepper-and-salt wing pattern and broad, grayish brown mesonotum with pattern of punctiform brown dots, as well as the presence of frontal tubercles, it greatly resembles species of the nubeculosus group of the subgenus Monoculicoides Khalaf such as the North American variipennis (Coquillett), but all those species have but one elongate spermatheca and the male parameres fused. It is possible that arubae is a very primitive member of this group.

\section{The stigmalis group}

This group consists of moderately large species with pruinose, blackish mesonotum and bare, very poorly marked wing; second radial cell very long and narrow, forming a blackish stigma; antenna with sensoria present on segments III, viII- $x$; four tibial spines; two spermathecae; male genitalia with ventral root of basistyle foot-shaped; apicolateral processes short; paramere with simple basal knob, stem straight without ventral lobe, the apex fringed; aedeagus with high, rounded basal arch and broad apex.

Panama species: One: C. stigmalis Wirth. 


\section{Culicoides stigmalis Wirth}

Figure 89

Culicoides stigmalis Wirth, 1952, Journ. Parasit., vol. 38, p. 245 (female; Guatemala; fig. wing, palpus, spermathecae).-Vargas, 1953, Rev. Inst. Salub. Enf. Trop., vol. 13, p. 229 (male; Oaxaca, Mexico; fig. genitalia).

Female: Length of wing $0.90(0.88-0.92, \mathrm{n}=9) \mathrm{mm}$.

Head.-Eyes narrowly separated, bare. Antenna with flagellar segments in proportion of $17: 15: 17: 18: 18: 18: 18: 18: 23: 23: 25: 25: 25$, antennal ratio $0.91(0.88-0.94, \mathrm{n}=8)$; distal sensory tufts present on segments III, VIII-X. Palpal segments in proportion of 10:17:25:9:14, third segment short and scarcely swollen, $2.2(2.0-2.5, \mathrm{n}=9)$ times as long as greatest breadth, with a small, shallow sensory pit. Mandible with $14(13-14, \mathrm{n}=3)$ teeth.

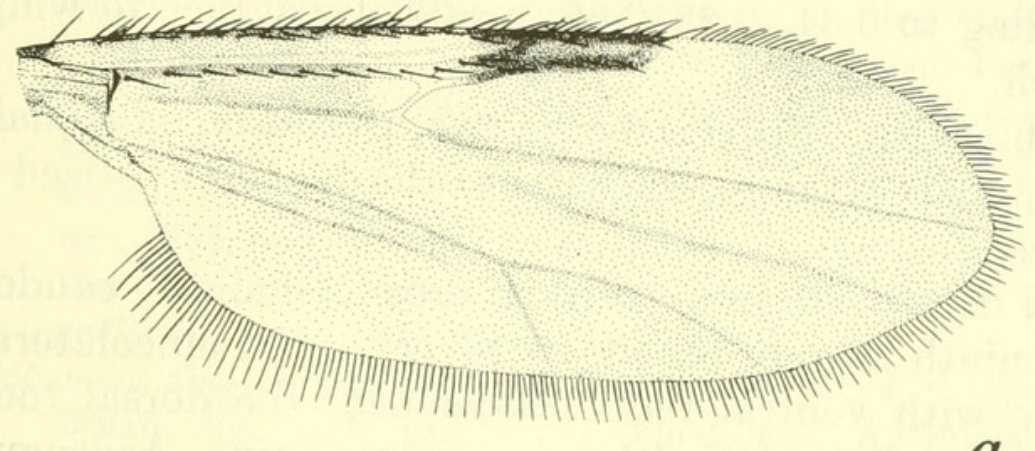

$a$
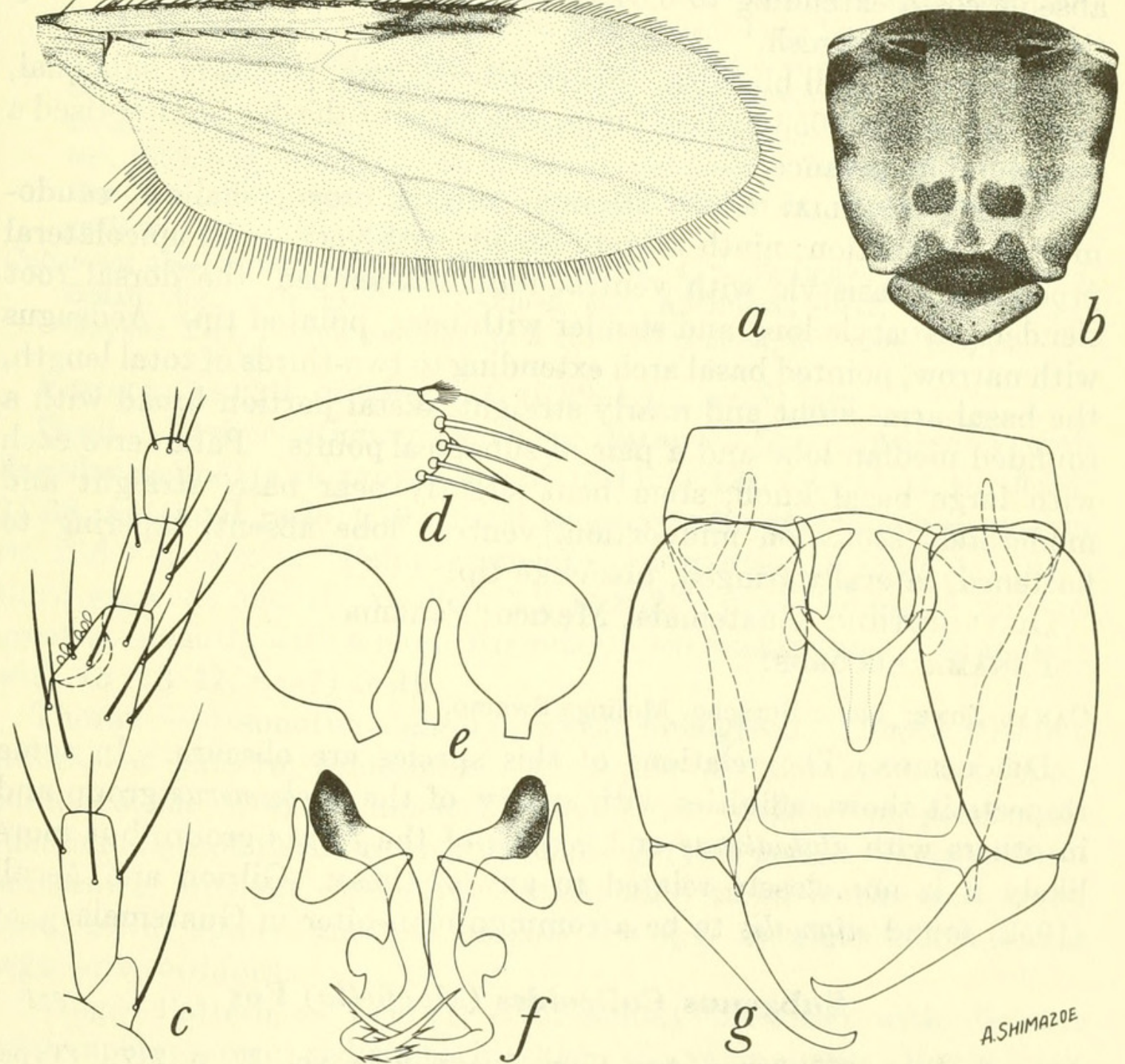

FIGURE 89.-Culicoides stigmalis Wirth. $a-e$, Female: $a$, wing; $b$, thoracic pattern; $c$, palpus; $d$, tibial comb; $e$, spermathecae. $f, g$, Male: $f$, parameres; $g$, genitalia, parameres removed. 
Thorax.-Mesonotum uniformly dull dark brown, almost black, with abundant vestiture of semi-appressed, fine, black hairs and coarse, suberect, black bristles. Scutellum, postscutellum and pleuron uniformly blackish. Legs uniformly dark brown, hind tibia with a faint basal pale ring; femora rather stout as in species of the pachymerus group; legs with abundant bristly hairs; hind tibial comb with four $(n=9)$ spines, the one nearest the spur longest.

Wing.-Pattern as figured; second radial cell blackish, very long, about three times as long as broad; three yellowish areas on anterior part of wing, a broad one at base of wing, one over r-m crossvein broadly to middle of cell $\mathrm{M}_{2}$, and a small narrow poststigmatic spot; wing otherwise uniformly grayish, darker along veins, sometimes with other very faint pale spots, one in distal part of anal cell, one in cell $\mathrm{M}_{4}$ and one in cell $\mathrm{M}_{2}$ behind medial fork. Macrotrichia entirely absent; costa extending to $0.64(0.63-0.66, \mathrm{n}=9)$ of distance to wing tip. Halter brownish.

Abdomen.-Dull blackish. Spermathecae two, pyriform, subequal, each measuring 0.053 by $0.031 \mathrm{~mm}$., the bases of the ducts sclerotized a considerable distance.

Male Genitalia: Ninth sternum with a broad, shallow, caudomedian excavation; ninth tergum broad, with very small apicolateral processes. Basistyle with ventral root foot-shaped, the dorsal root slender; dististyle long and slender with bent, pointed tip. Aedeagus with narrow, pointed basal arch extending to two-thirds of total length, the basal arms stout and nearly straight; distal portion broad with a rounded median lobe and a pair of subapical points. Parameres each with large basal knob, stem bent slightly near base, straight and moderately stout on midportion, ventral lobe absent, tapering to flattened, laterally fringed, bladelike tip.

Distribution: Guatemala; Mexico; Panama.

Panama Records:

Canal Zone: Loma Boracho, Mojinga Swamp.

Discussion: The relations of this species are obscure. In some respects it shows affinities with species of the pachymerus group and in others with alahialinus and gorgasi of the furens group, but more likely it is not closely related to any of these. Gibson and Ascoli (1952) found stigmalis to be a common man-biter in Guatemala.

\section{Subgenus Culicoides (Macfiella) Fox}

Macfiella Fox, 1955, Journ. Agr. Univ. Puerto Rico, vol. 39, p. 217. (Type: Ceratopogon phlebotomus Williston.)

Medium-sized species with the second radial cell very dark; wing with the pale spot present straddling middle of vein $\mathrm{M}_{2}$; mesonotum 
blue-green pruinose, with or without brown punctiform dots; eyes contiguous; fourth tarsal segment cordiform; antenna with sensoria present on segments $\mathrm{III}^{-\mathrm{X}}$ or on $\mathrm{III}, \mathrm{VI}-\mathrm{X}$; palpal pit absent; six or seven tibial spines; two spermathecae; male genitalia with ventral root foot-shaped; parameres separate, basal knob simple, stem straight, with simple, bent distal point.

There are two species in this subgenus, both of which occur in Panama: phlebotomus (Williston) and willistoni Wirth and Blanton.

\section{Culicoides phlebotomus (Williston)}

Figure 90

Ceratopogon phlebotomus Williston, 1896, Trans. Ent. Soc. London, vol. 3, p. 281 (female; St. Vincent Island; fig. wing, palpus).

Culicoides phlebotomus, Kieffer, 1906, Genera Insectorum, fasc. 42, p. 55.-Hoffman, 1925, Amer. Journ. Hyg., vol. 5, p. 285 (female; Puerto Rico; fig. wing).--Painter, 1926, United Fruit Co. Med. Rep., vol. 15, p. 258 (Honduras, biology).-Fox, 1942, Puerto Rico Journ. Pub. Health Trop. Med., vol. 17, p. 419 (pupa; Virgin Islands; fig.).-Ortiz and Mirsa, 1952, Rev. Sanid. Asist. Soc., vol. 17, p. 275 (male, female; Venezuela; fig. spermathecae, antenna, palpus, tarsus, wing, male genitalia).-Wirth and Blanton, 1953, Ent. News, vol. 64, p. 114 (male, female; Puerto Rico, Mexico, Honduras, Nicaragua, Panama, Venezuela, Brazil; fig. wing, tarsus, male genitalia; synonym, amazonius Macfie).

Culicoides amazonius Macfie, 1935, Stylops, vol. 4, p. 52 (male, female; Tutoia, Brazil; fig. male genitalia).-Floch and Abonnenc, 1942, Inst. Pasteur Guyane Terr. l'Inini, publ. 37, p. 3 (French Guiana; fig. wing, palpus).

Female: Length of wing $1.03(0.89-1.15, \mathrm{n}=8) \mathrm{mm}$.

Head.-Eyes contiguous a short distance, bare. Antenna with flagellar segments in proportion of $16: 11: 11: 12: 12: 11: 11: 11: 16: 18: 20$ : $21: 38$, antennal ratio 1.19 ; distal sensory tufts present on segments III, and v or vi to X. Palpal segments in proportion of $13: 24: 26: 10: 13$, third segment slightly swollen, $2.2(1.8-2.5, \mathrm{n}=7)$ times as long as greatest breadth, with a large, irregular, open sensory area. Mandible with $15(13-17, \mathrm{n}=7)$ teeth.

Thorax.-Mesonotum densely grayish, blue-green pollinose, without prominent pattern, sometimes with a pair of faint brownish longitudinal striae, with prominent blackish hairs. Scutellum, postscutellum and pleuron dark brown with dense grayish pollen. Legs yellowish brown, without distinctive bands; hind tibial comb with seven $(6-8, n=8)$ spines, the one nearest the spur longest; fourth tarsal segments cordiform.

Wing.-Pattern as figured; color smoky brownish with distinct white spots; second radial cell blackish, the veins surrounding it very greatly thickened, the cell itself narrow; pale spot over r-m crossvein well developed; cell R, with four pale spots, three spots in a triangle in poststigmatic area, the distal spot large and usually broadly at- 

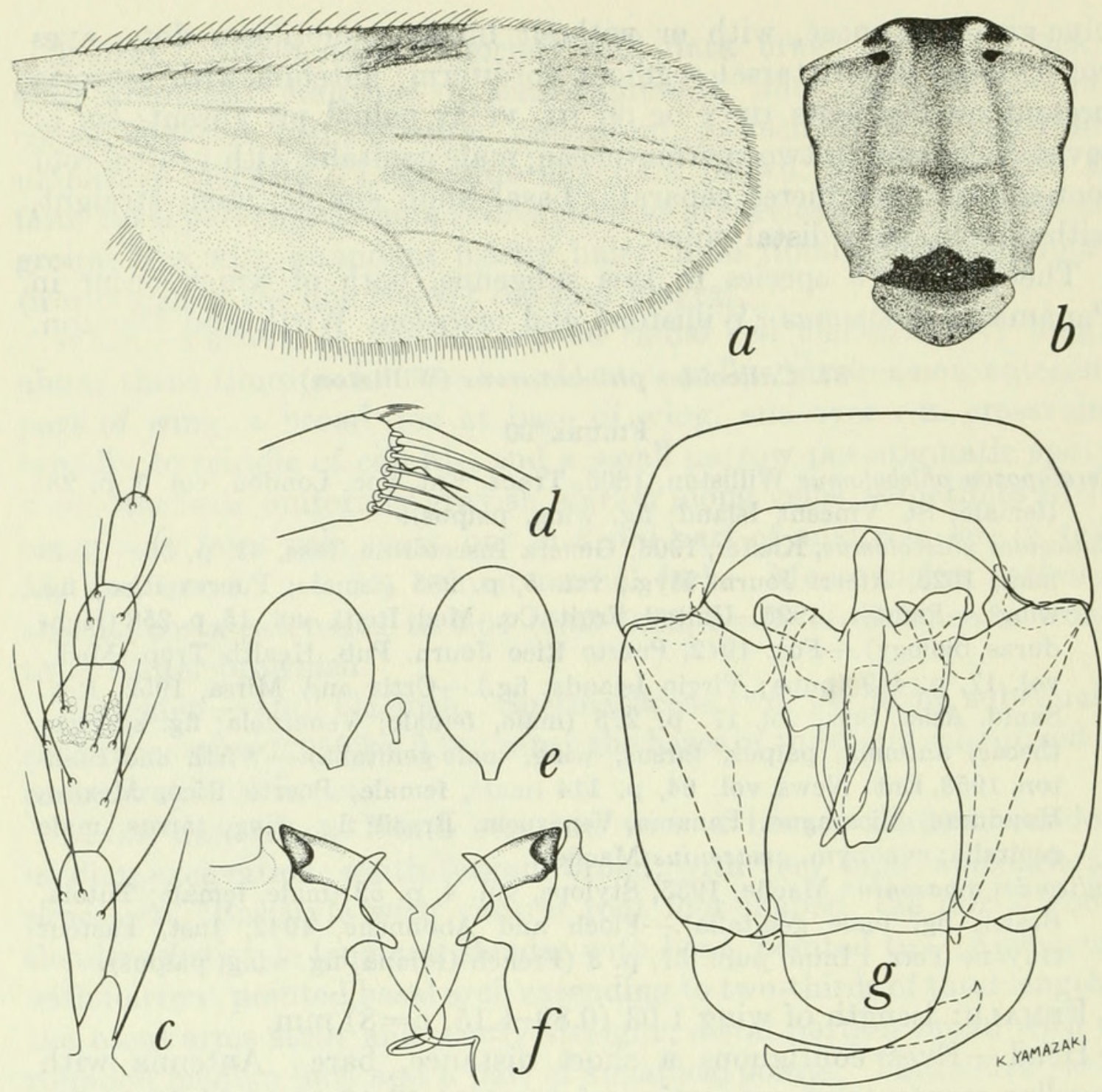

FigUre 90.-Culicoides phlebotomus (Williston). a-e, Female: $a$, wing; $b$, thoracic pattern; $c$, palpus; $d$, tibial comb; $e$, spermathecae. $f, g$, Male: $f$, parameres; $g$, genitalia, parameres removed.

taining anterior wing margin; one pale spot in cell $\mathrm{M}_{1}$, located far from wing margin; pale spot present straddling middle of vein $\mathrm{M}_{2}$; one pale spot in distal part of cell $\mathrm{M}_{2}$, located far from wing margin; small round pale spot present in center of cell $\mathrm{M}_{4}$; anal cell with one pale spot in distal portion and a pale streak near base; cell $\mathrm{M}_{2}$ with a pale spot lying behind medial fork and one lying in front of mediocubital fork; a pale spot lying just distad of basal arculus and one lying over base of mediocubitus. Macrotrichia very sparse on distal fourth of wing; costa extending to $0.55(0.53-0.58, \mathrm{n}=8)$ of distance to wing tip. Halter pale.

Abdomen.-Brownish black. Spermathecae two, ovoid, unequal, measuring 0.058 by $0.043 \mathrm{~mm}$. and 0.048 by $0.041 \mathrm{~mm}$., the bases of the ducts not sclerotized. 
Male genitalia: Ninth sternum with a broad, rounded, caudomedian excavation; ninth tergum broad, short and tapering to very small apicolateral processes. Basistyle with ventral root foot-shaped but with very slender ankle and the heel developed nearly as long as the anterior toe, dorsal root slender; dististyle greatly curved from near base, with slender pointed tip. Aedeagus with a stout transverse bridge bearing a posteroventral, curved, pointed hook from the midportion; a long, nearly straight dorsal, rodlike sclerite passes the dorsal side of midportion of the basal bridge, the pointed anterior end extending well proximad of the bridge, the broad, rounded, flattened posterior end only slightly longer than the anterior hook. Parameres each with large, laterally directed, basal knob, the stem abruptly bent at base of the straight midportion, gradually tapered and distally curved ventrad in a filiform, simple tip.

Distribution: St. Vincent; Brazil; Ecuador (Palmar, Guayas); French Guiana; Honduras; Mexico; Nicaragua; Panama; Puerto Rico; Trinidad; Venezuela; Virgin Islands.

PANAMA RECORDS:

CANAL Zone: Fort Kobbe, Fort San Lorenzo, Loma Boracho, Mandinga River,

Mindi Dairy, Mojinga Swamp.

Coclé Province: Puerto Farallón, Río Hato.

Colón Province: Chagres River, Piña, Puerto Farallón, Salud.

Darién Province: Garachiné, Jaqué, Punta Patiño.

Panamá Province: Arraiján, Camarón, Chame, Isla Taboga, San Carlos, Tocumen, Viqué Cove.

Archipiélago de las Perlas: Isla del Rey.

Discussion: The undotted mesonotum will readily separate this species from the closely related willistoni Wirth and Blanton.

\section{Culicoides willistoni Wirth and Blanton}

Figure 91

Culicoides willistoni Wirth and Blanton, 1953, Ent. News, vol. 64, p. 116 (male, female; Panama; fig. wing, palpus, male genitalia).

Female: Length of wing $0.92(0.86-0.99, \mathrm{n}=5) \mathrm{mm}$.

Head.-Eyes contiguous, bare. Antenna with flagellar segments in proportion of $14: 11: 12: 13: 13: 12: 12: 12: 16: 17: 20: 20: 32$, antennal ratio 1.06; distal sensory tufts present on segments III-X. Palpal segments in proportion of $10: 21: 31: 10: 12$, third segment slightly swollen, $2.6(2.2-2.8, \mathrm{n}=5)$ times as long as greatest breadth, with sensoria scattered over mesal side of distal half of segment. Mandible with $14(14-15, \mathrm{n}=5)$ teeth.

Thorax.-Mesonotum densely bluish gray pruinose, with prominent pattern of scattered brown dots, each dot surrounding the base of one of the stout, brown, mesonotal hairs; the brown areas often 

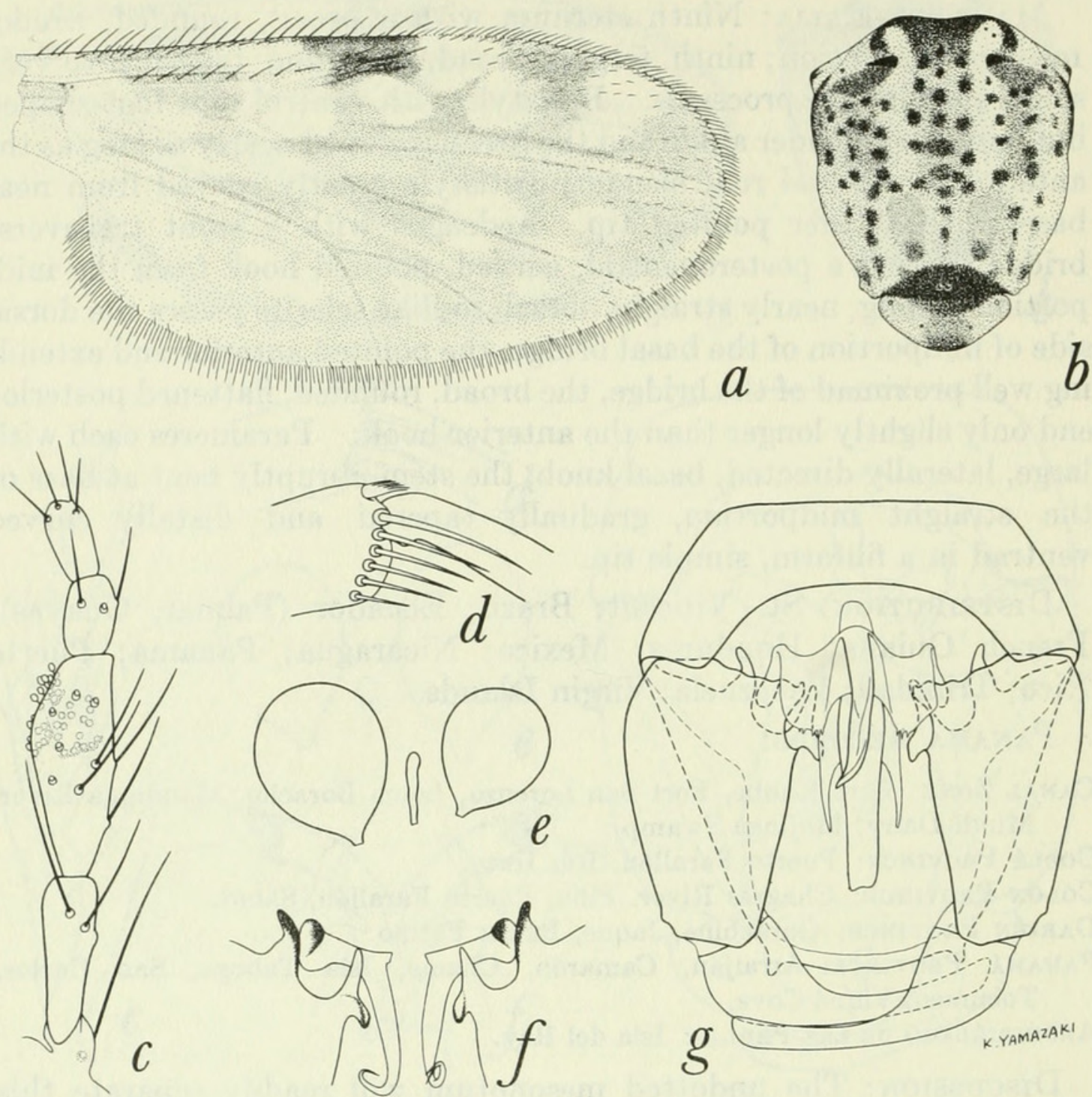

Figure 91.-Culicoides willistoni Wirth and Blanton. $a-e$, Female: $a$, wing; $b$, thoracic pattern; $c$, palpus; $d$, tibial comb; $e$, spermathecae. $f, g$, Male: $f$, parameres; $g$, genitalia, parameres removed.

confluent on middle of anterior margin and on sublateral areas between the suture and wing bases. Scutellum bluish gray pruinose, dark brown in middle; postscutellum and pleuron blackish with variable grayish pollinosity. Legs brown; bases of femora pale; femora with subapical, tibiae with subbasal and hind tibia with apical, narrow pale rings; hind tibial comb with six $(n=5)$ spines, the one nearest the spur longest; fourth tarsal segments cordiform.

Wing.-Pattern as figured; grayish with distinctly white spots; second radial cell blackish, very narrow, the radial veins thickened; pale spot over $r-m$ crossvein very large, extending into base of cell $\mathrm{M}_{2}$; cell $\mathrm{R}_{5}$ with four pale spots, the three poststigmatic spots small and round and situated in a triangle, distal spot large and irregular, and broadly meeting anterior wing margin, a blackish area located in 
the dark area proximad of distal spot; branches of media and cubitus narrowly pale margined; pale spot present straddling middle of vein $\mathrm{M}_{2}$; one pale spot, well separated from wing margin, in apex of each of cells $\mathrm{M}_{1}, \mathrm{M}_{2}, \mathrm{M}_{4}$ and anal cell, the pale spot in anal cell elongate, another indistinct pale streak in basal portion of anal cell; cell $\mathrm{M}_{2}$ with a pale spot lying behind medial fork, one lying in front of mediocubital fork, and one lying across proximal part of cell and connected with the pale area at basal arculus. Macrotrichia confined to a few in apices of cells $\mathrm{R}_{5}, \mathrm{M}_{1}$ and $\mathrm{M}_{2}$; costa extending to $0.55(0.53-0.56$, $\mathrm{n}=5$ ) of distance to wing tip. Halter whitish.

Abdomen.-Dark brown, narrow apices of terga with pale gray margins. Spermathecae two, pyriform, unequal, the larger measuring 0.053 by $0.036 \mathrm{~mm}$., the bases of the ducts sclerotized a short distance.

Male genitalia: Ninth sternum with shallow, rounded caudomedian excavation; ninth tergum tapered, with very short apicolateral processes. Basistyle with ventral root foot-shaped, the ankle slender, the heel and toe portions of subequal lengths, dorsal root slender; dististyle strongly bent basally, slender with pointed tip. Aedeagus with short, transverse basal arms, a short, stout, pointed median process projecting anteriorly from between them; posterior margins of basal arms with short, plate-like expansions; aedeagus bearing posteriorly a straight, spatulate, distally truncated, dorsal blade with a strong, ventrally curved process arising from the basal arms with its distally pointed tip curving towards the dorsal blade and about twothirds as long. Parameres each with large, laterally directed, basal knob, stem moderately bent near base, a distinct, triangular projection on mesal side at the site of the bend, nearly straight in midportion, gradually narrowed distally to slender, filiform point.

Distribution: Panama.

PANAMA RECORDS:

Chiriqui Province: Rio Tabasará.

Cocle Province: Chirú, El Barrero, El Salado, La Venta, Puerto Farallón, Puerto Obaldía, Río Hato (type locality).

Darién Province: Garachiné.

Herrera Province: Puerto Chitré.

Panama Province: El Espino, Panamá Viejas, Puerto de Chorrera, Río Las Lajas, San Carlos, Tocumen, Viqué Cove.

Archipiélago de las Perlas: Isla del Rey.

Discussion: $C$. willistoni is confined to the Pacific coast beaches of Panama. It can readily be distinguished from the more widespread phlebotomus (Williston) by the mesonotal pattern of brown dots, paleringed legs, and more extensive pale wing spots including narrow pale margins to the veins. 


\section{Alphabetical List of Species and Synonyms}

(Species number in parentheses, synonyms in italics)

acotylus (43)

aethionotus (41)

alahialinus (56)

alambiculorum (29)

almirantei (81)

amazonius (87)

antefurcatus (20)

arubae (85)

aureus (78)

azureus (47)

balsapambensis (63)

barbosai (57)

beebei (15)

bimaculatus (4)

cacozelus (30)

camposi (38)

caprilesi (82)

carpenteri (39)

carsiomelas (42)

castillae (64)

chrysonotus (19)

commatis (23)

contubernalis (3)

covagarciai (15)

crescentis (21)

daedaloides (27)

daedalus (22)

debilipalpis (76)

diabolicus (4)

dicrourus (51)

diminutus (7)

dovei (59)

dunni (26)

efferus (12)

elutus (10)

evansi (32)

fairchildi (38)

fieldi (69)

filariferus (4)

flochabonnenci (64)

\begin{tabular}{|l} 
fluvialis $(60)$ \\
foxi (5) \\
furens (59) \\
gabaldoni (71) \\
galindoi (35) \\
gibsoni (64) \\
ginesi (79) \\
glabellus (70) \\
glabrior (80) \\
gorgasi (58) \\
grahambelli (80) \\
guyanensis (44) \\
heliconiae (1) \\
hertigi $(30)$ \\
hoffmani (73) \\
hylas (2) \\
imitator (74) \\
inamollae (6) \\
insignis (6) \\
iriartei (33) \\
jamaicensis (31) \\
kintzi (82) \\
lanei (46) \\
leopoldoi (65) \\
limai (36) \\
lutealaris (18) \\
luteovenus (11) \\
lyrinotatus (53) \\
macrostigma (55) \\
maculithorax (59) \\
magnipalpis (40) \\
marshi (14) \\
metagonatus (16) \\
mirsae (77) \\
miyamotoi (78) \\
mojingaensis (48) \\
nigrigenus (17) \\
ocumarensis (4) \\
ortizi (45) \\
pachymerus (83)
\end{tabular}

painteri (6)

palpalis (3)

pampoikilus (24)

panamensis (29)

panamericanus (43)

paraensis (75)

patulipalpis (66)

paucienfuscatus (49)

phaeonotus (25)

phlebotomus (87)

pictipennis (45)

pifanoi (50)

pilosus (28)

poikilonotus (30)

propriipennis (62)

pseudodiabolicus (4)

pusilloides (8)

pusillus (9)

rangeli (67)

recifensis (44)

reticulatus (54)

rostratus (13)

rozeboomi (1)

scopus (34)

spurius (72)

stigmalis (86)

stubalensis (44)

tenuilobus (37)

tetrathyris (61)

transferrans (68)

tricoloratus (50)

trinidadensis (7)

undecimpunctatus (75)

uniradialis (84)

vargasi (33)

venezuelensis (45)

verecundus (3)

volcanensis (52)

willistoni (88)

wokei (41) 
Adamson, A. M.

\section{References}

1939. Observations on biting sandflies (Ceratopogonidae) in Trinidad, B. W. I. Trop. Agr., vol. 16, pp. 79-81.

Arnett, R. H., Jr.

1950. Notes on the distribution, habits, and habitats of some Panama culicines (Diptera : Culicidae). Pt. 4. Ecology. Journ. New York Ent. Soc., vol. 58, pp. 99-115.

Barbosa, F. A. S.

1943. Descrição de "Culicoides recifensis" n. sp. e do macho de "Culicoides reticulatus" Lutz (Diptera, Chironomidae). Rev. Brasil. Biol., vol. 3, pp. 261-264.

1944. "Culicoides insignis" Lutz, com a descrição do Hipopigio (Diptera, Chironomidae). Rev. Brasil. Biol., vol. 4, pp. 259-261.

1947. Culicoides (Diptera: Heleidae) da Região Neotrópica. Anais Soc. Biol. Pernambuco (Brazil), vol. 7, pp. 3-30, pl.

1951. A change of specific name in the genus Culicoides (Diptera, Heleidae). Proc. Ent. Soc. Washington, vol. 53, p. 163.

1952. Novos subsidios para o conhecimento dos Culicoides Neotrópicos (Diptera : Heleidae). Imprensa Industrial, Recife. 21 pp., $10 \mathrm{pl}$.

Barretto, M. P.

1944. Sôbre o gênero "Culicoides" Latreille, 1809, com a descrição de três espécies (Diptera, Ceratopogonidae). Anais Fac. Med. Univ. São Paulo, vol. 20, pp. 89-105, 4 pls.

Blanton, F. S.; Galindo, P.; and Peyton, E. L.

1955. Report of a three-year light trap survey for biting Diptera in Panama. Mosquito News, vol. 15, pp. 90-93.

Blanton, F. S.; Graham, O. H.; and Keenan, C. M.

1955. Notes on Culicoides furens (Poey) at Fort Kobbe, Canal Zone. Mosquito News, vol. 15, pp. 13-18.

Buckley, J. C. C.

1934. On the development in Culicoides furens Poey, of Filaria (Mansonella) ozzardi Manson, 1897. Journ. Helminth., vol. 12, pp. 99-118.

1938. On Culicoides as a vector of Onchocerca gibsoni (Cleland and Johnston, 1910). Journ. Helminth., vol. 16, pp. 121-158.

\section{Carpenter, S. J.}

1951. Studies of Culicoides in the Panama Canal Zone (Diptera, Heleidae). Mosquito News, vol. 11, pp. 202-208.

Carter, H. F.; Ingram, A.; and Macfie, J. W. S.

1920. Observations on the Ceratopogonine midges of the Gold Coast with descriptions of new species. I-II. Ann. Trop. Med. Parasit., vol. 14 , pp. $187-274,5$ pls.

CaUsey, O. R.

1938. Culicoides of Siam with descriptions of new species. Amer. Journ. Hyg., vol. 27, pp. 399-416, 8 pls.

Chapman, F. M.

1917. The distribution of bird life in Colombia. Bull. Amer. Mus. Nat. Hist., vol. 36, pp. 1-729, 41 pls. 
Chardrome, M., and Peel, E.

1951. Recherches sur la répartition des filairs dans la région de Coquilhatville et la transmission de Dipetalonema streptocerca par Culicoides grahami Austen. Mem. Inst. Roy. Colon. Belge Sect. Sci. Nat. Med., vol. 19, pp. 3-83.

Costa Lima, A. DA

1937. Chave das especies de Culicoides da região neotropica (Diptera : Ceratopogonidae). Mem. Inst. Oswaldo Cruz, vol. 32, pp. 411-422.

DAMpF, A.

1936. Los Ceratopogónidos o jejenes (Insecta, Diptera: fam. Ceratopogonidae), como transmisores de filarias. Med. Rev. Mexicana, vol. 16, no. 268 (May 25), pp. 227-233.

Dove, W. E.; Hall, D. G.; and Hull, J. B.

1932. The salt marsh sand fly problem. Ann. Ent. Soc. Amer., vol. 25, pp. 505-527.

DunN, L. H.

1934. Entomological investigations in the Chiriqui Region of Panama. Psyche, vol. 41, pp. 166-183.

EDWARDS, F. W.

1922. On some Malayan and other species of Culicoides, with a note on the genus Lasiohelea. Bull. Ent. Res., vol. 13, pp. 161-167, 1 pl.

Edwards, F. W.

1939. In Edwards, Oldroyd, and Smart. British blood-sucking flies. London, British Museum. 156 pp., 45 pl.

F AIRChILD, G. B.

1943. An annotated list of the bloodsucking insects, ticks and mites known from Panama. Amer. Journ. Trop. Med., vol. 23, pp. 569-591.

Fiedler, O. G. H.

1951. The South African biting midges of the genus Culicoides (Ceratopogonid., Dipt.). Onderstepoort Journ. Vet. Res., vol. 25, pp. 1-33.

Floch, H., and Abonnenc, E.

1942. Cératopogonidés hématophages de la Guyane Française. Inst. Pasteur Guayane Terr. I'Inini, publ. no. 37, 10 pp.

Foote, R. H., and Pratt, H. D.

1954. The Culicoides of the eastern United States (Diptera, Heleidae). Publ. Health Monogr. No. 18, 55 pp.

Forattini, O. P.

1953. Culicoides trinidadensis Hoffman 1925 (Diptera, Ceratopogonidae). Arq. Fac. Hig. Saude Pub. Univ. São Paulo, vol. 7, pp. 123-126.

Forattini, O. P., and Galvão, A. B.

1955. Rédescrição de Culicoides maruim Lutz, 1913 e C. reticulatus Lutz, 1913 (Diptera, Ceratopogonidae). Rev. Brasileira Mal., vol. 7, pp. 225-233.

Fox, I.

1942. The respiratory trumpet and anal segment of the pupae of some species of Culicoides (Diptera: Ceratopogonidae). Puerto Rico Journ. Publ. Health Trop. Med., vol. 17, pp. 412-425.

1946. A review of the species of biting midges or Culicoides from the Caribbean Region (Diptera : Ceratopogonidae). Ann. Ent. Soc. Amer., vol. 39, pp. 248-258.

1947. Two new Central American biting midges or Culicoides (Diptera : Ceratopogonidae). Kuba, vol. 3, pp. 90-91. 
1948. Hoffmania, a new subgenus in Culicoides (Diptera: Ceratopogonidae). Proc. Biol. Soc. Washington, vol. 61, pp. 21-28.

1949. Notes on Puerto Rican biting midges or Culicoides (Diptera: Ceratopogonidae). Bull. Brooklyn Ent. Soc., vol. 44, pp. 29-34.

1952a. Light trap studies on Culicoides in Puerto Rico-' Journ. Econ. Ent., vol. 45 , pp. $888-889$.

1952b. Six new Neotropical species of Culicoides. Ann. Ent. Soc. Amer., vol. 45 , pp. 364-368.

1955a. A catalogue of the bloodsucking midges of the Americas (Culicoides, Leptoconops and Lasiohelea) with keys to the subgenera and Nearctic species, a geographic index and bibliography. Journ. Agr. Univ. Puerto Rico, vol. 39, No. 4, pp. 214-285.

1955b. Nuevos aelantos en el estudio del genero Culicoides. Bol. Lab. Clin. Luis Razetti 1955, pp. 635-639.

Fox, I., and Hoffman, W. A.

1944. New Neotropical biting sandflies of the genus Culicoides (Diptera: Ceratopogonidae). Puerto Rico Journ. Publ. Health Trop. Med., vol. 20 , pp. 108-111.

GAD, A. M.

1951. The head-capsule and mouth-parts in the Ceratopogonidae (Diptera-

Nematocera). Bull. Soc. Fouad 1er d'Ent., vol. 44, pp. 17-75.

Gibson, C. L., And Ascoli, W. F.

1952. The relation of Culicoides (Diptera: Heleidae) to the transmission of Onchocerca volvulus. Journ. Parasit., vol. 38, pp. 315-320.

Goldman, E. A.

1920. Mammals of Panama. Smithsonian Misc. Coll., vol. 69, no. 5, pp.

Griscom, L. 1-309, 1 map, $39 \mathrm{pl}$.

1935. The ornithology of the Republic of Panama. Bull. Mus. Comp. Zool., vol. 78, pp. 259-382.

1940. Origin and relationships of the faunal areas of Central America. Proc. Eighth Amer. Sci. Congress, vol. 3, pp. 424-430.

1950. Distribution and origin of the birds of Mexico. Bull. Mus. Comp. Zool., vol. 103, pp. 341-382.

Gutsevitch, A. V.

1952. Contribution to the fauna of sandflies of the genus Culicoides of the forest zone (Diptera, Heleidae). Parasit. Symp. Zool. Inst. Parasit. Sec., vol. 14, pp. 75-94. [In Russian.]

HALL, D. G.

1932. A new biting Culicoides from saltmarshes in the Southeastern States. Proc. Ent. Soc. Washington, vol. 34, pp. 88-89.

Henrard, C., and Peel, E.

1949. Culicoides grahami Austen. Vecteur de Dipetalonema streptocerca et non de Acanthocheilonema perstans. Ann. Soc. Belge Méd. Trop., vol. 29, pp. 127-143.

Hill, M. A.

1947. The life-cycle and habits of Culicoides impunctatus Goetghebuer and

Culicoides obsoletus Meigen, together with some observations on the life-cycle of Culicoides odibilis Austen, Culicoides pallidicornis Kieffer, Culicoides cubitalis Edwards and Culicoides chiopterus Meigen. Ann. Trop. Med. Parasit., vol. 41, pp. 55-115. 
Hoffman, W. A.

1925. A review of the species of Culicoides of North and Central America and the West Indies. Amer. Journ. Hyg., vol. 5, pp. 274-301.

1939. Culicoides filariferus, new species. Intermediate host of an unidentified filaria from southwestern Mexico. Puerto Rico Journ. Publ. Health Trop. Med., vol. 15, pp. 172-174.

Hopkins, C. A.

1952. Notes on the biology of certain Culicoides studied in the British Cameroons, West Africa, together with observations on their possible role as vectors of Acanthocheilonema perstans. Ann. Trop. Med. Parasit., vol. 46, pp. 165-172.

Hopkins, C. A., and Nicholas, W. L.

9152. Culicoides austeni, the vector of Acanthocheilonema perstans. Ann. Trop. Med. Parasit., vol. 46, pp. 276-283.

JobLING, B.

1928. The structure of the head and mouth-parts in Culicoides pulicaris L.

(Diptera, Nematocera). Bull. Ent. Res., vol. 18, pp. 211-236.

Kenoyer, L. A.

1929. General and successional ecology of the lower tropical rain-forest at Barro Colorado Island, Panama. Ecology, vol. 10, pp. 201-222.

Kettle, D. S., and Lawson, J. W. H.

1952. The early stages of British biting midges Culicoides Latreille (Diptera : Ceratopogonidae) and allied genera. Bull. Ent. Res., vol. 43, pp. 421-467, 6 pls.

KhalaF, K.

1954. The speciation of the genus Culicoides (Diptera, Heleidae). Ann. Ent. Soc. Amer., vol. 47, pp. 34-51.

LaNe, J., ANd Ortiz, I.

1950. Sinonimia en Culicoides (Diptera, Ceratopogonidae). Rev. Sanid. Asist. Soc., vol. 15, p. 460.

LAwson, J. W. H.

1951. The anatomy and morphology of the early stages of Culicoides nubeculosus Meigen (Diptera, Ceratopogonidae $=$ Heleidae). Trans.

LEE, D. J. Roy. Ent. Soc. London, vol. 102, No. 9, pp. 511-570, 1 pl.

1948. Australasian Ceratopogonidae (Diptera, Nematocera). Pt. 1. Relation to disease, biology, general characters and generic classification of the family, with a note on the genus Ceratopogon. Proc. Linn. Soc. New South Wales, vol. 72, pp. 313-331.

LeE, D. J., AND REYe, E. J.

1953. Australasian Ceratopogonidae (Diptera, Nematocera). Pt. 6. Australian species of Culicoides. Proc. Linn. Soc. New South Wales, vol. 77, pp. 369-394. 1 pl.

Lutz, A.

1913. Contribuição para o estudo das "Ceratopogoninas" hematofagas do Brasil (parte sistemática). Mem. Inst. Oswaldo Cruz, vol. 5, pp. 45-73, 3 pl.

1914. Contribuição para o connecimento das "Ceratopogoninas" do Brasil (Aditamento terceiro e descrição de espécies que não sugam sangue). Mem. Inst. Oswaldo Cruz, vol. 6, pp. 81-99, 2 pls.

MACFie, J. W. S.

1937. Ceratopogonidae from Trinidad. Ann. Mag. Nat. Hist., ser. 10, vol. 20 , pp. 1-18. 
1940. A report on a collection of Ceratopogonidae (Diptera) from British Guiana. Ent. Monthly Mag., vol. 76, pp. 25-32.

1948. Some species of Culicoides (Diptera, Ceratopogonidae) from the Mirsa, A., Mirsa, M., and Ortiz, I. State of Chiapas, Mexico. Ann. Trop. Parasit., vol. 42, pp. 67-87.

1952. Primer hallazgo de formas evolutivas de microfilarias en el tórax de Culicoides (C. pifanoi Ortiz, 1951) en Venezuela. Rev. Sanid. Asist. Soc., vol. 17, pp. 159-162.

Mirsa, M., and Ortiz, I.

1952. Estudios en Culicoides (Diptera, Ceratopogonidae) 10. Sobre la hembra de Culicoides dominicii Ortiz, 1951. Bol. Lab. Clín.

Myers, J. G. “Luis Razetti," vol. 16, pp. 475-478.

\section{OrTIz, I.}

1935. The sand-fly pest (Culicoides). Trop. Agr., vol. 12, pp. 71-73.

1949. Nota sobre nuevos Ceratopógonidos hematofagos para Venezuela. Bol. Lab. Clín. "Luis Razetti,” vol. 15, pp. 326-329.

1950a. Estudios en Culicoides. II. Diptera, Ceratopogonidae Culicoides lanei n. sp. de Panama. Rev. Sanid. Asist. Soc. vol. 15, pp. 431-433.

1950b. Estudios en Culicoides. IV. Revisión de las especies americanas del sub-genero Hoffmania Fox 1948, con la descripción de los nuevos especies. Rev. Sanid. Asist. Soc., vol. 15, pp. 437-460.

1950c. Estudios en Culicoides. V. Informes sobre una nueva especie y lista de los machos cuyas genitalias son conocidad. Rev. Sanid. Asist. Soc., vol. 15, pp. 461-465.

1951a. Estudios en Culicoides (Diptera. Ceratopogonidae). VI. Culicoides briceñoi n. sp. Bol. Lab. Clín. "Luis Razetti," vol. 16, pp. 442-448.

1951b. Estudios sobre Culicoides (Diptera, Ceratopogonidae). VII. Culicoides dominicii $\mathrm{n}$. sp. y clave para el reconocimiento de las especies venezolanas. Nov. Cient. Contr. Ocas. Mus. Hist. Nat. La Salle, zool. ser., no. 5,12 pp.

1951c. Estudios en Culicoides (Diptera, Ceratopogonidae). IX. Sobre los caracteres diferenciales entre Culicoides paraensis (Goeldi, 1905), C. stellifer (Coquillett, 1901) y C. lanei (Ortiz, 1950). Descripción de cuatro nuevas especies con la redescripción de algunas otras poco conocidas. Rev. Sanid. Asist. Soc., vol. 16, pp. 573-591.

1952. Nota sobre la presencia de "Culicoides eublepharus" Macfie, 1948 (Diptera, Ceratopogonidae) en Venezuela-descripción la armadura genital del macho. Acta Cient. Venezolana, vol. 3, p. 129.

1953a. Nueva contribución al conocimiento de los caracteres morfológicos externos de las hembras Americanas del género Culicoides Ltr. (Diptera, Ceratopogonidae) con una espermateca. Rev. Sanid. Asist. Soc., vol. 18, pp. 797-806.

1953b. Sobre una nueva especie del género Culicoides (Diptera, Ceratopogonidae) próxima de C. horticola Lutz 1913. Rev. Sanid. Asist. Soc., vol. 18, pp. 807-812.

1954. Sobre dos nuevos dípteros hematofagos del genero Culicoides (Nematocera, Ceratopogonidae). Arch. Venezolana Patol. Trop. Parasit. Méd., vol. 2, pp. 221-226.

Ortiz I., and Leon, L. A.

1954. Los Culicoides (Diptera : Ceratopogonidae) de la República del Ecuador. Bol. Inf. Cient. Nac., vol. 7, pp. 564-590. 
Ortiz, I., And Mirsa, M.

1950. Estudios en Culicoides (Diptera, Ceratopogonidae). VIII. Sobre una nueva especie del grupo haematopotus: Culicoides venezuelensis n. sp. Arch. Venezolana Patol. Trop. Parasit. Med., vol. 2, pp. $137-144,1$ pl.

1951. Estudios en Culicoides (Díptera, Ceratopogonidae). Descripción de dos nuevas especies: Culicoides avilaensis y C. discrepans, y del macho de C. leopoldoi Ortiz, 1951. Redescripción de C. limai Barretto, 1944, C. baueri Hoffman, 1925, C. lichyi Floch \& Abonnenc, 1949 y C. pusillus Lutz, 1913. Rev. Sanid. Asist. Soc., vol. 16, pp. 593-605.

1952a. Culicoides de Venezuela. Redescripción de 10 especies con la descripción de algunos sexos no conocidos. Rev. Sanid. Asist. Soc., vol. 17 , pp. $257-279$.

1952b. Sobre las especies Americanas del género “Culicoides" Latr. (Diptera, "Ceratopogonidae") con una espermateca. Acta Cient. Venezolana, vol. 3, pp. 125-128.

Painter, R. H.

1926. The biology, immature stages, and control of the sandflies (biting Ceratopogoninae) at Puerto Castilla, Honduras. Ann. Rep. Med. Dep. United Fruit Co. 1926, pp. 245-262, 1 pl.

Picado, C.

1913. Les broméliacées épiphytes considérées comme milieu biologique. Bull. Sci. France Belgique, vol. 47, pp. 215-360, 19 pls.

Posnette, A. F.

1944. Pollination of cacao in Trinidad. Trop. Agr., vol. 21, pp. 115-118. Price, D. A., and Hardy, W. T.

1954. Isolation of the bluetongue virus from Texas sheep-Culicoides shown to be a vector. Journ. Amer. Vet. Med. Assoc., vol. 124, pp. 255-261.

Root, F. M., and Hoffman, W. A.

1937. The North American species of Culicoides. Amer. Journ. Hyg., vol. 25 , pp. $150-176,8$ pls.

Ryckman, R. E., and Ames, C. T.

1953. Insects reared from cacti in Arizona. Pan-Pac. Ent., vol. 29, pp. 163-164.

Schuchert, C.

1935. Historical geology of the Antillean-Caribbean region. $811 \mathrm{pp}$.

Standley, P. C.

1928. Flora of the Panama Canal Zone. Contr. U. S. Nat. Herbarium, vol. 27 , pp. 1-416.

Steward, J. S.

1933. Onchocerca cervicalis (Railliet and Henry, 1910) and its development in Culicoides nubeculosus Mg. Rep. Inst. Anim. Path., Cambridge Univ., vol. 3, pp. 272-284.

ToIT, R. M. DU

1944. The transmission of blue-tongue and horse-sickness by Culicoides. Onderstepoort Journ. Vet. Res., vol. 19, pp. 7-16.

ToKUNAGA, M.

1937. Sand flies (Ceratopogonidae, Diptera) from Japan. Tenthredo, vol. 1, pp. 233-338. 
VARGas, L.

1944. Culicoides diabolicus en Mexico. Caractres del macho. Rev. Inst. Salub. Enf. Trop., vol. 5, pp. 163-169.

1945. Nota sobre Ceratopogónidos y Culicoides. Rev. Inst. Salub. Enf. Trop., vol. 6, pp. 41-49.

1949. Lista de los Culicoides del mundo (Diptera, Heleidae). Rev. Soc. Mexicana Hist. Nat., vol. 10, pp. 191-218.

1953a. Beltranmyia n. subg. de Culicoides (Insecta: Heleidae). Rev. Inst. Salub. Enf. Trop., vol. 13, pp. 33-36.

1953b. Culicoides wirthomyia n. sp. y Culicoides stigmalis Wirth 1952. Rev. Inst. Salub. Enf. Trop., vol. 13, pp. 227-233.

1954 Dos nuevas especies de Culicoides Mexicanos. Rev. Inst. Salub. Enf. Trop., vol. 14, pp. 25-32.

VArgas, L., and Wirth, W. W.

1955. Culicoides blantoni n. sp. (Dipt., Heleidae). Rev. Inst. Salub. Enf. Trop., vol. 15, pp. 33-35.

WARMKe, H. E.

1951. Studies on pollination of Hevea brasiliensis in Puerto Rico. Science, vol. 113, pp. 646-648.

1952. Studies on natural pollination of Hevea brasiliensis in Brazil. Science, vol. 116, pp. 474-475.

Williams, R. W.

1951. Observations on the bionomics of Culicoides tristriatulus Hoffman with notes on $C$. alaskensis Wirth and other species at Valdez, Alaska, summer 1949. Ann. Ent. Soc. Amer., vol. 44, pp. 173-183.

1955a. Studies on the Culicoides of Baker County, Georgia (Diptera, Heleidae). I. Preliminary survey and observations. Ann. Ent. Soc. Amer., vol. 48, pp. 30-34.

1955b. Observations on the bionomics of some Culicoides of Cheboygan County, Michigan (Diptera, Heleidae). Bull. Brooklyn Ent. Soc., vol. 50, pp. 113-120.

Wirth, W. W.

1952a. The Heleidae of California. Univ. California Publ. Ent., vol. 9, pp. 95-266.

1952b. Two new species of anthropophilic Culicoides from Guatemala (Diptera: Heleidae). Journ. Parasit., vol. 38, pp. 245-247.

1955a The biting midge genera Psychophaena and Tetraphora of Philippi 1865. Rev. Chilena Ent., vol. 4, pp. 233-235.

1955b. Report on a collection of biting midges of the genus Culicoides from Guatemala. (Diptera, Heleidae). Proc. Ent. Soc. Washington, vol. 57, pp. 109-117.

1956. The heleid midges (Diptera, Heleidae) involved in the pollination of rubber trees in America. Proc. Ent. Soc. Washington, vol. 58, pp. 241-250.

Wirth, W. W., and Blanton, F. S.

1953a. Studies in Panama Culicoides (Diptera: Heleidae) I. Descriptions of six new species. Journ. Washington Acad. Sci., vol. 43, pp. 69-77.

1953b. Studies in Panama Culicoides (Diptera, Heleidae) II. Descriptions of six additional new species. Journ. Parasit., vol. 39, pp. 229-236.

1953c. Studies in Panama Culicoides (Diptera, Heleidae) III. A new species related to phlebotomus (Williston). Ent. News, vol. 64, pp. 113-120. 
1955a. Studies in Panama Culicoides (Diptera, Heleidae) IV. Description of three new species. Bull. Brooklyn Ent. Soc., vol. 50, pp. $100-106$.

1955b. Studies in Panama Culicoides (Diptera, Heleidae) V. Descriptions of three new species of the subgenus Oecacta Poey. Bull. Brooklyn Ent. Soc., vol. 50, pp. 121-127.

1956a. Studies in Panama Culicoides (Diptera, Heleidae) VI. The hylas group of the subgenus Hoffmania. Journ. Washington Acad. Sci., vol. 46, pp. 95-99.

1956b. Studies in Panama Culicoides (Diptera, Heleidae) VII. The species of the pulicaris and covagarciai Groups. Proc. Ent. Soc. Washington, vol. 58, pp. 211-227.

1956c. Studies in Panama Culicoides VIII. The Neotropical species of the guttatus group of the subgenus Hoffmania (Diptera, Heleidae). Proc. Ent. Soc. Washington, vol. 58, pp. 305-326.

1956d. Studies in Panama Culicoides (Diptera, Heleidae) IX. Two new species related to leoni Barbosa and reevesi Wirth. Bull. Brooklyn Ent. Soc., vol. 51, pp. 45-52.

1956e. Redescriptions of four new species of Neotropical Culicoides of the debilipalpis group (Diptera, Heleidae). Journ. Washington Acad. Sci., vol. 46, pp. 186-190.

1956f. A new species of salt marsh sandfly from Florida, the Bahamas, Panama and Ecuador, its distribution and taxonomic differentiation from Culicoides furens (Poey) (Diptera, Heleidae). Florida Ent., vol. 39 , pp.157-162.

Wоке, P. A.

1954. Observations on Central American biting midges (Diptera, Heleidae).

Ann. Ent. Soc. Amer., vol. 47, pp. 61-74. 


\section{$2 \mathrm{BHL}$ Biodiversity Heritage Library}

Wirth, Willis Wagner and Blanton, Franklin S. 1959. "Biting midges of the genus Culicoides from Panama (Diptera: Heleidae)." Proceedings of the United States National Museum 109(3415), 237-482. https://doi.org/10.5479/si.00963801.109-3415.237.

View This Item Online: https://www.biodiversitylibrary.org/item/32759

DOI: https://doi.org/10.5479/si.00963801.109-3415.237

Permalink: https://www.biodiversitylibrary.org/partpdf/17098

\section{Holding Institution}

Smithsonian Libraries

\section{Sponsored by}

Smithsonian

\section{Copyright \& Reuse}

Copyright Status: NOT_IN_COPYRIGHT

Rights: https://www.biodiversitylibrary.org/permissions/

This document was created from content at the Biodiversity Heritage Library, the world's largest open access digital library for biodiversity literature and archives. Visit BHL at https://www.biodiversitylibrary.org. 